
Qlla k. Wathius. 80t. 1549. 

AN ELEMENTARY

\section{TEXT-BOOK OF BOTANY}





\section{AN ELEMENTARY}

\section{TEXT-B00K OF BOTANY}

BY

SYDNEY H. VINES M.A., D.Sc., F.R.S.

Fellow of Magdalen College and Sherardian Professor of Botany in the University of Oxford: Honorary Fellow of Christ's College and formerly Reader in Botany in the University of Cambridge; Fellow of the University of London

WITH 397 ILLUSTRATIONS

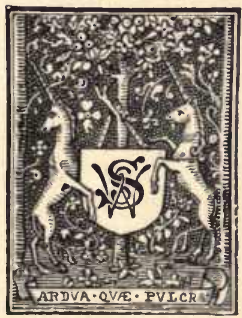

Z

SWAN SONNENSCHEIN \& CO Lim. NEW YORK : THE MACMILLAN COMPANY 1898 
ButLer \& TANNer,

The Selwood Printing Works,

Frome, AND LONDON. 


\section{P R E F A E .}

os THE preparation of this work was undertaken to meet a demand OD which appeared to exist for a less bulky and expensive volume co than my Students' Text-Book of Botany. I have so far succeeded $\rightarrow$ that this book contains about 200 pages less than the Students' CText-Book; but it is still about so much larger than the last issue $z$ of Prantl's Elementary Text-Book, which it is intended to replace. However, I am convinced that it is not possible, with advantage to the student, to compress even the elementary facts and conceptions of Botanical Science into a much smaller space than this.

This book is not, however, merely an abridgment of the Students' Text-Book. More 'important than the diminution of the bulk by one quarter is the simplification which the contents have undergone by the omission of certain difficult and still debatable topics, such as, for instance, the details of nuclear division, or the alteros nation of generations in the Thallophyta. I have also thought it desirable to follow, in the main, the classification of Phanerogams laid down in the Genera Plantarum of Bentham and Hooker. Moreover, there has been a considerable rearrangement of the matter, and the more fundamental recent discoveries - such as that of spermatozoids in the Gymnosperms-have been incorporated. Hence the contents of this book differ in various material points from those of the Students' Text-Book-a difference which I hope at some future time to render more marked by preparing an edition of the Students' Text-Book of a more advanced character and on a somewhat larger scale.

A word in conclusion as to how to use this book. It is convenient to divide-as is done here-the subject-matter of Botany into the four parts, Morphology, Anatomy, Physiology, Systematic; but it must not be forgotten that these are all parts of one subject, different methods of studying one object, namely, the plant. Hence they must not be pursued separately, but together. For instance, the morphology of the leaf cannot be profitably studied without a knowledge of its structure and of its functions; and it 
is also important to know what is the systematic position of each of the various plants whose leaves afford the material for study. In a word, the student should not attempt to read the book straight through from the beginning as if it were a novel. On the contrary, he may begin with any one of the four parts as his main subject; but that part must be studied in close relation with the other three parts, a procedure which is facilitated by the large number of cross-references in the text.

S. H. V.

July, 1898. 


\section{ERRATA}

P. 83, line 18 from top; for "erythrophl" read "erythrophyll."

"161, " 7 " ; " "the" (last word in the line) read "but."

"244, " $29 \quad$ " ; " "Sytonemaceæ "read "Scytonemaceæ."

" 273, " 6 from bottom; for "ooblastema-filaments" read "gonimoblastic filaments."

" 526, " $9 \quad$ " $\quad$; " "arilode " read "arillode."

", 541, " 7 from top; for "brocteoles " read "bracteoles." 


\section{CONTENTS.}

\section{PART I.-MORPHOLOGY.}

1. Introductory

2. The Life-History of Plants

3. The Segmentation of the Body . . . . .

4. The Symmetry of the Body and of the Members . . . . 4

5. The Development of the Body and of the Members a . 8

6. The Arrangement of the Lateral Members . . . . . 10

7. Development of Branch-Systems . . . . . . . 18

8. Cohesion and Adhesion . . . . . . . . . . . . 21

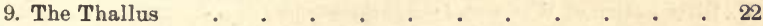

10. The Shoot . . . . . . . . . . . 22

11. The Stem \& . . . . . . . . . 27

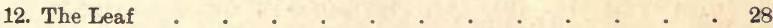

13. The Root . . . . . . . . . . . . . 44

14. Hairs and Emergences . . . . • • • • . 46

15. Reproduction . . . . . . . . . . . 49

16. General Morphology of the Asexual Reproductive Organs . . 51

17. General Morphology of the Sexual Reproductive Organs . . 58

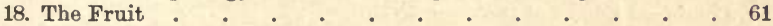

19. The Seed . . . . . . . . . . . . 62

PART II.-ANATOMY AND HISTOLOGY.

20. Introductory

CHAPTER I.-THE CELL.

21. The Structure and Form of the Cell . . . . . . . 66

22. The Protoplasm . . . . . . . . . . . 68

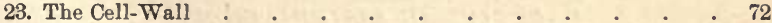

24. Cell-Contents . . . . . . . . . . . 78

25. Cell-Formation . . . . . . . . . . . 83

CHAPTER II.-THE TISSEES.

26. The Connexion of the Cells . . . . . . . . 88

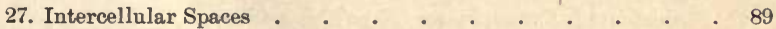

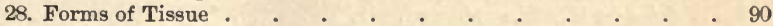

29. General Morphology of the Tissue-Systems . . . . . 101

30. The L' rimary Tegumentary Tissue . . . . . . . 106

31. The Primary Ground-Tissue . . . . . . . . 110 
32 The Stele

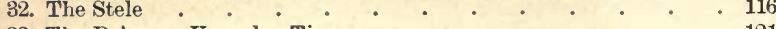

33. The Primary Vascular Tissue . $\quad$. $\quad$. . . 121

34. Histology of the Development of Secondary Members . . . 132

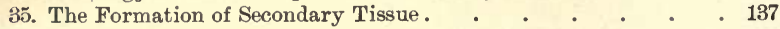

36. Formation of Tissue in consequence of Injury. . . . 155

\section{PART III.-PHYSIOLOGY.}

37. Introluctory

157

CHAPTER I.-GENERAL PHYSIOLOGY.

38. The Functions . . . • . • . • . 157

39. The External Conditions . . . . . . . . . 159

40. The Functions of the Tissues . . . . . . . 162

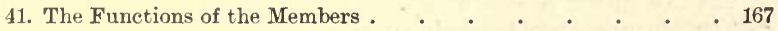

CHAPTER II.-SPECIAL PHYSIOLOGY OF THE NUTRITIVE FUNCTIONS.

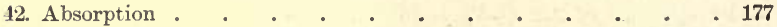

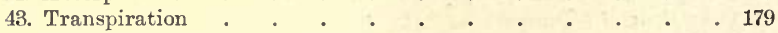

44. Distribution of Water and other Substances . . . . . . 181

45. Metabolism . . . . . . . . . . . 185

CHAPTER III.-SPECIAL PHYSIOLOGY OF MOVEMENT.

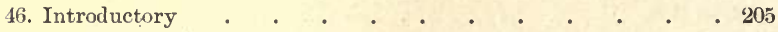

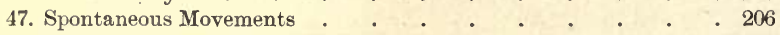

48. Induced Movements . . . . . . . . . . . 211

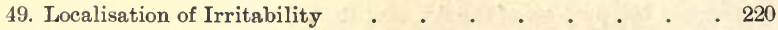

50. Transmission of Stimuli . . . . . . . . . 221

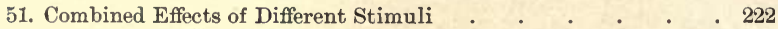

52. Conditions of Movement . . . . . . . . . . . 223

53. Mechanism of the Movements . . . . . . . . . 224

CHAPTER IV.-SPECIAL PHYSIOLOGY OF REPRODUCTION.

54. Introductory . . . . . . . . . 227

55. Vegetative Multiplication . . . . . . . . . 228

56. Spore-Reproduction . . . . . . . . . . 230

\section{PART IV.-CLASSIFICATION.}

Introductory

GROUP I. THALLOPHYTA . . . . . . . . 237

Class I. Algæ . . . . . . . . . . . 237

Sub-Class I. Cyanophyceæ (Phycochromaceæ). . . . 244

Sub-class II. Chlorophyceæ. . . . . . . . 246

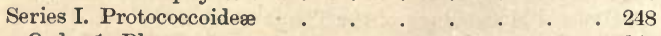

Order 1. Pleurococcaceæ . . . . . . . . . 248

" 2. Protococcaceæ . . . . . . . . 248 
Series II. Volvocoideæ

Order 1. Chlamydomonadaceæ . . . . . . 249

2. Volvocaceæ. . . . . . . . 249

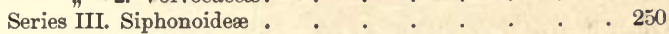

Order 1. Siphonaceæ. . . . . . . . . 250

" 2. Cladophoraceæ . . . . . . . 252

"3. Hydrodictyaceæ . . . . . . 253

Series IV. Confervoideæ . . . . . . . . 253

Order 1. Conjugatæ . . . . . . . . . 254

" 2. Ulothrichaceæ . . . . . . . . 256

" 3. Ulvaceæ . . . . . . . . 257

" 4. Edogoniaceæ . . . . . . . . 257

Series V. Charoideæ $. \quad . \quad . \quad 260$

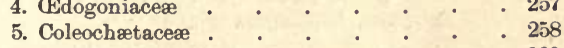

Order 1. Characeæ . . . . . . . . . 260

Sub-Class III. Phæophyceæ . . . . . . . . 263

Order. Diatomaceæ . . . . . . . . . 265

Series (a). Phæosporeæ . . . . . . . . 265

Series (b). Phæogamæ . . . . . . . . 268

Order. Fucaceø . . . . . . . . . . 268

Sub-Class IV. Rhodophyceæ . $\quad . \quad$. $\quad . \quad$. $\quad . \quad$. $\quad$. 271

Class II. Fungi . . . . . . . . . . 275

Sub-Class I. Schizomycetes . . . . . . . . 280

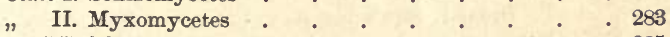

" III. Phycomycetes . . . . . . . . 285

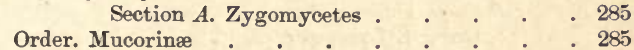

Section $B$. Oomycetes . . . . . . 287

Order 1. Peronosporaceæ . . . . . . . 287

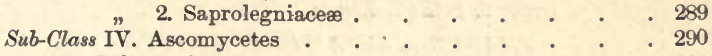

294

"2. Pyrenomycetes . • • . . . . . . 295

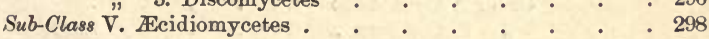

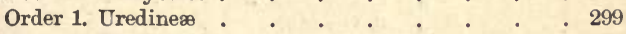

2. Ustilagineæ . . . . . . . 300

Sub-Class VI. Basidiomycetes $\quad . \quad$. $\quad . \quad$. $\quad . \quad$. 301

Series I. Protobasidiomycetes . . . . . . 305

" II. Autobasidiomycetes . . . . . . 305

Subsidiary Group. Lichenes . . . . . 305

GROUP II. BRYOPHYTA (MUSCINEE) . . . . . 309

Class III. Hepaticæ (Liverworts) . . . . . . . 318

Order 1. Marchantiaceæ . . . . . . . 320

2. Jungermanniaceæ . . . . . . . 324

3. Anthocerotaceæ . . . . . . . 330 
PAGE

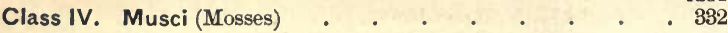

Order 1. Sphagnaceæ . . . . . . . 340

Order 2. Bryineæ • • • . • • • • 342

GROUP III. PTERIDOPHYTA (VASCULAR CRYPTOGAMS). 346

Class V. Filicinæ . . . . . . . • . . 354

Sub-Class. Eusporangiatæ

Homosporeæ.

Order 1. Ophioglossaceæ . . . . . . . 354

" 2. Marattiaceæ . . . . . . . . 355

Heterosporeæ.

Sub-Class. Leptosporangiatæ

Homosporeæ (Filices) . . . . 358

Order 1. Hymenophyllaceæ . . . . . . 371

"2. Polypodiaceæ . . . . . . . 371

" 3. Cyatheaceæ . . . . . . . . 372

" 4. Gleicheniaceæ . . . . . . 372

"5. Schizæaсеæ. . . . . . . . 372

"6. Osmundaceæ $\quad$ • . . . . $\quad . \quad 372$

"Heterosporeæ (Hydropterideæ) $\quad .373$

"7. Salviniaceæ . . . . . . . 380

" 8. Marsileaceæ . . . . . . . 380

Class VI. Equisetinæ . . . . . . . . . 380

Order 1. Equisetaceæ . . . . . . . 380

Class VII. Lycopodinæ . . . . . . . . . 386

Sub-Class. Homosporeæ

Order 1. Lycopodiaceæ . . . . . . . . . 386

" 2. Psilotaceæ. . . . . . . . . 389

Sub-Class. Heterosporeæ

Order 3. Selaginellaceæ • . . . . . . 389

PHANEROGAMIA (SPERMAPHYTA) . . . 394

GROUP IV. GYMNOSPERME . . . . . . . . 419

Class VIII. Gymnospermæ

Order 1. Cycadaceæ . . . . . . . . 431

" 2. Coniferæ . . . . . . . . 432

"3. Gnetaceæ • • • • • • . 437

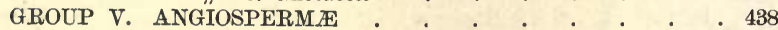

Class IX. Monocotyledones . . . . . . . . 476

Sub-Class I. Spadicifloræ . . . . . . . . 482

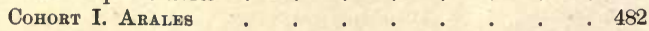

Order 1. Araceæ . . . . . . . . . . . 482

"2. Lemnaceø . . . . . . . 484

" 3. Турһасеæ . . . . . . . 484

Cohort II. Palmales . . . . . . . . 484

Order 1. Palmaceæ . . . . . . . . 484

Sub-Class II. Glumifloræ . . . . . . . . 486

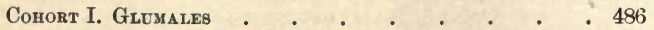

Order 1. Graminaceæ . . . . . . . 486

" 2. Cyperaceæ

492 
Sub-Class III. Petaloideæ

Series I. Hypogynæ. Sub-Series Apocarpa.

Cohort I. Alismales

Order 1. Naiadaceæ . . . . . . . . 494

"2. Juncaginaceæ. . . . . . . 495

" 3. Alismaceæ . . . . . . . . 495

" 4. Butornaceæ . . . . . . . 495

Cohort I. Liliales . • • • • • • • . 496

Order 1. Liliaceæ . . . . . . . . . 496

2. Juncaceæ . . . . . . . 499

Series II. Epigynæ.

Cohort I. HydRales . . . . . . . . 500

Order 1. Hydrocharidaceæ . . . . . . 500

Cohort II. Dioscoreales . . . . . . . 500

Order 1. Dioscoreaceæ . . . . . . . 500

„2. Bromeliaceæ . . . . . . . 501

Cohort III. Amomales (Scitaminez) . . . . . 501

Order 1. Mnsaceæ. . . . . . . . 501

" 2. Zingiberaceæ . . . . . . . 502

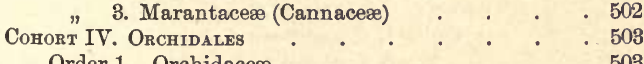

СоноRT V. NARcissales $. \quad . \quad . \quad . \quad . \quad . \quad 507$

Order 1. Amaryllidace» . . . . . . . 507

"2. Iridaceæ . . . . . . . . 508

Class X. Dicotyledones . . . . . . . . . 509

Sub-Class I. Monochlamydeæ . . . . . . . 514

Cohort I. Urticales . . . . . . . . 514

Order 1. Urticaceæ . . . . . . . . . 514

"2. Moraceæ . . . . . . . . 515

" 3. Cannabinaceæ . . . . . . . 515

"4. Ulmaceæ. . . . . . . . 516

Соноrt II. Amentales . $\quad$ • . . . . . . 517

Order 1. Betulacæ. . . . . . . 517

"2. Corylaceæ . . . . . . 518

" 3. Fagaceæ . . . . . . . . . 520

" 4. Juglandaceæ . . . . . . . . 521

"5. Salicaceæ. . . • • • . . 522

Сohort III. Chenopodiales . . . . . . . 522

Order 1. Chenopodiace» . . . . . . 522

" 2. Polygonaceæ . . . . . . . . 523

Cohort IV. Asarales . . . . . . . . . 524

Order 1. Aristolochiaceæ . . . . . . 524

Cohort V. Santalales . . . . . . . . 524

Order 1. Santalaceæ . . . . . . . . 524

" 2. Loranthaceæ . . . . . . . 525

Cohort VI. Euphorbiales . . . . . . . 525

Order 1. Euphorbiace». . . . . . . . 526

Sub-Class II. Polypetalæ . . . . . . . . 527 
Series I. Thalamifloræ

Cohort I. Ranales • • • • • • • • 527

Order 1. Ranunculaceæ . . . . . . . 527

"2. Magnoliaceæ . . . . . . . 530

” 3. Nymphæасеæ . . . . . . . 530

"4. Berberidaceæ . . . . . . . 531

Сohort II. Caryophyllalfs. • • • • • . 531

Order 1. Caryophyllaceæ . . . . . . 531

Cohort III. Parietales $. \quad . \quad . \quad . \quad . \quad . \quad .533$

Order 1. Papaveraceæ . . . . . . . . 533

2. Fumariaceæ . . . . . . . 533

3. Cruciferæ • . . . . . . 534

4. Cistaceæ . . . . . . . . 538

5. Violaceæ . . . . . . . . . 538

Cohort IV. Guttifrerales . . . . . . . . . 539

Order 1. Hypericaceæ . . . . . . . 539

Cohort V. Malvales . . . . . . . . . 539

Order 1. Tiliaceæ . . . . . . . . . . 539

„2. Malvaceæ . . . . . . . 540

Cohort I. Geraniales . . . . . . . . 541

Order 1. Geraniaceæ . . . . . . . . 542

\# 2. Linaceæ . . . . . . . . . . 542

" 3. Oxalidaceæ . . . . . . . . . 543

" 4. Balsaminaceæ . . . . . . 543

„5. Rutaceæ . . . . . . . . 543

Cohort II. SA Sindales . . . . . . . . . 544

Order 1. Sapindaceæ . . . . . . . . 544

" 2. Aceraceæ . . . . . . . . . 545

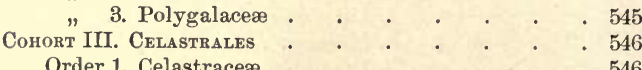

"2. Rhamnaceæ . . . . . . . . 546

" 3. Ampelidaceæ . . . . . . . 547

Cohort I. Umbellales . . . . . . . 547

Order 1. Umbelliferæ . . . . . . . 548

"2. Araliaceæ . . . . . . . 550

Cohort II. Passiflorales . . . . . . . . 550

Order 1. Cucurbitaceæ. . . . . . . 551

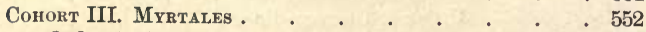

Order 1. Onagraceæ . . . . . . . . 552

" 2. Lythraceæ • • . . . . . . 553

” 3. Myrtaceæ . . . . . . . . 553

Сohort IV. Rosales . . . . . . . . . 554

Order 1. Rosaceæ . . . . . . . . . 554

"2. Leguminosæ . . . . . . . 557

Cohort V. Saxifragales $\quad . \quad . \quad . \quad . \quad . \quad . \quad .559$

Order 1. Saxifragaceæ . . . . . . . . 560

" 2. Crassulaceæ.

561 
Sub-Class III. Gamopetalø .

\section{Series I. Hypogynæ}

Cohort I. Lamiales

Order 1. Labiatæ . . . . . . . . . 562

Cohort II. Personales. $\quad$. $\quad$. $\quad$. . . . 564

Order 1. Scrophulariaceæ • • . • . . 564

$"$ 2. Plantaginaceæ $. \quad . \quad \cdot \quad \cdot \quad . \quad$. 565

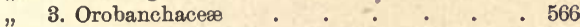

4. Lentibulariaceæ . . . . . . 566

Cohort III. Polemoniales - • . . . . . 567

Order 1. Convolvulaceæ . . . . . . . . 567

" 2. Polemoniaceæ. . . . . . . . 567

"3. Solanaceæ • • • • • . . 567

" 4. Boraginaceæ . . . . . . . 569

Cohort IV. Gentianales . . . . . . . 570

Order 1. Gentianaceæ . . . . . . . 570

"2. Oleaceæ . . . . . . . . 570

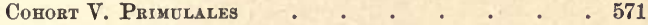

Order 1. Primulaceæ . . . . . . . . 571

" 2. Plumbaginaceæ . . . . . . . 572

Cohort Vi. Ericales . • • . . . . . 572

Order 1. Ericaceæ. . . . . . . . 572

"2. Pyrolaceæ • . . . . . . . 573

" 3. Vacciniaceæ . . . . . . . 573

Series II. Epigynæ

Cohort I. Campanales . • • • • • • . 574

Order 1. Campanulaceæ . . . . . . . . 574

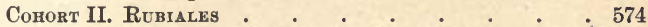

Order 1. Rubiaceæ . . . . . . . . 575

"2. Caprifoliaceæ . . . . . . . 576

Соновт III. Asterales.

Order 1. Valerianaceæ . . . . . . . 577

"2. Dipsace». . . . . . . . 577

" 3. Compositæ . . . . . . . 579

INDEX, PART I.-Morphology, Anatomy, and Physiology . . . 583

" "II.-Classification and Nomenclature . . . . 597 



\section{P A R T}

\section{MORPHOLOGY.}

§ 1. Introductory. An ordinary flowering-plant consists of a number of parts which are distinguished as roots, stems, leaves, fruits, etc. These may be considered scientifically in two ways; either with reference to their functions in the economy of the plant, when they are regarded as the organs by which these are performed, and are the subjects of physiological study; or, their functions being disregarded, their relative position, the place and mode of their origin, the course of their growth, and their relative size may be considered; that is, they may be studied from a purely morphological point of view, when they are regarded merely as parts of a whole, and are designated as members. Hence the province of morphology is the study of the form of the body of plants, and of the members of which it consists, including the development of the body and its members, as also the intimate structure (Anatomy and Histology) of the body and its members, in so far as structure throws light upon the morphology of any part of the body.

The body of a plant, like that of an animal, consists essentially of living substance known as protoplasm. The body may consist only of protoplasm, without any investing membrane to give it a determinate form (e.g. Myxomycetes); or it may consist of a mass of protoplasm enclosed by a membrane (e.g. Phycomycetous Fungi and Siphonaceous Algæ); or it may consist, as in the higher plants, of a mass of protoplasm segmented by partition-walls, or septa, into structural units termed cells. In all cases, however, the form and constitution of the body is determined by the protoplasm: for the cell-walls of which, in many cases, the body largely consists, and which give to it definiteness of form, are developed from and by the protoplasm. The study of the morphology of plants is, therefore, the study of the processes and products of the formative activity of their protoplasm; and these are to be traced

M.B. 
both in the variety of form presented by different plants, and in the various stages in the development of any one individual plant.

$\S 2$. The Life-History of Plants. The consideration of this subject is a necessary preliminary to the detailed study of Morphology. The great majority of plants are more or less polymorphic: that is, the plant assumes, as a rule, at least two quite different forms in the course of its life. Most commonly it presents but two forms which, while they may differ more or less widely in form and structure, are essentially distinguished by the fact that the one, termed the sporophyte, has asexual reproductive organs which produce asexual reproductive cells, termed spores, each of which is capable by itself of giving rise to a new organism; whilst the other, termed the gametophyte, has sexual reproductive organs, which produce sexual reproductive cells, termed gametes, and though each of these cells is by itself incapable of giving rise to a new organism, yet by the fusion of two of these gametes of different sex, a cell is formed which is of the nature of a spore, since from it a new organism can be developed. These two forms alternate more or less regularly in different plants, the asexuallyproduced spore of the sporophyte giving rise to a gametophyte; the sexually-produced spore of the gametophyte giving rise to a sporophyte. Such a life-history presents what is known as alternation of generations; that is, an alternation of a sexual with an asexual form.

The alternation of generations is conspicuous in the Bryophyta and the Pteridophyta, as is fully explained in the chapters specially devoted to those groups. It also occurs in the lifehistory of the Phanerogams, and may be traced, more or less imperfectly, in some of the Thallophyta. But since the tracing of it in the last-named group is attended with some uncertainty, that group will be excluded from further consideration here. In the groups Bryophyta, Pteridophyta, and Phanerogamia, the two generations attain very different degrees of development. In the Bryophyta, the gametophyte is the more conspicuous generation; it is the form to which the name attaches, and upon which the classification is mainly based; whereas, the sporophyte is, as it were, an appendage to the gametophyte, and is generally known as the Moss-fruit. In the Pteridophyta, the sporophyte is the conspicuous form to which the name of the plant attaches; but, though small and inconspicuous, the gametophyte is an independent organism known as the prothallus. In the Phanerogamia, as in 
the Pteridophyta, the sporophyte is the plant such as we know it, whilst the gametophyte is so much reduced that it may be regarded as an appendage upon the sporophyte. Thus, in tracing the morphology of the two generations from the Bryophyta upwards, the relations between them are gradually reversed; so that the higher the plant is in the scale of organisation, the more conspicuous is its sporophyte, the less conspicuous its gametophyte.

The following pages refer mainly to the morphology of the sporophyte of the higher plants, that is, of the Pteridophyta and Phanerogamia, except when the gametophyte or one of the Bryophyta or Thallophyta is especially mentioned.

$\S 3$. The Segmentation of the Body. The body of a plant may be either segmented into members, or unsegmented. The members of a segmented body may either be all similar, or they may be similar and dissimilar. Segmentation into similar members is termed branching. When the body is segmented into dissimilar members, it is said to be morphologically differentiated.

When the body is morphologically undifferentiated, that is, when it is either unsegmented or segmented only into similar members (i.e. branched), it is termed a thallus. A Thallophyte is a plant having a body of this constitution and of simple structure (e.g. Yeast, Spirogyra).

The primary segmentation of the body into dissimilar members consists in the differentiation of root and shoot.

The Root is usually segmented, but only into similar members. It occasionally gives rise to (adventitious) shoots.

The Shoot may be either unsegmented, or segmented into similar or dissimilar members. A shoot which is either unsegmented, or segmented only into similar members, is termed a thalloid shoot (e.g. Lemna, the Duckweed). A shoot which is segmented into dissimilar members consists generally of stem and leaves.

The characteristics of the principal members are as follows :-

The shoot bears the true (spore-producing) reproductive organs : it is generally differentiated into stem and leaf.

The stem is the axial member of the shoot, and bears the leaves.

The leaf is the lateral member of the shoot: it is borne upon the stem, but differs from it more or less in form.

The root never bears leaves or true (spore-producing) reproductive organs.

The hair is an appendage which may be borne on either root, stem, or leaf. 
The stem, leaf, and root of any one plant present the same kind of complexity of structure: the hair is of much simpler structure as a rule.

\section{$\S 4$. The Symmetry of the Body and of the Members.} Whatever the form of the body or of a member, it has three axes at right angles to each other. When these three are all equal, the body is a sphere (e.g. Volvox, Fig. 1): when two are equal, and both longer than the third, the body or the member is a flattened circular expansion (e.g. Pediastrum and the leaf-blade of Tropæolum): when one is longer than either of the others, the body or the member is cylindrical or prismatic in form when the two shorter axes are equal (e.g. the stem generally), and of a flattened form when one of the shorter axes is longer than the other (most leaves).

In most cases two opposite ends are distinguishable in the body or member, a base and an apex. The base is in all cases the end by which the body is attached to the substratum, or the members to each other, the free end being the apex. The axis or imaginary line joining the base and the apex, whether or not it be longer thau the other axes, is termed the organic longitudinal axis. When the body shows no distinction of base and apex (e.g. Spirogyra), there is no organic longitudinal axis.

Any section, real or imaginary, made parallel to the longitudinal axis, is a longitudinal section : it is a radial longitudinal section if it includes the longitudinal axis: it is a tangential longitudinal section if it does not include it. A section made at right angles to the longitudinal axis is a transverse section: the section of the longitudinal axis is the organic centre of the transverse section, and it commonly is also the geometrical centre of the transverse section, but occasionally the geometric and organic centres do not coincide. Thus, in transverse sections of tree-trunks, the annual rings are comparatively rarely arranged symmetrically around the geometrical centre. The longitudinal axis, then, is a line passing through the organic centres of the successive transverse sections.

Two kinds of symmetry may be distinguished; the multilateral, including the radial; and the bilateral, including the isobilateral and the zygomorphic. The determination of the nature of the symmetry of a body or member depends upon (a) its external form, (b) the arrangement and form of the members which it may bear, (c) its internal structure.

1. Multilateral and Radial Symmetry. Absolute multilateral symmetry is only presented by a body or member which is 
spherical and has no distinction between base and apex. For example, the body of Volvox can be divided into symmetrical halves in any plane passing through the centre (Fig. 1).

The more limited form of multilateral symmetry, which may be conveniently distinguished as radial, is that which obtains in cylindrical bodies or members. It is multilateral symmetry about the longitudinal axis. In this case the body or member can be divided in various planes along the longitudinal axis into a number of similar halves.

A mushroom with a central stalk, an apple, a cylindrical treetrunk, are radially symmetrical as regards their external form.

As regards the position of the lateral members, the trunks of Pines and Spruces, with branches arising on all sides, are radially symmetrical; and, as regards the form of the lateral members, the flowers. of the Rose and of the Tulip are radial.

A radial body or member can be divided by radial longitudinal sections in two or more planes, into symmetrical halves, which are to each

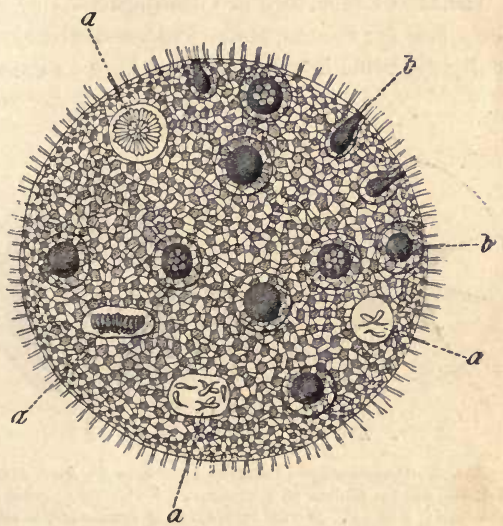

Fie. 1.-Volvox Globator (after Cohn; xabont 100), illnstrating multilateral symmetry. other as an object and its image reflected in a mirror (in Fig. 2, A, the halves obtained by the sections $1-1,2-2,3-3,4-4,5-5)$. The possible number of such similar halves is not always the same, but it is in any case at least four. In a mushroom or a Fir-stem, there are many possible planes of symmetrical section; but in a Tulip, the sections being taken through the longitudinal axes of the floral leaves, only three are possible; and in an apple if they pass through the loculi of the core, only five (Fig. $2 \mathrm{~A}$ ).

The two halves are not always as exactly alike as an object and its reflected image; this is not the case, for instance, in a Fir-trunk, because the lateral branches are not borne at the same level. The two halves are, 
however, essentially similar. When, however, a body is divisible in at least two planes into precisely similar halves, it is said to be polysymmetrical.

2. Bilateral Symmetry. A body or member is said to be bilaterally symmetrical when it presents an interior, a posterior, and two lateral surfaces; the lateral surfaces, or flanks, being different from the anterior and posterior. Such a body or member is divisible into two symmetrical halves, either in two planes, or in one plane only; when it is so divisible in two planes, the halves resulting from the section in one plane are different from the halves resulting from section in the other.

Bilateral members are distinguished as isobilateral or as zygomorphic (or monosymmetrical), accordingly as they are symmetrically divisible in two planes or in one plane.
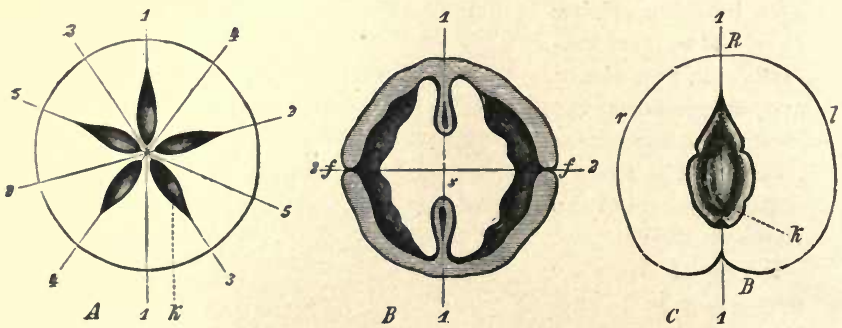

FrG. 2.-Diagrammatic transverse sections of $A$ an apple; $B$ a walnut; $C$ a peach; 1-1, 5-5, are the planes of symmetry. A with five planes of symmetry, is radially symmetrical; $k$ carpel. $B$ with two planes of symmetry, is isobilateral; $f$ the sutnre; s the seed. $C$ with a single plane of symmetry, is zygomorphic and dorsiventral; $R$ dorsal surface; $B$ venural surface; $r$ right, and $l$ left flank; $k$ stone.

a. Isobilateral Symmetry. Isobilateral symmetry is usually manifested in the external form. Thus, a walnut is at once seen to be divisible into two symmetrical halves by section, either through the suture, or at right angles to this plane (Fig. $2 B$ ); so also a flattened erect leaf like that of the Iris.

It may be manifested by the position of the lateral members; for instance, in many shoots (e.g. the Elm) the leaves are borne in two rows, right and left, one row on each flank.

It may be manifested also in the internal structure. Thus, a transverse section of a walnut (Fig. $2 B$ ) shows that internal, as well as external, isobilateral symmetry exists. But this does not 
obtain in all cases; the internal structure of isobilateral leaves is often not strictly isobilaterally symmetrical.

b. Zygomorphic Symmetry. A zygomorphic or monosymmetrical body or member is divisible into two similar halves in one plane only (Fig. $2 \mathrm{C}$ ). Of this there are two principal cases:First, that in which the anterior and posterior halves are similar, whilst the right and left halves are dissimilar, in other words, when the plane of symmetry is lateral; the body or member is then laterally zygomorphic (e.g. flower of Corydalis): secondly, that in which the anterior and posterior halves are dissimilar, whilst the right and left halves are similar, in other words, when the plane of symmetry is antero-posterior; the body or member is then said to be dorsiventrally zygomorphic, or, briefly, dorsiventral. Less frequently, as in some flowers, the plane of symmetry is neither lateral nor antero-posterior, but intermediate between the two, the zygomorphy being oblique.

Of these possible forms of zygomorphic symmetry, the dorsiventral is the most common. The term is derived from the use of the terms dorsal and ventral to indicate, respectively, the dissimilar anterior and posterior halves of the body or member.

The application of the terms dorsal and ventral to the two dissimilar halves of the body or a member requires some explanation. Generally speaking, the under surface of a dorsiventral body is the ventral, the upper the dorsal. In the case of leaves, however, the terms dorsal and ventral are used with reference to the parent stem : the upper or inner surface is here the ventral, the outer or lower, the dorsal.

The difference between the dorsal and ventral halves may be exhibited in their external form. Thus, the dorsal and ventral halves of many fruits (peach, Fig. $2 C$; or a pea-pod) may be distinguished at once by their form. Or the difference may be in the nature of the members which they bear ; thus, creeping dorsiventral shoots commonly bear (adventitious) roots or root-hairs on their ventral, and branches or leaves on their dorsal surface; or the one surface may bear lateral members, and the other none. Or, finally, the difference may exist in their internal structure; thus, in dorsiventral foliage-leaves, the internal structure of the dorsal half is different from that of the ventral half.

It must not be overlooked that the terms radial, isobilateral, and dorsiventral, may be all applicable to one and the same body or member, according to the particular feature which is taken into consideration. For example, a branch of the Silver Fir is, in its 
general appearance, dorsiventral; a dorsal and a ventral half are readily distinguishable. But, since the leaves are arranged symmetrically around it, it is in this respect radial. Again, since the lateral branches arise right and left upon its flanks, it is in this respect isobilateral. Hence it is important to distinguish clearly between the symmetry of any part of the body as a whole, and that of its constituent members. Thus in many isobilateral and dorsiventral shoots, the stem, regarded by itself, is radially symmetrical; the isobilaterality or dorsiventrality of the shoot being, in these cases, indicated only by the mode of arrangement of the leaves upon the stem.

The causes which determine the symmetry of the body or of a member are mainly inherent; but it has been ascertained in many cases that external conditions have a preponderating influence, such as the intensity and direction of the incident rays of light, or (as in certain dorsiventral flowers) the action of gravity.

When a body or a member cannot be symmetrically divided into two similar halves in any plane whatever, it is said to be asymmetric. The asymmetry in these cases is frequently associated with dorsiventrality; as in some Mushrooms (e.g. Lenzites abietina); in some foliage-leaves which are oblique, that is, the right and left halves of which are not symmetrical (e.g. Elm, some Begonias); and in some flowers (e.g. Aconitum, Delphinium).

$\S 5$. The Development of the Body and of the Members. The body, consisting of the primary members, is developed from the spore. It is not proposed to enter now into the somewhat complicated details of the various modes of embryogeny occurring in the different groups of plants; but rather to consider the development of the secondary members, that is, of those members which are produced directly or indirectly by the primary members.

Whilst the plant is still an embryo, the whole of its protoplasm is capable of growth, and is said to be in the embryonic condition. As the development of the embryo into the plant proceeds, most of the protoplasm passes over into the adult state, and is no longer capable of growth. Certain portions of it, however, retain the embryonic condition and properties, remaining capable of growth: these portions of the protoplasm are termed groving-points, and may persist throughout the whole life of the plant. Such growingpoints usually, but not exclusively, exist at the tip or apex of the primary stem and of each of its branches, as also at the apex of 
the primary root and its branches. The leaf has, with rare exceptions (e.g. some Ferns), no persistent growing-point, and this is also true of some stems. Members in which there is no persistent growing-point are said to have limited growth.

The growing-point adds, in the first instance, to the size of the member to which it belongs, and is the means by which it grows in length. But, in the case of the stem, it does more than this ; it gives rise also to new members, either branches or leaves. It is, in fact, the only source of origin of such new members. When the growing-point is multicellular, the branches and leaves arise from the superficial layers of cells; so that their mode of origin is exogenous. Moreover, these members are developed in a regular order, such that the youngest of them are to be found nearest to the growing-point, the older ones further away: this order of development is termed acropetal succession.

As a general rule, the secondary members are developed laterally on the parent member, the latter continuing its growth in length. But in a few cases, more particularly when the body is a thallus or the stem is thalloid, the growing-point divides into two, each of which forms the growing-point of a new secondary member similar to the parent. This mode of branching is known as dichotomy.

In the root, the new members, except when dichotomy occurs, are not developed at or from the growing-point, but at some distance behind it. Unlike the branches and leaves produced by the stem, the branches of the root are not developed at the surface, but from a tissue lying deeply within the structure of the parent root. (See Part II.) This layer, although it is situated among cells which have become adult, retains its embryonic properties, and gives rise to the growing-points of the several lateral roots. Hence the origin of the secondary roots is endogenous, as their growingpoints are developed within the tissue of the parent root, and have to force their way through it in order to reach the surface. The order of development of the lateral roots is acropetal.

It sometimes happens that secondary members are developed out of their proper order or not in their proper place; they are then said to be adventitious. This is rare in the case of stems and leaves, but is common in the case of roots. Roots are, for instance, frequently developed adventitiously on stems, instead of from the primary root which is their normal position. When they are developed on stems their origin is almost always endogenous.

The secondary members commonly persist; but frequently they 
become separated from the member bearing them, and fall off after a time, when they are said to be deciduous. Leaves are nearly always deciduous. In most perennial plants the foliage-leaves all fall off at some season of the year, which, in temperate climates, is the autumn. But in "evergreen" trees and shrubs, the leaves, which may last for more than one year, do not all fall off at once. Those parts of the plant which are connected with reproduction are especially deciduous; for instance, the leaves forming the perianth of the flower, sometimes the whole inflorescence (e.g. catkin), sometimes the fruit (e.g. cherry), the seeds, etc. When a

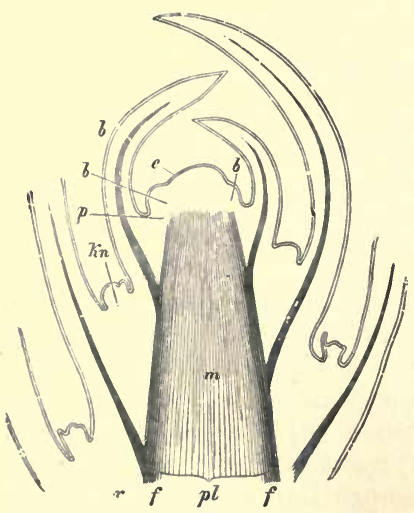

FIG. 3. - Disgrammatic Jongitudinal section through the growing-point of a stem: $b$ the leares; $k n$ their axillary buds; 6 epidermis; vascular bundles. member thus falls off it leaves a more or less permanent scar: the scar which marks the position of a fallen leaf is a leaf-scar.

Hairs and reproductive organs are generally developed as lateral outgrowths upon the members, but they are occasionally developed directly from the growing-point. They are usually developed from one or more superficial cells, but in some cases the deeper layers of cells also take part in their formation.

All lateral members may be developed either singly or several together at the same level on the parent member. When in any cross-section of the parent member not one only, but two or more lateral members occur at the same level, they are said to form a whorl; for instance, of secondary roots round a parent root, or of leaves round a stem as in Herb Paris (Paris quadrifolia). The members of a whorl may be developed either simultaneously, or one after the other; hence a whorl may be either simultaneous or successional. Members not developed in whorls are said to be scatterce.

$\S 6$. The Arrangement of the Lateral Members. The arrangement of the leaves on the stem is most intimately con- 
nected with the acropetal order of their development; and since the arrangement of the lateral shoots depends on that of the leaves, the same laws determine the arrangement of both these sets of members which apply generally to all acropetally developed members of plants. These laws are most conspicnously exhibited in the arrangement of the leaves, and they will be fully discussed with reference to these members only.

The leaves are developed in very close apposition at the growingpoint of the stem. The portions of the stem, termed internodes, which lie between the individual leaves may either remain quite short, as in the case of the rosette of leaves of the Plantain and of the Houseleek, of the fascicled leaves of the Larch, and in most flowers ; or they may undergo a considerable elongation so that the leaves become widely separated. The boundaries of the internodes - the places, that is, at which the leaves are inserted-termed nodcs, are sometimes prominently developed, more particularly when the leaves are arranged in whorls, e.g. Labiatæ, or when they ensheath the stem. The portion of the surface or the stem from which the leaf arises is the insertion of the leaf, and its organic centre is called the point of insertion.

So long as the internodes have not begun to elongate, and the leaves are still folded together so as to cover the apex of the stem, the growing end of each shoot is known as a bud. The bud which lies at the apex of a shoot, the lower portion of which has already undergone elongation, is a terminal bud; the lateral buds are the early stages of shoots developed laterally upon a growing main shoot, which often remain in this condition for a considerable time. The arrangement of the lateral buds, and consequently that of the branches which are developed from them, is closely related to that of the leaves; thus whilst in the Pteridophyta the bud may be developed immediately below or by the side of a leaf, in the Phanerogams it is nearly always developed in the axil of a leaf, that is to say, in the angle made by a leaf with the internode above its insertion. In the latter case the buds make their appearance at the first formation of the leaves (Fig. $3 \mathrm{kn}$ ). As a general rule, they are developed in the axil of every leaf, typical exceptions being the leaves that form the flower, and those of many of the Conifers. In some cases certain of the internodes do not elongate, and therefore the leaves, which have been really developed singly, or their axillary buds, appear to have been developed at the same level on the stem, thus forming a spurious 
whorl, as in the case of the upper leaves of the Tiger-lily and of the whorled branches of the Pines.

The distribution of the lateral members over the surface of the parent axis is either (see $\S 4$ ), multilateral, bilateral, or dorsiventral.

1. Radial Arrangement. The arrangement of the leaves on the stem (phyllotaxis) is very various; this is particularly conspicuous in the cases where the leaves are arranged in whorls, for which reason these will be first discussed. If a whorl consists, for instance, of two leaves, it is obvious that they will be placed exactly opposite to each other on the surface of the stem, and that the distance between them, measured from the points of insertion,

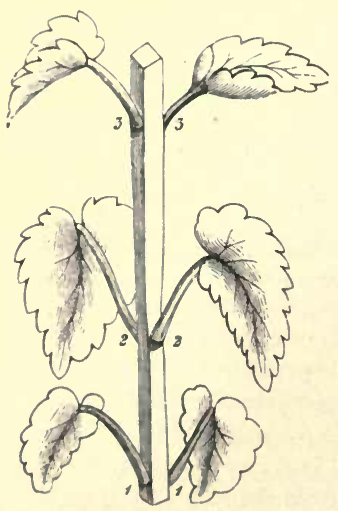

FiG.4.-Stem of Laminm with whorls of two leaves : 1-1, 2-2, 3-3, the suces. sive whorls.

will amount to just half the circumference of the stem. Similarly, if the whorl consist of three leaves, the distance between any two adjacent leaves will be one-third of the circumference, and so forth. The lateral distance between the points of insertion of two adjacent leaves, measured on the circumference of the stem, is called their divergence, and it is expressed in fractions of the circumference.

Moreover, it is a rule, though not without exceptions, that the successive whorls alternate, so that the leaves of any whorl lie opposite to the intervals between the leaves of the whorls above and below it. Thus the leaves of alternate whorls are exactly above each other(Fig. 4).

This arrangement, as in fact all relation of position, may be very plainly exhibited by means of diagrams (e.g. Figs. 5 and 6 ). Such a diagram consists of a ground-plan of the stem, regarded as being a cone, and looked at from above; the insertion of each leaf will lie upon one of a series of concentric circles, and the higher the insertion of the leaf upon the stem, the nearer to the centre will be the circle of the diagram upon which its insertion is indicated.

It may be perceived in the diagram Fig. 5, that when the leaves 
are arranged in alternate whorls, they form twice as many longitudinal series on the stem as there are leaves in each whorl, provided, of course, that the number of leaves in each whorl is the same. The longitudinal series, which are indicated in the diagram by radii, are called orthostichies.

This particular arrangement of alternate whorls of two leaves occurs very frequently, and is termed the decussate arrangement. The two leaves of each whorl are said to be opposite. It is comparatively rare for equal successive whorls to be superposed; that is, that the leaves of each whorl should lie ex-

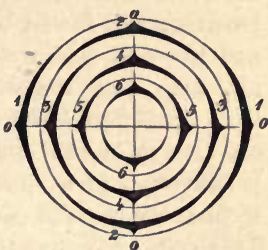

FiG. 5.-Diagram of a stem with alternate two-leaved whorls : $0,0,0,0$, the four orthostichies : $1,1,2,2,3,3$, the successive whorls.

actly above or below those of the others, so that there are only as many orthostichies as there are leaves in each whorl; but it sometimes occurs in flowers.

Examples of decussate leaves: the Caryophyllaceæ, the Labiatæ, the Caprifoliaceæ, to which belong Syringa (Lilac), Lonicera (Honeysuckle), and Sambucus (Elder); the Maple, the Horse-Chestnut, and the Ash. In Rhamnus cathartica the two leaves of each whorl are usually at a slightly different level.

Alternate whorls of many leaves occur in Equisetum and Hippuris; alternate whorls of 3 (irrespectively of flowers) occur in the common Juniper, in Catalpa, and occasionally in the Horse-Chestuut and the Maple.

When successive whorls consist of unequal numbers of members, the relations of alternation become highly complicated, as in the shoot of Polygonatum verticillatum and in the flowers of the Pomeæ (Apple, etc.)

When the leaves are arranged in a scattered manner it is easy to detect that, within a certain region of the stem, their divergence is constant; that is, that the dis-

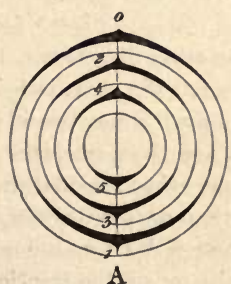

Fic. 6. $-A$, Diagram of a stem bearing leaves with \& divergence of $\frac{1}{3} ; B$, a stem bearing leaves with a divergence of $\frac{1}{3}$. tance between any leaf and its immediate predecessor and successor 
is a certain fraction of the circumference. In the simplest case, when the divergence is $\frac{1}{2}$ (Fig. $6 \mathrm{~A}$ ), starting with any leaf 0 , the insertion of the next leaf, in succession on the stem, which may be numbered 1, will be on the opposite side to that of the leaf 0 ; and the next leaf, numbered 2, will be opposite to 1 and exactly above 0 . Thus there are two orthostichies. But since each leaf is at a different level, in proceeding from leaf 0 to $1,2,3$, and so $c n$, always in the same direction, the circumference of the stem is traversed in a spiral which, in the course of each whole turn, touches the bases of two leaves and intersects the same orthostichy. This spiral will pass through the insertion of every leaf, and as it does so in the order of their development, it is known as the genetic spiral. The number of leaves through which the genetic

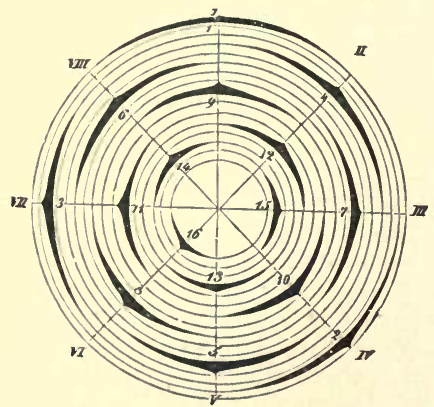

FiG. 7.-Diagram of a stem with a constant divergence of if: I, II, III, etc., the orthostichous lines. (After Sacbs.) spiral be followed in the other direction. If it be continued in this direction, it will pass round the stem twice in each spire. For the sake of simplicity, the spiral is not traced in this longer way, but in the shorter way. When the numerator of the fraction of divergence is not 1 , but some other rational number, the spiral passes round the stem more than once within the spire, in fact, just as many times as is expressed by the numerator of the fraction of divergence; the denominator of the fraction expresses the number of the orthostichies. In Figs. 7 and 8, which represent a constant divergence of $\frac{s}{8}$, it is easy to see that eight orthostichies are present, leaf 9 being over 1, 10 over 2, and so on; also that the spiral returns to a leaf on the same orthostichy after three turns, and thus goes thrice round the stem in one spire. 
If it is required to determine the arrangement of the leaves (phyllotaxis) on a stem, it is necessary to find the leaf which is exactly above the one, numbered 0 , selected as a starting-point, and then to count the number of leaves which are met with in following the shorter spiral round the stem between these two leaves. The number of the leaf which lies in the same orthostichy is the denominator of the fraction of divergence, and the numerator is the number of turns made by the spiral between the two leaves.

When the number of orthostichies is greater than 8 , it becomes very difficult to detect them, particularly when the leaves are closely arranged as in the rosette of the House-Leek, the florets in the capitulum of the Sunflower, or as the scales in a Fir-cone. Another set of lines lying obliquely then strike the eye, called parastichies, which also run round the stem in a spiral, but touch only some of the leaves; for instance, in Fig. 8, the line which connects the leaves $3,6,9$, and 12 . It is evident that the number of parallel parastichies must be as great as the difference between the numbers of the leaves in any one such line. Thus in Fig. 8, again, another parastichy connects the leaves $2,5,8,11$, and so on; and a third, the leares $1,4,7$, 10 , etc. From this it is possible to deduce a simple method for ascertaining the phyllotaxis in complicated cases; the parastichies which run parallel in one direction are counted, and the leaves in one of them are numbered according to the above-mentioned rule; by repeating the process in another system of parastichies which intersects the first, the number of each leaf will be found.

The commonest divergences are the following :

$$
\frac{1}{2}, \frac{1}{3}, \frac{3}{5}, \frac{8}{8}, \frac{5}{13}, \frac{8}{21}, \frac{13}{34} .
$$

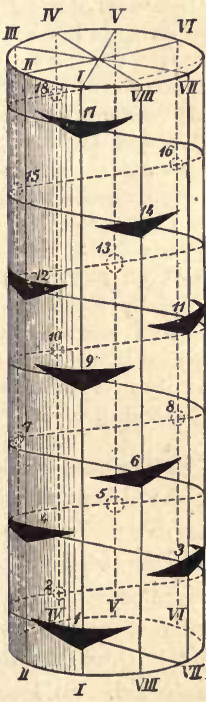

FiG. 8.-Diagram of a stem the leaves of which have the constant divergence of t, the leaves of the anterior surface are indicated by their insertions, those of the posterior by circles; they are connected by eight orthostichies, I, I ,II, II, etc.

This series is easy to remember, for the numerator of each fraction is the sum of those of the two preceding, and it is the same with the denominator. There are, however, divergences 
which are not included in this series, e.g. $\frac{1}{4}, \frac{2}{7}, \frac{2}{9}$, etc. In some cases the construction of a spiral with a constant divergence is impossible, as in Salvinia.

The causes of this regularity of arrangement of the leaves lie partly in the mode of origin of the leaves at the apex of the stem, and partly in the displacements which they undergo in the course of their subsequent growth.

Instances of the divergence $\frac{1}{2}$ : all Grasses, and the smaller branches of the Elm, the Lime, the Hornbeam, and the Beech; in these, particularly in the last, the leaves undergo displacement, so that on the under side of the branch the divergence is less, and on the upper side it is greater than $\frac{1}{2}$.

Divergence of $\frac{1}{3}$ is found in all the Sedges, and in the branches of the Alder and Aspen.

Divergence of $\frac{2}{5}$ may be regarded as the most frequent; it occurs in many herbaceous plants and in most of the smaller branches of the Willow, the Poplar, the Oak, the Rose, the Cherry, and the Apple.

The acicular leaves of the Firs and Spruces usually have a divergence of $\frac{3}{8}$ and $\frac{5}{13}: \frac{8}{21}$ occurs very commonly in the cones.

Finally, it may be observed that the genetic spiral turns sometimes to the right and sometimes to the left on the stem; in botanical terminology, a spiral is said to be right-handed when it runs in such a direction that if the observer ascended along it he would have the axis on his right; and left-handed, when it runs in the contrary direction.

It has been already pointed out that these laws of position stand in the closest relation to the progressive development of the lateral members. It can be demonstrated that the relation of position, when once established, is maintained, because each new lateral member arises just at the spot on the growing-point where there is the greatest amount of space between the members already formed, and it thus falls into the order which its predecessors have established. So long as the relation of size between the rudiments of the lateral members and the surface of the common axis remains constant, the divergence will likewise remain constant; but if this relation be altered, if, for example, the newly developed members are smaller than their predecessors, it will be readily understood that the number of orthostichies and parastichies must be increased. Hence we find changes in the divergence taking place just in those regions in which the size of the lateral members alters, for instance, at the base and at the apex of Pine-cones, and at the base of the inflorescences of Compositæ. Furthermore, subsequent alterations may be induced by the growth either of the axis or of the developing lateral members. 
2. Isobilateral Arrangement obtains when similar lateral members arise on two diametrically opposite sides of the common axis, and thus form two rows or orthostichies. Usually the members of the two rows arise at different levels, so that they alternate (Fig. $6 \mathrm{~A}$ ). In this case, also, it is possible to construct a genetic spiral; such that at every half-turn it passes through the insertion of a lateral member, and connects all the existing members in the order of their age. Since the divergence is $\frac{1}{2}$, it is obviously quite immaterial in which direction this spiral may be traced. Examples of this alternate arrangement are given on the previous page. It is only rarely that the members of the two rows stand in pairs at the same level, thus forming superposed whorls of two members each; this is the case with the leaves of many Naiadacer, probably in consequence of subsequent displacement.

3. Dorsiventral Arrangement. This arrangement of lateral members may be manifested in very different ways. In some cases the common axis bears lateral members on one side only; in others, the common axis bears dissimilar lateral members on its different sides. As examples of the former, the flowering shoots of Vetches and their allies, which bear flowers on one side only, may be mentioned. The stem of Marsilea is an example of the latter; it bears leaves on the dorsal surface, lateral branches on the flanks, right and left, and roots on the ventral surface : this relation holds good also in the case of Azolla and Pilularia. In Salvinia the dorsal surface of the stem bears the foliage-leaves, the flanks the branches, and the ventral surface the aquatic leaves : in Selaginella, likewise, the leaves are borne on the dorsal and ventral surfaces, and the branches on the flanks. In Utricularia and in the inflorescence of the Boraginaceæ, the branches are borne on the dorsal surface, the leaves (when present) on the flanks. In the Lemnacer the branches are produced on the dorsal, the roots on the ventral, side of the shoot.

The members borne on the flanks, in these cases, are in rows, one on each flank; and a similar serial arrangement can usually be traced in the members borne on the dorsal and ventral surfaces. Thus, in the inflorescences of the Boraginaceæ, the flowers are arranged in two longitudinal rows; in those of the Vetches there may be two rows (Vicia Faba, commonly), or many rows (Vicia Cracca). Similarly in some Ferns (Lygodium palmatum, Polypodium Heracleum) there is a single dorsal row of leaves. In Azolla, Pilularia, and Marsilea, there are two dorsal rows of leaves;

I.B. 
in Selaginella there are two ventral and two dorsal rows of leaves, and in Salvinia two ventral and four dorsal rows.

The whorled arrangement is not excluded by dorsiventrality: for instance, in Salvinia, the leaves are arranged in alternating whorls of three, two of the leaves being borne dorsally, and the third ventrally, and thus the four dorsal and the two ventral rows of leaves are produced.

The affinity between the dorsiventral arrangement and the isobilateral is indicated by the fact that whilst many axes develope their lateral appendages on their flanks, they eventually come to be dorsal. For instance, the creeping shoots of Butomus and other plants produce their leaves in two lateral rows, which, however, eventually undergo displacement on to the dorsal surface: again, in the twigs of the Beech, the two rows of leaves approach each other on the ventral surface, and the lateral branches approach each other on the dorsal (p. 16).

Dorsiventral or isobilateral arrangement may not uncommonly be found in the same plant with radial arrangement, but in different parts: thus in the Hornbeam and the Elm the leaves of the primary shoot of the seedling are arranged radially, whilst on the twigs of the adult plant the leaves are arranged bilaterally (see p. 16).

§ 7. Development of Branch-Systems. Just as it is possible to ascertain the laws governing the relative positions of all members growing in acropetal succession from a study of the leaves (which are alway developed in that order), so the study of the branching of stems will lead to the general laws which regulate branching. Any member with its branches composes a branch-system; and every branching member is, with reference to its branches, the axis of a system. The following types of branch-systems may be distinguished, according to the arrangement of the members :-

1. The branching is termed a Dichotomy or Polytomy, when the direct apical growth of a member ceases, two or more growing-points which are equally vigorous, at any rate at their first development, being formed at the apex. The member which bears the branches is called the base or podium, and each of these branches may become the base of a new dichotomy or polytomy. They may either continue to grow with equal vigour, and then, in the case of a dichotomy, the branching remains distinctly bifurcate (Fig. $9 \mathrm{~A}$ ); as in the leaf of Schizcea dichotoma, where 
the branches all lie in one plane, and the roots of Selaginella, where the branches lie in various planes: or the system may become sympodial, if at each bifurcation one branch becomes more strongly developed than the other; in such a case the bases of the successive bifurcations appear to constitute an axis, which is called the pseud-axis or sympodium, on which the weaker branches appear as lateral branches (Fig. $9 \mathrm{~B}, \mathrm{C}$ ). The sympodium may consist of bifurcations belonging to the same side of the successive dichotomies, either to the left or to the right (Fig. $9 \mathrm{~B}$ ), when it is said to be a helicoid (bostrychoid) dichotomy, e.g. the leaf of Adiantum pedatum: or it may consist alternately of the right and left bifurcations of successive dichotomies (Fig. $9 \mathrm{C}$ ), when it is said to be a scorpioid (cincinnal), dichotomy, as in the stem of most Selaginellas.

2. The branching is said to be racemose when the member continues to grow in its original direction, and produces lateral branches in acropetal succession behind its apex; it is therefore the common base of all the lateral shoots, and hence the system is termed monopodial. Each branch may subsequently branch again in the same manner. The primary axis continues to grow more vigorously than the lateral axis, and each lateral axis stands in the same relation to its lateral axes.

3. The branching is said to

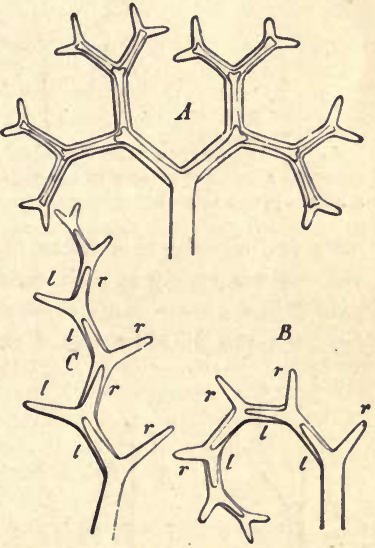

FiG. 9.-Diagram of the various modes of development of a dichotomons branch-system. 4 One developed by repested bifurcation. $B$ Hellcoid dichotomy; here the left-hand branch is always more vigorous than the right $(r)$. $C$ scorpioid dichotomy; the right and left branches are alternately more vigorons in their growth.

be cymose, when at an early stage the growth of each lateral axis begins to be more vigorous than that of the primary axis above the point of origin of the lateral axis, and when the lateral axis becomes more copiously branched than the primary axis. Hence two forms may arise :

(a) There may be no pseud-axis; this is the case when two or 
more lateral axes are developed in different directions and grow with nearly equal vigour (Fig. 10) and more vigorously than the

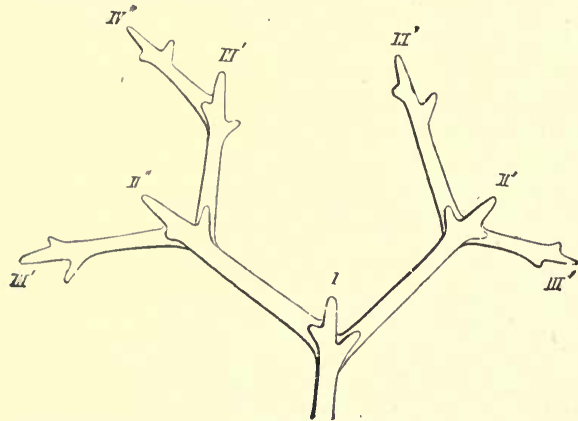

F1G. 10,-Diagram of a False Dichotomy or Dichasium; the Roman numerals indicate the order of development of the shoots of the nj stem. (From Sachs.)

primary axis, which soon ceases to grow ; such a system has a certain resemblance to a dichotomy or polytomy, and is called a false dichotomy (Dichasium) or a false polytomy (Polychasium): or ( $\beta$ ) a pseudaxis is formed ; this takes place when only one lateral axis developes vigorously in each case, as in Fig. $11 A$ where the lateral axis 2 has grown more vigorously than the mother-axis 1, and so on. (In the diagram the dark lines indicate the more vigorous
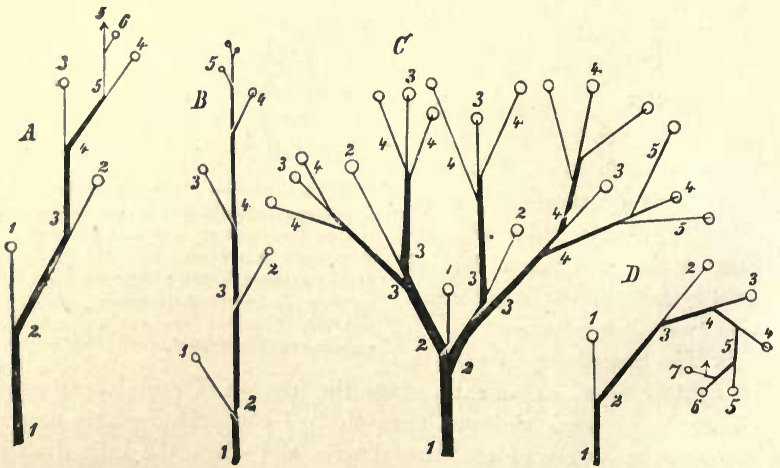

Fre. 11.-Cynose branchings represented diagrammatically. A B Scorpioid (cincinnal) cyme. C Dichasial cyme. D Helicoid (bostrychoid) cyme. The numerals indicate the order of succession of the lateral shoots which spring from ench other. (Figs A B and D are ground-plans; Fig. C is a projection int' the plane of the paper.) 
growth.) The pseud-axis which is thus formed is at first crooked, but in most cases it subsequently becomes straight (Fig. $11 \mathrm{~A}$ becomes $B$ ). If the stronger growth always occurs in the lateral shoots of the same side, the system is called a helicoid cyme (Fig. $11 \mathrm{D})$; if alternately in those of both sides,-it is called a scorpioid cyme (Fig. $11 A, B$ ). Such a branch-system is said to be sympodial.

As examples of these various modes of branching, the inflorescences, which will be treated of subsequently (Part IV.), may be especially mentioned; the following are selected from the vegetative organs:

Racemose branching is very evident in Conifers; the trunk is always more strongly developed than its lateral branches, and these than their lateral branches.

False Dichotomy is exhibited in the stem of Viscum, the Mistletoe, the apex of which either terminates in a flower or else dies; only the axillary buds of the two leaves develope into new annual shoots. As regards. the arrangement of the annual shoots, the same occurs in Syringa, the Lilac, in which the axillary buds of the uppermost pair of leaves form. the continuations of the stem, whilst the terminal bud dies; also in Rhamnus cathartica, in which the main axis is metamorphosed into a: thorn. In this case the branching of each annual shoot is racemose, but the successive annual shoots form a cyme.

The succession of the annual shoots of many trees, as the Birch, Elm, Beech, and Hazel, affords examples of the sympodial cyme; in these, each

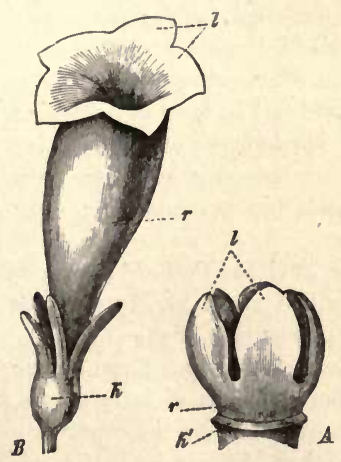

Fi木. 12.-Flower of Petunia: A very young ( $\times 50) ; B$ mature (nat. size); $k$ the calyx; $k^{\prime}$ the line along which the calyx has been removed; $r$ the tube, $l$ the lobes or teeth of the corolla. annual shoot either terminates in a flower, or it dies, and the uppermost lateral bud forms its continuation. Here, also, the branching of each annual shoot, apart from its apex, is racemose.

\section{§. Cohesion and Ad-} hesion. It sometimes happens that the originally free edges of parts subsequently grow together; for instance, the margins of the carpellary leaves to form ovaries. As a rule the rudiments of distinct members become united into one whole by the growth of their common base. For example, a gamopetalons corolla (see Part IV.) arises in this way, that the whorled leaf-rudiments are raised up by. 
the intercalary growth of their common base (Fig. $12 A, r$ ), and cnme to be merely lappets on the rim of a tube (Fig. $12 B$ ). This explanation applies also to perfoliate and connate leaves (see Fig. 20).

The union brought about in either of these ways may affect members developed at the same level, or members developed at different levels; in the former case the term cohesion is used; in the latter, the term adhesion. Examples of the former are afforded by gamopetalous corollas, syncarpous ovaries, etc.; and of the latter by epipetalous stamens, by leaves adhering to the shoots borne in their axils, as in the Lime, etc.

$\S 9$. The Thallus. The thallus offers considerable variety of form. It may be spherical ; or filamentous, branched or unbranched; or a flattened expansion, branched or unbranched; or a massive tuberous body. It commonly bears hairs. The symmetry of the thallus is multilateral, isobilateral, or dorsiventral. Complete multilateral symmetry is exhibited when the thallus is spherical (e.g. Volvox, Fig. 1); isobilateral symmetry when the thallus is flattened (e.g. Desmids, Coleochæte) with similar surfaces; dorsiventral symmetry, when the thallus is flattened, with dissimilar dorsal and ventral surfaces (e.g. most Hepaticæ, and Fern-prothallia).

The branching of the thallus takes place in accordance with the general laws laid down in $\S 7$; the flattened thallus frequently branches dichotomously (e.g. some thalloid Hepaticæ). The main axis and the branches may be either limited or unlimited in growth.

The branches of the thallus may be modified in form in connexion with some special function. Thus, the development of reproductive organs is in some cases confined to certain branches, and these then differ in form from the ordinary vegetative branches (e.g. some Hepaticæ).

$\S 10$. The Shoot. The shoot may be either thalloid (see p. 3) or leafy. The morphology of the thalloid shoot hardly requires special consideration : it is much the same as that of the thallus.

The general form of the leafy shoot varies widely. Even on one and the same plant there may be different forms of leafy shoots, the differences being due either to peculiarities in the conditions of development, or of function. Marked differences exist, for instance, between submerged, or subterranean, and aerial shoots; also between vegetative shoots and those bearing the reproductive organs. 
The form of the shoot depends largely upon the amount of elongation which the internodes of the stem undergo. Thus, there is in some plants (e.g. the Larch, Pine, and Taxodium, among the Coniferæ; and many Angiosperms) a well-marked distinction of two forms of vegetative shoots. These are the ordinary elongated branched shoots; and short shoots, termed divarf-shoots, which elongate but little, branch scarcely at all, and are frequently of but short duration (see p. 9). Again, in some plants (e.g. most Ferns and Conifers) the primary shoot continues to grow throughout the life of the plant; whilst in others, the growth of the primary shoot is limited, the further development of the shoot being effected by a lateral branch, itself of limited growth; so that, by the repetition of this process a cymose branch-system is produced (see p. 21). This mode of development by innovation occurs in many so-called uniaxial plants whose primary shoot terminates in a flower; and in the seedlings of the Lime, and of the Elm, which form no terminal bud at the close of the first year, the further development of the shoot being effected by the highest lateral bud.

In plants which live for more than one year, the shoot may either persist from year to year, or it may die down to the surface of the soil in each year, the subterranean parts being alone persistent. Shoots which last only one year are termed annual.

In those shoots of trees which are produced in one season's growth, the lowest internodes, especially those lying between the bud-scales, are very short; so that it is easy, by noticing the closely-arranged scars of the budscales, to determine, in a shoot several years old, the amount of growth during each year. The terminal and the lateral buds of such an annual shoot usually remain in the bud-condition during the first year until the beginning of the next period of growth, so that the age of such a branchsystem can be determined by the extent of the branching, the number of years corresponding to the number of times that branching has taken place. In some trees, however (e.g. the Oak), a second shoot, which had hitherto existed in the bud-condition, is regularly developed in the middle of summer. As a general rule, it is only the more anterior (near the apex) of the lateral buds on the shoot which develope in the subsequent year into branches, as is very clearly seen in the whorled branches of the Coniferæ; when, however, the more posterior lateral buds do develope, the branches produced are successively the shorter the further they are from the apex (e.g. Elm). Whilst in many trees (Coniferæ, Oak) the terminal bud of a shoot always grows into a new shoot in the next year, in others (Lime, Elm, sometimes Beech) this is not the case, but the elongation of the shoot is effected in a sympodial manner by means of the highest lateral bud (see p. 21).

In the Larch, the dwarf-shoots bear the fascicled leaves, and spring 
from the axils of the leaves of an ordinary shoot of the same year; they usually elongate but slightly each year, but they may, under certain circumstances, develope into ordinary shoots. In the Scotch Pine, the dwarfshoots bear only two green leaves, in addition to scaly leaves; they arise in the axils of the scaly leaves of the ordinary shoots of the same year, and

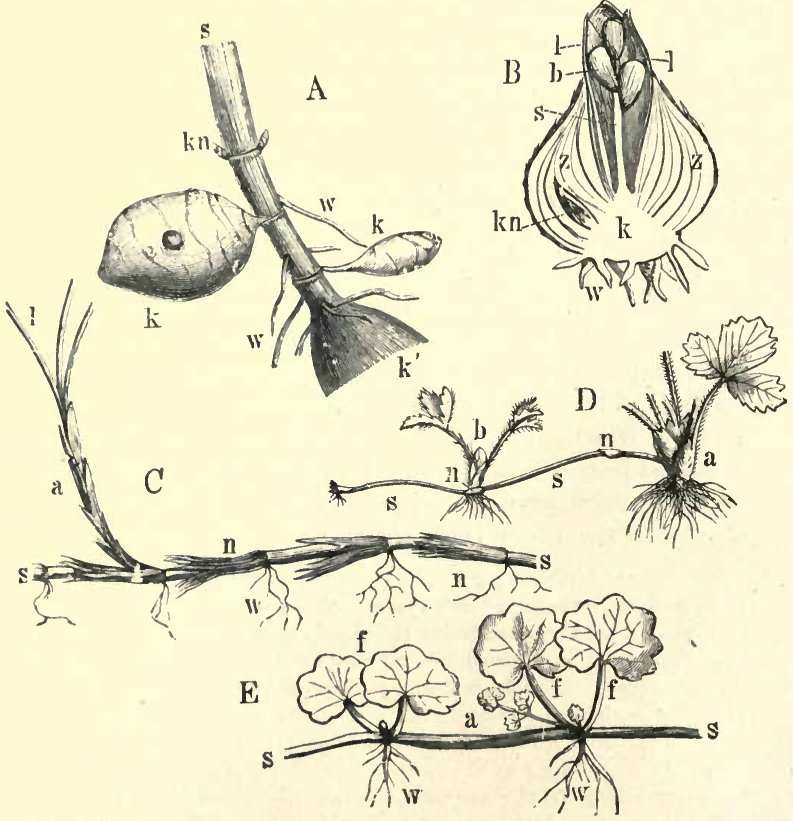

F10. 13.-Varions forms of shoots. A Tubers of Helianthus tuberosus ( $\frac{2}{3}$ nat. size); s lower part of the stem springing from last year's tuber $k^{\prime}$; in the axils of the npper leaves arise the buds $k n$, and in those of the lower leaves the tnbers $k$ with very small scaly leaves and buds. B Bnlb of Hyacinthus orientalis (reduced); $k$ the discoid stem, $z$ the scaly leaves, s the stalk whlch subsequently elongates and bears the flowers above gronnd, witb the bads $b$; 1 folisge-leaves ; w roots; $k n$ an axillary bad which becomes next year's bulb. C Elongated rhlzome of Carex Arenaria ( $t)$; scaly leaves $n$; $a$ erect shoot with scaly and folisge-leaves I. D Runner s of the Strawberry, Fragaria (reduced), springing from the plant $a$, with scaly leaves $n$, from the axil of which a new leafy shoot $b$ arises. $E$ Creeping shoot of the Ground Ivy, Glechoma hederacea (reduced); $f f$ decussate leaves ; the internodes are twisted; $a$ axillary shoot; $w$ root.

they fall off when the leaves die. In dicotyledonous trees, these dwarfshoots occur especially in advanced age, or when the growth of the tree is stunted. They are very conspicuous in the Apple, Pear, and other 
similar trees, and are the only parts of the tree which produce flowers and fruit: they are the fruit-spurs.

The Bulb and the Corm are examples of shoots with short stems; they are, in fact, forms of the bud produced underground.

The $B u l b$ consist of a flattened discoid stem, bearing a number of scaly leaves closely arranged on its upper surface, and roots on the lower surface. The leaves may either invest each other, as in the Onion, when the bulb is said to be tunicate (Fig. $13 \mathrm{~B}$ ); or they may only overlap at their edges, as in the Lily, when the bulb is said to be imbricate.

Aerial buds develope in some plants into small bulbs, termed bulbils, as in Lilium bulbiferum, Dentaria bulbifera, and in some species of Onion.

The Corm consists of a rounded or flattened stem which occupies a relatively larger proportion of space than that of the bulb, and is invested by only a few scaly leaves. It cccurs in Crocus and other Irideæ.

The Tuber is a dwarf-shoot, consisting of a swollen stem bearing small,

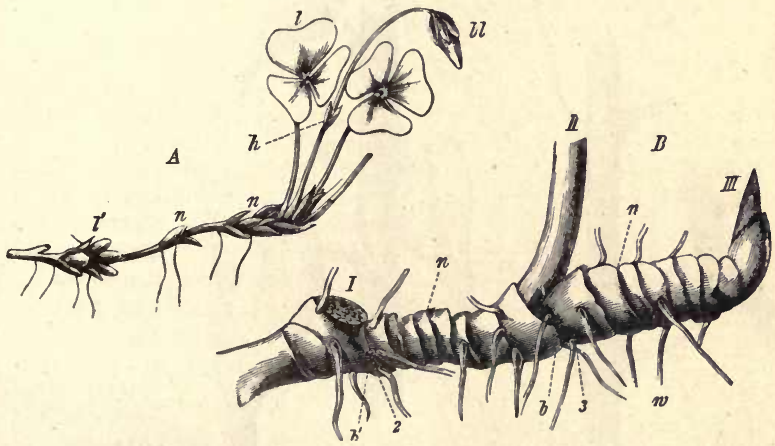

Frg. 14.-A Rhizome, with nnlimited growth, of Oxalis Acetosella (wood-sorrel); $n$ scales; $l$ foliage-leaves; $l$ 'remains of older foliage-leaves; $b l$ flower; $\boldsymbol{h}$ bracts. $\boldsymbol{B}$ Rhizome with limited growth of Polygonatum officinale (Solomon's Seal); I scar of last year's herbaceons aerial shoot; II aerial shoot of this year, which is the anterior portion of the shoot 2; III bud of next Jear's herbaceous aerial shoot, which is the continuation of the shoot 3 ; $n$, scales; $b$ and $b^{\prime}$ leaves from the axils of which the shoots 2 and 3 have arisen ; $v$ roots.

scaly leaves; it is usually developed underground, as in the Potato and and the Jerusalem Artichoke (Helianthus tuberosus, Fig. 13 A).

The morphological nature of the tuber is readily demonstrated by uncovering the underground shoots of a Potato-plant, when they develope into ordinary foliage-shoots. Again, if the development of tubers be prevented by cutting off the underground shoots, the buds in the axils of the leaves above the ground develope into tubers.

The Flower is another form of dwarf-shoot, the leaves of which, when present, are arranged closely together. The morphology of the flower is discussed in subsequent paragraphs. 
Shoots may grow erect into the air; or they may grow horizontally either above or below the surface of the soil.

A shoot which grows horizontally on the surface of the soil is termed a creeping shoot (Fig. $13 \mathrm{E}$ ).

The Runner or Stolon is allied to the creeping shoot. It is an elongated lateral shoot which takes root at some distance from the parent plant, and which by the dying away of the intermediate portion, becomes a new indivilual. The runner may grow either just above (Fig. $13 D$ ), or just below the surface of the soil; it bears sometimes scaly leaves, sometimes foliageleaves (e.y. Hieracium Pilosella). Runners usually spring from shoots

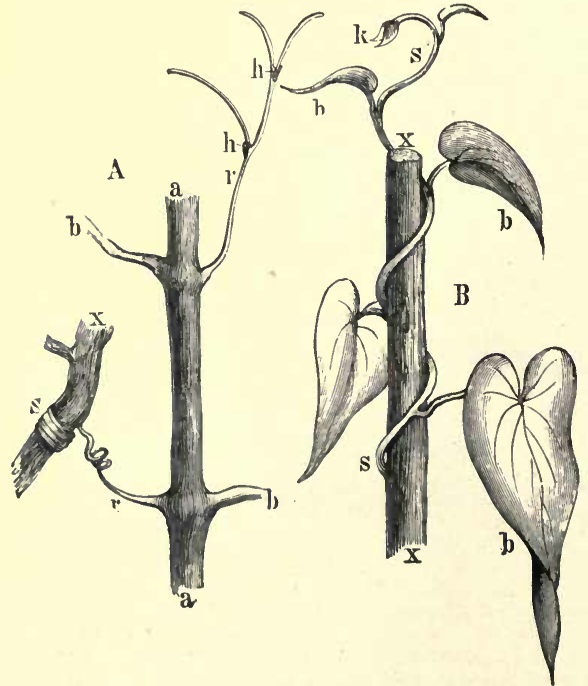

Fig. 15. -A Part of the shoot of the Vine ( nat. size) with two tendrils $r r$; the npper one bears small leavas $h$ and branches; the lower one has become attached to a support $x$ and has rolled up spirally; $b$ b petioles; in this case the tendrils are branches which are peculiar in that they are opposite to the leaves. $B$ Twining shoot of Ipomcea 8 , with leaves $b$ and a bud $k ; x x$ is the snpport. with limited growth, but s o me $\mathrm{imes}$ from those with unlimited growth, e.g. Struthiopteris.

Wh e $\mathrm{n}$ a shoot grows horizontally beneath the soil, it is termed a $R h i$ zome. It is $\mathrm{ch}$ a racteristic of those plants the subterranean parts of which alone are persistent. The growth in length of the rhizome is sometimes unlimited, sometimes limited. Whe $n$ the former is the case, it continues to elongate at its a pex, and bears either only foliage-leaves (e.g. Pteris aquilina); or foliage-leaves and scales in regular alternation (Fig. $14 A, l, n$ ), in the axils of which annual shoots arise; or only scales in the axils of which annual shoots bearing foliage-leaves and flowers arise, as in Herb Paris. More commonly, the growth in length is limited, in which case the apex grows out into an aerial annual shoot, whilst from the axil of a leaf at its base one 
or more subterranean shoots are produced which carry on by innovation the elongation of the rhizome. If the older portions of the rhizome persist for a long time, the basal portions of the annual shoots together form a sympodium (Fig. $14 B$ ); if, however, they soon perish, then each annual shoot appears to constitute a distinct individual (e.g. Ranunculus acris, Neottia). It is by the simultaneous formation of a number of short innovation-shoots that the tufts of Grasses and Sedges are produced. The innovation-shoots commonly develope roots of their own, but they may remain connected with the main root of the plant as in Anemone Pulsatilla.

In rare cases (Psilotum among Vascular Cryptogams) the functions of roots are performed by subterranean shoots; these shoots are more slender than the subaerial shoots, and bear the merest rudiments of leaves.

Shoots which are unable to grow erect by themselves obtain, in some cases, the advantages of that position by climbing. The structure of the shoot may be modified so as to subserve climbing. Branches are in some cases (Uncaria) developed in the form of hooks, and may or may not bear leaves; these hooks serve to attach the plant to others. In other cases, branches bearing small scaly leaves are developed into tendrils, which twine round supports. In other cases the whole shoot twines round a support (Fig. $15 \mathrm{~A}, \mathrm{~B}$ ).

Branches are sometimes developed as thorns (Fig. 16). Thorns are hard, pointed structures; they sometimes form the extremity of an ordinary shoot, as in Rhamnus cathartica; or they are dwarf-shoots, as in Cratogus coccinea; they may bear branches which spring from the axils of scaly leaves, as in Gleditschia and the Sloe (Fig. 16).

The morphology of the constituent members of the leafy shoot, namely the stem and the leaf, will now be considered.

$\S 11$. The Stem. The stem of an annual plant or of an annual shoot is succulent in texture, and is said to be herbaceous.

A primary stem which persists for several years, though it is herbaceous at first, becomes hard and woody in texture, and is termed a trunk.

The stem is commonly branched; but it may be unbranched, as in Tree-Ferns, Cycads, many Palms and Grasses.

The form of the stem varies very. widely. It may be short and much thickened, as in the bulb, corm and tuber, mentioned above (p. 24) and in some Cacti; or a portion of it may be

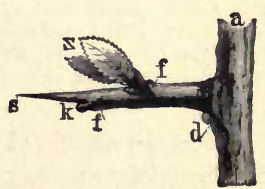

Fig. 16.-Thorn of the sloe, Prunus spinosa : a branch, $d$ leaf-8car, from the axil of which the thorny branch $z$ springe; on the thorn are $f f$ leaf-scars; in the axil of the upper one is the branch $z$, in that of the lower, the bud $k$. much thickened into a tuber, as in certain epiphytic Orchids, where one or more of the basal internodes form a pseudo-bulb 
and in Vitis gongylodes, where any internode may become tuberous.

The form of the elongated stem is commonly cylindrical or prismatic. The prismatic form is, in some cases, determined by the arrangement of the leaves ; thus, stems bearing decussate leaves (see Fig. 4, p. 12), that is, leaves arranged in four orthostichies, are quadrangular. When the stem has an angular form, the edges frequently grow out into a leafy expansion: such a stem is said to be vinged. In some cases, as in Grasses, Bamboos, Pinks, etc., the stem presents a jointed (tumid) appearance at the nodes; a stem with this peculiarity is termed a culm or haulm.

When the development of the foliage-leaves of a shoot is degenerate, the stem performs the functions of the leaves: it is then of a green colour, and generally assumes such a form as to have a

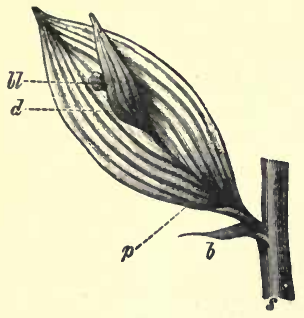

F1G. 17. - Phylloclade of Ruscus Hypoglossum (nearly nat. size) : s stem; $b$ leaf, in the axil of which the phylloclade $p$ is developed; $d$ leaf of the phylloclade bearing flowers $b l$ in its axil. relatively large surface. Thus, the whole stem and its branches may become flattened, as in Opuntia (Cactaceæ) and in Genista sagittalis (Papilionaceæ): or certain branches only, termed phylloclades, are flattened and leaf-like as in Ruscus (Liliaceæ), Phyllanthus (Euphorbiaceæ), Mühlenbeckia (Polygonaceæ), Carmichaelia (Papilionaceæ), Phyllocladus (Coniferæ), and are either isobiliterally or dorsiventrally symmetrical. The phylloclades frequently bear flowers, but not always in the same position. Thus, in Ruscus androgynus the flowers are borne on the margin of the phylloclade; in Ruscus aculeatus and $R$. Hypoglossum, they are borne on the upper surface of the phylloclade; and in R. Hypophyllum, on the under surface.

Leaf-like branches are also formed in Asparagus; they are not flattened, but are small and acicular; something of the same kind also occurs in Equisetum.

$\S 12$. The Leaf. All leaves, except the primary leaves or cotyledons, are developed exogenously as lateral outgrowths upon the growing-point of a stem.

In most plants the leaf undergoes differentiation or segmentation along its longitudinal axis or phyllopodium. In the most com- 
plete case, the phyllopodium is differentiated into three regions : a basal portion, the leaf-base or hypopodium; an apical portion, the epipodium ; and an intermediate portion, the mesopodium, leafstalk, or petiole; but the last-named portion is frequently absent. Most commonly the leaf assumes a flattened form in consequence of the development of a relatively thin membranous wing along one or other of these regions in the lateral plane: the epipodium is typically winged, and then constitutes what is known as the blade or lamina of the leaf; the mesopodium is rarely winged, the hypopodium more frequently so.

The growth in length of the leaf is at first apical in all cases; it may continue to be apical (e.g. Ferns generally); or apical growth may be early arrested, further elongation being effected by basal growth (e.g. Iris, Onion, Myriophyllum, Potentilla anserina); or, more rarely, basal and apical (e.g. Achillea Millefolium, and other Compositæ) growth may occur simultaneously.

A characteristic feature of leaves is that their growth in length is limited; but this is not without exception; in fact, there are all intermediate forms between those which have limited and those which have unlimited growth. Thus, in most Phanerogams the leaves have limited growth; the cells of the leaf are all actually formed at the time of its unfolding, and all that takes place subsequently is that the cells grow to their definitive size. In a few of these plants, however, (e.g. Guarea and other Meliaceæ) the pinnate leaves have an apical growing-point by which new cells

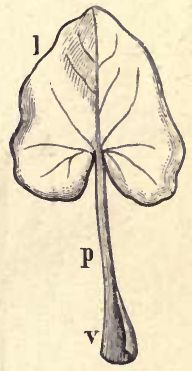

Fig. 18.-Leaf of Ranunculus Ficaria : v leaf. base (hypopodium); $p$ petiole (mesopodium) : $i$ lamina (epipodium). are formed, and the growth in length of the leaf and the development of lateral branches is carried on after the leaf has unfolded. Long-continued apical growth appears to be the general rule in Ferns: in Pteris aquilina and in Aspidium Filix-Mas the leaf grows for three years; and in Gleichenia, Lygodium, many Hymenophyllaceæ, and Nephrolepis, the leaf grows for many years after its appearance above the soil. The most striking example of long-continued basal growth is that of the two leaves of Welwitschia which persist and grow basally as long as the plant lives, and consequently attain a great length.

The leaves are inserted upon the nodes (p. 11) of the stem, the 
plane of insertion being usually transverse to the longitudinal axis of the parent stem.

The Hypopodium or Leaf-Base. The leaf-base commonly developes into a cushion of tissue, termed the pulvinus, which forms the articulation by which the leaf is attached to the stem; in the Gooseberry the pulvinus developes into a spine. In many cases the leaf-base is sheathing, and embraces a part or the whole of the circumference of the node; in the former case the leaf is said to be semi-amplexicaul; in the latter, amplexicaul (e.g. Grasses, Onion, Fool's Parsley).

The leaf-base sometimes produces a pair of opposite lateral

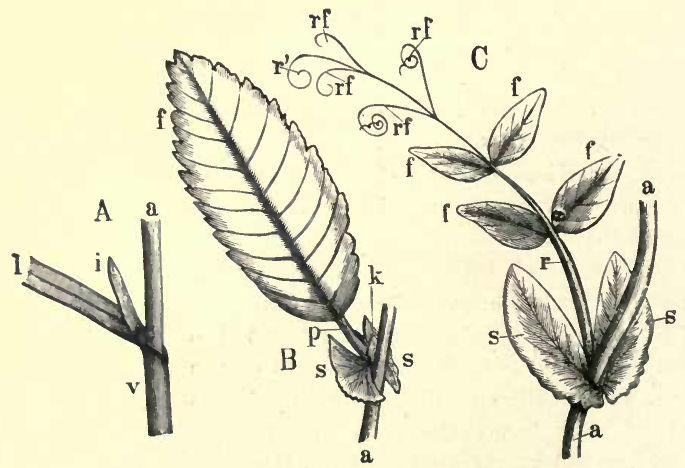

F1G. 19.- 4 Part of a sessile leaf of Grass (Poa trivialis) with the ligule $i$; $a$ the haulm; $v$ the sheathing leaf-base; $l$ lamina of the leaf. $B$ Leaf of a Willow (Salix Caprea); $a$ stem; $s$ stipnles; p petiole; $f$ lamina; $k$ axillary bnd (nat. size). C Leaf of a Pea (Pisum arvense) ; $a$ stem; s s stipules; $r$ mesopodium or petiole; $f f$ leaflets; $r f$ of the upper leaflets metamorphosed into tendrils; $r^{\prime}$ end of the epipodium, likewise transformed into a tendril.

branches which are termed stipules; when they are present the leaf is said to be stipulate, and when they are absent, as is more commonly the case, the leaf is said to be exstipulate. The stipules are commonly winged appendages, similar in colour and texture to the lamina, and they are then said to be leafy (Fig. $19 \mathrm{~B}, \mathrm{C}$ ), as in the Willow, the Violet, and the Rubiaceæ where they are branched; and they are especially large in plants, like the Pea, where the lamina is relatively small: in other plants, on the contrary, they are small brownish scales, which fall off soon after the leaf is un- 
folded, as in the Beech, the Elm, and the Lime. Sometimes the stipules appear as teeth on the upper margin of the sheathing leafbase, as in the Rose. Occasionally the two stipules are connate, that is, they are more or less united; when they cohere by their outer margins they form a single opposite stipule, opposite, that is, to the leaf to which they belong, as in Astragalus; when they cohere by their inner margins they form an axillary stipule, that is, a stipule in the axil of the leaf to which they belong, as in Melianthus and Houttynia cordata; in the Polygonaceæ they cohere by both their inner and outer margins, thus forming a tube, termed an ocrea, which surrounds the internode above the insertion of the leaf ; when the stipules of opposite leaves cohere they form on each side an interpetiolar stipule, as frequently in the Rubiacer and in the Hop; this may also take place when there are several leaves in a whorl, as in the epicalyx of certain Rosaceæ.

In some cases (e.g. Smilax) the stipules are developed in the form of tendrils, and in other cases (e.g. Robinia) as spines.

Stipules are

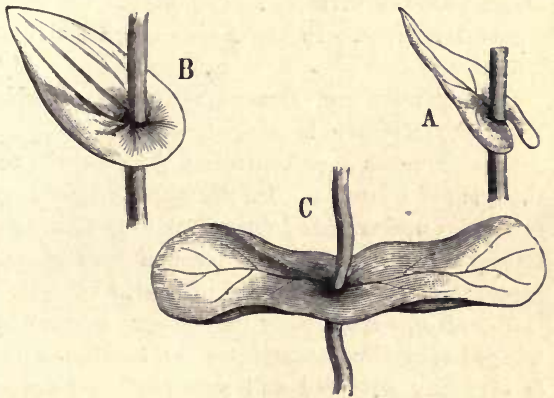

FrG. 20.-The insertion of sessile leaves. A Auriculate leaf of Thlaspi perfoliatum. B Perfoliate leaf of Buplourum rotundifolium. C Connate leaves of Lonicera Caprifolium. comparatively common in Dicotyledons; they are absent in the Coniferæ; absent in Monocotyledons, excepting the Naiadaceæ and Smilax; absent in most Pteridophyta, except the Marattiaceæ among Ferns. In Tropacolum majus only the two leaves which succeed the cotyledons have stipules.

The leaflets of a compound leaf sometimes have stipules at their bases, as in Phaseolus, which are distinguished as stipels.

In a leaf without a petiole it sometimes happens that the leafbase is winged in continuity with the lamina; the result is that the wings extend round the stem, either incompletely (Fig. $20 \mathrm{~A}$ ) when the leaf is said to be auriculate; or completely $(B)$ when it 
is said to be perfoliate; when this occurs in two opposite leaves, the leaves become connate $(C$; see p. 22$)$.

There is, in some cases, a delicate membranous ventral outgrowth on the leaf at the junction of epipodium and hypopodium, termed the ligule; it occurs in Grasses (Fig. $19 \mathrm{~A}$ ), in Selaginella and Isoetes, and in the perianth-leaves of some flowers (Narcissus, Lychnis).

The Mesnpodium or Pctiole is commouly, but not always; present. When it is present the leaf is said to petiolate; when it is absent, sessile. It is developed by intercalary growth in a portion of the primordial leaf lying between the hypopodium on the one side and the epipodium on the other. The most common form of the petiole is somewhat cylindrical; though, where the dorsiventrality of the leaf is well-marked, it is convex on the lower (dorsal) surface, and flattened or grooved on the upper (ventral) surface. In the Aspen (Populus tremula) it is flattened laterally.

Occasionally (e.g. Orange, Fig. $23 G$; Nepenthes, Fig. 28; Dionra) the petiole is winged.

In some cases (e.g. Australian Acacias) the petiole has somewhat the form of a lamina. Its flattened surfaces are directed laterally, the edges upwards and downwards, so that the symmetry is isobilateral. A petiole of this form is termed a phyllode. In such cases, the lamina, originally present, soon falls off.

The Epipodium may be either winged or unwinged. The winged epipodium constitutes the lamina or blade of the leaf, and is typically flattened and expanded in form and dorsiventral in symmetry: but this is not always the case, for in some plants it assumes the form of a sac or pitcher (e.g. Utricularia, Nepenthes, etc.), and in others the symmetry is isobilateral (e.g. adult leaves of Eucalyptus Globulus).

The form of the unwinged epipodium presents great variety; thus, in Lathyrus Aphaca the epipodium branches into leaftendrils, and this is partially the case also in the Sweet Pea (Fig. $19 \mathrm{C})$; it may be cylindrical or prismatic, as in Onion, Sedum, Mesembryanthemum, Aloe; acicular as in Pinus; narrow, and flattened anteroposteriorly (ensiform) so that the margins correspond to the dorsal and ventral surfaces of a dorsiventral leaf, with isobilateral symmetry, as in Iris and Gladiolus.

The flattened dorsiventral lamina is normally so placed with regard to the parent stem that a plane, which includes the longi- 
tudinal axes of both the stem and the leaf, cuts the lamina into two lateral halves; in other words, it is so placed that its upper (ventral) surface faces the apex of the stem, and its lower (doreal) surface is directed away from it. As a rule, the two lateral halves of the lamina are symmetrical; but in some cases (e.g. Elm, Begonia) they are unsymmetrical, when the lamina is said to be oblique.

The ultimate form of the lamina mainly depends upon the degree of elongation of the epipodium. When the epipodium elongates considerably, the lamina has a well-marked primary axis from which more or less numerous secondary axes of growth successively spring, and these in turn bear lateral axes of a higher
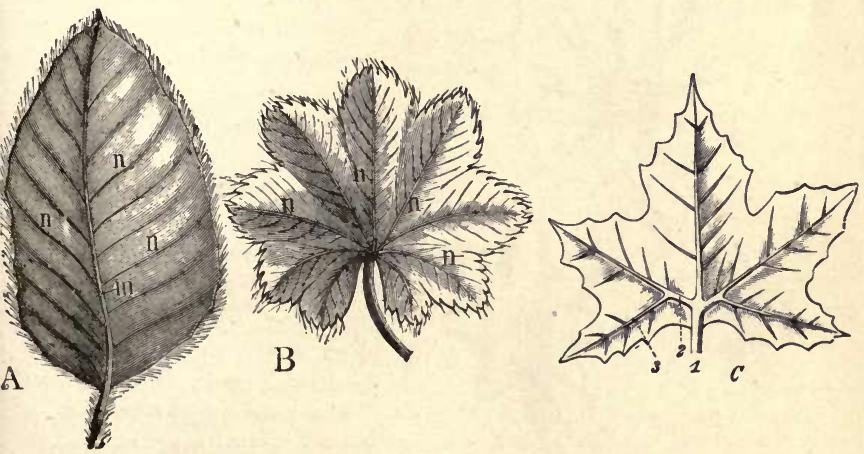

Fig. 21.-A Pinnate leaf of the Reech, Fagus sylvatica; $m$ mid-rib, $n$ lateral ribs. $B$ Palmate leaf of Alchemilla vulgaris (nat. size.) C Pedate leaf of the Plane ( $\frac{1}{z}$ nat. size). 1, 2, 3 , are the ribs or axes of the 1st, 2 nd, and $3 r d$ order.

order: the resulting lamina is then of the pinnate type (Fig. 21 A). When, however, the epipodium remains short, it constitutes merely an intercalary growing-point from which a number of equal secondary axes spring, and the resulting lamina is of the palmate type (Fig. $21 B$ ).

The development of the peltate lamina, closely connected with that of the palmate type, is effected by a peculiar form of basipetal growth. In peltate foliage-leaves (e.g. Tropæolum, Nelumbium, Hydrocotyle, Cotyledon, Lupinus, etc.) the petiole is inserted in the middle of the under surface of the lamina, so that the long 
axis of the former is perpendicular to the plane of expansion of the latter. At first the development is that of a palmate leaf, the petiole being inserted at the base of the lamina, and at the point of insertion there is an intercalary growing-point from which spring several axes (Fig. $22 \mathrm{~B}, 12,3$ ) in basipetal succession. But in this case the last-formed axes( $+-4,5-5$, in the figure) grow out in front of the petiole, with the result that the whole lamina gradually comes to lie perpendicularly to the petiole.

The main axes of growth frequently grow thicker than the rest of the lamina, so that they project as ribs on the under surface. The thickened pri-

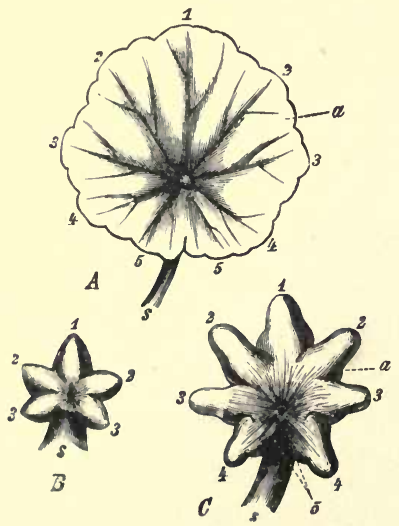

F10. 22.-Development of peltate leaf of $\mathrm{Hy}$ drocotyle: $A$ full-grown (nat. size); $B$ very young; $C$ somewhat older ( $B$ and $C \times 50$ ); $S$ petiole; 1-5 primary axes of growth in young leaves, ribs in adult leaf; $a$ secondary axes of growth. mary axis (epipodium) of a pinnate lamina is termed a mid-rib.

The Branching of the Leaf is commonly confined to the epipodium, and then it takes place in the lateral plane; less commonly it occurs in the mesopodium (e.g. species of Ophioglossum, Botrychium, Marsilea), and then (as in these plants) the branching frequently takes place in the antero-posterior (or dorsiventral) plane.

The branching of the epipodium is, like that of a stem or a root, either dichotomous or lateral, and essentially the same forms of branch-systems are produced. Dichotomous branching is comparatively rare; it has been observed in the Hymenophyllaceæ, the branches either remaining distinct or forming sympodia. The two first leaflets of Marsilea are said to be formed by dichotomy. Lateral branching is the more common form, and the resulting branchsystems are typically monopodial. But in some cases (e.g. leaf of Plane, Fig. $21 C$; of Helleborus, and of some Aroids) there is apparently cymose branching with formation of a sympodium.

The ribs of the lamina are branches of the epipodium. The 
degree of segmentation of the lamina depends upon the relation between the growth of the various main axes and the marginal growth of their respective wings (see Figs. 21 and 22). When these keep pace with each other the lamina is altogether unsegmented, that is, its margin is entire; when the growth of the axes is rather more vigorous than that of the corresponding wings, the margin becomes somewhat uneven (dentate, serrate); when the difference between them is considerable, the lamina is lobed; and when still greater, it consists of a number of distinct segments, leaflets, connected only by their common attachment to the mid-rib, in the case of pinnate leaves, or to the petiole in the case of palmate or peltate leaves. Whilst inequalities of the margin are indications of branching, the lamina is regarded as simple so long as the segmentation is incomplete; it is only when the segmentation is complete, as in the last-mentioned case, that the leaf is said to be compound.

The following examples will serve to illustrate the foregoing principles. The simple leaf of the Beech (Fig. 21) has an entire pinnate lamina; the leaf of the Shepherd's Purse (Capsella Bursa-Pastoris, Fig. 23 C) is simple, but the lamina is deeply pinnately lobed. Various forms of compound pinnate leaves are represented by Fig. $19 C$ and by Fig. $23 B, D$, $E, F, H$, where the distinct segments or leaflets, termed pinno, are inserted on the common primary axis. In $H$ each pinna is itself compound, being segmented into pinnules which bear che same relation to the secondary axis of each pinna as that secondary axis does to the primary axis of the whole leaf; such a leaf is said to be bipinnate, and when the segmentation is carried further the leaf becomes tripinnate, etc.

In compound pinnate leaves, the leaflets are commonly opposite to each other. When only one pair of leaflets is present, the leaf is said to be unijugate; when two pairs, bijugate; when many pairs, multijugate. When the axis (whether primary or secondary) is terminated by a leaflet, the leaf is said to be imprripinnate (Fig. $23 D$ ); when there is no terminal leaflet, the leaf is paripinnate (Fig. $23 \mathrm{E}$ ). When, as in the Potato and Potentilla anserina. pairs of small leaflets alternate with pairs of larger ones, the componnd leaf is said to be interruptedly pinnate. The difference in size of the leaflets is simply due to the more active growth of the larger ones.

The order of development of the leaflets of compound pinnate leaves depends upon the position of the growing-point in the longitudinal axis (see p. 29). When it is apical, the leaflets are developed in acropetal succession (e.g. Pea, Ailanthus, etc.); when it is basal, in basipetal succession (e.g. Myriophyllum, Potentilla anserina); when there is both an apical and a basal growing- 
point, in divergent succession, that is, both acropetally and basipetally (e.g. Achillea Millefolium, etc.).

With regard to palmate leaves, Fig. $23 \mathrm{~A}$ is an example of a deeply lobed lamina; and $B$, of a compound palmate leaf of the Clover in which will be observed that there are three leaflets; such a leaf is said to be
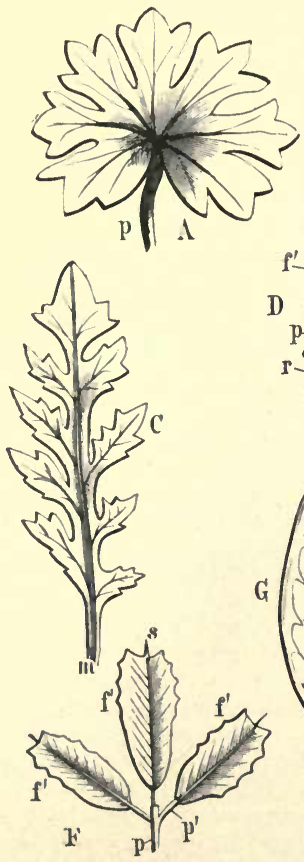

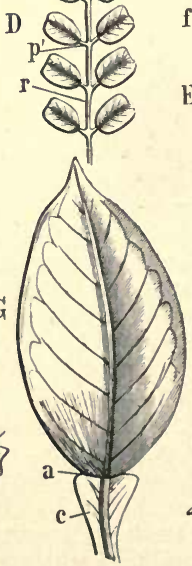

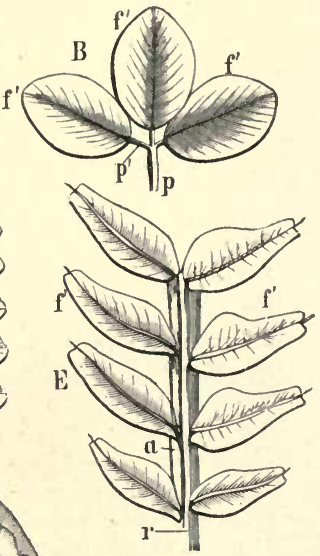

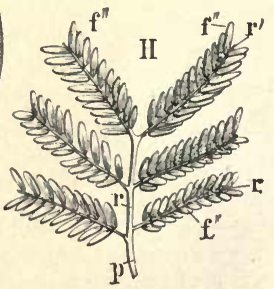

Fig. 23.-Segmentation of leaves. $p$ Petiole; $p^{\prime}$ petiolnle; $f^{\prime}$ leaflet; $r$ phyllopodinm. $A$ Palmatifid or palmately lobed leaf of Geraninm. B Ternate (componnd palmate) leaf of Clover. C Pinnatisected leat of Shepherd's Purse (Capsella). Componnd pinnate leaves: $D$ Imparipinnate leat of Hippocrepis comosa; $t$ terminal leaflet. $\boldsymbol{E}$ Paripinnate leaf of Pistacia Lentiscus; $a$ wing of the phyllopodium. F Imparipinnate nnijngate lenf of Medicago. This differs from $B$, which is ternate, inasmuch as the secondary leaf-atalks $p^{\prime}$ do not all spring from one point, but the common leaf-stalk $p$ extends beyond the insertion of the single pair of pinnæ; s projecting rib, or mucro. G Leal of the Orange; the articnlation a between the blade and the winged petiole shows that it is really a compound leaf with a single terminal leaflet. H Bipinnate leaf of Acacia : $r^{\prime}$ secondary axis; $f^{\prime \prime}$ secondsry pinnæ or pinnules. 
ternate. This segmentation may be repeated in the leaflets, when the leaf is said to be biternate, triternate, etc. On comparing Fig. $23 B$ and $F$, the close relation between pinnate and palmate leaves becomes apparent. A ternate leaf is usually considered to belong to the palmate type, but it might almost equally well be regarded as an imparipinnate unijugate leaf.

Occasionally the margin of the lamina bears outgrowths which are not connected with branching, but are of the nature of emergences, as in the Cherry Laurel, Naias, various Conifers, etc.

A number of terms are used in Descriptive Botany for the purpose of precisely describing the various parts of plants. The more important of these terms, and those the meaning of which is not obvious, will now be defined.

(1) The Outline of bilateral bodies, such as the lamina of the leaf, but of multilateral bodies, such as fruits, as well, is said to be linear when the two margins run nearly parallel to each other; e.g. the leaves of most Grasses. If the margins are curved and intersect at each end at an angle, the outline is said to be lanceolate or elliptical, accordingly as the long axis is many times longer than, or only twice as long as, the transverse axis. If the two curved margins round off at each end, then the terms oblong and oval are to be substituted for the two preceding.

If the longest transverse diameter lies relatively near to the base, then the outline is said to be ovate; if relatively near to the apex, obovate.

(2) The Apex may be either acule or obtuse; when it is long drawn out it is said to be acuminate; when there is a sharp projecting point, it is said to be mucronate (Fig. $23 F$ ); truncate, when it is, as it were, cut short across (Fig. $23 \mathrm{D}$ ); emarginate, when there is a depression in the obtuse apex; obcordate, when the apical depression is deep.

(3) The Base may be described by many of the preceding terms, but the following are especially applied to it: it is cordate when it is deeply indented in the median line; sagittate, when the lobes on each side of the indentation are angular and diverge backwards; hastate, when the lobes diverge outwards.

(4) The Margin is said to be entire when it does not present any depressions or prominences; when the prominences are slight and rounded, the margin is said to be crenate; dentate or toothed, when the prominences are pointed and stand straight outwards; serrate, when the pointed prominences slant forward.

If the incisions in the margin are deep, the part, a leaf-blade for instance, or a gamosepalous calyx, is said to be lobed when the incisions do not extend to the middle; if they extend to the middle, it is said to be partite; and dissected when they extend nearly to the base (Fig. $23 C$ ).

The segmentation of the lamina takes place in some Monocotyledons (Palms) in an altogether different manner from that described above. The lamina is at first entire, but it becomes divided by the dying away of strips of tissue. 
The Venation of the Lamina. The mid-rib and other ribs of the lamina indicate the course of the larger vascular bundles; and from these numerous branches are given off which permeate the tissue of the lamina, constituting its Venation. When the leaf decays, the ribs and the vascular tissue persist longer than than soft parts as a skeleton which retains the general form of the lamina. In Ouvirandra fenestralis most of the softer tissue decays whilst the leaf is still living, so that the lamina consists of little more than the vascular skeleton.

The main features of the venation are determined by the type of development of the lamina. In a pinnate lamina, the venation is pinnate; in a palmate lamina, palmate; in a pedate leaf, pedate; in a dichotomously branching lamina, the venation is also dichotomous, or as it is specially termed,

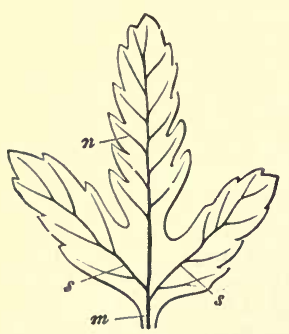

Fig. 24.-Leaf of a Young Fern, with free pinnate venation : $m$ the midrib; s the large lower lateral veins; $n$ the weak upper lateral veins. ( $\times$ 3.)

(Fig. 24); of Ginkgo (Salisburia), Araucaria imbricata and others, among Coniferæ; of most Cycads; of WaterCrow foots, etc.

$b$. The venation is said to be parallel, when numerous adjacent veins run parallel to each other towards either the apex (Fig. 25) or the margin of the blade, and then unite by curving inwards (Fig. 25 a). They are connected in their course by short veinlets (Fig. $25 v$ ) which run usually at right angles to them. This form of venation is to be found in the leaves of most Monocotyledons, such as Grasses, Lilies, and Palms, with various modifications. For example in some cases (e.g. Orchis Morio) many veins enter the blade, but they branch scarcely at all; in other cases lateral veins spring at an acute angle from a midrib which is prominent at the base at least, and then run towards the apex (e.g. Maize and other Grasses, Dracænas, etc.); in others, again, the lateral veins spring almost perpendicularly from the well-developed mid-rib, and run out to the margin 
parallel to each other, and then turn towards the apex of the leaf (e.g. Canna, Musa, etc.).

c. The venation is said to be reticulate, when the veins branch repeatedly at various angles, and the branches for the most part anastomose (Fig. 26). Some of them, however, end blindly in the meshes of the network. This kind of venation is characteristic of Dicotyledons; but it also occurs in some Monocotyledons (e.g. Paris, Dioscorea, Smilax, many Araceæ) and many Ferns.

The Different Kinds of Leaves.-The leaves of different plants, as might be expected, are not alike, but differ more or less widely in size, shape, colour, and texture. But even the leaves borne on

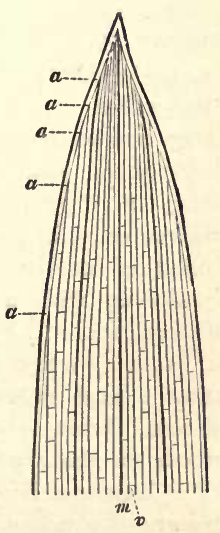

Fra. 25.-A pex of a Grass-leaf showing parallel venation: $m$ middle vein; $a$ anastomoses; $v$ veinlets. $(\times 4$.)

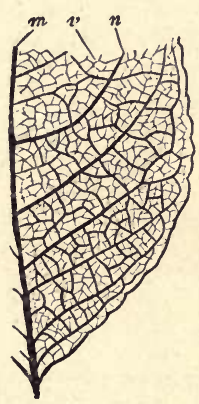

Fia. 26.-Portion of a leaf of Salix $\mathrm{Ca}$ prea with reticulate venution: $m$ midrib; $n$ the larger lateral ribs; $v$ the anastomising veins (nat. size).

one and the same plant are not all alike, the reason of their dissimilarity being that, as there are different functions to be performed, the leaves are variously adapted in form and structure to the performance of these functions.

1. Foliage-leaves are usually known simply as leaves (Fig. 27 $L)$. They are conspicuous on account of their green colour, and in accordance with their nutritive function (see Part III.) they are expanded as much as possible to the sun-light. If they are small they are very numerous (Conifers), and the larger they are the fewer they are (Sunflower, Paulownia). They nearly always 
possess a well-developed lamina, which presents the various peculiarities of conformation previously described.

The texture of the leaf is dependent upon the mode and duration of its existence. The texture of most leaves may be described as herbaceous. Leaves of this kind last usually for only a single season, and die or fall off in the autumn. Leaves of firmer texture,

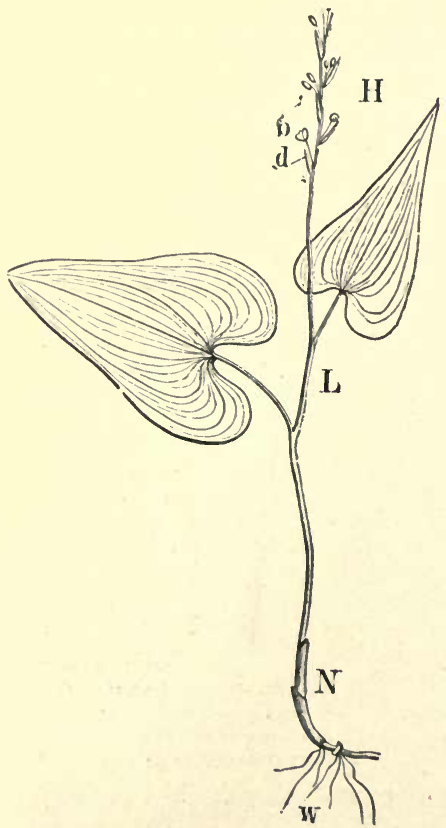

Fic. 27.-Three kinds of leaves on the stem of Maianthomum bifolium (nat. aize) : N cataphyllary region; $L$ region of the foliage-leares; $H$ hypsophyllary region; $d$ the bracts; $b$ the flowers in their axils; w roots. which are said to be coriaceous, survive the winter, and either fall off when the new leaves are developed (the Privet), or continue to live for several years (Holly, Box, and most Conifers); the acicular leaves of the latter may persist for as many as twelve years (Silver Fir). Fleshy or succulent leaves occur in plants inhabiting dry regions or positions, such as Aloe, Sedum, etc.

It is worthy of note that foliage-leaves of different form sometimes occur on the same shoot. For instance, it is commonly the case that the first leaves of young plants are of a form different from, and usually simpler than, that of those which are subsequently produced, and exhibit a greater resemblance to those of allied plants. Thus, Eucalyptus Globulus has at first oval dorsiventral leaves, and subsequently elongated isobilateral leaves. Again, the primary leaves or cotyledons, when they develope into foliage-leaves, are always different in form from the subsequently developed foliage-leaves, being much 
simpler. In many water-plants, the submerged leaves are different from those which float at the surface; thus, in many species of Potamogeton, the submerged leaves are narrow and ribbon-like, whereas the floating leaves are broadly elliptical ; in many aquatic species of Ranunculus, the former are finely diyided, whereas the latter have a circular lamina. Again, the submerged leaves of Salvinia are filamentous, whereas the floating leaves are flattened and oval.

The simultaneous occurrence of two forms of foliage-leaf on a plant is termed heterophylly.

In certain plants the foliage-leaves assume remarkable forms in connection with their adaptation for catching small animals or for collecting water (e.g. Nepenthes, Cephalotus, Sarracenia, Utricularia, Dischidia, etc.). In these the lamina is metamorphosed into a pitcher or ascidium. The development of the pitcher begins in very much the same way as that of the lamina of a peltate leaf; but instead of remaining flat, it becomes tubular by continued basal intercalary growth (see p. 34). The leaf may, as in Sarracenia and Darlingtonia, be sessile; or it may be petiolate, as in Cephalotus and Nepenthes: in $\mathrm{Ne}-$ penthes (Fig. 28) the petiole is winged for some distance in its lower portion. The lid, when present, is a development of the apical, or sub-apical (Nepenthes), portion of the lamina; as its first development it adheres firmly to the rim of the ascidium, from which it eventually separates, except at the point of attachment; the lid is bilobed.

2. Leaf-Tendrils (see p. 32) are leaves or parts of leaves which have

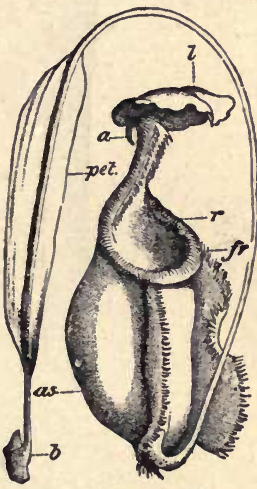

FiG. 28.-Pitchered leaf of Nepenthes : a organic apex of lesf ; $b$ leaf-base; pet petiole, winged in its basal portion; as ascidium; $l$ its lid; $f r$ fringe of ascidium (reduced). a somewhat filamentous form, and which possess the property of twisting spirally round foreign bodies, thus fixing the plant (see Part III.). In species of Clematis, Tropæolum, etc., this function is performed by the petiole of the foliage-leaf; but in the Vetches and Peas there is a division of labour of this kind, that the anterior leaflets of the pinnate leaf are modified into tendrils (Fig. $19 C$, 
$r f)$; in Lathyrus Aphaca all the leaflets undergo this metamorphosis, and the special functions of the foliage-leaves are discharged by the stipules. The tendrils of the Cucurbitaceæ are also metamorphosed leaves.

3. Leaf-Spines are leaves or parts of leaves which are modified into pointed, hard, woody structures. Spiny teeth are often present on foliage-leaves (c.g. Holly, Thistles); in species of Caragana and Astragalus the phyllopodium of the pinnate leaf becomes a spine after the falling-off of the green leaflets; finally, the entire leaf becomes spiny in Berberis (Fig. 29).

4. Scales or cataphyllary leaves (Fig. $27 \mathrm{~N}$ ). These are usually of a yellow or brown colour, of simple

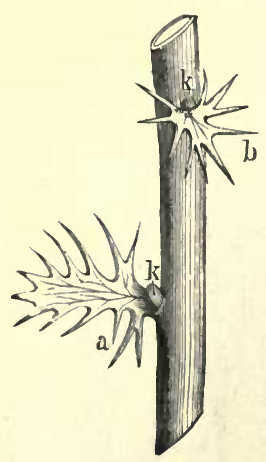

Fig. 29.-Leaf-spines of Berberis vulgaris, at the base of a shoot of one year's growth: a leaf-spine with broad surface; $b$ with a smaller surface; $k k$ axillary buds (nat. Bize). structure, without projecting veins, and are attached to the stem by a broad base. They may be regarded in some case as leaf-bases, the laminæ of which have not developed ; and in other cases, as entire leaves which have remained in a rudimentary condition. They always occur on subterranean stems (e.g. the scales of the Onion, see also Figs. 13 and $14 n$ ), and sometimes on aerial stems. Many plants which are not green (Orobanche, Neottia) produce only cataphyllary leaves in addition to the floral leaves. The most common form in which they occur upon aerial stems is that of scales investing the buds of trees. In this case they are the lowest leaf-structures borne by the annual shoot, and usually fall off as the bud developes.

Some few indigenous trees have naked buds without scales, as Viburnum Lantana, Cornus sanguinea, Rhamnus Frangula; their buds are protected by a dense growth of hairs.

The following varities of bud-scales may be distinguished :-

a. The bud-scales are the stipules of leaves which develop a lamina; as in Alnus, Liriodendron, Marattiaceæ.

b. The bud-scales are the stipules of leaves which develop no lamina : Oak, Beech.

c. The bud-scales are leaf-bases, the lamina not being developed; Maple, Ash, Horse-Chestnut, Prunus Padus. 
d. The bud-scales are laminæ: Lilac, Privet, A bietineæ.

In the last case the bud-scales may be caused to develop into foliageleaves by cutting off the top of the branch, or removing its leaves, at the time when the bud-scales are developing.

Cataphyllary leaves are sometimes thickened'so as to serve as depositories for nutritive substances, as in the bulbs of the Onion, Lily, etc.

5. Bracts and Floral Leaves (Hypsophylls and Sporophylls; Fig. $27 H$ ). These leaves are generally peculiar in form, texture, and colour; their morphology is discussed in connection with that of the reproductive organs in $\S 16$, as also in Part IV.

Vernation and Prefoliation. The forms of young leaves and their relative position in the bud, that is their vernation and prefoliation (ostivation and prefloration of floral leaves), require special consideration.

The vernation (or astivation) is said to be plane when the leaf is not folded at all; it is conduplicate when the two halves of the leaf are folded inwards face to face on the midrib as on a hinge (e.g. the Bean): it is plicate when the leaf is folded in numerous longitudinal or oblique pleats (e.g. the Beech); it is crumpled, when the foldings are in all directions (e.g. the petals of the Poppy); it is involute, when the lateral halves are rolled inwards towards the mid-rib on the ventral surface (e.g. the Violet); it is revolute, when they are rolled inwards towards the mid-rib on the dorsal surface (e.g. the Dock); it is convolute when the whole leaf is rolled up from one lateral margin to the other, so as to form a single roll (e.g. Canna); or, finally, it is circinate, when the leaf is rolled longitudinally on itself from the apex downwards (e.g. Ferns).

The prefoliation (or prefloration) is said to be valvate when adjacent leaves in the bud merely touch by their margins; when some are overlapped by others it is imbricate; an intermediate form is that in which one margin of each leaf is directed obliquely inwards, and the other obliquely outward overlapping the inner margin of the next leaf, and is termed contorted or twisted (e.g. petals of the Periwinkle.)

Valvate prefoliation is only possible in the case of whorled leaves, whereas imbricate prefoliation is characteristic of spirally arranged leaves. A common form of imbricate prefoliation or prefloration is the quincuncial, which occurs in the many dicotyledonous flowers which have a $\frac{2}{5}$ calyx; the five imbricate sepals are so arranged that two are wholly internal, two wholly external, and one partly internal and partly external, connecting the outer two with the inner two (see Part IV., Phyllotaxy of the Flower). Where the phyllotaxy is distichous $\left(\frac{1}{2}\right)$, the vernation of the leaves is generally conduplicate, and the margins of each older leaf overlap those of the next younger leaf, giving rise to a form of imbricate prefoliation distinguished as equitant (e.g. Iris); in some cases the over- 
lapping is by one margin only, in which case the prefoliation is to be semi-equitant.

$\S 13$. The Root. It must be clearly apprehended that a subterranean member is not necessarily a root; nor can a member be termed a root because it is found to absorb water and salts in solution, for in rootless plants this function may be discharged by shoots, or leaves, or hairs; nor can a member be termed a root because it serves as an organ or attachment to the substratum, for such organs may be emergences (see p. 48); only such members can be regarded as roots which bear neither leaves nor true reproductive organs.

The root is sometimes wanting in plants where it might be expected to be present, in plants, that is, of which the body is not a thallus (e.g. Salvinia, Psilotum, Utricularia, Epipogum, Corallorhiza).

There are certain peculiarities connected with the structure and development of the root which contribute to its morphological distinction. As a rule, the growing-point of the root is not exposed, like that of stems or leaves, but is covered by a structure termed the root-cap. As a rule also, the growing-point of the root, whether normal or adventitious, is developed, not at the surface, but in the interior of the tissue, that is, endogenously (p. 9).

There are exceptions to both these rules. The primary root of some parasitic plants, such as Orobanche and Cuscuta, has no root-cap, as also the small lateral roots which spring from the larger roots of the HorseChestnut. In some cases (e.g. old roots of Azolla caroliniana, Hydrocharis, Pistia Stratiotes) a root-cap is present at first, but eventually disappears, the growth in length of the root being arrested.

Exogenous development has been observed in the adventitious roots of Cardamine pratensis (roots of adventitious buds developed on leaves); of Neottia Nidus Avis; of Nasturtium officinale and silvestre; of Ruppia rostellata (embryo); Lycopodium, Phylloglossum.

The root which is developed at the opposite pole of the embryo to the primary shoot, is termed the primary root. When the primary root persists and continues its growth (as in Oak, Radish, Bean, etc.), it is termed a tap-root. In many cases (generally in Monocotyledons) the growth of the primary root is limited, so that it attains but feeble development. In other cases (e.g. Orchids, Selaginella) no primary root is developed, all the roots being adventitious. The symmetry of the root is most com- 
monly radial. In some cases, however, the root is isobilateral, as is shown as well by its internal structure as by the development of two opposite longitudinal rows of lateral roots. In other cases (e.g. attached aerial roots of epiphytic Orchids; roots of Podostemaceæ) its symmetry is more or less distinctly dorsiventral.

Roots branch either dichotomously (c.g. Isoetes), or laterally (see p. 9). In lateral branching the secondary roots are developed in acropetal succession on the primary root, and so on. Since the lateral roots are not developed upon the growing-point of the parent root, the terminal apical portion of the parent root consequently bears no lateral roots. On anatomical grounds (see Part II.) the secondary roots are arranged in longitudinal rows on the primary roots; an arrangement which also obtains in the branches of the secondary roots, and of higher orders.

The form of the root is usually cylindrical; when it is very delicate, as in Grasses, it said to be fibrous. The primary or the secondary roots may become much swollen, serving as depositories for nutritive substances ; the Turnip, the Carrot, the Beet, the Radish, have swollen primary roots; the Dahlia has swollen secondary roots.

Various terms are employed to designate the different forms of swollen roots; that of the Turnip is termed

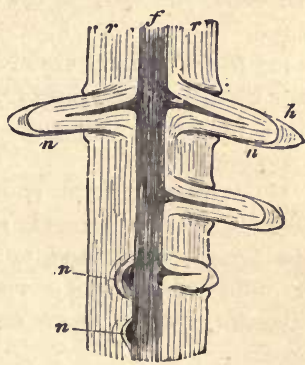

Fig. 30.-The lateral roots $n$ aris. ing endogenonsly from the pericycle of the tap-root of Vicia Fuba (longitudinal sec. mag. 5 times): $f$ axial cylinder (stele); $r$ cortex of the main root; $h$ root-cap of the lateral root. napiform; that of the Carrot, conical; that of the Radish, fusiform or. spindle-shaped; those of the Dahlia and of some terrestrial Orchids, tuberous.

Many plants have aerial roots which are peculiar both morphologically and physiologically. The roots of epiphytes, that is, plants (mostly Orchids and Bromeliaceæ) which grow on trees without, however, being parasitic, never reach the ground, but serve as means of attachment: they frequently contain chlorophyll and serve as organs of assimilation, especially in Podostemaceæ. Some plants climb by means of aerial roots (e.g. Ivy, Tecoma radi- 
cans), which are developed on the ventral surface of the dorsiventral stem, and adhere closely to the tree-trunk or wall on which the plant is climbing.

In some rare cases the aerial root is a tendril, as in Vanilla aromatica, Lycopodium rupestre and other species, and in some Melastnmaceæ (Medinilla radicans, Dissochæta).

Roots are occasionally developed as thorns, as in the Palms Acanthoriza and Iriartea, and in Myrmecodia (Rubiaceæ).

In some species of Jussiæa (e.g. J. repens) which live in swamps, some of the adventitious roots develope into floats, containing large intercellular spaces.

$\S 14$. Hairs and Emergences. Under these terms are included various appendages of a lower morphological value than the stem, the leaf, or the root, upon all of which they may be borne.

(a) Hairs. Hairs are always developed from superficial cells; a hair usually takes origin from a single superficial cell, but sometimes from more than one. Their growth is generally apical, but sometimes basal.

Hairs vary in form and structure; they may be unicellular, when they are termed simple; or multicellular, when they are termed compound or articulate: they may be branched or unbranched; they may be filamentous or scaly. They subserve various functions, being protective, secretory, or absorbent.

Various terms are used to describe hairs: filamentous hairs which are secretory have frequently a dilated apex, and are termed capitate; flattened hairs which are star-shaped, are termed stellate; discoid flattened hairs are termed radiate or peltate; the erect flattened hairs of Ferns are termed palea or ramenta. When hairs are stiff they are termed bristles or setce.

Special terms are used to indicate the nature and the distribution of the hairs on a member. A surface which bears no hairs is said to be glabrous; when the hairs are scattered the surface is pilose; when the hairs are close and short, villous; when they are longer, tomentose. When the hairs are rather stiff, the surface is hirsute; when bristly, hispid. When the hairs are borne on the margin only, the member is said to be ciliate. A surface with closely appressed hairs is lepidote; a member bearing ramenta is ramentaceous.

The root-hairs demand special notice. Root-hairs are hairs which perform the functions of absorption and attachment; they are commonly developed on roots, though not always, for they are absent 
from the roots of a number of aquatic plants (e.g. Butomus umbellatus, Caltha palustris, Hippuris, Myriophyllum, Menyanthes, Nymphæa, Lemna); they may be developed on the thallus, or the thalloid shoot, in the gametophyte of Liverworts and homosporous Vascular Cryptogams; on the stem, though rarely (e.g.
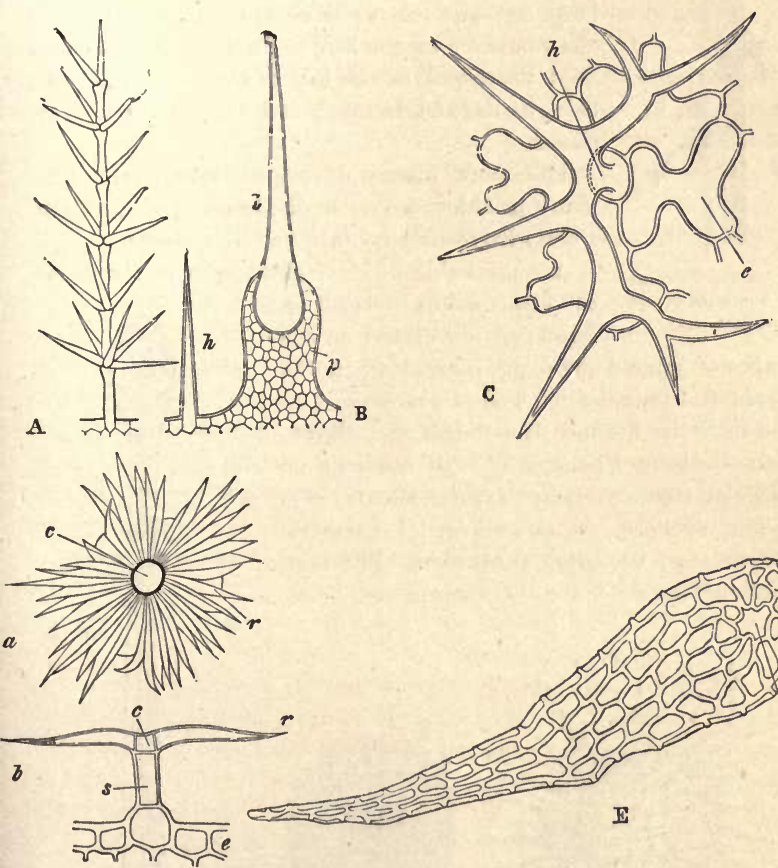

3

D

Fra. 31.-Different form of hairs. $A$ Branched compound hair (Verbascum). $B$ b Stinging-hair with basal cushion $p ; h$ simple hair (Urtica). C Branched simple hair, eeen from the surface; $\theta$ epidermis (Matthiola). D Scaly componnd hair (Hippophae); $a$ seen from the surface; $b$ seen in section; $c$ central cell; $r$ radiating cells; 8 stalk-cell; $\theta$ epidermis. $E$ Ramentum (Asplenium); $b$ the point of attechment.

Corallorhiza, Epipogum, Psilotum), or even on leaves. They are always unicellular, and it is only rarely that they are found 
to branch. On roots, at any rate, they are developed in acropetal succession.

(b) Emergences. These appendages differ from hairs in that they are developed not only from superficial cells, but from others lying beneath them.

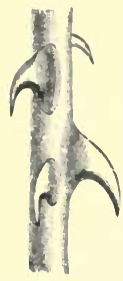

Fig. 32.-Prickles on the stem of the Rose (nat. size).

The commoner forms of emergences are prickles, (Fig. 32) and varts; more specialised forms are the tentacles of the leaf of Drosera (Figs. 33 and $34)$; the ligule of the leaf of Grasses (Fig. 19A), Selaginella, and Isoetes; and the corona of Narcissus.

The more highly developed emergences (e.g. many prickles, tentacles of Drosera) of Vascular Plants frequently contain vascular tissue.

A remarkable kind of emergence is the organ of attachment, termed a hapteron, developed on the stalks of some Algæ (e.g. Laminaria), on the stems and branches of Podostemaceæ and on the tendrils of some Ampelideæ and Bignoniaceæ among Phanerogams: it contains no vascular tissue even in Vascular Plants.

The suckers, or haustoria, of parasitic plants (e.g. Cuscuta, Orobanche, Thesium, Rhinanthus, etc.), are also emergences, being

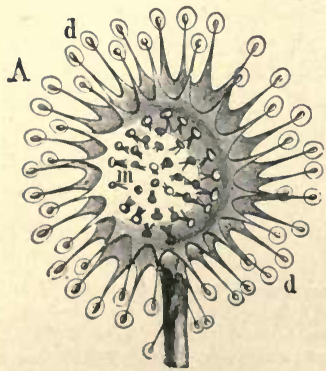

Fia. 33.-Leaf of Drosera rotundifolia. A Expanded; $d$ the glandular tentacles of the edge of the leaf; $m$ the short tentacles in the middle. $B$ The marginal tentacles have bent towards the riddle at the touch of an insect, $x$.

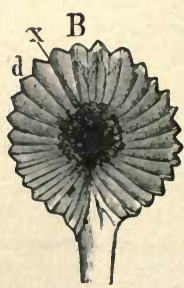

Frg. 34-Tentrole of Drosera rotundifolia. (After Strasbnrger: $\times 60$.) 
developed from the cortical tissue of the root or stem bearing them. Those of Rhinanthus, Thesium and Orobanche, are developed exogenously; those of Cuscuta, endogenously. They contain vascular tissue.

§ 15. Reproduction. Reproduction consists essentially in the development of one or more new organisms from the whole or from a part of the protoplasm of a parent organism.

This may be effected either by the separation of a member or a portion of the body, which, by developing the missing members, constitutes a new individual; or by the production of special reproductive cells termed spores. Two modes of reproduction are therefore distinguishable: vegetative multiplication, and sporereproduction.

1. Vegetative Multiplication is essentially connected with the process of growth.

The simplest modes of this occur in unicellular plants. In Pleurococcus, for instance, the cell divides into two, each of which constitutes a new organism. In this case the parent ceases to exist as an individual. In Yeast, the cell produces out-growths each of which becomes an independent unicellular organism. In this case the number of the progeny is not limited, and the parent organism persists. This is termed multiplication by gemmation.

In more complex plants vegetative reproduction is commonly effected in this way, that the main axis of the shoot or of the thallus, dies away: the branches thus become isolated and constitute independent organisms. This occurs very commonly in the protonema of Mosses, in the rhizomes of many Phanerogams, etc. In those cases in which the leaves produce adventitious buds (e.g. Bryophyllum calycinum, many Ferns), the adventitious buds develope into independent plants after the leaf has fallen from the plant bearing it.

In many plants special organs for vegetative multiplication are produced, which may be generally termed gemma. In a few cases the gemmæ are unicellular, as those of some Algæ, Fungi, and Hepaticæ. In other plants, multicellular gemmæ are produced: as in other Hepaticæ where they are developed in special receptacles (cupules) on the upper surface of the thallus (Lunularia, Marchantia), or on the margin of the leaves. In some Mosses flattened gemmæ are produced in receptacles formed of leaves at the apex of the shoot, as in Tetraphis pellucida, and Aulacomnion androgynum: and

M.B. 
rounded tuberous gemmæ are frequently formed on the protonema. The prothallia of some Ferns (Trichomanes) are reproduced by fewcelled filamentous gemmæ; and that of Lycopodium Phlegmaria by ovoid tuberous gemmæ.

In the Vascular Cryptogams and Phanerogams, vegetative reproduction is generally effected by buds, the leaves or stem of which have become swollen, serving as depositories for nutrient substances. These buds may be subterranean, and then they are of considerable size, when they are termed bulbs or corms according to their structure (see p. 25): or the buds may be borne on a swollen subterranean stem (e.g. potato-tuber); or be associated with tuberous roots (e.g. many terrestrial Orchids). Sometimes they are aerial, being borne on the stem; on account of their small size they are termed bulbils (e.g. Lilium bulbiferum, Dentaria, Nephrolepis tuberosa, etc.). In Psilotum, however, vegetative propagation is effected by small flattened gemmæ, oval in shape, and consisting of a few large cells forming a single layer.

2. Spore-Reproduction. The term spore is applied to a specialised asexual reproductive cell which is capable, by itself, of giving rise to a new organism.

There are two principal modes of origin of spores, and all plants produce spores in one or other of these modes. In the one, the spores are formed from the protoplasm of any part, or of some special part, of an organism; in the other, they are formed by the fusion of two masses of protoplasm derived either from two distinct organisms, or from distinct parts of the same organism. In the former case they are said to be formed asexually; in the latter, they are formed sexually, the fusion of the two masses of protoplasm being a sexual process (p. 2); the organs concerned are distinguished respectively as ascxual and sexual, and are in all cases confined to the shoot.

The spore is generally a single cell, consisting of a nucleated mass of protoplasm containing various nutritive substances (oil, starch, etc.). It generally has a cell-wall, which is commonly thick, and in some cases consists of two layers, an outer, the exine (or exospore), which is cuticularised, and an inner, the intine (or endospore), which is delicate and consists of cellulose.

In some cases the spore has no cell-wall. It may then be capable of spontaneous movement. When motile, it usually swims by means of one, two, four, or many delicate protoplasmic filaments 
termed cilia. Motile spores are termed zoospores. Ciliated zoospores are common among the Algæ, and they occur in some Fungi.

The spores produced asexually by the sporophyte of any one plant are commonly of one kind only; when this is the case the plant is said to be homosporous. But in some of the Pteridophyta, and in all Phanerogams, which are therefore said to be heterosporous, there are two kinds of asexually produced spores, which differ in size and in the nature of the organisms to which they respectively give rise, and are distinguished as microspores and macrospores. In the Phanerogains, the microspores are commonly termed pollen-grains; and the macrospores, embryo-sacs.

$\S 16$. General Morphology of the Asexual Reproductive Organs. In the great majority of plants the asexual production of spores takes place in the interior of an organ termed a sporangium.

Whilst in some plants the asexual production of spores is not limited to any particular portion of the body, in others it is so limited. When this is the case, the portion of the body which performs this function differs more or less widely in form from the vegetative portions, and it is distinguished as the sporophore. When the body is differentiated into root and shoot, the sporophore is always part of the shoot.

In those plants in which the shoot is differentiated into stem and leaf, the development of spores is commonly confined to the leaves. A leaf bearing one or more sporangia is termed a sporophyll.

(a) The Sporangium. In unicellular plants (e.g. Yeast, Hæmatococcus) the cell, that is the whole body of the organism, becomes one sporangium. In this case the development of spores closes the life of the organism, for the protoplasm is used in the formation of the spores, and the cell-wall is ruptured to allow of their escape.

In simple multicellar plants (e.g. Ulva, Ulothrix) each cell eventually acts as a sporangium, giving rise to spores. With the formation of spores the life of each cell is closed; so that when all the cells have formed spores the life of the organism is ended.

In plants of higher organization the formation of spores is limited to certain cells, so that the formation of spores no longer necessarily puts a term to the life of the organism. It is in these plants that distinct sporangia are to be found.

In the Algæ and Fungi, the sporangium, when present, usually consists of a single cell. In all plants higher than the Algæ and 
the Fungi, the sporangium is multicellular. It is, however, unilocular, that is, it contains but one cavity in which spores are developed, though this is sometimes chambered by incomplete walls (trabecula) as in Isoetes.

In the Bryophyta, where the sporophyte apparently produces only a single sporangium, termed the capsule or theca, this organ constitutes the whole (Riccia) or a considerable portion of the sporophyte. Its structure is simple in Riccia and other Hepaticæ, but it becomes highly elaborate in the true Mosses (e.g. Polytrichum). It must, however, be borne in mind that the theca of the Bryophyta does not correspord to a single sporangium of a Feru or a Phanerogam, but to at least a cluster (sorus) of such sporangia: hence the exceptional complexity of its structure.

In the Pteridophyta and the Phanerogams the sporophyte produces a number of sporangia. In the heterosporous forms there are two kinds of sporangia which respectively produce the two kinds of spores; those which produce macrospores are termed macrosporangia; those which produce microspores, microsporangia. In the Phanerogams the macrosporangium is commonly termed ovule, and the microsporangium pollen-sac.

When the shoot of the sporophyte is differentiated into stem and leaf, the sporangia are generally borne on the leaves (sporophylls): but in some plants they are borne on the stem. This is the case in most Selaginellas, among the Pteridophyta : the macrosporangia (ovules) are borne on the stem in various Phanerogams; among Gymnosperms, in the Taxeæ; among Angiosperms, in the Polygonaceæ, Chenopodiaceæ, Amaranthaceæ, Primulaceæ, Compositæ, Gramineæ, Naiadaceæ, Piperaceæ, and others, the macrosporangia being either terminal or lateral: the microsporangia are less commonly borne on the stem, but this is the case-in some Angiosperms, such as Naias and Casuarina.

The sporangia may be borne singly, or, as is more commonly the case, in groups, each such group being termed a sorus. The sporangia of a sorus are generally quite distinct from each other; but in some cases (e.g. most Marattiaceæ, Psilotum, Tmesipteris) the sporangia are coherent, forming what appears to be a multilocular sprangium but is really a synangium.

In those heterosporous plants in which the sporangia are in sori, the two kinds of sporangia are borne in distinct sori, the only exception to this rule is afforded by the Marsileacer, where each sorus includes both microsporangia and macrosporangia. 
The mature sporangium of these higher plants is either borne upon a stalk (sometimes termed funicle); or it is sessile, and then it is commonly more or less imbedded in the tissue of the parent member, as in the case of the sporangia of the Ophioglossaceæ, and of the pollen-sacs of most Phanerogams.

The development of the sporangium begins, in all cases, at the surface of the parent member. The area which bears the sporangium, especially when a number of sporangia are developed close together, generally projects more or less as a cushion of tissue to which the term placenta is applied. In the Ferns (except Marattiaceæ, Ophioglossaceæ, and Isoetaceæ) and in the Hydropterideæ (Rhizocarps), the sporangium is developed from a single superficial cell : in the rest of the Pteridophyta and in the Phanerogams it is developed from a group of superficial cells, and in some cases from cells of deeper layers as well. These Ferns and the Hydropterideæ are hence distinguished as leptosporangiate from the rest of the Vascular Plants which are said to be eusporangiate.

The most important morphological feature in the development of the multicellular sporangium is the differentiation of the sporogenous tissue, that is, of the mother-cells of the spores. These are derived from a hypodermal cell or group of cells, termed the archesporium, which may be distinguished at an early stage in the development of the sporangium, by the highly granular protoplasm and the large nucleus. The mother-cells of the spores are usually formed by the division of the archesporial cell or cells, but occasionally the archesporial cells themselves become spore-mothercells. The sporogenous cells, as they develope, become more or less completely invested by a layer of highly granular cells, forming a membrane termed the tapetum, which temporarily separates them from the wall of the sporangium; the tapetum may be derived wholly or in part from the archesporium or from the wall of the sporangium.

In most cases the asexually-produced spores are set free from the organism producing them. An exception to this is offered by the macrospore (embryo-sac) of Phaverogams, in which plants the macrospore remains permanently enclosed in the macrosporangium (ovule), and the macrosporangium remains attached for a considerable time to the plant bearing it. It is on account of this peculiarity that seeds are produced in Phanerogams. The production of seeds is the characteristic difference between Phanerogams and Cryptogams. The spores are usually set free by the rupture or 
dehiscence of the sporangium. In some cases the wall of the sporangium simply degenerates; in other cases there is a special mechanism, sometimes very elaborate, for its dehiscence. In a few cases the whole sporangium falls off from the parent plant, e.g. the mierosporangia and macrosporangia of Salviniaceæ; here the spores never become free from the wall of the sporanginm, but germinate inside it.

(b) The Sporophore. Beginning with the lower plants, a wellmarked asexual spore-producing organ is to be found in many Fungi, where it represents, in fact, the shoot of the body, and is a specialized, erect-growing branch of the mycelium. It may be simple (e.g. Mucor, Peronospora, Eurotium) or compound (Agaricus).

The sporophyte of the Bryophyta affords a good example of a highly specialised sporophore in an organism the shoot of which is not differentiated into stem and leaf. The entire shoot of the sporophyte constitutes the sporophore, which consists (except in Riccia) of a longer or shorter stalk (seta), bearing a terminal capsule (theca) of more or less complex structure.

In the majority of the higher plants, in which the shoot of the sporophyte is differentiated into stem and leaf, there are wellmarked sporophores (see Fig. 27). The sporophore may be the terminal portion of the primary shoot or of a branch; or it may be an entire branch. It is commonly known, among Phanerogams, as the inflorescence, but there is no reason for confining the use of this term to this group of plants. The sporophore or inflorescence is characterised by its limited growth in length, and can usually be distinguished from a vegetative shoot by peculiarity of form, and, when they are present, by the nature of its leaves.

The distinction of an inflorescence from a vegetative shoot is easy when the former is an entire branch borne latterly on the latter; but when a monopodial vegetative shoot terminates in an inflorescence, the transition from the one region to the other is so gradual, that it is difficult to determine where the one begins and the other ends.

The sporophore may be simple, or it may be branched, and it then affords some of the most striking examples of the various branch-systems (see p. 18). When the branch-system is such that there is a well-defined main axis, this is termed the rhachis, of the inflorescence. The rhachis and the branches of the inflorescence are commonly elongated and cylindrical, or flattened, or prismatic in form; but they are in many cases dilated at the apex into a flattened, depressed or conical receptacle, as in the Compositæ, etc. 
The sporophore may be destitute of leaves (e.g. Salisburia adiantifolia). When it bears leaves they usually differ more or less widely in form, colour, and structure from the foliage-leaves of the plant. Of these leaves there are two kinds: those which bear sporangia, hence termed sporophylls; those which do not bear sporangia, termed hypsophylls (see p. 43).

When no sporophylls are present, the sporangia are borne directly by the rhachis or the branches of the sporophore, at or near the apex, in a cluster if there are several. When sporophylls are present, they are also usually collected together at the apex of the rhachis or of a branch, in consequence of the shortness of the terminal internodes. Any axis of the sporophore, bearing one or more sporangia or sporophylls, is termed a flower (p. 25).

When hyposophylls are present, some of them are commonly aggregated round the sporangia or the sporophylls, as in most Angiosperms, constituting what is termed the perianth of the flower.

When the rhachis is unbranched, it bears a single terminal flower (e.g. Equisetum, Violet); when it branches, each axis, of whatever order, terminates in a flower. It is on this account that the growth of the axes of inflorescences is limited. It occasionally happens, as a monstrosity, that the axis grows through the flower and produces foliage-leaves; this is termed proliferation.

When the rhachis bears a single terminal flower it is commonly termed the peduncle of the flower; when the rhachis is branched, the branches may be so short that their flowers appear to spring directly from the rhachis and the flowers are said to be sessile; when the branches are longer and bear terminal flowers, they are termed pedicels, and the flowers are said to be pedicillate. For further details as to inflorescences, see Part IV.

When no sporophylls are present, the form of the flower is extremely simple. When sporophylls are present, the form of the flower varies with the degree of elongation attained by the terminal internodes of the axis. When they elongate to some extent, the flower forms a cone, as in Equisetum, Lycopodium, Selaginella, Pinus. When they remain short, as generally in Angiosperms, the apex is more or less broadened, forming a flattened, depressed, or shortly conical torus on which the sporophylls and the perianthleaves are borne. The various forms of flowers are described in detail in Part IV. 
In heterosporous plants it is commonly the case that the two kinds of sporangia are borne together on the same axis of the sporophore; that is, they are included in the same flower (e.g. Selaginella, most Angiosperms), but they are frequently confined to distinct axes, as in the Gymnosperms, and in some Angiosperms (e.g. Beech, Birch, Oak, Walnut, etc.); these distinct flowers are distinguished, according to the kind of sporangia which they respectively bear, as microsporangiate or macrosporangiate; in some cases one individual bears exclusively microsporangiate, and another exclusively macrosporangiate flowers, as in the Hemp, the Yew, etc.

(c) The Sporophylls. In many cases, most Ferns and Lycopodinæ, for example, the sporophylls are similar to the foliageleaves, differing only in that they bear sporangia; but more commonly the sporophylls are distinguished by some peculiarity in form or structure. Thus in the Flowering Fern (Osmunda regalis) the sporophylls differ from the foliage-leaves in that no green laaf-tissue is developed in them; and in the Phanerogams they differ widely from the foliage-leaves.

The distribution of the sporangia among the sporophylls in heterosporous plants is an important point. In the Hydropterideæ (Rhizocarpæ), both the microsporangia and the macrosporangia are borne by the same sporophyll; but in all other heterosporous plants they are borne by distinct sporophylls, which may be distinguished respectively as microsporophylls and macrosporophylls. In the Phanerogams the microsporophyll is termed a stamen; the macrosporophyll, a carpel; but there is no reason for applying special terms to this group of plants.

In heterosporous plants, both kinds of sporophylls are generally present in one and the same flower: when, however, the flower includes only microsporophylls, it is termed microsporophyllary or staminate; and when it includes only macrosporophylls, it is termed macrosporophyllary or carpellary.

In some cases the sporangia are borne, not upon, but in close relation with, a leaf, which is nevertheless regarded as a sporophyll. Thus, in Selaginella, the sporangium is in the axil of the sporophyll. Again, the leaves which invest the macrosporangia (ovules) of Polygonaceæ, Primulaceæ, etc., are termed carpels, though they do not actually bear the sporangia.

The distribution of the sporangia on the sporophyll is various. They may be borne exclusively on the under (dorsal) surface, 
as in most Ferns, Equisetum, and Gymnosperms (pollen-sacs); or exclusively on the upper (ventral) surface as in the Lycopodinæ, Marsileaceæ, macrosporangia of Coniferæ and of some Angiosperms (e.g. Butomus); or on both surfaces, as in Osmunda; or on the lateral margins, as in Ophioglossum and the Hymenophyllaceæ, and in many Angiosperms (e.g. Leguminosæ, Violaceæ, Liliaceæ); or on the apices of segments of the sporophyll, as in the Salviniaceæ.

The number of the sporangia borne by a sporophyll also varies widely. In some cases there is only one, as in Selaginella, Lycopodium, Isoetes ; or two, as in most Coniferæ; or four, as in most Angiosperms (microsporangia); or many, as in the Filicinæ.

In most cases the sporangia are free on the surface of the sporophyll; but in some cases they are enclosed in a cavity formed either by the infolding and junction of the margins of the sporophyll, or by the junction of the margins of adjacent sporophylls. The sporangia of the Marsileaceæ are thus enclosed by the sporophyll, as are also the macrosporangia of all Angiosperms. In the latter group the resulting structure is termed the ovary.

(b) The Hypsophylls (Fig. 27, p. 43). Under this common term are included bracts and perianth-leaves.

Bract. This term is generally applicable to the leaves, other than the sporophylls and perianth-leaves, which are borne by the rhachis or branches of the inflorescence: those which are borne on the pedicels of individual flowers are, however, distinguished as bracteoles or prophylla.

The bract is frequently not distinguishable from a foliage-leaf; but it may be reduced to a scaly leaf; or it may be very large and even highly coloured, when it is said to be petaloid. An example of the occurrence of bracts in the Pteridophyta is afforded by Equisetum, where there is a whorl of small bracts, forming what is known as the ring, just below the cone or flower. In some Monocotyledons (e.g. Palms, Arums, etc.) there is a large bract, termed a spathe, which invests the whole inflorescence; it is usually not green in colour, as in the Trumpet Lily (Zantedeschia athiopica) where it is white. In some cases the bracts are arranged in whorls round the inflorescence (e.g. Compositæ) forming an involucre.

The bracteoles sometimes form an investment, termed an epicalyx, to the flower (e.g. Malva, Camellia, etc.).

The Perianth-leaves are leaves developed in immediate relation 
with the sporophylls, or with the sporangiferous axis, of a flower, to which they form an investment termed the perianth. A perianth is present only in Phanerogams, and is confined almost exclusively to the Angiosperms: the Gnetaceæ are the only Gymnosperms in which it is represented. The leaves may be arranged in a single whorl, or in two or more: they may be all alike, either green and inconspicuous, or of other bright colours and conspicuous; but most frequently the leaves of the outer whorl (sepals constituting the caly $x^{2}$ are small and green in colour, being especially protective in function, whilst those of the inner whorl (petals constituting the corolla) are large and brightly coloured, being especially attractive in function. (For further details, see The Flower, Part IV.)

\section{$\S 17$. General Morphology of the Sexual Reproductive} Organs. The general morphology of the sexual reproductive organs agree in many respects with that of the asexual reproductive organs.

In the great majority of plants the sexual reproductive organs give rise to sexual reproductive cells, termed gametes (p. 2); hence the organs may be generally termed gametangia. In some cases the formation of gametangia is limited to a certain portion of the body of the gametophyte which differs more or less from the vegetative portions of the shoot and may be distinguished as a gametophore. When a part of the body is differentiated as a shoot, the gametophore is part (or the whole) of the shoot.

(a) The Gametes. A gamete is a sexual reproductive cell-a reproductive cell, that is, which is incapable by itself of giving rise to a new organism; in this respect it differs from a spore. A spore is, however, formed from the fusion of two gametes of different sexes: that is, by a sexual process (see p. 50).

In those of the lower Algæ and Fungi in which sexual sporeformation takes place, the gametes produced by the organism are all externally similar; hence these plants are termed isogamous; the sexual process, which consists here in the fusion of two similar gametes, is termed conjugation; and the spore formed by conjugation is termed a zygospore.

In all the higher plants, hence termed heterogamous, the gametes are not all alike; but there are two kinds, the male and the female. The male and female gametes may be generally distinguished by their difference in size, the male being the smaller, and by the greater activity of the male gamete in connection with the sexual 
process which is here termed fertilisation, the male gamete being considered to fertilise the female; product, an oospore.

The gametes of isogamous plants, in those cases in which they are set free from the gametangium and are free-swimming, are well defined, ciliated, somewhat pear-shaped masses of protoplasm destitute of a cell-wall (e.g. Botrydium, Ulothrix, Ectocarpus, etc.), and are distinguished as planogametes. When, however, they are not free-swimming (as in the Conjugate Algæ) they have no defined form nor are they ciliated.

The gametes of heterogamous plants. The male gamete, when the conditions are such that it must of necessity be free-swimming, is generally a well-defined ciliated mass of protoplasm, termed a spermatozoid. Spermatozoids occur in the heterogamous Green and Brown Algæ (e.g. Vaucheria, Volvox, Sphæroplea, Edogonium, Chara, Fucus), in the Bryophyta, in the Pteridophyta, and in a few Gymnosperms. In the lower forms the spermatozoid is more or less rounded or pear-shaped, somewhat resembling a planogamete of the isogamous forms: but in the higher it is club-shaped or filamentous, thicker at the posterior end, pointed at the anterior end where the two or more cilia are borne, and more or less spirally coiled. It has no cell-wall.

When, owing to the proximity of the male and female organs at the time of fertilisation, the male gamete has no considerable distance to traverse (e.g. most Phanerogams), it is not differentiated as a spermatozoid, but is simply an amorphous cell without a cell-wall.

The female gamete, or oosphere, is not ciliated, nor is it, as a rule, set free, but remains in the female organ until after fertilisation : but in some Algæ (e.g. Fucus), the oosphere is extruded from the female organ before fertilisation. It is, generally speaking, spherical in form, as its name denotes. It has no cell-wall.

The gametes are developed from one or more mother-cells in the gametangium. In isogamous plants, as a rule, each mother-cell gives rise to more than one gamete, and commonly to a considerable number (e.g. Botrydium, Ulothrix); but in Ectocarpus and some other Phæosporous Algæ, each mother-cell produces but a single gamete. Whilst in the higher heterogamous plants the male gametes are each developed singly from a mother-cell, in the lower it is the rule that the male gametes are produced several together from one mother-cell. The female gametes are developed singly in the mother-cell, except in the Saprolegniacer among Fungi, and in some genera of Fucaceæ (Pelvetia, Ozothallia or Ascophyllum, 
Fucus), in which from two to eight (Fucaceæ) or up to twenty (Saprolegniaceæ) oospheres are produced from one mother-cell.

(b) The Gametangia. The general morphology of the gametangia is very much the same as that of the sporangia.

With regard to the terminology employed in designating these organs, they are said to be male when they contain protoplasm which is capable of effecting fertilisation; and female, when they contain protoplasm capable of being fertilised. When there is no external indication of the physiological nature of the organ, it is simply termed a gametangium. But when the male and female or gans respectively are clearly differentiated, special names are given to them in order to indicate peculiarities in their structure or function, or the group of plants to which they belong. In the first place a distinction must be drawn, in the case of these differentiated gametangia, between those which give rise to clearly differentiated gametes, and those the protoplasm of which does not undergo such differentiation. To the former category belongs the male organ, termed antheridium, in which spermatozoids are developed, and the female organs, termed oogonium or archegonium, in which one or more oospheres are differentiated. To the latter category belong the male organ termed pollinodium (e.g. in Peronosporaceæ and some Ascomycetes), and the female organs termed procarp (Florideæ) or archicarp (Ascomycetous Fungi).

In the lowest plants in which the sexual formation of spores takes place, the whole cell, when the organism is unicellular, or any cell, when the organism is multicellular, becomes a gametangium, without being specially modified for the purpose. This is the case, not only in isogamous plants (e.g. Pandorina, Ulothrix, Conjugatæ), but in some heterogamous plants (e.g. Sphæroplea) in which the gametes are perfectly differentiated into spermatozoids and oospheres.

In plants of higher organisation there are specialised gametangia. In the simpler forms of these the male and female gametangia are externally similar, as in the Volvocaceæ, Ectocarpus, and Cutleria, among the Algæ, and in the Zygomycetes and some Ascomycetes (e.g. Eremascus) among the Fungi. In the more complex forms, the male and female gametangia are dissimilar.

The undifferentiated gametangia are generally unicellular and unilocular; but they are multicellular and multilocular in some Phrosporous Algæ (c.g. Ectocarpus, Cutleria). 
The differentiated gametangia are of various structure. The antheridium is unicellular in most of the lower plants (Green Algæ, except Characeæ; Fucaceæ). In all the other cases it is multicellular, and of simple structure, except in the Characeæ, where the structure is extremely complex. In some cases (Rhizocarps) the antheridium consists almost entirely of the mothercells of the spermatozoids ; in most cases the mother-cells are surrounded by a parietal layer of cells. The pollinodium is generally unicellular.

The oogonium is unicellular. The archegonium is generally multicellular, consisting of a cellular wall investing the oosphere, usually prolonged into a tubular neck; but in most of the higher plants, the archegonium is reduced to a single cell, the oosphere. The archicarps and procarps are unicellular in some cases, multicellular in others; in most cases the organ is prolonged into a filament, the trichogyne, by means of which fertilisation is effected. The oogonia (except those of Peronosporaceæ, Saprolegniaceæ, and Characeæ) and the archegonia, open, so that their contents are in direct relation with the surrounding medium; in the procarps and archicarps this is not the case.

Further details are given in Part IV. in connexion with the plants to which the various organs belong.

(c) The distribution of the Sexual Organs. The male and female organs are either borne by the same gametophyte, or they are borne by distinct male or female gametophytes; in the former case the organism is said to be monocious, in the latter diocious.

When in monœcious plants the male and female organs are both present in the same sorus, as in some Algæ (e.g. Fucus platycarpus, Halidrys and other monœcious Fucaceæ) and in some Mosses, the sorus is said to be bisexual or hermaphrodite, and the plant is said to be monoclinous; when they are borne in different sori on the same plant (e.g. in Hepaticæ generally, some Mosses), the sorus is said to be unisexual, male or female as the case may be, and the plant diclinous. These terms are also applied to the flowers of Phanerogams.

$\S 18$. The Fruit. Although the forms of fruit occurring among plants are so various in their form and in their structure, it is possible to include them all in a single definition. A fruit is the product of a process of growth initiated as a consequence of a sexual act in structures which are not themselves immediately concerned in the sexual act. 
To begin with instances among the lower plants; in most of the Red Algre and Ascomycetous Fungi, the effect of the fertilisation of the female organ is not merely that the female organ gives rise to sporangia; but the adjacent vegetative tissues are stimulated to growth, forming an investment to the structures developed directly from the fertilised female organ, the whole constituting a fruit, known in the one case as a cystocarp, in the other as an ascocarp.

Similarly, in the Bryophyta, and to a less extent in the Pteridophyta, the effect of the fertilisation of the oosphere is not merely to cause the formation of an oospore and the development of an embryo, but the wall of the archegonium is stimulated to fresh growth and forms an investment, the calyptra, which encloses the embryo; sporophyte for a longer or shorter period, the whole constituting at this stage a fruit.

The most remarkable instances of fruit-formation are, however, to be found in the Phanerogams. Here, as a result of the fertilisation of the oosphere, various parts of the flower are stimulated to growth; most commonly it is only the macrosporophylls (carpels) which are so affected, but the stimulating influence may extend to the perianth-leaves or to the axis of the flower, the resulting tissues being either hard and woody, or soft and succulent (see Part IV., under Phanerogams). The peculiar feature of the fruit of these plants, as contrasted with those of the lower plants, is that here the tissues affected all belong to the sporophyte, whereas in the lower plants they belong to the gametophyte; this is the necessary result of the peculiar relation of the female gametophyte to the sporophyte which obtains in the Phanerogams (see p. 3).

$\S 19$. The Seed. As this is a struçture which is peculiar to Phanerogams (p. 53), its morphology is discussed in connection with that group (see Part IV.). 


\section{ANATOMY AND HISTOLOGY.}

$\S 20$. Introductory. The body of a plant, like that of an animal, consists essentially of living matter termed protoplasm. The body may consist simply of a mass of protoplasm, as the plasmodium of the Myxomycetes ; or it may consist of a mass of protoplasm invested at the surface by a definite membrane which is not protoplasmic (e.g. Phycomycetous Fungi and Siphonaceous Algæ); or it may consist of a mass of protoplasm segmented into portions by non-protoplasmic partition-walls. A body of this last type of structure may be conveniently distinguished as septate, from those of the two former types which are unseptate.

On examining the protoplasm of any plant, it will be found to contain certain well-defined protoplasmic bodies termed nuclei; it is, in fact, the case that all protoplasm is nucleated. In an unseptate body, such as those mentioned above, the nuclei, which are very numerous, are scattered irregularly throughout the protoplasm. In the septate body of certain plants (e.g. higher Fungi; some Algæ, such as Cladophora and Hydrodictyon) the septation of the body and the distribution of the nuclei stand in no direct relation to each other, the protoplasm being segmented into portions each of which includes a number of nuclei ; such a plant-body may be designated as incompletely septate. In the rest of the septate plants, the septation of the protoplasm and the distribution of the nuclei stand in a direct relation to each other, such that each of the portions into which the protoplasm is segmented contains but a single nucleus; a plant-body of this structure may be described as completely septate.

The portions of protoplasm which are delimitated by the septa in the body of a completely septate plant, are, both morphologically and physiologically, units of protoplasm. They are frequently spoken of as cells, but it is more accurate to reserve this term to the protoplasmic unit together with the wall (cell-wall) by which it is invested. The structure of the body or any part of it can 
only be accurately described as cellular when it consists of one or more such cells, that is, when it is either unicellular (e.g. Yeast, Hæmatococcus, etc.) or multicellular. The body of an unseptate plant (such as the Phycomycetous Fungi and the Siphonaceous Algæ), as also a segment of the body of an incompletely septate plant (such as Cladophora, Hydrodictyon, etc.), is not a single cell, but is an aggregate of protoplasmic units enclosed within a common wall. Such a body, or part of a body, may be conveniently distinguished as a conocyte, and the plants in which it occurs may be said to have coenocytic structure.

Even in typically cellular plants structures occur which are cœnocytic. Thus, in the early stages of its development in the embryo-sac of a Phanerogam, the endosperm is generally unseptate, cousisting of a layer of protoplasm with many nuclei scattered through it; it eventually becomes a cellular tissue by the delimitation of the constituent units by means of cell-walls. Again, a "laticiferous cell" of a Euphorbia (and other Phanerogams) is essentially a cœnocyte like the body of a Vaucheria or a Botrydium.

On the other hand, there is such a thing as a multinucleate cell. It has been observed, for instance, in old internodal cells of Chara, and in old parenchymatous cells of Lycopodium and of various Phanerogams (e.g. Tradescantia, Taraxacum, Cereus, Solanum, etc.) that, from being uninucleate, they become multinucleate by the direct division or fragmentation of the nucleus.

The distinction between a cœnocyte and a multinucleate cell would appear to be this: that the former is either multinucleate from the first or becomes so at a very early stage in its development, whilst the latter becomes multinucleate at a quite late period.

There is another kind of structure occurring in cellular plants which has to be distinguished from both the cell and the cœenocyte : that is the syncyte. This structure is formed. by the fusion of already-formed cells, the cell-walls, when present, being more or less completely absorbed, so that the cavities of the fused cells becomec ontinuous. The commonest case of this occurs in the development of vessels, where the transverse septa of a longitudinal row of cells are absorbed so that a continuous tube is formed.

But even in the fully-developed cellular plant-body it appears to be very frequently the case that the protoplasm in one cell is not absolutely cut off from that of the adjacent cells, but that there is 
continuity of the protoplasm; that is, that the protoplasm of one cell is connected with that of the contiguous cells by means of very delicate protoplasmic fibrils which traverse the pits or pores of the intervening cell-walls (Fig. 35). This connection appears, however, to exist from the first development of the cells, and thus differs from the case of the syncyte where the absorption of the intervening cell-walls is a secondary process.

The term tissue is generally applied to any continuous aggregate of cells; but it is essential to define the term more accurately. A true tissue is an aggregate of cells which (1) have a common origin, whether formed simultaneously (e.g. development of endosperm of Phanerogams), or successively, as in the case of a tissue developed from a growingpoint; which (2) are coherent from the first and are governed by a common law of growth; and which (3) are physiologically interdependent and cannot, in fact, exist otherwise than as part of the tissue.

The tissue of which the body of a plant consists may be either homogeneous or heterogeneous ; that is, the cells may be all alike, constituting

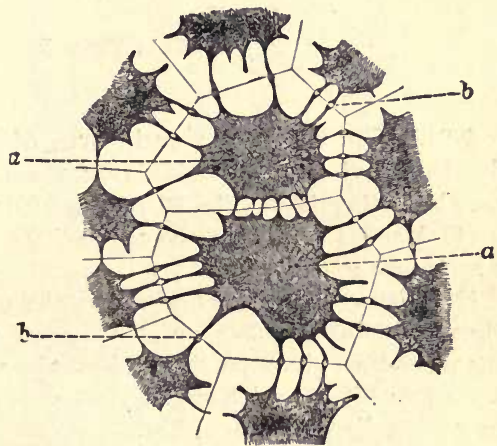

FIG. 35 (highly magnifed, after Gardiner).-Continuity of the protoplasm of contignons cells of the endosperm of a Palm-seed (Bentinckia) : a contracted protoplasm of a cell; $b$ a group of delicate protoplasmic fibrils passing through a pit in the cell-wall. therefore but one kind of tissue; or they may not be all alike, the different kinds of cells being more or less grouped together so as to form different kinds of tissue. A body which consists of different kinds of tissues is said to be histologically differentiated. The structural differences between the various forms of tissue in a histologically differentiated body are essentially connected with the special adaptation of each form of tissue to the performance of some particular function in the economy.

It is a remarkable fact that, whilst the cells of the various

M.B. 
tissues of a histologically differentiated body present characteristic peculiarities of form, size, and relative arrangement, the most striking distinctive peculiarities are exhibited, not, as in animals, by the protoplasm of the cells, but by the cell-walls in respect of their thickness, their chemical composition and physical properties, and their markings.

Inasmuch as the cellular plants are the more numerous, and present greater variety of structure, the following account deals almost exclusively with them. And since the cell is the structural unit of these plants, it will be advantageous to study the cell as such first, and then to proceed to the study of the tissues.

\section{CHAPTER I}

THE CELL

§ 21. The Structure and Form of the Cell. In a fully developed living cell the following three principal constituents may be distinguished (Fig. $36 \mathrm{~B}, C$ and $D$ ) :-

(1) A closed membrane, the cell-vall $(h)$, consisting generally of a substance termed cellulose.

(2) A layer of semi-fluid substance, the protoplasm $(p)$, lying in close contact at all points with the internal surface of the cell-wall; the protoplasm gives the chemical reactions of proteid. In it lies a nucleus $(k)$, in which one or more smaller bodies, nucleoli $(k k)$ may generally be distinguished.

(3) Cavities, one or more, in the protoplasm, termed vacuoles (s), which are filled with a watery liquid, the cell-sap.

The structure of a coenocyte is essentially the same as that just described, except that several (sometimes very many) nuclei are present.

The young cell presents a somewhat different appearance (Fig. 36 A). At this stage the protoplasm occupies the whole cellcavity. But, in the subsequent development of the cell, the increase in bulk of the protoplasm does not keep pace with the superficial growth of the cell-wall. Hence, since the protoplasm must remain in contact with the cell-wall at all points, the result is that cavities, the vacuoles, are formed which become filled with cell-sap (Fig. $36 \mathrm{~B}$ ). The vacuoles, small at first, increase with the growth of the cell, and may fuse together to a greater or less 
extent owing to the gradual withdrawal of more and more of the protoplasm into the now extensive parietal layer.

Cells such as these are examples of the kind of cells which compose the succulent parts of plants, such as the cortex of stems and roots, the tissue of leaves, succulent fruits, etc.; in fact the bulk of the actually living tissues of the plant. In the higher plants it is generally the case that a considerable number of the cells of the body eventually lose the whole of their protoplasmic contents, containing, in fact, nothing but air or water; such are cork-cells and vascular wood-cells. Such structures are no longer living cells, but are merely their skeletons, and are of use only in virtue of the mechanical properties of their cell-walls.

On the other hand, there are frequently found in connection with the processes of reproduction, what have been termed primordial cells, such as zoospores, gametes, spermatozoids, and oospheres (see p. 59), each of which is simply an unit of protoplasm without any cellwall, though the zoospores event-

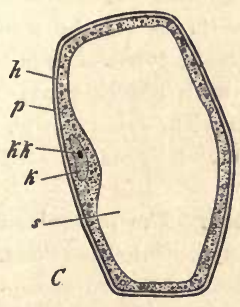

1
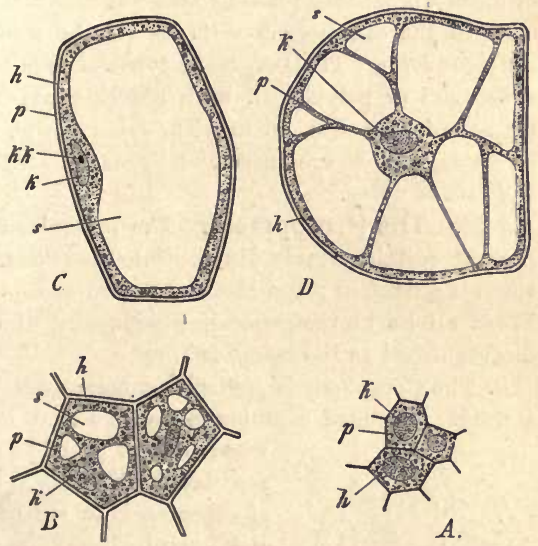

D

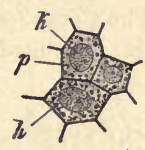

A.

Frg. 36.-Cells and their structure. A Young cells from the ovary of Symphoricarpus racemosus $(\times 300) ; B$ cells from an older ovary of the same plant $(x 300) ; C$ and $D$ from the fruit of the same plant $(\times 100) ; h$ cell-wall; $p$ protoplasm; $k$ nucleus; $k k$ nucleolns; $s$ vacuole. In $C$ there is a single large vacuole, the whole of the protoplasm forming the parietal layer. In $D$ there are several vacuoles, and the nucleus lies in a central mass of protoplasm connected with the parietal laser by numerons strands.

ually secrete a cell-wall when they come to rest, as do also the oospheres after fertilisation.

The size and form of the cell vary widely. While some cells are so small that little more than their outline can be discerned with the help of the strongest magnifying power (about 0.001 of a 
millimeter in diameter), others obtain a considerable size (from 0.1 to 0.5 millim.), so as to be distinguishable even by the naked eye (e.g. in pith of Dahlia, Impatiens, Sambucus). Many grow to a length of several centimetres, as the hairs upon the seed of Gossypium (cotton); and if cœnocytes be included, such as the laticiferous tubes of the Euphorbiaceæ, the Siphonaceous Algæ, and the Phycomycetous Fungi, very much larger dimensions in length are attained.

The Form of such cells as constitute an entire individual, or exist independently, not forming part of a tissue (e.g. spores), is generally spherical, or ovoid, or cylindrical. The different organs of highly organised plants consist of many varieties of cells, and even in the same organ cells lie side by side which are of very different form. The two main types of cells are, first, such as are spheroidal or polyhedral, with nearly equal or slightly differing diameters (Fig. 36), as in pith, juicy fruits, fleshy tubers; and secondly, such as are narrow and greatly elongated (Fig. 72), as in the case of fibres.

$\$ 22$. The Protoplasm. The protoplasmic contents of a cell present certain clearly differentiated portions. In the first place there is a nucleus; and there are more or less numerous plastids. These all lie in the general protoplasm of the cell which may be distinguished as the cytoplasm.

a. The Cytoplasm is of viscid tenacious consistence, but it is not a fluid. Chemical examination shows that it consists (at least,

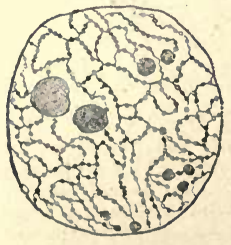

Fro. 37.- Resting nucleus from the young endosperm of Fritillaria imperialis, showing the flbrillar network with its chromatin. granules, and several nu. cleoli (after strusburger: $\times 1000)$. which belongs, however, to the cytoplasm. It consists mainly of associated with this are varying quantities of other organic substances, such as fats, and carbohydrates, together with water, and a small proportion of inorganic ashconstituents. As it is the seat of all the nutritive processes of the cell, it must obviously contain at different times all the various chemical substances which enter into, or are formed within the cell.

b. The Nucleus is always situated in the cytoplasm. It consists of various proteid substances. Its structure, when at rest, may be generally described as follows. It when dead) of proteid substance ; intimately 
a semi-fluid clear ground-substance, the nucleo-hyaloplasm. In the nucleo-hyaloplasm lies a fibrillar network in which are distributed a number of granules of a substance termed chromatin. One or more small granules, termed nucleoli, are to be seen lying in the ground-substance. On treating the nưcleus with staining reagents, the fibrillar network becomes stained on account of the absorption of the colouring-matter by the chromatin-granules, as also do the nucleoli. Its form is most commonly spherical, but it may be lenticular, or elongated, and straight or curved.

A formation of a nucleus de novo does not take place under any circumstances; hence all the nuclei in a plant have been derived by repeated division from the nucleus of the spore from which the plant was developed. The nucleus divides into not more than two parts, which are similar to each other in all respects.

c. The Plastids are differentiated portions of the protoplasm which, like the nucleus, are not formed de novo, but multiply by division. Their form varies widely. Structurally, they seem to consist of a groundsubstance, denser at the surface, with imbedded fibrils.

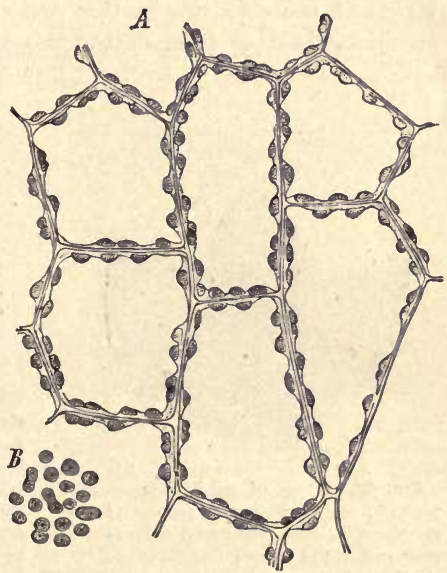

Fre. 38.-Chloroplastids in the cytoplasm of the cells of the prothallium of a Fern. A Optical section of the cells; $B$ part of a cell seen from the snrface. Some of the plastids have begun to divide. $(\times 400$.

The plastids may either be colourless, when they are termed leucoplastids; or coloured, when they are termed chromatophores. The chromatophores are distinguishable as chloroplastids, when they contain the green colouring-matter chlorophyll; or as chromoplastids when they contain no chlorophyll, but some other colouring-matter. Plastids are not found in the Fungi, nor, apparently, in the Cyanophyceæ among the Algæ.

The Leucoplastids may be spheroidal, fusiform, or cylindrical in 
shape; they are especially numerous in the neighbourhood of the nucleus. In parts of plants which, in the ordinary course, eventually become exposed to light, the leucoplastids develope. into chloroplastids. Conversely, when a part which is normally exposed to light is kept in darkness, the chloroplastids become replaced by leucoplastids. The essential function of the leucoplastids is to form starch-grains.

The Chloroplastids or Chlorophyll-bodies, are of various form. The characteristic feature of them is their function, which is twofold. In the first place, they can, like the leucoplastids, generally produce starch-grains; in the second place, they are capable, in virtue of the colouring-matter present in them, of constructing organic substance from carbon dioxide and water under the in-

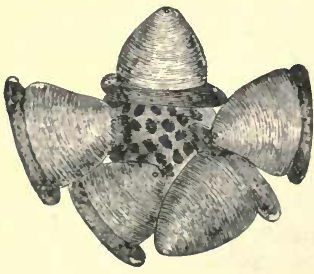

Fig. 39.-Group of rod-like leuco. plastids, each bearing a pyramidal starch-grain, collected round the nu. cleus in a cell of the psendo-bulb of an Orchid (Phajus grandifolius). ( $\times 850$ : after Bchimper.)

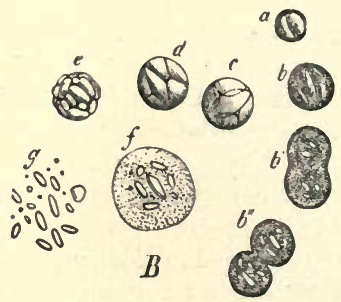

Fie. 40.-Isolated chloroplastids with starchy contents from the leaf of Funaria hygrometrica (550). a A young corpuscle; $b$ an older one, $b^{\prime}$ and $b^{\prime \prime}$ have begnn to divide; $c d e$ old corpuscles in which the starchy contents fill almost the whole space; $f$ and $g$ after maceration in $w$ ater by which the substance of the corpnscle has been destrojed and only the starchy contents romain. (After Sach8.)

fluence of light (see Part III.). Their function is thus not only starch-forming or amyloplastic, but also assimilatory. These two functions may be, and usually are, carried on simultaneously; hence when, under the influence of light, organic substance is being produced in the chloroplastid, it usually becomes filled with starch-grains, and sometimes to such an extent that the substance of the chloroplastid constitutes but the wall of a vesicle (Fig. 40). But starch-grains may be formed in a chloroplastid, as in a leucoplastid, in the absence of light; the organic substance required for the building-up of the starch-grain being not produced 
in the chloroplastid itself, but supplied from other parts of the plant.

These plastids are termed chloroplastids, because the colouringmatter upon which their assimilatory function depends is most commonly the familiar green colouring-matter, chlorophyll. But they are not always green. In some of the Algæe they are red or brown, because in addition to chlorophyll there is present in the one case (Rhodophyceæ), a red colouring-matter, phycoerythrin, and in the other (Phæophyceæ) a brown colouring-matter, phycoxanthin or phycophain. These substances are, however, related to chlorophyll.

When the colouring-matter is dissolved out by alcohol or some other solvent, the protoplasmic plastid is left colourless, but unchanged in form or size. The chlorophyll appears to exist in an oily solution, and to be confined to the fibrillar portions of the plastid, in the form of droplets (grana).

The most common form of chloroplastid-the only one occurring in the higher plantsis the chlorophyll-corpuscle (Fig. 40), which is flattened and discoid. Usually, many corpuscles are present in a cell, but occasionally (e.g. Anthoceros) there is only one. In the Algæ the chromatophores,

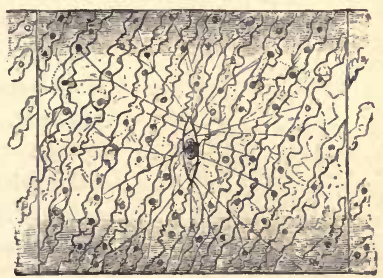

Fig. 41.-Spirogyra majuscula (after Strasburger: $\times 210$ ). $\Delta$ cell of a flament, showing the nucleus suepended in the centre; slso the spirally-wound chromatophore with pyrenoids. though sometimes small and discoid (e.g. Vaucheria, Fucus, etc.), are more commonly large, occurring singly, and of very various form.

The chromatophores of the Algæ present a great variety of form. Generally speaking, those of the higher forms are small corpuscles of a more or less discoid form; while in the lower forms the chromatophores are few in number, often single, in each cell, and are relatively large, assuming commonly the shape of a flattened plate, sometimes elongated and straight or spirally coiled (Fig. 41). In the latter case the large flattened chromatophores present one or more spherical thickenings, each of which is termed a pyrenoid (Fig. 41), and consists of a homogenous colourless mass of proteid substance. The pyrenoid is generally surrounded by a layer of starch-grains : this is, in fact, the only part of the chromatophore in which starch can be detected. 
Chromatophores multiply by division into two, effected by median constriction (Figs. $38 \mathrm{~B} ; 41$ ): pyrenoids, when present, are multiplied in the same way.

The chloroplastids ultimately undergo degeneration, when, as in the case of falling leaves, for instance, all that remains of them is a few yellow granules.

In many cases the green colour of parts of plants containing chloroplastids is masked by the presence of other colouring-matters held in solution in the cell-sap (e.g. the leaves of Amaranthus, Coleus, Copper Beech, Copper Hazel, etc.).

The Chromoplastids are generally derivatives of chromeplastidswhich have undergone a change both in form and colour. They occur most commonly in the cells of yellow floral leaves, such as

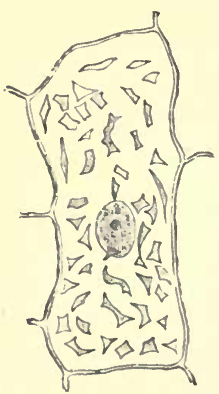

Fig. 42.-From the upper side of the calyx of Troprealum majus. The inner wall of an epidermal cell with the chromoplastids. (After Strasburger: $\times 540$.) those of Tropæolum (Fig. 42): in the superficial cells of many fruits of a red or orange colour (e.g. berries of Solanum, fruit of Tomato). The yellow colour of the root of the Carrot is due to the presence of leucoplastids, in each of which there is a large orange-coloured crystal of carotin. The chloroplastids of many Coniferæ (e.g. Biota orientalis) assume a reddish colour at the beginning of winter.

Many of the primordial reproductive cells are motile (zoospores, planogametes, spermatozoids), and move by means of cilia. A cilium is a delicate filament of protoplasm which is contractile, and by its oscillations serves to propel throngh the water the body to which it belongs. The number of cilia borne by these cells varies considerably: there may be a single cilium (e.g. zoospores of Botrydium, and occasionally those of Hydrodictyon): or a pair (generally in planogametes; frequently in zoospores; less commonly in spermatozoids, as those of most heterogamous Algæ, of the Bryophyta, and of Lyeopodium and Selaginella): or four (e.g. zoospores of certain green Algæ, Ulothrix, Cladophora, Ulva); or many (e.g. all motile cells of Edogonium; zoospores of Vaucheria; spermatozoids of Filicinæ and Equisetinæ). Cilia also occur in free-swimming Algæ, such as Volvox, etc.

$\S 23$. The Cell-Wall is a non-protoplasmic membrane consisting, at least at its first formation, of an organic substance termed cellulose, of water, and of a small proportion of inorganic 
mineral constituents. Its growth, as well as its first formation, is the result of the vital activity of the protoplasm; it is, in fact, formed from and by the protoplasm.

1. The Growth of the Cell-Wall. The cell-wall grows in surface and in thickness.

a. The grouth in surface of the cell-wall may take place in either of two ways, both of which are, however, dependent upon pressure exerted from within upon the wall. In the one case the stretched wall grows continuously by means of material supplied to it by the cytoplasm, the wall remaining unbroken. In the other, the stretched wall is ruptured at certain parts, new portions of cell-wall heing at once intercalcated to close the gap. The former is of more common occurrence: the latter has been observed in some Algæ, for instance in the growth of the cells of Edogonium, and in connexion with the apical growth and with the development of lateral members in Caulerpa, Cladophora, and Polysiphonia.

Growth in surface takes place to such an extent that the volume of the cell not infrequently becomes a hundred-fold greater than it was originally. Thus, for instance, in a leaf still enclosed in a leaf-bud, the cells of which it will consist wheu fully developed are all actually present, and it is simply by their increase in volume that the leaf attains its full size.

In the comparatively rare cases in which the superficial growth of the cell-wall is equal at all points, the cell preserves its original form: but more commonly the cell-wall grows more vigorously at certain points than at others; thus, for instance, a primarily spheroidal or cuboidal cell may become tubular, cylindrical, fusiform, stellate, etc.

$b$. The grouth in thickness of the cellwall is effected by the deposition of successive layers on the internal surface of the first-formed layer. The cell-wall does not usually begin to thicken until after its growth in surface has ceased, the cell having then attained its definite size; but cases of simultaneous growth in surface and in thickness have been observed.

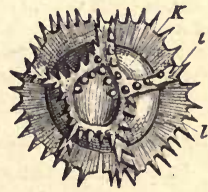

Fro.43.-Ripe pollen-grain of Cichorium Intybus; the almost spherical surface of the cell-wall is furnished with ridge-like projections prolonged into spines, and forming \& network. (After Sachs.)

The growth in thickness of the cell-wall is also rarely uniform; the cell-wall commonly becomes more thickened at some points 
than at others, and thus acquires inequalities of surface. In the case of isolated cells or of free cell-walls, the prominences existing in this way on the external surface appear as warts, tubercles, spines, etc. (Fig. 43). Cells that are united to form tissues have their inequalities on the internal surface of the cell-wall, the prominences sometimes having definite form, and projecting into the interior of the cell; such are the annular (Fig. $44 r$ ) and spiral thickening (Fig. $44 s$ ) of the walls of certain vessels; in the so-called reticulated cell-walls, the thickening is in bands which are united into a network, so that circular or oval thin spaces are left. In other cases, isolated and relatively small thin spaces are left in the wall in the course of the growth in thickness, which
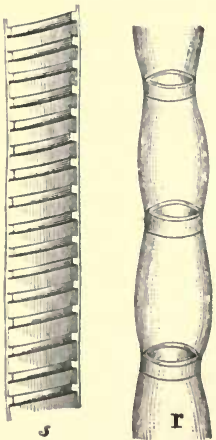

Fio.41. $-r$ Annular, s spiral thickening of the walls of ves. sels; $r$ seen from outside, $s$ in longitudinal section highly msgnifled (diagrammatic). appear, when seen on the external surface, as bright spots, commonly called pits, and are seen in section to be canals of greater or less length, according to the relative thickness of the walls (Figs. 45, 46). Very frequently the pit, when seen from the surface, presents the appearance of two concentric circles, or ellipses; for this reason, that the opening of the canal into the interior of the cell is narrow, whereas the external opening is broad (Fig. $48 \mathrm{~A}$ ). Such bordered pits occur in the wood-cells of Conifers (Fig. 49), in the walls of many vessels (Fig. 48), and elsewhere. The scalariform thickening of the walls of many vessels arises from the regular and close arrangement of bordered pits which are much elongated transversely.

The Structure of the Cell-wall. When the cell-wall is at all thickened it presents indications of structure.

It presents, in the first place, a layered appearance when examined in longitudinal or transverse action (Fig. 46). This layering or stratification of the cell-wall is readily intelligible when it is remembered that the thickening of the wall is due to the deposition of successive layers from within.

It presents, secondly, a delicate striation, when examined in surface-view, the lines running at a larger or smaller angle to the long axis of the cell, sometimes even transversely. The planes of striation are commonly different in the different layers constitu- 


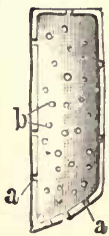

F16. 45. - A cell $n$ ich pitted kalls, from the wood of the Elder (Sam. bucus). A longitudinal section showing the pits in the lateral walls as channels, $a$; and in the farther wall as roundish spots, b. $(\times 210$.

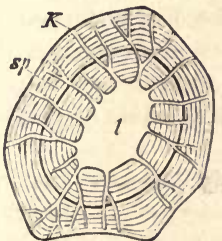

Fig. 46.-Transverse section of a bast-cell from the root of Duhlia variabilis ( $\mathrm{x}$ $800)$; t the cell-cavity ; $K$ pitcanals which penetrate the stratification; sp a crack by which an inner system of layers has become separated. (After Sachs.)

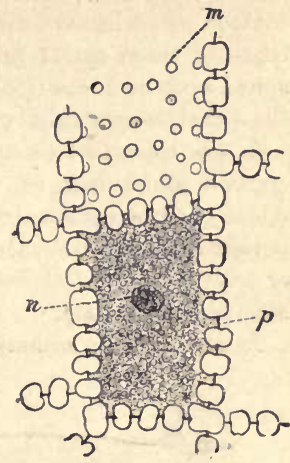

Fre. 47.-Cells from the endosperm of Ornithogalum umbellatum showing simple pits : $m$ plts seen in surface view ; $y$ closing membrane seen in lon. gitndinal section; $n$ nucleus. ( $\times 240$ : after Strasburger.)

ting the thickness of the wall, and these seem in the surface-view to cross each other (Fig. 50). The cause of striation appears to be this, that when a considerable area of cell-wall has to be formed, it is deposited by the protoplasm not as one continuous sheet, but

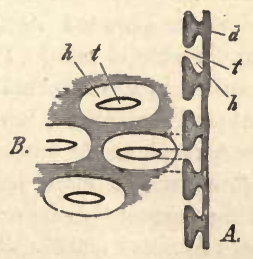

FIG. 48.-Oval bordered pits in the wall of a vessel of Helianthus. $A$ In longitudinal section. $B$ As seen from the surface; $t$ the pit ; $h$ the pit-chamber. $(\times 600)$.

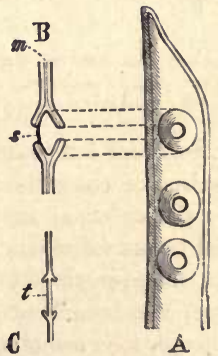

F16. 49.-Circular bordered pits on the wood-cells of the Pine. $A$ Seen from the surface. $B$ In section; s the closing membrane; $m$ the middle lamella. C An earlier stage, in section. $(\times \$ 00$,diagram.) 
in the form of delicate spirally-wound bands with their edges in contact. The lines of the striation are the planes of contact of the edges of these spiral bands. A well-marked illustration of the spiral mode of deposition of cell-wall by protoplasm is afforded by the spiral vessels already mentioned (Fig. $44 \mathrm{~s}$ ).

3. The Chemical Composition of the Cell-wall. As a rule, the organic constituent of the newly formed cell-wall is cellulose $\left.\mathrm{C}_{6} \mathrm{H}_{10} \mathrm{O}_{5}\right)$, a carbohydrate, the characteristic reaction of which is that it turns blue when treated with sulphuric acid and iodine, or with a mixture of iodine, iodide of potassium, and chloride of zinc (chlor-zinc-iod).

It is, however, commonly the case that when a cell-wall has undergone thickening, some

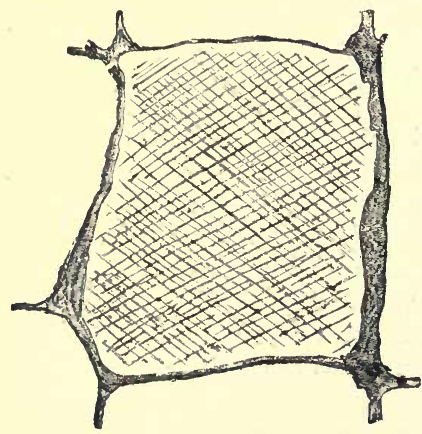

Fre. 50.-Surface view of the wall of a cell showing striation, from the pith of Dahlia varia. bilis. ( $\times 249$ : after Strasburger.) at least of its constituent layers do not consist of cellulose. The chemical changes which are presented by cell-walls may be distinguished as follows :-

$a$. The cell-wall may undergo cuticularisation: e.g. walls of epidermal cells or cork-cells, of spores. The cuticularised or corky cellwall contains a substance termed cutin. It is but slightly permeable to water; it is extensible and highly elastic; it turns yellow when treated with sulphuric acid and iodine, or with iodised chloride of zinc. The cuticularisation of the cell-wall is most marked in the external layers ; in fact the external layer consists entirely of cutin, whilst the internal layers (of which there may be several, as the cuticularised wall is often much thickened) consist more and more largely of cellulose, the innermost layer consisting frequently of pure cellulose, though it is sometimes more or less lignified (cork). This can be shown by treating the cuticularised tissue with strong chromic acid for some time, or by warming it in a mixture of nitric acid and chlorate of potash, when the cutin is removed, and the remaining tissue gives the characteristic cellulose-reactions. 
$\beta$. The cell-wall may undergo lignification; that is, the cell-wall becomes impregnated with a substance termed lignin, which makes it hard and elastic, and though readily permeable to water it cannot absorb or retain much in its substance. The characteristic tests for lignin are, that a cell-wall containing it $(a)$ turns yellow when treated with aniline chloride and hydrochloric acid, and $(b)$ turns pink when treated with phloroglucin and hydrochloric acid. When a lignified cell-wall is macerated in a mixture of nitric acid and chlorate of potash, or in a strong solution of chromic acid, the lignin is dissolved out and the wall ceases to give the lignin-reactions, and now gives the cellulose-reactions. Lignification takes place in the sclerenchymatous and tracheal tissues, less commonly in the parenchymatous tissue, of the sporophyte of the Pteridophyta (Vascular Cryptogams) and Phanerogams; it does not occur in any of the lower plants, nor in any gametophyte.

$\gamma$. The cell-wall may become more or less mucilaginous; in its dry state it is then hard and horny; when moistened, it absorbs a large quantity of water, becoming greatly increased in bulk and gelatinous in consistence; it usually turns blue when treated with sulphuric acid and iodine, or with iodised chloride of zinc, but in some cases it does not give this reaction; and in yet others (e.g. asci of Lichens, bast of Lycopodium, endosperm of Peony, and cotyledons of various leguminous seeds) it turns blue with iodine alone. Mucilaginous cell-walls are common in the coats of seeds (e.g. Flax or Linseed, Quince); they are very remarkable in the case of the macrospores of Pilularia and Marsilea ; in tissues, they are well seen in the Malvaceæ: they occur in all sub-divisions of the vegetable kingdom.

In some cases the change goes so far as to result in the conversion of the cell-wall into gum, soluble in water, as in some species of Astragalus and in certain Rosaceous trees (Cherry, Plum, Almond, Peach, etc.).

These modifications may occur either singly or together in the different layers of one cell-wall, as in corky, or suberised cell-walls, where cuticularisation and lignification occur simultaneously.

8. Mineral matters are also frequently deposited during growth in considerable quantity in the cell-wall, particularly salts of lime and silica; they are usually intercalated between the solid organic particles of the cell-wall, so that they cannot be directly detected, but remain, after burning, as a skeleton which retains the form of 
the cell. Silica is present in the stems of Grasses and of Equisetaceæ. Calcium oxalate sometimes occurs in a crystalline form (Fig. 51.) Calcium carbonate is also frequently deposited in cellwalls, as in certain Algæ (e.g. Acetabularia, Corallina, Jania, etc.); also in hairs of some of the higher plants (e.g. many Boraginaceæ); but most peculiarly in the cystoliths present in the epidermal cells of the leaves of Ficus clastica, and of the Urticaceæ and Acanthaceæ: it may occur either as granules or as crystals.

A cystolith (Fig. $52 \mathrm{~A}$ ) consists of a basis of cellulose incrusted with calcium carbonate. On treating a section, containing a cystolith, with acid, the calcium carbonate is dissolved with evolution of bubbles of $\mathrm{CO}_{2}$, leaving the cellulose basis $(B)$ which presents both striation and stratification. The cellulose basis is, in fact, a local thickening of the cell-wall.

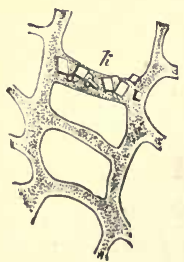

Fig.! 51,-Crystals o calcium oxalate in the wall of the bast-cells of Cephalotaxus Fortunei. ( $\times 600$ : after Solms.)

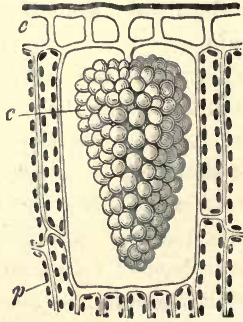

A

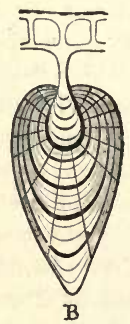

B

F1G. 52.-A cystolith from the leaf of Celtis Tala $(\times 200)$. A Normal condition; c cysto. lith; epidermal layer; $p$ palisade-tissne. $B$ The cystolith after treatment with hydrochloric acid which has dissolved the calcium carbonate, leaving the stratified cellulose basis.

$\S 24$. Cell-Contents. The following are the principal cellcontents which are not protoplasmic and are, in fact, not living: they are moreover not universally present in cells, but are confined to special cells, and frequently to special plants: starchgrains; fats; proteid grains and crystalloids; mineral crystals ; the cell-sap, and the substances dissolved in it.

a. Starch-grains are small solid granules of various shaperounded, oval, lenticular, etc.-consisting of starch with a certain amount of water and a small proportion of incombustible ash. They are specially abundant in those parts of plants which serve 
as depositories of reserve-materials, e.g. rhizomes and roots of perennial plants during the winter, tubers of the potato, seeds such as those of the cereal and leguminous plants. They can be extracted by maceration from the organs in which they occur, and then appear as a white powder which is known as starch. Starch is a carbohydrate; its percentage composition is the same as that of cellulose, and may be represented as $\mathrm{C}_{6} \mathrm{H}_{10} \mathrm{O}_{5}$, but its molecule is smaller and less complex. It is readily detected by the characteristic blue colour which it assumes on treatment with an aqueous solution of iodine. When boiled with water, or when treated with potash, the grains swell enormously and form a paste.

The substance of the starch-grain is always stratified, being disposed in layers round an organic centre, the hilum; this stratification, as also in the case of cell-walls, is the result of the deposition of successive layers one on the other. The hilum is the most watery portion of the grain, whilst the external layer is the most dense.

It is, as already mentioned (p. 70), the rule that starchgrains are produced by means of plastids; in parts of plants exposed to light, by chloroplastids; in parts of plants not exposed to light, by leucoplastids. In the former case the grains are usually formed in the interior of the plastid (see Fig. 40); in the latter case, on its surface (Fig. 39).

It not uncommonly happens that compound starch-grains are to be found. Spuriously compound grains are simply grains which have become adherent in consequence of mutual pressure; they occur frequently in the interior of the plastids (see Fig. 40). The truly compound grains (Fig. $53 \mathrm{~B}-E$ ) are formed in this way, that one plastid produces simultaneously two or more rudimentary starch-grains; as these increase in size, they eventually come into contact; the further deposition of starchy layers must necessarily be of such a kind that they surround, not each individual grain, but the aggregate of adjacent grains; the young grains thus become bound together by investing layers, and a grain is produced which has apparently a number of hila.

The form of the starch-grains is characteristic in the different plants in which they occur; thus those of the Potato (Fig. 53) are excentrically oval; those of leguminous plants (Fig. 55), concentrically oval; those of Rye, Wheat, and Barley, lenticular (Fig. $56)$.

The distribution of starch throughout the different classes of 
plants is a matter of considerable interest. Generally speaking, it is confined to plants which possess chloroplastids, though a substance turning blue with iodine has been found to occur, diffused throughout the protoplasm, in certain Schizomycetes (Clostridium butyricum, Sarcina ventriculi, Bacterium pastorianum). But, on the other hand, it is not always present in plants which possess typical chloroplastids; thus, it is absent, for instance, from the Onion, species of Vaucheria, etc. In the case of plants which have other colouring-matters besides chlorophyll, starch may be

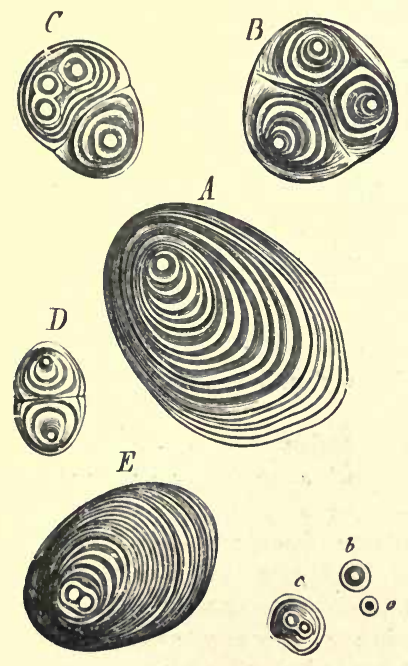

Fig. 53.-Excentric starch-grains from the tuber of a Potato $(\times 800)$. A A fully developed simple grain. $B-E$ Compound grains; $a b$ young simple grains; $c$ young compound grain. (dfter Bachs.) genous food when the seed germinates. They consist of a mixture of proteid substances belonging to the globulins and the albumoses. They present no indications of structure, and are much larger in oily than in starchy seeds.

The proteid grain generally contains a mass of mineral matter. Most commonly this is a rounded body, the globoid (Fig. 54), con- 
sisting of double phosphate of lime and magnesia ; less frequently there is a crystal, or a cluster of crystals, of calcium oxalate.

In the large grains of oily seeds it is frequently the case that a portion of the proteid (globulin) of the grain crystallises out, constituting the crystalloid; there are occasionally two or more crystalloids in the grain (Fig. 54).

ס. Mineral Crystals are frequently found in the cells of plants. They sometimes consist, but in comparatively few cases, of calcium carbonate; for example, the crystals in the protoplasm of Myxomycetes, and the crystalline masses occurring in the cells of the

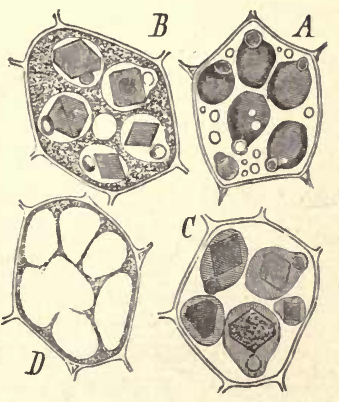

Fig. 54.-Cells from the endosperm of Ricinus communis $(\times 800): A$ fresh, in thick glycerine; $B$ in dilnte glycerine; $C$ warmed in glycerine; $D$ after treatment with alcohol and iodine; the grains having been destroyed by sulphuric acid, the cytoplasm remaining behind as a net-work. In the grains the globoid may be recognised, and in $B C$ the crystalloid. (After Sachs.)

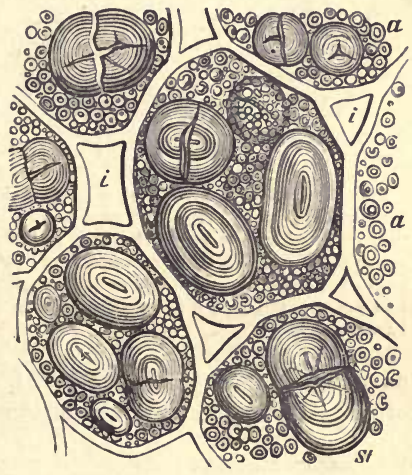

FiG. 55.-Cells of a very thin section throngh a cotyledon of the embryo in a ripe seed of Pisum sativum; the large concentrically strati. fied grains St are starch-grains (cnt throngh); the small granules $a$ are sleuron, consisting of proteids; i the intercellular spaces. (After Sachs.)

pericarp and testa of some plants (e.g. Celtis australis, Lithospermum officinale, Cerinthe glabra).

In all other cases the crystals consist of calcium oxalate, which crystallises in two systems according to the proportion of water which it contains; to the one system, the quadratic, belong the octahedra (Fig. $57 k$ ); to the other, the clinorhombic, belong the acicular crystals, distingnished as raphides, which occur in bundles in the cells of Monocotyledons more especially (Fig. 58), and are generally associated with mucilage in the cell.

M.B. 
It sometimes happens that the crystal, or group of crystals, becomes surrounded by a layer of cellulose attached to the wall at

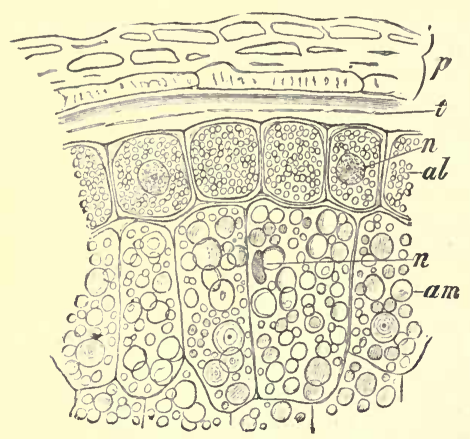

Frg. 56.-Part of a section of a grain of wheat, Tritivum vulgare; $p$ pericarp; $t$ seed-coat or testa; internal to which are cells belonging to the endosperm; the external layer contains small proteid. grains (al) but no starch, the more internal cells contain starch-grains $a m$; $n$ the nuclens. (After Strasburger : $\times$ 240.) one or more points (e.g. leaf of Citrus vulgaris, pith of Kerria japonica).

$\epsilon$. The Cell-Sap saturates the cell-wall, the protoplasm, in fact the whole organised structure of the cell; it also fills the vacuole, when present, in the cytoplasm. It is a watery solution of the most various substances. In all cases it holds salts in solution, consisting mainly of alkaline bases in combination either with inorganic acids, such as the nitric, phosphoric, or sulphuric, or with organic acids, such as malic (e.g. apple and other fruits), citric (lemon, etc.), and others. It frequently contains tannin, and nitrogenous substances

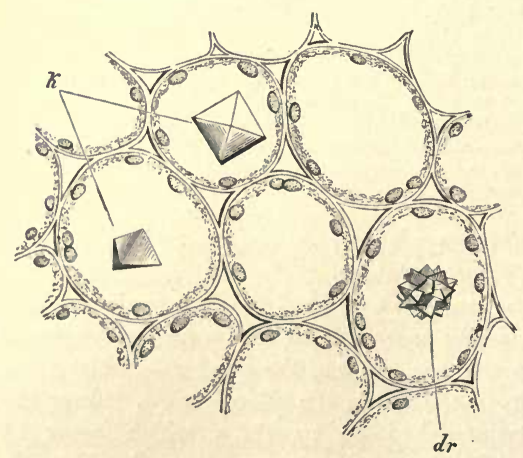

FIG. 57.-Crystals of calcium oxalate in the cells of the petiole of a Begonia $(\times 200)$ : $k$ solitary crystals; $d r$ cluster.

such as asparagin. It very commonly is rich in sugar: either grape-sugar $\left(\mathrm{C}_{6} \mathrm{H}_{12} \mathrm{O}_{6}\right)$, as in the grape and other fruits, and in fact most parts of plants at particular times; or canesugar $\left(\mathrm{C}_{12} \mathrm{H}_{22} \mathrm{O}_{11}\right)$ as in the Sugarcane, the Maple, and the Beetroot. In some plants (e.g. Jerusalem Arti- 
choke, Dahlia, Globe Artichoke) the cell-sap is rich in inulin, a substance having the same percentage composition as starch (represented by the formula $\mathrm{C}_{6} \mathrm{H}_{10} \mathrm{O}_{5}$ ): when a portion of tissue of one of these plants, such as a piece of the tuberous root of the Dahlia, is kept in spirit, the inulin slowly precipitates in the form of sphærocrystals

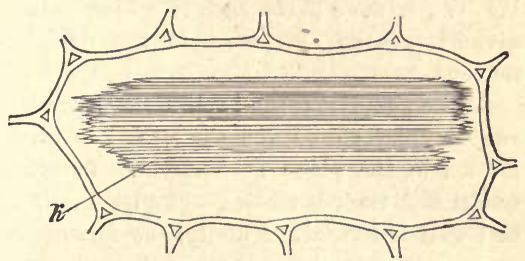

Fig. 58.-Raphides $(k)$ in a cell of a bulb-scale of Urginea maritima $(\times 200)$. (Fig. 59) adhering to the walls.

The cell-sap also very frequently holds colouring-matters in solution ; for instance, the colouring-matters of most red and blue flowers (erythrophyl and anthocyanin); of many fruits, such as the Cherry and Elderberry; of "copper leaves," such as those of Copper Beech and Hazel, and of the Beet-root.

\section{$\S 25$. Cell - Formation.} The formation of a cell is necessarily dependent upon a pre-existing cell; the direct development of a cell from the necessary chemical substances - that is, spontaneous generation-has not yet been observed. Moreover, it can only take place when the protoplasm concerned is in the embryonic condition; as, for instance, in growing-points, germinating spores, etc.

The development of cells always takes place in such wise that the whole or part of the protoplasm of a cell, the mother-cell, undergoes re-

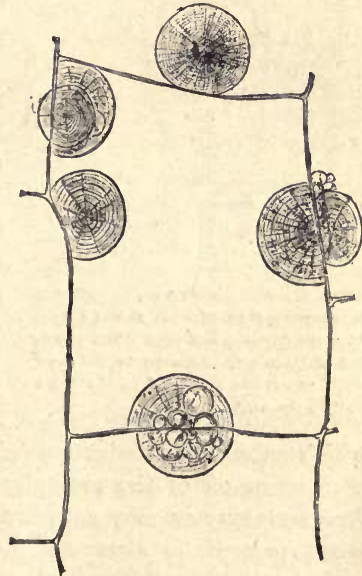

FIG. 59.-Sphærocrystals of inulin in the tissue of the tuberous root of Dahlia variabilis after prolonged action of alcohol. (After Strasburger: $\times$ 240.) 
arrangement. The following are the principal modes of cell-formation :

I. Cell-division. The protoplasm of the mother-cell divides into two or more parts, each of which constitutes a new cell. The division of the cytoplasm is usually preceded by that of the nucleus.

In the simplest case of cell-division the nucleus divides into two, the cytoplasm does the same, and a cellulose-wall or septum is formed in the plane of division. In other cases the secondary nuclei and their investing cytoplasm may again divicie before any cell-wall is formed. Finally, the formation of a cell-wall may be

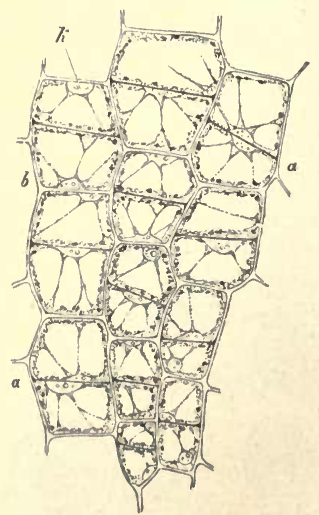

F1G. 60.-Cell-division in the cortex of the growing stem of Vicin Faba $(\times 300)$. At $a$ the division has just taken place, the nncleus still adheres to the new $w a l l ;$ at $b$ it has retreated to the older wall: $k$ the nncleus. postponed until the division of the nuclei and of the cytoplasm has been repeated an indefinite number of times. The varieties of celldivision which thus arise may be arranged as follows:

1. In growing vegetative organs, a division of the cell takes place, such that the whole of its protoplasm, without any rounding-off or contraction, is divided into two parts : the new wall is formed between the two masses of protoplasm only along the plane of division (Fig. 60). The wall is sometimes formed simultaneously at all points of the plane of division, as in the development of stomata, and sometimes, as in certain Algæ, e.g. Spirogyra, it grows as a ring from without inwards.

2. The formation of the cells which subserve reproduction (see $\S 15$ ) is always accompanied by a rounding-off of the protoplasm. These cells are generally set free, and may or may not have a wall when set free: the wall, when present, is always formed over the whole surface of the young cell.

a. The whole cytoplasm of the mother-cell may become aggregated around four newly-formed nuclei; this process occurs principally in the formation of the pollen of phanerogamous 
plants (Fig. 61), and in the formation of the spores of Mosses and Vascular Cryptogams. The details of this process are not the same in all cases. In some (development of the pollen-grains of Monocotyledons and of the microspores of Isoetes) the nucleus of the mother-cell divides into two, and this is followed by a corresponding division of the cytoplasm, a cellulose wall being formed between the two cells. Each of these now divides in the same manner, in a plane at right angles to that of the first division, and thus the four special mother-cells are produced lying in one plane. In other cases (development of the pollen-grains of Dicotyledons, of the spores of Mosses, Ferns, and Equisetums) the nucleus of the mother-cell divides into two, and each of these secondary nuclei divides again

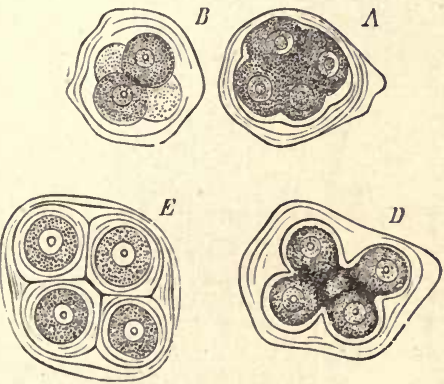

Fro. 61.-Division of the mother-cells of the pollengrains of $A$ lthae rosea. At $\boldsymbol{A}$ and $B$ the division of the protoplasm into four has begun; in $D$ the in-growth of the membrane is shown, and in $E$ the walls are complete. (After Sachs.)

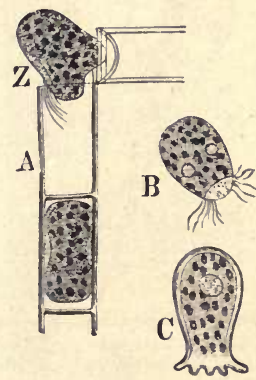

Fig. 62.-Rejurenescence as exhibited in the formation of the zoospores of Edogonium. A Portion of a flament; in thelower cell the protoplasm is beginning to contract, in the npper the young primordial cell is escaping (Z). B A zoospore. C The beginning of germination. ( $\times 350$.)

in to two, the divisions taking place in planes at right angles to each other and to that of the first division; as a consequence, the four nuclei do not lie in one plane, but are arranged tetrahedrally. Cellwalls are now formed, so that four special mother-cells are produced. In the case of the pollen-grains of Dicotyledons, the wall of the primary mother-cell thickens and grows inwards at certain points (Fig. $61 D$ ) so as to constrict the cytoplasm somewhat, and the newly-formed walls become attached to these projections. In all cases the protoplasm in each of the four special mother-cells 
surrounds itself with a proper wall which becomes the coat of the pollen-grain or of the spore.

$b$. The number of the nuclei derived by repeated division from the nucleus of the mother-cell before any cell-wall is formed is indefinite. Each of them becomes surrounded by a portion of the cytoplasm.

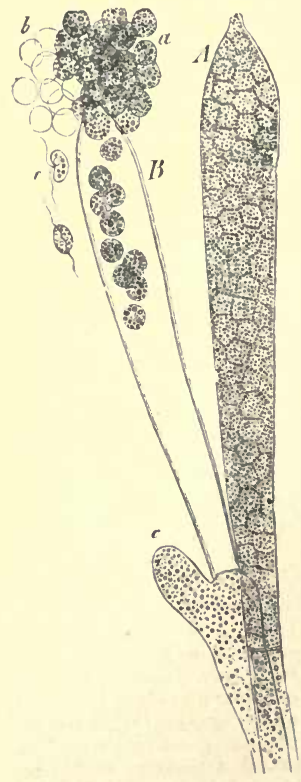

FIG. 63.-Zoosporangia of an Achlya $(\times 530): A$ still closed; $B$ allowing the zoospores to escape, beneath it a lateral shoot $c$; $a$ the zoospores just escaped; $b$ the abandoned membranes of the zoospores which have already swarmed; \& swarming zoospores. (After Sachs.)

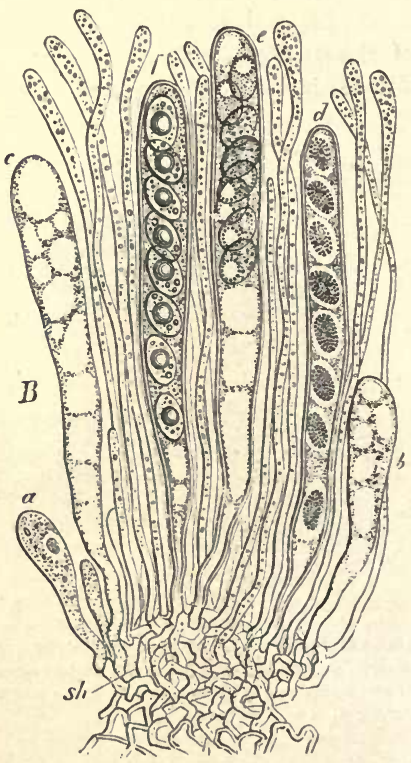

Fit. 64.-Cell-formation in the asci of Peziza convexula; af successive steps in the develop. ment of the asci and spores: sh mycelium. (After Sach8: $\times$ 550.)

It is in this way that the zocspores of many Algæ and Fungi are formed (Fig. 63), and it is usually not until some time after their escape from the mother-cell that they become clothed with a cellwall. The spores formed in the asci and sporangia of Fungi (Fig. 


\section{CHAPTER II.}

THE TISSUES.

$\S 26$. The Connexion of the Cells. According to their arrangement in space, the following combinations of cells may be distinguished :

A. Filaments, where the cells are connected only by their contiguous ends, and so form a filament, e.g., many Algæ, as Spirogyra (Fig. 65), (Edogonium (Fig. 62), and many hairs.

B. Surfaces, when the cells form a single layer and are in contact in two directions of space (length and breadth), e.g. many Algæ and the leaves of many Mosses.

C. Masses, when the cells are in contact on all sides.

The tissues commonly consist of cells which have originated from common mother-cells by their repeated division into two, and which have been connected from the first in consequence of the mode of formation of the septa (Fig. 60). In a few special cases tissues are formed otherwise (spurious tissues); either cells which have been hitherto isolated become adherent and then continue their growth in common; or filaments consisting of rows of cells become interwoven and exhibit a common growth, without however having become adherent in every case (Fig. $64 \mathrm{sh}$ ).

The Common Wall of cells combined into a tissue is, in the first instance, usually extremely thin and delicate, and appears

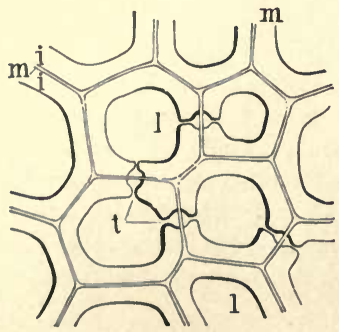

FIG. 68.- Transverse section of the cortical cells of Trichomanes speciosum $(\times \mathrm{b00})$. Middle lamella $(m) ; i i$ the cell-wall adjoining the lamella; $l$ cell cavity; bordered-pits which meet in adjoining cells; the pits on each side are divided by the middle lamella. under the strongest magnifying power as a simple plate (Fig. 60). As it increases in thickness a middle lamella usually becomes visible (Fig. 66), which divides the wall into two parts, one of which apparently belongs to each of the contiguous cells. This middle lamella is nothing more than a specially differentiated part of the wall which belongs to both of the cells in common. Its chemical composition, which is different to that of the remainder of the wall, permits of its solution (in nitric acid and chlorate of potash), 
so that the individual cells may be separated. When the common wall of similar cells is pitted, the pits on each side accurately meet (Fig. $66 t$ ) ; if, however, certain cells of a tissue undergo a special modification, as in the vessels, the unequal thickening of the membrane may be confined to one side only of the common wall; in the case of spiral thickening of the cell-wall this is self-evident.

In certain cases the septa between the cavities of adjacent cells become wholly or partly absorbed, as, for instance, occasionally the thin partition between bordered-pits; the transverse walls of such cells as combine to form the vessels are wholly absorbed, if they lie at right angles to the long axis of the vessel (Fig. $73 \mathrm{Cab}$ ); if they lie obliquely, they are broken through in various ways. In a similar manner the transverse septa (and more rarely isolated areas on the longitudinal wall also) of the sieve-tubes ( $(28$, Fig. $74 \mathrm{~B}$ ) are perforated by closely-set and very fine open pits, and are then known as sieve-plates. Hence a vessel is a syncyte (see p. 64).

$\S 27$. Intercellular Spaces are lacunæ between the cells of a tissue. They may be formed in two ways : either by a splitting of the common wall of adjacent cells, that is schizogenously; or by the disorganization of certain cells, that is lysigenously. They contain either air or certain peculiar substances.

The intercellular spaces which contain air are usually formed schizogenously. They occur almost exclusively in parenchymatous tissue, at the angles of junction of a number of cells (Fig. $67 \mathrm{z}$ ). Sometimes these spaces-then called air-chambers - attain a considerable size, so that whole masses of tissue are separated from each other, as in the petioles of the Water Lily and of other aquatic plants.

The large cavities in the stems and leaves of Rushes and of other allied plants,

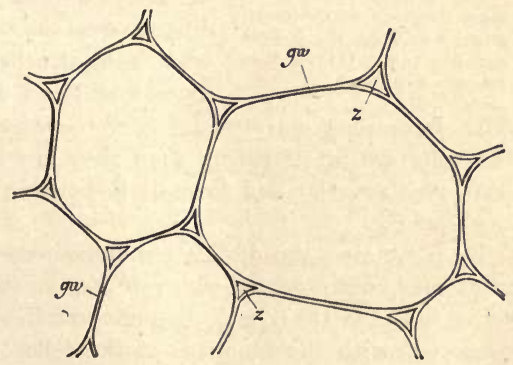

FiG. 67.-Intercellular spaces $(z)$ between cells from the stem of Zea Mais ( $\times$ :bE0); gro the common wall. (After Sachs.)

are produced lysigenously by the drying-up and rupture of considerable masses of cells: this is true also with reference to the 
cavities extending through whole internodes of many herbaceous stems (Grasses, Umbelliferæ, Equisetaceæ), and those occurring in leaves (Leek).

The intercellular spaces which contain certain peculiar substances are treated of under the head of Glandular Tissue in $\S 28$.

$\S 28$. Forms of Tissue. According to the form and arrangement of the constituent cells, the thickness and chemical composition of their walls, the nature of their contents, etc., it is possible to classify the forms of tissue in various ways.

Taking, first, the capacity for growth and cell-formation, embryonic tissue or meristem is distinguishable from adult or permanent tissue. The former consists of cells (e.g. in the growingpoint of a cellular plant) which grow and divide: whereas the latter consists of cells which have ceased to grow and divide,

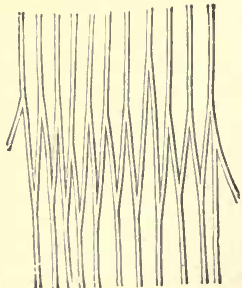

F1G. 63. - Prosenchymatous tissue, longitudinal section (dirgram, magnified), the pointed ends of the elongated cells fit in between each other. having attained their definitive form and size; and whilst meristem consists entirely of true cells, permanent tissue may consist wholly or in part of cells which have lost their protoplasm.

Taking, next, the form of the individual cells and the mode of combination into a tissue which their form determines, two forms of tissue termed parenchyma and prosenchyma are distinguished. In parenchymatous tissue there is no great difference in the three axes of the somewhat cubical cells, and the cells are in contact by broad flat surfaces (Figs. 60, 68). In prosenchymatous tissue, on the other hand (Figs. 68, 70 f), the cells are much longer than they are broad, having pointed ends which overlap and dovetail in between those of other cells of the tissue.

By combining the distinctive characters which have just been mentioned, with others which relate to the nature of the cellcontents and to the constitution of the cell-wall and are intimately connected with the functions of the cells, the following forms of permanent tissue may be distinguished :-

1. Thin-walled parenchymatous tissue consists of cells having cell-walls of cellulose. So long as the cells are functionally active they contain protoplasm; they may eventually lose their cell-contents and become dry and filled with air (e.g. pith of Elder). This 
form of tissue is the main seat of the protoplasm in the plant, and it is in the cells of this tissue that the chemical processes connected with nutrition are more particularly carried on. It is especially well-developed in fleshy and succulent parts (e.g. leaves, fruits, tubers, tuberous roots, etc.).

2. Thick-walled parenchymatous tissue. Of this there are two principal forms: (1) that in which the cell-walls are lignified; (2) that in which they are not lignified but consist of cellulose. The former occurs as wood-parenchyma in the secondary wood, and in the secondary medullary rays, of Dicotyledons. The latter commonly occurs as collenchyma just below the surface of herbaceous parts such as mid-ribs of leaves, petioles, young shoots, etc., and serves to give them firmness (Fig. 69). Both forms of this tissue retain their protoplasm for a long time after complete differentiation. The middle lamella (p. 88) of thick-walled parenchyma with cellulose walls, consists of a peculiarly dense form of cellulose.

3. Cuticularised tissue consists of cells of various form, generally parenchymatous, the walls of which have undergone more or less complete cuticularisation (see p. 76). The most conspicuous examples of this tissue are the epidermis, and the cork; in the former, the cuticularisation is confined almost exclusively to the external wall of the cell (Fig. $69 \mathrm{e}$ ), and the cells retain their cytoplasm; in the latter, the cuticularisation extends over the whole cell-wall, and the cytoplasm is soon lost. In both cases the cuticularisation is most marked

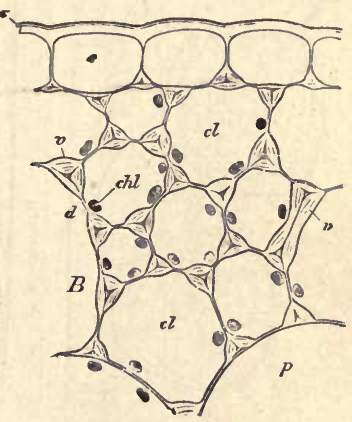

Fic. 69.- Transverse section of part of leaf-stalk of a Begonia ( $\times$ 550: after Sachs). e epidermis, the cells of which have thickened and cuticularised ex. ternal walls; $c$ cuticle. $B$ Collench5. matous tissue, with walls thickened at the angles $v$; the walls of the epidermal cclls are similarly thickened where they abut on the collenchyma; cl individual collenchymatons cells; chl chloro. plastids; $p$ large thin-walled parenchymatons cell. in the external layers of the cell-wall. In cork-cells there is a certain amount of lignification of the walls as well. The middle lamella (p. 88) of cuticularised tissue consists entirely of cutin (or suberin). Whilst cuticularisation generally occurs in the walls of free cells (e.g. spores), or of the superficial cells (epidermis) 
of a multicellular body, it occurs sometimes in internal tissue (e.g. endodermis).

4. Sclerenchymatous tissuc, or sclerenchyma, consists typically of prosenchymatous cells which lose their protoplasm relatively early, and then contain only water or air, and are distinguished as fibres; but in some cases they retain their protoplasm, and are then distinguished as fibrous cells. The cell-walls are thickened, sometimes so much so as almost to obliterate the cavity or lumen (Fig. 70); they are frequently lignified throughout, or only partially, or not at all (e.g. bast-fibres of Flax and Hemp); they commonly have simple round pits, or oblique and narrow bordered pits (Fig. 72).

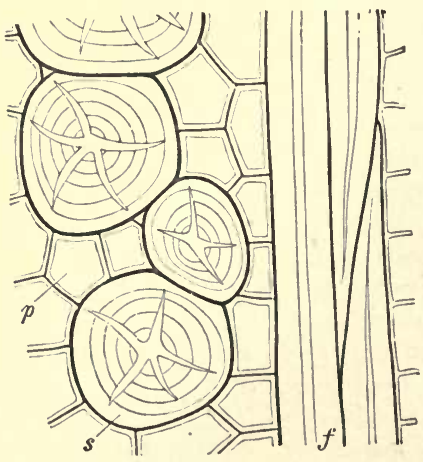

Fre. 70.-Longitudinal section of the cortex of the Oak, showing 8 short sclerotic cells : $f$ tbrous sclerenchyma; $p$ parenchymatons cells. $(\times 300$.)

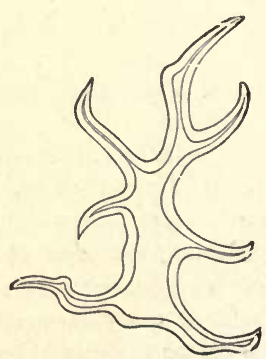

Fre. 71.-Isolated sclerotic cell from the lesf of Exostemma (Rubiacere). ( $\times$ 300.)

Sclerenchymatous tissue usually occurs in masses so as to give firmness and rigidity to the various parts in which it is present; it constitutes, together with the collenchyma, the mechanically supporting-tissue or stereom of the plant.

Isolated sclerotic cells (without protoplasm) of irregular form (Fig. 71) are of frequent occurrence (e.g. in the flesh of Pears, in coriaceous leaves as those of Camellia, Hakea, Olea, etc.): when these cells project freely into air-cavities (e.g. Nymphæaceæ, Aroids, Limnanthemum, Rhizophora) they are sometimes called internal hairs; short, straight cells occur in the secondary bast and cortex of many trees (Fig. 70). 
5. Tracheal tissue consists of cells which early lose their protoplasm; their cell-walls are generally, but not always, lignified, and are either pitted with simple or bordered pits, or have annular, spiral, or reticulate, etc., thickenings (see p. 74); when fally developed the tissue contains only either air or water.

The following varieties of this tissue may be distinguished:-
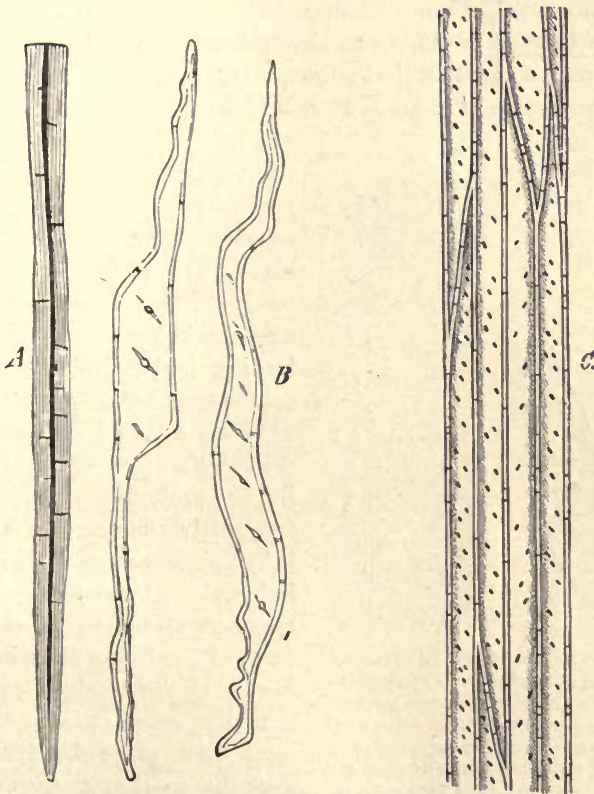

Fre. 72.-Sclerenchymatous tiseue. A The end of a bast-fibre, with strongly thickened pitted walls (longitudinal section $\times 300$ ). $B$ Wood-fibres from the root of the Cucumber ( $\times 300$ ), surface view and section. C Fibres from the stem of Melianthus tubcrosus ( $\times 500$ ).

a. The tracheids, which are closed, generally prosenchymatous cells (Fig. $73 \mathrm{~B}$ ), occur characteristically in the wood of certain plants (e.g. most Pteridophyta, Coniferæ) and are then completely lignified; but they also occur elsewhere, as in the tegumentary tissue (velamen) of the aerial roots of certain Orchids, where they are partially lignified; in certain cells of the anther-wall; 
and in the leaves and cortical tissue of the stem of Sphagnum (gametophyte) where they are not lignified at all (Fig. $73 \mathrm{~A}$ ).

b. The trachea are true vessels, that is, syncytes (p. 64), the contiguous cell-cavities having been rendered continuous by the complete or partial absorption of the intervening walls (Fig. 73 $\mathrm{Ca}$; ; the former is more frequently the case when the intervening walls are horizontal, the latter when they are oblique; they occur in the wood of many Phanerogams.

Tracheal tissue is the characteristic constituent of the vascular tissue-system to be deseribed subsequently; it is especially adapted for the conduction of water. It should be noted that in all forms

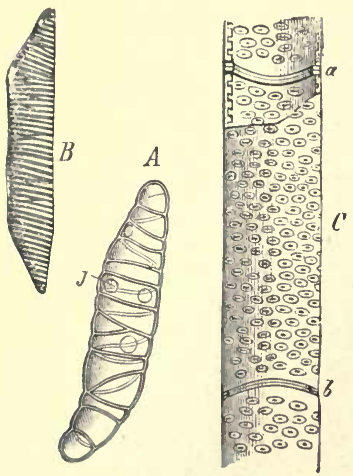

Fig. 73.-Tracheal tissue. A Tracheid from the leaf of Sphagnum; $j$ The holes in the externsl wall. $B$ Sealariform tracheid from the leat of Polypodium vulgare. C Part of a trachea with bordered pits from the stem of Helianthus; it has been cat into at the upper end; $a$ and $b$ the articulations, where the absorbed transverse walls existed.

of lignified tissues, whether tracheal, sclerenchymatous, or parenchymatous, the middle lamella is the most highly lignified part (p. 88); it dissolves readily in a mixture of nitric acid and chlorate of potash, thus leading to the isolation of the constituent cells.

When a vessel with a pitted wall abuts upon cells containing living protoplasm, it not unfrequently happens that the thin pit-membranes begin to bulge, in consequence of the pressure upon them of the contents of the living cells, into the cavity of the tracheal cell, and actually grow. Cell-division may take place in these ingrowths, so that a mass of cellular tissue is formed in the cavity of the vessel. These ingrowths are termed tyloses; they are constantly to be found in some kinds of wood (e.g. Robinia), and occasionally in many others.

6. Sieve-Tissue. This tissue consists mainly of long articulated tubes, the contents of the contiguous segments communicating by means of the sieve-plates, which usually lie on the transverse walls, either singly, when the transverse wall is horizontal, as generally in herbaceous plants (Fig. 74), or several together, when 
the transverse wall is oblique, as generally in woody plants (Fig. 75). Each sieve-plate is a thin area of the wall which is perforated by a number of closely placed open pits. The sieveplate is covered on both surfaces and the pits are lined by a peculiar substance termed callus (Figs. $74 C \dot{c} ; 75 B C c$ ), which at least in many plants periodically closes the pits in autumn. Sieve-plates may also occur on the lateral walls. The rest of the wall of the sieve-tube is rather thin: it is never lignified, but consists of cellulose. The long straight sieve-tubes are connected in their course by short transverse branches, so that they form one continuous system of tubes.

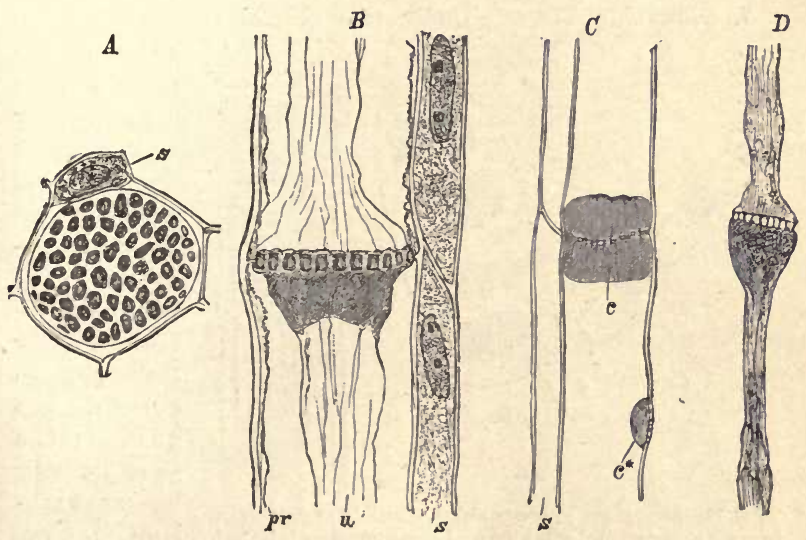

FrG. 74.-Sieve-tissue of an berbaceous Angiosperm (Cucurbita Pepo). A Transverse sieve-plate in surface-view; $B$ in longitudinal section; $C$ sieve-plate closed by a plate of callus c; $c^{*}$ sieve-plate on lateral wall, closed by callus; $D$ contents of tube left after solution of the wall by sulphuric acid; 8 companion-cells ; pr lining layer of protoplasm; $u$ mucilaginons contents. ( $\times 5+0$ : alter Strasburger.)

In their normal active condition each segment of the sieve-tube is lined by a layer of protoplasm (Fig. $74 \mathrm{~B} \mathrm{pr}$ ), in which starchgranules are sometimes to be found, enclosing some mucilaginous substance; there is, however, no nucleus present; the reaction of the contents is alkaline.

With the sieve-tubes of Angiosperms are closely associated cells, termed companion-cells (Fig. 74s), which are filled with granular proteid contents and have well-marked nuclei; each companion- 
cell is of common origin with the corresponding segment of a sieve-tube, both being derived from one mother-cell. Companioncells are not developed in Gymnosperms and Pteridophyta.

The sieve-tissue, like the tracheal tissue, is a characteristic constituent of the vascular tissue-system: it is very frequently associated with tracheal tissue so as to form one vascular bundle, but it may occur in independent bundles (e.g. in the pith of the stem of some Solanaceæ, Campanulaceæ, and Compositæ, and in the cortex of the stem of Cucurbitaceæ, and some other plants), and generally in roots. Tissue of this kind has been found to be present in plants so low in the scale as some of the larger Algæ (Laminariaceæ).

7. Glandular Tissue. Under this general term are included

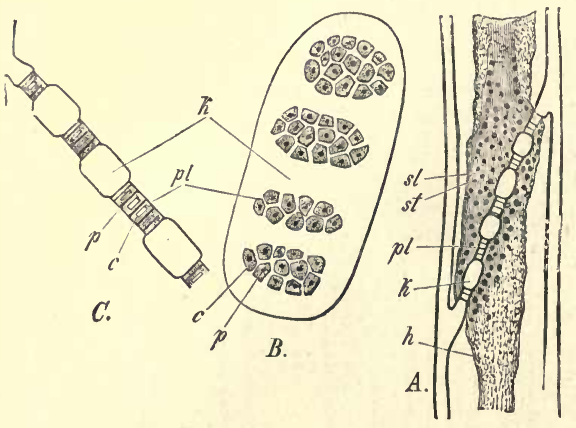

Fra. 75.-Sieve-tissue of woody plants. Portions of sieve-tubes from the secondary bast of the Vine. A Entire transverse wall and adjacent parts in longitudinal section $(\times 300): p l$ the gieve-plates; $k$ tbe thicker portions of the cell-wall; $h$ the protoplasmio lining; sl mucilaginons substance; st starcb-granules. $B$ Part of a transverse wall seen from the surface. C The same in section $(\times 700)$ : $p$ pits ; c callus; $p l$ the four sieve-plates. cells which produce more or less peculiar $\mathrm{substances}$ termed secreta, by a $\overline{\text { process }}$ known as secretion. The cells may be is olated, or they may be collected into groups; the secretum may be accumulated in the cavity of the secreting cell, or it may be thrown out at the surface (excreted); the process of secretion may or may not involve the destruction of the secreting cell.

The following are the chief varieties of glandular tissue :-

(a) Solid multicellular glands. Good examples of these are the chalk-glands of the leaves of many Saxifragaceæ and Crassulaceæ, and the nectaries present in flowers (floral nectaries) or in other parts (extra-floral nectaries) of various plants. In both these forms of gland the secretum, chalk in the one case and sugar in 
the other, is in solution, and is excreted at the surface. In the chalk-gland the secretum escapes through a special channel, a water-stoma (p. 108). In the nectary the secretum is simply poured out on the surface of the gland.

(b) Hollow multicellular glands are intercellular spaces surrounded by secreting cells, and are, in some cases, of schizogenous, in others of lysigenous, origin (see p. 89). The secretum may be mucilage, or gum, or a mixture of gum and resin (gum-resin), or

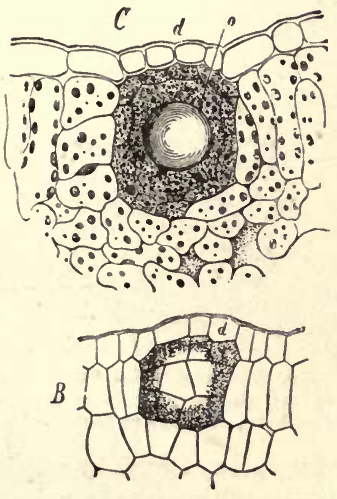

Fra. 76.-Lysigenous oil-gland below the upper surface of the leaf of Dictam. nus Fraxinella $(\times 320): B$ at an early stage ; $C$ mature ; $c$ mother-cells of the gland before their absorption; 0 a large drop of ethereal oil. (After Sachs.)
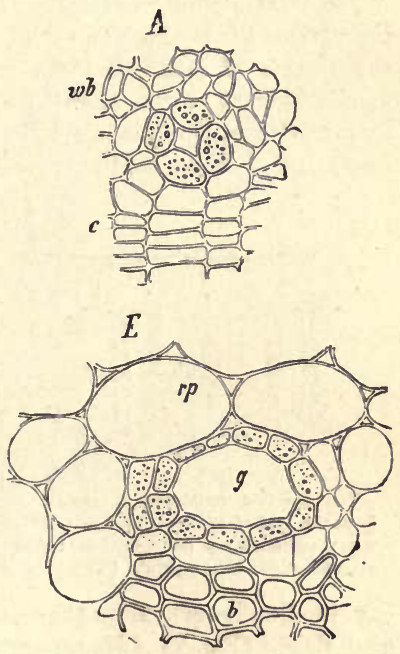

FIG. 77.-Schizogenous resin-duct in the young stem of the Ivy (Hedera Helix), transverse section $(\times 800)$ : $\boldsymbol{A}$ an early, $\boldsymbol{E}$ a later, stage; $g$ the resin-dncts; $c$ the cambium; $v b$ the soft bast; $b$ bast-fibres: $r p$ cortical parenchyma. (After Sachs.)

ethereal oil, or a mixture of ethereal oil and resin (balsam). The cavities are either rounded closed spaces, or are elongated canals, extending for some distance through the tissue; the former are usually of lysigenous, the latter of schizogenous, origin.

As examples of lysigenous hollow glands, may be mentioned the cavities filled with gum, which occur in the tissue of Cherry-trees; the oil-glands of the Orange and Lemon, and in the leaves of the 
Rue, the Myrtle, and Hypericum, where they can be discerned with the naked eye as transparent dots. The development of these oil-glands begins with the division of one or two cells of the young leaf, a group of cells being formed, in the cytoplasm of which oildrops make their appearance. The walls between the cells (Fig. $76 B . C$ ) undergo absorption, so that a cavity is formed which is bounded by the closely-packed adjacent cells, and contains a large oil-drop formed by the fusion of the oil-drops of the original cells.

The most striking examples of schizogenous hollow glands are the various kinds of ducts, such as the resin-ducts which permeate the tissues of most Coniferæ and Anacardiaceæ; the gum- or mucilage-ducts of the Marattiaceæ, some species of Lycopodium, Cycads, Canna, Opuntia, etc. ; the gum-resin-ducts of the Umbelliferæ, and of some Araliaceæ (e.g. Ivy, Fig. 77) and Compositæ

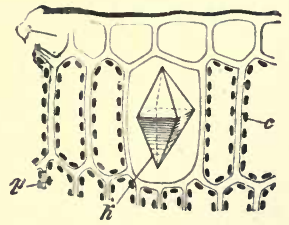

Fig. 78. Sac containing a crystal, from the leat of Rhamnus Frangula : upper epidermis; $p$ palisade-tissue : $c$ chloroplastids; $k$ the crystal. $(\times 200)$

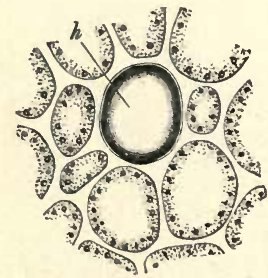

FLG. 79.-Part of section of the petiole of the Camphor-tree (Cinnamomum Camphora), showing a resin-sac $h$.

(e.g. the Sunflower). Here the cells of the group formed by a series of divisions (Fig. $77 \mathrm{AE}$ ), separate from each other so as to leave a passage, of which they form the wall, and into which they pour their secreta.

(c) Sacs, each consisting of a single cell. To this category belong the cells which contain crystals, as those in the tissues of many Monocotyledons (Fig. 58), in the bast of many dicotyledonous trees, in leaves (Fig. 78) and petioles (Fig. 57): the cells which contain mucilage, as in the parenchyma of the Lime and the Mallow, in the bark of Elms and Firs, in the pseudo-bulbs of Orchids, etc.: the cells which contain tannin, as in many Ferns and other plants : the cells which contain oil-resin, as in the Lauraceæ (Camphor, Fig. 79), the Zingiberaceæ, many Conifers (wood of Silver Fir), etc.

These cells are frequently arranged in longitudinal rows: for 
instance, the tannin-sacs of the Hop; the sacs containing raphides and mucilage in Tradescantia and many other Monocotyledons; the gum-resin sacs ("vesicular vessels") of the bulb-scales of the Onion; the sacs containing crystals of calcium oxalate in the cortex of many woody Dicotyledons; the sacs. containing milky juice or latex (commonly gum-resin) in the Sycamore, the Convolvulaceæ, and the Sapotaceæ (especially in Isonandra Gutta, the latex of which constitutes gutta-percha).

(d) Laticiferous vessels. These structures resemble the sacs containing milky juice (latex) in the nature of their contents, and differ from them structurally only in that the walls between adjacent cells have become absorbed, thus forming syncytes (p. 64).

In the simplest case, the laticiferous vessel merely consists of a longitudinal row of cells whose transverse septa have become absorbed, thus forming a syncyte of the nature of a vessel. When two such vessels are in contact laterally, the cellwalls are absorbed at the point of junction,

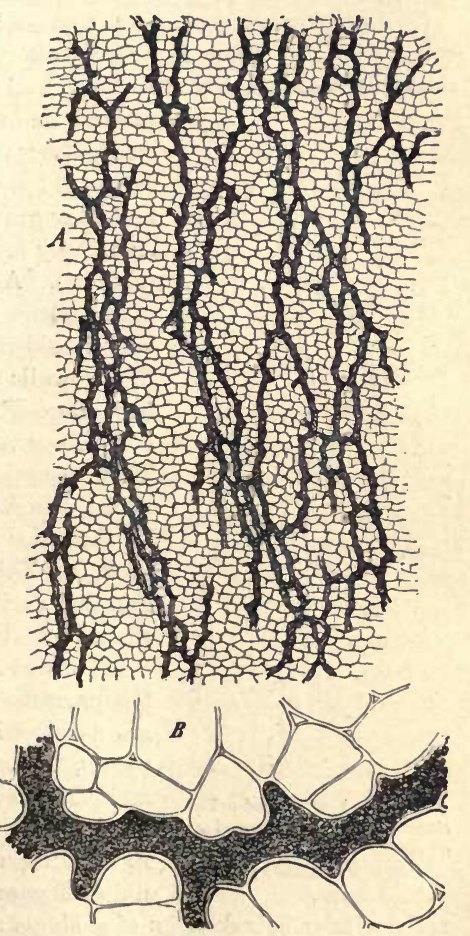

FIG. 80,-Laticiferous vessels from the cortex of the root of Scorzonera hispanica, tangential section : $A$ slightly magnifed; $B$ a small portion highly magnifled. (After Sachs.) and in this way a continuous system of laticiferous vessels is formed. This occurs in the greater Celandine (Chelidonium majus), and in the Banana (Musa) where, however, the latex is not milky. 
More commonly, as in the Cichorieæ (e.g. Dandelion, Scorzonera), the Campanulaceæ, and in most Papaveraceæ (e.g. Poppy), the cell-fusions take place in all directions, producing a dense network (Fig. 80).

Structures apparently of the nature of laticiferous vessels occur in certain Basidiomycetous Fungi (e.g. Lactarius).

(e) Laticiferous cœnocytes, commonly known as "laticiferous cells," occur in some Euphorbiaceæ (the Spurges), in the Urticaceæ (Nettles), Apocynaceæ, and Asclepiadaceæ. As already explained (p. 64), these "cells" are really

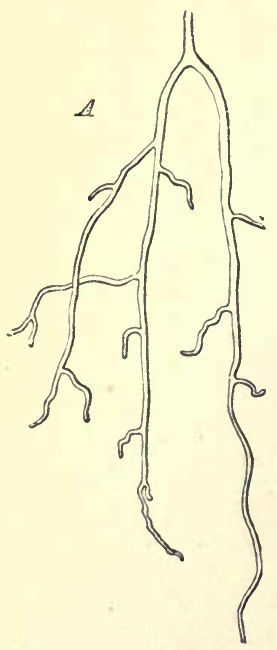

F1G, 81.-A portion of a laticiferous coenocyte dissected out of the leat of a Euphorbia. ( $x$ 120: after Haberlandt.) coenocytes; they are visible in the early stages of the development of the embryo, and they grow and branch in the tissue as if they were independent organisms (Fig. 81). As they extend from one end of the plant to the other, they attain a very considerable length in many cases. Their walls are frequently thickened (e.g. Euphorbia), but, like those of the laticiferous vessels, they are not lignified. They contain protoplasm with many nuclei which multiply by division, and in the older parts latex is abundantly present. The latex of the Euphorbiacer contains curious rod-like or dumb-bellshaped starch-grains.

(f) Epidermal Glands. Whilst all the preceding forms of glandular tissue are developed in the internal tissues of plants, somewhat similar glandular structures are developed from the superficial layer (epidermis), most commonly in the form of hairs (p. 46), either unicellular or multicellular. When the multicellular hair consists of a single row of cells, the secretion is generally confined either to a large terminal cell, or to several of the distal cells; in any case the secretion begins with the terminal cell, and extends backwards to other cells towards the base. The gland, though epidermal in origin, does not, however, always project from the surface, but may be more or less sunk in the internal tissue (e.g. glands in the leaf of the Psoralea hirta). 
The secretum (which may consist of mucilage, or gum-resin, or ethereal oil, balsam, etc.) is accumulated either in the cavity of the secreting cells (e.g. mucilaginous hairs at the growing-point of Liverwort-gametophytes and of Fern-sporophytes), or between the external cuticle and the deeper layers of the cuticularised cellwall (e.g. mucilaginous hairs [colleters] on the buds of many Phanerogams, resinous hairs generally; Fig. 82).

\section{$\S 29$. General Morphology of the Tissue-} Systems. When a form of tissue constitutes a complex which extends continuously throughout the body of a plant, or over considerable areas, it is spoken of as a tissue-system: for instance, a laticiferous system; a resin-duct system; a sieve-tube system; a mechanical tissue-system (stereom) including collenchyma and sclerenchyma; a glandular tissue-system; a tegumen-

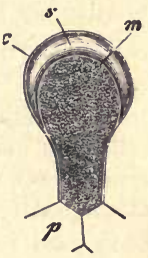

Fie. 82. - Glan. dular hair from the. base of a ramentum of Aspidium Filix mas $(\times 200): 8$, the secretum, lying between the outer and inner layers of the cell.wall, $c$ and $m$. tary tissue-system : or a more elaborate system may be produced by the combination of two or more systems: for instance, the sieve-tube system and the tracheal system taken together constitute the vascular tissue-system.

These tissue-systems are, however, characterised rather by their function, that is physiologically, than by their development, that is morphologically. From the latter point of view the following primary tissue-systems are distinguished: (1) The Tegumentary Tissue; (2) The Ground-Tissue; (3) The Stele. The study of these tissues will be begun by the consideration of the structure of the growing-point in stems and roots.

As already pointed out (p. 8), the growing-point consists, in the higher plants, of embryonic tissue, the cells of which may be of approximately uniform size, constituting a small-celled primary meristem; or there may be at the organic apex a cell conspicuously larger than the rest, the apical cell; or a group of several larger initial cells.

a. Growing-points consisting of small-celled meristem are, with rare exceptions, to be found in the roots and stems of Phanerogams, as also in the root of Lycopodium and Isoetes among the Pteridophyta. Although the cells are all embryonic, they nevertheless present such a degree of differentiation as to make it possible to distinguish the three primary tissue-systems. 
In the stem, a growing-point of this kind usually presents the appearance shown in Fig. 83. It consists, in the first place, of a well-defined superficial layer which, on being traced backwards, is seen to be continuous with the primary tegumentary tissue (epidermis) of the older parts ; this layer is, in fact, the embryonic epidermis or dermatogen $(d)$; it is quite distinct, morphologically; from the subjacent cells, and is characterized by the fact that its cells only undergo division in planes perpendicular to the surface (anticlinal), and not in any plane parallel to the surface (periclinal). Consequently, whilst the dermatogen increases in area, so as to keep pace with the growing tissues within, it does not become many-layered, but remains a single layer of cells.

In the middle of the growing-point is a solid mass of somewhat elongated cells $(p p)$ con-

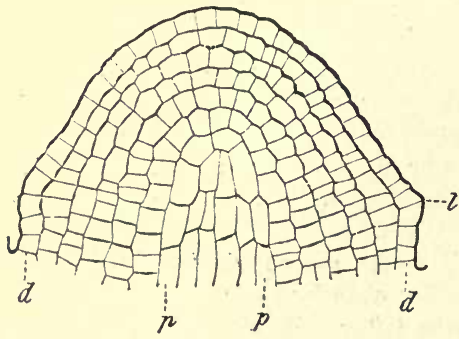

FIG.83.-Median longitudinal section of the growing-point of the stem of Hippuris vulgaris. The growing-point consists of a small-celled meristem, differentiated into dormatogen $d$, plerome $p p$, and periblem consisting of the five layers of cells between the plerome and the dermatogen; $l$ rudiment of a leaf. (After de Bary : $\times 225$.) stituting the plerome, and terminating in one or more initial cells ; on tracing this backwards into the older part of the stem it is found to give rise to a single axial cylinder of tissue, the stele, in which the vascular tissue is developed. Such a stem is said to be monostelic: stems having a growingpoint of this structure are, almost without exception, monostelic.

Between the dermatogen externally and the plerome internally, is a layer-less frequently several layers-of cells constituting the periblem; below the apex the cells undergo divisions both anticlinally and periclinally, so that both the area and the number of the layers are increased. On tracing the periblem backwards into the older parts, it is found to be continuous with the ground-tissue which, in monostelic members, is known as the primary cortex.

The growing-point of the root (Fig. 84) of one of these plants essentially resembles that of the stem in its structure; the smallcelled meristem is differentiated, at least primarily, into dermatogen, 
plerome, and periblem. But there is this distinctive peculiarity about the dermatogen of the root, that its cells undergo division, not anticlinally only, as in the stem, but periclinally also, so that the epidermis of the root is many-layered (except in Hydrocharis

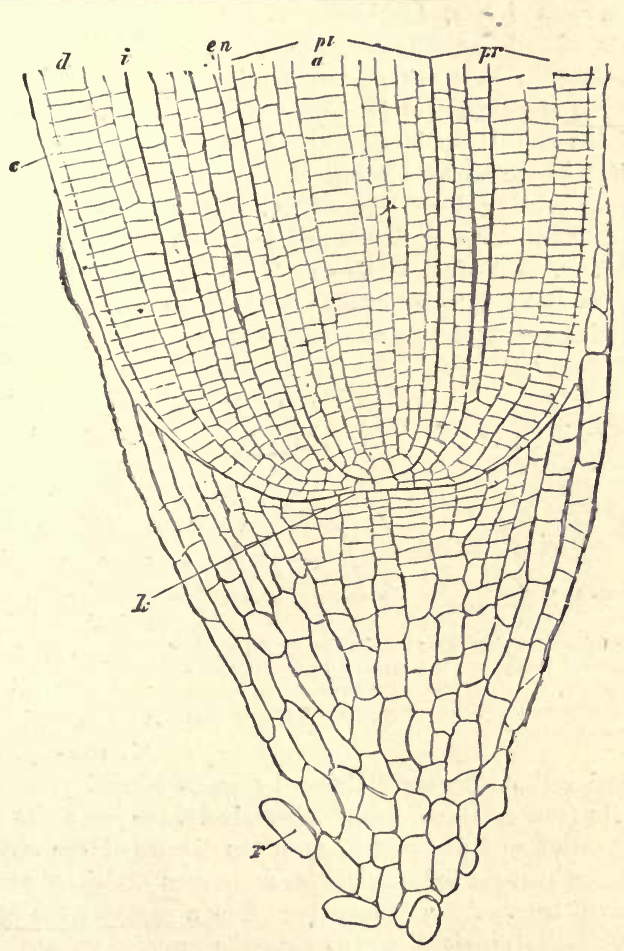

Fra. 84.-Median longitudinal section through the growing-point of the root of Horderm vulgare (Barley) : $r$ root cap; $k$ initial cells of the dermatogen of the many-layered epidermis; $d$-on cortex; $d$ epiblem with mucilaginous external layer of cell-wall $e$; $i$ cortical tissue with intercellular spaces; en endodermis; the whole periblem $(p r)$ is derived from the single layer of two initial cells at the apex; pl plerome; $a$ row of cells which give rise to a large central wood-ressel. (After Strasburger : $\times 180$.)

and Lemna, where it remains a single layer). This many-layered epidermis, however, is gradually exfoliated as the parts grow 
older, and persists only at the apex constituting the root-cap (see p. 44). The only other important fact to be noticed at present is that the root, as a rule, is monostelic.

b. Growing-points with a single apical cell are to be found in stems and roots of most Pteridophyta: for instance, in the stems and roots of all Leptosporangiate Filicinæ, and in those of Ophioglossaceæ); in those of the Equisetinæ; and in those of some species of Selaginella (S. Martensii and Kraussiana). The shape of the apical cell is generally a three-sided pyramid with a spherical base, the base being at the surface of the member and the apex being directed inwards; less commonly the apical cell has only two sides or flanks and is then somewhat lenticular in shape (e.g. that of the rhizome of Pteris aquilina, stem of Salviniaceæ, and frequently in the above species of Selaginella).

In growing-points of this structure it is seen (Fig. 85) that the
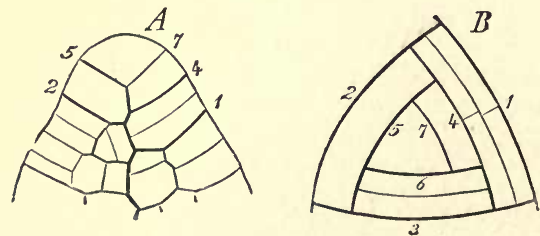

Fra. 85.-Diagrams illnstrating the division of the apical coll of the stem of Equisetum: $A$ longitudinal section; $B$ surface view. The numbers 1-7 indicate the successive segmental walls; the fainter lines indicate the walls of subsequent divisions of the segments. embryonic tissuesystems are not continuous as in the Phanerogams, but are interrupted at the apex by the large apical cell. The apical cell is, in fact, the initial cell for all the three primary tissue-systems.

The apical cell undergoes division by walls formed parallel to each of its (two or three) flanks successively, the segments thus formed growing and dividing to form the tissues of the stem or root. In the root the apical cell also undergoes divisions parallel to its curved base. After the cutting off of a segment the apical cell grows to its previous size, so that the repeated segmentation does not diminish the bulk of the apical cell.

The segments cut off parallel to the base of the apical cell of the root (Fig. $86 k$ ) constitute the dermatogen. These dermatogensegments grow and divide both anticlinally and periclinally to form the root-cap; but this many-layered epidermis only persists at the growing-point, since it becomes entirely exfoliated as the parts grow older. 
c. Growing-points with a group of common initial cells occur in certain Pteridophyta (e.g. in the stems and roots of Marattiaceæ, of Osmunda sometimes; stems of Lycopodium, Isoetes, some Selaginellas). In these cases, there is a group of frequently four cells which are the common initials of the tiss̃ue-systems. The general relations of the tissue-systems are here essentially the

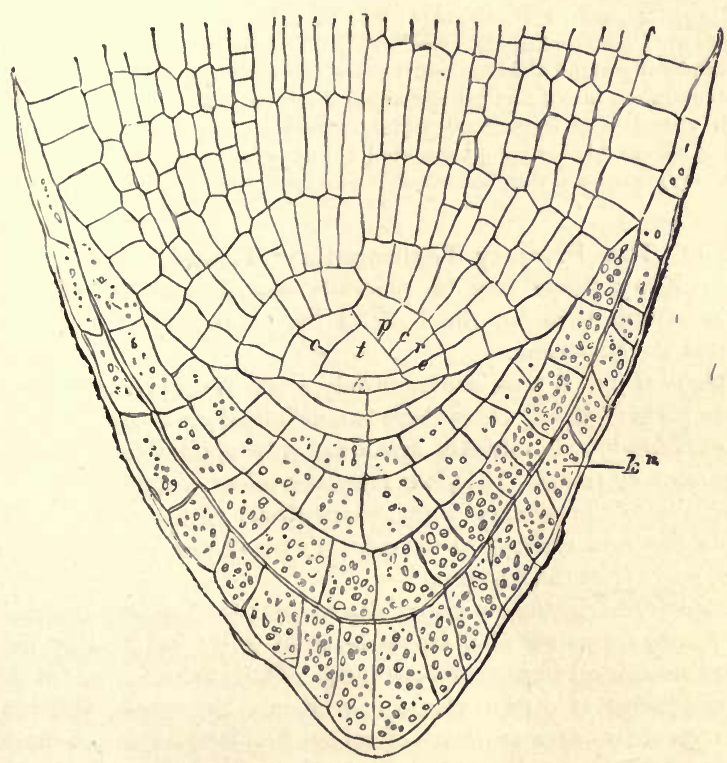

Fig. 86.-Median longitudinal section through the apex of the root of Pteris cretica; $t$ apical cell; $k$ initial segment of dermatogen; $k a$, outermost layer of root-cap; $p$ wall marking limit between the plerome $P$ and the periblem $\mathbf{P b} ; c$ wall marking the inner limit of the outer cortex. (After Strasburger: $\times 210$.)

same as in those forms in which the growing-point has a single apical cell.

The Growing-point in the lower plants. In the gametophyte of the Bryophyta, the growing-point of the stem or of the thallus has either a single apical cell (all Mosses; Jungermanniaceæ) or a group of apical cells 
(Marchantiaceæ, Anthocerotaceæ): the growing-point of the sporophyte of the Liverworts has a group of four initial cells, whilst that of the Mosses has a single two-sided apical cell.

In the higher Algæ, the shoot (or thallus) also grows by means of a single apical cell: in the more filamentous forms (e.g. some Floridex, Characex) the apical cell is hemispherical in form, and segments are only cut off by transverse walls parallel to the flat base; in other more bulky forms of Florideæ there is a group of initial cells; in nearly all these forms a more or less distinct differentiation of a central medullary tissue and of a cortical tissue takes place: in the Fucaceæ there is a single apical cell in the growing-point, with either three or four flanks, along which the segments are cut off; wher the apical cell is four-sided, segments are also cut off internally along the truncate base of the cell; the tissues soon show differentiation into a cortical and a medullary region.

In unseptate or imperfectly septate plants, having apical growth (e.g. Siphonaceous Algæ, Cladophora, etc.), the growing-point (like the rest of the body) is not cellular, but consists merely of embryonic protoplasm.

$\S 30$. The Primary Tegumentary Tissue. The primary tegumentary tissue may be generally described as the external layer of cells covering the body of the plant, and is commonly termed the epidermis.

Morphology. A true epidermis only exists in those plants, and in those parts of them, where there is a definite dermatogen; and the word epidermis is, strictly speaking, only applicable to such a tegumentary tissue. It is, however, convenient to apply this term generally to the primary tegumentary tissue of the shoot, and to apply the term epiblem to the primary tegumentary tissue of the root, apart from the root-cap.

Structure. In the great majority of cases the primary tegumentary tissue consists of a single layer of cells; but to this rule there are several important exceptions. Thus, the epidermis of the foliage-leaves of certain plants (e.g. Ficus, Peperomia, Begonia) consists of two or more layers of cells. Similarly, the root-cap to be found in nearly all roots is a many-layered epidermis. Again, the aerial root of certain epiphytic plants (Orchids, Aroids) has a many-layered epiblem, known as the velamen, consisting of empty tracheidal cells with reticulated and perforated walls (see p. 93).

The cells of the epidermis of the shoot of land-plants, are characterised by the thickening and cuticularisation of their cellwalls (see p. 76). The external wall is usually much more thickened than the other walls; its outermost layer, termed the cuticle, is 
always cuticularised, and is clearly defined from the inner layers, which may be also more or less cuticularised. The cuticle may be stripped off as a membrane, over a considerable area; it frequently forms surface-projections. Particles of wax are included in the cuticle of many plants, and serve to prevent the surface from being wetted by water. This wax often appears on the surface in the form of small granules, rods, or flakes, and this forms the bloom, which is easily wiped off: it sometimes attains a considerable bulk, as in the fruits of Myrica cerifera and the trunks of some Palms (Ceratoylon andicola and Klopstockia cerifera). The epidermal cells are sometimes sclerotic, as in prickles, thorns, and leaf-spines. Chloroplastids are not usually present in the epidermal cells of land-plants : they are, however, to be found in the epidermal cells of most Ferns, of Selaginella, and of some Phanerogams, and generally in those of aquatics.

The form of the epidermal cells, as seen in surface view, presents considerable variety. Generally speaking, the cells of an elongated member are themselves elongated in the same direction as the member; whereas, in broad, flattened members, there is less difference between

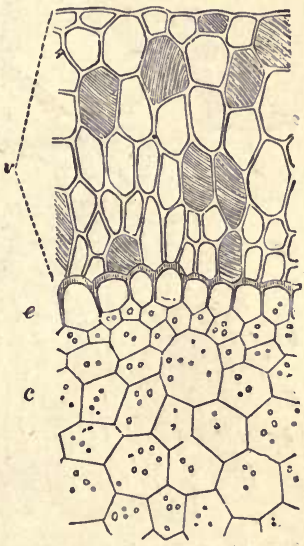

Fie. 87.-Part of a transverse section of the air-root of an Orchid : $v$ many-layered epiblem, or velamen; c cortex; e exodermis. (Magnifled; after Unger.) the diameters of the cells: in either case the side-walls of the cells very frequently have an undulating outline, so that adjoining cells fit closely together forming a continuous membrane, the continuity of which is, however, interrupted in certain cases by welldefined apertures, termed stomata, which permit communication between the intercellular spaces of the internal tissues and the external air.

The Stomata are confined exclusively to the sporophyte-generation, and make their first appearance in the Moss-sporogonium. Each stoma is an aperture bounded by two (sometimes only one, as in the Mosses) specialised epidermal cells, termed guard-cells, which always contain chloroplastids. The aperture of the stoma 
leads into the air-cavity (Fig. 88), a large intercellular space between the epidermis and the subjacent tissue, which communicates with other more internal intercellular spaces. The stoma originates thus : a young epidermal cell is divided by a septum into two halves, each of which becomes a guard-cell; the septum

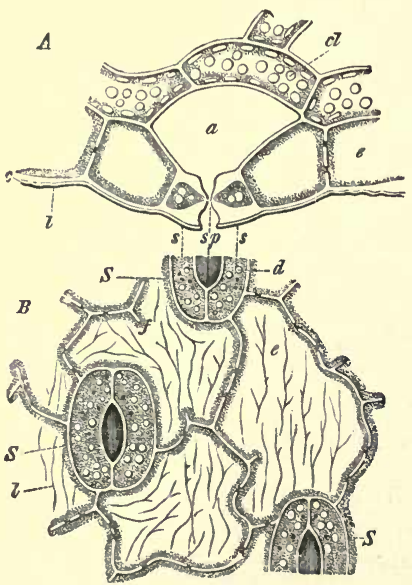

Fig. 89.- Epidermis with stomata, from the lower surface of the leaf of Hellehorus foetidus : $A$ in section; $B$ surface view ( $\times 300)$; e epidermal cells; $c$ cnticle; $l$ thickenings of the external wall; $f$ folds of the lateral walls; $s$ stoma; 8 guard-cells; sp aperture; $a$ air-cavity; cl mesophyle. then gradually splits into two, and thus the aperture between the guard-cells is formed; when the septum does not quite reach across the mother-cell, the aperture is surrounded by a single annular guard-cell, as in the Mosses. The size of the aperture may be increased or diminished by changes in the bulk of the guard-cells; the mechanism and conditions of this process are considered in Part III.

Stomata are found on almost all sub-aerial parts of the sporophyte of landplants from the Mosses upward ; they are especially abundant on leaves (as many as 600 to the square millimetre), and, in dorsiventral leaves, more particularly on the lower (dorsal) surface, but in floating dorsiventral leaves (e.g. Nymphæa) they are confined to the upper surface; in radial and isobilateral leaves the distribution of the stomata is uniform on all sides; they are wanting in submerged leaves, and are always absent from roots.

A peculiar form of stoma is found in some plants, known as a vaterstoma (Fig. 89). In consists of two large, almost spherical, guard-cells which cannot alter their form so as to close the aperture. Water-stomata occur on the leaves of some of those plants (e.g. Alchemilla, Crasula, Ficus, Saxifraga, Colocasia, Papaver, Tropreolum) which excrete water in the form of drops; they are situated over the termination of the vascular 
bundles on the margins or at the apex of the leaf; when chalk-glands are present (p. 97), water-stomata are developed in connexion with them.

In some plants (e.g. Grasses) which excrete drops of water, the water escapes through fissures in the epidermis of the leaf.

The epidermis of the submerged shoots of water-plants differs from that of land-plants in that it is not cuticularised, in the absence of stomata, and in that its cells frequently contain chloroplastids.

The epiblem of the subterranean root is commonly known as the piliferous layer because it is the layer from which the root-hairs (see p. 46), when present, are developed. Its cell-walls are not cuticularised, but are frequently (especially in the root-hairs) more or less mucilaginous. It is generally of but short duration, and to be found only on the younger parts of roots which are the regions of active absorption : on its disappearance the exodermis becomes the superficial layer.

In aerial roots (Orchids,

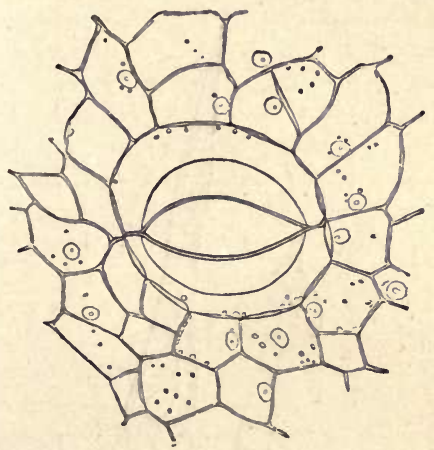

Fre. 89.-Water-8toma from the margin of the leaf of Tropcolum majus, with surrounding epidermal cells. (After Strasburcer: $\times 240$.) etc.) where the epiblem persists as a velamen (see Fig. 87, p. 107) of one or several layers of cells, the walls are thickened, cuticularised (especially the superficial layer), and somewhat lignified.

The many-layered root-cap (see p. 103), in its younger, more internal part, consists of parenchymatous cells, with cell-walls of cellulose, forming a compact tissue without intercellular spaces. As the cells grow older, and come to be situated more externally, they lose their protoplasmic contents. The disintegration of the root-cap is due, in some cases, to the mucilaginous degeneration of the middle lamella of the cell-walls; whilst in other cases, where the cell-walls become cuticularised, the superficial layers of the cap are successively split off and exfoliated by the pressure of the internal growing tissues.

Hairs (see p. 46), are frequently developed on the primary 
tegumentary tissue, and are generally formed each as an outgrowth of a single superficial cell (Fig. 90; see also Fig. 31, p. 47; and Fig. 82, p. 101).

The hairs of the subaerial parts of plants are, like the epidermal cells, cuticularised. In many cases the protoplasmic contents disappear at an early stage (as in Cotton, the hairs on the outer coat, or testa, of the seed of Gossypium) and are replaced by air. Sometimes the cell-wall contains deposits of lime or of silica. The hairs are frequently glandular (see p. 100).

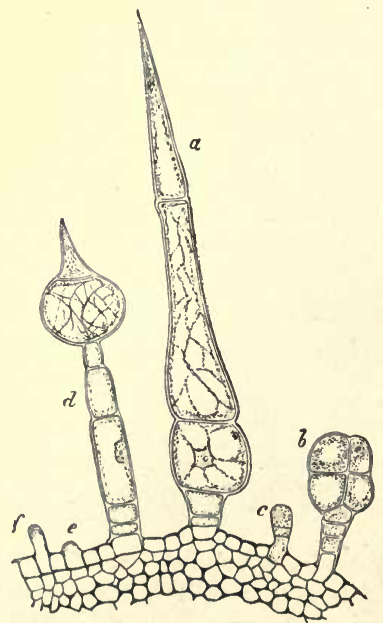

FrG. 90.-Hairs on a young ovary of Cucurbita $(x$ 100): b glandular hair; $i f f$ early stages of development.

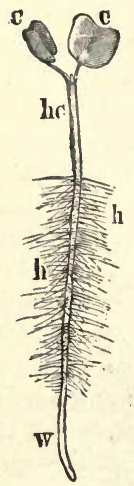

FrG. 91.-Roothairs $(h)$ on the primary root $(w)$ of a seedling of the Buckwheat : he hypocotyl; cc cotyledons.

The root-hairs (Fig. 91 ; also see p. 46) are developed each from a single cell of the piliferous layer; they are not developed in the immediate neighbourhood of the growing-point, but at some little distance behind it. Moreover, as they grow older, the root-hairs die off; hence they are only to be found on a very limited region of a primary or a secondary root.

§ 31. The Primary Ground-Tissue is constituted by the tissue which belongs neither to the epidermis, on the one hand, nor to the stele on the other. 
Morphology. The limits of this tissue vary with the structure of the part concerned. The external limit of the ground-tissue is the layer of cells lying immediately beneath the primary tegumentary tissue. Again, when the member is monostelic, the internal limit of the ground-tissue is the layer termed the endodermis, which abuts upon the central stele; in this case the ground-tissue consists of several layers of cells bounded externally by the true epidermis (if present), or reaching to the surface, and bounded internally by the stele, when it is spoken of as the cortex of the member of which it forms part. In a polystelic member, the internal limit of the ground-tissue is still the endodermis, but each individual stele is invested by a distinct endodermis; here the primary groundtissue includes not merely the superficial layers (cortex), but also the tissue between and among the steles.

The following are the regions or layers of the primary groundtissue which can be distinguished morphologically.

1. The hypoderma is the external region of the ground-tissue: the external layer of the hypoderma is distinguished as the exodermis.

2. The general ground-tissue.

3. The endodermis, the layer of the ground-tissue which abuts on a stele; in monostelic members the endodermis is the innermost layer of the cortex.

Structure. Speaking generally, the ground-tissue consists mainly of parenchymatous cells which have cellulose walls and retain their protoplasmic cell-contents; however, supporting-tissue (stereom) is largely differentiated in the ground-tissue, whether as collenchyma or as sclerenchyma. In cylindrical members (stems, roots, etc.) the cells are generally somewhat elongated in the direction of the long axis of the member.

1. The hypoderma of stems and leaves commonly consists of either collenchymatous or sclerenchymatous stereom (see p. 92):

collenchymatous hypoderma is especially characteristic of the stems and leaf-stalks of herbaceous Dicotyledons (see Fig. 69, p. 91 ), but it occurs also among Pteridophyta in the petioles of the Marattiaceæ :

sclerenchymatous hypoderma may form a continuous layer of more or less prosenchymatous cells (e.g. stem of some Ferns, Equisetum hiemale, most Selaginellas, leaf of many Cycads, Conifers, some Orchids, etc.); or it may form numerous isolated strands (e.g. stems of Cyperaceæe, species of Juncus [Fig. 
$98 C]$, some Umbelliferæ and Papilionaceæ, many Equisetums; leaf-blade of Cyperaceæ, Typha, Sparganium, many Palms). The spines of leaves (e.g. Holly), also entire spiny leaves or stipules, various emergences, such as the warts of Aloe verrucosa and the prickles of the Rose, and the thorny branches of many plants (e.g. Hawthorn, etc.) owe their hardness mainly to the development of sclerenchymatous hypoderma, the cells of which are generally elongated and fibrous, though they may be short as in Aloe rerrucosa and the Rose.

The hypoderma of the root commonly consists of a single layer of cells, which is then the exodermis; but in some plants the hypoderma consists of several layers (e.g. the Date, Pandanus, Asparagus, etc.).

The walls of the exodermal cells generally undergo cuticularisation and frequently become very much thickened, especially on the lateral and external walls, in view of the position which it eventually occupies as the external layer of the root (see p. 109). In some cases it presents a peculiar localised thickening in the form of a band extending round the upper, lower, and lateral walls of the cells, a thickening which is therefore confined just to the surfaces which are in contact with other cells belonging to the same layer, and which appears in a transverse section as a dark dot on the radial walls of the cells.

In some cases the cells of the exodermis are prosenchymatous and sclerenchymatous (e.g. species of Carex).

When the exodermis is invested by tegumentary tissue, as in aerial roots of Orchils (Fig. 87), some of its cells retain their thin unaltered walls, and are the passage-cells, by means of which water can penetrate into the interior of the root.

3. The general ground-tissue of stems, leaves, and roots, lying within the hypoderma, consists mainly of parenchymatous tissue, with, frequently, a considerable differentiation of masses of fibrous sclerenchymatous stereom.

In aerial stems and foliage-leaves, the more external, at least, of these cells frequently take part in the assimilatory processes of the plant; the cells contain chloroplastids and constitute assimilatory tissue. Towards the most highly illuminated surface of the member, the cells are frequently so arranged that their longer axes are perpendicular to the surface, that is, are parallel to the incident rays of light; assimilatory tissue of this structure is termed palisade-tissue: the whole of the internal ground-tissue of a leaf-blade is termed generally mesophyll. 


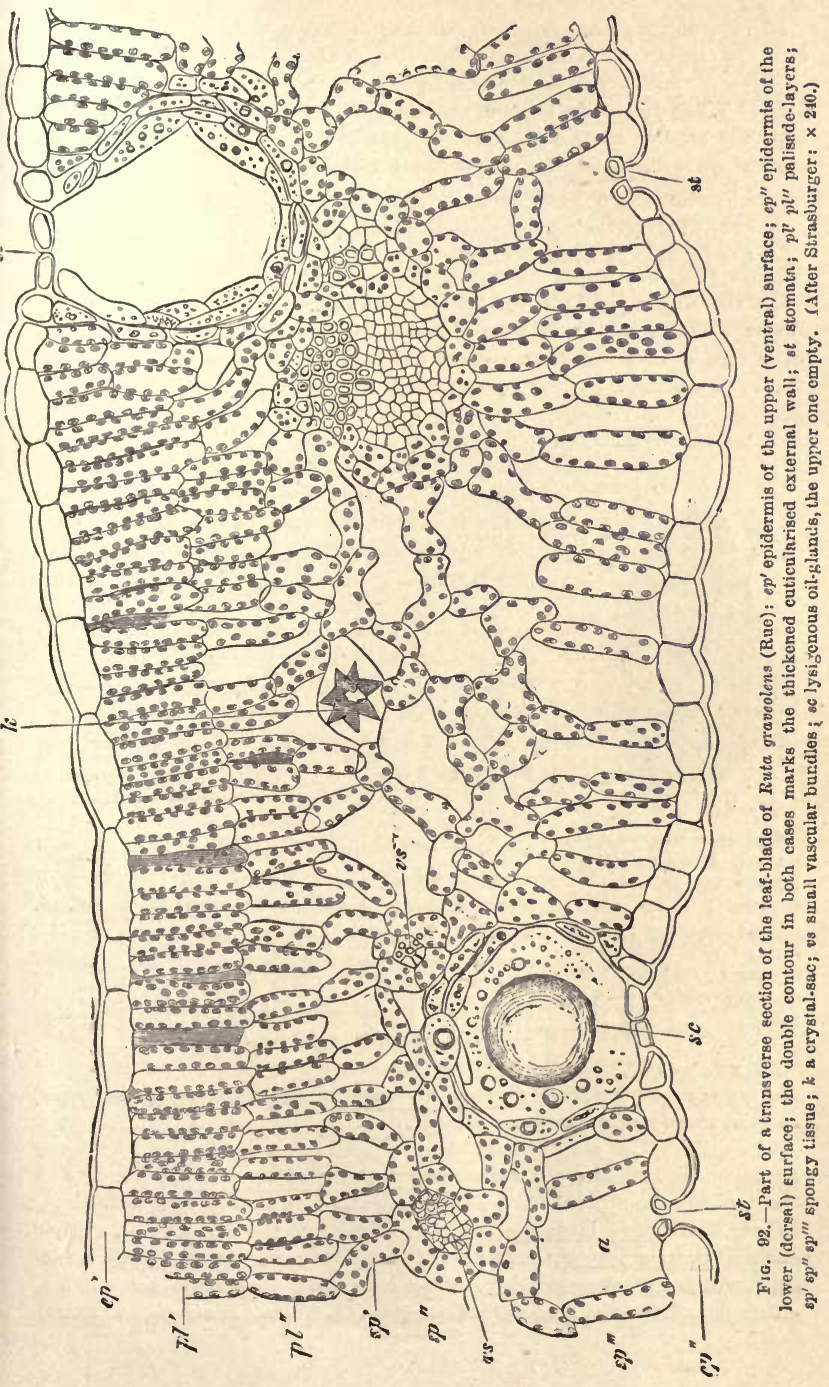


In view of its great physiological importance a somewhat detailed account of the structure of the mesophyll of the leaf-blade seems necessary.

The mesophyll consists of parenchymatous thin-walled cells of various form. When the blade is thin, the whole mesophyll consists of assimilatory tissue; but when it is more or less fleshy and succulent, the more central part consists of cells without chloroplastids, the assimilatory tissue being confined to the surface.

When the mesophyll is altogether assimilatory, the arrangement of the cells is correlated with the symmetry of the leaf-blade. In a dorsiventral lamina (Fig. 92) the structure of the mesophyll is different in relation with the upper (ventral) and the lower (dorsal) surfaces. Towards the npper surface, which is more directly exposed to light, the somewhat elongated cylindrical cells form a compact palisade-tissue one or more layers in thickness; whereas, towards the lower shaded surface, the cells are less regular, frequently somewhat stellate in form, leaving large intercellular spaces between them, constituting what is known as the spongy parenchyma. The loose structure of the

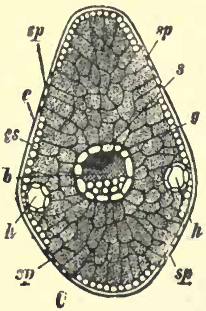

FIG. 93. - Diagrammatic transverse section of the acicular leaf of a Fir: 6 epidermis; es sclerenchy. matous hypoderma; sp stomata; $h$ resin-ducts; s endodermis enclosing the single meristele; $g$ wood; $b$ bast.

In some cases, the mesophyll is not differentiated into palisade and spongy parenchyma, but consists of rounded cells (e.g. succulent leaves, such as those species of Crassula, etc.).

The cells of the assimilatory tissue sometimes present other forms and arrangements. Thus the assimilatory tissue of the leaf of Pinus and Cedrus consists of polyhedral cells, the walls of which present infoldings, the effect of which is to increase the surface of the cell-wall. In other cases it consists entirely or in part of elongated cells, resembling palisadecells, which are arranged with their long axes parallel to the surface, either parallel to the long axis of the leaf (e.g. Galanthus nivalis, the Snow- 
drop; Leucojum vernum, the Snowflake;) or transversely (e.g. Iris germanica, Erythronium Dens-Canis, species of Gladiolus and Tritonia).

The colourless mesophyll of succulent and coriaceous leaves consists of large cells containing much watery sap constituting in fact an aqueous tissue (e.g. leaves of Alo", Mesembryanthemum, some Myrtaceæ etc.). In some Orchids (e.g. Oncidium maximum), the cells of the aqueous tissue are scattered among the assimilatory cells; in many Orchids the cells of the aqueous tissue are tracheidal, having spirally-thickened walls, as they are also in the stem and leaf of Nepenthes.

In many cases, especially in aquatic plants, the ground-tissue has large air-cavities, either lysigenous or schizogenous (see p. $89)$; generally speaking, they are of schizogenous origin in aquatic plants, of Iysigenous origin in landplants. These cavities frequently extend thronghout the whole length of the root or the leaf and through an entire internode of the stem; but they may be interrupted at intervals by diaphragms (e.g. leaf of some Monocotyledons;

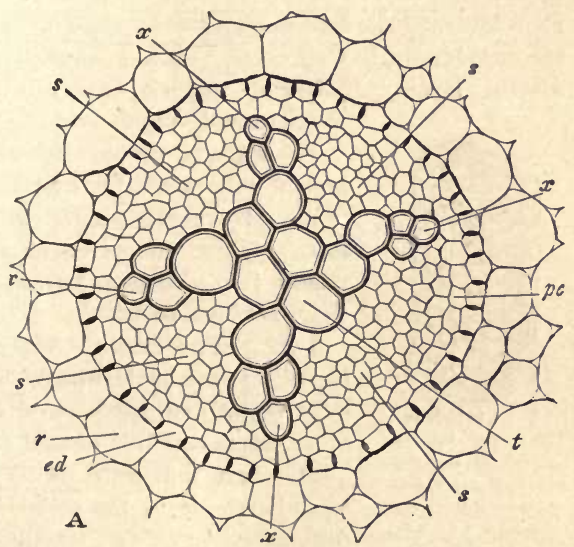

Fic. 91. - Transverse section of central portion of the root of Ranunculus repens ( $\times 300)$ : ed the endodermis, enclosing the single central stele; its radial walls show the sections of the cuticularised thickening-bands; $x$ the four protoxslem-bundles; $t$ the solid xylem; s the four phloem-bundles; pc the pericycle; $r$ the cortical tissue.

root of Hydrocharis; stem of Alisma, Pontederia, Marsilea). When these cavities are largely developed the member becomes a float (e.g. root of Jussiæa).

4. The Endodermis is, in the great majority of cases, a single layer of cells; it is but rarely altogether wanting; it sometimes consists of two layers, formed by the tangential division of the cells of the primitively single layer (e.g. root of Equisetum; stem of some Pteridophyta, such as Aspidium, Pteris, Salvinia and Azolla). 
Most commonly the cells of the endodermis are thin-walled, with a suberised thickening-zone extending round the lateral and upper and lower surfaces of the wall, and showing in transverse section (Fig. 94) as a black dot on the radial wall. This peculiar marking is by no means always present: it is frequently wanting in the endodermis of the stem, in which case the endodermis can, in many cases, be distinguished by the presence of starch-grains in its cells. When the endodermis is double, this marking is confined to the outer of the two layers.

This marking is not confined to the endodermis; it sometimes occurs also in the exodermis of roots (see p.112), and in one or more layers of the internal cortex in some roots (one layer, next the endodermis, in Cupressus, Taxus, Prunus, Rosa, Lonicera, etc. ; several layers, Juniperus, Sequoia, many Cruciferæ such as Mustard and Wallflower, Fig. 95).

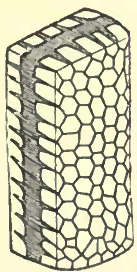

Fia. 95. -1 cell from the internal cortex of the root of the Mustard, scen obligiuely from the internal sarface, showing the su. berised thickening zone. (After van Tieghom: $\times$ 350.)

The walls of the endodermal cells frequently become sclerotic either over their whole surface, or more frequently on the internal lateral surfaces. When this is the case, some of the cells remain thin-walled, as passage-cells, opposite to the wood-bundles within.

$\S 32$. The Stele. The plerome, constituting the young stele, always gives rise to vascular tissue and usually to a certain amount of other tissue which is termed conjunctive tissue.

The first indication of the development of vascular tissue in the stele is afforded by the differentiation of a varying amount of procambium, consisting of somewhat elongated narrow cells formed by repeated longitudinal division, which is the embryonic tissue from which the vascular tissue is eventually formed. The procambium frequently constitutes one solid central strand, surrounded by more or less conjunctive tissue constituting the pericycle; this is sometimes the case in slender roots (see Fig. 94), in slender monostelic stems (e.g. many aquatic Phanerogams, such as Callitriche, Elodea, etc.; among Pteridophyta, Isoetes, Salviniaceæ, Lycopodiaceæ, Hymenophyllum, Schizæa), and generally in the steles of polystelic stems. More commonly, however, the procambium of stout roots and monostelic stems is developed as a number of strands variously arranged in the stele, generally 
in a circle or in several circles; the strands thus forming an incomplete hollow cylinder enclosing a central mass of conjunctive tissue, the medulla or pith, whilst the conjunctive tissue between the strands constitutes the medullary rays.

In all cases the stele (whether one or more) is at an early stage marked off from the ground tissue, the layer of the ground-tissue which abuts on the stele being specially differentiated as a sheath, the endodermis (p. 115), which forms a continuous covering to the stele or any isolated portion of it.

All primary stems are typically monostelic to begin with, but as they increase in bulk this type of structure is departed from in various ways; typical monostely is, however, the rule in the stem of Phanerogams, and is frequent in that of Pteridophyta (in Hymenophyllum, Osmunda, Lycopodium, Isoetes, some species of Selaginella). Some stems are, however, polystelic. In these the original single stele passes over, as the stem grows and enlarges, into a varying number of steles which can be traced to the growing-point as distinct plerome-strands. Polystely is rare in stems which have a growing-point without an apical cell, whilst it is common in stems where the growing-point has an apical cell, or a group of common initial cells : hence it is rare in Phanerogams (occurs in Auricula and Gun-

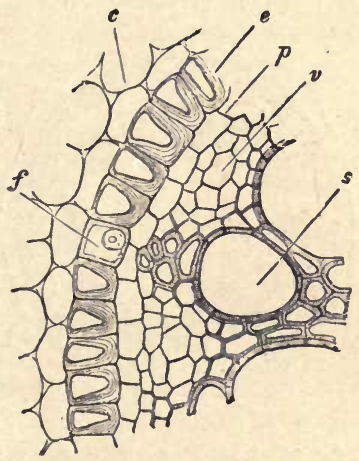

FiG. 96.-Part of a transverse section of the stele of a root of Iris florentina: e sclerotic eudodermis, with $f$ a thin-walled passage-cell; $v$ bast; 8 wood-vessel; $c$ cortical ground-tissue; $p$ pericycle. (After Strasburger : $\times 240$.) nera), and is common in Pteridophyta (especially Leptosporangiate Ferns, and some Selaginellas: see p. 102).

A common modification of the polystelic structure is that which is termed gamostelic; in this case the several steles are not distinct for any considerable distance in their longitudinal course; but some or all of them fuse with each other at more or less frequent intervals; this is common in Ferns.

The general morphology of the tissues of the leaf is essentially the same as that of the stem which bears it. When the stem is 
polystelic, one or more complete steles enter the petiole of the leaf which is, consequently, either monostelic or polystelic. When the stem is monostelic, each leaf receives a portion, termed a meristel', of the stele of the stem; this meristele may be either entire, or be split up into a number of parts, each of which may consist of but a single vascular bundle.

The Conjunctire Tissue. The morphology of the conjunctive tissue of the stele varies somewhat in accordance with the development of the vascular tissue. When a solid vascular cylinder is produced, there may he no conjunctive tissue at all, the whole of the plerome having developed into vascular tissue ; or the conjunctive tissue may be limited to one or more peripheral layers, the pericycle, investing the

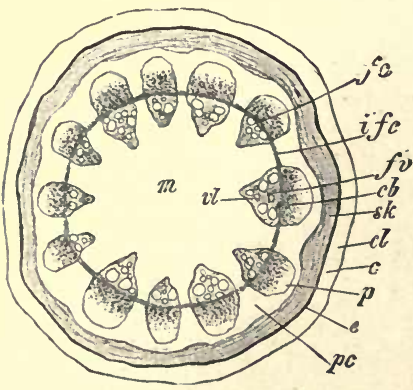

FiG. 97.-A transverse section of a young stem of Aristolochin Siph, illnstrating the arrangement of the primary tissues in a monostelio stem, in which the vascular cylinder is hollow, enclosing a pith (after Strasburger: $\times 9$ ) : 0 cortical tissue, with collenchyma $\mathrm{cl} ; \theta$ endodermis; $p c$ pericycle, continnous by means of interfascicnlar conjunctire tissue (medullary rays) with the medullary coujunctive tissue $m$ (pith); sk ring of sclerenchyma belonging to the pericyole; fo vascular bundles in an interrupted circle; they are open and collaternl; cb bast; $p$ protophloem; $f c$ fascicular cambium; ifc Interfascicular cambinm; $v l$ wood; the central pointerl end of each wood-bundle consists of protoxslem, and the central ends of the whole ring of wood-bindles constitute the medullary sheath. and, to a less degree, of other Conifers (Fig. 93). The tissue consists of parenchyma with some fibrous sclerenchyma; in the parenchyma two special kinds of cells can be distinguished, which constitute what is some- 
times termed the transfusion-tissue; namely, cells with unlignified and unpitted walls, distinguished by their abundant protoplasmic and proteid contents; tracheidal cells with slightly lignified walls and bordered pits, without protoplasmic contents; the former may be regarded as an extension of the sieve-tissue of the bundle, the latter as an extension of the tracheal tissue.

The Pericycle is altogether wanting in a few cases only; it is absent when the endodermis consists of two layers (see p. 115); it is also absent from the slender roots and stems of some waterplants.

It is usually a continuous membrane; but in some cases it is interrupted by projections of the vascular tissue (e.g. by the xylem-bundles in the root of some Gramineæ and Cyperaceæ). It may consist throughout of a single layer of cells (e.g. roots of most Angiosperms [Fig. 96] and of some Vascular Cryptogams); or of more than one layer throughout (roots of some Dicotyledons, e.g. Vine, and of Gymnosperms generally; commonly in the stem and leaf-stalk); or in part of one layer and part of more than one (e.g. root of some Ferns and Leguminosæ).

The pericycle may be homogeneous or heterogeneous; that is, it may consist of the same kind of tissue throughout, or of several kinds of tissue. The typical homogeneous pericycle consists of thin-walled parenchymatous cells, with protoplasmic contents, which are capable of becoming merismatic. In some cases the primarily thin-walled cells eventually become sclerotic, either throughout the whole pericycle, or in certain parts only; this commonly occurs in the roots of Monocotyledons.

Generally speaking, the pericycle of the root is homogeneous; when it is heterogeneous, it is so in consequence of the presence of glandular tissue (secretory ducts) (e.g. Umbelliferæ, Hypericaceæ); it never contains fibres.

The pericycle of the stem and of the leaf-stalk, on the contrary, is generally heterogeneous, owing principally to the differentiation of a portion of it into collenchyma (e.g. some Compositæ, Barkhausia fotida, Sonchus oleraceus), or into fibres (Fig. 97) which are generally sclerotic, but not in all cases (e.g. Apocynacex, Cnnvolvulaceæ, Flax); or it may be heterogeneous in consequence of the presence of secretory ducts (c.g. Hypericum, some Umbelliferæ); or, in consequence of the presence of both secretory ducts and of fibres (e.g. Ligulifloral and Tubulifloral Composites).

The Pith (or medulla) consists, typically, of parenchymatous 
cells with thin walls and protoplasmic contents; but in many cases. sclerenchyma is differentiated in it.

The most important fact with regard to the parenchyma of the pith is that, in many cases, the cells forming the central portion of the pith soon die, or even the whole of them (e.g. Elder). When this is the case, the dead cell-walls frequently undergo disorganisation, so that the stem becomes hollow.

The sclerenchyma of the pith may consist of scattered strands (e.g. stems of some Palms); or it may form a ring connecting the inner ends of the bundles of the hollow vascular cylinder (e.g. Bongainvillea spectabilis, woody Piperaceæ.

The bulk of the pith varies very much.
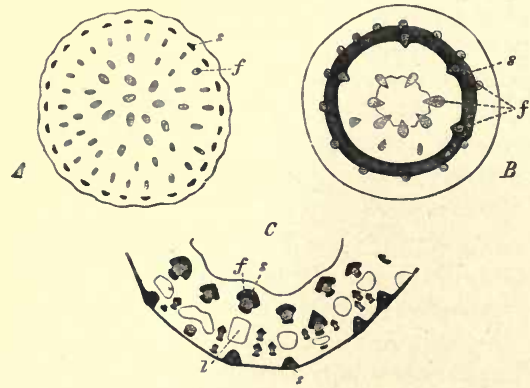

Fig. 98.-Diagram (after Schwendener) illnstrating the distribution of the snpporting-tissue or srereom, as seen in trans. verse section of stems: $\boldsymbol{A}$ of Arum maculatum having isolated cortical stereom-strands; $\boldsymbol{B}$ of Allium vineale, with continuous pericyclio stereom-ring; $C$ of Juncus glaucus (hollow), with hypodermal stereom-strands and conjunctive stereom-strands; $f$ vascular bnndles; $s$ stereom-strands; $l$ air-cavities.
It is relatively very large in tuberous shoots, such as Potato, Apios, etc.

The Interfascicular Conjunctive Tissue consists typically of parenchymatous cells with thin walls and protoplasmic contents ; but it is frequently sclerenchymatous where it abuts on the vascular bundles, thus contributing to the formation of a more or less complete sheath of sclerenchyma round them (e.g. many Monocotyledons): in woody plants the cells of the medullary rays become lignified.

The various systems of sclerenchymatous supporting-tissue (stereom) described above, the hypodermal, the cortical, the pericyclic, the interfascicular, and the medullary, may be connected with each other in various combinations. Thus, the hypodermal and the cortical systems may be continuous; or the hypodermal, cortical, and pericyclic; the pericyclic and the interfascicular, etc.; as the mechanical conditions of the member may render necessary (see Fig. 98). 
$\S$ 33. The Primary Vascular Tissue. The primary vascular tissue is differentiated from the procambium of the stele in the form of strands or bundles, vascular bundles. The vascular tissues of the bundles are either tracheal tissue (p. 93), which is always lignified, and is termed wood or xylem; or sieve-tissue (p. 94), which is termed bast or phloem. A vascular bundle may consist, either exclusively of wood or of bast; or of both wood and bast, when it is said to be a conjoint bundle. It is generally the case that a varying proportion of sclerenchyma (stereom) is associated with the vascular tissue; hence the bundles are frequently spoken of as fibro-vascular bundles. As a rule, an equal number of wood-bundles and of bast-bundles are differentiated in a stele, whether they be isolated or conjoined; there may be only one of each (e.g. finer branches of the dichotomous roots of most Lycopodiums) or there may be a very considerable number (c.g. stems of Monocotyledons).

With regard to the occurrence of vascular tissue in the gametophytegeneration, and in the sporophyte of the lower plants, it may be stated that lignified vascular tissue (i.e. wood) does not occur in any gametophyte, nor in the sporophyte of any plant below the Pteridophyta. However, in the stem of the gametophytic shoots of some Mosses there is a solid central stele consisting of tissue which is functionally vascular tissue; the same is true of the stem (seta) of the Moss-sporophyte in certain cases. Sieve-tissue has been found in some of the larger Brown Seaweeds (p. 96).

The primary vascular tissue-system extends continuously throughout the body of the sporophyte of the higher plants; the vascular bundles of root, stem, and leaf are all in direct communication.

The arrangement and course of the vascular bundles are intimately connected with the morphology of the plant and with the differentiation of its members. In elongated members (stems, petioles, roots) the bundles run longitudinally, so that a transverse section of such a member shows transverse sections of its vascular bundles.

In the primary root the longitudinal course of the bundles is simple; there is an axial vascular cylinder, either solid or hollow, consisting of straight, more or less distinct bundles of wood and bast, and extending from the growing-point backwards to where the root merges into the stem; from this cylinder there arise 
lateral offsets, which constitute the steles of the lateral branches of the root.

In the stem the course of the bundles is more complicated, on account of the fact that the stem bears lateral members, leaves, which differ from itself or from its branches. In some cases, the bundles of the stem, when traced upward toward the growingpoint, are found to terminate in the young leaves; whilst in other

cases the bundles end

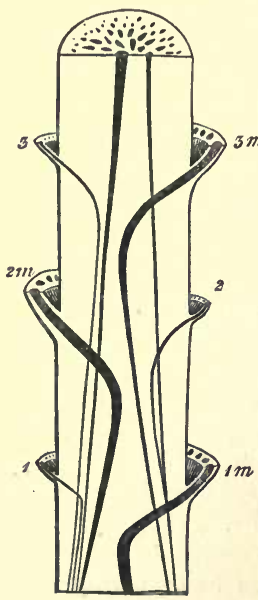

A

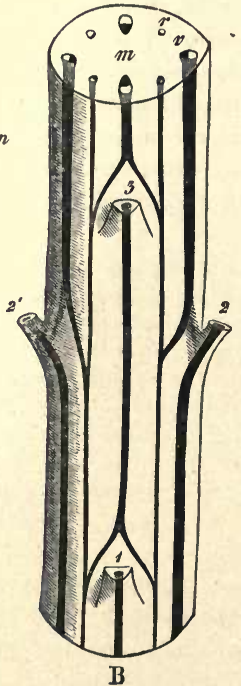

Fic. 99.-Diagram of the course of the vascular bundles in stems. A Longitudinal section through the axis of a Palm-stem, showing a transverse section of halt of it. The leaves (cut off above the insertion) are hypothetically conceived of as distichous and amplexicaul, and so are seen on both sides of the stem, $1 \mathrm{~m} 2 \mathrm{~m} 3 \mathrm{~m}$ being the median line of each. $B$ Outside view and transverse section of Cerastium (hypotbetically trunsparent, to show the internal bundles). The decussate leaves $(1,2,3)$ are cut off. The bundle proceeding from each leaf divides into two above the lenf immediately below it, and the branches of all the bundles nuite to form the four thin bundles which alternate in the section with the thicker ones. In the section, $m$ is the pith, $r$ the cortex, $v$ the medullary ray. The xylem in the fibro-vascular bundles is indicated by shading. (like those of the root) in the plerome of the growing - point; bundles of the former kind are distinguished as common (i.e. common to stem and leaf), and, in their course in the stem, are termed leaftraces; bundles of the latter kind are distinguished as cauline (i.e. confined to the stem).

Stems with common bundles are generally monostelic ; the leaftraces do not, however, follow a uniform course in all cases. Thus, they may proceed to the centre of the stem and form a solid vascular cylinder (e.g. Isoetes among Pteridophyta ; and certain aquatic Monocotyledons, such as species of Potamogeton,etc.). Or they may form a hollow cylinder. In the simplest case 
of this (as in Osmundaceæ, most Gymnosperms and Dicotyledons) the bundles (leaf-traces) entering the stem from a leaf are few in number, or even only one; they penetrate to an equal depth in the stem, and run vertically downwards through one or two internodes, joining at a node with the bundles entering the stem from a lower leaf; sometimes their lower ends are bifurcate so that they join with the bundles of the lower leaves (Fig. $99 \mathrm{~B}$ ). When the leaf-traces entering the stem from a leaf are more numerous, they penetrate to various depths in the stele, and their course is usually not vertical, but more or less curved: they may then form two circles (e.g. Cucurbitaceæ, Phytolacca, Piperaceæ); or many circles, more or less irregular, trenching on the pith (e.g. many Ranunculaceæ, such as Cimicifuga, Thalictrum; Nymphæaceæ; Monocotyledons generally). A good example of this is afforded by a Palm stem (Fig. 99 A). The median leaf-traces first tend toward the centre of the stem; they then bend outward, thinning out gradually as they descend, and coalesce with the lateral bundles, which do not penetrate so deeply, in the pericycle at a point much lower down. Furthermore, each bundle is somewhat twisted in its course, so that the lower end lies toward a different side of the stem from that on which it entered it. In these cases, when there is a well-defined external ring, the more internal bundles are termed medullary bundles.

The relative position of the phloem and of the xylem in a conjoint bundle is subject to some variation; they may either be side by side, when the bundle is said to be collateral; or the one may more or less completely invest and surround the other, when the bundle is said to be concentric.

In the collateral bundle, the wood and the bast are so situated that they both lie on a straight radial line drawn through the bundle from the centre of the member to the surface, the wood being nearer the centre, and the bast nearer the surface (see Fig. 97). This type of bundle is common in the stems and leafstalks of Phanerogams and of some Pteridophyta (Osmundaceæ, Ophioglossaceæ, Equisetum).

In some stems (e.g. Solanaceæ, most Convolvulaceæ, Cucurbitaceæ, etc.) there is a second bast-bundle on the inner (medullary) side of the wood of the conjoint bundle; such a bundle is distinguished as bicollateral.

In a concentric bundle, either the bast is surrounded by the wood, or the wood by the bast, more or less completely: the 
bicollateral bundle is, in fact, a structure intermediate between the collateral and the concentric bundle. The former type of concentric bundle occurs in the rhizomes of various Monocotyledons (Acorus, Iris, Cyperus, Carex, etc.), and in the medullary bundles of the stem of some Dicotyledons (Rheum, Statice, Ricinus, Piper, etc.). The latter type is rare in Phanerogams (e.g. the cortical

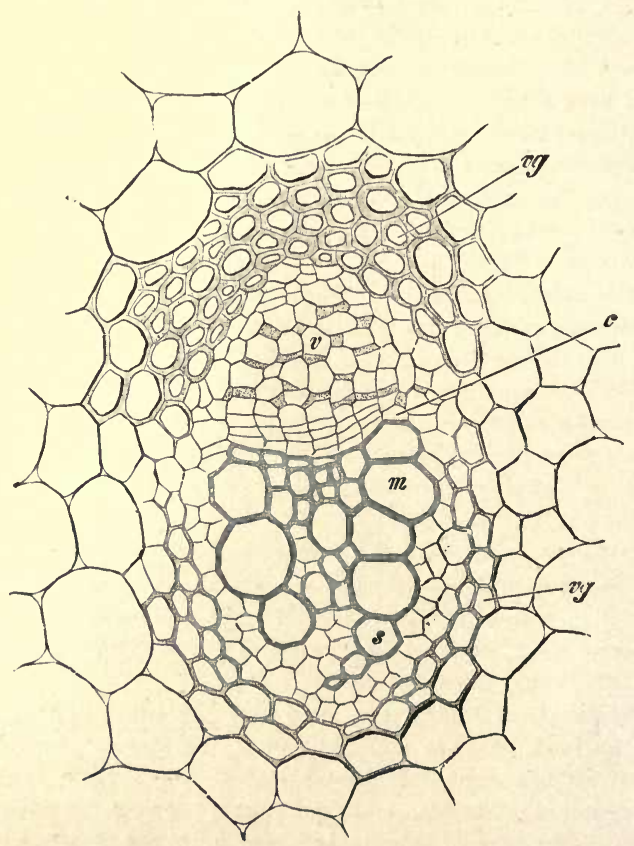

FrG. 100.-Transverse section of an open, collateral, conjoint, vascular bundle of the stem of Ranunculus repens : 8 spiral vessel of the protoxylem at the inner (central) end of the wood; $m$ pitted ressel of the wood; $c$ cambium; $v$ a sieve-tube of the bast with adjacent granular companion-cells; $v g$ sheath of sclerenchymatous conjunctive tissue. (After Strasburger: $\times$ 180.)

and medullary bundles of the Melastomaceæ); but it prevails in the Filicinæ and in Selaginella, when the bundles (two or more) of each stele of the polystelic stem, form a central mass of wood completely, or nearly completely, surrounded by a ring of bast. 
The relative position of the phloem-bundles and xylem-bundles when they are distinct from each other is such that they alternate with each other so that a radius drawn from the centre to the surface of the member cuts through either a phloem or a xylembundle, but not through both (Fig. 102). This arrangement obtains only in monostelic members; it is common to all roots, and occurs in the stem of Lycopodium and $\mathrm{Ps}$ i lot u m though in a less regular manner than in roots. It is commonly termed the radial arrangement.

The Differentiation of the Primary Vascular Bundle. The first

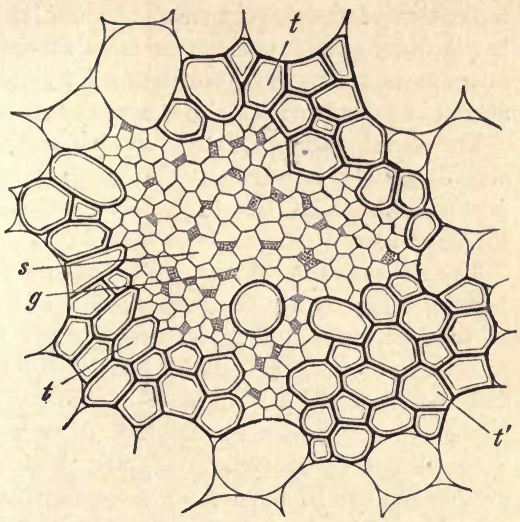

FIG. 101.-Trangverse section of a concentric bundle, with external wood, from the rbizome of Iris $(\times 350): t$ tracheæ; $t$ protoxylem; $s$ sieve-tubes; $g$ companion-cells, of the internal bast.!

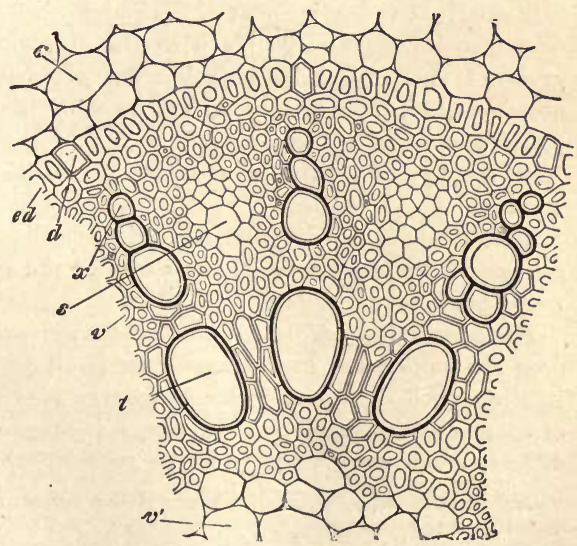

Frg 102.-Part of a transverse section of the stele of the Sargaparilla-root (Smilax) : $r$ cortex; ed endodermis with passagecells $d$; the pericycle and the interfascicular conjunctive tissue 0 are sclerenchymatons; $v^{\prime}$ the pith; $x$ the protoxylem, and $t$ a pitted vessel of a wood-bundle: $s$ a bast-bundle. The alternation, or radial arrangement, of the wood and bast-bundle is shown. $(\times 300$. 
indication of the development of vascular tissue in the plerome is the differentiation of one or more strands of narrow elongated merismatic cells, the procambium (p. 116); each procambiumstrand of the plerome becomes a vascular bundle of the stele.

The development of the vascular tissue does not take place simultaneously throughout the whole transverse section of the procambium-strand, but begins at one definite point, and extends in one or more directions from that point.

The development of the xylem-bundle (or part of a conjoint bundle) begins with the differeutiation of one or a few tracheids or tracheæ, constituting the protoxylem; the walls of the corresponding procambium-cells become spirally thickened and lignified, and the protoplasmic contents of the cells disappear. It is an important generalisation that spiral or annular vessels (or tracheides) are characteristic of, and absolutely confined to, the protoxylem of the bundle. The remainder of the primary wood (i.e. the wood which is developed from the procambium) is then gradually differentiated, the walls of the tracheides or tracheæ presenting one or other of the various kinds of pitted marking (p. 74 ).

Similarly, the development of the phloem-bundle (or the phloem of a conjoint bundle) begins with the differentiation of a small group of sieve-tissue, constituting the protophloem, which does not, however, differ in any marked manner from the rest of the primary phloem, but their cavities soon become obliterated, so that they then look like strands of swollen cell-wall (Fig. 103).

The details of the differentiation of the primary vascular tissue are essentially the same as in the case of the secondary vascular tissue described on p. 145 .

The longitudinal differentiation of the primary vascular tissue does not take place in the same order in all cases. In roots, and in stems with cauline vascular tissue, the longitudinal differentiation proceeds acropetally. In stems with common bundles the differentiation usually begins in the procambium-strand at a node, proceeding both downwards in the internode of the stem, and outward into the young leaf.

In the majority of instances, the whole of the procambium-strand becomes differentiated into permanent tissue, either wood or bast; this is true for all roots, and for the stems of nearly all Pteridophyta and Monocotyledons (Fig. 103). Bundles of this kind are 
said to be closed. In the stems of most Gymnosperms and Dicotyledons, on the other hand, the whole of the procambium is not converted into the primary wood and bast of the collateral conjoint bundle, but a portion of it persists as an embryonic merismatic tissue, the cambium, forming a transverse zone between the wood

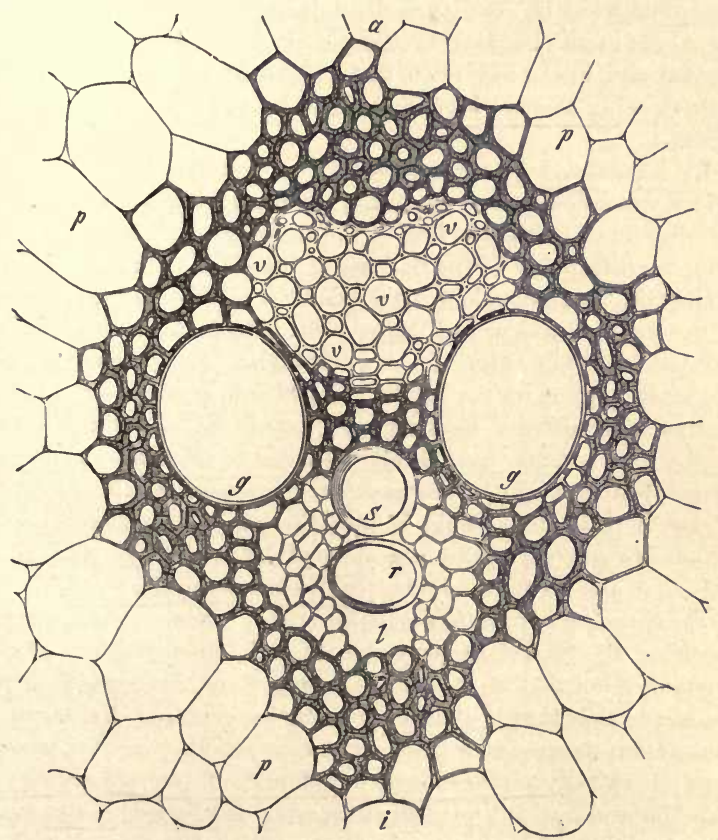

Fie. 103.-Transverse section of a conjoint, collateral, closed, vascular bundle of the stem of a Monocotyledon (Zea Mais): $a$ outer or peripheral end of the bnndle; $i$ inner or central enl; $p$ conjunctive tissue, the portion immediately investing the bnndle being sclerenchymatons; l lysigen ous intercellular space; $8 \mathrm{r}$ spiral and annular vessels constituting the protoxylem; $g \mathrm{~g}$ large pitted vessels, between which lie the smaller pitted vessels of the wood; $v v v$ sieve-tnbes of the bast with intervening companion-cells; just ontside the bast, and within the sclerenchymatous sheath, the remains of the protophloem sre visible. (After Sachs : $\times$ 553.)

on the inner (central) side and the bast on the outer side (see poes Figs. 97, 105). Such a bundle is said to be open. 
Some few Dicotyledons have closed bundles (i.e. no cambium) in the stem, e.g. Adoxa, Ranunculus Ficaria, Nymphæaceæ, Myriophyllum, Utricularia, etc.

The position of the protoxylem and of the protophlocm in the transverse section of the bundle is not the same in the different members. The protophloem is in all cases superficial : and though the protoxylem is also generally superficial, it is sometimes internal (as in the bundles in the petiole of Cycads, in the stem of Isoetes, and in the concentric steles of stems and petioles of many Ferns), being more or less surrounded by the rest of the primary xylem.

In members, whether monostelic or polystelic, in which the primary bundles or the steles are arranged in one or more circles (or other figure corresponding to the sectional outline of the member), the orientation of the bundles in the stele, as indicated by the position of the protoxylem, bears a definite relation to the symmetry of the transverse section of the member. For instance, in medullate monostelic stems (Fig. 97) the protoxylem forms the innermost or central portion of the bundle; the broken circle of protoxylemgroups is sometimes specially designated the medullary sheath. In the root, whether the vascular cylinder be medullate or not, the protoxylem is always outermost or peripheral, abutting on the pericycle (Fig. 102). This is also the case in monostelic stems which are not medullate (e.g. stem of Lycopodium). The protophloem is always external, abutting on the pericycle.

The transition from the root to the stem. Inasmuch as, generally speaking, the type of primary structure of the root differs so considerably from that of the corresponding stem, the transitiun from the one to the other is a matter of some importance. Taking as an illustration the case of a plant with a monostelic stem, the passage from the radially arranged separate bundles of the primary ront to the collateral conjoint bundles of the stem is effected on this wise : -generally speaking, on tracing the wood-and bast-bundles of the root upwards into the stem, the wood-bundles are found to twist on themselves so that the protoxylem of each bundle, from being peripheral in the root, comes to be central in the stem; at the same time they change their position somewhat so that they come to lie on the same radii as the bast-bundles, or the bast-bundles may also deviate somewhat from their straight course, and thus the conjoint collateral bundles come to be constituted. As a rule, these changes of position are accompanied by an increase in number of the bun- 
dles, each of the bundles of the root bifurcating above, so that there are commonly twice as many bundles in the stem as in the corresponding root.

The structure of the primary bundle. The primary wood (whether in $\mathrm{s}$ D isolated or a conjoint bundle) consists essentially of lignified tracheal tissue (tracheæ, or tracheids, p. 93), together with a varying proportion of wood-parenchyma, more or less lignified, the cells being occasionally somewhat fibrous. The protoxylem (see p.

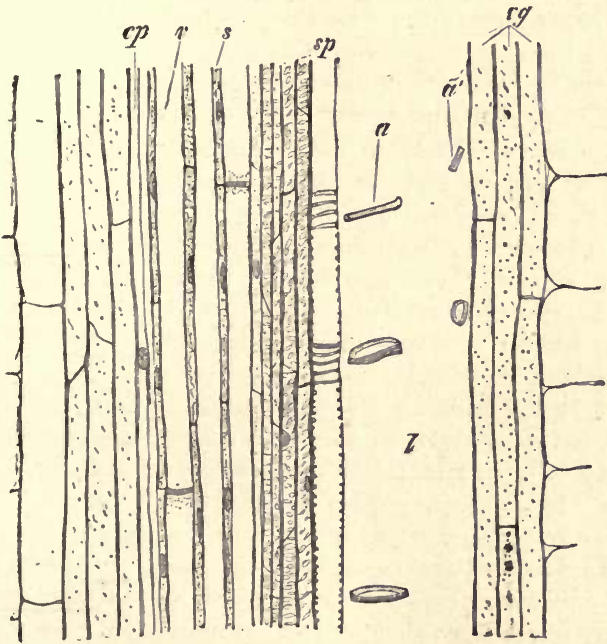

Frg. 104. - Radial longitndinsl section of a conjoint, closed, collateral bundle from the stem of a Monocotyledon (Zea Mais; after Strasburger, $\times 180$ ) ; to the right is the central (medullary) limit of the bundle; to the left the peripheral (cortical) limit : $c$ p protophloem; v sieve-tubes of the bast, with companion-cells s; sp $a a^{\prime}$, the protoxylem; $a a^{\prime}$ remsins of ruptured anunlar vessel lying in the lysigenous lacuna $l$; $0 \mathrm{~g}$ sheaths of eclerenchy matous corjunctive tissue. (Compare this with Fig. 105.)

126 ) is usually a conspicuous feature; in transverse section, on account of the relative smallness of its tracheæ (or tracheids); in longitudinal section, on account of the loose spiral or annular thickenings of their walls. The looseness of the spiral or annular markings is due to the fact that these vascular cells are the first formed constituents of the bundles, and that consequently they are considerably stretched by the continuance, for a time, of the 
growth in length of the adjacent undifferentiated tissues; hence the successive thickenings become more or less widely separated, and the wall of the vessels may be torn and destroyed (Fig. 104).

The primary bast or phloem consists essentially of sieve-tissue (p. 94) and of parenchyma. The sieve-tissue consists in all cases mainly of sieve-tubes of simple structure (Fig. 74, p. 95), constituting the vascular tissue of the bast, with which companioncells are associated in Angiosperms but not in Gymnosperms and Pteridophyta. In some Angiosperms, particularly in the closed bundles of Monocotyledons (Fig. 103), there is no bast-parenchyma, the whole bast consisting of sieve-tubes and companion-cells : but this tissue is generally present, and is readily distinguishable from the companion-cells by the larger size of its cells. In some cases (e.g. some Palms) the bast-parenchyma is to some extent replaced by sclerenchymatous fibres; otherwise the occurrence of fibres in the primary bast is rare.

The cambium is present in the collateral primary bundles of the stem of most Gymnosperms and Dicotyledons; it is never present in primary bundles of any other type of structure; nor, on the other hand, is it always present in a collateral bundle (absent in Equisetum, Monocotyledons, some herbaceous Dicotyledons, see p. 128). It lies between the bast externally and the wood internally, and consists essentially of a single layer of merismatic embryonic cells rich in protoplasmic contents, and with walls of cellulose. In transverse section (see Fig. 100) the cells are oblong, with their longer axes placed tangentially; in longitudinal section the cells are seen to be elongated and somewhat prosenchymatous, like the procambium-cells, where they abut on the wood or on the bast; but where they abut on primary medullary rays they are short and parenchymatous.

The Termination of the Vascular Bundle. The gradual thinning out and termination of the vascular bundle can nowhere be more satisfactorily studied than in leaves. The bundles, when traced towards their ultimate ramifications, are seen to diminish in bulk in consequence, partly, of a reduction in number of the constituent elements, and partly also to the smaller size of the elements which still remain. The mode of termination of the vascular bundles in foliage-leaves is briefly as follows. In many cases the bundles have only free ends, as in most Pteridophyta (e.g. Adiantum, Selaginella), and generally in small reduced leaves. In others, there are no free ends, but the finer branches anastomose with each 
other to form a closed system; this is characteristically the case where the venation is parallel (e.g. Monocotyledons, see p. 38). In others, again, the finer branches anastomose, forming a network from the meshes of which the ultimate branches project among the mesophyll-cells as free ends: this obtains generally among Dicoty-
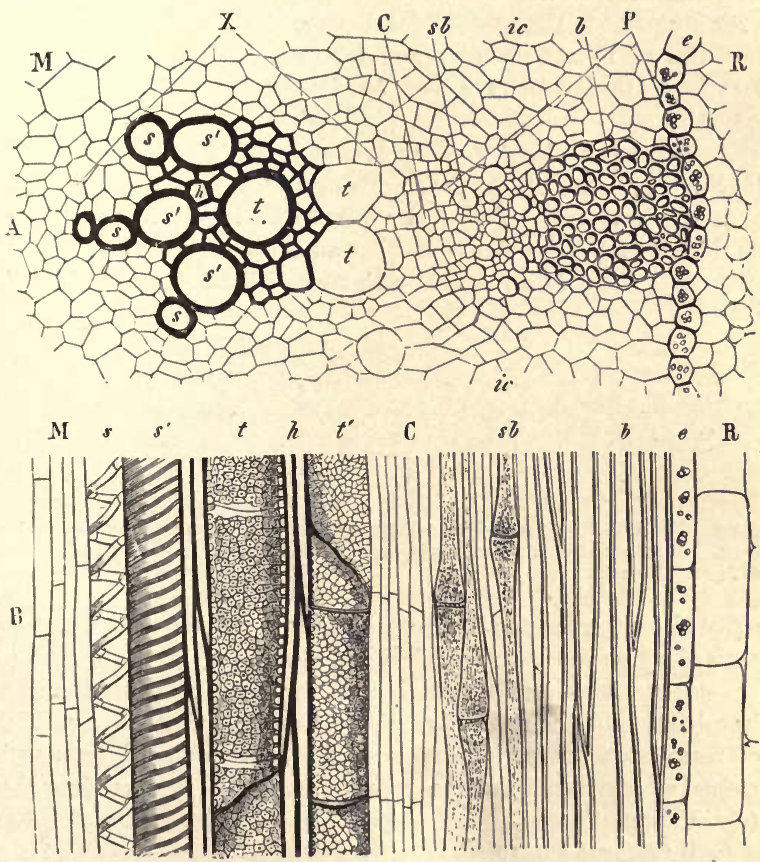

F1G. 105.-A Tranverse section of an open conjoint, collateral, vascular bundle in the stem of the Sunflower. $M$ Pith. $X$ X Jlem. $C$ Cambinm. $P$ Phloem and pericycle. $R$ Cortex; small, and $s^{\prime}$ large spiral vessels (protoxylem); $t$ pitted vessels ; $t$ ' pitted vessels in conrse of formation from the cambium; $h$ wood-fibres; $s b$ sieve tubes; $b$ fibres of the beterogeneous pericycle; endodermis or bundle-sheath; ic inter-fascicnlar conjunctive tissne. $B$ Radial vertical section through a similar bundle (somewhat simplified) lettered like the former. $(\times 150$.)

ledons. The free ends of the bundles consist of one or two rows of short tracheids with close spiral markings; no sieve-tubes can 
be traced quite to the extremity; they disappear further back, and their place is taken by parenchymatous cells.

Bundles often terminate in connection with glandular tissue; for instance, in chalk-glands and nectaries.

\$34. Histology of the Development of Secondary Members. It has been already pointed out (p. 9) that the growing-point is the seat of development, not only of new tissue, but also of new members; and further (p. 18), that secondary members are developed either by dichotomy or by lateral outgrowth.

A. Development of normal branches of the shoot or of the thallus only takes place at the growing-point.

a. By dichotomy. Two modes may be distinguished accordingly as the growing-point has or has not an apical cell:

-when there is an apical cell, true dichotomous branching is

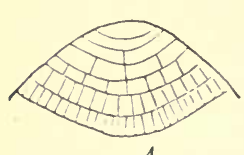

A

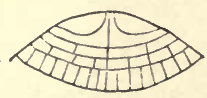

$B$

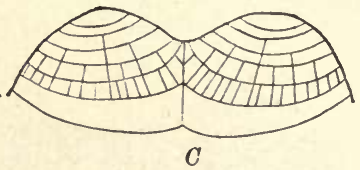

FIG. 108. $-A B C$ snccessive stages in true dichotomons branching by longitudinal division of an apical cell; from the shoot of an Alga Dictyotn dichotoma (bighly magnified; after Nregeli).

effected by the longitudinal division of the apical cell into two, each of which becomes the apical cell of a branch:

-when there is no apical cell, the growing-point becomes broadened, and the central portion of it passes over into condition of permanent tissue, leaving two distinct masses of embryonic tissue, which constitute the growing-points of the two branches (e.g. Marchantiaceæ).

b. By lateral outgrouth :

- $u$ hen there is a single initial cell in the growing-point, the growing-point of the branch is developed either directly from the initial cell itself, as in some Algæ, or more commonly from a segment of the initial cell, as in many Algæ, Mosses, Liverworts, etc. :

- when there is not a single initial cell (e.g. Phanerogams), the growing-point of the branch is formed by division of cells of the periblem, including several layers, which grow and divide, forming a lateral protuberance with the growth of which the dermato- 
gen keeps pace; the primary meristem of the branch undergoes differentiation into tissue-systems corresponding to those of the parent members, and continuous with them.

Normal branches, however the details of their development may vary, agree in this, that they are, with rare exceptions, of exogenous origin.

B. Development of Leaves only takes place at the growing-point of a stem, and always by lateral outgrowth (see p. 28).

When the growing-point of the stem has a single initial cell, the growing-point of the leaf is developed either from the apical cell itself, or, more commonly, from the whole or a part of a segment of the apical cell.

When the growing-point of the stem has not a single initial cell, as in Phanerogams, the growing-point of the leaf is formed by the division of cells belonging to one or more of the superficial layers of the periblem, accompanied by growth and division of the corresponding cells of the dermatogen.

The primary meristem of the leaf becomes differentiated into tissue-systems corresponding to, and continuous with, those of the stem which bears it. In the developing leaves of those vascular plants which have common bundles (see p. 127), the differentiation of the protoxylem begins at the point of junction of leaf and stem, extending outwards in the procambium-strands of the leaf, and inwards in those of the stem.

The development of secondary branches of the leaf takes place in essentially the same manner as that of the leaf from the stem. Dichotomous branching of the leaf (see p. 34) takes place in the same way as dichotomous branching of the stem.

It will be seen that the development of a leaf on any stem takes place in essentially the same way as the development of a lateral branch on that stem; it is only later that leaves and branches assume their distinctive characters.

C. Development of Branches of the Root. It has been pointed out that the only normal secondary members produced by the root are root-branches or secondary roots; these may be developed either by dichotomy or by lateral outgrowth.

a. By dichotomy. This has only been observed in certain sporophytes among the Pteridophyta (Lycopodium, Isoetes). Here the growing-point broadens, under the root-cap, the central portion passing over into permanent tissue, whilst the two sides remain merismatic and form the growing-points of the two secondary 
roots; the old root-cap is exfoliated, and each growing-point forms a new one for itself. The successive dichotomies take place in planes at right angles to each other.

b. By lateral outgrouth. It has been already stated (p. 9) that the lateral development of secondary members does not take place at the growing-point of the root, but at a considerable distance behind it, where the tissues have already assumed their permanent differentiation. The lateral roots are developed endogenously from a layer of this tissue which remains embryonic longer than the

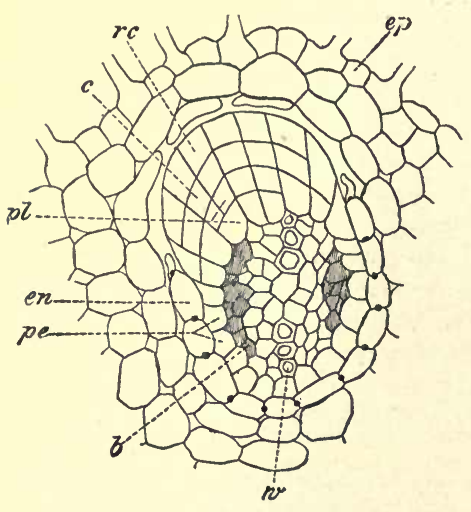

A.

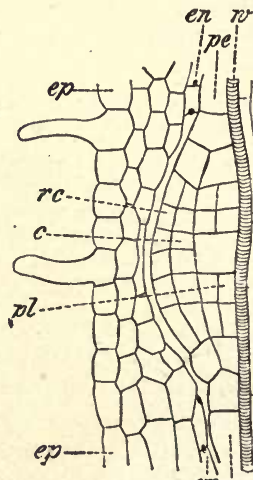

en pe

B.

Fra, 107.- nlustrating the development of a secondary root in a Phanerogam. $A$ transverse, $\boldsymbol{B}$ longitudinal, section; ep epiblem; en endodermis; pe pericycle; $v$ protoxylem and $b$ phloem of the parent-root; rc root cap; $c$ periblem, and $p l$ plerome, of the developing lateral secondary root. (Tessdalia nudicaulis; $\times$ about 800 ; after van Tieghem).

adjacent tissues. This layer may be either the pericycle, as in Phanerogams, or the endodermis, as in most Vascular Cryptogams.

In the Phanerogams (Fig. 107), the growing-point of a lateral root is formed by the growth and division of a group of pericyclecells, lying usually just externally to the outer end of a xylembundle; hence there are as many longitudinal rows of lateral roots produced as there are xylem-bundles in the parent root, and corresponding with them in position. But to this rule there are some exceptions; for instance, when, as in the Grasses and Cyperaceæ, 
the pericycle is wanting opposite to the xylem-bundles, the lateral roots are developed, not opposite to the xylem-bundles, but opposite to the phloem-bundles. Again, when there are only two xylembundles in the parent root, four rows of lateral roots are produced, each root being developed on one side of a xylem-bundle of the parent root: a similar displacement occurs in Umbelliferæ, Araliaceæ and Pittosporaceæ, where the pericycle is interrupted opposite to each xylem-bundle by an oil-duct (see p. 119).

In most Vascular Cryptogams (except Lycopodium and Isoetes, where secondary roots are produced only by dichotomy), the apical cell of a secondary root is formed from one of a row of large endodermal cells, the rhizogenic cells, lying just externally to each xylem-bundle of the parent root. In Equisetum, where the endodermis consists of two layers (see p. 115), the secondary roots are developed from cells belonging exclusively to the inner layer, which are adjacent to the xylem-bundles.

It will be understood that, in order to reach the surface, the lateral secondary roots must penetrate the external tissues of the parent root. This is not effected by purely mechanical means, but by chemical action, leading to solution and absorption, exerted on the tissues, either by the rootlet itself, or, more commonly, by a digestive sac which invests the rootlet, and is formed in Phanerogams by the growth and division of the cells of the endodermis (and sometimes one or two layers of cortical cells), in Vascular Cryptogams, by the growth and division of one or more of inner layers of cortical cells just external to the endodermis of the parent root.

D. Development of Hairs. These structures are in all cases developed from the superficial cells of the parent member, that is, from dermatogen-cells in those parts in which this layer is differentiated; in the great majority of cases each hair arises from a single superficial cell. Hairs are generally developed in acropetal succession, but considerable irregularity is not uncommon, and they are frequently developed on members in which the tissues have already acquired their permanent characters (see p. 46).

E. Development of Emergences. When exogenous they are developed from the superficial and from one or more of the subjacent layers of tissue of the parent member, that is, from the dermatogen and periblem of those members in which this differentiation of the primary meristem obtains. When they are endogenous (e.g. haustoria of Cuscuta, see p. 49), they are developed exclusively from the periblem.

F. Development of Reproductive Organs. The question as to 
the relation of these members to the primary meristem, only arises with reference to those plants, the bodies of which consist of many layers of tissue; their origin in plants, the bodies of which consist either of filaments, or of flattened expansions of a single layer of cells, need not be considered here.

In the cases under consideration, the reproductive organs may be developed either from the superficial layer alone, or from that and one or more of the subjacent layers.

Organs developed from the superficial layer alone (dermatogen when differentiated): these may be developed each from a single cell, as all sexual organs, and the sporangia of all leptosporangiate Ferns and Rhizocarps (Hydropterideæ); or they may be developed from a group of superficial cells, as the sporangia of the Ophioglossaceæ and Marattiaceæ (eusporangiate Ferns), of Equisetum, and of Lycopodinæ.

Organs developed from the superficial and deeper layers. In most cases the organ is developed from the superficial and one or more of the subjacent layers, e.g. microsporangia (pollen-sacs) and macrosporangia (ovules) of most Phanerogams.

The primitive sporogenous tissue (archesporium, see p. 53) is, in the sporangia of all Vascular Plants, derived from the hypodermal layer of the young sporangium; it may consist of a single cell, or of a row of cells, or of a layer of cells. In the Mosses the archesporium is more deeply seated, arising from the external layer of the endothecium (rudimentary plerome) as in most Mosses, or from the innermost layer of the amphithecium (rudimentary periblem) as in Sphagnum and in the Liverwort Anthoceros.

\section{G. The Development of Adventitious Secondary Members (see} p. 9).

1. On the stem. The most common case is that of the development of roots, but occasionally shoots (buds) are developed adventitiously.

The adventitious development of roots on the stem takes place most commonly by the division of a group of pericycle-cells to form a growing-point, in the way described on page 134 with reference to the development of normal lateral roots on the parent root. In any one plant the two processes are similar in every detail.

The adventitious development of buds on the stem may take place either exogenously or endogenously. In the former case the buds may be developed each from a single epidermal cell (e.g. 
Begonia prolifera, underground shoots of Psilotum), or from the epidermis and subjacent layers (e.g. Linaria vulgaris). In the latter case the adventitious bud arises from the pericycle (e.g. Cuscuta, hypocotyl of Convolvulus arvensis).

2. On the root. Adventitious buds may be formed either exogenously or endogenously on the root; in the former case they arise from the superficial layers (e.g. Aristolochia Clematitis); in the latter, from the pericycle (e.g. Alliaria officinalis, Anemone sylvestris, etc.).

3. On the leaf. Adventitious buds developed on leaves are of exogenous origin, the epidermis being more especially concerned in their production (Begonias). Adventitious roots are usually of endogenous origin, being derived from cells of the pericycle.

Adventitious buds and roots are also developed from the callus (see $\$ 36$ ) formed on the injured surfaces of stems, roots, and leaf-stalks : the former may be endogenous or exogenous, the latter are endogenous.

$\S 35$. The Formation of Secondary Tissue. In addition to the formation of primary tissue from the primary meristem of the growing-point, as above described, a formation of secondary tissue takes place in many plants, which is in most cases associated with a growth in thickness.

A. The Normal Formation of Secondary Tissue in the stem takes place in most Gymnosperms
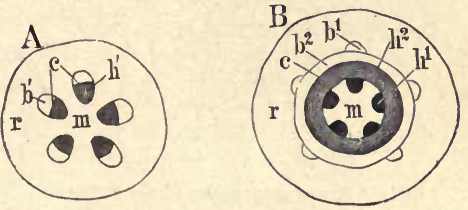

Fig. 108,-Diagrammatic transverse sections of a normal dicotyledonous stem which grows in thickness. $A$ Very young: there are five isolated bundles; $m$ pith; $r$ cortex ; $b^{\prime}$ primary bast ; $h^{\prime}$ primary wood; $c$ cambium. $B$ After growth in thickness has commenced; $h^{2}$ secondary wood; $b^{2}$ secondary bast. and Dicotyledons, and is effected by the continuous merismatic activity of the cambium of their open collateral bundles. These are arranged in a circle in a transverse section (Fig. 108 A): the commencement of growth in thickness is preceded by tangential divisions in the conjunctive tissue (Fig. 105) which lies between the bundles; this gives rise to cambium which becomes continuous with that of the vascular bundles. A closed hollow cylinder is thus formed, which appears, in a transverse section, as a ring, the cambium-ring (Fig. $108 \mathrm{BC}$ ), completely separating 
the pith from the cortex : it consists of two portions corresponding to its mode of origin; fascicular cambium, i.e. the cambium belonging to the vascular bundles, and the interfascicular cambium, i.e. that which is formed between the bundles in the primary medullary rays (see Fig. 97).

A cambium-ring is likewise formed in the root of these plants (Fig. 109. The first indication of the formation of a cambiumlayer is the division of the cells of the conjunctive parenchyma on the inner surface of each bast-bundle: then those on the flanks of the bast-bundles begin to divide; and thus a number of arcs of cambium are formed, extending from the inner surface of each bust-bundle to the pericycle. The pericycle-cells lying externally

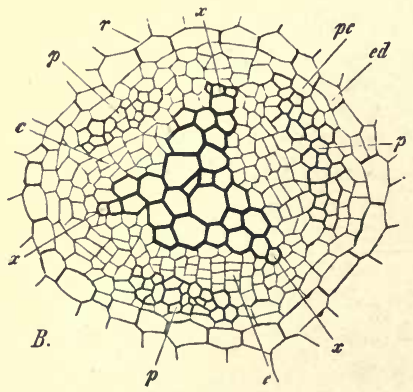

Fig. 109.-Transverse section of the stels of the root of Sambucus nigra, where Eecondary growth in thickness is commencing. $r$ Cor. tex; ed endodermis; pc pericycle; $x x x$ the three groups of protoxylem; $p p p$ the three groups of phloem; $c$ dividing cells of the conjunctive tissue forming part of the developing cambium-ring.

to the outer ends (protoxylem) of the wood-bundles now divide, and connect the arcs of cambium. Thus a continuous cambium-layer is formed, which has at first a wavy outline, as seen in transverse section, but which becomes circular as the development of the secondary tissue proceeds.

The cambium-layer of the primary root is continuous with that of the primary stem; hence, in a plant in which stem and root grow in thickness, there is a continuous layer of merismatic tissue extending from one end of it to the other; for the cambium of the branches of both stem, and root is continuous with that of the primary members; and further, the cambium is continuous with the merismatic tissue of the growing-points of the primary stem and root and of their branches.

The cells of the cambium-ring, in the stem and root alike, constantly undergo both tangential and radial division, so that the number of the cells increases in the radial direction as well as in the circumferential; the growth of these cells produces an extension of the organ in both these directions. Of the cells formed by 
tangential division, those lying on the inner side of the cambium, are transformed into the elements of the wood (Fig. $108 \mathrm{~B} \mathrm{~h}^{2}$ ), those on the outer side, into the elements of the bast, while the cells of the intermediate zone continue to be capable of dividing. The activity of the cambium thus gives rise to secondary wood and secondary bast, as distinguished from the primary constituents of the bundle, which existed previously to, and independently of, the activity of the cambium. The primary wood of the bundle is thus the innermost part of it, and the primary bast the most external.

Not only does the fascicular cambium add secondary wood and bast to the primary bundles of the stem, but the interfascicular cambinm generally forms (except Cucurbitaceæ, Aristolochia, and some other plants, where it only fcrms conjunctive tissue) new secondary bundles between the primary, and in this way a compact ring of wood and of bast is formed. These secondary bundles are of course destitute of protoxylem and protophloem.

In roots the secondary vascular tissue is developed in essentially the same manner as in the stem; the wood inwards, the bast outwards, from the cambium-layer; and the same forms of tissue are produced. It is, however, only in certain cases (e.g. Taraxacum, Rubia, Taxus, Cnpressus, etc.) that the cambium of the root produces wood internally, and bast externally, over its whole surface, so that a complete ring of secondary vascular tissue is formed : in most cases secondary vascular tissue is formed only opposite to the primary bast-bundles, whereas,

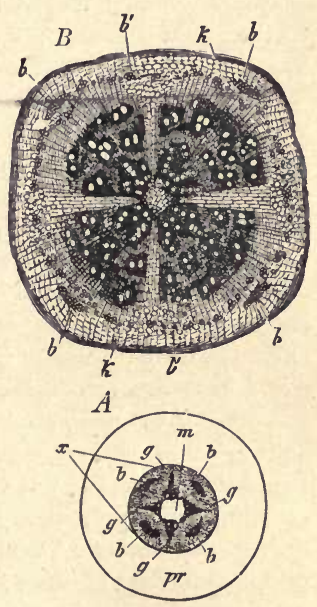

Fig. 110. $-A$ Transverse section of a young root of Phaseolus multiflorus : $p r$ cortex ; $m$ pith ; $x$ stele; $g$ primary xylem-bundles; $b$ primary phloem. bnndles. B Transverse section of an older root of the same plant, which is growing in thickness : $b^{\prime}$ secondary bast; $k$ periderm: the fonr rays extending to near the centre consist of secondary ground-tissue, and correspond in position to the primary wood-bnndles. (Slightly magnifled; after Sachs.) opposite to the primary wood-bundles, the cambium produces only ground-tissue, thus giving rise to broad medullary rays opposite to these bundles (Fig. 110). 
The Tissues developed from the Cambium.-In stems and roots in which the growth in thickness is normal, the cambium gives rise to secondary wood, secondary bast, and secondary conjunctive tissue (medullary rays).

The stmeture of the secondary wood differs essentially from that of the primary wood only in that it includes no spiral or annular vessels resembling those of the protoxylem (see p. 126). It always includes tracheal tissue; nearly always wood-parenchyma (see p. 91); frequently sclerenchyma: the cell-walls of all these forms of tissue are usually more or less completely lignified.

The secondary tracheal tissue may consist either solely of tracheæ (e.g. Platanus, Fraxinus excelsior and Ornus, Citrus, Viscum, Hydrangea); or solely of tracheids (e.g. Coniferæ, Drimys Winteri); or, as is generally the case, of both tracheæ and tracheids. The cell-walls of the tracheal tissue are, as a rule, marked with bordered pits; but occasionally, especially in soft wood, the walls are reticulately thickened.

The secondary wood-parenchyma consists of oblong cells, which are generally so arranged that their long axes are parallel to that of the member of which they form part: they occur in short longitudinal strands, consisting commonly of a single row of cells (Fig. $111 C$ ), but sometimes, in the middle only, of more than one row. They are true cells, containing protoplasm and a nucleus, and other substances, such as starch (especially in perennial steins and roots in winter), tannin, etc. Their walls are generally lignified, but usually not very much thickened, and have circular or elliptical simple pits. In many soft fleshy stems and roots (e.g. Potato, Radish, Turnip, Beetroot), where this tissue is the principal product of the activity of the cambium, the cell-walls are not lignified.

The secondary sclerenchyma consists of elongated prosenchymatous cells, with more or less thickened lignified walls marked with narrow oblique bordered pits (Fig. 72, p. 93; Fig. 111 $A, B)$. Two forms of this tissue are distinguishable: uoody fibres destitute of protoplasmic contents, which are connected by transitional forms with the tracheids (see p. 92): fibrous cells, with protoplasmic cell-contents, which are allied to the wood-parenchyma; in fact, one fibrous cell corresponds to a row of wood-parenchyma cells; the walls of the fibrous cells sometimes remain thin, as in Viscum and some other plants, where they replace the wood-parenchyma both structurally and functionally. 
Both the woody fibres and the thick-walled fibrous cells may eventually become chambered by the formation of delicate transverse septa.

The structure of the secondary wood of the root is, in some cases (e.g. Conifers), almost identical with that of the corresponding stem; this is the case, to a somewhat less degree, in woody Dicotyledons; whilst in herbaceous Dicotyledons the structure may be very different in the two members, owing,
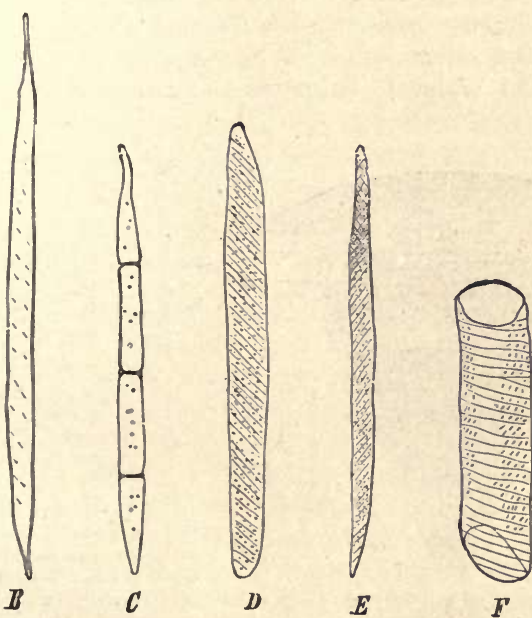

FsG. 111.-Isolated constituents of the secondary wood of the Lime (Tilia parvifolia). $A$ and $B$ wood-fibres; $C$ wood-parenchyma; $D$ and $E$ tracheids; $F$ segment of a wood-vessel (trachea). $G$ is a bast-libre. ( $\times 180$ : after Strasburger.)

chiefly, to the development of more medullary ray, but less woody tissue, in the root (see above p. 139).

A transverse section of a stem or a root of most coniferous or dicotyledonous trees or shrubs exhibits, even to the naked eye, a series of concentric layers in the secondary wood known as the annual rings (Fig. 112). These layers result from the fact that the wood formed in the spring is differently constituted from that which is formed 
later in the vear. The anatomical cause of the distinctness of the annual rings is the same in all cases, namely, that the lastformed xylem-elements of an annual ring have a very small radial diameter as compared with those formed when growth is resumed in the following spring. In Conifers this distinction is emphasized by the fact that the spring-wood is formed of thin-walled tracheids (Fig. 113 $f$ ) and the autumn-wood of smaller thickwalled tracheids (Fig. $113 \mathrm{~h}$ ). In dicotyledonous trees the number and size of the vessels diminishes in each annual ring from its inner to its outer limit. When this takes place very gradually, the eye cannot detect any conspicuous difference between the spring- and autumn-wood (as in the wood of the Beech, Lime, Maple, and Walnut); but some kinds of wood show a ring of

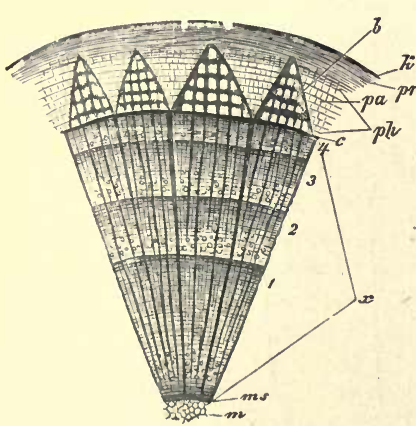

F10. 112.-Part of a transverse section of a twig of the Lime, four years old (slightly magnifled) : $m$ pith; $m s$ medullary sheath; $x$ secondary wood; 1234 annual rings; $c$ cambium; pa dilated outer ends of primary medulary rays; $b$ bast; pr primary cortex; $k$ cork.

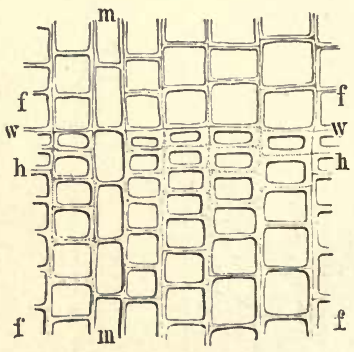

FIG. 113.-Transverse section of portion of the secondary wood of a branch of the Fir at the junction of two annual rings: $m$ a medullary ray - all the other cells belong to the wood; $f$ large-celled spring-wood; $h$ small-celled autumnwood; w the limit between the autumnwood of one year and the spring-rood of the following year; between $h$ and $w$ is the flattened limiting layer ( $x$ 250).

conspicuously large vessels in the spring-wood, while in the autumn-wood there are numerous much smaller vesséls (as in the wood of the Oak, Elm, and Ash).

The thickness of the annual ring varies in different plants, and even in any one plant, under different conditions of growth; and not only the thickness, but also the number and relative distribution of the constituents of the wood.

The secondary wood gradually becomes distinguishable into an 
older internal portion, the heart-wood (duramen), and a younger outer portion, the sap-wood (alburnum). This arises from the fact that, as the wood becomes older, the cells of the wood-parenchyma and the fibrous cells die and lose their protoplasmic cell-contents; as a consequence, the heart-wood has less water in its composition than the sap-wood. In some cases this change is accompanied by a coloration of the cell-walls of the heart-wood, with the result that the distinction of duramen and alburnum is most marked (e.g. Pine, Larch, Oak); it is but rarely that this distinction is not observable (e.g. Buxus, Acer pseudoplatanus and platanoides).

The structure of the secondary bast essentially resembles that of the primary bast. It always consists of sieve-tubes and of parenchyma, and very frequently of thick-walled fibres as well.

The sieve-tubes of the secondary bast have the compound sieveplates shown in Fig. 75, p. 96 ; in Dicotyledons they have companion-cells developed in relation with them. The parenchyma very much resembles that of the secondary wood, except that its cell-walls are not lignified; it is abundantly developed in certain fleshy roots (c.g. Taraxacum, Rubia, and the Carrot and Parsnip), where it constitutes the chief part of the secondary bast. Prosenchymatous cells with unlignified walls, corresponding to the thinwalled fibrous cells of the secondary wood (p. 140), are sometimes present. The bast-fibres closely resemble the woody fibres, but their walls are not lignified (Fig. $111 G$ ).

In many cases the secondary bast contains no bast-fibres (e.g. Abietineæ, Fagus, Betula, Alnus, Platanus, Cornus, Ephedra, etc.). When, as is usually the case, bast-fibres are present, their arrangement presents considerable variety : there may be alternating tangential layers of fibres (hard bast) and of sieve-tubes and parenchyma (soft bast), as in the case of the Cupressineæ and some Taxoideæ, and, though with less regularity, in many Dicotyledons (e.g. Vitis, Spiræa, species of Acer, Tilia, species of Salix, etc.); more commonly the tangential layers of fibres are interrupted here and there by soft bast (e.g. Quercus, Corylus, Carpinus, Pyrus, Juglans, Sambucus, Rhamnus, Ulmus, Populus); or there may be scattered groups of fibres (e.g. Cinchona, Morus, Larix, Celtis Ficus elastica).

The secondary bast does not, as a rule, attain so considerable a size as the secondary wood, nor does it exhibit annual rings: this is due to the fact that, except in some fleshy roots, it is formed in smaller quantity, and further, to the fact that the older bast be- 
comes crushed and flattened by the development of the more internal layers subsequently formed.

The structure of the secondary conjunctive tissue (medullary rays). The cambium-ring not only adds to the existing primary medullary rays, but gives rise to new (secondary, tertiary) rays in the successive years of growth (see Fig. 112), amongst the vascular tissue.

The cells of the medullary rays are typically parenchymatous, somewhat brick-shaped, with their long axes along radii from the

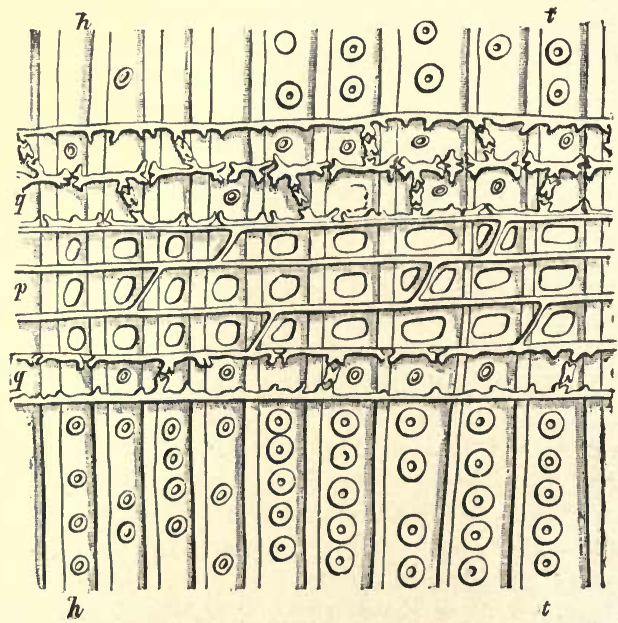

Fig. 114.-Radial longitudinal section of the wood of the stem of a Pine, along the length of a medullary ray $q p q$, consisting of six horizontal rows of cells, one above the other :$t$ tracheids with bordered pits; the tracheids $h$ with smaller bordered pits are the autumn. wood of one year, those to the right with larger pits constitute the spring.wood of the next Jear; $q$ tracheidal elements of the meduilary ray ; $p$ true cells of the ray : where the cells of the medullary ray abut on the tracheids the pits are simple and large $(x 300)$.

centre to the periphery of the member (Fig. 112); their more or less thickened walls are lignified, and they have protoplasmic contents. Occasionally, however, some of the cells of a ray lose their protoplasmic contents and constitute tracheids (e.g. Abietineæ, Fig. $114 q q$ ); in some few cases the ray consists of long fibrous cells, in place of parenchyma (e.g. shrubby Begonias).

The medullary ray is, then, a strand of cells passing radially 
among the longitudinally arranged tissues of the wood and of the bast (Fig. 112). Its size varies, even in the same member, both as regards its vertical (height) and its lateral (breadth) dimensions. With regard to the former, the ray may consist of only a single row of cells (as in Abietineæ, Quercus, Fagus); the limits may be generally stated at 1-12 rows of cells, though in some cases they are considerably larger than this when they include resin-ducts (e.g. Abietineæ) or other forms of secretory tissue. In any case, the secondary medullary rays, unlike the primary, do not extend throughout the whole length of an internode. The breadth of the secondary medullary rays is never nearly so great as their height: as seen in tangential longitudinal section, they are narrow above and below and broader in the middle; it is only in the middle that they ever consist of more than one row of cells in breadth, the upper and lower margins consisting of a single row only. With regard to their radial extent, it is only the primary medullary rays which extend from pith to pericycle; the subsequently formed rays (secondary, tertiary, etc.) extend between the wood and the bast of the year in which they were formed.

As instances of especially large secondary medullary rays should be mentioned those formed in roots (see Fig. 110, p. 139) where the cambium forms only conjunctive tissue opposite the primary xylem-bundles. Again, in some few stems (see p. 139) the formation of secondary vascular tissue is confined to the fascicular cambium, the interfascicular cambium in the primary medullary rays giving rise only to conjunctive tissue; hence the primary medullary rays persist as broad bands of conjunctive tissue between the bundles, and are not broken up, as is usually the case, by the formation of secondary bundles from the interfascicular cambinm.

The Differentiation of the Secondary Tissues.-The cells, formed as the result of division in the cambium, which are to become transformed into secondary permanent tissue have, to begin with, the same form and structure as the corresponding cambiumcells, but they gradually under-gochanges in both respects, as they become transformed into permanent tissue.

M.B. 
The development of the young cell into one or other of the various forms of permanent tissue already described, may be either accompanied or unaccompanied by cell-division. In the former case, the divisions may be transverse or longitudinal; the

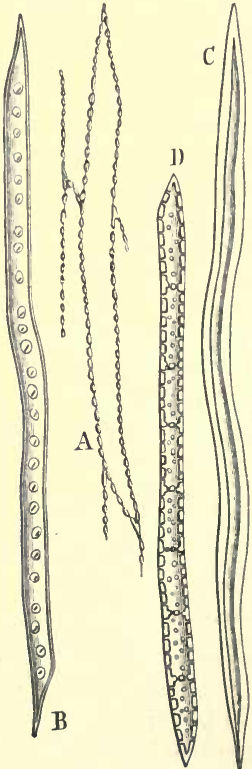

Fig. 116.-A Developing vascular cells, derived from the cambium, seen in tangential section. B Tracheid seen from outside. $C$ Woody fibre; and $I$ vertical row of wood-parenchyma-cells seen in section, from the Oak; isolated by maceration. cell undergoes transverse division when the product is a row of short cells (e.g. woodparenchyma, Fig. $116 \mathrm{D}$, and Fig. $111 \mathrm{C}$; bast-parenchyma; secondary medullary rays, wood-vessels with short segments): the cell generally undergoes longitudinal division once or twice, by tangential walls, soon after it has been cut off from the cambium; but this does not take place in the line of the medullary rays, where the radial diameter of the young cells is greater than it is near the bast or the wood: again, the young cell may undergo longitudinal division in a plane other than the tangential, as for instance the longitudinal division of the mother-cell, which separates the sieve-tube-segment from the companion-cell in the bast of Angiosperms.

The developing cell may retain its original form and size (e.g. small medullary rays; rows of parenchyma-cells, bast or wood; thin-walled fibrous cells): but more commonly the mature product differs very materially from the young cell, being very much wider (e.g. tracheæ), or very much longer longitudinally (wood- and bast-fibres), or very much longer radially (e.g. cells of medullary ray); that is to say, the development of the young cell into permanent tissue is generally accompanied by very considerable growth.

The radial and tangential divisions of the cambium-cells take place in such a manner that the products are, at first, arranged in very definite radial rows. When the resulting tissue consists of elements which are for the most part essentially alike, this regular radial arrangement persists in the permanent tissue; for instance, in the wood of Conifers (Fig. 113), which consists almost exclu- 
sively of tracheids; but where some of the elements (as generally in the wood of Dicotyledons) attain a much greater size (as seen in transverse section, Fig. 105), the original radial arrangement is lost.

In those cases in which the permanent tissues consist of very long or very wide fibres or vessels, it is evident that the relative position of the original cells must have undergone considerable change in the course of development; the long fibre is in contact, longitudinally, with a greater number of cells than was originally the case ; and similarly, the wide trachea touches, at its circumference, a larger number of cells than did the cell, originally, from which the segment of the vessel was developed. This gradual change of relative position constitutes what is termed slidinggrouth; it is the expression of the independent growth of each cell in the course of its development into the particular element of the permanent tissue which it is destined to form. This process is by no means confined to the vascular tissues, but takes place wherever a young developing cell grows more actively, in any dimension, than the cells with which it is at first in contact; a notable example is the growth of the laticiferous conocytes of Euphorbia (see p. 100).

Whilst undergoing these changes of form, the developing cells undergo, as already indicated, changes in the structure and chemical composition of their cell-walls in accordance with the particular kind of tissue to which they are to give rise; and, in some cases (tracheæ, tracheids, fibres) they lose their protoplasmic cell-contents; the walls become more or less thickened, not spiral or annular as in primary wood, but pitted (with simple pits ; or circular bordered pits; or oval bordered pits, either small and numerous, or large extending across a whole face of the wall, giving it a scalariform appearance, see p. 74); and then the absorption, more or less complete, of the septa takes place, which leads to the formation of the vessels.

Glandular tissue is frequently developed in the secondary wood and bast, in the form, sometimes, of sacs containing crystals, in the parenchyma (inclnding medullary rays) of the wood (e.g. Vitis, and some leguminous trees) or more commonly in that of the bast: of resin-ducts which occur in the secondary wood of certain Abietineæ, running horizontally in the medullary rays and vertically in the wood, but rarely found in the secondary bast, whereas in other plants which possess these structures, they are rare in the wood but abundant in the bast (e.g. Anacardiaceæ, etc.): of laticiferous vessels, rare in the wood (except the 
Papayaceæ, where the wood consists largely of parenchyma), abundant in the bast.

In Monocotyledons there is no primary cambium-layer, the bundles being all closed. In some cases, however, secondary growth in thickness is effected by a ring of meristem quite external to the primary bundles; this occurs in the stems and roots of some arborescent Liliacer, such as

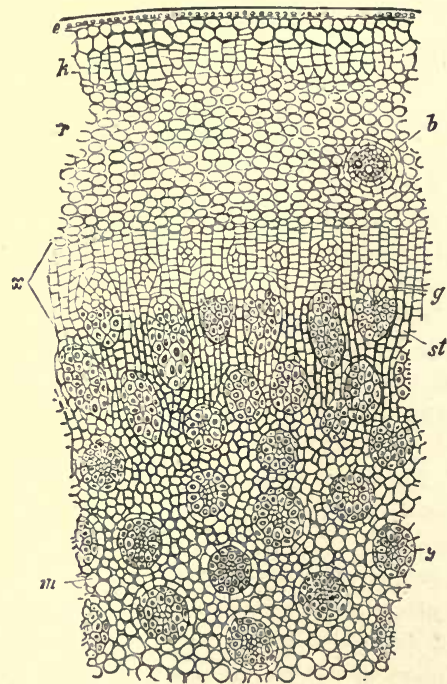

Fig. 117.- Portion of a transverse section of the stem of a Dracana: $\boldsymbol{e}$ epidermis; $\boldsymbol{k}$ periderm; $r$ primary cortex, with a leaf-trace-bundle $b ; x$ merismatio zone in which new bundles $g-g$ are in course of development; $m$ primary, and st secondary, ground tissue. (Magnified : after Sach8,)
Yucca and Dracæna, where a ring of meristem is usually developed in the pericycle, but in the roots of Dracæna it is formed partly from the pericycle and partly from the cortex. This meristem-ring is not termed a cambiumring, because it does not form wood on one side and bast on the other, but it forms, centrifugally, entire closed concentric (with external wood) bundles, together with intervening ground-tissue (Fig. 117).

The development of secondary vascular tissue takes place almost exclusively in such stems as are monostelic and in which the primary bundles are common. It is clear that the additions to the primary bundles in the older internodes of the stem, as well as any secondary bundles which may have been formed from the cambium are not common, but cauline; they are, however, in communication with the primary common bundles of the young unthickened internodes which are bearing leaves; in fact, the newly-formed secondary vascular tissue of the lower internodes of the stem is in communication, on the one hand with the root, and on the other with the leaves; and the channels of communication between root and leaf are maintained year by year by the annual formation of young conducting-tissue, both wood and bast, in the older parts of the stem and of the root. 
It will be remarked that the development of secondary vascular tissue takes place in those plants the stems of which branch more or less (e.g. an Oak), while it usually does not take place in those plants the stems of which do not branch (e.g. the Palm), or do so only slightly. It is obvious that, when the stem is of branching habit, the number of leaves must increase year by year, whereas when the stem does not branch the number of leaves does not vary materially. Hence the whole matter may be summed up thus, that the development of secondary vascular tissue in a stem is directly correlated with an increase in the area of leaf-surface: as in each year the leaf-surface of a tree increases in consequence of repeated branching, so does the annual ring of secondary vascular tissue become larger in circumference and possibly also of greater thickness; when, however, the tree begins to grow old, and its branches, instead of increasing in number, begin to die off, then the annual growth in thickness becomes arrested. Some further explanation of this is given in Part III.

B. The formation of Secondary Tegumentary and Cortical Tissue. It is clear that the more or less considerable development of secondary tissue in the interior of a young stem or root, must have a very considerable effect on the primary cortex, and on the primary tegumentary tissue. This effect will be one of pressure and tension; the radial growth of the stelar tissue will exert a radial pressure upon the external tissues, while the tangential growth of the stelar tissue will exert a tangential tension on the external tissues. The radial pressure of so firm a structure as is usually that of the secondary vascular tissue tends to cause more or less rapid obliteration of the softer cortical tissue; whilst the tangential tension stretches the cortical cells and tends to cause them to grow tangentially, and to multiply by radial division. According to the predominance of the radial pressure or of the tangential tension, the primary cortex is either rapidly destroyed, or it persists for a very considerable period.

It may be stated generally that the epidermis and the primary cortical tissue of herbaceous dicotyledonous stems keep pace by growth with the formation of new tissue in the interior. This is true also of most woody shoots during the first year of their growth and in certain cases (e.g. Mistletoe, Holly, Accr striatum; etc.) of woody shoots during their entire existence; in some cases (e.g. Euonymus) the epidermis persists and grows for several years, but is at length disorganised. These primary tissues per- 
sist also in some roots (e.g. Vicia Faba, Alchemilla vulgaris), in which the development of secondary vascular tissue is not very active. The extension of the tissue is effected by tangential growth and radial division of the cells.

The secondary tegumentary and cortical tissue is formed by a layer of merismatic cells, which is known as the Phellogen.

In the stem the place of origin of the phellogen is by no means uniform. It is sometimes formed by the epidermis becoming merismatic (e.g. Pomeæ, Salix, Vibumum Lantana, Euonymus, Solanum, etc.) : most commonly it is the hypodermal layer of cells, the outermost layer of the cortex, which becomes merismatic and constitutes the phellogen (e.g. Platanus, Acer, Fagus, Quercus, Castanea, Betula, Alnus, Ulmus, Populus, Ailanthus, Abies pectincta, etc.): in other cases the phellogen is formed at a greater depth from the surface, being developed from a more internal layer of cells of the cortex, sometimes even from the endodermis (e.g. Coffea arabica; subterranean shoots of some Leguminosæ such as Lotus corniculatus, Trifolium alpestre); or, finally, it is stelar, being formed from a layer of cells belonging to the pericycle (e.g. Hypericum, Erica, most Caryophyllaceæ, Lonicera, Vitis, Clematis, Berberis, Rosa, Spiræa, Ribes, etc.).

The development of tissue from the phellogen follows the same law as in the case of the cambium. Generally speaking, a tissue, the periderm, is formed on the outer side of the phellogen by repeated centripetal division; whilst on the inside of the phellogen a tissue, the phelloderm, is formed by repeated centrifugal division. The periderm constitutes the secondary tegumentary tissue of the stem or root; the phelloderm constitutes the secondary cortex. The developmental relations between the two tissues are not constant. In some cases the formation of phelloderm only begins after a considerable mass of periderm has already been produced; but in others, the formation of the two tissues goes on almost simultaneously. The relation between the amount of periderm and the amount of phelloderm formed by one and the same phellogen is by no means uniform: whilst the development of periderm is most marked in subaerial stems with superficial phellogen, there is little or no phelloderm in these stems; again, in subaerial stems with a deeply-placed (e.g. pericyclic) phellogen, periderm and phelloderm are developed about equally; finally, in subterranean stems with a pericyclic phellogen, the well-developed phelloderm may exceed the periderm. 
In the root, as in the stem, the position of the phellogen, and the products of its activity, are various. The phellogen is developed but rarely (e.g. Solidago) from the epiblem; more commonly from the exodermis, or from the next internal layer of the primary cortex, as in a few woody Dicotyledons (e.g. Jasminum) in which the formation of secondary vascular tissue takes place relatively late; and in the Cycads among Gymnosperms. In the great majority of Dicotyledons and Gymnosperms the phellogen of the root is stelar in origin, being derived from the pericycle.

As in the stem, so in the root, the phelloderm is more highly developed when the phellogen is deeply placed than when it is superficial; but even with a uniform position of the phellogen, the relation between the periderm and the phelloderm developed, varies considerably: thus, among plants with a pericyclic phellogen, whilst the development of periderm and phelloderm is sometimes about equal (e.g. Willow), no phelloderm but only periderm is developed in Nerium, whilst in some others (e.g. Vicia Faba, Alchemilla vulgaris), where the primary cortex persists (see p. 149), only phelloderm is developed.

It frequently happens in both stems and roots that the firstformed primary phellogen has but a limited period of merismatic activity; this is always the case when the primary phellogen is of deep origin (pericyclic in roots), whereas when it is of superficial origin (e.g. epidermal or hypodermal phellogen in stem of Beech, Hornbeam, Silver Fir, Cork-Oak, Cork-Elm), the primary phellogen is frequently persistent. In the former case, however, when the primary phellogen has passed over into some form of permanent tissue, a new secondary phellogen, also of limited duration, is developed internally to the first, and this process is repeated at intervals; hence the phellogen-layers become successively more and more deeply seated, penetrating at length into the bast-tissue of the stele.

The periderm, or secondary tegumentary tissue, the tissue formed externally from the phellogen, consists of parenchymatous cells more or less cubical in form, though sometimes somewhat elongated tangentially (Fig. 118); the cell-walls may be thin or considerably thickened; generally speaking, the walls are completely suberised (see p. 76), whence the tissue is often termed Cork; the cells gradually lose their protoplasmic contents, and become filled with air ; moreover, no intercellular spaces are formed in the tissue.

In view of its structure, it is clear that the periderm is a tissue 
which offers an obstacle to the passage of water; hence all the tissues, in a stem or root, lying externally to the periderm can receive no supplies of water, and must dry up, and are eventually exfoliated. The more deeply seated the phellogen, tho greater is the amount of primary tissue thrown off; thus, when the phellogen arises in the inner layers of a heterogenous pericycle (see p. 119), as in Berberis, Lonicera, etc., where the outer portion of the pericycle is fibrous, the epidermis, the primary cortex, and the outer portion of the pericycle are exfoliated.

The cells of the periderm are not always completely suberised. In some cases (roots and stems of Onagraceæ, Hypericaceæ, some

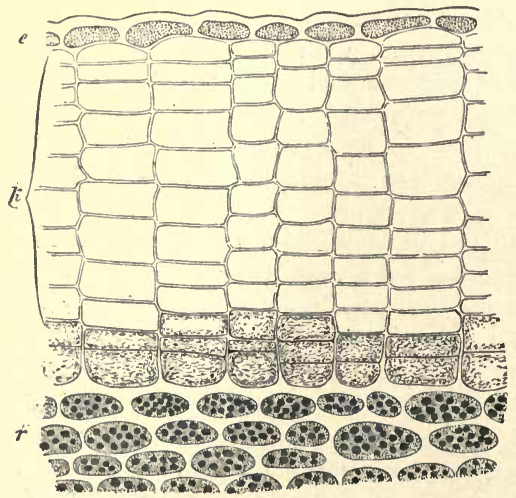

Frg. 118.-Periderm of one-year's shoot of Ailanthus glandulosa (trans. Eect.; $\times 350$ ) : e the dead epidermis; $k$ cork; the inner shaded layers are merismatic, the innermost being the phellogen, those external to it being young periderm cells; $r$ primary cortex.

pact layers of cells with a suberised zone.

When the primary periderm is of superficial origin, it forms for many successive years the external investment of the branch; it may attain considerable thickness, as in the Cork-Oak, and at the same time exhibit an alternation of dense and loose layers (e.g. the Birch, in which the layers may be peeled off in thin white sheets); sometimes (as in Acer campestre and the Cork-Elm) it forms winglike projections from the angles of the branches. In a few trees, as the Silver Fir, the primary periderm persists for some years, or, as 
in the Beech, during the whole life of the tree; the onter cork-cells split off as the trunk of the tree increases in thickness, while the phellogen, growing and extending in a tangential direction, gives rise to new layers of cork. When, as in most cases, new layers of phellogen arise after a few years in the deeper tissues, leading to the development of corresponding layers of periderm, an external investment of a more or less complicated structure comes to be formed. In consequence of the impermeability to water of these secondary layers of periderm, all the tissues lying externally to them become dried up. These dried-up tissues, which may belong to different tissuesystems and include the most various forms of cells, constitute what is known as Bark. When the primary periderm is superficial, the new secondary layers of periderm are only ares of the circumference, and as their margins are in contact with the periderm which has been previously formed (Fig. 119), a scaly bark is formed; that is, isolated patches of tissue are transformed into bark.

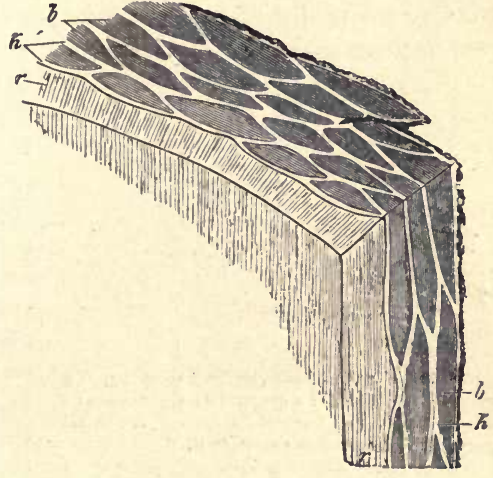

Fig. 119.-Formation of Scaly Bark in a Larch, as seen in a piece of the outer portion of the stem cut both transversely and longitndinally (nat. size); $r$ the secondary cortex; $k$ plates of cork ; $b$ the scales of bark cut off by the cork.

This bark is stretched and torn by the increasing size of the trunk, and the scales of it may be shed, as is the case in the Plane, or they may adhere one upon the other, as in the Pines and Larches, or remain connected by the bast-fibres in long strips as in Robinia. When, on the other hand, the primary periderm has been formed in the deeper layers of the cortex, the secondary periderm often forms complete concentric rings; thus hollow cylinders of the cortex are transformed into bark (ringed bark). The longitudinal rupture of this kind of bark is effected by the bast-fibres enclosed in it (e.g. Vine, Clematis, and Thuja).

There are frequently in the periderm of both stems and roots 
organs corresponding to the stomata of the epidermis, serving, like them, to admit air to the living internal tissues; these are the Lenticels. They are usually circumscribed circular areas of the periderm where the cork-cells formed in the course of the summer are not arranged closely together, but are separated by intercellular spaces. In winter the lenticels are closed by a layer of ordinary periderm. They are most easily detected in branches of one year's growth, where they are to be seen in the summer in the form of brownish or whitish specks. When the periderm of the stem is superficial, the lenticels are developed under the places where the stomata occur in the epidermis, and these spots are commonly the starting-points of the formation of the periderm; but this is not the case in stems with a deep periderm, nor is it ever the case in roots.

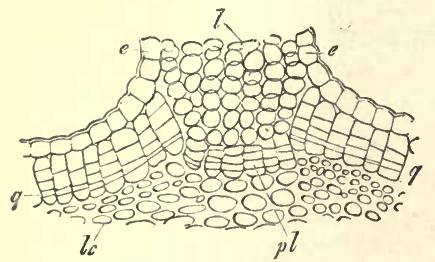

FiG. 120.-Lenticel in the transverse section of a twig of Elder $(\times 300)$ : e epidermis; $q$ phellogen; $l$ cells, and $p l$ the phellogen of the lenticel; lc cortical parenchyma containing chlorophyll.

In many trees, as the Birch, the lenticels become much extended in width by the growth of the branch in circumference. When the periderm is very thick, as in the Cork-Oak, the lenticels form deep canals filled with a pulverulent mass of cells. Sometimes lenticels are not formed; they are not present in the stems of some plants which have a pericyclic phellogen (e.g. Vitis, Clematis, Rubus, Lonicera).

The phelloderm or secondary cortical tissue, the tissue formed internally from the phellogen, consists of cells which have essentially the same structure as those of the primary cortex: the secondary cortex can, however, be distinguished from the primary by the regular radial rows in which, like those of the periderm, its cells are arranged. The cells have protoplasmic cell-contents, and, when developed near the surface of aerial stems, they contain chloroplastids ; their walls are usually thin and consist of cellulose, but, like those of the cells of the primary cortex, they may become more or less thickened and eventually lignified.

Just as the periderm replaces the disorganised epidermis as a tegumentary tissue, so the phelloderm replaces the primary cortex as a nutritive (metabolic) tissue when the primary cortex becomes obliterated under the conditions explained on p. 149. 


\section{$\$ 36$. Formation of Tissue in consequence of Injury.} When the internal tissues of most parts of plants are laid bare by injury, they are gradually covered by a formation of cork taking place in the outermost layer of cells which remain uninjured and capable of growth. This is easily seen in injured fruits, leaves, and herbaceous stems, in which the wounds that have been covered by a layer of cork are distinguished by a grey-brown colour. The process is very easy to observe in potato-tubers, for each portion of living tissue taken from one, if only prevented from drying too quickly, will soon be covered over the whole surface by a layer of cork precisely similar in structure to the ordinary rind. In plants in which the wood is well developed, cork is not immediately formedparticularly when the cambitum is wounded or laid bare -but all the living cells which border on the wound become merismatic and give rise to a homogenous parenchymatous tissue known as the Callus. If the wound is small, the callus-cells proceeding from the different sides soon come into contact and close up into a single mass of tissue, which then gives rise to cork on its outer

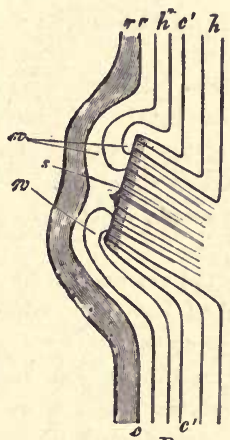

$B$.

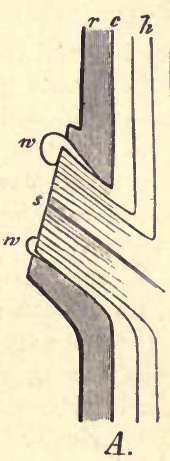

F1G. 121.-Diagrammatic longitudinal section of a woody stem: $A$ a short time after the amputation of a lateral branch $s ; B$ when the wound is completely closed; $r$ cortex; $c$ cambium; $h$ wood; $c^{\prime}$ position of the cambium. layer at the time of amputation; $h^{\prime}$ wood formed since the amputation; $v$ tho cushicn of callus formed over the surface of the wound. surface, and, joining the old cambium at the margins, forms a new layer of cambium which fills up the cavity. If the wound is a large one, cork and new cambium are formed in the callus at the margins of the wound, and it is not wholly closed till after repeated rupture of the approaching cushions of callus. The wood exposed by the wound, which usually assumes a dark colour under the influence of the air, does not grow with that formed from the new cambium of the callus: hence inscriptions, for instance, which are cut in the cortex so as to reach the wood, though subsequently covered by a number of annual layers of wood corresponding to the number of years, 
may easily be found. A similar explanation accounts for the fact that the surfaces of the stumps of cut-off branches become overgrown: the callus first appears as a ring from the cambium exposed in the transverse section, and afterwards closes like a cap over the old wood (Fig. 121). Foreign bodies-nails, stones, and stems of other plants-may thus become enclosed in the wood of a tree and be over-grown by it; the cortex, being forced against the foreign object by the pressure of the growing wood, splits, and the callus formed in the rent grows round the object, enclosing it and producing new cambium.

Stems of plants of the same species will grow together if they are in close contact; the callus formed by the cortex of both, coalesces and gives rise to a common cambium. On this depend the various modes of artificial grafting, in which branches or buds with a portion of the cortex are taken from a variety or an allied species and placed so that their cambium is in contact with that of a stem which serves as the stock, and subsequently they grow together.

In conclusion, the mechanism by which decidnous members (see p. 10). are detached has to be considered: the fall of the foliageleaf may be taken as the illustration. In some cases (e.g. Palms; some Ferns, as in the section Phegopteris; the Oak) the leaves simply wither on the stem, when they are non-articulated, and are gradually destroyed and removed; but in most cases they are thrown off by a vital act before they wither, when they are said to be articulated. The fall of the articulated leaf depends upon the growth and division of all the living cells lying in a transverse layer near its insertion: by this means several $(3-6)$ layers of compact tissue are formed. A median layer of this tissue, the abscission-layer, becomes disorganised, and then the leaf is beld in position only by the vascular tissue which enters it from the stem. This soon breaks under the weight of the lamina, especially if it be agitated by the wind, and the leaf falls. The disorganisation of the median layer is often accelerated by the action of -frost. The scar on the stem (leaf-scar, p. 10) either simply dries up, or a layer of cork is formed over it by the merismatic tissue which remains: in any case the vessels become sealed with mucilage. 


\section{PART III}

\section{PHYSIOLOGY}

§ 37. Introductory. The province of physiology is the study of those phenomena which, taken together, constitute the life of the plant; in other words, whilst morphology is concerned with what plants are, and histology with their structure, physiology deals with what they do. These phenomena may be classified, according to their nature, into functions, or different kinds of physiological work.

The body of the plant, whether it be unicellular or multicellular, is one physiological whole. In the lower and simpler plants the various functions are equally discharged by all parts of the body ; but in more highly-organised plants the functions are distributed among the members and tissues, that is, there is physiological division of labour. In these higher plants each member, and each tissue, is adapted to the performance of one or more functions, and is the organ (p. 1) by which these special kinds of physiological work are done.

The performance of their functions by the organs of the plant is, however, materially affected by various external conditions. For instance, the activity of the assimilatory function of green leaves is altogether dependent upon exposure to light of adequate intensity. Hence the object of physiology is not only to distinguish and study the various functions, and to demonstrate the relation between them and the internal structure and the external form of the organs performing them, but also to determine what are the external conditions by which the performance of the various functions is affected, and the modes in which these conditions exert their influence.

\section{CHAPTER I \\ GENERAL PHYSIOLOGY}

$\S 38$. The Functions. In entering upon the consideration of the vital phenomena of plants, it must be clearly understood that these phenomena all depend upon the living protoplasm; that the 
vital functions are performed by the protoplasm, though the other cell-contents and the cell-walls are not without their physiological importance. With regard to the functions themselves, it is apparent, in the first place, that the outcome of the physiological activity of the plant is the maintenance of itself, and the production of new individuals resembling itself. Hence a distinction may at once be drawn between the nutritive and the reproductive properties of protoplasm. Moreover, during its life, the plant responds, in a more or less marked manner, to the action of external forces, such as light, gravity, etc. This is a manifestation of another property of the protoplasm, namely irritability or sensitiveness. Very commonly the response to the action of the external forces is of the nature of movement; but movements may also be performed spontaneously.

It is clear that nutrition necessarily depends upon the absorption of food from without; hence the plant is capable of performing the function of absorption. From the food absorbed, protoplasm is ultimately formed; the building up of protoplasm out of the food is termed assimilation, and the property by means of which this function is performed is termed the metabolic property of protoplasm. But the metabolic processes going on in the protoplasm are not only such as lead to its maintenance or increase in bulk; on the contrary, the protoplasm is continually undergoing decomposition. It is to be clearly apprehended that there are two sets of chemical processes continually and simultaneously going on in living protoplasm. Of these, which together constitute the metabolism of the plant, one set includes those processes which lead to the formation of more complex substances from simpler ones; the other, those processes which lead to the formation of simpler substances by the decomposition of more complex ones. The former are designated the constructive metabolism, or more shortly the anabolism, of the protoplasm; the latter are designated the destructive metabolism, or the catabolism, of the protoplasm. It must also be clearly understood that these two sets of prosesses affect not only the state of the matter or substance of which the plant consists, but also the state of the energy in the plant; for the anabolism is accompanied by a conversion of kinetic into potential or latent energy; and the catabolism, by a conversion of potential into kinetic energy.

The products of metabolism may be classified as plastic products and waste-products : the former are such as can be further worked up in anabolism; the latter are not so used, but are withdrawn 
from the sphere of the metabolic activity, by being either excreted, or secreted in the insoluble form in special receptacles (see p. 96). Of the products of catabolism, carbon dioxide is the most constant.

There is one property of living plant-cells which is of such fundamental importance, particularly in connexion with movement, that it requires special mention. It is this, that the cells tend to take up such large quantities of water, that a considerable pressure is set up in the cell between the cell-sap, on the one hand, and the elastic cell-wall on the other. This state of tension is known as turgidity or turgescence, and a cell in this state is said to beturgid. The conditions upon which turgidity depends are three: first, the presence of substances in the cell-sap which attract water; second, the presence of a layer of protoplasm lining the cell-wall; third, the presence of an elastic cell-wall. With regard to the first of these conditions, the necessity for it is obvious. It appears that the substances in question are especially the organic acids or acid salts, which are abundantly produced in the metabolism of plants. The significance of the second condition is, that the layer of protoplasm prevents, at least within certain limits, the escape of the cell-sap as the pressure in the cell increases, and it is on this account that a high tension can be attained. Finally, the presence of an elastic cell-wall is a necessary factor, for without resistance there can be no tension.

$\S 39$. The External Conditions. The functions of the plant can only be carried on under a certain coincidence of favourable external conditions. Thus, an ordinary green plant will only flourish when the conditions are such that it is supplied with appropriate food, with water, and with free oxygen for its respiration, and is exposed to a suitable temperature and to sufficiently intense light.

The importance of a supply of food and of water is sufficiently obvious to need no further explanation here. The importance of a supply of oxygen is that without it the normal catabolic processes would either cease, or be so far suppressed that the plant would no longer manifest its vital phenomena; for instance, it would cease to grow, and would eventually die.

Inasmuch as the influence of heat and light is so comprehensive, it may be generally considered now, the detailed consideration of these and other external conditions being relegated to the discussion of the functions which they especially affect. 
HEAT. Every function of the plant can only take place within certain limits of temperature : that is, between a certain minimum and a certain maximum degree. Between these limits there is for each function a degree of temperature, the optimum, at which that function is carried on with the greatest activity; any fall of temperature from this optimum, or any rise above it, leads to a diminished activity of the function. These general laws have been arrived at by observation of such processes as movement, absorption by the roots, assimilation, etc.

It may be stated generally that all the functions of plants inhabiting temperate climates begin to be carried on at a temperature a few degrees above the freezing-point; as the temperature rises to $25^{\circ}-30^{\circ} \mathrm{C}$. the activity of the functions is increased and the optimum attained; with a further rise the activity of the functions is diminished, and at $45^{\circ}-50^{\circ} \mathrm{C}$. they commonly cease altogether. In the case of plants which naturally grow in warmer climates, the minimum-temperature is somewhat higher than that stated above. Thus a pumpkin-seed will not germinate at a temperature below $13^{\circ} \mathrm{C}$.

The power of withstanding the injurious effect of exposure to too high a temperature depends mainly upon the proportion of water which the plant, or any particular part of it, contains. Thus, dry peas can withstand exposure for an hour to any temperature up to $70^{\circ} \mathrm{C}$., whereas, when they have been soaked in water, exposure to a temperature of $54^{\circ} \mathrm{C}$. proves fatal. Most parts of plants are killed by prolonged exposure to a temperature, in air, of about $50^{\circ} \mathrm{C}$, and in water, of about $45^{\circ} \mathrm{C}$.

Injury or death by exposure to cold, is only induced when the temperature falls-in some cases many degrees-below freezingpoint. Some plants - just those, namely, such as Lichens, and some Fungi and Mosses, which can undergo dessication without injury are not killed by exposure to low temperature. Here, also, the liability to injury depends upon the amount of water contained in the tissue. Thus, dry seeds and the winter-buds of trees can readily withstand low temperatures; but when they contain a considerable quantity of water, as when the seeds are germinating or the buds unfolding, they are very susceptible to injury. When a part of a plant, which contains a large proportion of water, is exposed to a low temperature, a portion of the water contained in the cells escapes from them and becomes frozen on their surface, the whole tissue at the same time contracting; the water does not 
freeze in the interior of the cells. The water which has thus escaped and frozen forms an incrustation (Fig. 122), consisting of a number of elongated ice-crystals arranged side by side. This ice is very pure, for the substances in solution in the cell-sap remain behind in a more concentrated form.

The effect on the trunks of trees of exposure to cold is to cause radial splits, which close up again as the temperature rises, the which actually heal only in the cortex. The splitting is due to the unequal contraction of the wood, which is greater in the external more watery portion, than in the interior.

Light. The influence of light may be considered under two heads: (1) the chemical effects, produced for the most part by the less refrangible rays of the spectrum; (2) the mechanical effects, produced mainly by the highly refrangible rays.

The most conspicuous chemical effects are manifested in plants which normally contain chlorophyll. They are :-

\section{a. The formation of chlorophyll:} in Phanerogams the colouring-matter of the chloroplastids cannot acquire its green hue (except in the seedlings of Conifers and some other plants), but remains yellow (etiolin), unless exposed to light of not too great in-

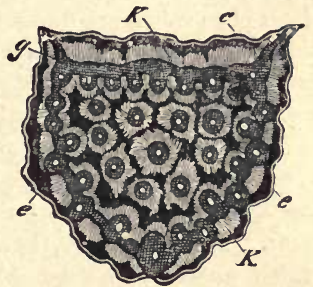

Fie. 122.-Transverse section of a frozen leaf-stalk of Cynara Scolymus : $e$ the detached epidermis; $g$ the paren. chyma in which lie the transverse sections of the vasenlar bundles (left white); $K K$ the incrustation of ice consisting of densely-crowded prisms (the cavities of the ruptured tissue are left black in the figure). tensity. This effect is not confined to the rays of low refrangibility, but is produced (with equal intensity of light) also by those of high refrangibility. The formation of chlorophyll is also dependent on temperature, and will not take place if it be too low; hence the shoots of plants developed in the early spring remain yellow if the weather is cold.

b. The assimilation of carbon dioxide by the chloroplastids will only take place in the presence of light of considerable intensity ; it is especially a function of the rays of low refrangibility, as will be subsequently explained. This is also true of the first steps in the assimilation of mineral nitrogenous food (nitrates).

The most conspicuous mechanical effects, exhibited by plants of all kinds are :- 
a. The paratonic effect. All parts of plants grow more rapidly in feeble than in strong light, as is shown by the excessive length attained by the shoots of plants grown in the dark; hence, light exercises a retarding influence on the rate of growth; it likewise inhibits the spontaneous movements of motile leaves.

b. The phototonic effect. Dorsiventral leaves, when growing, generally cease to grow, and when motile lose the power of movement, if long kept in darkness; but they soon regain the power of growth and of movement on being again exposed to light; this condition of motility induced by light is known as phototonus.

c. The directive effect. The direction of the incident rays of light effects the position of growing and other motile members: these phenomena are designated by the general term heliotropism.

The various influences of light are well illustrated by plants grown in darkness, or etiolated plants. For instance, an etiolated potato-shoot has a stem with excessively long internodes, a result of the absence of the paratonic effect of light; very small leaves, in consequence of the absence of the phototonic effect; no chlorophyll, in consequence of the absence of the chemical action of light. Etiolation can, however, be induced, not only in plants which normally possess chlorophyll, but in others as well; for instance, Fungi grown in darkness exhibit the characteristic excessive elongation. Again, plants grown in light of low refrangibility (yellow or red) show the elongation characteristic of etiolation; chlorophyll is formed, and the leaves are fairly well developed, but there is no heliotropic curvature: grown in light of high refrangibility (blue), the stem is stunted and the leaves very small, though chlorophyll is developed, and heliotropic curvature is well marked; they soon die.

$\S 40$. The Functions of the Tissues. In dealing with this subject, it is important to distinguish between the vital and the physical functions; to distinguish, that is, the functions which depend upon the activity of the living protoplasm, from those which depend upon some chemical or mechanical property of the cell-sap, or of the cell-wall, of the constituent cells. The following remarks apply especially to the higher terrestrial plants.

a. The Tegumentary Tissue (pp. 106, 149), whether primary (epidermis) or secondary (periderm), has as its primary function the mechanical protection of the underlying tissues: but it has the further functions of absorption and of preventing excessive loss of water by transpiration. 
The absorptive function is confined to the primary tegumentary tissue: it is by means of this tissue that absorption is carried on by subterranean roots, either with or without root-hairs (see pp. 109, 110), as also by the general surface of submerged parts of aquatic plants (p. 109).

The prevention of excessive transpiration is effected by the more or less well-marked cuticularisation of the walls of the epidermal and peridermal cells of sub-aerial parts. Since these walls, though more or less pervious to gases, are almost or altogether impervious to watery vapour, the watery vapour evolved in the interior of the plant has to escape through special apertures, namely the stomata and the lenticels: and the transpiration is further regulated (see p. 108) by the opening and closing of the stomata. The importance of the tegumentary tissue in preventing desiccation is directly established by the fact that parts of plauts, deprived of their tegumentary tissue quickly dry up: and indirectly, by the relation between the degree of development of this tissue and the conditions of life of the plant. Thus, this tissue is highly developed in plants which grow in dry situations, whereas in the submerged parts of aquatic plants it is imperfectly differentiated, and there are usually no stomata or lenticels: hence, the more the conditions of life tend to promote transpiration, the more highly-developed is the tegumentary tissue.

b. The Parenchymatous Tissue (see p. 90), consisting as it typically does of cells which contain living protoplasm, is the seat, not only of the metabolic processes, but also of the movements and irritability of plants.

Different nutritive functions are discharged by various regions of this tissue. For instance, the parenchymatous tissue of subaerial parts, lying near the surface and exposed to light, contains chlorophyll, and carries on the assimilation of carbon: this applies especially to the leaves. Again, the cells of this tissue are frequently glandular (see p. 96), containing or excreting various waste-products: or they serve as depositories of reserve plastic substances (e.g. starch, etc.), or as conducting-tissue for organic substances.

Further, the cells of this tissue, having usually extensible walls, are capable of becoming turgid and of varying in bulk : hence they are the seat of the movements of those members, or parts of them, in which movement is a mechanical possibility; and when 
turgid, they give a considerable degree of rigidity to the member of which they form part.

The intercellular spaces (p. 89) of this tissue, which are especially large in submerged parts of aquatic plants, are of great importance in connection with transpiration and the distribution of gases in the plant: they communicate with the interior by means of the stomata and the lenticels.

c. The Sclerenchymatous Tissue (see p. 92), more especially the prosenchymatous or fibrous form of it, has the purely mechanical function of giving firmness to the members in which it is present. Whilst it is true that a considerable degree of rigidity is afforded by turgid parenchymatous tissue, and that many members containing little or no sclerenchymatous tissue can grow erect (e.g. conidiophores of Moulds, and succulent stems of herbaceous annuals), yet this source of rigidity is precarious, as it is so largely dependent upon external conditions, and is therefore insufficient in the case of perennial plants. In these plants rigid tissue (stereom) is developed, and it is distributed in the body in just such a manner as most adequately meets the mechanical requirements in each particular case (p. 120, Fig. 98). Stereom is most perfectly developed in the stems of land-plants which grow erect and have to support the weight of many leaves and branches; whereas in water-plants the development of stereom is rudimentary, for their stems, being supported by the water, do not need to be highly rigid.

When it is developed in the walls of fruits or in the seed-coats, the sclerenchymatous tissue serves to protect the seed from being eaten or digested by animals.

d. The Tracheal Tissue of the Xylem (see p. 93). It is clear that when a plant-body is massive, partly subterranean and partly sub-aerial, there must be some means for readily distributing the water and other substances absorbed by the root. This distribution may take place by diffusion from cell to cell; and, as a matter of fact, this mode of distribution suffices in some plants in which the seat of absorption is not far from that of consumption (e.g. larger Fungi and Algæ). But when these points are widely separated, special conducting-tissue, in the form of the tracheal tissue of the xylem, is differentiated.

The function of this tracheal tissue is demonstrated by the following experiment. If a cut be made all round the stem of a dicotyledonous tree, to such a depth as to penetrate far into the xylem, 
the effect is that the leaves borne on the stem and its branches above the incision, will soon droop and wither. This is due to loss of water, in consequence of which the cells of the leaves lose their turgidity, and the leaf-blades and petioles are no longer sufficiently rigid to maintain their position of expansion." The loss of water is the result of the continuance of transpiration in the absence of a supply of water to meet it. The incision which has destroyed the continuity of the young wood has also cut off the supply of water from the root. The relation between the development of the xylem and the activity of transpiration is well illustrated by the comparison of the vascular bundles of a land-plant with those of an allied submerged aquatic species. The former transpires actively and has well-developed xylem: the latter does not transpire at all, and has quite rudimentary xylem.

Conduction takes place in dicotyledonous tree-trunks only through so much of the peripheral portion of the wood as includes living parenchymatous cells. The thickness of this conducting region varies widely; it is relatively small where the wood is sharply differentiated into alburnum and duramen (see p. 143), and in such trees (e.g. Oak) section of the alburnum is soon followed by the withering of the leaves above the wound; it is more considerable in trees like the Beech, in which the transition from alburnum to duramen is gradual ; and it is most extensive in those, such as Birch and Maple, in which there is no differentiation of alburnum and duramen. The dead portion of the wood does not conduct, but at most only serves as a reservoir of water.

The tracheal tissue of the xylem discharges a purely mechanical function in connexion with the conduction of water; it is incapable of any vital action inasmuch as it contains no protoplasm.

The liquid conducted from the roots to the leaves by the tracheal tissue is not pure water, but holds in solution substances absorbed by the roots from the soil; hence this tissue plays an important part in the distribution of food-materials in the plant.

e. The Sieve-Tissue (see p. 94). The function of the sieve-tubes or phloem-vessels is to convey proteids from the organs in which these substances are deposited or are being formed, to other parts in which they are either being consumed or deposited as reserve plastic material. This is demonstrated by the following experiment:- If a ring of tissue, extending inwards as far as the cambium, be removed from the trunk of a young dicotyledonous tree, the sieve-tubes will all be cut through, and their continuity inter- 
rupted. The effect of this upon the tree is that the portion of the trunk below the wound, and the roots, cease to grow, and slowly die, whereas the trunk and branches above the wound remain bealthy and continue to grow until the roots are no longer able to absorb water, etc., from the soil with sufficient activity. Inasmuch as the cortical tissue, through which the sugar travels, is necessarily also cut through, the operation deprives the lower parts of the body of the whole of their supply of organic plastic material from the leaves, but does not interfere with the conduction of water from the roots to the leaves.

The sieve-tubes differ from the vessels of the xylem in that they contain living protoplasm; their function is therefore probably not purely mechanical, but it is vital, though the relation of the protoplasm to the conduction of proteids in the sieve-tubes is not clear.

The companion-cells, and in their absence the cells of the bastparenchyma, which abut on the sieve-tubes, apparently serve in the leares as the means by which the nitrogenous products of anabolism are brought to the sieve-tubes, and in other parts as the means by which the proteids of the sieve-tubes are distributed to the adjacent tissues; there is some evidence to show that these cells themselves actually carry on the formation of the proteids which form the characteristic contents of the sieve-tubes.

f. The Glandular Tissue (p. 96). The essential function of the glandular tissue is to secrete, and the secreta are either plastic substances or waste-products.

It may be stated generally that the excretion of plastic substances on the surface of plants has special reference to their relation with insects. Thus, the excretion of sugar by floral nectaries is to attract insects to visit the flowers, and thus to ensure the advantages of cross-pollination at a certain, though relatively inconsiderable, cost. The excretion of sugar by extrafloral nectaries is an expense incurred by the plant with the object of attracting to it insects of a kind which will keep off noxious insects or other animals ; these organs are especially characteristic of myrmecophilous (ant-loving) plants, which by this means provide themselves with a police of ants to keep off either other injurious (e.g. leaf-cutting) species of ants, or insects of other kinds (e.g. boring bees, etc.), or even herbivorous mammals.

The secretion of waste-products has, as its immediate object, the removal of these substances from the sphere of metabolism; but 
their deposit at or near the surface serves the purpose of protection in various ways. For instance, the secretion of wax on the surface is an obvious protection against wet. Similarly there can be little doubt that when the system of resin-ducts, in plants which contain them (e.g. most Conifers, etc.), is opened by a wound, the resin serves to protect the raw surface both mechanically and antiseptically; and this doubtless also applies to the latex present in many plants. Further, these waste-products, by their bitter, acrid, or astringent taste, by their frequently poisonous properties (e.g. alkaloids), or by their hardness, serve to protect the plants from being eaten by animals ; for instance, the presence of raphides, or of strongly acid sap, in the cells of leaves, etc., has been proved to protect them against the attacks of snails. The secretion of mucilage by the glandular hairs (colleters) often developed near the growing-points of stems and leaves, serves to keep the young tissues moist.

The special functional importance of the laticiferous tissue is not fully understood. There is no doubt that it is, in the first place, a reservoir of waste-products, since the latex generally consists largely of such substances (e.g. caoutchouc, as in Siphonia elastica; alkaloids, as in the opium of the Poppy, etc.). But the latex has also been found to contain plastic substances, such as proteids and carbohydrates, and in one case (the Papaw) a proteolytic enzyme, and it has hence been inferred that this tissue may serve to conduct plastic substances throughout the plant; but this inference has not been satisfactorily established.

$\S 41$. The Functions of the Members. It has been pointed out (p. 3) that, in its highest development, the plant-body consists of the following members : root, stem, leaf. These members will now be considered from the physiological point of view.

a. The Root. The most general of the functions of the root is that it absorbs the solid food of the plant in solution from the substratum, whatever it may be, on which the plant is growing; and that, at the same time, it acts as an organ of attachment: in submerged plants the latter is its main use.

In some few cases the plant is rootless (p. 44): under these circumstances other members become modified to perform the absorbent function of the root; in Salvinia, the aquatic leaves; in Psilotum, the subterranean shoots. In the "carnivorous" plants (e.g. Drosera, Dionæa, Nepenthes), though they possess roots, the leaves are adapted for the absorption of organic food in solution. 
In a typical land-plant the development of the root-system is such as to ensure an adequate supply of food from the soil, and a supply of water sufficient to maintain the general turgidity of the plant in spite of continued loss of water by transpiration.

The root of such a plant is adapted for the performance of its functions both in its structure and in its properties. The most striking structural adaptation is that the walls of the superficial cells of the younger parts are not cuticularised, but remain per-
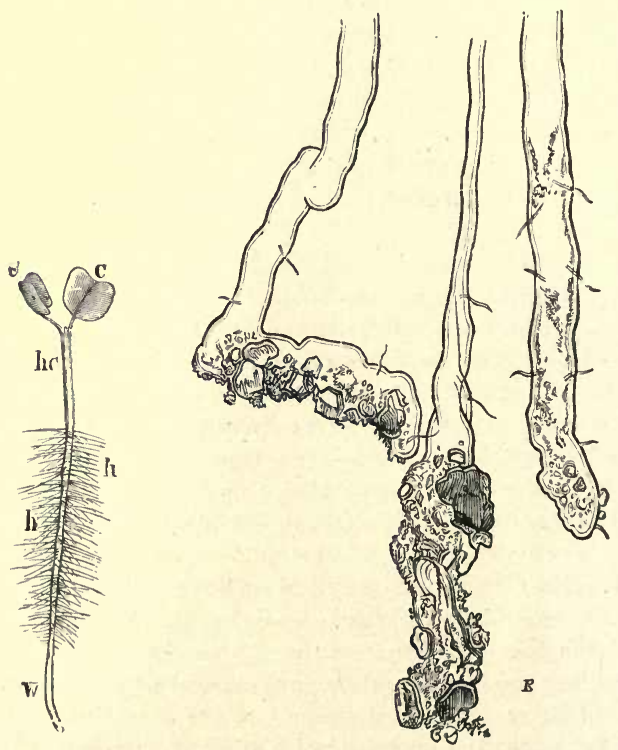

Fir. 123.-A Root-hairs $(h)$ on the primary root $(w)$ of a seedling grown in water; of Bnckwheat (Polygonum Fagopyrum); hc hypocotyl; $c$ cotyledons. B (after Sachs) Ends of root-hairs showing their intimate connexion with particles of soil which adhere to the mucilaginous external layer of the cell.walls.

vious to water. Generally speaking, the absorbent area of the root is increased by branching; and, in many cases, also by the growing-out of the superficial cells of this region into root-hairs (see p. 46). It appears that the development of root-hairs is determined by the difficulty of obtaining water, on the one hand, and by the relative activity of transpiration on the other: thus 
root-hairs are usually not developed by aquatic plants, the roots of which, at least, are habitually immersed in water; nor by plants in which the transpiring surface is relatively small in proportion to the root-system (e.g. small-leaved Conifers; saprophytes, such as Monotropa and Neottia). The root-hairs not only promote the absorption of water, but also the absorption of salts from the soil, coming, as they do, into very intimate relation with the minute particles of the soil. They thus give the root a firmer hold on the soil, and render it more serviceable as an organ of attachment.

In many cases the root becomes adapted to serve as a depository of reserve plastic materials: such are the tuberous roots ( $p .45)$ of various plants, in which secondary growth in thickness (see pp. 140,143 ) produces a large amount of parenchymatous tissue, in the cells of which the plastic substances (starch, etc.) are deposited.

The physiological adaptation of the root is even more remarkable in its properties than in its structure, as is shown by its irritability to the action of various stimuli. Thus the action of the force of gravity causes roots (at least primary roots) to grow towards the centre of the earth (positive geotropism): the action of light, as a rule, causes the growing root to curve away from the source of light (negative heliotropism): a moist body causes the root to curve towards it (positive hydrotropism): contact with hard substances produces curvatures by which the direction of growth of the root is altered.

These various kinds of irritability are of great importance in ensuring the due performance of its functions by the subterranean ront. Positive geotropism causes it to penetrate into the soil, and this is also promoted by negative heliotropism: positive hydrotropism causes it to grow towards the moister parts of the soil, and thus tends to ensure an adequate supply of water. Its sensitiveness to contact enables the root to get round obstacles which it may meet with in the soil.

b. The Stem. The function of the stem is essentially this: to bear the foliage-leaves and the reproductive organs, and to bear them in such a way that they shall occupy the most favourable position for the performance of their respective functions. Further, it is the means of communication between the roots and the leaves. Occasionally it is specially modified to subserve other functions.

It has been already pointed out that the form of the stem varies widely in plants, and the most characteristic forms have been described (p. 27). The general physiological meaning of this variety 
of form is that different plants attain the most favourable position of their foliage-leaves and reproductive organs in different ways which depend upon the particular combination of external conditions under which they severally have existed.

The internal structure of the stem varies to some extent with its general habit, and mainly in the arrangement and relative degree of development of the sclerenchyma ; thus, the sclerenchyma is more largely developed in an erect than in a trailing perennial stem.

There is one point in connexion with the relation of the vascular tissue of the stem to the leaves which require special consideration. It has been pointed out ( $\mathrm{p} .149$ ) that vascular tissue is formed secondarily in the stems (and roots) of most Dicotyledons and Gymnosperms, whereas it is not so formed in those of most Monocotyledons and Vascular Cryptogams. A consideration of the general habit of the plants in question at once affords a clue to this remarkable diversity. In the plants of the former groups, the stem, as a rule, branches considerably, and consequently there is every year an increase in the area of the leaf-surface of the plant; whereas in the plants of the latter groups, the stem branches but little if at all, and the area of leaf-surface remains approximately constant in the adult plant. It is clear that, in the former case, the increase of leaf-surface necessitates an increase in the conducting vascular tissue, a demand which is met by the annual formation of an ever-widening ring of vascular tissue by the cambium. Hence, in a plant of this kind, the vascular bundles in the leaves of any one year are continuous, in the stem, with the new vascular tissue formed in that year by the cambium.

Stems may be specially modified both in external form and internal structure for the performance of special functions. Thus, in leafless plants, in which the stem or its branches have to discharge the functions of the leaf, they may become phylloid; that is, it may assume a flattened, leaf-like appearance (p. 28). The cortical ground-tissue of the stems of such plants resembles the mesophyll of foliage-leaves, not only in that the cells contain chlorophyll-corpuscles in abundance, but also in the more or less complete differentiation of a superficial palisade-layer from a more deeply placed spongy tissue.

Again, stems may be specially modified to serve as depositories of reserve materials (e.g. tubers of potato), or of water (e.g. stems of Cactaceæ), when they are much thickened by the development of a large quantity of parenchymatous ground-tissue, in the cells 
of which the water or the reserve-materials are deposited. Or they may be developed into thorns (p. 27) as a protection against being eaten.

The physiological adaptation of stems is such that the movements which they perform in response to the action of external stimuli are always such as shall place the foliage-leaves and the reproductive organs in the most favourable position. Most stems, for instance, grow away from the centre of the earth (negative geotropism) and towards the light (positive heliotropism); these stems consequently grow up into the air, and take up such a position with regard to the direction of the incident rays of light that the leaves may be adequately exposed to them. Others, again, grow horizontally under the influence of gravity (diageotropism) and of light (diaheliotropism), and in this way spread out their leaves to the sun's rays.

In some cases stems which tend to grow erect into the air are unable to do so in consequence of being insufficiently rigid to maintain their own weight, and that of their leaves, etc. Such stems are enabled to obtain the necessary support by becoming attached to foreign bodies, such as other plants, rocks, etc. This attachment is sometimes purely accidental, as in the case of the hookclimbers, such as the Bramble, where the stem is covered with prickles which become fixed as the swaying shont is blown about by the wind. But in other cases the attachment is the result of the mode of growth of the stem or its branches, in virtue of which they twine round any suitable foreign body with which they may come in contact. In some cases the stem and its branches are sensitive to contact, e.g. Dodder; in others, this sensitiveness is restricted to certain specially modified branches, termed tendrils (see p. 27, e.g. Vitis, Passiflora), and it is possessed by them in a very high degree.

c. The Leaf. In the discussion of the morphology of the leaf it was pointed out that the forms of leaves are very varions; so much so that it was necessary to classify them into a number of categories. Each of these will now be briefly considered with regard to its functions.

(1) Foliage-leaves. It may be stated generally with reference to land-plants that the two great functions subserved by the leaf are, first, the construction of organic substance from the raw materials of the food ; and second, the exhalation of watery vapour, or transpiration. 
The internal structure of the leaf is in direct relation to these two functions (see p. 114). The particular significance of the form and arrangement of the cells of the mesophyll is made clear by the following considerations. The palisade-layers occur always, beneath the epidermis, at those surfaces which are directly exposed to the sun's rays. Further, if a plant which, when grown exposed to sunlight, has well-marked palisade-layers in its leaves, be grown in the shade, it will be found that the palisade-layers are imperfectly differentiated, even if they can be detected at all. The development of the palisade-layers is clearly a peculiarity of leaves which are exposed to sunlight. One explanation is this, that bright light not only promotes the assimilatory function, but also promotes the oxidation and decomposition of the chlorophyll. The palisade-tissue affords a means of protection from the latter effect. When a leaf-surface is exposed to diffuse daylight, the position of
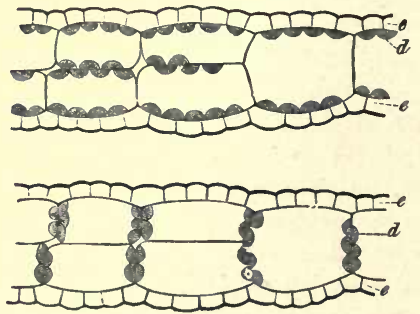

Fig. 124.-(After Stabl). Sections of the thalloid stem of Lemna trisulca, illnstrating epistrophe and apostrophe of the chloroplastids: $\boldsymbol{A}$ position in diffuse daylight (epistrophe); $\boldsymbol{B}$ position in intense sunlight (apostrophe). the chlorophyll-corpuscles in the palisade-cells is such 4 as to expose them as fully as possible to the light; they are disposed on the surface-walls, both upper and lower, of the palisadecells (epistrophe). When, however, diffuse daylight is replaced by direct sunlight, the position of the corpuscles is changed (see Fig. 124) so that their margin, and not their surface, is presented to the sun's rays ; they are removed to the lateral walls and towards the inner end of the cell (apostrophe). It is clear that the elongated form of the cells facilitates this withdrawal of the corpuscles from too intense light, to light of a degree of intensity which promotes the assimilatory function to the utmost extent compatible with a due economy of the chlorophyll.

The spongy portion of the mesophyll is the tissue especially adapted to the transpiratory function. By means of the large intercellular spaces which form a system of channels throughout this tissue communicating with the external air by means of the stomata, a very large cell-surface, from which transpiration can 
readily take place, is brought into direct relation with the external air. Transpiration takes place from the cells of the spongy mesophyll into the intercellular spaces, and the watery vapour then escapes from the leaf by the stomata.

Leaves are adapted not only structurally, but also by their irritabilities, to the performances of their functions. They are sensitive to the directive action of light and of gravity and, in the course of their growth they take up a definite position termed, on account of the predominating influence of light in determining it, the fixed light-position. The response of the dorsiventral leaf to the directive action of gravity, is generally one of diageotropism, that is it places its blade horizontally, with the ventral surface uppermost; and similarly, its response to light is to expose the upper surface of its blade at right angles to the direction of the incident rays (diaheliotropism). The response of the isobilateral and of the radial leaf to the action of gravity is one of negative geotropism, so that they grow erect; and to light, one of positive heliotropism, as they tend to direct their apices towards the source of light.

Changes in the external conditions act as stimuli, which, in many cases, induce a movement of the foliage-leaves involving change of position: most
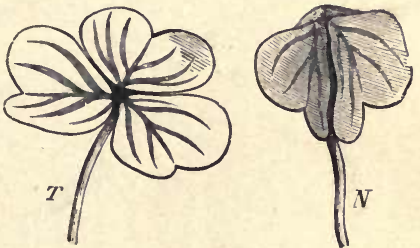

F1G. 125.-Leaf of Oxalis by day $(T)$ and by night (N). In the latter, each leaflet is folded inwards at right angles along its midrib, and is also bent downwards. frequently these movements are performed by growing leaves, but also sometimes by adult leaves with a permanent motile mechanism. They have been observed in the growing leaves (and cotyledons) of many plants (e.g. Chenopodium, Impatiens, Polygonum, Linum, etc.), and in the adult leaves of many Oxalidaceæ and Leguminosæ. The common feature of these movements is that they serve to vary the area of surface presented to the sky by the leaf. They are commonly known as "sleep-movements," or nyctitropic movements, because they are usually associated with the alternation of day and night. With a falling temperature and a diminishing intensity of light the leaves assume the "night-position," presenting a diminished surface, generally only the edge, to the zenith, the leaflets of compound 
leaves at the same time approaching each other, with the result that they are protected from injury by cold in consequence of excessive radiation of heat: with a rising temperature and an increasing intensity of light, the leaves assume the "day-position," presenting their upper surfaces to the zenith. But the day-position is frequently liable to modification, with a view to the reduction of transpiration and to the protection of the chlorophyll from the action of too intense light, by movements which diminish the leafarea exposed to the direct rays of the sun;-and so, in some cases, the edge, and not the upper surface, is presented to the sun: these movements are designated "diurnal sleep" or paraheliotropism.

Some foliage-leaves, but only such as have a special motile mechanism, respond by movement to the stimulus of a touch.

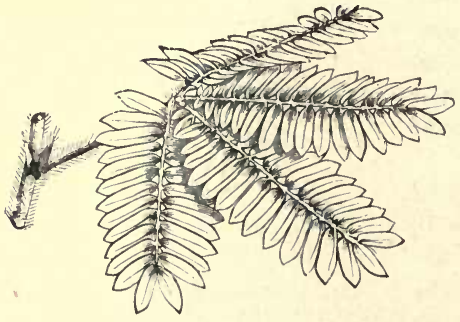

A

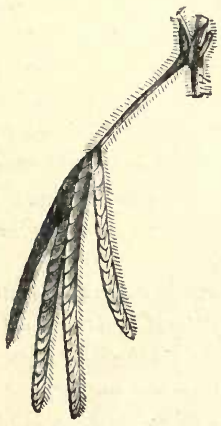

$B$

Frg. 126 (after Duchartre).-Leaves of Mimosa pudica: A normal diurnal position ; $B$ position assumed on stimulation.

This is the case in the "sensitive plants," such as Mimosa pudica and some other species: the leaflets of the pinnate leaves of these plants close together when touched, or when the plant is shaken, and they are thus protected to some extent from injury by hail, rain, or even wind. Other instances of movement in response to touch are afforded by the "carnivorous" genera, Dionæa and Aldrovanda, in which, when an insect alights on the upper surface of the expanded leaf and touches the sensitive hairs, the two lateral halves of the blade suddenly close together, like a hinge, with the midrib as the axis.

Sensitiveness to loug-continued contact is manifested by the 
petioles of various plants (e.g. Tropæolum, Clematis); sometimes by the whole phyllopodium (Lygodium); in many cases leaves possessing this sensitiveness are modified into leaf-tendrils (see p. 41 ; as in Cucurbitaceæ, etc.); leaves of this kind serve as organs of attachment for climbing.

Foliage-leaves are sometimes modified into pitchers or ascidia (p. 41): these serve the purpose in some cases (e.g. Nepenthes) of capturing insects and of digesting and absorbing them: in other cases (e.g. Dischidia) they collect water and organic detritus; in Dischidia adventitious roots are developed, which lie in the pitchers and absorb water, together with dissolved substances, therefrom.

Leaf-spines, like stem-thorns, appear to be exclusively protective against the attacks of herbivorous animals.

(2) Cataphyllury or Scaly Leaves (p. 42) serve to protect growing-points and young leaves of buds, and in this they are assisted by the secretinghairs (colleters, p. 101) which they frequently bear: they sometimes serve as depositories of reserve plastic materials (e.g. scales of Onion-bulb).

(3) Floral Leaves.

a. Hypsophyllary Leaves. The leaves included under this

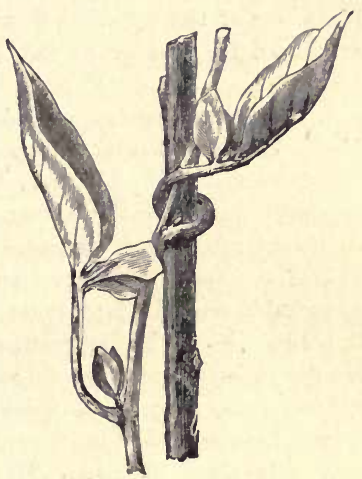

FIG. 127 (after Darwin).-Petiole of Solanum jasminoides clasping a stick. head are the bracts (and bracteoles) and the perianth-leaves (p. 57).

When green, the bracts perform the ordinary functions of foliageleaves; but when they are collected around a flower (epicalyx) or an inflorescence (e.g. involucre of Compositæ, Euphorbia, etc.) they serve to protect the floral organs during their development. When highly-coloured (e.g. in Araceæ, Euphorbiaceæ, Nyctaginaceæ), they serve to attract insects to visit the otherwise inconspicuous flowers.

The sepals, like the bracts, are commonly green, and then they perform the ordinary functions of foliage-leaves, and also serve to protect the other floral organs: when petaloid (e.g. many Ranun- 
culaceæ and Liliales), they attract insects for the purpose of crosspollination.

The petals are brightly-coloured in most flowers, and it is their special function to attract insects. Not uncommonly they are specially modified as nectaries (c.g. Helleborus), and thus further contribute to ensure the visits of insects.

The perianth-leaves (and sometimes also the bracts), are often capable of performing movements leading to the opening and closing of the flower or inflorescence: thus the flowers of the Crocus, Tulip, and Poppy, and the inflorescence of the Daisy, open under the influence of rising temperature and increasing intensity of light, closing under the contrary conditions: the closing is a protection of the essential floral organs against cold and wet; it is essentially similar to the nyctitropic movements of foliageleaves.

b. Sporophyllary Leaves. As already stated (p. 55) the "sporophylls are the essential organs of the flower, when they are aggregated on a special shoot, and have, in any case, the function of asexually producing the spores. They are more or less generally modified in form and structure in connexion with this function; and in the many different forms of flowers these leaves present remarkable special adaptations which mainly refer to the process of pollination, to the distribution of the seed, etc. It is impossible to enter upon a further consideration of the biology of the flower, but the phenomena of movement presented by the essential floral organs deserve special mention. Thus the two lobes of the stigma (e.g. Mimulus, Bignonia, Martynia), close together on being touched: the movement doubtless ensures the adhesion of the pollen brought by an insect. The stamens are irritable in many plants. For instance, in Berberis, when an insect touches the irritable base of one of the nearly horizontal stamens, the stamen rises up on its point of attachment as on a hinge, and strikes the insect with the anther, thus dusting it with pollen. Again, the syngenesious stamens of Centaurea shorten on stimulation by touch: the flower is protandrous; consequently, as the filaments contract, the pollen shed by the coherent anthers is pushed out of the open end of the anther-tube by the style within, and is removed by the insect. 


\section{CHAPTER II.}

\section{SPECIAL PHYSIOLOGY OF THE NUTRITHE FUNCTIONS.}

$\S 42$. Absorption. The food of plants is absorbed, generally speaking, either from the soil or from the air.

- Plants which do not possess chlorophyll (e.g. Fungi) usually obtain the whole of their food from the soil; whereas plants which do possess chlorophyll absorb from the air one of the most important constituents of their food, namely carbon dioxide, though in exceptional cases it is obtained from other sources; for instance, parasitic plants absorb their food from the hosts upon which they live, and the "insectivorous" plants absorb a portion, at least, of their food, from the insects which are caught by their specially adapted leaves. Submerged aquatic plants absorb their food entirely or mainly from the water in which they live.

The food of plants is always absorbed in the fluid form; either as a liquid or as a gas. The liquid food, consisting of a watery solution of various substances, is absorbed from the soil most commonly by the roots, or, in the absence of roots, by other members (shoots, leaves) which have become specially adapted for the performance of this function; the gaseous food $\left(\mathrm{CO}_{2}\right)$ is absorbed from the air by the green parts of plants, and, in the more highly differentiated forms, more especially by the leaves. It not infrequently happens that chemical elements are found in plants which are known to be present in the soil in the form of compounds which are insoluble in water. These compounds are brought into solution by various means. For instance, the soil usually contains carbon dioxide, which is evolved from the decomposing animal or vegetable matter which is commonly present, and from the absorbent organs themselves; and it is well known that various substances, such as calcium carbonate and certain silicates, which are insoluble in pure water, are soluble in water charged with carbon dioxide. Again, the sap which fills the vacuoles and saturates the walls of roothairs, has an acid reaction, due to the presence of organic acid, and this acid sap will dissolve many substances which are insoluble in pure water. The solvent effect of this acid sap is well demonstrated by means of the familiar experiment with a slab of marble. If a highly-polished slab.of marble be fixed in the bottom of a flower- 
pot, and a plant be grown in the soil above it, the roots will come into contact with the slab and will apply themselves to its surface. On subsequently examining the slab of marble, it will be found to have become corroded where the roots had been in contact with it. The corrosion is due to the solution, by the acid sap of the roots, of particles of the marble.

Absorption of Liquids. The main idea connected with this function is the taking up of water and other substances into the plant from without; but it must not be overlooked that, in a multicellular plant, the cells absorb from each other.

In any case, the function of absorption depends upon the physical process of diffusion through membrane of substances in solution, or osmosis. For instance, supposing two adjacent cells, one of which has its cell-sap charged with sugar, whereas that of the other has none; the sugar will diffuse through the intervening cell-wall until the sap in both cells holds the same proportion in solution. This being the mode of absorption, it is clear that the food-materials can only be absorbed in the fluid form, either as liquids or gases.

So far the function of absorption would appear to be a simply physical process. It must, however, bo borne in mind that the cell-wall is lined by living protoplasm which modifies the purely physical diffusion through the cell-wall, both as regards the nature and the relative quantity of the substances which pass into or out of the cell ; so that the physical laws of osmosis, as determined by experiments with dead membrane, are not directly applicable to the osmotic phenomena of a living cell.

Absorption of Gases. The absorption of gases depends, like the absorption of water and substances in solution, upon diffusion. Supposing an absorbent cell, the sap of which holds, to begin with, no gases in solution, to be brought into relation with a mixture of gases, these gases will be dissolved at the surface in proportion to their solubility and to the amount of each gas present in the mixture ; that is, the amount absorbed of each gas depends, in the first instance, upon its solubility and its partial pressure. The relative amount of each gas absorbed over a period of time will further depend upon the extent to which it undergoes chemical alteration after absorption.

Land-plants absorb gases, in the manner described above, at all points of their surface; by their shoots from the air, by their roots from the gaseous mixture in the interstices of the soil; the stomata 
of the sub-aerial parts are of great importance in connexion with this process. Submerged water-plants absorb, in solution, the gases dissolved in the water.

The absorbed gases remain in solution in the cell-sap, so that living cells do not contain bubbles of gases. Moreover, gases travel in the plant mainly by diffusion from cell to cell, though their distribution may also be effected by means of the intercellular spaces.

§ 43. Transpiration. Every part of a plant which is exposed to the air, except such as are covered by a thick layer of cork, is continually exhaling watery vapour. This may be demonstrated by placing a leafy branch under a cold bell-glass, when it will shortly be observed that the internal surface becomes covered with drops of water, the watery vapour exhaled by the branch having condensed upon the cold glass. Again, the drooping of cut flowers or herbaceous branches is due to the loss of water by transpiration.

It must be clearly understood that transpiration is not simply evaporation. If it were so, then clearly equal amounts of water should be evaporated in a given time by equal areas of watersurface and of living plant-surface. But this is not the case. All observations show that the amount of water transpired from a given area of living plant-surface in a given time, is only a small fraction of that evaporated in the same time from an equal surface of water. On the other hand, the evaporation from dead plantsurface is as active, or even more so, than from a free surface of water. Transpiration, whilst ultimately depending upon the purely physical process of evaporation, is essentially evaporation modified by the living substance, protoplasm, from and through which it takes place, and is therefore a vital function.

Inasmuch as most aerial leaves and stems have a more or less well-developed and cuticularised tegumentary tissue, the transpiration from the external surface is insignificant. In such cases the transpiration takes place mainly through the thin uncuticularised walls of the cells of the ground-tissue into the intercellular spaces, and the watery vapour escapes from the intercellular spaces into the external air by means of the stomata and the lenticels. The stomata, especially, are organs for the regulation of transpiration. As already mentioned (p. 163), the stomata open and close, their opening and closing being dependent upon variations in the turgidity (p. 159) of the guard-cells. When the guard-cells are highly 
turgid, that is, when they are tensely filled with cell-sap, they curve so as to separate from each other in the middle line, thus opening the stoma; when they are flaccid, their free surfaces are brought into contact, and the stoma is closed. The opening or closing of the stomata is a function of transpiration as affected by the hygrometric condition of the air, and by the supply of water in the plant: so that when the transpiration is normal, as determined by a certain relation existing between the hygrometric condition of the air and the supply of water to the transpiring leaf, the stomata are open; but when transpiration becomes excessive, by the air becoming drier, or by a diminution in the supply of water to the leaf, the stomata close, even before any trace of flagging is shown by the leaf. Thus the stomata act as regulators of transpiration, and their opening or closing depends partly on external and partly on internal conditions.

The water lost by transpiration is supplied to the transpiring organs from the roots. If the loss by transpiration is compensated by the absorbent activity of the roots, the transpiring organs remain fresh and turgid. But if, as is frequently the case on a hot summer day, the loss of water by transpiration is greater than the supply from the roots, the transpiring organs, more especially the leaves, become flaccid and droop, and they are only restored to the turgid condition in the evening when the temperature of the air falls and the intensity of the light diminishes; in a word, when the external conditions become such as to lead to a dininution of the transpiration.

There is, however, besides the flaccidity of the herbaceous members of the plant, another means of observing the effect of transpiration upon the amount of water contained in the tissues. If the stem, or a branch, of an actively transpiring plant be cut through under mercury or some other liquid, it will be observed that the liquid will at once make its way for a considerable distance into the woody tissue of the cut stem or branch. This is due to the fact that, in consequence of the withdrawal of water from them, the gases in the vessels are at a lower pressure than that of the atmosphere. This is termed the negative pressure in the vascular tissue.

These various points can be readily observed in low-growing plants, such as the Cabbage. On a hot summer day the leaves become flaccid, and the existence of a negative pressure in the vessels of the stem can be ascertained. In the evening, when the 
activity of transpiration is diminished, but active absorption of water from the warm soil by the roots continues, the leaves become turgid, and water gradually accumulates in the vascular tissue. During the night this accumulation of water in the vascular tissue goes on until it becomes quite full, so that there comes to be not only no negative pressure, but a positive pressure. This positive pressure, were there no means of relieving it, might become injurious to the tissues; but it is relieved by the filtering of drops out of the closed terminations of the vascular bundles in the leaves, these drops making their way to the surface through openings over the ends of the bundles, which are either the ordinary stomata, or the specially-modified water-stomata (p. 108). A row of such drops on the margin of the leaves may be observed in many plants in the early morning. It appears, then, that during the day the loss of water by transpiration is greater than the supply by absorption, whereas during the night the contrary is the case.

With regard to the physiological significance of transpiration, it is important in that it causes a rapid current of liquid, the transpiration-current, to flow through the plant from the roots to the transpiring organs, more especially the leaves. This ensures the distribution, not only of the absorbed water, but also of the substances absorbed in solution from the soil. It will be noticed that the conditions which promote transpiration, namely, light and warmth, are just those which are most favourable to the performance of their anabolic processes by the organs which contain chlorophyll. Thus, when the leaves are actively producing organic substance, they are actively transpiring, and they are therefore constantly receiving supplies of the substances absorbed from the soil, substances some at least of which are essential to the chemical processes in operation. Transpiration has, then, an important bearing upon nutrition. There seems to be, in fact, an optimum activity of transpiration, that is to say, a certain activity of transpiration which promotes to the utmost the formation of organic substance; so that if the average activity of transpiration falls short of, or exceeds, this optimum, the nutrition of the plant suffers, as shown by a diminished formation of organic substance.

- 44. Distribution of Water and other Substances. It is clear that, when the plant-body is so far differentiated that only certain parts of it are in a position to absorb water and substances 
in solution from without, there must be a distribution of the absorbed substances from the absorbent surfaces to the other parts. Further, when the plant-body is differentiated into parts which do, and others which do not, contain chlorophyll, there must be a distribution of the produced organic substance from the former to the latter. In plants of relatively low organisation, the distribution takes place entirely by diffusion through the cell-walls, that is by osmosis, when the plant is multicellular: and even in the highest plants diffusion plays an important part.

With regard to the distribution of water and substances absorbed in solution from without in the more highly organised plants there is a special conducting tissue, the wood or xylem of the vascular bundles, extending from the roots, the absorbent organs, to the leaves, the transpiring organs (see p. 164.)

The Root-Pressure. The existence of the root-pressure can be easily ascertained. It is manifested spontaneously by that exudation of drops on the margin of the leaves of low-growing plants during the night, to which allusion has already been made (p. 180). An artificial manifestation of it is induced in stems which are cut across at a time when, owing to active absorption and feeble transpiration, the plants are rich in water; drops exude from the xylem-vessels at the cut surface of that part of a stem which is still in connexion with the root. A familiar case of this is the "bleeding" of certain shrubs and trees when pruned in the spring. It is possible, in this way, to estimate both the activity and the force of the root-pressure. By collecting the water which exudes from the cut surface of the stem, the amount of water absorbed by the root in a given time is determined; and by attaching a mercurial manometer to the cut surface of the stem the force of the root-pressure can be measured. For instance, 3,025 cubic millimetres of liquid were collected from a Stinging Nettle in 99 hours; and the root-pressure required a column of mercury 354 millimetres in height to counterbalance it: in other words, the root-pressure of the Nettle was nearly half an atmosphere, and was capable of supporting a column of water about 15 feet high.

The essential point in the mechanism of the root-pressure is the forcing of liquid by filtration under pressure from the parenchymatous cells into the xylem. The process is probably to be explained somewhat in this way. When a certain degree of turgidity is attained in the parenchymatous cells abutting on the 
xylem, their protoplasm undergoes a molecular change, in consequence of which it becomes permeable and ceases to offer resistance to the escape of the cell-sap; consequently, under the elastic contraction of the distended cell-walls, a portion of the cell-sap is forced out of the cell into the vascular tissue. From this point of view, the root-pressure of a plant is simply the expression of the force of the elastic contraction of the cell-walls of the parenchymatous cells abutting on the xylem-bundles in the root.

With regard to the external conditions which affect the rootpressure, the most important is the temperature of the soil; a rise of temperature up to the optimnm increases the root-pressure, but any further rise causes it to diminish, and if the soil be heated so as to kill the roots, the root-pressure altogether disappears.

The liquid forced into the tracheal tissue is by no means pure water; it holds various substances in solution, such as mineral salts absorbed from the soil; in the spring it is relatively rich in organic substances, such as proteids, sugar, acids, colouringmatters, etc., derived from the reserves stored in the parenchymatous cells of the root, which are being conveyed to the opening buds.

The Transpiration-Current. The mechanism by which, after the liquid has been forced into the xylem of the root, a sufficient current is maintained through the stem of a lofty tree to supply the actively transpiring leaves, is still one of the incompletely solved problems of physiology.

It might be assumed that the transpiration-current is maintained simply by the root-pressure. There is no doubt that, in low-growing plants (see p. 180), the root-pressure is sufficient to force liquid to all parts of the plant; and this is probably trne also of lofty trees. The objection is that no root-pressure can be detected in any plant at the time when transpiration is active, when, on the contrary, there is negative pressure (p. 180) in the vessels. Moreover, a transpiration-current is maintained for a time by entire plants whose roots have been killed hy heat, as also by cut-off shoots.

The present position of the question as to the mechanism of the transpiration-current in lofty trees, may be stated as follows. In the spring the wood is full of water forced into it by root-pressure. When the leaves unfold and begin to transpire, water is gradually withdrawn from the conducting tracheal tissue, and the tissue is 
at any rate for the most part, occupied by a system of short columns of water with intervening gas-bubbles, the columns of water being in communication by delicate films along the cellwalls. If the whole of the tracheal tissue be in this state, it is suggested that as water is withdrawn from the upper part of the wood by the transpiration of the leaves, a current is set up, the water travelling along the cell-walls, between them and the gasbubbles. But it may be that a continuous system of tracheids completely filled with water is maintained, and that it is through this that the current travels. The conducting-tissue is supplied with water, in the first instance, from that which fills the nonconducting tissue of the wood (and the old wood or duramen, if present), and ultimately by the root. It may be thought that the suction due to transpiration would be incapable of maintaining the current; but this difficulty is met by the consideration that the water is held in position by the capillarity and the cellular structure of the tracheidal tissue, and that the system of columns of water and gas-bubbles does not move as a whole, since the latter cannot pass the pit-membranes of tracheids. Moreover the force of transpiratory suction is considerable, though it has not been accurately measured.

The Distribution of Organic Plastic Substances. These substances may be generally stated to consist of organic substances of two kinds, nitrogenous and non-nitrogenous, and these are distributed through different channels.

1. The nitrogenous substances travel, in plants or in parts of plants which are not supplied with vascular tissue, in the form of amides (see p. 186) by osmosis from cell to cell. But in vascular plants it is known that they also travel in the sievetissue from one member of the plant to another, in the form of indiffusible proteids. There is no evidence that the very slow movement of the contents of the sieve-tubes is effected by any special mechanism; it appears to be simply induced by the demand for these substances at any point, and it is doubtless promoted by the swaying of the stem and branches.

2. The non-nitrogenous substances travel through the plant in the form of glucose and maltose (see p. 187), in solution; they travel by diffusion from cell to cell, and more especially in the elongated parenchymatous cells, forming the conducting-sheath, which, in the leaf, consists of mesophyll-cells closely investing the vascular bundles, and, in the stem, belong to the inner cortex. 
This layer is not the endodermis, but lies externally to it; the endodermis frequently contains starch-grains, and is sometimes termed the starch-sheath, but it is rather a depository than a conducting-tissue.

The direction in which organic substances travel in the plant seems to be determined simply by the demand for them. Just as the water and the substances in solution absorbed by the roots travel to the transpiring and assimilating organs, so the organic substances produced in the assimilating organs travel in the plant to those parts in which organic substance is either being used in growth, or is being stored up as reserve material. In a Potato-plant, for example, part of the organic substance formed in the leaves travels to the growing-points of the roots and of the shoots, where it is required for the development of new leaves, flowers, branches, etc., whilst the residue travels to the underground shoots which are developing into tubers and are storing up quantities of starch. Similarly, these organic substances travel apparently by the same channels and in the form of the same chemical compounds, from organs which serve as depositories of reserve material, when these stores are drawn upon to supply the growth of developing parts. For instance, when a' Potato-tuber begins to sprout, the starch, which is the principal reserve material, is drawn upon, being gradually converted into sugar, in which form it travels to the growing-points of the young shoots and supplies a large proportion of the plastic material necessary for their growth.

§ 45. Metabolism. This subject will be subdivided into: 1, Chemical Composition; 2, Food of Plants ; 3, Anabolism ; 4, Catabolism ; 5 , Products of Metabolism.

1. Chemical Composition. As a preliminary, a general account of the chemical composition of plants will be given.

All parts of living plants contain a considerable quantity of water: this forms not merely the principal constituent of the cellsap, but also saturates the cell-walls, the protoplasm, in short, all organised structures; it is, in fact, one of the peculiarities of organised structures that minute particles of water are interposed between the particles of solid matter of which they consist. By heating to $100^{\circ}$ or $110^{\circ} \mathrm{C}$., all the water contained in any part of a plant is expelled, and in consequence it will naturally lose weight. The amount of this loss, that is, the quantity of contained water, is very different in various plants; ripe seeds dried in the 
air contain from 12 to 15 per cent. of water, herbaceous plants 60 to 80 per cent., and many water-plants and Fungi as much as 95 per cent. of their whole weight.

The residue, which gives off no more water at a heat of $100^{\circ} \mathrm{C}$., the dry solid, consists of a great variety of chemical compounds ; these are partly organic, that is to say, combinations of carbon with other elements, and partly inorganic. The organic substances which occur in the living plant (with the exception of salts of oxalic acid) all contain hydrogen. Some of them, such as many oils, consist of these two elements only (carbon and hydrogen), but by far the greater number, including cellulose, starch, and sugar, as well as the vegetable acids and certain oils, contain oxygen also. The proteid substances consist of carbon, hydrogen, oxygen, nitrogen, sulphur, and sometimes phosphorus; in other bodies which contain nitrogen, as asparagin and many alkaloids, there is no sulphur or phosphorus; from certain other alkaloids, for instance nicotin, oxygen is also absent.

The commoner organic substances of which the plant-body consists may, in the first instance, be divided into those which do and those which do not contain nitrogen in their molecule.

The most important nitrogenous substances may be classified as follows :-

1. Proteids: these are substances with a large molecule of complex constitution, to which no chemical formula has yet been assigned; they may be soluble or insoluble in water, and when soluble are mostly indiffusible; they are generally of a viscid nature (like white of egg) and are rareìy crystallisable.

2. Amides (or Amido-acids): these substances are soluble in water, not coagulated on boiling, diffusible, and crystallisable. Those commonly occurring in plants are Asparagin $\left(\mathrm{C}_{4} \mathrm{H}_{8} \mathrm{~N}_{2} \mathrm{O}_{3}\right)$, Leucin $\left(\mathrm{C}_{12} \mathrm{H}_{26} \mathrm{~N}_{2} \mathrm{O}_{4}\right)$, Tyrosin $\left(\mathrm{C}_{9} \mathrm{H}_{11} \mathrm{NO}_{3}\right)$.

3. Alkaloids: these substances are, chemically, organic bases, occurring in plants in combination with organic acids; they are insoluble or but slightly soluble in water, soluble in alcohol; most of them are solid at ordinary temperatures, and arecrystalline, whilst others are liquid (Coniin, Nicotin); they are generally poisonous.

The more familiar alkaloids are Coniin $\left(\mathrm{C}_{8} \mathrm{H}_{15} \mathrm{~N}\right)$ from Conium; Nicotin $\left(\mathrm{C}_{10} \mathrm{H}_{14} \mathrm{~N}_{2}\right)$ from Tobacco; Morphin $\left(\mathrm{C}_{17} \mathrm{H}_{19} \mathrm{NO}_{3}\right)$, and other opium-alkaloids from the Poppy ; Strychnin $\left(\mathrm{C}_{21} \mathrm{H}_{22} \mathrm{~N}_{2} \mathrm{O}_{2}\right)$ from Stryclenos Nux vomica; Quinin $\left(\mathrm{C}_{20} \mathrm{H}_{24} \mathrm{~N}_{2} \mathrm{O}_{2}\right)$ from the Cinchona; 'Thein $\left(\mathrm{C}_{8} \mathrm{H}_{10} \mathrm{~N}_{4} \mathrm{O}_{2}\right)$ from Tea; Theobromin $\left(\mathrm{C}_{7} \mathrm{H}_{8} \mathrm{~N}_{4} \mathrm{O}_{2}\right)$ from Theobroma Cacao.

Some colouring-matters are also nitrogenous (e.g. chlorophyll, and indigo $\mathrm{C}_{8} \mathrm{H}_{5} \mathrm{NO}$ ), as also some glucosides (see below).

The principal non-nitrogenous substances are :-

1. Carbohydrates: substances consisting of $\mathrm{C}, \mathrm{H}$, and $\mathrm{O}$, the $\mathrm{H}$ and $\mathrm{O}$ be- 
ing present in the same proportions as in water $\left(\mathrm{H}_{2} \mathrm{O}\right)$; of these there are the following classes :

a. Amyloses: general formula $n\left(\mathrm{C}_{6} \mathrm{H}_{10} \mathrm{O}_{5}\right)$; of these cellulose and starch are the most common, the former entering largely into the composition of cell-walls, the latter occurring as a reserve material in the form of 1. starch-grains; they are neither of them soluble in water under ordinary circumstances : dextrin or amylin, a product of the action of diastase on starch, is soluble in water but not crystallisable: inulin (see p. 83) occurs in many Compositæ and allied orders (Campanulaceæ, Lobeliaceæ) in solution in the cell-sap; it is slightly soluble in cold water and is crystallisable. The gums and mucilages also belong to this group.

b. Sucroses: $\mathrm{C}_{12} \mathrm{H}_{22} \mathrm{O}_{11}$ : soluble in water and crystallisable: cane-sugar occurs in many plants (esp. Sugar-cane and Beet-root); maltose is the chief product of the action of diastase on starch.

c. Glucoser : $\mathrm{C}_{6} \mathrm{H}_{12} \mathrm{O}_{6}$ : soluble in water and crystallisable: they occur in fruits (grape-sugar).

The sucroses and glucoses are commonly known as sugars.

A substance termed Mannite $\left(\mathrm{C}_{6} \mathrm{H}_{14} \mathrm{O}_{6}\right)$ occurs in the cell-sap of Fraxinus Ornus and some other plants: though not a carbohydrate, it is closely allied to this group; crystallisable, but not readily soluble in water.

2. Organic Acids: these occur in the plant either free or, more commonly, as neutral or acid salts in combination with organic or mineral bases; some are constituents of the fats and fixed oils (e.g. palmitic and oleic acids; see below): the more common are oxalic acid $\left(\mathrm{H}_{2} \mathrm{C}_{2} \mathrm{O}_{4}\right)$ malic acid $\left(\mathrm{H}_{2} \mathrm{C}_{4} \mathrm{H}_{4} \mathrm{O}_{5}\right)$, tartaric acid $\left(\mathrm{H}_{2} \mathrm{C}_{4} \mathrm{H}_{4} \mathrm{O}_{6}\right)$, citric acid $\left(\mathrm{H}_{3} \mathrm{C}_{6} \mathrm{H}_{5} \mathrm{O}_{7}\right)$.

3. Glucosides : substances of complex constitution which owe their name to the fact that they give rise, on decomposition, to glucose among other products : such are amygdalin, $\mathrm{C}_{23} \mathrm{H}_{27} \mathrm{NO}_{11}$ (seeds, etc., of many Rosaceæ); coniferin, $\mathrm{C}_{16} \mathrm{H}_{22} \mathrm{O}_{8}$ (coniferous wood); myrosin, or myronate of potash, $\mathrm{KC}_{10} \mathrm{H}_{19} \mathrm{NS}_{2} \mathrm{O}_{10}$ (seeds of Mustard); salicin, $\mathrm{C}_{12} \mathrm{H}_{18} \mathrm{O}_{7}$ (in bark of Willows and Poplars); yallo-tannin, $\mathrm{C}_{34} \mathrm{H}_{28} \mathrm{O}_{22}$ (in Oak-bark).

Though some of these substances (e.g. amygdalin and myrosin) contain nitrogen, it is more convenient to classify them with the more numerous non-nitrogenous glucosides.

4. Fats and Fixed Oils: these substances, as they occur in the seeds and fruits of plants, are mixtures of free fatty acids with glycerin-compounds (glvcerides) of fatty acids ; thus palm-oil is a mixture of palmitic and oleic acids with their glycerides palmitin, $\mathrm{C}_{3} \mathrm{H}_{5}\left(\mathrm{C}_{16} \mathrm{H}_{31} \mathrm{O}\right)_{3} \mathrm{O}_{3}$, which is a solid fat, and olein, $\mathrm{C}_{3} \mathrm{H}_{5}\left(\mathrm{C}_{18} \mathrm{H}_{33} \mathrm{O}\right)_{2} \mathrm{O}_{3}$, which is a fluid fat or oil : olive-oil consists chiefly of olein with some palmitin: castor-oil, of ricinolein (the glyceride of ricinoleic acid) and stearin (the glyceride of stearic acid): linseed-oil, of linolein (the glyceride of linoleic acid) and palmitin.

The organic compounds can for the most part be resolved into volatile products - chiefly carbonic acid, water, and nitrogen-by exposure to great heat with free access of air, that is, by combus- 
tion. The inorganic residue is a white, or, if the combustion is imperfect, a grey powder, the ash.

As the result of chemical processes attending the combustion, the sulphur and phosphorus previously contained in the organic compounds appear as sulphates and phosphates in the ash, and the carbonic acid formed during combustion combines with some of the inorganic substances. These, therefore, must not be included in an accurate estimate of the constituents of the ash.

The ash usually constitutes but a small percentage of the whole dry solid of the plant. The amount of ash increases with the age of the plant, or of any part of it, inasmuch as there is no considerable excretion by the plant of the mineral substances absorbed. The percentage of ash in the dry solid of the plant, or of any organ, may vary widely at different times. The following analyses of various portions of plants will give an idea of its amount and composition :-

1000 PARTS OF DRY SOLID MATTER CONTAIN :

\begin{tabular}{|c|c|c|c|c|c|c|c|c|c|c|}
\hline & $\frac{\dot{\pi}}{4}$ & 㷰 & 歇 & 苛 & 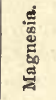 & 赵选 & 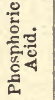 & 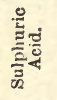 & 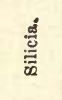 & 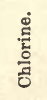 \\
\hline Clove & $68 \cdot 3$ & $21 \cdot 96$ & $1 \cdot 39$ & $24 \cdot 06$ & $7 \cdot 44$ & 0.72 & $6 \cdot 74$ & $2 \cdot 06$ & $1 \cdot 62$ & $2 \cdot 66$ \\
\hline Wheat, grain. & $19 \cdot 7$ & $6 \cdot 14$ & 0.44 & 0.66 & $2 \cdot 36$ & 0.26 & $9 \cdot 26$ & 0.07 & 0.42 & 0.04 \\
\hline Wheat, straw . & $53 \cdot 7$ & $7 \cdot 33$ & 0.74 & $3 \cdot 0 y$ & $1 \cdot 33$ & 0.33 & $2 \cdot 58$ & 1.32 & $36 \cdot 25$ & 090 \\
\hline Potato tubers. & $37 \cdot 7$ & $22 \cdot 76$ & 0.99 & 0.97 & $1 \cdot 7 ?$ & 0.45 & 653 & 245 & 0.80 & $1 \cdot 17$ \\
\hline Apples . . & $14 \cdot 4$ & $5 \cdot 14$ & $3 \cdot 76$ & 0.59 & $1 \cdot 26$ & $0 \cdot 20$ & $1 \cdot 96$ & 0.88 & 062 & \\
\hline Peas (the seed) & $27 \cdot 3$ & $11 \cdot 41$ & 0.26 & $1 \cdot 36$ & $2 \cdot 17$ & $0 \cdot 16$ & $9 \cdot 95$ & 0.95 & 0.24 & 0.42 \\
\hline
\end{tabular}

2. The Food of Plants. The constituents of the ash do not form a merely accidental mixture; it has been proved by experiment that certain inorganic compounds are absolutely necessary to the life of the plant. Those chemical elements which the plant requires for its nutrition, and which must therefore be regarded as part of its food, are:-

I. Non-metallic Elements :-Carbon, hydrogen, oxygen, nitrogen, sulphur, phosphorus, and perhaps chlorine. These elements exist in the plant, for the most part, as organic compounds; but they also occur to some extent as inorganic compounds, carbonates, nitrates, phosphates, sulphates, of the metals mentioned below.

II. Metallic Elements :-Potassium, calcium, magnesium, iron. 
Besides these we find in the ash of many plants-though they cannot be regarded as essential to nutrition-the following elements : sodium, lithium, manganese, silicon, iodine, bromine, and in rare cases, also aluminium, copper, zinc, cobalt, nickel, strontium, and barium. Fluorine must also exist in vegetables, for it is found in a perceptible quantity in the dentine of animals which feed directly or indirectly on vegetables.

The essential elements of the food will now be severally discussed.

Carbon. Plants which possess chlorophyll obtain their carbon mainly from the air (or, in the case of submerged plants, from the water) in the form of carbon dioxide. The absorption of carbon dioxide is, however, limited to those cells which actually contain chlorophyll, and it can only go on even in those cells so long as they are exposed to sufficiently intense light.

Although plants possessing chlorophyll can and do use carbon dioxide as carbonaceous food, yet there is reason to believe that they may supplement this by absorbing more complex carbon-compounds. In certain cases (e.g. Drosera, Dionæa, Utricularia, etc.), green plants are provided with a special mechanism, in the form of modified leaves, for obtaining a supply of organic carbon-compounds. Such plants are said to be insectivorous. The case of Drosera may be selected for illustration. The upper surface and the margin of a leaf of this plant bears numerous glandular appendages, the tentacles (see Fig. 33, p. 48). The glands at the ends of the tentacles coutinually excrete a viscid liquid. When an insect comes into contact with one of the marginal glands, it sticks to it; this stimulates the tentacle, and it moves, curving inwards to the centre of the leaf, and gradually the other marginal tentacles incurve over the insect (Fig. $33 \mathrm{~B}$ ). The glands then secrete an acid liquid containing a digestive enzyme which acts upon and dissolves the soft parts of the insect, and the products of this digestion are absorbed.

Plants which do not possess chlorophyll are incapable of using carbon dioxide as carbonaceous food, but require more complex carbon-compounds. Such plants are, all Fungi, and among the higher plants, Cuscuta (Dodder), Orobanche (Broomrape), Neottia, etc., though in some of these latter, a small, but altogether insignificant quantity of chlorophyll has been detected. These plants absorb the complex carbon-compounds which they require, either from living animals and plants, or from the organic substances formed by animals or plants : in the former case they are termed parasites, in the latter saprophytes. In some cases plants destitute of chlorophyll obtain their carbonaceous food from green plants, without 
however, being strictly parasitic upon them since they do not destroy or injure them. This association of two distinct plants is termed symbiosis. The best instance of it is afforded by the Lichens, where a Fungus and an Alga are associated symbiotically.

It is remarkable that certain plants which possess chlorophyll are nevertheless parasitic in habit; for instance, Viscum (the Mistletoe) which is parasitic on various trees, Rhinanthus (the Rattle) and other Scrophulariacex, also Thesium (Bastard Toad-flax,) which are attached to the roots of other plants by their haustoria. The nutritive processes of these green parasites are not yet fully understood, but it seems probable that they absorb from their hosts the substances which they should normally obtain from the soil, though in a somewhat modified form.

The great majority of the saprophytes are Fungi, such as the various Agarics which grow in the soil of woods (humus) which is formed by decayed leaves and is rich in organic matter; the Moulds and Yeasts which grow in saccharine juices, or fruits, etc.; and Saprolegnia which attacks the corpses of animals. Some of these Fungi, notably the Yeasts and the various kinds of Bacteria (Schizomycetes), are peculiar in that they not only decompose the amount of organic substance which they require for their nutrition, but they give rise to widespread decompositions which are known as fermentation and putrefaction. Amongst the higher plants there are many saprophytes which grow in soils rich in humus: they may be almost destitute of chlorophyll (e.g. Monotropa; Neottia and some other Orchids): or they may possess it in considerable quantity (e.g. some Orchids; Pyrola; Ericaceæ), in which case they are probably only partially saprophytic ; plant3 of this kind grow mostly in the leafsoil of forests, or in peat on moors.

Hydrogen. The hydrogen of the plant is mainly absorbed in the form of water $\left(\mathrm{H}_{2} \mathrm{O}\right)$, but it may-also be absorbed in combination with nitrogen as ammonia-compounds $\left(\mathrm{NH}_{3}\right)$, and also in combination with carbon when complex carbon-compounds are absorbed by the plant.

Oxygen is absorbed in combination with carbon, as $\mathrm{CO}_{3}$, and with hydrogen, as $\mathrm{H}_{2} \mathrm{O}$, and in many of the inorganic salts of the food, such as sulphates, phosphates and nitrates, as well as in more complex carbon-compounds. Oxygen is also absorbed uncombined, in connexion with the catabolic processes, in respiration.

Nitrogen, which is an essential constituent of proteid substances, is only exceptionally assimilated in the free form; although it is present in large quantities in the atmosphere, most plants perish if the soil in which they grow contains no compounds of nitrogen. Nitrates and compounds of ammonia are widely distributed, and it is in this form that nitrogen is mainly taken up by plants; it seems 
probable that plants possessing chlorophyll absorb their nitrogen in the form of nitrates only.

Nitrogen may be also absorbed, at any rate, by parasites, saprophytes, and insectivorous plants, in the form of nitrogenous carboncompounds.

Although it is generally true that plants cannot assimilate uncombined nitrogen, nevertheless certain plants (Papilioneæ, such as Pess, Beans, etc.) will grow and flourish in a soil from which all traces of nitrogen-compounds have been carefully removed. The nature of the means by which this result is attained is not yet completely determined, but the principal facts are briefly as follows. In the first place, the roots of these papilionaceous plants have been found to bear peculiar gall-like outgrowths termed tubercles. The tubercles are the result of the attack of a Fungus which penetrates into the root through the root-hairs. The green plant and the Fungus appear to exist in a state of symbiosis, with the result that the green plant is adequately supplied with combined nitrogen although growing in a soil from which such compounds are originally ubsent. In explanation of these facts there can, first, be no doubt that the supply of combined nitrogen obtained by the green plant is ultimately derived from the free nitrogen of the atmosphere; and, secondly, that the supply is not obtained from the atmosphere directly by the leaves, but indirectly by the roots through the soil. Nor can there be much doubt that the tubercles are associated with the process of the assimilation of the free nitrogen, and that it is effected by the Fungus.

The tubercles are structures formed by the hypertrophy of the cortex of the root: their cells are rich in sugar and starch: the branches of the fungus-mycelium penetrate most of the cells, and there bud off innumerable gemmules (sometimes called bacterioids). The tubercle eventually becomes disorganised; the gemmules are then set free into the soil, and are doubtless the means by which other roots become attacked by the Fungus.

Sulphur, which is a constituent of proteids and a few other substances occurring in plants, such as oil of Mustard, is derived from the sulphates of the soil.

Phosphorus is absorbed from the soil in the form of phosphates, and enters into the composition of some of the proteid substances; phosphates constitute a large proportion of the ash of seeds.

As regards Chlorine, it has been experimentally proved so far to 
be indispensable in the case of one plant only, the Buckwheat (Polygonum Fagopyrum).

Iron, though it is met with in very small quantities, is absolutely necessary for the formation of chlorophyll. The leaves produced by plants which are not supplied with iron during their growth, are white so soon as their own store of iron is exhausted; these leaves, which are said to be chlorotic, become green in consequence of the formation of chlorophyll if the soil be supplied with iron, or even if their surface is washed with a very weak solution of iron.

Potassium. Unless the soil contains potassium-compounds, the assimilation of carbon dioxide by plants possessing chlorophyll does not go on, as is shown by the fact that, under these circumstances, the plant does not increase in dry weight. Potassium-salts are especially abundant in those parts of the plant which are rich in carbohydrates such as starch and sugar, as in potatoes, beet-roots, and fruits.

Calcium and Magnesium have been shown to be necessary to the normal development of plants: they are absorbed as nitrates, phosphates and sulphates, and thus serve as bases for the absorption of these other important elements. Little is known as to their direct use : they may be of importance in neutralising the organic acids (especially oxalic) formed in the plant.

The distinction of the essential from the non-essential elements has been arrived at by the method of water-culture, which consists in growing plants from the seed with their roots in a solution of various salts in distilled water. By varying the salts in the solution, and observing the effect of the change on the health of the plant, the relative importance of the different elements can be ascertained. The following are examples of solutions containing all the essential elements :-

1.

Potassium nitrate

Calcium phosphate

Magnesium sulphate

Ferric chloride
2.

Calcium nitrate

Potassium sulphate Magnesium phosphate

Ferric chloride.

In these two mixtures, as well as in others of the same acids and bases which might be formulated, all the essential elements are included in forms suitable for absorption; the proportion of mixed 
salts should not, however, exceed about $3 \%$ by weight of the liquid.

The following is a brief account of the non-essential mineral constituents of the food.

Silicon, is absorbed from the soil as silica $\left(\mathrm{SiO}_{2}\right)$ or as silicates. It cannot be regarded as of nutritive importance, since plants which are usually rich in silica can be brought to an apparently normal development under conditions which render the absorption of silica impossible. It is usually deposited in the cell-walls, as in Diatoms, Equisetum, many Grasses, etc.

Iodine and Bromine are found in the many marine plants, especially in Algæ, and are prepared from them; it is not known that they are of any value in the economy of the plant.

Sodium, being universally distributed, is found in plants.

Lithium occurs in the ash of several plants, particularly in Tobacco.

Zinc, Copper, and other metals, though they are not commonly present in the ash of plants, are nevertheless taken up by plants from soils which are rich in them; from this it appears that plants may absorb substances which are not necessary and may be even injurious.

3. Anabolism. Under this term are included all the chemical processes going on in the plant which lead to the formation of complex substances from simpler ones (p. 158). Of these, those which are undergone by the food of the plant constitute assimilation.

In the case of plants which contain chlorophyll, the first step in the assimilation of the food is the construction from carbon dioxide and water of an organic molecule which contains carbon, hydrogen and oxygen. The process may be represented by the following equation :-

$$
\mathrm{CO}_{2}+\mathrm{H}_{2} \mathrm{O}=\mathrm{CH}_{2} \mathrm{O}+\mathrm{O}_{2} \text {. }
$$

That some process of the kind takes place is proved by the fact that when green plants are placed under the necessary conditions, that is, when they are supplied with carbon dioxide, with water and with salts from the soil, and are exposed to light, they gain in weight in consequence of an increase in the amount of their dry organic substanoe, and they give off oxygen. Moreover, the volume of the free oxygen evolved is actually equal to that of the carbon dioxide absorbed, as indicated in the equation.

There are three points connected with the performance of this 
process which require special notice: the part played by the mineral food, the action of light, the function of chlorophyll.

With regard to the first point, it appears that the process in question cannot be performed unless potassium-salts are supplied to the plant. There is no reason to believe that this metal takes any direct part in the process; but it has an indirect, though none the less well-marked effect upon it (see p. 192).

The importance of exposure to light is briefly this. The chemical process represented in the foregoing equation is one which involves the doing of work; for, from the simple and stable molecules $\mathrm{CO}_{2}$ and $\mathrm{H}_{2} \mathrm{O}$, a more complex and less stable molecule $\mathrm{CH}_{2} \mathrm{O}$ is produced. Work cannot be done without energy, and the plant cannot evolve in itself the energy necessary. It avails itself, therefore, of the kinetic or radiant energy of the sun's rays. Hence the importance of exposure to light is that the plant, by absorbing the light-rays, obtains the energy required for the chemical work which has to be done.

Next, as to the function of chlorophyll. The function of chlorophyll is to serve as the means by which the rays of light are absorbed, and their energy made available for the performance of the chemical work by the protoplasm with which the chlorophyll is associated. When light which has passed through a solution of chlorophyll is examined with a spectroscope, the spectrum is seen to present certain dark bands, known as absorption-bands, in the red, yellow, green, blue, and violet, the band in the red being the most conspicuous. These bands indicate that certain of the rays of the solar spectrum do not pass through the chlorophyll, but are arrested and converted into another form of energy. It is this energy which, in the living plant, the chlorophyll places at the disposal of the protoplasm for the construction of an organic molecule out of carbon dioxide and water, as expressed in the foregoing equation. Protoplasm without chlorophyll is incapable of making use of the kinetic energy of the rays of light for the performance of this chemical work.

The product of this process of carbon-assimilation is (as indicated in the foregoing equation) a non-nitrogenous organic substance having the composition of a carbohydrate. A leaf which is actively assimilating carbon under the influence of light is generally found to contain relatively large quantities of carbohydrate, in the form either of sugar or starch.

The performance of this process can be readily demonstrated. 
If a water-plant (e.g. a leaf of Potamogeton natans, or a portion of the shoot of Elodea canadensis) be placed in water which holds carbon dioxide in solution, and be exposed to sunshine, it will be seen that from the cut surface of the leaf or stem bubbles of gas are given off at regular intervals (Fig. 128). These consist of oxygen.

The relation of light and of chlorophyll to the formation of organic substance by a green plant can be demonstrated by the starch-method. For instance, if a leaf of a starch-forming plant, which has been exposed to bright light for some hours, be removed, decolourised by alcohol and tested with iodine, it will assume a dark blue colour, showing an abundant accumulation of starch. If a leaf, still on the plant, be exposed, not to white light, but to a spectrum, the starch will be found to have accumulated in those portions of the leaf upon which have fallen the rays of light which correspond to the principal absorption-bands of the chlorophyllspectrum.

It is, generally speaking, only plants possessing chlorophyll which can create organic substance. Inasmuch, therefore, as organisms, whether plants or animals, which do not possess chlorophyll require for their nutrition more or less complex organic substances, they are entirely dependent for their food upon organisms which do possess chlorophyll.

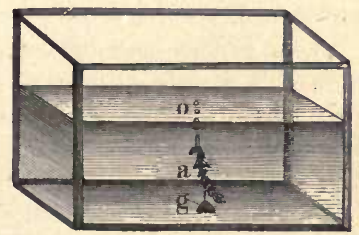

Fig. 128.-Evolution of oxygen from a water-plant (Etodea canadensis) : $a$ the cut stem; $g$ a weight that keeps the stem in its place; o the gas-bubbles rising from the cut surface.

This process is also of great importance in another direction. All living organisms, speaking generally, absorb free oxygen and evolve carbon dioxide in respiration. Those organisms which possess chlorophyll prevent the excessive accumulation of carbon dioxide in the atmosphere, and keep up the supply of free oxygen, in that, under the influence of light, they absorb the former gas from the air, and replace it by an equal volume of the latter.

The characteristic difference between the anabolic capacity of plants which do and of those which do not possess chlorophyll is then this, that the former can produce, from carbon dioxide and water, organic substances containing the elements $\mathrm{C}, \mathrm{H}$, and $\mathrm{O}$, whereas the latter cannot produce these, but must be supplied with them as food. From this point onwards the anabolic 
processes in the two cases are, as far as is known, identical. From the simpler plastic substances containing $\mathrm{C}, \mathrm{H}$, and $\mathrm{O}$, whether they have been formed from $\mathrm{CO}_{2}$ and $\mathrm{H}_{2} \mathrm{O}$ in the one case, or have been absorbed as organic food from without in the other, other more complex substances such as sugar, etc., are formed, probably by the polymerisation or condensation of the simpler molecules. Further, the nitrogen of the food, absorbed either as nitrates or salts of ammonia, is worked into the anabolic processes, so that nitrogenous organic substance is produced. Probably the first formed nitrogenous substances are comparatively simple crystallisable substances, such as asparagin and leucin, which belong chemically to the amides (see p. 186). The next step is doubtless the formation of those more complex nitrogenous substances, the proteids, and here sulphur, and phosphorus in some cases, is introduced into the molecule; and finally the series of assimilatrry processes concludes with the formation of molecules of protoplasm.

These various assimilatory processes are not, however, carried on simultaneously with equal activity. In plants which contain chlorophyll, when under conditions favourable for carbon-assimilation, the construction of non-nitrogenous organic substance from $\mathrm{CO}_{2}$ and $\mathrm{H}_{2} \mathrm{O}$ appears to be the most active process, for an accumulation of non-nitrogenous organic substance can be detected in the green parts of these plants when assimilation is being carried on. Most commonly this excess of non-nitrogenous organic substance is accumulated in the form of starch-granules which are formed in the chloroplastids; less eommonly in the form of sugar which is held in solution in the cell-sap (e.g. leaves of Onion). This excess of non-nitrogenous organic substance in the green parts soon disappears, however, when, by withdrawal from the influence of light, its further formation is arrested. For instance, if a plant which has been exposed to light and whose leaves are rich in starch, be placed in the dark for some hours, the starch will then be found to have almost or entirely disappeared.

The organic substance resulting from the anabolism of the plant, is partly used in the growth of the plant, in forming new protoplasm, cell-walls, etc., and is partly stored up, in various organs, in the form of reserve materials which serve either for the growth of the plant itself at a subsequent period (roots, tubers, etc.), or for the nutrition of new individuals in the early stages of their growth (spores, seeds, etc.). 
4. Catabolism. Under this term are included all the chemical processes going on in the plant which lead to the formation of simple substances from more complex ones.

The chief physiological importance of the catabolic processes is this: that, inasmuch as they consist in the decomposition of relatively complex and unstable substances into others which are relatively simple and stable, they necessarily involve a conversion of potential into kinetic energy; and it is by means of the kinetic energy so evolved that the plant exhibits those phenomena, such as growth, movement, etc., which characterise it as a living organism. The degree of activity of life depends directly upon the degree of catabolic activity ; when catabolism ceases, life ceases ; the organism is dead. A good illustration of this is afforded by the scarcely perceptible catabolism of seeds, bulbs, etc., when quiescent, and their very active catabolism when they begin to germinate.

The catabolic processes of the plant are carried on either by the living protoplasm itself, or by means of certain substances formed by the protoplasin, which are termed enzymes.

The catabolic processes carried on by the protoplasm are mainly such as depend upon the absorption of free oxygen from without, and are accompanied by an evolution of carbon dioxide; in fact this gaseous interchange between the plant and its environment, termed Respiration, is the external manifestation of the performance of these catabolic processes. The seat of these processes is the protoplasm, and it is mainly the molecules of protoplasm that are decomposed; in other words, just as the construction of the protoplasm-molecule is the ultimate result of anabolism, so the decomposition of the protoplasm-molecule is the central fact of catabolism.

The reason, then, why most plants die when they are deprived of free oxygen, is that they are unable to carry on, under thesecircumstances, those catabolic processes by which the energy essential to the maintenance of life is evolved; just as a fire goes out, that is the oxidation of the coal stops, under the same conditions.

Though it may be generally stated that living plants at all times absorb free oxygen, and that the maintenance of life depends upon a constant absorption of free oxygen, yet there are exceptions. There are, for instance, certain Fungi, such as Yeast and Bacteria, which can live in the absence of free oxygen. Under these conditions they carry on other processes of decomposition into 
which free oxygen does not enter, provided that suitable material is accessible; these processes are termed fermentations, and the plants organised ferments. Thus, Bacteria cause putrefaction and other similar fermentations in the most various organic substances with which they happen to come into contact. Similarly Yeast is the calse of the alcoholic fermentation of sugar, which may be represented by the equation

$$
\mathrm{C}_{6} \mathrm{H}_{12} \mathrm{O}_{6}=2 \mathrm{C}_{2} \mathrm{H}_{6} \mathrm{O}+2 \mathrm{CO}_{2} \text {. }
$$

The chief kinds of enzymes which have been found in plants are:-

1. Those that act on carbohydrates, converting the more complex and less soluble carbohydrates into others of simpler composition and greater solubility.

2. Those that act on fats, decomposing them into glycerin and fatty acid.

3. Those that act on glucosides, glucose being a constant product.

4. Those that act on the more complex and less soluble proteids, converting them into others which are more soluble and probably less complex, or decomposing them into non-proteid nitrogenous substances (amides, etc.).

The chemical action of some of these enzymes are illustrated by the following equations :-

1. Conversion of starch into sugar (amylolylic enzyme, commonly termed diastase : :-

$$
\begin{aligned}
& \text { Starch. } \\
& 3\left(\mathrm{C}_{6} \mathrm{H}_{10} \mathrm{O}_{5}\right)+\mathrm{H}_{2} \mathrm{O}=\mathrm{C}_{12} \mathrm{H}_{22} \mathrm{O}_{11}+\mathrm{C}_{6} \mathrm{H}_{10} \mathrm{O}_{5}
\end{aligned}
$$

2. Conversion of cane-sugar into grape-sugar (invert enzyme) :-

$$
\text { Cane-sugar. Dextrose. Lævulose. }
$$

8. Action of fat-enzyme:-

$$
\mathrm{C}_{12} \mathrm{H}_{22} \mathrm{O}_{11}+\mathrm{H}_{2} \mathrm{O}=\mathrm{C}_{6} \mathrm{H}_{12} \mathrm{O}_{6}+\mathrm{C}_{6} \mathrm{H}_{12} \mathrm{O}_{8}
$$

$$
\begin{aligned}
& \text { Olein, Oleic acid. Glycerin. } \\
& \mathrm{C}_{57} \mathrm{H}_{104} \mathrm{O}_{6}+3 \mathrm{H}_{2} \mathrm{O}=3 \mathrm{C}_{18} \mathrm{H}_{34} \mathrm{O}_{2}+\mathrm{C}_{8} \mathrm{H}_{8} \mathrm{O}_{3}
\end{aligned}
$$

It will be noted that, in every case, the action of the enzyme involves the taking up of one or more molecules of water.

The action of the enzymes which act on proteids (proteolytic enzymes) cannot be represented by equations, inasmuch as no formulæ for the various proteids have at present been arrived at. It may be generally stated that their effect is, like those of the other forms, to induce decomposition with the assumption of water. The proteolytic enzymes, acting some in an acid medium, others in an alkaline, convert the more complex proteids, such as globulins, into simpler ones, such as peptone; 
and further cause the decomposition of peptone into amides, such as asparagin, leucin, and tyrosin.

The chief importance of the enzymes in the economy of the plant is that by their means the reserve materials, which are accumulated to such a large extent in the form of substances, such as starch, fat, cellulose, proteids of aleuron-grains, which are either not soluble in water, or if soluble are only slightly diffusible, are converted into substances, such as amides and certain sugars, which are both readily soluble and diffusible, and which can therefore travel osmotically from one part to another. For instance, as mentioned above, the excess of carbohydrate formed in the leaves when they are actively assimilating, is commonly stored up in the form of starch. This carbohydrate is eventually conveyed to other parts of the plant; but, since starch is insoluble, it cannot be conveyed in that form ; it is, in fact, converted into maltose by an amylolytic enzyme present in the leaves, and it is in this form that non-nitrogenous organic substance is conveyed away from the leaf where it has been produced. Other striking illustrations of the importance of enzyme-action are to be found in the chemical changes going on in germinating seeds, bulbs, tubers, etc. When a starchy seed, or a starchy tuber like the potato, germinates, the starch-grains are gradually dissolved, the starch being converted into maltose. When the tuber of the Dahlia or Artichoke, which contains inulin as the non-nitrogenous reserve material, germinates, the inulin disappears and is gradually replaced by grape-sugar. When an oily seed germinates, the oil-drops become less and less apparent, as the oil is gradually decomposed by enzyme-action into glycerin and fatty acids; the next step is the formation of carbohydrate (sugar or starch), probably from the products of the decomposition of the oil, a process which involves the absorption and fixation of oxygen, since carbohydrates contain a higher percentage of oxygen than does any form of fat or oil; and then, finally, any starch so formed is converted into sugar. Similarly, the aleuron-grains in a germinating seed gradually disappear, the indiffusible proteids composing them being decomposed by the action of a proteolytic enzyme into peptone, and then into amides, in which form they are conveyed osmotically to the growing embryo. Finally, it is obvious that the indiffusible proteids which are conveyed from part to part in the sieve-tissue of vascular plants (see p. 165) must eventually be 
distributed osmotically in the form of diffusible compounds, probably amides, to the adjacent parenchymatous tissues, and it is probable, though not yet ascertained, that here again a proteolytic enzyme is involved.

Respiration. This term is applied to the gaseous interchange, consisting in the absorption of free oxygen and the evolution of carbon dioxide, which takes place (with but few exceptions) between the living plant and the atmosphere, and which may be regarded as the external expression of the oxidative catabolic processes going on in the tissue of the plant. This gaseous interchange goes on over the whole surface of the body; but in those parts which possess stomata or lenticels, it is mainly conducted through these apertures.

Respiration seems to be somewhat diminished under the influence of bright light; but its activity is promoted by a rising temperature, and to some extent by greater moistness of the air. The relation to temperature is such that respiration takes place at temperatures even slightly below $0^{\circ} \mathrm{C}$; t that it increases in intensity with a rise of temperature, but in greater proportion, up to an optimum of $40^{\circ}-45^{\circ}$; and then sinks as the temperature further rises until the fatal degree is reached.

The relation of the volume of the gases absorbed and evolved in respiration, that is, of oxygen and carbon dioxide, is a matter of importance. It may be generally stated that the relation is definite and constant for any given plant, or for any part of it, at a given stage of development, all other conditions being constant: the proportion $\frac{\mathrm{CO} 2}{0}$ may be unity, or less or more than unity, according to the nature of the plant under experiment, and is not affected either by temperature or by light.

Respiration can be demonstrated by placing a quantity of germinating seeds, or opening flower-buds, in an air-tight glass receiver (somewhat as in Fig. 129), through which a current of air is drawn previously freed from $\mathrm{CO}_{2}$ by passing through solution of caustic potash. On examining the gas drawn from the receiver, by passing it through a clear solution of lime-water, it will be found that the lime-water becomes turbid in consequence of the formation of calcium carbonate, the $\mathrm{CO}_{2}$ in the gas withdrawn combining with the lime.

5. The Products of Metabolism. The relation between the anabolism and the catabolism of the plant may be generally stated thus, that the construction of organic substance in the former is greater than the decomposition of it in the latter, so that on the 
whole there is an accumulation of organic substance in the body of the plant. The organic substance is accumulated to some extent In the actual structure or fabric of the plant, as protoplasm and cell-wall, and to some extent in the form of compounds which may be present in some or all of the cells, but which do not constitute any portion of the fabric. These compounds may or may not be of nutritive value; in the former case they are termed plastic products, in the latter waste-products, of metabolism (see p. 158).

The most important of the plastic products are enumerated below. They are all found accumulated as reserve materials in various parts of plants.

Non-nitrogenous reserve mattrials:-

a. Carbohydrates; in solid granules, starch; in many seeds, and tubers,

in thickened cell-walls, cellulose; as in Dateseed, Coffee-seed, Vegetable Ivory,

dissolved in cell-sap; grape-sugar, as in the Onion and in fruits; cane-sugar, as in the Sugar-cane and the Beetroot; inulin, as in the Jerusalem Artichoke and Dahlia. etc.).

b. Fats; in drops in many seeds (Rape, Linseed, Castor-oil, Palm,

Nitrogenous reserve materials :-

a. Proteids; in solid granules (aleuron; p. 80 ), in seeds, more especially oily seeds.

b. Amides; asparagin, etc., in solution in the cell-sap of bulbs, tubers, bulbous roots, etc.

The uaste-products are most probably all formed as the result of catabolic processes; though their formation is often associated, both as to time and place, with active anabolism. They may be classified into nitrogenous and non-nitrogenous.

The principal nitrogenous waste-products appear to be the alkaloids (see p. 186). They are probably products of the nitrogenous catabolism of plants; and it is suggestive that they principally occur deposited in the cells of deciduous parts, such as leaves, seeds, bark, etc.

The principal non-nitrogenous waste-products are, water; free oxygen (green plants in light); carbon dioxide, and some other highly oxidised carbon-acids, such as the oxalic ; resins and ethereal oils, tannins, aromatic substances, etc.

Of these waste-products, some are retained in the cells of the 
plant, whereas others are thrown off or excreted. The nitrogenous waste-products are deposited either in cells or in the laticiferous tissue : there is practically no excretion of such waste-products by plants. Similarly, those of the non-nitrogenous waste-products which are not gaseous at ordinary temperatures, are retained by the plant. For instance, oxalic acid is deposited in the form of crystals of calcium oxalate either in the cavities or in the walls of the cells (see pp. 78, 81) : the crystals may have either six molecules of water of crystallisation, when they are quadratic; or two molecules, when they are prismatic (raphides). The resins and ethereal oils are usually excreted by the cells in which they are formed, into intercellular spaces (resin-ducts, oil-glands, see p. 97 : the tannins are mostly stored in cells, dissolved in the cellsap.

The oxygen which is set free in connexion with the decomposition of $\mathrm{CO}_{2}$ in the green parts under the influence of light, is exhaled in the gaseous form; this is also the case with the carbon dioxide produced in catabolism. In some cases, however, some portion of the carbon dioxide forms calcium carbonate, which is either deposited in the solid form (e.g. cystoliths, see p. 78), or is excreted by means of the chalk-glands (p. 96).

In some cases, substances of nutritive value are excreted by plants, as for instance, the sugary liquid known as nectar by special glands, the nectaries (see p. 26), of flowers, and the digestive liquid poured out by the glands of the insectivorous plants. This loss of substance is, however, compensated for by the advantages gained by the excretion. The nectar attracts insects, and so ensures cross-fertilisation, and the excretion of the insectivorous plants results in the digestion of the entrapped insects (see p. 189).

The mechanism of excretion may be generally illustrated by reference to two cases: to the nectaries, and to the chalk-glands. The former afford an example of that mode of excretion in which the necessary force is supplied by the excreting cells themselves: the latter, of that mode in which the necessary force is derived from another source. Excretion by nectaries can be well observed in the case of Fritillaria imperialis (Fritillary, or Crown Imperial). At the base of each of the petals of the flower, there is an oval depression which is the gland or nectary and is seen to be occupied by a large drop of nectar. If the flower be cut off, and the drop be removed from the nectary by means of blotting-paper, it will be shortly replaced by a fresh drop. It is therefore clear 
that in this case the excretion of the liquid is effected, not by the root-pressure, for the flower is no longer in connexion with the root, but by the cells themselves. The mechanism of excretion seems to be this, that the cells of the nectary become turgid, and when a certain degree of turgidity has been attained, filtration under pressure takes place, and liquid is pressed out. Excretion by chalk-glands can be well observed in some of the Saxifrages. The chalk-glands are here situated at the end of the finer vascular bundles round the margin of the leaves, each gland being at the bottom of a depression in the surface, and communicating with the surface by two or three water-stomata (see p. 109). So long as the leaf is in connexion with the rest of the plant, and provided that transpiration is not too active, drops of water holding chalk in solution are poured out by these glands on to the surface through the water-stomata. The excretion stops, however, directly the leaf is removed, or the stem is cut through. In this case the excretion clearly depends upon the root-pressure; the gland itself has no excreting power, but it simply accumulates the chalk which is then washed out by the current of water forced through the gland by the root-pressure.

In connexion with the catabolic processes there is an evolution of energy constantly going on in the plant, which is for the most part lost to the plant, or dissipated, most commonly in the form of heat, in a few cases in the form of light, and also commonly in the form of movement. The evolution of heat by plants is not usually sufficient to cause the temperature of the plant-body to be higher than that of the surrounding air. This is partly due to the fact that the catabolic processes of plants are not generally very active, and partly to the continual loss of heat by radiation and in connexion with transpiration. It is however easy, under appropriate conditions, to demonstrate the evolution of heat. If a quantity of seeds be made to germinate in a heap, they will be found to be distinctly warm (Fig. 129). This happens on a large scale in the process of malting barley. When a large quantity of barley-grains are germinating on a malting-floor, they become quite hot: they have, in fact, to be continually turned to prevent overheating. The conditions are here most favourable: for the catabolic processes are extremely active in germinating seeds, and there is but little loss of heat by radiation and transpiration. Similar observations may be made with opening flower-buds, the opening of the bud being also a period of great catabolic activity. In some cases, 
as in the Araceæ, where the inflorescence consists of a great number of flowers which open simultaneously, and which are protected by a large leaf, the spathe, a rise of temperature as much as $18^{\circ} \mathrm{C}$. has been observed.

The few plants in which an evolution of energy in the form of

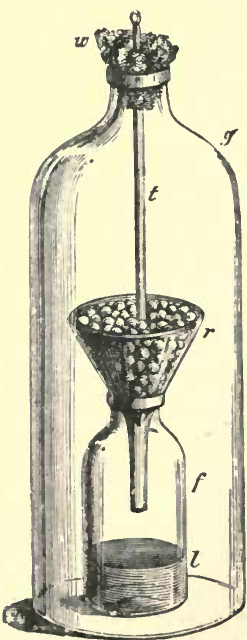

Fra. 129.-Apparatus for detecting the rise of temperatare in smell opening flowers or germinating seeds. The seeds are heaped as closely as possible in the funnel $r$ which is inserted into the mouth of a bottle containing a solution of caustic potash. This absorbs the carbon dioxide prodnced by respiration. The whole is enclosed in a gless vessel, and a delicate therw ometer is inserted throngh the cotton wool wbich closes the month. The bulb of the thermoweter is plunged in among the seeds. The tempera. ture in this apparatus will be higher than in another arranged in thesame way for comparison, and in which the fiowers or seeds have previously been killed. light has been clearly established are all Fungi. It is commonly termed phosphorescence. The so-called phosphorescence of decaying wood is due to the presence of the mycelium of Agaricus melleus, and that of putrefying meat and vegetables to Schizomycetes of the nature of Micrococci. Various other species of Agaricus have been found to be luminous.

Movement of some kind is manifested by all plants. All plants exhibit that slow movement which is termed growth: in many, there is a more or less well-marked movement of the protoplasm in the cell or cells of which the plant-body consists, which is known as cyclosis, circulation, or rotation : some are capable of locomotion during the whole or a portion of their life, a peculiarity which is shared by many reproductive cells, such. as zoospores and spermatozoids: in some cases, the floral or the foliage-leaves of the plant can perform movements, as the foliageleaves of the Sensitive Plant, of the Telegraph-plant, of Dioncea muscipula (Venus' Fly-trap), the stamens of Berberis and of the Cynareæ, or portions of leaves as the tentacles of Drosera (Sun-dew, see p. 189). These movements are considered in detail in the next chapter.

The connexion between these various forms of dissipation of energy and the catabolic processes, is clearly demon- 
strated by the fact that any change which prejudicially affects the activity of catabolism, similarly affects the dissipation of energy. For instance, in the absence of free oxygen, a condition which diminishes catabolic activity in most cases, germinating seeds or opening flowers cease to evolve heat; the luminous Fungi cease to emit light; growth, and the other more conspicuous movements are arrested: similar effects are produced by exposure to a low temperature.

\section{CHAPTER III.}

\section{SPECIAL PHYSIOLOGY OF MOVEMENT.}

§46. Introductory. The movements to be specially considered here are such as may be characterized as vital; that is, they are essentially manifestations of the life of the protoplasm. This statement is rendered necessary by the fact that movements do occur in plants which are dependent upon purely physical causes; instances of these are afforded by the rupture of pollensacs and other sporangia, the twisting and untwisting of awns (as in the fruits of Erodium and Stipa), the bursting of fruits (as in the Balsam, Impatiens Noli-me-tangere, and the Squirting Cucumbers, such as Ecbalium, Momordica, and Elaterium). These movements may be due, in the simpler cases, either to expansion and contraction of hygroscopic cell-walls resulting from variations in the moisture of the air, or to the imbibition with water and the consequent swelling-up of mucilaginous substances in the cells; in the more complicated cases the movement depends upon tensions set up between different layers of tissue in consequence of unequal expansion.

The vital movements are either spontaneous or induced. In the former case they are the result of causes operating in the organism itself; in the latter, they are the result of causes acting upon the organism from without.

The following are the principal phenomena of movement exhibited by plants; the streaming movement of protoplasm (cyclosis); the expansion and contraction of contractile vacuoles; the locomotion of entire organisms; the movements of cellular members. 
$\S 47$. The Spontaneous Movements may be conveniently considered under the two heads of movements of protoplasm, and movements of cellular members.

A. Movements of Protoplasm. Under this head are included such spontaneous movements as can be directly observed in the protoplasm. The first to be noted is the streaming movement, which can be frequently observed either in naked protoplasm (e.g. plasmodia of Myxomycetes), or in the protoplasm of cœenocytes clothed by a cell-wall (e.g. hyphæ of Fungi), or in that of cells (e.g. leaf of Elodea and Vallisneria, internodal cells of Characeæ, root-hairs of Trianea bogotensis, hairs of the stamens of Tradescantia, etc.). The movement takes place in the more fluid portion of the protoplasm, and is made evident by the granules of various kinds which are carried along by the current. The direction of the movement varies somewhat according to circumstances: the current travels in one direction, and this simple longitudinal movement is all that can be observed in plasmodia and in hyphæ; but in cells, owing to their shortness, it can be observed to travel up one long side, across the end, and down the other side; and when the cytoplasm forms not merely a parietal layer, but forms strands traversing the vacuole (e.g. Fig. $36 \mathrm{D}$ ), currents can be observed in these strands also.

The contractile vacuoles are small, more or less nearly spherical, cavities which make their appearance in the protoplasm and then suddenly disappear. In their relatively slow expansion (diastole), they become filled with cell-sap, which is forced out on the sudden contraction (systole). They have been exclusively found in motile organisms, such as the Volvocineæ, the plasmodia of Myxomycetes, the zoospores of many Algæ and of some Fungi.

In the second place the protoplasmic movements which involve locomotion have to be considered. The simplest case of this is the amøeboid movement exhibited, among plants, by the zoospores of the Myxomycetes and of some Algæ, and by the naked masses of protoplasm which constitute the plasmodia of the Myxomycetes. There is here no specialised motile organ, but any part of the protoplasm may be protruded as a pseudopodium into which the remainder of the protoplasm gradually flows, and thus locomotion of the whole is effected.

The locomotory movements of most zoospores, of spermatozoids, and of entire organisms such as Volvox, Pandorina, etc., is effected by means of specialised motile organs, which are delicate proto- 
plasmic filaments termed cilia (see p. 51); each cell may have one, two, four, or many cilia (see Figs. 1, 62, 63).

Locomotion is also exhibited by other Algæ, such as Diatoms, Oscillatorias, etc., but the mechanism is not fully understood.

B. Movements of Cellular Members. Instances of the movement of parts of plants consisting of one or more cells having a cell-wall, are afforded by all growing members, and by some specially modified mature members; the movements of the latter are termed movements of variation, those of the former, movements of grouth.

These two kinds of movements can be readily distinguished from each other, inasmuch as the movements of variation are rapid and can be easily observed, whereas the movements of growth are slow and can only be followed by means of special apparatus.

a. Movements of Variation. The majority of the movements of variation are induced, a few only being spontaneous. An instance of spontaneous movement is afforded by the rising and falling of the lateral leaflets of the trifoliolate leaf of Desmodium gyrans, the Telegraph-plant. It must, however, be pointed out that the power of spontaneous movement may be possessed by plants though they do not manifest it under ordinary circumstances. Thus the leaves of the Sensitive Plant (Mimosa pudica) move spontaneously in darkness, but they will not do so in the light. This is also true of various Leguminosæ and Oxalidaceæ.

b. Movements of Growth. Before entering upon a description of the movements of growth, a clear idea must be formed of what growth really is. By grouth is meant change of external form, which is usually, though not necessarily, accompanied by increase in bulk; the change of form being rendered permanent by the deposition of new substance: it is a function of embryonic protoplasm (see p. 8).

The growth of the plant-body takes place to a greater or less extent in all three dimensions of space. For instance, when it takes place equally in all three dimensions, a spherical body is produced, as in Protococcus and Volvox. Occasionally it takes place especially in two dimensions, the result being a flattened body, such as a Fern-prothallus or an Ulva. More commonly, however, it takes place especially in one direction, so that the plant-body assumes an elongated form. An extreme case of this 
is afforded by Spirogyra and other filamentous Algæ. It is this growth in length which has been more especially studied physiologically, and in what follows, "growth" may be taken to mean "growth in length," unless there is some definite statement to the contrary.

The growth in length of the plant-body takes place at first throughout its whole extent; but at a later period it is limited, as a rule, to particular regions (see p. 8). In the growing portion of any member two regions may be distinguished: the formative region, which is the growing-point proper: and the region of elongation adjacent to it (Fig. 130). In the formative region the construction of the new tissue from plastic substances takes place, as is specially manifested in the formation of cell-walls accompanying the cell-division going on in this region of a multicellular growing-point; but the amount of elonga-

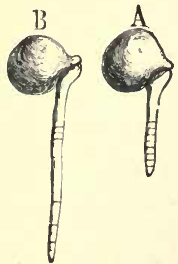

F're. 130.-The growing primary root of the Pea in two stages. $A$ The root is marked by lines atequal distances. In $B$ the differonces in rapidity of growth are perceptible: the nppermost lines have not been separated; the root has ceased to grow here. The lowest likewise are still close toge. ther; at the apex elonga. tion has not taken place. In the intermediate zones the elongation has been very great. tion is slight. In the region of elongation, the formative processes have ceased: in multicellular plants little or no cell-division takes place in this region; the cells are here fully formed, and they simply require to increase in bulk, to grow in fact, in order to attain the mature form. Beyond the region of elongation comes the portion of the member which has already ceased to grow. It must be clearly understood that each portion of the growing-point passes through these three phases. For instance, in a multicellular apical growing-point, each cell is produced in the formative region; and as in consequence of the continued formation of younger cells in front of it at the apex, it comes to lie at an increasing distance from the apex, it passes through the stage of growth, to become an adult tissue-element.

The movement of growth in length is altogether spontaneous. It may be generally described as the travelling of the organic apex in a line which is the continuation of the longitudinal axis of the growing member. Both the rate and the direction of growth are liable to variation.

Variations in the Rate of Growth. When a member begins to 
grow, its rate of growth is at first slow ; it then accelerates, until a maximum rapidity is attained; after which it diminishes untiI growth ceases altogether. This gradual riseand fall in the rate of growth, extending over the whole of one period of growth, is termed the grand period of grouth.

This periodicity is manifested also in each cell of the growing region. A young cell grows but slowly; as it becomes older, and is gradually removed from the growing-point, its rate of growth increases up to a maximum; as it becomes still older and is still more remote, the rate of growth sinks, until finally the adult stage is reached, and growth ceases.

Careful observation of growing members has shown that, in addition to the spontaneous variation constituting the grand period of growth, small irregular variations are constantly taking place, which, since they are apparently spontaneous, are termed irregular spontaneous variations.

Another point which must be taken into account is the energy of grouth; that is, the relative capacity of different members for growth in length. The differences in the energy of growth in growing members manifest themselves in differences either in the length of the grand period, or in the rate of growth; in other words, members may grow for a longer or shorter time, or they may grow more or less rapidly. In any case the result is that members attain different lengths. For instance, it is easy to observe that the lower internodes of most stems remain short; that those above them are longer; that those of a certain part of the stem are the longest; and that the upper ones again are short. In the same way the size of the leaves attached to these various parts of the stem increases from below to about the middle, and then diminishes.

Variations in the Direction of Growth. Although it is true, as stated above, that the result of growth is, generally speaking, that the apex of the growing member is moved onwards in a line which is the continuation of the axis of the growing organ; yet, during the actual process of growth, this relation of position is not maintained, because the rate of growth is at no time uniform througheut the transverse section of the region of elongation. Suppose a radial stem rising vertically from the soil; the longitudinal axis of the fully grown portion of this stem is vertical, but this is not true of the growing portion. If the apex be looker down upon from above it will be seen to travel in an orbit round 
the prolongation of the longitudinal axis of the fully grown portion. When the stem is radially symmetrical, the orbit is approximately circular; but in cases in which the member tends to be bilaterally symmetrical, one diameter of the orbit becomes proportionally elongated, the orbit being then oval, or elliptic, until, finally, when the bilateral symmetry is strongly marked, the orbit becomes a straight line, the growing-point simply oscillating from side to side. Whilst the growing-point is travelling
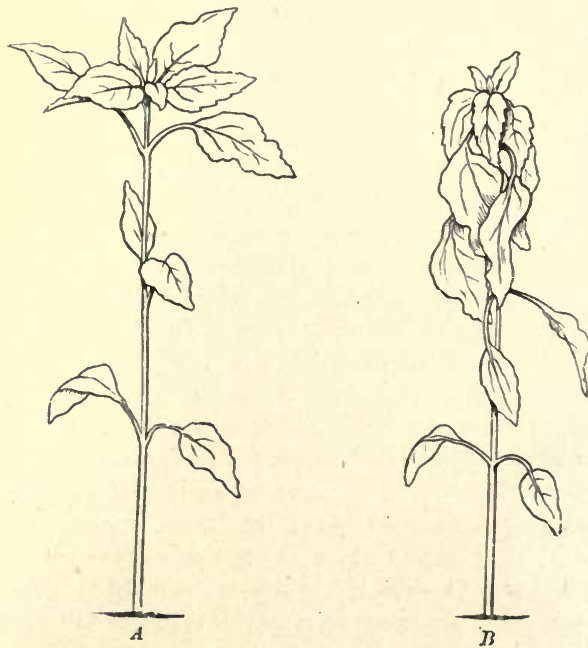

Fig. 131. - Ilustration of the epinastic growth of the leaves of the Sunflower (Helianthus annuนs). 4 represents the position of the leaves when the plant is exposed to light; $B$ represents the position of the leaves when the plant has been kept in darkness for twentyfour hours. In $\boldsymbol{A}$ the leaves are expanded in consequence of the directive (diaheliotropic) action of the incident rays of light. In $B$ the leaves, in the absence of light, have become recnrved in virtue of their inherent epinastic growth.

in its orbit, it is at the same time being raised upwards; so that it describes a path which is, according to the form of the orbit, a circular spiral, an elliptical spiral, or a zig-zag. These changes of position are, however, not permanent; for example, though the growing-point may be travelling upwards in a spiral, the fullygrown stem does not resembie a corkscrew, but is straight. 
These spontaneous changes in position of growing-points are designated generally by the term Nutation.

All growing members nutate in a more or lešs marked manner; but the most conspicuous instances are afforded by slender structures, such as tendrils, and the internodes of twining stems.

A peculiar form of nutation is commonly exhibited by dorsiventral members, such as leaves. In the early stages the one surface of the leaf grow's much faster than the other, thus leading to certain peculiar forms of vernation and æstivation (see p. 43); in the later stages the other side grows the faster, and so the expansion of the leaf is brought about. When it is the upper surface which is growing the faster, whether along the transverse or the longitudinal axis of the leaf, it is said to be a case of epinasty (Fig. 131); when the lower surface, it is said to be a case of hyponasty. A striking example is afforded by leaves having circinate vernation, as many Ferns, Drosera, etc.; this form of vernation is due to the growth of the leaf being at first longitudinally hyponastic. The convolute, involute, and conduplicate forms are all the result of transverse hyponastic growth in the early stages of development of the leaf, whereas the revolute form is the result of transverse epinastic growth.

$\S 48$. Induced Movements. All parts of plants which can exhibit movement are also irritable; that is, they respond to the action of external agents either by a movement or by a change in the rate or the direction of their movement. The following are the principal causes, or stimuli, of movement, or change of movement:-

a. Mechanical ; contact or pressure ;

b. Variations of temperature;

c. Variations in the intensity of light;

d. Changes in the direction of incidence of the rays of light;

$e$. Changes of position with regard to the line of action of gravity (vertical);

$f$. Differences of degree of moisture in the surrounding medium.

a. Irvitability to Mechanical Stimuli. This form of irritability is most strikingly manifested by motile mature members, and less markedly by certain growing members.

The following are instances of irritability to contact manifested by mature motile members: by the leaves of the sensitive plants (see p. 174), and by those of Dionæa and Drosera; by the stamens of Berberis, Mahonia, the Cynareæ, and the Cistaceæ; by the lobes of the stigma of Mimulus, Martynia, and Bignonia (p. 176). 
The most familiar case is that of Mimosa pudica, the Sensitive Plant. The leaf of this plant is bipinnate, consisting of a primary petiole bearing at its free end four secondary petioles, upon which the leaflets or pinnæ are inserted (see Fig. 126). The primary petiole is articulated to the stem; each secondary petiole to the primary petiole; and each pinna to the secondary petiole, by a pulvinus. When stimulated, the pinnæ fold together forwards and upwards: the secondary petioles move sideways so as to come closer together and to lie almost parallel; and the primary petiole sinks downwards; the pulvini act as hinges upon which the various parts move.

It is only a few growing members which react perceptibly to mechanical stimulation; such are tendrils, the petioles of leafclimbers (e.g. Tropæolum, Clematis, Solanum jasminoides), the stem of at least one stem-climber, namely that of Cuscuta (Dodder), and roots. In these cases the contact must be of relatively long duration, becoming, in fact, pressure.

The irritability of growing members to mechanical stimulation is, however, less marked than that of the mature motile members mentioned above. Even in the most sensitive growing members, such as tendrils, the resulting movement is comparatively slow. The movement induced in these members is that they tend to curve round the object with which they have come into contact. The result of this is that fresh portions of the member come into contact and are stimulated to curve, so that the member forms coils round the object, and thus becomes firmly attached to it. In the case of roots, when the growing-point is more or less injured by pressure or otherwise, a curvature is induced of such a kind that the injured side becomes convex, with the result that the growing-point, and consequently the direction of growth, is deflected from the obstacle or other cause of injury.

b. Irritability to Variations of Temperature. Movement, like the other functions (see p. 160), is affected by temperature, but this influence is not stimulating but tonic: it does not induce movement, but merely modifies the activity of movement. A sudden variation of temperature may, however, act as a stimulus and induce a movement. This kind of irritability has been detected in various leaves: for instance, a rise of temperature causes certain flowers (e.g. Tulip, Crocus) to open, and a fall of temperature causes them to close: similarly a fall of temperature causes the leaves of such plants as the Sensitive Plant and the WoodSorrel (Oxalis Acetosella) to fold up, whereas a rise of temperature causes them to expand (see Figs. 125, 126). 
c. Irritability to Variations in the Intensity of Light (Paratonic Effect of Light; p. 162). This is exhibited in a marked manner by the majority of motile members, more especially leaves. When, for instance, the intensity of the light is diminished, the perianthleaves of many flowers and the foliage-leaves and cotyledons of many plants perform movements which are termed nyctitropic or sleep-movements (see p. 173). Thus, the flowers close; and the foliage-leaves change their position in various ways, assuming what is known as the nocturnal position, so that thəy no longer present the surface, but the margin of the blade to the sky. Conversely, when flowers or leaves which have assumed the nocturnal position are exposed to light, or to brighter light than before, they resume their normal expanded (diurnal) position.

Another remarkable manifestation of this irritability is that movements of variation in some cases, and movements of growth in most cases, are retarded or arrested by exposure to light of a sufficient intensity.

In illustration of the effect of light upon movements of variation, it may be stated that certain members, such as the leaves of the Sensitive Plant, which perform spontaneous movements of variation, are unable to do so when exposed to bright light: uuder this condition the leaves become fixed, as it were, in the diurnal position. This is not, however, the case with all mature motile members: for instance, the movement of the lateral leaflets of the Telegraph-plant (Desmodium gyrans) continues even in bright sunlight.

The paratonic action of light on movements of growth is strikingly exhibited in various ways. It is well demonstrated by etiolated plants (see p. 162), that is, by plants which have been kept in darkness for some considerable time. A characteristic feature of etiolated shoots is the excessive length of their internodes, as compared with those of a shoot which has been growing for the same period exposed to the normal alternation of day and night. This excessive elongation in darkness-which occurs as a rule in all radial and isobilateral members which usually grow exposed to light-is the result of the absence of the retarding paratonic action of light.

The effect of the paratonic action of light can also be estimated by direct measurement of the growing member. As the result of a great number of comparative measurements, it has been found, in regard to members of all kinds, that the rate of growth is more rapid in darkness than in light. 
An interesting demonstration of the relation of the rate of growth to light is afforded by the observation of the growth of any member at given intervals-every hour, or every two or three hours--during an entire day of twenty-four hours. By this means it has been ascertained that a growing member exhibits a regular daily periodicity in the variations in its rate of growth, which has a direct relation to the alternation of day and night.

The paratonic action of light varies with its intensity: the more intense the light the more marked the paratonic action. Exposure to very intense light may entirely arrest growth for the time being."

It has been found that the different rays of the spectrum are not equally active; the paratonic effect of the more highly refrangible rays (violet, indigo, blue) is far greater than that of the rays of lower refrangibility.

d. Irritability to the Direction of Incidence of the rays of Light (Heliotropism). This kind of irritability is extremely common, and generally manifests itself in the most striking manner. The most active rays of light are those of high refrangibility (violet, indigo, blue).

A remarkable example of this is afforded by the zoospores of various plants (e.g. Ulothrix, Hæmatococcus, Botrydinm, etc.). When light falls obliquely upon them, these zoospores arrange themselves in the water so that their long axes are parallel to the direction of incidence of the rays; this phenomenon is termed Phototaxis. Moreover, the direction of their movement is also determined by the direction of incidence of the light. They move in the line of incidence, but they may move either towards or away from the source of light; the direction depending partly on the intensity of the light, and partly on the degree of irritability of the zoospore. When a zoospore moves towards a source of light, it is said to be positively phototactic; when away from it, negatively phototactic. Another important case is the change of position of the chlorophyllcorpuscles in the cells (see p. 172).

Motile cellular members, whether mature or growing, are, as a rule, sensitive to the directive influence of the incident rays of light. Among mature motile members, foliage-leaves are those which most markedly respond to the directive or heliotropic influence of light; among growing members, it is more especially stems and leaves which are sensitive, but roots have in many cases been found to be so. All these irritable members take up a definite 
position, the light-position (p. 173), with reference to the direction of incidence of the rays of light. Members capable of performing movements of variation can, if necessary, change their lightposition, whereas the light-position of other members can only be changed so long as they are growing.

The particular position which the member assumes under the heliotropic influence of light, depends upon its organisation. Three classes of members, namely the dorsiventral, the isobilateral, and the radial, have therefore to be considered.

It may be generally stated of dorsiventral members, that, for a certain mean intensity of light, their light-position is such that the morphologically upper surface is directed towards the source of light, and lies in a plane perpendicular to the direction of incidence of the rays : that is, they are diaheliotropic.

The case of motile foliage-leaves may be taken first in illustration, such as those of the Sensitive Plant, Robinia, Scarlet Runner, etc. When these leaves are exposed to light of sufficient intensity to cause them to assume the diurnal position (see p. 174), their upper (ventral) surfaces are at right angles to the direction of incidence of the rays. If, on the one hand, the light to which they are exposed becomes less intense than this, they will manifest no sensibility to its direction of incidence, but will merely assume the nocturnal position. If, on the other hand, the light becomes more intense, then the leaves will alter their position so that the blades will present their edge, instead of their ventral surface, to the incident rays (paraheliotropism, see p. 174).

In the case of foliage-leaves and other dorsiventral members which cannot execute movements of variation, the light-position is assumed in the course of development, and is fixed. Since it cannot be altered in relation to variations in the intensity of the incident rays, the position assumed is determined by the most frequent direction of incidence of the rays of suitable intensity. For instance, the fixed light-position of the foliage-leaves of plants growing free in the open, is usually not such that the upper surface is horizontal, facing the zenith; but such that it is directed towards that quarter of the sky from which, not the brightest sunlight, but the brightest diffuse daylight, falls perpendicularly upon it. In fact, it is not unusual to find that the fixed lightposition of leaves, when the light is of high average intensity, is such that the surfaces are vertical, so that the margin is presented to the zenith. Under these circumstances both surfaces are equally 
exposed to light, and the structure of the leaf becomes more or less isobilateral (see p. 114).

The fact that the ultimate position of dorsiventral leaves is mainly determined by light, is demonstrated by removing themwhilst still growing, and therefore capable of a change of position-from its influence. In darkness these leaves take up an altogether different position (see Fig. 131), becoming curved in various ways; when again exposed to light they resume their previous diaheliotropic position.

With reference now to radial members, it may be generally stated that the essential feature of their response to the directive influence of light is that they tend to place their long axes in the direction of incidence of the brightest light falling upon them. Whereas in the case of dorsiventral members the important point is the relation of the morphologically upper surface to the direction of the incident rays; in the case of radial members the important point is the relation of the long axis to the direction of the incident rays.

An exact coincidence between the direction of the long axis of the member and that of the incident rays is, however, not always attained in nature, on account of the antagonistic action of other directive iufluences. This point is more fully discussed on p. 222.

It must be mentioned that, inasmuch as there are no radial members which are both heliotropically irritable and capable of performing movements of variation, all that is here said refers to growing radial members.

In illustration, the case of a radial member which has been grown in the dark may be taken, and it may be assumed to be vertical. Light is allowed to fall upon it from one side; the effect is a gradual curvature of the member, as it continues to grow, so that its long axis comes to coincide more or less nearly with the direction of the incident rays.

But the curvature may be in one of two directions; it may be .either such that the apex of the member comes to point towards the source of light, or such that it points in the opposite direction. When the former is the case the member is said to be positively heliotropic; when the latter, it is said to be negatively heliotropic.

The nature of the curvature, whether positive or negative, depends upon the specific irritability of the member. Thus, generally speaking, primary shoots, including such forms as the stems 
of Chara and Nitella, the peduncles of flowers, the stipes of the larger Fungi, and the conidiophores of Moulds, as also radial leaves such as those of the Onion, are positively heliotropic. Negative heliotropism has been observed in many roots, especially aerial roots, and in the root-hairs of Marchantia. With regard to shoots, the hypocotyl of Viscum, the Mistletoe, is negatively heliotropic.

Although the relation between the external symmetry of the member and its heliotropic irritability is generally that indicated above, yet there are exceptions : all dorsiventral members are diaheliotropic; but not all radial members are positively or negatively heliotropic, for some of them are diaheliotropic. It seems that continual exposure to intense light falling on one side induces at least physiological dorsiventrality in some radial members (e.g. shoots of Ivy and Tropæolum).

The flattened, typically isobilateral, leaves of various Monocotyledons, such as those of Iris, appear to be positively heliotropic.

$e$. Irritability to the Directive Influence of Gravity (Geotropism).

The effects of the stimulating directive action of gravity must be clearly distinguished from those which are due to the mere weight of the parts. It is only the former which are referred to by the term geotropism. The geotropic curvatures are effected with considerable force, and will take place even against considerable resistance; for instance, it has been observed that the primary roots of seedlings will curve downward into mercury.

Geotropic irritability is manifested by various members, such as stems, leaves, and roots. The phenomena of geotropism in the three categories of members, the dorsiventral, the radial, and the isobilateral, will now be studied.

With regard to dorsiventral members, it appears that many leaves, both growing and motile, lateral shoots of Conifers and of many dicotyledonous shrubs, runners, etc., which are dorsiventral, take up such a position, when acted upon solely by gravity, that their longitudinal axis is horizontal-that is, at right angles to the line of action of gravity, the vertical-and that their morphologically superior surface is directed upwards. If these members are moved out of this position so that their long axis is not horizontal, they curve until it is so ; or if they be so moved that the normally upper surface faces downwards, they twist until it faces upwards. These members behave in respect to the line of action of gravity 
just as they do to the direction of the incident rays of light. They are diageotropic, just as they are diaheliotropic.

It is a familiar fact that at all points of the earth's surface typical radial members, such as primary shoots and roots, grow with their long axes vertical, but with this difference, that the direction of growth of the primary shoots is away from the centre of the earth, whereas that of the primary roots is towards the centre of the earth. It can be readily demonstrated (by Knight's machine) that this vertical direction of growth is due to the force of gravity, that it is, in fact, a phenomenon of geotropism. But the effect produced is precisely opposite in the two cases; primary shoots grow in a direction opposed to that of the action of gravity, they are negatively geotropic; primary roots grow in the same direction as that of the action of gravity, they are positively geotropic. If these members be moved out of their normal position, they will return to it by performing geotropic curvature.

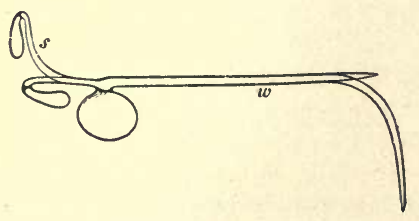

Fig. 132. - Geotropic curvature of a Pea-seedling placed horizontally. The thicker outline indicates the original positions of the primary shoot and root; the ehoot 8 has curved upwards in the conrse of its growth, the root $w$ has curved downwards. The bud at the apex of the shoot is nutating.

The principle of Knight's machine is to expose growing plants to the action of centrifugal force, either alone or together with gravity. The object of it is to demonstrate that gravity is the directive force which determines the relative directions of growth of shoots and roots. When seedlings are grown on a rapidly rotating vertical wheel, in consequence of the continuous change in position with regard to the vertical, it is obvious that the directive action of gravity is eliminated, for all parts of the seedlings are acted upon by gravity for successive equal times in opposite directions: the only force in action is the centrifugal force. The result is that the primary roots grow towards the centre of the wheel, in a direction contrary to that of the line of action of the centrifugal force, whilst the primary shoots grow outwards, away from the centre of the wheel, in the same direction as the action of the centrifugal force. It is clear from these facts (1) that a purely physical force can determine the direction of growth of roots and shoots: (2) that the physical force employed (centrifugal force) affects primary roots and shoots in a precisely contrary manner: and it may be concluded that since the phenomena produced by the action of centrifugal force in these experiments are quite analogous to those observable in nature, the cause 
of the natural phenomena is also a purely physical force, and the force of gravity is the one which meets all the necessary conditions.

The geotropic influence of gravity is greatest when the radial member is in a horizontal position; that is, the curvature into the normal position then takes place with the greatest rapidity. But the visible effect is the more marked, the further the member is removed from its normal position; for instance, when a primary shoot is turned upside down, a curvature of $180^{\circ}$ has to be performed in order that the apex may again point upwards.

In addition to the primary shoots of seedlings, the following radial members are negatively geotropic; the stipes of Mushrooms, the conidiophores of Moulds, the stems of Characeæ, the stalks of the receptacles of Liverworts, the peduncles of many flowers, the setæ of Mosses, etc. Also isobilateral leaves, such as those of Iris; when placed horizontally in darkness, whether flat or edgeways, they curve upwards.

In addition to the primary roots of seedlings, the following radial members are positively geotropic; the hyphæ of Fungi which penetrate into the substratum, the root-like filaments of Vaucheria and other Algæ, the rhizoids of Muscineæ, the rhizomes of Yucca filamentosa and of Cordyline rubra, etc.

An instance of the absence of geotropic irritability in a growing member is afforded by the hypocotyl of the Mistletoe.

The degree of geotropic irritability is not the same in all radial members. It may be generally stated that the lateral branches both of shoots and roots are less irritable than primary shoots and roots. For instance, the secondary branches of roots grow, not vertically downwards, but obliquely outwards and downwards, in the soil.

It has been observed in some cases that the nature of the geotropic irritability of a member may change in the course of its development. For instance, the peduncle of the Poppy is positively geotropic whilst the flower is in the bud, but negatively geotropic during flowering and fruiting. Again, the flowers of the Daffodil are negatively geotropic when in the bud, but they become diageotropic as they open.

$f$. Irritability to Differences in the degree of Moisture in the surrounding Medium (Hydrotropism).

Irritability of this kind is especially characteristic of earth-roots which possess it in a high degree. It can be readily demonstrated by a well-known experiment. Peas or Beans are made to germinate in a sieve full of damp sawdust, the sieve being suspended 
in a slanting position. The primary roots grow downwards through the sawdust, and escape into the air (which is kept moist). At first they grow vertically downwards in consequence of their positive geotropism, but they soon curve upwards towards the moist surface. They do this in virtue of their hydrotropic irritability, and it is clear that they are positively hydrotropic.

g. Irritability of other kinds. It has been ascertained by experiment that members of various kinds may be stimulated to curvature by other causes, such as differences of temperature on the two sides, galvanic currents, the flowing of currents of water, and by the presentation of various chemical substances; but these various phenomena are not of such immediate importance to the well-being of the plant as those which have been described above in detail.

The stimulating action of certain chemical substances (chemiotaxis is, however, of some importance in connexion with the reproductive processes. It had been frequently observed that the motile male cells (spermatozoids) of plants possessing them appeared to be attracted to the female organ, fertilisation being thus ensured, but the cause of this has only recently been ascertained, and only in certain cases. It appears that the female organ, when it is fit for fertilisation, excretes into the surrounding water a substance which attracts the male cells. In Ferns and Selaginella this substance is a compound of malic acid; in Mosses it is canesugar.

$\S 49$. Localisation of Irritability. Among members which perform movements of variation, there are many instances of welldefined localisation of irritability. Thus, in the Sensitive Plant, no movement ensues when the upper side of the pulvinus of the primary petiole is touched, but only when the sensitive hairs on the under side of the pulvinus are touched; and, in the leaflets, it is the upper side of the pulvinus which is sensitive. In Drosera, the irritability of the tentacles is localised in the terminal gland. In Dionæa, movement only ensues when the irritable hairs on the upper surface of the leaf are touched.

Among growing organs, tendrils offer well-marked localisation of irritability. In most tendrils the lower or basal part is either not at all sensitive, or is sensitive only to prolonged contact. Most tendrils have their tips slightly hooked, and their irritability is localised in the concavity of this curvature. The tendrils of Cobara scandens and of Cissus discolor are irritable on all sides; 
in those of Mutisia the inferior and lateral surfaces are irritable, but not the superior. The irritability of the root to the pressure of obstacles (see pp. 169, 212) is localised in the.tip.

The foregoing examples sufficiently prove the localisation of irritability to mechanical stimulation: and the question arises whether or not irritability to other stimuli is also localised. It has been ascertained that this is the case, in connexion with heliotropism and geotropism, at least in certain plants. Thus, the heliotropic irritability (i.e. sensitiveness to the directive influence of light) of the cotyledons of certain Grasses, though not absolutely confined to the tip, has been found to reside especially in that part, and the same is the case with the primary shoot of many dicotyledonous seedlings and with young shoots of various plants. The geotropic irritability of roots also resides in the tip, and this appears to be also true of other members.

$\S 50$. Transmission of Stimuli. The most striking instances of this are offered by motile leaves, such as those of the Sensitive plant and of Drosera. If the terminal pair of leaflets of a pinna of the leaf of the Sensitive Plant be irritated, not only will they fold up, but each of the other pairs of leaflets of the same pinna will fold up in succession; if the stimulus is sufficiently strong, its effect may extend to other pinnæ causing their leaflets to fold up, or to the secondary petioles causing them to converge, or even to the main petiole which then sinks downward (see Fig. 126). Stimulation of one leaf, if sufficiently powerful, will cause movement in another. In the case of Drosera, stimulation of the central tentacles of a leaf causes the inflexion of the marginal tentacles (p. 48).

In so far as heliotropic and geotropic irritability is localised in the tips of growing members, these must also afford instances of transmission of stimuli. The stimulus acts upon the irritable tip and the impulse is transmitted to the region in which the curvature takes place.

The means by which stimuli are transmitted is a matter which is still under discussion; but it appears that the means of transmission is not the same in all cases. Whilst in some, such as tendrils and the leaves of Drosera, the stimulus is probably transmitted by means of the delicate protoplasmic filaments which connect the protoplasm of adjacent cells (see p. 65); in others, for instance Mimosa pudica, the stimulus is transmitted as a disturbance of the hydrostatic equilibrium of the cells: it would, in fact, appear that 
whilst the former means of transmission suffices for a short distance, the latter is necessary when the distance to be traversed is considerable. In Mimosa pudica there appears to be a special tissue along which the stimulus is conducted: it belongs to the bast, and consists of large elongated cells with pitted cellulose walls.

$\S 51$. Combined Effects of different Stimuli. Inasmuch as it is commonly the case that the motile members, whether growing or mature, are irritable to stimuli of various kinds, it is clear that the assumption by them of any particular position is the resultant effect of the stimuli which may be acting simultaneously. The phenomena in question are strikingly manifested by growing members, and it is to these that the following account especially refers.

According to the position assumed in the course of their growth under the influence of various external directive influences, plantmembers may be conveniently classified into those which have their long axis vertical, and those which have their long axis oblique or horizontal, the former are distinguished as orthotropic, the latter as plagiotropic. Most radial and isobilateral members are orthotropic; all dorsiventral, and some radial members are plagiotropic. For instance, radial primary shoots and roots are orthotropic; all dorsiventral leaves, etc., are plagiotropic ; lateral branches of shoots and roots, even though radial, are plagiotropic.

The directive influences which mainly determine the direction of growth of radial primary shoots are gravity and the direction of the incident rays of light, and the shoots themselves are negatively geotropic and positively heliotropic. If only the conditions are such that each side of the shoot receives an equal amount of light, as when the plant grows quite in the open, no heliotropic curvature takes place, and the shoot grows erect. But when one side of the plant is shaded, as when it grows by the side of a hedge, the shoot in most cases curves heliotropically out of the vertical. This curvature is the resultant effect of the negative geotropism of the shoot which tends to keep it straight, and its positive heliotropism which tends to make it curve more than it actually does. Unilateral illumination usually causes some degree of curvature in shoots, because, as a rule, their heliotropic irritability is higher than their geotropic irritability. Exceptions to this rule have been found in the inflorescences of Verbascum and Dipsacus, which remain erect even when one side is shaded. 
Similarly, the influences which ordinarily determine the direction of growth of radial primary roots, are gravity and the distribution of moisture in the soil. If the soil is uniformly moist, the root grows vertically downwards under the influence of gravity; but if the soil is not uniformly moist, the root will curve out of the vertical towards the moister area, because its hydrotropic is greater than its geotropic irritability.

The conditions which determine the plagiotropic position of most radial lateral branches of shoots are these: they are negatively geotropic, and they are diaheliotropic, at least in intense light. In darkness they grow erect, in virtue of their negative geotropism. Some radial subterranean rhizomes are, however, diageotropic. The oblique growth of lateral roots is simply due to their feeble geotropic irritability.

The conditions which determine the plagiotropic position of dorsiventral members are these: they are both diageotropic and diaheliotropic. But inasmuch as their heliotropic is higher than their geotropic irritability, their ultimate position is that in which the incident rays of appropriate intensity fall nearly or exactly at right angles upon the upper surface.

It will be observed that, as a rule, in growing members which are heliotropically irritable, this irritability is higher than any other; consequently the ultimate position assumed by the member is mainly determined by the direction of the incident rays of light, and it is termed, therefore, a light-position (see p. 215), although other directive influences may have contributed to its assumption.

The most remarkable case of combined effects is afforded by the growth of twining stems. A twining stem, at its first development, is straight, but after it has come to consist of two or three internodes its apex hangs over to one side, for the stem is not sufficiently rigid to support its own weight. It then exhibits circumnutation in a marked manner. If once it comes into contact with a more or less vertical support of appropriate thickness, it twines round it.

The commonly accepted explanation of twining is that it is due to the negative gentropism of the stem, combined with its circumnutation modified by contact with the support; but it is doubtful if this explanation is adequate. It has been suggested, with some show of reason, that twining stems may be irritable, like tendrils, though in a less degree, to continuous contact with a support.

$\S 52$. Conditions of Movement. Inasmuch as the movements under consideration are vital, they can only take place when 
the external conditions are favourable to the life of the plant. The following conditions are essential ; a moderate temperature, extremes of heat and cold arrest movement; a supply of water, all movements are arrested by drought; a supply of free oxygen, in the case of most plants (p. 197); and, in some cases, exposure to light of a certain intensity.

The importance of exposure to light as a condition of movement requires special consideration. It has been ascertained to be essential to movements of the most different kind. For instance, a Bacterium (Bacterium photometricum) bas been found to be motile only when exposed to light. Again, various movements of variation, such as those of the foliage-leaves of Mimosa, etc., do not take place unless the plant either is, or recently has been, exposed to light. But the most important case is the arrest of growth of dorsiventral members when kept in darkness. For example, if a potato-tuber sprouts in a dark chamber, the produced shoots have excessively elongated internodes (see p.162), but very small leaves; the growth of the leaves is arrested in darkness. On the other hand, intense light retards movement (e.g. its action on growth) or altogether arrests it (e.g. arrest of spontaneous movement of the leaves of the Sensitive Plant).

What is exactly the influence of light in promoting movement is not understood, but it is termed the pholotonic influence (p. 162): it induces, that is, a particular condition, the condition of phototonus, in the protoplasm, without which movement is impossible. It appears that the rays of low refrangibility (red-yellow) are most favourable for the phototonic condition.

Irritability also depends upon the above essential conditions : in fact, induced movements are more rapidly arrested by unfavourable conditions than are spontaneous movements. For instance, when a Sensitive Plant is kept in continuous darkness, the leaves first lose their power of responding to stimuli, and later their spontaneous movements cease.

Irritability may also be abolished by special means. For instance, exposure to the vapour of chloroform or ether destroys the irritability of the leaves of the Sensitive Plant. Again, it may be abolished by repeated stimulation, the interval between the stimulations being very short. This has been observed in the case of the leaves of the Sensitive Plant and of Dionæa.

$\S 53$. Mechanism of the Movements. The ultimate factor in the mechanism of the vital movements of plants, whether spon- 
taneous or induced, is the motility of the protoplasm. With regard to the streaming movement of the protoplasm, it is probably due to wave-like contractions and expansions of the protoplasm. The mechanism of the movements of the contractile vacuoles appears to be this: the systole of the vacuole is due to the sudden active contraction of the protoplasm, the contained liquid being expelled; the diastole, to the active but gradual expansion of the protoplasm, the cavity of the vacuole, as it enlarges, being filled with liquid. The protrusion and retraction of pseudopodia in amœboid movement may be accounted for in the same way; the protrusion is probably analogous to the diastole of the contractile vacuole, the retraction to the systole. A similar explanation may be offered of ciliary movement.

The movements of cellular members take place in a definite region, which may be distinguished as the motile region; this is, in growing members, the region of elongation (see p. 208); and, in mature members, is a more or less well-marked region of motile tissue which may constitute a distinct motile organ (e.g. pulvinus of a motile leaf). The movements depend essentially upon variations in bulk of the cells, and these, in turn, upon variations in turgidity. It is clear that if the turgidity, that is the hydrostatic pressure of the cell-contents, increases, the cell will expand provided that the wall be extensible; and conversely, that if the turgidity diminishes, the cell will shrink, provided the wall be elastic. Movement can only take place when the cell-walls possess these physical properties: hence, the pulvinus of mature motile leaves consists mainly of parenchymatous cells with unlignified walls, the lignified tissue being reduced as much as possible: similarly, in the elongating region of growing-members the cellwalls are thin and unlignified. But whilst the movements of variation (p. 207) are the result of a sudden loss of turgidity, which is either spontaneous or the effect of stimulation, the movement of growth depends upon the maintenance of turgidity, and the variations in the rate of growth (see p. 208) are the expression of variations in the degree of turgidity.

The following instances will serve to illustrate the foregoing considerations.

A simple case is offered by the induced movement of the stamens of the Cynareæ (p. 176). When at rest, the cells of the filaments are expanded in the direction of their length, and are turgid; on stimulation, the cells suddenly shorten and become flaccid, having

M.B. 
lost a portion of their cell-sap. The expanded state is regained by the gradual expansion of the cells, turgidity being restored by the absorption of water.

In the foregoing case, all the cells of the motile portion are affected; but in many cases some only of the cells are affected. Thus, in the case of the leaf of the Sensitive Plant, the primary petiole, when at rest, stands out nearly at right angles to the stem (Fig. 126, p. 174): on stimulation, it sinks downwards so as to form an acute angle with the internode below its insertion. The mechanism is this: when at rest, the cells of the pulvinus are all turgid, and they support the petiole in its normal position : on stimulation, the cells of the lower portion of the pulvinus lose their turgidity, water escaping from them into the intercellular spaces; these cells, being flaccid, are unable to counteract the downward pressure of the still turgid cells of the upper half of the pulvinus, and to support the weight of the leaf; consequently the primary petiole sinks downwards. The same mechanism obtains in the movements of the leaflets and of the secondary petioles; the only difference being that, in the pulvinus of a leaflet, it is the cells of the upper half of the pulvinus which lose their turgidity on stimulation, so the leaflet is raised upwards; and, in the pulvinus of the secondary petiole, it is the cells of the inner half which lose their turgidity, so the secondary petioles approach the middle line. This account is also applicable to all side-to-side movements, such as that of the leaf of Dionæa, and that of the stamens of Berberis and Mahonia.

The heliotropic or other curvatures taking place in the elongating region of growing cellular members, are due to the shortening of the cells on the side becoming concave, and to the elongation of the cells on the side becoining convex. The mechanism of the curvature seems to depend in this case not so much upon a difference of turgidity between the cells of the two sides as upon a difference in its effect: whereas turgidity induces the usual longitudinal elongation of the cells of the convex side, it induces longitudinal shortening in the cells of the concave side in consequence of extension in the other dimensions.

Turgidity is then the main factor in the mechanism of the movements of cellular members; its mechanical importance is further strikingly illustrated by the great rigidity of turgid members, and by the great force, equivalent in some cases to twenty times the atmospheric pressure, which they develope in opposition to ex- 
ternal resistance, as when the roots of tree cause the splitting of walls or of pavements. Although one essential factor in turgidity (see p. 159) is the purely physical osmotic activity of substances in the cell-sap, it must not be forgotten that it also depends upon the resistance offered by the protoplasm to filtration under pressure: so that the maintenance of turgidity is after all a vital act. The maintenance of turgidity appears, in fact, to depend upon a certain state of molecular aggregation of the protoplasm lining the cell-wall, in which it offers resistance to the escape of the cell-sap; whereas in the flaccid condition the state of molecular aggregation of the protoplasm is such that it readily permits the escape of the cell-sap under the elastic pressure of the cell-wall.

Whilst the fundamental mechanism of the movement of mature motile members and that of growing members is essentially the same, there is this secondary difference between the two cases. The change of position which is the result of the movement of mature members, is reversible; they can return to their former position : the change of position, curvature for instance, of growing members is reversible only so long as it has not been rendered permanent by actual deposition of sulestance. Thus the changes of position due to the nutation (p. 211) of growing members are only temporary, for they are of brief duration; but changes of position due to some directive influence acting for a considerable time become permanent, for instance, the light-positions (p. 223) assumed by growing members.

\section{CHAPTER IV.}

\section{SPECIAL PHYSIOLOGY OF REPRODCUTION.}

§ 54. Introductory. It has been already stated (see p. 49) that reproduction consists essentially in the throwing off by the individual of a portion of its protoplasm which does not merely grow but developes into a new organism; and that two modes of reproduction, vegetative multiplication and spore-reproduction may be conveniently distinguished, though they are not absolutely distinct.

Reproduction has been considered so far mainly from the morphological standpoint, and it now remains to discuss it from the physiological point of view. The most important general consideration is that reproduction is a function of embryonic, as 
distinguished from adult, protoplasm. But it must not be overlooked that all embryonic protoplasm is not necessarily reproductive : and it is interesting to trace the differences in this respect, presented by various kinds of embryonic protoplasm. To begin with, there is no doubt that the merismatic cells of the cambium are embryonic; but they are not at all reproductive, for they cannot give rise to a new member, still less to a new organism; they caun only add to the bulk of the body of which they form part, by the development of new tissue. Again, the protoplasm of a growing-point is embryonic, but it is only imperfectly reproductive; it possesses this property to the extent that it not only contributes to the increase of the member to which it belongs, but also developes new members. Finally, the protoplasm of a reproductive cell, such as a spore, is embryonic and is completely reproductive; for it does not in any degree contribute to the bulk of the parent-organism, but gives rise to a new individual.

$\S 55$. Vegetative Multiplication. This mode of reproduction is distinguished as vegetative, because it is carried on by the vegetative organs of the plant, and, in the simpler cases, it is not distinguishable from the ordinary processes of growth; though, in its higher forms it approximates to reproduction by spores. The simpler cases referred to are those of unicellular organisms : these, when they have reached by growth their characteristic limit of size, undergo cell-division, with the result that each new cell constitutes a new individual: here, multiplication is effected by a purely vegetative process, which, in a multicellular plant, would merely result in an increase in the number of the cells of which the individual consists. Much the same thing occurs in higher plants when (as in many Bryophyta, and in rhizomatous Pteridophyta and Phanerogamia) the main shoots die away, and the isolated lateral branches constitute new independent individuals. Something of a similar kind also takes place in the artificial multiplication of plants by means of cuttings : in many plants, but by no means all, if a shoot be cut off and be kept under favourable circumstances with its cut end in suitable soil, the cutting will complete its segmentation by the development of roots, and will then be a new individual. Not uncommonly, certain parts of the body may become more or less specially modified to effect vegetative propagation: for instance buds become developed into bulbs or into bulbils (see p. 25), or portions of the stem or the root become tuberous. But the specialisation 
which may be regarded as the highest of all, because it approaches most nearly to spore-reproduction, and involves the entire development of all the new members, is that of gemmæ in which the vegetative reproductive body is not merely a modified member of the parent, but is a special development consisting in some cases of only a single cell (e.g. gemmæ of some Algæ and Liverworts; oidium-cells of Fungi). Something of the same kind occurs amongst the higher plants, such as some Ferns, Bryophyllum, etc., where an entirely new structure, a bud, is developed on the leaf, and produces stem, leaves and roots; it is in this way that Begonias are artificially propagated (see p. 136).

An interesting artificial mode of vegetative propagation is that known as grafting or budding, in which a young shoot or a bud, termed the scion, of one plant is inserted into the stem of another, though allied plant, the stock (see p. 156); the scion and the stock grow together so as to form one plant, the seion retaining its own peculiar eharacters (e.g. grafting of fruit-trees, budding of roses).

An important fact connected with vegetative reproduction is that it is associated with a rejuvenescence of the protoplasm. For example, when an adult cell of a unicellular plant, such as Pleurococcus (Fig. 137), divides, it gives rise, not to adult cells, but to young ones: and a cutting produces a young plant, not an old one.

The relation of vegetative reproduction to the alternation of generations is of importance. In the lower plants (e.g. Bryophyta) where the gametophyte is the conspicuous generation, it is this generation which multiplies itself vegetatively, although vegetative reproduction of a somewhat different kind has been artificially induced in the sporophyte of some Mosses; but in the Phanerogamia it is exclusively the sporophyte which thus multiplies itself. In the Pteridophyta, whilst vegetative multiplication of the sporophyte is common, the gametophyte still retains this capacity in certain cases (some Ferns; Lycopodium). Vegetative multiplication does not, as a rule, affect the alternation of generations, each generation producing its like: the exceptions are afforded by cases in which the one generation is developed vegetatively from the other; that is, where vegetative propagation replaces spore-formation. For instance, in some Ferns, the prothallium is developed vegetatively from the Fern-plant, without the intervention of spores (apospory); and the Fern-plant vegetatively from the prothallium, without the intervention of sexual organs (apogamy). 
§ 56. Spore-Reproduction (see p. 50). The highest degree of reproductive capacity is that possessed by spores. Though they are single cells, they are nevertheless capable, each by itself, of giving rise to a plant-body which, as in the higher plants, may present complete morphological and histological differentiation.

The advantages gained by the development of spores are, first, that they are readily scattered, so that the plants developed from them grow at a distance from each other; this is, for instance, the meaning of the development of free swimming zoospores by plants (Algæ) living in water. Secondly, spores, especially in the lower plants, are highly resistent to unfavourable conditions, such as drought and extremes of temperature; so that they serve to maintain the species under conditions which would be fatal to the plant itself.

In Phanerogams the function of maintaining the species through a period of unfavourable conditions, as also the dissemination of the new plants, is transferred to the seeds which, like the spores of lower plants, have a great capacity for endurance.

Most plants, and probably all, produce spores; and from the physiological point of view there are two modes of origin of spores : they are developed either ascxually or sexually. In the lowest plants (e.g. Cyanophyceæ, Schizomycetes, etc.), as also in others which have become sexually degenerate (Fungi, such as the Acidiomycetes and Basidiomycetes), spores are only produced asexually: whereas in some sexual plants there is an exclusively sexual formation of spores (some Algæ, such as the Conjugatæ, the Fucaceæ, and the Charoideæ). In the higher plants (Bryophyta, Pteridophyta, Phanerogamia) spores are produced both sexually and asexually.

Sexual Spore-formation.-The sexual process consists typically in the fusion of two gametes, that is, of two sexual reproductive cells, neither of which is capable, by itself, of developing into a new individual.

The first question which naturally arises is as to the nature of sexuality ; the question, nainely, as to what difference, if any, can be observed between a gamete and an asexually-produced spore. To this question no answer can at present be given; no difference can be detected between a gamete and a spore. It must not, however, be concluded that because there is no observable difference between a gamete and an asexually-produced spore, there is no difference whatever between them; on the contrary it is clear 
that they differ widely, since the former cannot (except in rare cases), whilst the latter can, develope by itself into a new organism.

The second question is as to the nature of sex: what is the difference, if any, between a male and a female gamete? In some cases there is a marked external difference; for instance, in the Pteridophyta, Bryophyta, and many Algæ, the female gameteis a large motionless oosphere, whilst the male gamete is a small actively-swimming spermatozoid. But this marked difference is not essential, it is merely adaptive; it is an adaptation to a more or less aquatic mode of life or, at least, of fertilisation. Moreover, it is obviously inapplicable in explanation of the many cases in which the two conjugating gametes are externally quite similar. Nor has minute microscopic investigation brought to light any distinguishing criterion. But it must not be concluded on this account that there is no difference between a male and a female gamete; it is obvious that there is an essential physiological difference between them. For, were it otherwise, it would be impossible to account for such a fact, for instance, as that even where, as in many Algæ, the gametes are all extruded into thewater, fusion never takes place between two male or two femalegametes, but only between a male and a female.

Brief allusion may be made to the means by which the sexual process is ensured. It might be thought that the most effectual means would be the development of the male and female organs in close propinquity on the same individual. No doubt this is the case, but the result is to ensure the less advantageous mode of the process, the mode of self-fertilisation; in fact, in many cases in which the male and female organs are thus developed close together, as in monocious plants (p. 61), self-fertilisation is prevented by the male and female organs maturing at different times. The real problem is, then, to ensure a sexual process between two gametes derived from distinct individuals. The end is attained either directly, by bringing the diverse gametes together; or indirectly, by bringing the spores together, and consequently also the gametophytes.

The method of bringing the two gametes together is essentially connected with the aquatic mode of fertilisation. It has been observed and investigated in plants in which, whilst the oosphere is motionless and remains in the female organ, the spermatozoids are free-swimming; and it is among, the most 
striking phenomena of chemiotaxis (see p. 220). In various Mosses and Ferns it has been ascertained that, on the opening of the archegonium, the mucilage which is extruded includes some substance which diffuses in to the water and attracts to the archegonium any spermatozoid that may be present; in Mosses the substance in question is cane-sugar; in the Ferns, a salt of malic acid.

The method of bringing the spores together, so that they may germinate near each other, is especially characteristic of heterosporous plants, and more particularly of those which grow erect on dry land. It is thus most strikingly exhibited in the pollination of the Phanerogams, where the microspores are carried by the wind or by insects into such a position that they germinate in proximity to the macrospores.

In order that a sexual process may take place between them, a certain relationship must exist between any two gametes of opposite sex; when the limit is overstepped in the direction of either a too close or a too remote relationship, the process will either not take place at all, or the offspring will be few and feeble.

The most fertile sexual process is that taking place between the gametes of different individuals of the same species. It has been proved that the offspring of such cross-fertilisation have the advantage in vigour and fertility over the progeny of one of the same plants when self-fertilised. . It has, in fact, been proved that in many Phanerogams the pollen of a flower is incapable of fertilising the oospheres of its own ovules; and that the pollen from another flower of the same plant is only slightly, if at all, more potent.

A sexual process may also take place between varieties of the same species; between distinct species of the same genus; and even between species belonging to different genera. Such a process is known as hybridisation, and the progeny as hybrids, the hybrid being distinguished as a variety-hybrid, species-hybrid, or genushybrid, according to circumstances.

Effects of the Sexual Process. The sexual process is not always limited in its effect to the production of a spore which will give rise to a new individual. For instance, when the female cell is borne by the parent at the time of fertilisation, the act of fertilisation induces a more or less marked growth and change in the adjacent organs and tissues of the parent, leading to the formation of a fruit (see p. 61). 
PART IV.

\section{CLASSIFICATION.}

Introductory. A systematic classification of plants may be arrived at by either of two methods. In the first, the different forms of plants are arranged according to some one given principle; by this means order is established, and a definite position in the system is assigned to each plant. Many such systems have been devised, and are known as artificial systems. The principle of classification in such a case must be determined more or less arbitrarily and without considering whether or not, in the resulting arrangement, the plants which are nearly allied are always brought together, and those which are less nearly allied are kept apart. The best known of these artificial systems is that of Linnæus, called the sexual system, which classifies plants by the number and mode of arrangement of the floral organs. This system is, however, only applicable to Phanerogams.

The natural system, to the gradual development of which a more exact knowledge of the reproduction of Cryptogams has largely contributed, has for its object the classification of plants according to their fundamental relationships; and as these are established once for all by Nature itself, the natural system is not based upou any arbitrary principle of classification, but depends upon the state of our knowledge of these fundamental relationships. These find their chief expression in the structure and other characteristics of the reproductive organs, as well as in the peculiarities of polymorphism presented by the life-history (see p. 2). This is more particularly true with regard to the definition of the larger groups of the Vegetable Kingdom; within these groups relationships may be exhibited sometimes in one way and sometimes in another, so that it is not possible to lay down any universal rules for determining close affinities.

As the investigation of this subject is still far from complete 
the natural system cannot be regarded as being perfectly evolved; the various general sketches which have hitherto been given are therefore no more than approximations to the truth.

The following are the main divisions of the Vegetable Kingdom :-

1st Groce. Thallophyta.

Class 1. Algæ.

Class 2. Fungi.

2xD Grocp. Bryophyta.

Class 3. Hepaticæ.

Class 4. Musci.

3RD Grocp. Pteridophyta.

Sub-kingdom

Cryptogamia.

Class 5. Filicinæ.

Class 6. Equisetinæ.

Class 7. Lycopodinæ.

4TH Group. Gymnospermæ.

Class 8. Gymnospermæ.

รัтн Group. Angiospermæ.

Class 9. Monocotyledones.

Class 10. Dicotyledones.

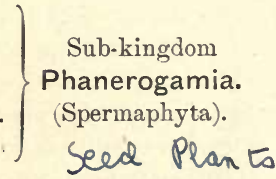

In considering the distinguishing characteristics of these great groups, it may be pointed out, in the first place, that whereas in the Bryophyta, Pteridophyta, and Phanerogamia, without exception, the life-history presents a regular alternation of generations, in the Thallophyta the alternation is generally irregular and is, in many cases, altogether wanting. The Bryophyta differ from the Pteridophyta and the Phanerogamia, in that $(a)$ in their lifehistory, "the plant"- - that is, the form to which the name is attached (see p. 2) -is the gametophyte, whereas in the two latter groups it is the sporophyte; and in (b) the relatively rudimentary differentiation, both morphological and histological, of the sporophyte, whereas their gametophyte is more highly differentiated than that of the two latter groups. Finally, though resembling them in many respects, the Gymnospermæ and the Angiospermæ differ from the Pteridophyta in that they produce seeds : in fact, the Phanerogamia may be contrasted, as seed-bearing plants (Spermaphyta), with the three groups (Thallophyta, Bryophyta, Pteridophyta) of plants which do not bear seeds, and which are collectively termed Cryptogamia. 
Furthermore, the Thallophyta are characterised by the fact that the female organ is never an archegonium, whereas in the other three groups it is never anything else than an archegonium, though it may present variations of form and structure (see p. 61).

Considered with reference to plants now actually living, the above-mentioned Classes are of very unequal extent; for while certain of them, as the Equisetinæ, include few forms, and those for the most part very closely allied, others, as the Dicotyledones and the Fungi, include an enormous number of very different forms. These discrepancies arise from the very nature of the natural system, for a great diversity does not necessarily display itself within the limits of a single Class; and it must not be forgotten that when the living representatives of a Class, for instance the Equisetinæ or the Lycopodinæ, are few, they are but the surviving remnant of once various and numerous forms which have become in great measure extinct.

Those Classes which include a sufficiently large number of forms are subdivided into subordinate divisions, as (1.) Sub-classes, (2) Series, (3) Cohorts, (4) Orders, and these again, if necessary, into Sub-orders, etc. ; but these names are applied in the most arbitrary manner to the different sub-divisions. The two narrowest systematic conceptions, viz., Geuus and Species, are used to indicate an individual plant. Under the term Species are included all individuals which possess in common such a number of constant characters that they may be considered to be descended from a common ancestral form. New peculiarities may arise in the course of multiplication: the individuals characterised by these new peculiarities are regarded in classification as varieties of the species. When several species resemble each other so distinctly that their general characters indicate a relationship, they are grouped together in a Genus. The limits of genera are consequently by no means fixed, but vary according to the views of individual botanists. In the larger genera the species are grouped into Sub-genera.

The scientific name of every plant consists-on the plan introduced by Linnæus - of two words, the first indicating the name of the genus, and the second that of the species. Thus, for instance, the greater Plantain, Plantago major, and the Ribwort, Plantago lanceolata, are two species of the genus Plantago. Since in early times the same plants were often described under different names, and as differrent plants were often designated by the same name, it 
is necessary in systematic works, in order to avoid confusion, to append to the name of the plant the name of the botanist who is the authority for it. Thus Plantago lanceolata L., indicates that Linnæus gave the plant this name, and at the same time that the plant meant is the one which Linnæus described and to which he gave the name. Again, the Spruce Fir is called Picea excelsa Link, while the same plant was placed by Linnæus in the genus Pinus under the name Pinus Abies L., and by De Candolle in the genus Abies (Don) as Abies excelsa DC.; hence these names are synonymous: but Pinus Abies Duroi, or Abies excelsa Link, is another plant altogether, the Silver Fir (Abies pectinata DC).

The method by which each plant has its place assigned to it in the natural system is exhibited in the two following examplesI. Plantago major; II. Agaricus muscarius :

I. Sub-kingdom : Phanerogamia.

Group : Angiospermæ.

Class : Dicotyledones.

Sub-class: Gamopetalæ.

Series : Hypogynæ.

Cohort: Lamiales.

Order: Plantaginaceæ.

Genus: Plantago.

Species : major.

II. Group: Thallophyta.

Class : Fungi.

Sub-class: Basidiomycetes.

Series: Autobasidiomycetes.

Order: Hymenomycetes.

Family: Agaricinæ.

Genus: Agaricus.

Sub-genus: Amanita.

Species: muscarius. 


\section{GROUP I.}

\section{THALLOPHYTA}

This group includes the more lowly-organised plants. As already mentioned, the alternation of generations is here either irregular or wanting. The morphology of these plants is such that the body is generally a thallus, though in certain cases there are more or less distinct indications of that differentiation of the body into root, stem, and leaf, which is so familiar in the sporophyte of the Pteridophyta and Phanerogamia. In those forms in which the sexual organs are differentiated, the female organ may be an oogonium, or a procarp, or an archicarp, but it is never an archegonium.

These plants are further characterised by the simplicity of their structure: the body may be unicellular, cœnocytic and unseptate or incompletely septate (see p. 63), or it may be multicellular. One conspicuous structural feature (shared, however, with the Bryophyta), is the absence of lignified cell-walls, the cell-walls consisting generally of some form of cellulose, and being frequently mucilaginous. In the lower forms, vegetative reproduction by some mode of cell-division is not uncommon.

The division of the group into the two classes Algæ and Fungi appears to be artificial, inasmuch as it is based upon a single character, the presence (Algæ) or absence (Fungi) of chlorophyll. But the division is really natural, since this one character is correlated with various others. It is, indeed, becoming usual to regard the Algæ and the Fungi as altogether distinct groups: but it appears to be preferable to continue to regard them as classes of the group Thallophyta, inasmuch as the Fungi have doubtless arisen from the Algæ, and since they possess many features in common.

\section{Class I.-ALG无.}

Many of these are plants of the simplest structure, which either live in water in the form of green, blue-green, red, or brownish filaments or måsses of cells, or clothe damp surfaces, such as rocks, walls, or the bark of trees, with a covering of one or other of these colours. In the sea they attain often a very considerable bulk; some of them are of a very beautiful red or brown colour, and 
attract the attention of the observer, partly by their considerable size, and partly by the elegance of their form.

The most important feature in which the plants of this Class differ from the Fungi is the presence of chlorophyll and the consequent mode of life. The Algæ are able to form the organic substances necessary for their nutrition, whereas the Fungi are obliged to obtain them from other organisms ( $p$. 195). The presence of chlorophyll is obvious enough in the green Algæ, but it exists also, though less evidently, in Algæ which have a bluish-green, olivegreen, brown, or red colouring-matter in addition in their chromatophores. The nature of this additional colouring-matter is usually the same throughout whole families which also resemble each other in their modes of reproduction. Hence this characteristic affords a trustworthy basis for classification, on which the Algæ are divided into the following sub-classes :-

Sub-class 1: Cyanophycex (or Phycochromaceæ), blue-green Algæ, containing a blue colouring-matter phycocyanin;

$"$

2: ChLOROPHYCEE, green Algæ, containing only chlorophyll and its derivatives;

$n$

3: PhжорнусEж, brown Algæ, containing a yellow or brown colouring-matter phycophoin;

9

4: RHODOpHyCe£, red Algæ, containing a red or purple colouring-matter phycoerythrin.

The colouring-matters phycocyanin, phycophæin, and phycoerythrin, can be extracted by means of water; they thus differ from chlorophyll, which is insoluble in water. The presence of chlorophyll in the Cyanophyceæ, Phæophyceæ, and Rhodophyceæ, can be proved by extracting the other colouring-matters with water; the plants then assume a green colour.

Structure. The body may be unicellular; or cœnocytic and unseptate (as in the Siphonaceæ), or incompletely septate (Cladophoraceæ); or multicellular. The unicellular forms either exist singly, or a number may be held together in a colony by a mucilaginous common cell-wall, either as a filament (e.g. some Desmidieæ) or a mass (palmelloid Protococcaceæ, Chroococcaceæ). In some of the multicellular forms (e.g. Spirogyra, Pandorina; Ulva) all the cells of the body are quite similar; at first vegetative, they eventually become reproductive, so that there is no distinction between nutritive and reproductive cells: in these histologically 
uudifferentiated forms the body is termed a conobium. Even the most highly organised forms attain but a low degree of histological differentiation, amounting (as e.g. in the Fucaceæ) only to a distinction between peripheral assimilatory tissue and central conducting tissue : in some of the Laminariaceæ the conducting-tissue has the form of sieve-tubes.

Morplology. The body may be entirely undifferentiated; this condition is most common in the unicellular forms, but it also occurs among the multicellular (e.g. Volvox); or it may present a distinction of base and apex (e.g. Rivularia); or it may be differentiated into root and thalloid shoot (e.g. Botrydium, Fucus); or into root, stem, and leaf (e.g. Cladostephus, Chara, Polysiphonia).

The undifferentiated body (thallus), as also the thalloid shoot,
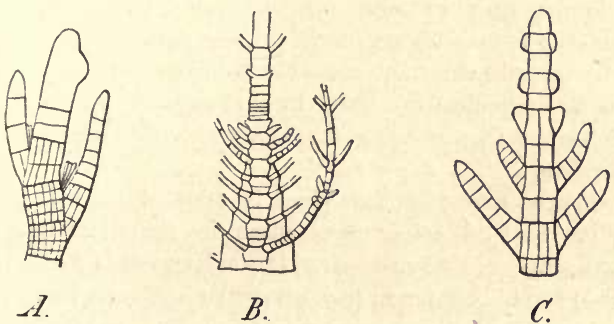

F1G. 133.-Growing-points of Algæ. A Apical growing-point, with apical cell, of Stypocaulon scoparium $(\times 30)$. B Intercalary growing-point (where the transverse lines are close together) of Desmarestia ligulata in longitadinal section ( $\times 60)$. C Apical growingpoint, with apical cell, of Chotopteris plumosa ( $\times 40$ : afcer Faulkenberg).

presents great variety of form: it may be spherical, or filamentous, or a flattened expansion, and its symmetry may be multilateral, isobilateral, or dorsiventral.

The growth in length of the thallus or of the shoot is effected in a variety of ways. It may be either apical or intercalary (Fig. 133.) In cellular plants the apical growth is effected either by a single apical cell (e.g. Characeæ, Sphacelarieæ, Fucaceæ, Dictyota, Fig. 106, most Rhodophyceæ); or by a marginal series of apical cells (e.g. Coleochæteæ, some flattened Rhodophyceæ); whereas in those cœnocytic plants (Siphonoideæ) which grow apically, there is no apical cell, but an apical mass of embryonic protoplasm. In some scases of intercalary growth there is no growing-point, all the cells 
of the body being merismatic (e.g. Spirogyra, Ulothrix, Ulva). In some few cases (e.g. Volvocoideæ, Botrydium) there is no growth after the embryo-stage.

The primary root is never developed in due proportion to the shoot; consequently, in order to ensure the attachment of the plant, adventitious roots are very commonly formed on the shoot, and when the shoot is dorsiventral unicellular root-hairs are commonly developed on the surface in contact with the substratum. In some cases special organs of attachment (haptera, see p. 48), are developed on the shoot; they may be adhesive discs borne on on the ends of branches of the shoot (e.g. Plocamium coccineum), or root-like out-growths as in Laminaria bulbosa, where at the base of the shoot, a large umbrella-shaped out-growth is formed, bearing numerous haptera on its upper and outer surface.

The leaves vary in form. In a few cases they somewhat resemble the foliage-leaves of the higher plants: in others (e.g. Cladostephus, Chara) they resemble the stem and its branches, but are distinguished by their limited growth; in others again (e.g. Polysiphonia and other Rhodophyceæ), they are filamentous and hair-like.

The Reproduction of the Algæ is effected in various ways. Vegetative multiplication takes place in the unicellular forms (e.g. Cyanophyceæ, Protococcoideæ, Desmidieæ, etc.) by cell-division, in some of the higher forms (e.g. Sphacelaria, Chara, Melobesia) by means of multicellular gemmæ (see p. 49). Non-motile cells, with a cell-wall, which are probably gemmæ, are thrown off by Vaucheria geminata, and sometimes by other species of Vaucheria (Chlorophyceæ). Reproduction by means of asexually-produced spores occurs with but few exceptions (e.g. Conjugatæ, Fucaceæ, Characeæ). Sexual reproduction is general throughout the class, though it has not yet been observed in all forms; it appears to be definitely absent in the Cyanophyceæ, and in some of the lower Chlorophyceæ (e.g. some unicellular Protococcoideæ).

There are various modes of sexual reproduction in the group. The following is an enumeration of them (see also p. 58):-

I. Isogamy: the sexual cells are similar gametes; process, conjugation; product, a zygospore.

(a) Gametes ciliated (planogametes); set free; e.g. Ulothrix, Pandorina, Ectocarpus, Cutleria.

(b) Gametes not ciliated (aplanogametes); not set free in the Conjugatæ ; set free in the Diatomaceæ. 
II. Heterogamy :

(a) Oogamy: the female organ is an oogonium; the sexual cells are spermatozoids and oospheres, the former ciliated and free-swimming, the latter not ciliated but sometimes free-floating; process, fertilisation ; product, an oospore ; (e.g. Volvox, Vaucheria, (Edogonium, Coleochæte, Characeæ, Fucaceæ).

(b) Carpogamy; the female organ is a procarp in which no female cell is differentiated ; male cell free, not ciliated, a spermatium; process, fertilisation; product, a fructification termed a cystocarp (Rhodophyceæ).

The sexual cells are aplanogametes, planogametes, oospheres, spermatozoids and spermatia; though they differ widely in various respects, they agree in being nucleated masses of protoplasm destitute of a proper cell-wall.

The aplanogametes are characterised by the absence of cilia and of any defined form; they are confined to the Conjugatæ and Diatomaceæ.

The planogametes are somewhat pear-shaped, the anterior more pointed end being destitute of the chromatophores which are present in the more rounded portion. They have two cilia which are inserted, in the isogamous Chlorophycex, at the pointed end of the cell; in the isogamous Phæophyceæ, laterally at the junction of the anterior colourless portion with the posterior coloured portion of the cell. In conjugation, the planogametes first come into contact by their colourless anterior ends.

The oospheres are spherical cells, usually containing chromatophores either throughout their whole substance, or leaving a colourless area on one side, the receptive spot, at which the spermatozoid enters in the process of fertilisation (e.g. Edogonium, Vaucheria, Sphæroplea).

The spermatozoids may be somewhat pear-shaded, resembling the zoospores of the plant, but smaller (e.g. Coleochæte, Edogonium); or they may be more elongated and club-shaped (c.g. Sphæroplea, Volvox); or still more elongated and spirally twisted (Characeæ). They usually bear two cilia at the pointed end; but in Vaucheria, Volvox, and the Fucaceæ, they are inserted laterally; in Edogonium there is a circlet of cilia round the pointed colourless end. They are faintly coloured, in the Chlorophyceæ usually yellow.

The male cells of the Rhodophyceæ are peculiar on account of the absence of cilia, and are distinguished by the special name

M.B. 
spermatium:-the spermatia surround themselves with a proper wall at the time of fertilisation.

The sexual organs. In those Algæ in which the sexual cells are similar, and the sexual process is isogamous, the sexual organs are gametangia. In many cases they are unicellular and undifferentiated: thus, when the gametophyte is unicellular (e.g. Desmidieæ, Diatomacer) the cell itself constitutes the gametangium; and in some multicellular or cannocytic forms (e.g. Zygnemeæ, Hydrodictyon, Confervoideæ) the gametangia are simply ordinary vegetative cells or cœnocytes. In some isogamous Algæ, however, the gametangia are differentiated as lateral appendages, and are multicellular, as in the Phæosporeæ; in Cutleria it is even possible to distinguish the male from the female gametangium.

When the gametangium is unicellular or cœenocytic, it usually gives rise to a number of gametes; but in the Conjugatæ a single gamete is formed. When the gametangium is multicellular, each cell usually gives rise to a single gamete; but in the male gametangium of Cutleria 2-8 gametes are developed in each cell.

The female organ, the oogonium, is in all cases unicellular or a cœnocyte; in Sphæroplea it is undifferentiated, retaining the form of a vegetative segment of the incompletely septate plant; in most cases it is more or less spherical in form, and in some species of Coleochæte it is prolonged at the apex into a delicate tube, the trichogyne. It opens, in most cases, by the absorption of the wall, at a point opposite the receptive spot of the oosphere when that is present; but in others (e.g. Volvox, Chara) it remains closed. In the former case the spermatozoid enters by the aperture: in the latter, it bores its way through the wall of the oogonium which becomes mucilaginous at its exposed surface. The oogonium of the Fucaceæ ruptures and sets free the contained female cell or cells. Usually a single female cell (oosphere) is formed in an oogonium, by the rejuvenescence of its protoplasmic contents; but in various Fucaceæ, the protoplasm divides to form two, four, or eight oospheres, and in the coenocytic oogonium of Sphæroplea there are several oospheres.

The female organ of the Rhodophyceæ, the procarp, is sometimes unicellular (e.g. Nemalieæ), but more commonly multicellular. It is in nearly all cases prolonged into a trichogyne, the basal portion being termed the carpogonium. The trichogyne remains closed. The protoplasm of the procarp does not undergo 
differentiation into a female cell comparable with the oosphere of the oogonium.

The male organ, the antheridium, is with few exceptions. (e.g. Sphæroplæa) more or less differentiated in form, attaining its highest development in the Characeæ. It is usually unicellular; but in Edogonium it consists of two cells, and of many cells in the Characeæ where its structure is highly complex. When the antheridium is unicellular, it usually gives rise to a number of male cells, but in Coleochæte and most Rhodophyceæ only to one. When it is multicellular, each fertile cell gives rise to a single spermatozoid.

Sexual organs are not known in the following forms: Cyanophyceæ, some Protococcoideæ, some Siphonaceæ, some Phæosporeæ (e.g. Desmarestia ; Laminariaceæ, except Chorda).

The asexual reproductive cells of the Algæ are formed either sexually or asexually: the former are either zygospores, or oospores ; the latter are spores.

The zygospores and oospores occur exclusively in the Chlorophyceæ and Phæophyceæ: they are spherical nucleated cells with a cell-wall. The differentiation of the cell-wall varies with the nature of the spores and of the conditions to which they are likely to be exposed. In the Phæophyceæ the zygospore or the oospore germinates at once on its formation, and its wall remains thin, and consists only of a single layer. In the Chlorophyeeæ, the sexually produced spore usually undergoes a period of quiescence before it germinates, and except in marine forms (e.g. Acetabularia), it is exposed during this period to the danger of desiccation. As a protection, its wall consists of two layers, a delicate endospore, and a hard cuticularised exospore which often grows out into prominences, giving to the spore a stellate appearance.

The spores produced asexually may be resting-spores with a thick wall, which may consist of two layers as described above (e.g. many Cyanophyceæ): or cells destitute of a cell-wall, either ciliated (e.g. zoospores of Edogonium, Coleochæte, Sphæroplæa, Pandorina), or not ciliated (e.g. tetraspores and carpospores of the Rhodophyceæ).

The asexual reproductive organs are sporangia. In the simple unicellular forms, the whole body may become a sporangium (e.g. Hæmatoccoccus): in some coenobitic multicellular plants there are no definite asexual reproductive organs, but any of the cells of the body may act as such (e.g. Ulothrix, Pandorina, Coleochæte, 
Ulva) without any special morphological differentiation; this is true likewise of the cœnocytic Algæ Siphonoideæ, such as Botrydium, Vaucheria, Sphæroplea, Cladophora, where the whole or part of the body may act as a sporangium. Specially differentiated sporangia occur only in some Phæosporeæ, and in the Rhodophycer where they usually produce each four spores (tetraspores) and are hence termed tetrasporangia: specially differentiated sporangia are also developed in the cystocarp of the Rhodophyceæ where they are termed carposporangia: these organs are in all cases unicellular.

In the Cyanophyceæ the formation of spores is effected without any sporangium, for in these plants a cell of the body is converted into a spore by simple encystment.

As a rule a sporangium gives rise to a number of spores; but only one is formed in the sporangium of Vaucheria and of (Edogonium (see p. 85), and in the carposporangium of the Rhcdophyceæ.

Sub-Class I. Cyanophycex (also called Phycochromaceæ), or blue-green Algæ. The body consists of a single, more or less nearly spherical cell, as in most of the Chroococcaceæ (e.g. Glœocapsa, Fig. 134); or it is a multicellular layer one cell thick (e.g. Merismopedia); or it is filamentous, consisting of a row of cells (e.g. Oscillaria, Nostoc, Rivularia, Scytonema). When the body is filamentous, it sometimes presents a distinction of base and apex (e.g. Rivularia); and it is frequently branched. In most cases growth and cell-division go on in all the cells of the body, but in the Scytonemacer only at the apex. The plant is usually free, but it grows attached in some species of Rivulariaceæ and Sytonemaceæ. A characteristic feature of the sub-class is the more or less bulky mucilaginous cell-wall which invests the cells and filaments. The filaments of the Oscillariaceæ exhibit a gliding, oscillating movement, but the mechanism of it is not fully understood.

Reproduction is mainly effected in a purely vegetative manner. In the unicellular forms (Fig. 134) each cell-division necessarily leads to the formation of new individuals. In the flattened forms (e.g. Merismopedia), when the body reaches a certain limit of size, it simply breaks up into a number of portions each of which becomes a new individual. In the filamentous forms, vegetative propagation is effected by the breaking up of the filament into lengths, each such portion being termed a hormogonium; in most 
of them (except Oscillariacex) the limits of the hormogonia are indicated by large inert cells, heterocysts (Fig. $135 \mathrm{~A}$ ), which differ both in size and colour from the living cells to the filament. The

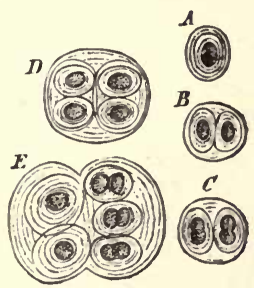

Frg. 134.-Gloocapsa ( $x \quad 300)$ in varions stages: $A$ becomes $B C D E$ by repeated division. (From Sachs.)

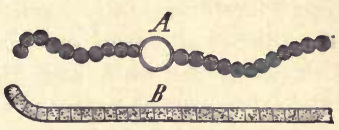

FIG. 135. - A Filament of Nostoc; the large unshaded cell is a heterocyst. $B$ Portion of a filament of Oscillaris $(+300)$.

hormogonia are motile, though the mechanism of their movements: is not understood; they eventually separate, and escaping from the common mucilaginous cell-wall of the filament, they developeby growth and cell-division into new filaments (Fig. $136 \mathrm{AB}$ ).

In many cases special reproductive cells, spores, are produced. Each spore is formed from a single cell of the body, which surrounds itself with a thick firm exospore; the spore germinates
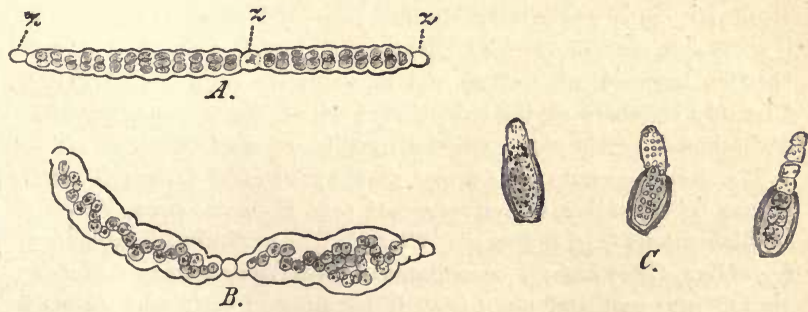

Frg. 136. - (After Thuret : $\times$ 330). $A$ and $B$ Development of a filament from a hormogonium of Nostoc vesicarium. A Cells of hormogoninm dividing at right angles to its long axis; $B$ rows of cells formad as $B$ uniting at alternate ends, so as to constitnte a Nostocflament; $z$ heterocysts. C Germinating spores of Anabena licheniformis.

under favourable conditions, the exospore being ruptured (Fig. $136 C$ ).

It is possible that zoospores are produced in some forms, but 
the evidence is at present inconclusive. No form of sexual reproduction has been observed in any member of this sub-class.

The cells of the Cyanophycer contain nuclear substance, but the nucleus is not well-defined; and the chlorophyll and the phycocyanin appear to be diffused throughout the cytoplasm, and not to be aggregated in special plastids.

The Cyanophyceæ resemble the Schizomycetes, among the Fungi, in many respects; as, for instance, in their general form and structure, in their vegetative multiplication, in their spore formation, in the absence of sexual reproduction, in the formation of a bulky mueilaginous cell-wall, and in their polymorphism. On these grounds they are frequently placed, along with the Schizomycetes, in a distant class Schizophyta. But this arrangement does not seem to secure any special advantage. It is more natural to regard the Cyanophyceæ and the Schizomycetes as parallel groups, the one belonging to the Algæ, the other to the Fungi.

The Cyanophyceæ are both marine and fresh-water; many grow on damp walls, rocks, etc.

Sub-Class II ChLorophyceæ, or Green Algæ. In the simpler forms the plant consists of a single cell (e.g. Protococcoideæ, some Desmidieæ): or it is coenocytic, as in the Siphonoideæ, either unseptate (Siphonaceæ) or incompletely septate (Cladophoraceæ, Hydrodictyaceæ); it is, in fact, only in this sub-class that the conocytic structure occurs among the Algæ: or the body is multicellular, with essentially similar cells and therefore conobitic (e.g. Spirogyra, Pandorina, Ulva), or exhibiting at least a distinction between vegetative and reproductive cells (e.g. Volvox). The only members of the sub-class in which there is any appreciable differentiation of the vegetative cells are the Characeæ.

The body presents all degrees of morphological differentiation; it may be a thallus, either spherical (e.g. Hæmatococcus, Volvox), or filamentous (e.g. Spirogyra, Ulothrix), or a flattened expansion (e.g. Ulva, Coleochæte); or a filament with rudimentary differentiation into root and shoot (e.g. (Edogonium); or it may present differentiation into stem, leaf, and root.(e.g. Characeæ). It may be free or attached. Growth and cell-division commonly go on in all the cells of the body, so that the growth is intercalary (e.g. Spirogyra, Edogonium, Ulva); it is but rarely that there is a definite growing-point, and then it is apical (Coleochæte, Characeæ, some Siphonoider); and in the cellular plants which have an apical growing-point, there is a single apical eell. 
Vegetative multiplication by division occurs in some of the lower forms (e.g. Protococcoideæ) of this sub-class. Reproduction by zoospores is general (absent in Plenrococcaceæ, Conjugatæ, most Volvocoideæ, Characeæ); they are formed, not in specialised reproductive organs, but in any cell or part of the body. A sexual process has been observed in members of every division of this sub-class : it is either isogamous, consisting in the fusion of planogametes or aplanogametes (Conjugatæ), with the formation of a zygospore; or oogamous, consisting in the fertilisation of an oosphere, which is in no case extruded from the female organ, by a spermatozoid, with the formation of an oospore. The sexual organs are either gametangia, or antheridia and oogonia; they are unicellular in all the cellular forms (except the antheridium of Characeæ and that of some species of (Edogonium), and present various degrees of specialisation. A gametangium gives rise to many planogametes, but to not more than one aplanogamete; the oogonium produces but a single oosphere, except in the cœnocytic Sphæroplea; the unicellular (as also the cœnocytic) antheridium gives rise to numerous spermatozoids, except in Coleochæte and in some species of Edogonium where it forms only one; in the multicellular antheridium of the Characeæ, numerous spermatozoids are developed singly in distinct mother-cells.

There is considerable polymorphism in many members of this sub-class, so that various forms which were considered to be independent members of the simpler families are now known to be merely phases in the life-history of more complex forms; for instance, various unicellular forms, such as Protococcus, Palmella, Gloosystis, etc., formerly classed among the Protococcaceæ, are now known to be stages in the life-history of other Protococcoideæ, Confervoideæ, Siphonoideæ, etc.

The Chlorophyceæ may be classified as follows:-

Series I. Protococcoideæ: plants unicellular, isolated or held together by mucilaginous cell-walls into colonies; non-motile; the body is a thallus, and has no apical growth; reproduction, vegetative by division, asexual by zoospores, rarely sexual and then isogamous with conjugation of planogametes.

Series II. Volvocoideæ: plants unicellular or multicellular, and when multicellular not filamentous; not attached, motile by means of cilia ; the body is a thallus, with limited growth; reproduction, vegetative by division, asexual rarely by zoospores, sexual, either isogamous with conjugation of planogametes, or oogamous. 
Series III. Siphonoideæ: plants cœnocytic, unseptate or incompletely septate; non-motile; the body may be a thallus or may be differentiated into stem, leaf, and root; with or without apical growth; reproduction, asexual by zoospores; sexual, either isogamous (planogarnetes), or oogamous.

Series IV. Confervoideæ: plants generally multicellular, filamentous, branched or unbranched; growth frequently intercalary, rarely apical; body attached or floating, a thallus, or sometimes with rudimentary differentiation into root and shoot; reproduction, asexual by zoospores, in some cases; sexual, isogamous (either planogametes or aplanogametes), or oogamous.

Series V. Charoideæ: plants multicellular; body attached, differentiated into stem (with apical growth), leaf, and root; reproduction, vegetative by gemmæ, no zoospores; sexual, oogamous, with multicellular antheridium of complex structure.

Series I. Pnoтососcondex. The forms included in this series are very various, and, inasmuch as their life-history is for the most part imperfectly known, it is uncertain to what extent they are independent, or are only phases in the life-history of each other or of higher Chlorophyceæ.

It appears, however, that they may be fairly classified into two orders :-

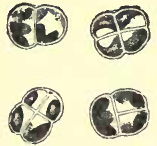

Fig. 137.-Pleurococcus vulgaris $(x$ 540): cells dividing.

Order 1. Pleurococcaceæ: cells isolated, or aggregated into colonies of more or less definite form; multiply only by :cell-division; no other mode of reproduction.

To this order belong such isolated forms as Pleurococcus and Oocystis; and such aggregate forms as Palmophyllum, Palmodictyon, Scenedesmus. They generally grow in fresh water; but Pleurococcus grows on damp trees, stones, etc., and Palmophyllum is marine.

Order 2. Protococcaceæ : cells isolated, or aggregated into colonies of more or less definite form; multiplication by cell-division is not general; reproduction, asexual by zoospores, or, less commonly, sexual isogamous (planogametes).

This order includes (1) isolated unicellular forms, either free, such as Chlorococcum, Halosphæra; or attached at one end, such as Sciadium, Characium; or inhabiting the tissues of higher plants, such as Chlorochytrium, Phyllobium, Endosphæra; (2) cells aggregated into mucilaginous masses of indeterminate form, e.g. Chlorosphæra which lies in or on submerged fresh-water plants; (3) cells aggregated into mucilaginous masses of determinate form, the whole colony being generally attached at some definite point (e.g. Apiocystis, Tetraspora), or free-floating (e.g. Dictyosphærium, Botryococcus).

In some of these forms there is what is termed a Palmella-stage, in which the cells multiply by division, surrounded by mucilage (e.g. Hormotila, Characium).

Isogamous reproduction by means of planogametes is known in some 
forms (e.g. Tetraspora, Chlorochytrium). The zygospore, on germination, usually gives rise to one or two zoospores.

Series II. Volvocompes. The body, in this series, is free-swimming for at least a considerable portion of its life, and consists of one or more cells clothed with a somewhat mucilaginous cell-wall, through which the cilia (usually two from each cell) project into the water. According to the unicellular or multicellular structure of the body, two orders may be distinguished:-

Order 1. Chlamydomonadaceæ: body a single cell, resembling in many cases a zoospore in appearance, but differing essentially from it in possessing a cell-wall; some forms have a resting Palmella-stage, in which they multiply by division; sexual process, generally isogamous with fusion of planogametes, but sometimes in Chlamydomonas it is really oogamous, consisting in the fusion of a small (male) aplanogamete with a larger (female) aplanogamete; the reproductive cells (planogametes or aplanogametes) are formed by division; the zygospore generally gives rise, on germination, to two or four motile or non-motile individuals.

The principal genera are Chlamydomonas, Hæmatococcus (or Sphærella), Phacotus.

Order 2. Volvocaceæ: body multicellular, consisting of a definite or indefinite number of cells, which may be all alike (coenobium), as in Pandorina (Fig. 138), which consists of 16 cells; or there may be a distinction between vegetative and reproductive cells (Volvox). Vegetative reproduction is effected by division of any or all of the cells of the body (Pandorina), or of certain non-motile gonidial cells (Volvox), from each of which a new individual is formed; sexual reproduction, isogamous by planogametes (Pandorina), or oogamous (Volvox).

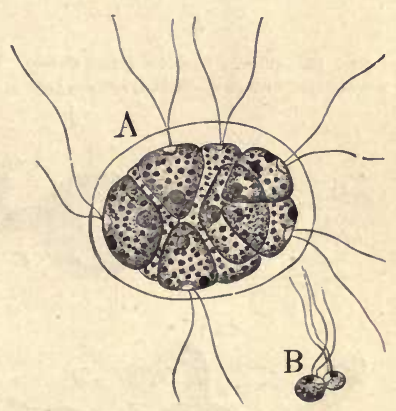

Fre. 138.-Pandorina Morum $(\times 400)$ : $A$ vegetative stage; $B$ two planogametes in process of conjugation.

In Pandorina any cell may divide to form a new individual, or to form planogametes; the zygospore sets free one or two zoospores on germination.

Volvox is sometimes monceious, sometimes diccious. The contents of the oospore undergo repeated bipartition until the requisite number of cells to form a new individual is attained. The vegetative development of new individuals from the gonidial cells of Volvox, takes place in precisely the same way as the development from the oospore: the small individuals formed vegetatively from the gonidial cells are set free into the cavity of the parent, where they remain until it dies, when they are 
set free. The spermatozoids of Volvox are club-shaped, yellow, and

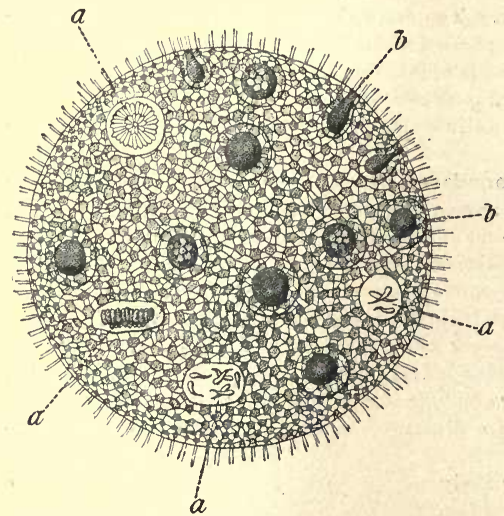

Fre. 139.-Volvox Globator (after Cohn: ' x about 100), monœcious, with antheridia $a$, and oogonia $b$. bear two cilia, inserted laterally.

Series III. SIPHoNoIDEx. The forms included in this series may be arranged in the three following orders : - Siphonaceæ, Cladophoraceæ, Hydrodictyaceæ.

Order 1. Siphonaceæ. The body is an unseptate, conocyte, septa being only formed in connexion with the development of reproductive organs ; it is usually attached, and presents a considerable variety of form; it may be thalloid and then be

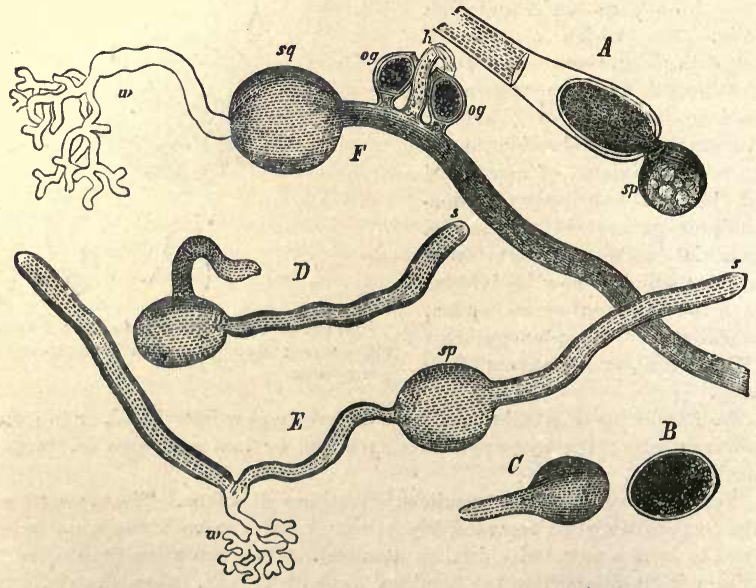

FIG. 140. - Taucheria sessilik $(\times 30): A s p$ a newly-formed zoogonidium; $B$ a resting zoospore; $C$, the commencement, $D$ and $E$ more advanced stages, of germination; sp zoospore; 8 apex of the green filament; $w$ a colourless adventitious root; $F$ filament with sexual organs; og oogonium; $h$ antheridium after rupture. (After Saohs.) 
tubular and much branched (usually in Vaucheria, Fig. 140); or it may be differentiated into root and shoot, the shoot assuming. various forms, such as a rounded cushion (Codium Bursa), or a simple vesicle (Botrydium, Fig. 142); or the shoot may be differentiated into stem and leaf (Acetabularia, Fig. 141); it has sometimes continuous apical growth (e.g. Vaucheria); the wall is sometimes impregnated with chalk (e.g. Acetabularia).

Asexual reproduction is known to take place in only a few forms; it is effected by zoospores, which are uniciliate in Botrydium, or multiciliate, as in Vaucheria, where they are sometimes non-motile. In Vaucheria the spores are formed singly in simple sporangia formed by septation of branches of the body; in Botrydium they are formed in large numbers from the protoplasm of the tubular body.

Sexual reproduction is generally isogamous by planogametes: Vau-

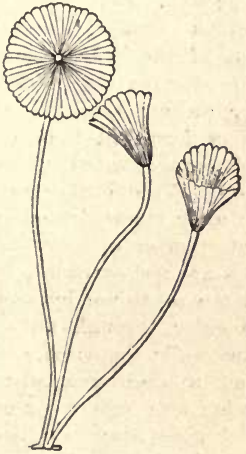

FrG. 141. - Acetabularia crenulata (after Kützing ; nat. size) : the terminal circular disc consists of a whorl of coberent leaves; in these the gametangia are formed.

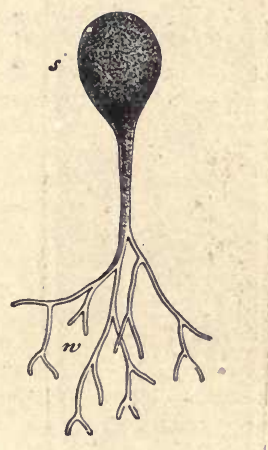

Frg. 142.-Botrydium granulatum $(\times 6)$ : 8 the green shoot; $w$ the colonrless root.

cheria is the only known oogamous form. Isogamy is known in Botrydium, Acetabularia, and others. In Botrydium and Acetabularia the gametangia are formed by the aggregation of the protoplasm (in the coherent leaves of the latter) into rounded masses which become surrounded by a wall, and are set free by the rupture of the parent organism; their contents undergo frequent division to produce the planogametes which are eventually set free. In Botrydium and Acetabularia the conjugating gametes are quite similar.

In Vaucheria, the sexual organs are unilocular antheridia and oogonia, and are developed as lateral branches which become shut off by a septum (Fig. 140); each antheridium gives rise to a number of biciliate spermatozoids; each oogonium gives rise to a single oosphere which is not 
extruded, and has a hyaline receptive spot directed towards the opening of the oogonium.

Vaucheria forms the green felt which covers the soil in damp flowerpots or other moist situations. Aquatic species occur in ditches, etc., often forming a thick scum on the surface.

Order 2. Cladophoraceæ. The body is incompletely septate and the segments are coenocytic; it is filamentous, branched or unbranched, sometimes differentiated into root and thalloid shoot, attached or free-floating,

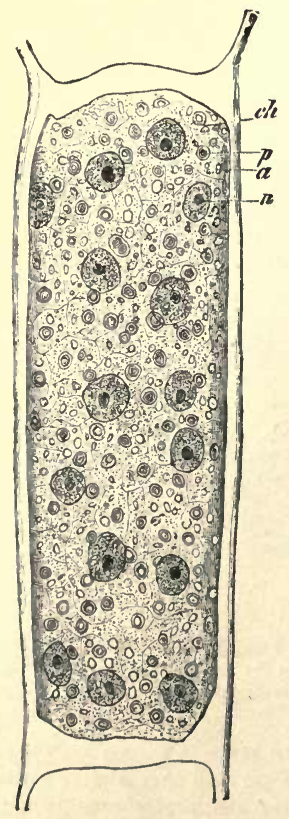

Fig. 143.-Cladophora glomerata (after Strasburger: $x$ 510). A conocyte of the fllament (chromic acid and carmine preparation): $n$ a nucleus; $c h$ a chloroplastid; the polygonal chloroplsstids form a continnous layer, the ontlines of the individusl plastids remaining vieible; $p$ pyrenoids; $v$ starchgrains. the shoot with or without apical growth: reproduction, asexual by zoospores; sexual, isogamous, or oogamous.

Fam. 1. Sphoroplea: the body consists of floating unbranched filaments, without distinction of base and apex, and with intercalary growth. Each segment contains numerous small chloroplastids. Any segment of the body may become a sexual reproductive organ, either an oogonium or an antheridium, without any change of form; in the oogonium several oospheres are formed by free cellformation (see p. 87), and likewise in the antheridium, after repeated nuclear division, a great number of spermatozoids; the oospheres are not extruded, but are fertilised in the oogonium by spermatozoids which enter through an opening formed in the wall; the oospore, at first green, assumes a bright red colour, and on germination sets free 2-8 zoospores, each of which gives rise to a new filament. Sphæroplea is the only genus, and it comprises but one species-S. annulina : it inhabits fresh water.

Fam. 2. Cladophoreae: body filamentous, generally attached by a basal root-segment, branched (e.g. Cladophora) or unbranched (e.g. Chætomorpha), with usually intercalary growth (though it is apical in Cladophora); each segment contains a peripheral layer of chloroplastids (Fig. 143), continuous or interrupted, in which are scattered pyrenoids; reproduction, asexual by zoospores in some forms (e.g. Cladophora), or vegetatively (e.g. Pithophora); an isogamous sexual process between planogametes has been observed in Cladophora: reproductive cells formed in 
all or any of the segments of the body without special modification; the zygospore appears to develope directly into a new plant (Cladophora).

Cladophora and Chætomorpha oocur in both salt and fresh water; Pithophora exclusively in fresh water; Urospora exclusively in salt water; Rhizoclonium occurs both in fresh and salt water, and also on damp soil. Cladophora is to be found attached to stones in ditches.

Order 3. Hydrodictyaceæ: body thalloid, a non-motile unattached crenobium, formed by the aggregation of originally distinct cells, of limited growth; a net (Hydrodictyon), or a flat plate (Pediastrum): reproduction, asexual by zoospores; sexual, isogamous by planogametes. These plants are confined to fresh water.

The following is a brief sketch of the life-history of Hydrodictyon. The asexual reproduction of this plant consists in the formation of a large number $(7,000-20,000)$ of zoospores in any one of the segments of the conobium; the zoospores do not escape from the segment, but swim actively within it for a time, when they come to rest, cohering, as they do so, to form a small net-like conobium, which is eventually set free by the disorganisation of the wall of the sporangium, and then grows to the full size. The sexual reproduction consists in the formation in a segment (gametangium) of the conobium, of a very large number $(30,000-100,000)$ of small planogametes; these are set free into the water, and conjugate to form zygospores. The zygospore, which has a thick wall and is angular in form, undergoes a period of quiescence ; on germination its contents divide into two or more cells which are set free as zoospores, and, after a brief period of motility, come to rest. Each then surrounds itself with a thick cell-wall, and assumes a peculiar angular form, on account of which it has been termed the polyhedron-stage. The polyhedron grows and its contents divide into a number of zoospores; the outer coat of the polyhedron then ruptures, and the contents, surrounded by the thin inner coat, are extruded; the zoospores then arrange themselves into a small Hydrodictyon-plant.

The life-history of Pediastrum is essentially the same as that of Hydrodictyon; but in Pediastrum the zoospores are set free, surrounded by a delicate membrane within which they come to rest and cohere to form a Pediastrum plant.

Series IV. Confervoidex. The principal forms included in this series may be arranged in the following orders:-

Sub-series A. Azoosporeæ: no zoospores.

Order 1. Conjugatæ: sexual reproduction by aplanogametes.

Sub-series $B$. Zoosporeæ; asexual reproduction by zoospores.

Isogamous Orders :-

Order 2. Ulothrichaceæ: body filamentous, unbranched.

Order 3. Ulvaceæ: body a flat or tubular cellular expansion.

Oogamous Orders :-

Order 4. Edogoniaceæ : body filamentous, unbranched (except Bulbochæte).

Order 5. Coleochætacæ: body filamentous, branched; oogonium with a trichogyne. 
An asexual formation of spores takes place in all the Confervoider except the Conjugatæ. A sexual formation of spores takes place in all the Confervoideæ; in the isogamous forms the product of conjugation is a zygospore; in the oogamous forms it is an oospore. In the isogamous forms the sexual organs, or gametangia; are not differentiated; any or all of the cells of the body may act as gametangia; the sexual cells are (except in the Conjugatæ) free-swimming similar planogametes; in the Conjugatæ the garnetes are not set free into the water and they are not eiliated. In the oogamous forms the sexual organs are antheridia and oogonir; they are more or less markedly differentiated. The sexual cells are oospheres and spermatozoids. The oospheres are formed singly in the oogonium. The spermatozoids are formed singly in the mother-cell; they resemble the zoospores of the respective plants, but are smaller and are not green.

In Ulothrix and Edogonium, the contents of the spore, whether zygospore or oospore, undergo division giving rise to two or more zoospores which are set free and, after a longer or shorter period of movement, come to rest and germinate, each developing into a plant. In Coleochæte, the contents of the oospore likewise undergo division, but the product is not several zoospores; it is a small multicellular body, each cell of which eventually sets free its contents as a single zoospore which, on coming to rest, develops into a plant.

The following is a brief account of the orders of the Confervoideæ:-

Order 1. Conjugatæ; the characteristics of this sub-order have been already stated; it need only be added that the plants are usually not attached. It includes the families Desmidieæ and Zygnemeæ; all freshwater.

Family 1. Desmidiece. These are unicellular organisms, either solitary or connected into filaments; they possess some power of locomotion. Each cell consists of a mass of protoplasm with a central nucleus, and contains two or more chloroplastids in which lie conspicuous pyrenoids. The cell-contents are arranged symmetrically in the two halves of the cell, and in many forms this bilateral symmetry is emphasised by a deep constriction in the median plane.

The Desmids multiply to a large extent by division; the cell is divided into two by the formation of a cell-wall in the median plane, and then each half produces a new half corresponding to itself; hence the two halves of a cell are of different ages. The only other mode of reproduction is by means of zygospores formed by the conjugation of two individuals. On germination the contents of the zygospore divide into two halves, each of which becomes an individual.

Among the commoner forms of the Desmidieæ are Closterium (Fig. 144), Staurastrum, Euastrum (Fig. $144 \mathrm{C}$ ). They can best be found in pools of peaty water on moors and bogs.

Family 2. Zygnemex. These plants, consisting of long, delicate, unbranched filaments composed of cylindrical cells, occur as floating green masses in ponds and springs. Each cell contains a peripheral layer of protoplasm in close contact with the cell-wall, enclosing a large central 
vacuole in which the nucleus is situated in a mass of protoplasm connected with the peripheral layer by several delicate protoplasmic filaments. The chloroplastids are the most conspicuous feature of the cell ; in Spirogyra (Fig.

145) the chloroplastids, of which there may be from one to four, lie in the parietal protoplasm; they are spirally twisted in Spirogyra, but are nearly straight in Sirogonium: like those of the Desmids, these chloroplastids contain several pyrenoids with associated starchgrains; in Zygnema (Fig. $144 A$ ) each cell contains two chloroplastids, suspended in the middle line,

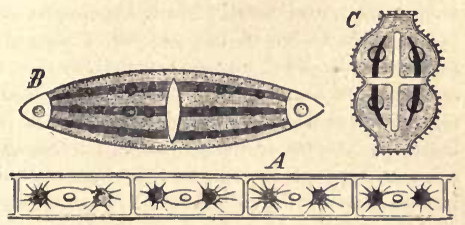

Fig. 14t.-A Fragment of a flament of Zygnema; in each cell are two star-shaped chloroplastids connected by a colonrless mass of protoplasm in which lies the nuclens. $B$ Closterium. C Enastrum, two Desmids with chloroplastids; in $B$ there is a vacuole at each end in which a number of granules may be seen in motion. each containing a pyrenoid with starch-grains.

The filaments elongate by the growth and division of all the constituent cells, and readily break up into segments, consisting of one or more cells, which grow into new filaments.

The sexual organs (gametangia) are quite undifferentiated; any or all of the cells of a filament may act as sexual organs, the whole of its contents being converted into a single non-ciliate gamete. The sexual process (conjugation) consists in the fusion of the gametes derived from two cells belonging generally to two filaments, but sometimes to the same filament. It is effected, in most cases, by the development of a lateral outgrowth from the middle of each gametangium; the two ontgrowths meet (Fig. 146) and their walls become absorbed at the point of contact so that the cavities of the two gametangia are continuous. The protoplasmic contents of each cell contract away from the wall of each gametangium to

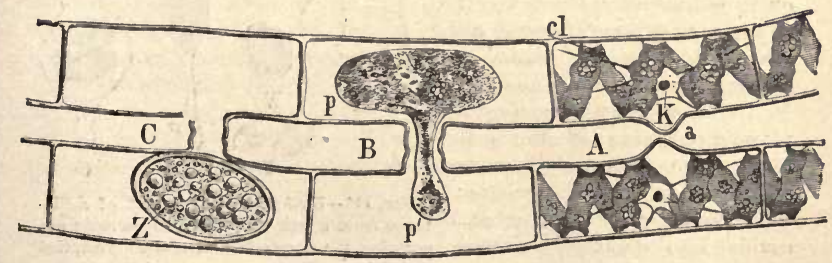

Fre. 145. - Conjugation in Spirogyra $(\times 400)$. At $A$ two cells of adjacent filaments are abont to conjugate, and are putting ont protuberances $(a)$ towards each other; cl chlcroplastid; $k$ nucleus. At $B$ the gamete $p$ of the one cell is passing over and fusing with that of the other $(p)$. At $C$ the process of conjugation is completed, the zygospore $Z$ being the product." 
form the gamete. The formation of the gamete takes place earlier in one gametangium than in the other, and the first formed gamete travels across the connecting channel into the cavity of the other gametangium when it fuses with the other gamete; the resulting cell surrounds itself with a wall, and constitutes a zygospore. Since the first-formed gamete is the more active in the process of corjugation, it may be regarded as a male cell, the other as a female cell, so that there is a rudimentary differentiation of sex. Further, since the cells of any one filament all behave alike in the process of conjugation, it is possible to speak of male and female filaments or individuals. In Zygogonium, however, the gametes are similar, both as regards the time of their formation and their share in conjugation; in this form the gametes meet in the connecting channel and there fuse to form the zygospore.

After a period of rest, the zygospore germinates; the outer coat is ruptured, and the contents, covered by a thin cell-wall, protrude as a filament which is divided by a transverse septum into two cells; of these, the one becomes elongated and remains narrow in the cavity of the spore, undergoes no further division, and contains little or no chlorophyll, whereas the other becomes broader, contains one or more chloroplastids and, by repeated division, forms a filament. Thus there is at first a differentiation of the body into root and shoot, but this soon ceases to be apparent. It is most clearly marked in Spirogyra. Principal genera: Zygnema, Spirogyra.

Spirogyra occurs as floating masses in ponds or slowly running water during the warmer parts of the year, but only where the water is pure. It may be found in conjugation about May or June.

Order 2. Ulothrichaceæ. The unbranched filament is attached by a narrow elongated, frequently colourless, root-cell; the growth in length of the filament is intercalary, that is, each cell elongates and divides by a transverse wall into two.

The reproductive organs are quite undifferentiated; any cell of the filament may become an asexual reproductive organ, or a sexual organ, a gametangium. In the former case the protoplasmic contents of the cell divide into two or four parts which are set free as zoospores; in the latter case the contents divide into eight or sixteen which are set free as planogametes. The zoospores are somewhat pear-shaped in form, the more pointed end being colourless

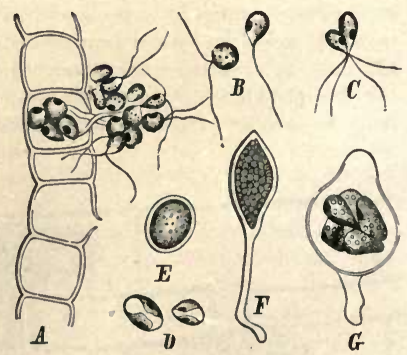

Fre. 146.-Ulothrix zonata: $A$ part of a fila. ment from a cell of which planogametes are escaping, the other cells having already emptied. themselves; $\boldsymbol{B}$ planogametes; $\boldsymbol{C}$ the process of conjugation; $D$ yonng zygospores; $E$ maturo zygospore; $F$ germinating zjgospore with hyaline root; $G$ the contents of the embryonic shoot dividing to form zoospores. 
and bearing four cilia and a pigment-spot: the planogametes resemble the zoospores but are proportionately smaller and have only two cilia. When the zoospores come to rest, they secrete a cell-wall, and become attached by the colourless end which forms the root-cell of the developing filament. The planogametes conjugate to form zygospores, but if they fail to conjugate they may germinate independently, and they do so in the same manner as the zoospores, only the resulting filament is smaller. The zygospore grows and attaches itself by its hyaline portion which developes into a root; after a period of quiescence its contents divide and are set free as $2-8$ zoospores Fresh water and marine. Principal genera : Ulothrix, Conferva.

Order 3. Ulvaceæ. The membranous body consists of a single flat layer of cells (Monostroma), or of a single tubular layer of cells enclosing a cavity (Enteromorpha), or of two layers in close contact (Ulva); the body is attached, at least when young, by a root, and is sometimes branched (esp. Enteromorpha); the growth of the body is intercalary, all the cells being concerned in it.

Any cell of the body may become a sporangium or a gametangium; the zoospores have four cilia, the planogametes two; conjugation of planogametes has been observed in the three above-mentioned genera; the zygospore, on germination, develops directly into a new plant, producing basally the root and distally a cellular filament which becomes the thalloid shoot. Inhabit both fresh and salt water.

Order 4. CEdogoniaceæ. Filaments unbranched (except Bulbochæte), attached by a root; growth intercalary. The mode of growth of the individual cells of Edogonium is peculiar; in the plane of division a ring of cellulose is formed round the cell-wall; the cell-wall then ruptures, and the cellulose-ring is stretched so as to form a membrane across the rent; as this process takes place repeatedly near the upper end of the cell, the projecting edges of the repeatedly ruptured cell-wall form a series of caps; the transverse septa, dividing the elongated cells into two, are always formed toward the lower end of the cells.

Any cell of the body may be a zoosporangium, setting free its protoplasmic contents as a single zoospore with a circlet of cilia round its more pointed colourless end. On coming to rest, the zoospore attaches itself by its colourless end, surrounds itself with a cell-wall, and grows into a filament; the colourless portion becomes the root-cell (see Fig. 62).

The sexual organs are differentiated. Some cells of a filament increase in size and become rounded in form, each constituting an oogonium. The protoplasm in each oogonium contracts away from the wall to constitute the single oosphere. Access to the oosphere is afforded either by the perforation of the oogonium-wall, or by the partial breaking-away of the cell immediately above the oogonium in the filament. The oosphere has a well-rnarked receptive spot. The antheridia are formed, either in the same or another filament as the species is monocious or diøcious, by the repeated transverse division of a cell of the filament; in some species the antheridium gives rise to a single spermatozoid, but in most it undergoes division into two cells each of which produces a spermatozoid. The sper-

M.B. 
matozoids resemble the zoospores, but are smaller and are yellow instead of green; they are set free, and finding their way to the oogonia, one enters an oogonium and fertilises the oosphere, penetrating into it at the receptive spot (Fig. 147).

In some species, termed gynandrosporous, the filaments produce no antheridia, but only oogonia. Some of the cells of such a filament undergo transverse division to form short cells which somewhat resemble

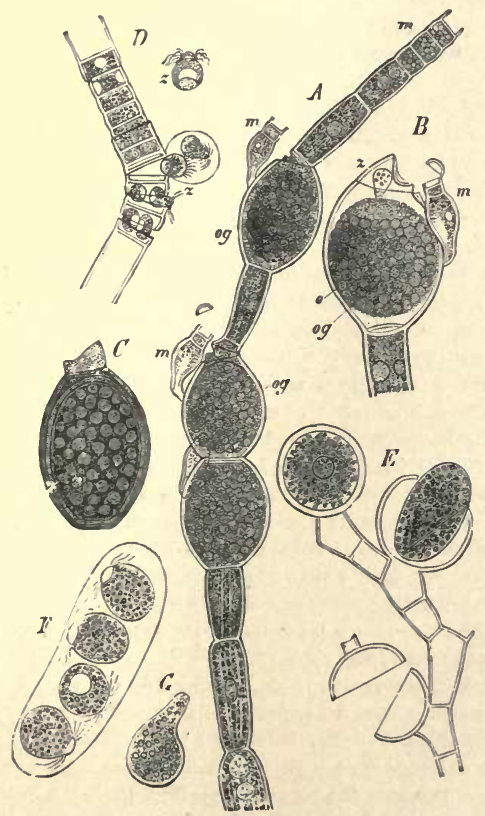

Frg. 147.-A Edogonium ciliatum (× 250). A Middle part of a sexnal flament with three oogonia $(\mathrm{og})$ fertilised by the dwart-male plants $(m)$, developed from androspores formed in the cell $m$ at the npper part of the flament. $B$ Oogonium at the moment of fertilisation: o the oosphere; og the oogoninm; $z$ the spermatozoid in the act of forcing its way in; $m$ dwarf-male plant. $C$ Ripe ospore. $D$ Piece of the male flament of $G E$. gemelliparum, z spermatozoids. $E$ Branch of a Bulbochate, with one oogonium still contsining an oospore, another in the нct of allowing it to escape; in the lower part an empty nogoninm. F The four zoospores formed from an oospore. G Zoospore come to rest. (A fter Pringsheim.) antheridia. The contents of each of these cells are set free as a single zoospore, termed an androspore, intermediate in size and colour between the ordinary zoospores and the spermatozoids, and resembling them in form. The androspore comes to rest, attaching itself to the wall of an oogonium (Fig. 147), and germinates, forming a small filament, known as a dwarf-male, which consists of a root-cell and two or three cells abore it; each of these upper cells is an antheridium, and its contents are set free as a single spermatozoid.

On germination, the contents of the oospore are set free as four zoospores, each of which develops into an Edogonium-plant. Freshwater plants: genera Edogonium, Bulbochrte.

\section{Order 5. Coleochæ-} taceæ. Body filamentous, branched, forming hemispherical or discshaped eushions on submerged stones or parts of water-plants; the mode of growth is es- 
sentially apical, though in the discoid forms the apical cells constitute a marginal series; most of the cells eventually develop the peculiar sheathing hairs which have suggested the name of the family. Freshwater: Coleochæte, the sole genus.

Any cell may set free its protoplasmic contents as a zoospore with two cilia.

The sexual organs, oogonia and antheridia, are differentiated, especially in the more distinctly filamentous forms. In the filamentous forms (e.g. C. pulvinata, Fig. 148) the oogonia and antheridia are borne at the ends of the branches; the terminal cell of a branch enlarges to form an oogonium, becoming spherical, and growing out into a long filament, the trichogyne; the antheridia are developed as small flask-shaped cells from the terminal
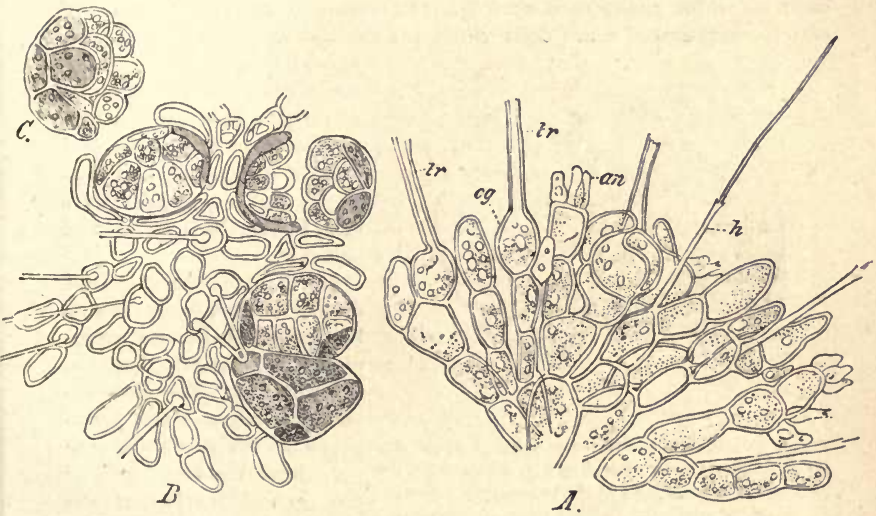

Fra. 149.-Coleochate pulvinata ( $\times 350$ : after Pringsheim). A Part of a sexual plant bearing oogonia og (with trichogynes $t r$ ) and antheridia $a n ; h$ hairs. $B$ portion of a plant in which a multicellular structure has been developed in each fertilized oogonium. $\boldsymbol{C}$ the isolated structure the investment of which is ruptured prior to the setting free of zoospores.

cells of a filament. In the discoid forms (e.g. C. scutata), the oogonia and antheridia are not terminal; the oogonium is simply an enlarged spherical cell and has no trichogyne; the antheridium is simply a small cell formed, in a group of four, by the division of one of the vegetative cells.

A single ousphere is formed in each oogonium, and a single spermatozoid in each antheridium. The spermatozoids, on being set free, find their way to the oogonia, and, entering by an opening in the wall (in the trichogyne when it is present), reach the oospheres and fertilise them.

The effect of fertilisation is not only to cause the oosphere to become an 
oospore by clothing itself with a proper wall, but also to cause the neighbouring cells to grow round the oogonium and form a compact cellular investment for it. Surrounded by this investment, the oospore falls to the bottom of the water, as the plant dies down, and undergoes a period of quiescence. On germination it grows, splitting the investment, and divides to form a small multicellular body, the existence of which shortly comes to an end by the escape of the whole of the protoplasmic contents of all the cells as zoospores, one from each cell (Fig. $148 C^{\prime}$ ).

Series V. Charoides. The forms included in this series constitute but a single order, the Characeæ.

Order I. Characeæ. The stem is distinctly segmented into nodes and internodes, the nodes being marked by the whorls of leaves which they bear. It consists of a longitudinal series of elongated cylindrical cells, each of which constitutes an internode, separated from each other by transverse plates of small cells which are the nodes. In Chara, there is,

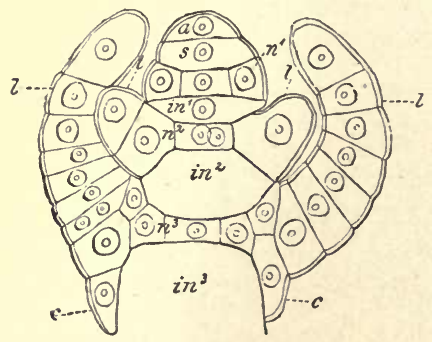

FrG. 149.-Diagram of growing-point of stem of Chara fragilis ( $\times 500$, after 8 achs): a apical cell; 8 segment lately cut off; $n^{2} n^{2} n^{8}$ snccessive nodes; in ${ }^{1} n^{2}$ in $^{3}$ snccessive internodes; $l$ leaves ; $c$ cortical cells growing down over in $n^{3}$ from $n^{3}$.

large vacuole filled with cell-sap. Each cell contains a single nucleus when young; but the long internodal cells, when old, are found to contain many nuclei produced by the fragmentation of the original nucleus.

The growth in length of the stem is unlimited, and is effected by means of a hemispherical apical cell (Fig. 149). This cell undergoes repeated division, a series of segments being cut off by transverse walls; after a segment has been cut off, the apical cell regains its normal size by growth, then another segment is cut off, followed by renewed growth, and so on. Each segment is immediately divided into two cells by a transverse wall; of these two cells the upper, in all cases, becomes a node, dividing by vertical walls into the small cells, central and peripheral, of which the node consists ; the lower, in all cases, becomes an internode; it does not divide, but simply grows in length. In Chara the young peri- 
pheral nodal cells keep pace with the growth of the internodal cells, forming the cortex over them.

The leaves and branches of the stem are all developed from the cells of the nodes; the leaves spring in a whorl, one from each of the peripheral cells of the node, and the branches are developed as buds in the axils of one or more of the leaves of each whorl.

The mode of growth and general morphology of the leaf is essentially the same as that of the main stem or one of its branches; it grows by means of an apical cell resembling that of the stem, and from the segments are formed nodes and internodes in regular succession; from the nodal cells of the leaf arise whorls of leaf-branches or leaflets. The only fundamental difference between the leaf and the stem of the Characer is that, whereas the apical growth of the latter is unlimited, that of the former is limited; the apical cell of the leaf at length ceases to divide, assuming a somewhat cylindrical form with a pointed tip.

The roots, with the exception of the first root of the embryo, are all adventitious, being developed from the lower nodal cells of the stem. They are simpler in structure than the stem or leaf, each consisting of a colourless filament of long, narrow cells; the growth is apical, though the apical cell is not specially differentiated as in the stem; the cells of the root are connected in a peculiar manner, the contiguous ends of the two cells having each somewhat the shape of the sole of a human foot; rootbranches are developed from that portion of the cell, just above the articulation, which corresponds to the heel of the foot.

The sexual organs (Fig. 150) are in all cases borne on the leaves; the antheridium is developed from the terminal cell of a leaf or of a leaflet; the oogonium replaces a leaflet. The plant may be either monœcious or diœcions.

The antheridium is a spherical body, of a green colour when young, but orange when mature, borne on a stalk. Its wall consists of eight cells, each of which is termed a shield, presenting marginal infoldings of the wall; the wall of the upper half of the antheridium consists of four triangular shields; that of the lower half consists likewise of four triangular shields, each of which has its lower angle truncated to admit of the passage of the stalk-cell. On the inner surface of each shield, at its centre, is attached a cylindrical cell, the manubrium, which extends to near the centre of the antheridium. Each manubrinm bears at its inner end a somewhat spherical cell, the capitulum. To each capitulum are attached usually six rounded cells, the secondary capitula. Connected with each secondary capitulum are two cells, each of which bears a pair of long filaments, each filament consisting of about two hundred cells. The cells of the filaments are the mother-cells of the spermatozoids, each cell giving rise to a single spermatozoid.

The male cell or spermatozoid consists of a club-shaped spirally-wound mass of protoplasm bearing two long cilia at its pointed anterior end. When the antheridium is mature the shields separate, the spermatozoids are set free from their mother-cells and escape into the water.

The oogonium is the enlarged terminal cell of the leaflet which it repre- 
sents. Beneath the oogonium proper is a node, the central cell of which constitutes the stalk-cell of the oogonium, whilst the five peripheral cells of the node grow out into filaments which gradually become spirally twisted and enclose the oogonium; the tips of these filaments project at the free end of the oogonium, constituting the crown or corona, and are cut off from the rest of the filaments either by one transverse wall, so that the

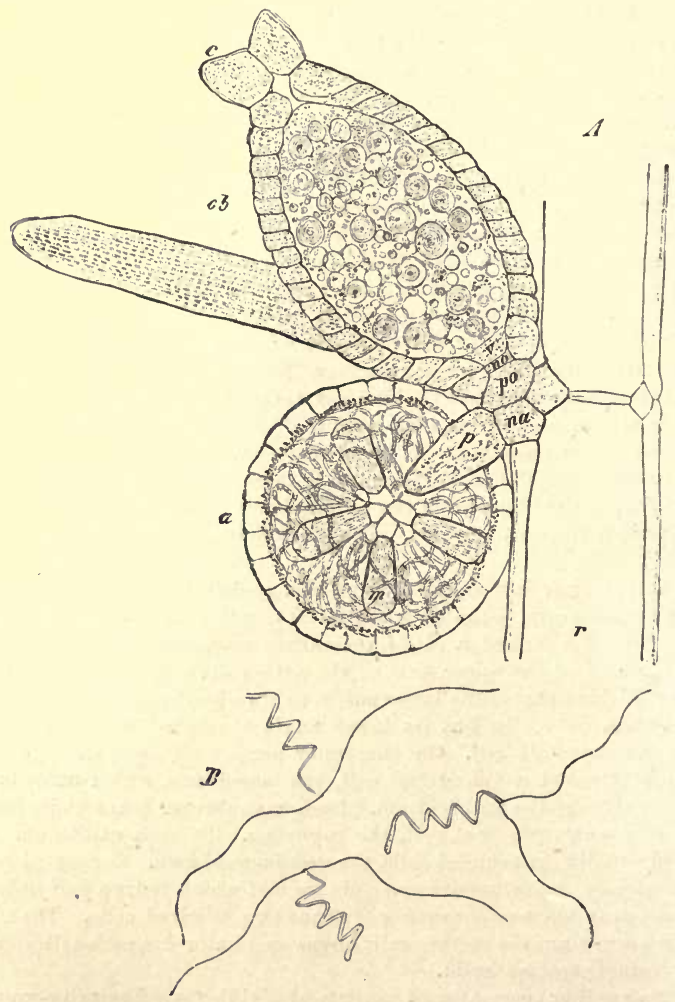

FrG. 150.-Chara fragitis, reproductive organs (after Strasburger). 4 Median longitu. dinal section through a leaf (gametophyll) $r$, and the sexnal organs which it bears; $a$ antheridium, borne on a nodal cell na by the stalk-cell $p ; m$ the manubria; ob an oogonium, borne on a nodal cell no and an internodal stalk-cell po; $c$ corona (all $\times 90)$. B spermatozoids $(x \quad 010)$. 
crown consists of five cells as in the Chareæ, or by two transverse walls, so that the crown consists of ten cells as in the Nitelleæ. Each oogonium contains a single oosphere, a nucleated mass of protoplasm containing starch-granules, with a well-marked clear area, the receptive spot, at the apical end.

At the time of fertilisation, the cells of the crown separate so as to form a channel leading to the apex of the oogonium. The wall of the oogonium is not ruptured, but it becomes mucilaginous. The spermatozoids enter the channel and reach the apex of the oogonium; one of them makes its way through the mucilaginous cell-wall, and, entering the oosphere at the receptive spot, fertilises it.

After fertilisation, the oosphere becomes an oospore, surrounding itself with a proper wall. The more internal walls of the investing filaments become thickened, and assume a dark brown colour. The whole organ falls off and undergoes a period of quiescence.

On germination, the oospore does not at once give rise to an ordinary Chara plant. It produces, in the first instance, an embryo, consisting of a filamentous root and a shoot of limited growth. The adult form is developed upon the embryo by the development of a lateral growing-point at the node of the embryonic shoot (see Fig. 151). Fresh water,

Sub-Class III. Phæophyces, or Brown Algæ. The body may consist of a single cell (e.g. Diatomaceæ), but is generally multicellular. When multicellular, it presents various degrees of morphological differentiation, being usually differentiated into shoot and root, and in some cases (e.g. Cladostephus, Sargassum) into stem, root, and leaf.

Vegetative multiplication is common in the unicellular forms, in which it is effected by division; in a few forms (e.g. species of Sphacelaria) it is effected by means of gemmæ.

In all but the lowest forms there is a distinction between reproductive and vegetative cells, the former developing into more or less highly differentiated reproductive organs. 
Asexual reproduction is effected by means of spores, either zoospores (as in the Phæosporeæ), or non-motile spores (as in some Phæogamæ). The spores are developed either singly, or more commonly several together, in unicellular (and also necessarily unilocular) sporangia.

Sexual reproduction is either isogamous or oogamous: when isogamous, it may be effected by aplanogametes (Diatomaceæ), but more commonly by planogametes (Phæosporeæ) which usually resemble each other ; but in some cases (e.g. species of Ectocarpus, Cutleriacex) they are of two kinds, differing in size and in the duration of their movement, the one which is smaller and more active being the male; when oogamous, it is effected by means of spermatozoids and oospheres, and is peculiar in that the oospheres, though not ciliated, are extruded from the female organ before fertilisation takes place. The sexual plants may be monøcious or diœcious. The sexual organs, in the isogamous forms, are gametangia, sometimes unicellular (Diatomaceæ) but more commonly multicellular (Phæosporeæ): in the latter case each cell of the gametangium gives rise either to a single planogamete or to several: they are in most cases all alike, though some (e.g. in species of Ectocarpus, Cutleriaceæ) consist of smaller and more numerous cells than the others and give rise to the smaller planogametes. In the oogamous forms, the oogonium is unicellular, giving rise to one or more (2-8) oospheres: the antheridium is sometimes multicellular, but it is unicellular in the Fucaceæ; in the former case each cell gives rise to a single spermatozoid, in the latter several spermatozoids are developed in the one cell.

Of the motile reproductive cells of this sub-class, the zoospores and the planogametes contain chromatophores, and have two cilia inserted laterally; the spermatozoids, however, have no chromatophores, nor have the smaller planogametes in those cases in which the conjugating planogametes differ in size; the oosphere has no receptive spot.

The following groups of the Phæophyceæ will be considered :-

Unicellular Forms:

Order Diatomaceæ: sexual reproduction isogamous by aplanogametes.

Multicellular Forms :

Series (a) Phwospores: sexual reproduction isogamous by planogametes; asexual by zoospores.

Order Ectocarpaceæ (Ectocarpus, Sphacelaria, Cladostephus, etc.). 
Order Laminariaceæ (Laminaria, Alaria, Chorda, etc.).

Order Cutleriaceæ (Cutleria Zanardinia).

Series (b) Рнғояам⿻: sexual reproduction oogamous; asexual, wantOrder Fucaceæ.

ing, or by non-motile spores.

Order Diatomaceæ. Cnicellular plants, either free, or connected into filaments or masses by mucilage; sometimes attached. Reproduction, vegetative by division; or by means of asexually produced spores; or sexual isogamous by the conjugation of aplanogametes. The cell-wall is impregnated with silica. Both fresh-water and marine.

The Diatomaceæ resemble the Desmidieæ in many respects; the two orders are, in fact, corresponding forms in the Phæophyceæ and the Chlorophyceæ respectively; but, besides their colour, the Diatoms differ from the Desmids in the presence of silica in their cell-wall.

The cell, or frustule, as it is called, is enclosed by a rigid wall. The wall, like that of the Desmids, consists of two halves, called valves, of different ages, which are not directly continuous, but are related to each other as the two parts of a pill-box, the one overlapping the other (Fig. 152). The cell-contents consist of a more or less vacuolated mass of protoplasm, which forms a layer in close contact with the inner surface of the cell-wall; in this there is a nucleus, sometimes parietal sometimes central, and chromatophores which may be very numerous and small, or few in number (sometimes only one) in the form of relatively large plates.

Vegetative multiplication by division takes place by the division of the protoplasm into two cells; each of these cells has one of the two valves of the parent frustule on one side of it; it then secretes a new ralve on its naked side, which is smaller than the older valve and fits inside its rim; thus two new individuals are formed.

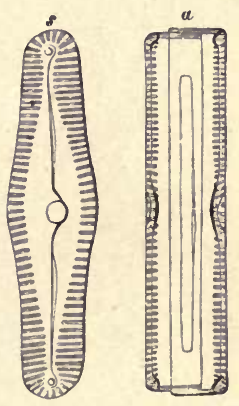

Fra.152.-Pinnularia, a Diatom (mag. and diag.); a lateral view, showing the mods of connection of the two balves of the frustule; 8 surface view.

It will be noted that this process of multiplication is accompanied by a decrease in size; and, were it repeated indefinitely, the cells would become very small. This process of diminution is interrupted by the formation of auxospores, either asexually or sexually: In the former case the protoplasmic contents of a cell escape from the separated valves, as an auxospore, which, after growing considerably, secretes two new valves forming a new and larger frustule. In the latter case, two naked cells which have thus escaped, conjugate to form an auxospore which becomes a new frustule. This process of conjugation differs, however, from that of the Desmidieæ, in that no resting zygospore is formed, but simply a new individual.

Series PHÆOSPOREA. The multicellular body is attached; it some-: 
times consists of a flattened dorsiventral branched filament, the branches of which are often coherent into a disc which adheres to the substratum by the ventral surface and bears vertical shoots on its dorsal surface (e.g. Ectocarpus, Myrionema, Pylaiella); the body is frequently more or less clearly differentiated into root and shoot, and in some cases (e.g. Cladostephus, Chrotopteris) the shoot is differentiated into stem and leaf ; adventitious roots are very generally developed.

The body presents a considerable variety of structure. In the simplest forms (e.g. Ectocarpus, etc.) it is filamentous and branched, the filament consisting of a single row of cells (monosiphonous); in others it is filamentous, consisting of several coherent longitudinal rows of cells (polysiphonous); in the most highly developed forms it consists of parenchymatous tissue frequently differentiated into a small-celled cortex and a medulla of large

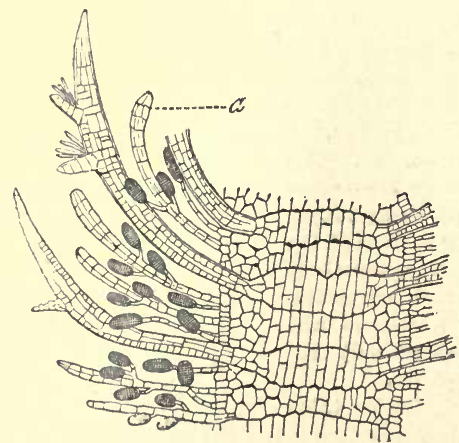

Fig. 153. - Longitudinal section through three internodes of a sexual plant of Cladostephus verticillatus (Ectocarpaceæ) : a gametophyll; the larger appendages are foliage-leaves. ( $\times 50$ : after Pringsheim.) cells elongated parallel to the long axis of the plant (e.g. Laminariaceæ).

Growth in length may be effected without a definite growing-point, all the cells being merismatic (e.g. generally in Ectocarpaceæ); or there may be a definite growing-point, which may be apical, with an apical cell (e.g. Sphacelarieæ); or the growingpoint may be intercalary, either sub-apical (e.g. Chordaria), or more or less basal (e.g. Laminariaceæ). The division of the apical cell, or of the initial cells, of the growing-point takes place only in one plane, the transverse. The segments thus formed undergo division either only transversely (monosiphonous forms), or longitudinally (polysiphonous), or in several planes.

The sporangia are in all cases unicellular. In the simple filamentous forms they are somewhat enlarged and rounded cells, either intercalary in position (e.g. Pylaiella), or terminal, occupying the place of a lateral branch, and generally sessile (e.g. Ectocarpus, etc.). In the more bulky thalloid forms, the sporangia may be merely developments of single superficial cells (e.g. Laminariaceæ) scattered singly or in groups (sori) over the whole surface. In others again they are borne as lateral branches on hair-like outgrowths from the superficial cells. In certain cases, where the shoot presents differentiation into stem and leaf (e.g. Cladostephus), the sporangia are borne on specialised leaves, sporophylls (Fig. 154).

The gametangia are in all cases multicellular, each cell constituting a 
loculus which gives rise to one or more planogametes. In their distribution and general morphology they resemble the sporangia. The gametangia of any one species are, as a rule, all exactly alike, but in some few cases they present two forms which differ in the size, and consequently in the number, of their constituent cells (e.g. Ectocarpus fenestratus and $E$. secundus, Cutleriaceæ); the small-celled gametangia are considered to be the male, and the large-celled the female organs. The plants may be monøecious or diøcious (Cutleria).

The zoospores and the planogametes are generally all very much alike: in Cutleria, however, and in those species of Ectocarpus which have two kinds of gametangia, the one kind of planogamete (female) is considerably
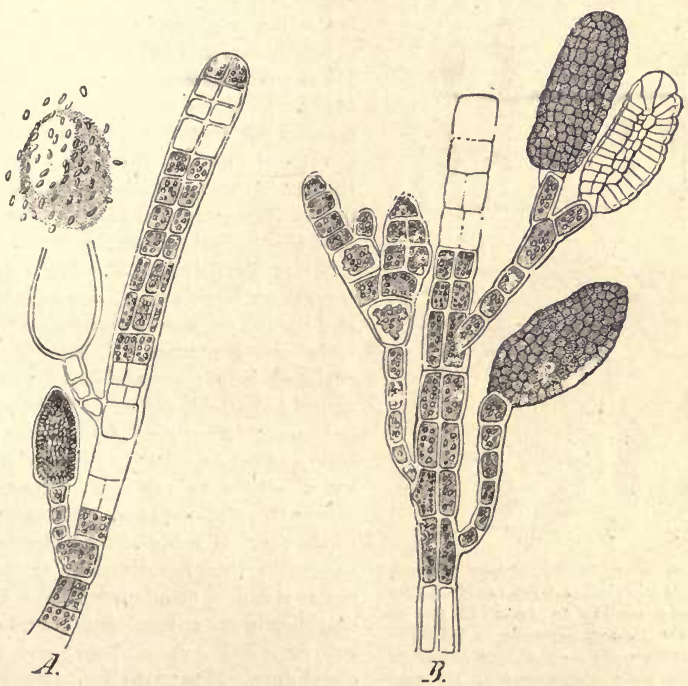

Frg. 154.-Fertile leaves of Cladostephus verticillatus: $A$ sporophyll; one of the anicellular sporangia has discharged its zoospores with a mass of mucilage; $\boldsymbol{B}$ gametophyll, bearing the multicellular gametangia. ( $\times 280$ : after Pringsheim.)

larger than the other (male), and has a shorter period of motility; the smaller planogametes are developed in the small-celled gametangia. A sexual process has been observed in but few cases (Ectocarpus siliculosus, Scytosiphon lomentarius, Cutleria). In the two former the planogametes are externally similar, but they behave diffenently in the process of conjugation, some coming to rest earlier than others, this indicating that they are female. When the female planogamete is at rest, it is approached 
by a number of the still motile male planogametes (Fig. 155), one of which fuses with it. In Cutleria the larger planogamete soon comes to rest, and then one of the smaller planogametes fuses with it. In Ectocarpus siliculosus the zy'gospore gives rise to a plant which resembles its parents: it has been observed that, if the planogametes fail to conjugate, they are capable of germinating independently.

The Plææosporeæ are almost exclusively marine, the only fresh-water forms being the genus Pleurocladia (Ectocarpaceæ) and two species of the genus Lithoderma. The size of the plants included in this series varies widely, from microscopic Ectocarpaceæ to gigantic tree-like Laminariaceæ, such as Macrocystis, Nereocystis, etc., which may attain a length of

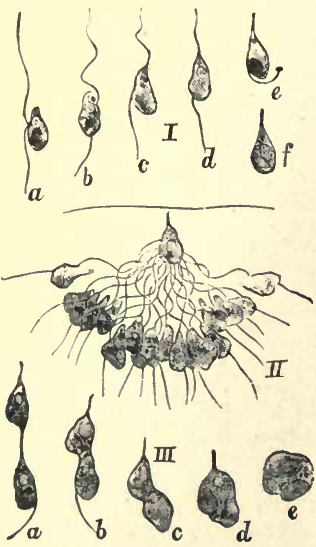

Fig. 155. - Sexual process in Ecto. carpus siliculosus: I a-f. female planogamete coming to rest: II resting female planogamete suspended from the surface of the water, with numerous motile male planngametes : III conjugation of a male and a female planogamete. ( $\times 700$ : after Berthold.) several hundred feet. In some of the Laminarias, which have cylindrical stalk-like region in their thalloid shoot, secondary growth in thickness takes place by means of a merismatic layer. In these large forms too, the conducting tissue is sometimes so far developed as to form sieve-tubes; though no woody tissue is developed, nor is it required in view of the fact that these plants live submerged.

Series PHÆOGAMÆ. The orders comprised in this group are characterised by the oogamous sexual process.

Order Fucaceæ. Body differentiated into root and shoot; shoot usually thalloid, either cylindrical or flattened; differentiated into stem and leaves in Sargassum; growth in length by a single apical cell; branching generally dichotomous. No asexual production of spores. Sexual organs, unicellular antheridia and oogonia; spermatozoids, ciliated, formed several together in the antheridium; oospheres, set free but not ciliated; one (Pycnophycus, Himanthalia), two (Pelvetia), four (Ascophyllum), or eight (Fucus) formed in each oogonium. Marine.

The body consists of what may be termed cortical and medullary tissue. The cortical tissue consists of closely-packed parenchymatous cells, the external layer of which, the limiting layer, is for a time merismatic, and plays an important part in the growth of the body. The medullary tissue consists of filamentous rows of cells the walls of which are mucilaginous and much swollen. The cortex is essentially the assimilatory tissue and the medulla the conducting tissue. 
In some of these plants (e.g. Fucus vesiculosus, Ascophyllum, Halidrys, Cystoseira, Sargassum) there are large intercellular spaces, filled with air, which project on the surface, and are known as air-bladilers; they serve as floats. In Halidrys and Sargassum the air-bladders are borne on special branches.

The sexual organs are in all cases borne in depressions of the surface known as conceptacles (Fig. 157). The conceptacles are commonly confined to special portions of the thallus; either to the tips of the branches $(e . g$.

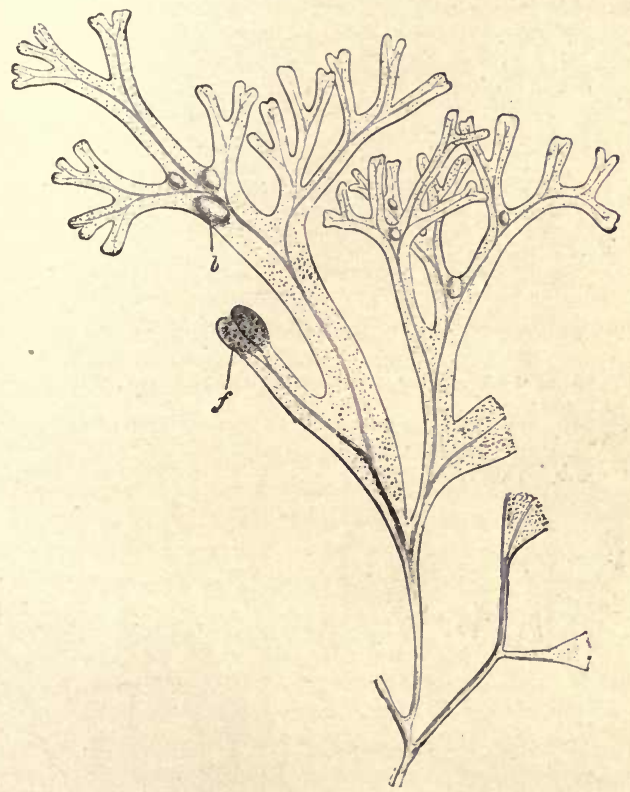

F1G. 156.-Fucus vesiculosus, about hslf nst. size : $b$ air-blsdders; $f$ fertile branch.

Fucus, Cystoseira) or to special branches, the gametophores (e.g. Himanthalia, Ascophyllum). From the inner surface of the conceptacle there arise a number of hairs (paraphyses) among which the sexual organs are borne. The oogonia (Fig. 158) are nearly spherical, and are borne on a short stalk consisting of a single cell; the antheridia (Fig. 158) are the lateral branches of some of the hairs. The plants may be monocious (e.g. Fucus platycarpus, Halidrys, Pelvetia, Cystoseira), or diøecious (e.g. Himanthalia, Ascophyllum, Fucus vesiculosus and serratus); in the former case each conceptacle contains both antheridia and oogonia. 
The oospore, which is the product of the fertilisation of an oosphere, germinates without any period of quiescence. It first becomes somewhat pear-shaped; it is then divided into two by a transverse wall; the more pointed of the two cells forms the primary root, whilst the other gives rise to the shoot (Fig. $158 d$ ).

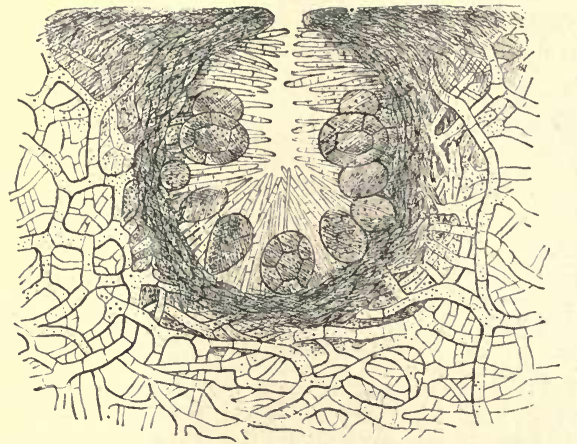

Fig. 157.-Section of a female conceptacle, with surrounding tissue, of Fucus vesiculosus. ( $\times 50$ : after Thuret.)
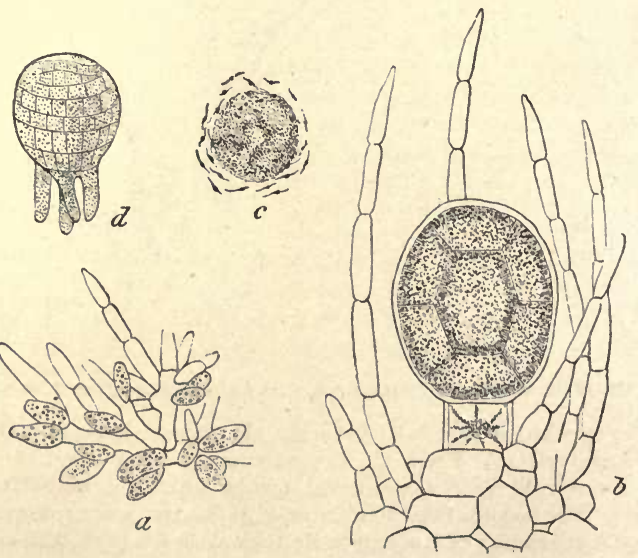

FrG. 153.-Fucus vesiculosus, a Paraphssis, from male conceptacle, bearing antheridia; $b$ an oogonium (with paraphyses), showing division of its contents to form oight oospheres; $c$ process of fertilisation, an extruded oosphere surrounded by spermatozoids; $d$ develop. ing embryo. ( $\times 160$ : after Thuret.) 
Sub-Class IV. Rhodophycex (FloRIdeE) or Red Algæ. Multicellular plants; body, generally differentiated into shoot and root; shoot, sometimes differentiated into stem and leaf; flattened or filamentous; when filamentous, consisting of a single longitudinal row of cells (monosiphonous) or of several rows (polysiphonous) with or without a small-celled cortex; the filamentous forms grow by means of a single apical cell from which segments are cut off either by transverse walls, or by oblique walls alternately right and left; the flattened forms grow by means of a marginal series of initial cells; but in the Bangiaceæ there is no growing-point, all the cells being merismatic: branching, generally monopodial, but sometimes sympodial (e.g. Plocamium, Dasya); adventitious roots common.

Vegetative reproduction by gemmæ (e.g. Monospora, Melobesia) is rare.

The plant, as a rule, produces tetraspores asexually, but they are usually not borne on individuals which produce sexual organs, but on distinct individuals, though there are exceptions to this rule (e.g. Lomentaria kaliformis, Callithamnion corymbosum, Polysiphonia variegata, etc.).

The spores are produced in unilocular sporangia, either singly, or two together, or sometimes as many as eight, but most commonly in fours; hence they are generally termed tetraspores. They may be formed tetrahedrally; or by transverse divisions, when they are said to be zonate; or by two divisions at right angles to each other, when they are said to be cruciate.

The arrangement of the sporangia on the shoot is various. In simple monosiphonous forms (e.g. Callithamnion) the terminal cells of short lateral branches become sporangia. In forms of more complex structure the sporangia are developed internally, within the superficial layer of tissue. The sporangia may be scattered over the surface of the shoot, or collected into special receptacles of various forms. In some cases (e.g. some Rhodomelaceæ, such as Polysiphonia) the sporangia are confined to certain specially modified branches which are termed stichidia. The tetraspores are set free as spherical unciliated cells without a cell-wall.

The sexual organs are antheridia and procarps; they are usually borne by distinct individuals, but in some cases on the same (e.g. Grateloupia, Halymenia, Halarachnion, Nemastoma, Dudresnaya coccinea and purpurifera, Gloesiphonia capillaris, Helminthora divaricata). 
The antheridia are small and unicellular; in the simple filamentous forms they occur singly or in groups at the ends of the branches; in others of more complex structure, they are produced in special receptacles (e.g. Corallinaceæ); in the flattened parenchymatous forms they occur in groups on the surface; in those forms in which the shoot is differentiated into stem and leaf (e.g. some Rhodomelaceæ such as Polysiphonia fastigiata and nigrescens, Chondriopsis tenuissima) the antheridia are confined to the leaves, the whole or part of the leaf being specially modified for this purpose. The male cells (spermatia) are formed singly

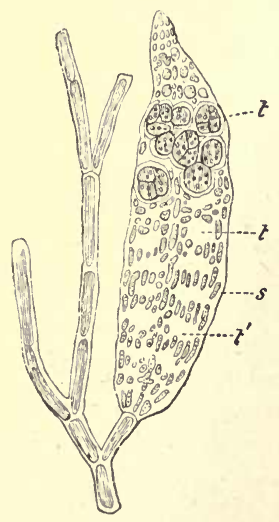

Fig. 159.-Portion of a branch of Dasya elegans, bearing a stichidium (s), with tetrahedral tetrasporangia $(t) ; \quad t$ empty tetrasporangium. (x 25; after Kü (zing.) in the antheridia, and are set free as small, spherical or oval, unciliated cells destitute of a cell-wall; they acquire a cell-wall at the time of fertilisation; they contain no chromatophores, except in Bangiaceæ.

The procarp presents considerable variety of form and structure. It may be unicellular (e.g. Bangiaceæ, Chantransia, Batrachospermum, Lemanea, Nemalion), or multicellular, as is more commonly the case. The unicellular procarp consists simply of a carpogonium prolonged (except perhaps in Bangia) into a filament termed the trichogyne. Various descriptions are given of the structure of the multicellular procarp; however, it appears to consist essentially of a unicellular carpogonium (with a trichogyne) together with one or móre specially differentiated auxiliary cells. In some cases (e.g. Dudresnaya coccinea, Squamariaceæ), the carpogonium and the auxiliary cells are not developed in the same procarp, but in distinct organs.

Whether the procarps be unicellular or multicellular, the carpogonia agree in that the trichogyne remains closed, and further, in that the protoplasm of the carpogonium does not undergo rejuvenescence to form a distinct female cell (oosphere) as is the case in the oogamous Algæ (see p. 241).

The carpogonium is (except in the Bangiaceæ) developed from the terminal cell of a lateral appendage; in some cases (e.g. 
Polysiphonia fastigiata and nigrescens) the lateral appendage is a leaf, the whole or part of which goes to form the procarp; in the Corallinaceæ the procarps are aggregated in receptacles.

The sexual process consists in the fusion of the protoplasmic contents of a spermatium with those of a trichogyne. The spermatium is brought by the water into contact with the projecting trichogyne to which it adheres, the spermatium being at this time covered with a cell-wall; the intervening cell-walls are absorbed at the point of contact, and the protoplasm of the spermatium enters the trichogyne.

The product of fertilisation is a fructification termed a cystocarp, consisting of a number of carposporangia. The cystocarp is developed either directly or indirectly from the carpogonium: directly, when the procarp is unicellular ; indirectly, when it is developed from both carpogonial and auxiliary cells: the trichogyne takes no part in the development of the cystocarp, being shut off by a septum.

The simplest mode of direct formation of the cystocarp occurs in the Bangiaceæ; the cavity of the carpogonium becomes chambered, by the formation of cell-walls, into usually eight cells, each of which is a sporangium, giving rise to a carpospore: only a single spore is formed in the genus Erythrotrichia. In other cases of direct formation (e.g. Nemalion, Batrachospermum), the carpogonium gives rise to a number of filaments, termed ooblastema-filaments, which bear a cluster of sporangia (Fig. 160).

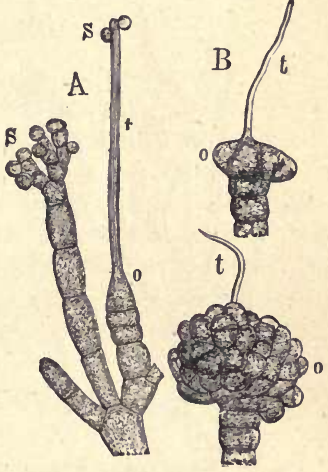

Fre. 16r.-Sexual organs of Nemalion $(\times 300), A$ ends of branches bearing a unicellular procarp $t-0$, and a group of antheridia s; the trichogyne $(t)$ of the procarp has two spermatia (s) adhering to it. B early stage in the development of the cystocarp; the fertilised carpogonium is undergoing growth and division. $C$ nearly matare cystocarp, consisting of a number of short filaments each terminating in a carposporangium. The development of the cystocarp is direct.

In the indirect formation of the cystocarp, the carpogonium fuses with one or more of the auxiliary cells. In the simplest case (e.g. Gigartinaceæ, Rhodymeniaceæ), the carpogonium fuses directly with the auxiliary cell (or cells), and from the latter the 
sporangia, or filaments bearing sporangia, are formed. In other cases the carpogonium gives rise to one or more elongated, branched, ooblastema-filaments which fuse with one or more auxiliary cells, and the sporangia are produced either from the ooblastemafilaments (e.g. Gelidiaceæ) or from the auxiliary cells (e.g. Squamariaceæ and other Cryptoneminæ).

In the Corallinaceæ, where the procarps are aggregated in receptacles, only a single cystocarp is formed from the whole group of procarps. Some of the procarps appear to be altogether abortive, and only those toward the centre of the group have trichogynes, whilst others seem to have only auxiliary cells: after
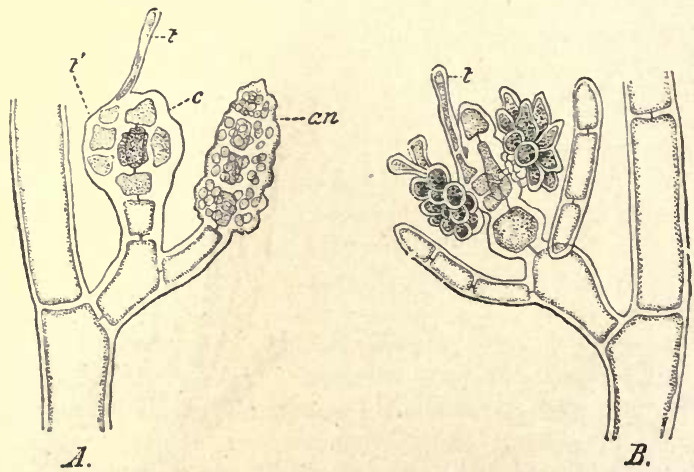

FIG.161.-Sexual organs of Spermothamnion hormaphroditum. 4 Male and female organs; $e$ multicellular procarp; $t$ trichogyne; $t^{\prime}$ trichophore; an terminal cluster of antheridia. B cystocarp developing from the fertilised procarp; a cluster of carposporangis is springing from each of the two opposite lateral auxiliary cells. The development of the c5stocarp is iudirect ( $\times 300$ : after Naegeii).

fertilisation, the carpogonia of the central procarps fuse with each other, and with the auxiliary cells of the other procarps, forming a large cell from the periphery of which the corposporangia, constituting the cystocarp, are developed.

In many cases the cystocarp consists merely of the cluster of sporangia (e.g. Bangia, Chantransia, Callithamnion, Dudresnaya); in other cases the cluster of sporangia is surrounded by a cellular investment, termed the pericarp, formed by the growth of adjacent sterile cells.

Each sporangium always gives rise to a single carpospore, which 
is set free as a somewhat spherical unciliated cell destitute of a cell-wall, and germinates without any quiescent period.

The germination of the tetraspores and of the carpospores has only been followed in a few cases. Generally speaking the spore becomes elongated in form, and is attached by the more pointed end which is almost colourless; division by a transverse wall then takes place; the elongated attached cell developes into the root, the other in to the shoot.

The Rhodophyceæ are almost exclusively marine; the only fresh-water forms are Batrachospermum, Lemanea, and species of Chantransia, Bangia, and Hildenbrandtia.

\section{CLASS II.-FUNGI.}

This class, like the preceding, includes many very simple organisms, as well as others of tolerably high development. None of them contain chlorophyll; hence they cannot assimilate sa simple a carbon-compound as carbon dioxide, but must take up their carbonaceous food in the form of rather complex compounds, and their structure and mode of life are correlated with this peculiarity (see p. 189). Some are parasites, such as the Rusts and Smuts, and absorb these complex carbon-compounds from other living organisms, whether plants or animals. Others are saprophytes, absorbing these compounds from the remains of dead organisms, or from organic substance formed by living organisms; the numerous and often large Fungi which grow on humus or leaf-soil in forests, or on the bark of trees, are examples of the former case; the Yeasts and Moulds which make their appearance on juicy fruits, saccharine liquids, etc., are examples of the latter. Some Fungi are symbiotic; that is, they live in intimate relation (symbiosis) with plants which possess chlorophyll, and obtain from them the necessary carbonaceous food, but without destroying, or apparently injuring them. They commonly live with Algæ, forming Lichens; or in connexion with the roots of trees (esp. Cupuliferæ) and of Orchids, Leguminosæ, and other plants, or with prothallia (e.g. Lycopodium), forming what is known as Mycorhiza.

The vegetative body may be unicellular, or coenocytic. In the former case it is small and rounded or rod-shaped in form. In the latter case the body is always a mycelium, consisting of more or less branched filaments, termed hypha. The mycelium may bo 
unseptate, as in the Phycomycetes, in which case the body resembles in structure that of the Siphonaceæ among the Green Algæ (see p. 250). Or the mycelium may be septate, as in the higher Fungi, in which case it appears to be always incompletely septate ; that is to say, the segments of the hyphæ which are marked out by the transverse septa, are not cells, each with a nucleus, but contain several nuclei, and are cœnocytes (as in the Cladophoraceæ among the Chlorophyceæ). The hyphæ grow in length at the apex in the manner of such Algæ as Vaucheria and Cladophora (see p. 239).

In some of the more complex forms, the hyphæ of the reproductive organs form compact masses of tissue of a somewhat parenchymatous appearance, in which there is no differentiation of tissue-systems, but the superficial layers of hyphæ form a kind of tegumentary tissue, termed generally cortex. Considerable differences in the nature of the cell-wall may obtain in different parts of such organs, some walls being soft and mucilaginous, whilst others are relatively hard withont, however, ever being lignified. In a few Mushrooms (e.g. Lactarius) some of the hyphæ form a system of laticiferous tissue, and in others glandular structures occur.

Except in the simplest forms, the body is generally more or less clearly differentiated into root and shoot. These members can be distinguished partly by their relative position, the root-hyphæ growing into the substratum, and the shoot-hyphæ into the air; and partly by the fact that the shoot-hyphæ bear the reproductive organs. Some parasitic forms have root-like organs, termed haustoria, which penetrate into the cells of the host; similar organs occur in some saprophytes, and in others (e.g. crustaceous Lichens) the roots (sometimes called rhizines) consist of bundles of hyphæ. There is in no case any differentiation of the shoot into stem and leaf.

The foregoing account does not apply to the body of the Myxomycetes, which consists of a multinucleate mass of protoplasm, termed a plasmodium, without any cell-wall. It is formed by the cohesion of a number of small, originally independent amoboid cells, like that of the Hydrodictyaceæ among the Algæ (see p. 253).

Vegetative propagation is common among the Fungi. The simplest form of it is simple cell-division (e.g. Schizomycetes), or that form of cell-division known as budding or sprouting (gemm- 
ation) (e.g. the Yeast-forms of various Fungi). It is effected in some cases (e.g. in some Zygomycetes, Ascomycetés, and Basidiomycetes) by unicellular gemma of various sizes (termed chlamydospores when they are relatively large and thick-walled; and are adapted for a period of quiescence; oidium-cells; when they are small and thin-walled and capable of immediate germination) which are formed by the segmentation of a hypha by transvêrse septa into short cells which become somewhat rounded and separate from each other; on germination, each may give rise to a mýcelium. In other cases (e.g. many Ascomycetes, such as the Sclerotinieæ, Pezizeæ, Claviceps, etc.; some Basidiomycetes, such as Coprinus stercorarius, species of Typhula and Agaricus), it is effected by bodies termed sclerotia; each sclerotium consists of a compact mass of hyphæ, filled with reserve materials, covered by a cortex of one or more layers of tissue, which are thick-walled and of a dark colour. They become detached from the mycelium on which they are formed, and are capable of retaining their vitality during a long dormant period; on germination they give rise to shoots bearing reproductive organs. A form of sclerotium is found also in the Myxomycetes. Here it consists of a plasmodium, or a part of a plasmodium, which has surrounded itself with a membrane, and remains for a longer or shorter time in a dormant condition : the individual amœboid cells may also surround themselves with a membrane and remain dormant, in the form of microcysts.

Reproduction is effected sexually or asexually. A sexual process takes place in the Zygomycetes, in the Peronosporaceæ, and in some Ascomycetes.

The modes of the sexual process are the following :-

I. Isogamy : sexual cells, similar aplanogametes which are not set free; process, conjugation; product, a zygospore; Zygomycetes.

\section{Hetèrogamy :-}

a. Oogamy: sexual cells, oospheres and undifferentiated male cells ; process, fertillsation ; product, an oospore; Peronosporaceæ.

b. Carpogamy: no differentiated female cell; female organ' fertilised by the undifferentiated contents of the male organ or by differentiated male cells, spermatia: product, a fructification termed an ascocarp: all the forms in which this mode occurs belong to the Ascomycetes. 
There is no sexual process in the Schizomycetes, the Myxomycetes, in some of the Phycomycetes (Saprolegniaceæ), the great majority of the Ascomycetes, the Ecidiomycetes, and the Basidiomycetes. In the Schizomycetes and Myxomycetes, the absence of a sexual process may be attributed to their rudimentary character: in the higher groups it is due to sexual degeneration. In the Saprolegniaceæ, female and, generally, male organs are developed, but the male organs are functionless; still the female organs produce oospores. In the majority of the apparently sexual Ascomycetes, even when both kinds of sexual organs are present (e.g. Erysipheæ, Penicillium, Sordaria) it is a question if any sexual process takes place: yet in all these cases an ascocarp is produced, either from the female organ or from the mycelium.

The sexual organs, with the exception of those of some Ascomycetes, are unicellular. They are either quite similar to each other, as in the Zygomycetes and some Ascomycetes (e.g. Eremascus), when they may be termed gannetangia; or they may be more or less differentiated, as in the Oomycetes, and in some Ascomycetes (

The male organ is a pollinodium in the Oomycetes and in some Ascomycetes (e.g. Pyronema, Erysipheæ, Ascobolus); it is generally unicellular but sometimes multicellular (e.g. Ascobolus). As it is developed in close proximity to the female organ, fertilisation is effected, in these forms, by absorption of the cell-walls at the point of contact of the two organs, or the development of a tube placing their cavities in communication.

In some Ascomycetes (the Laboulbeniaceæ) non-motile male cells (spermatia) are formed in unicellular antheridia. Spermatia occur in other Ascomycetes, as also in the Ecidiomycetes, but their sexuality has not been established in these cases.

The female organ is either a unicellular closed oogonium (Oomycetes), or a unicellular or multicellular archicarp (Ascomycetes). The archicarp may consist (like the procarp of the Rhodophyceæ) of two parts : a receptive portion, the trichogyne, which is a more or less elongated multicellular filament, and a sporogenous portion, the ascogonium, from which, after fertilisation has taken place, the one or more sporangia (asci) of the ascocarp are developed.

Sexual cells are only clearly differentiated in the case of the female cells of the Oomycetes and of the spermatia of some Ascomycetes. The female cells of the Oomycetes are oospheres, 
spherical cells destitute of a proper wall : the spermatia generally have a cell-wall.

In all other cases the protoplasmic contents of the sexual organs are not differentiated into cells of definite form; but the fusing masses of protoplasm of the Zygomycetes may be regarded as aplanogametes; and that portion of the protoplasmic contents of the pollinodium of the Peronosporaceæ which enters the oogonium and fertilises the oosphere, may be regarded as a male cell.

An asexual formation of spores is of general occurrence. In the Schizomycetes there are no special spore-bearing organs, but the protoplasm of the cells surrounds itself with a proper cell-wall, and becomes a spore.

In the Myxomycetes sporangia are formed, attaining, in some forms, a high degree of complexity of structure.

In the higher Fungi, the spores are formed, speaking generally, either in the interior of unilocular sporangia (e.g. Phycomycetes), or by abstriction, either singly or a number in succession, from certain special hyphæ (as in the Ascomycetes, Ecidiomycetes, and Basidiomycetes); in the latter case the spores are often distinguished as conidia.

In either case, the spores are borne upon an organ, a special brauch of the mycelium, termed a sporophore or conidiophore. This may consist of a single hypha (e.g. Mucor, Peronospora, Penicillium, Puccinia), when it is said to be simple; or of a number of coherent hyphr (e.g. the Mushroom, and the fructifications of other Basidiomycetes; the ascocarp of the Ascomycetes; the æcidium of the Acidiomycetes when it is said to be compound. The conidiophores may be scattered over the mycelium, or they may be collected into receptacles termed pycnidia.

The asexually-formed spores are but rarely motile (e.g. ciliated zoospores of Myxomycetes and Oomycetes); in all other Fungi they are non-motile and have a cell-wall. There is considerable variety in their form, colour, etc. In some cases the spores are compound; that is, they appear to consist of two or more cells (e.g. telentospores of Puccinia Graminis and other Acidiomycetes; ascospores of some Ascomycetes such as Pleospora, Hysterium, Cordyceps, etc.); each cell, however, germinates independently and is therefore itself a spore. These compound spores are formed by the division of a primary mother-cell.

The Life-History of the Fungi is generally very much complicated by. polymorphism. In most of the Schizomycetes there is 
remarkable polymorphism especially in the higher forms which pass through several distinct phases in the course of their life. Again, in some Ascomycetes and Ecidiomycetes there may be two or three forms bearing different kinds of reproductive organs, the different forms being parasitic on different hosts (hetercecism).

The Fungi may be classified as follows:-

Sub-Class I.-Schizonycetes: Body unicellular, or multicellular and filamentous; no special sporebearing organs; no sexual reproduction.

Süb-Class II.-Mýxomycétes: Body a plasmodium; spores formed in more or less well-developed sporangia; zoospores; no sexual reproduction.

Sub-Class III.-Phycomycetes: Body generally a cœnocytic unseptate mycelium; sexual reproduction general; zoospores present in most orders.

Section A.-Zygomycetes: sexual process isogamous; product, a zygospore.

Section B.-Oomycetes: sexual process oogamous ; product, an oospore.

Sub-Class IV.-Ascomycetes: Body usually an incompletely septate mycelium; sexual process carpogamous; the product is an ascocarp.

Sub-Class V.-ActDionycetes: Body an incompletely septate mycelium; no sexual process.

Sub-Class VI.-BASIdomycetes : Body an incompletely septate mycelium; no sexual process; compound sporophores are always formed.

Sub-Class I.-Schizomycétes. These organisms are either unicellular or multicellular; most of the unicellular forms are very minute. The cell consists of a mass of protoplasm; with a rudimentary nucleus, surrounded by a cell-wall which consists in some cases of cellulose, and in others of a proteid substance. In some cases the cells are coloured red, green, blue, etc.: a starchy substance, turning blue with iodine, is found in the cells of some forms (e.g. Bacillus Amylobacter).

The forms presented are extremely various. The individuals may be spherical, the Coccus-form (Fig. 162,a); or rod-shaped, the Bacterium-form (Fig. 162, b) ; or spirally-wound, the Spirillumand Spirochæte-forms (Fig. 162, $d$ ) : or straight free filaments, the Bacillus-form ; or straight filaments attached by one end, the Cre- 
nothrix-form; or the individuals may form cubical masses, as in Sarcina Ventriculi. Some forms (e.g. Bacillus, Spirillum, and some Coccus-forms) are capable of locomotion; they are provided with one (Coccus-form) or more (one or more at each end in Bacillus and Spirillum-forms) vibratile cilia, by means of which movement is effected.

A remarkable phase, common to the life-history of nearly all forms; more especially the unicellular, is the zoogloea-stage. It consists of great numbers of cells held together by bulky mucilage, to form either a membrane (e.g. the scum on

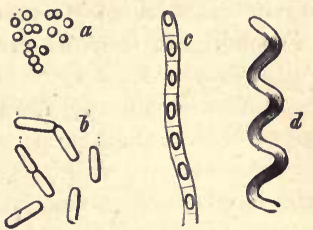

Fre. 162.-Different forms of Schizomycetes: $a$ Micrococcus; $b$ Bacterium; c Bacillus with spores; $d$ Spirillum (diag.: $\times 600$ ). putrefying liquids) or masses of the most various form. A striking zoogloea-stage is that known as Leuconostoc mesenterioides, which consists of wavy chains of cocci imbedded in a mass of mucilage, the whole resembling the structure of Nostoc in the Cyanophyceæ (Fig. 136, A, B).

Although a special name has been given to each of the multifarious forms assumed by the Schizomycetes; it must not be assumed that each form to which a name has been given con-
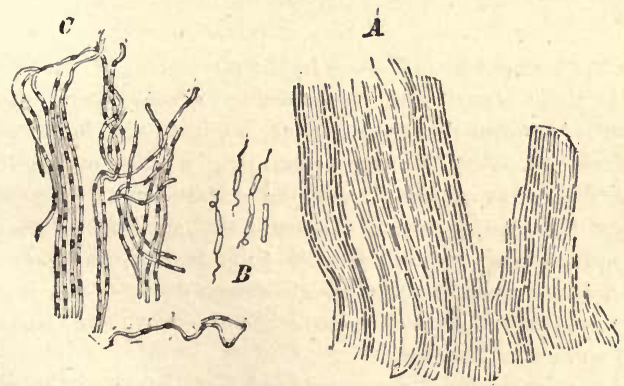

Fig. 163.-Bacillus subtilis: A zooglœa-stage; $B$ motilo stage; $C$ zoogloea-stage, with spore-formation. After Strasburger : $\times 800$.)

stitutes a distinct species. On the contrary, the Schizomycetes are highly polymorphic, and the various simpler forms are, for 
the most part, merely phases in the life-history of the more complex forms.

The Schizomycetes multiply mainly by cell-division (whence their name), and they do so with great rapidity under favourable conditions. In many forms reproduction is also effected by means of spores (e.g. Bacillus subtilis, Bacillus Anthracis, Clostridium butyricum). Each spore is formed from a cell, the protoplasmic contents contracting from the cell-wall and surrounding themselves with a thick proper wall; the spore is set free by the decay of the old cell-wall. Spore-formation generally takes place in the zoogloa-stage, and is promoted by conditions which are unfavourable to growth and multiplication by division. The vitality of the spores is remarkable, being retained under conditions, such as extremes of temperature, desiccation, etc., which would prove fatal to the organisms themselves.

A comparatively simple life-history is that of Bacillus subtilis, which makes its appearance in infusions of hay when allowed to stand. The infusion gradually becomes turbid, owing to the rapid multiplication of the Bacillus. At first the organisms move actively by means of cilia (Fig. $163, B)$, the motile form: after this the cells cease to be motile, and remain connected into filaments, the bacillus-form: then a membranous scum forms on the surface of the liquid, the zoogloea-form: at this stage spore-formation begins (Fig. 163, C) and the life-cycle is at an end. The spores give rise, on germination, to the motile form, and so the cycle is repeated.

The most conspicuous feature in the physiology of the Schizomycetes is their capacity for decomposing organic compounds, inducing various fermentative processęs, such as the lactic and the butyric fermentation of various kinds of sugars, etc. (but never the alcoholic fermentation), and the putrefactive fermentation of complex nitrogẹnous organic subștances, such as proteids, etc. Some are parasitic in the bodies of animals, such as Sarcina Ventriculi, Leptothrix buccalis which causes decay of the teeth, and the various forms of Bacteria which cause Phthisis, Cholera, Anthrax, and other dișeases.

The particular form presented, and the degree of the physiological activity manifested, at any given time, is determined by the external conditions, such as the nature of the obtainable food, the temperature, the presence or absence of oxygen, etc.; important variations in any of these conditions may induce change from one 
form of the organism to another, and may modify its physiological activity.

There is a general resemblance in organisation and reproduction between the Schizomycetes and the Cyanophycer, as well as a remarkable correspondence between individual forms belonging to the two groups. On this ground they are sometimes placed together in a distinct group, the Schizophyta. It is, however, preferable to place them respectively in the classes Fungi and Algæ as corresponding sub-classes.

Sub-Class II. Mrxomycetes. These organisms are characteristically saprophytic, living on decaying organic substances, such as spent tan, decaying leaves, tree-stumps, etc.

Their life-history is, in most cases (Endosporeæ), as follows:On the germination of the spores, the contents of each spore escape as a zoospore, a naked mass of protoplasm, enclosing a nucleus and a contractile vacuole, provided with a single cilium; this constitutes the mastigopod stage, and in this stage the cells multiply by division. After a period of active swimming, the zoospore draws in its cilium, and now creeps about by means of temporary protrusions of its protoplasm termed pseudopodia; this is the amoboid or myxopod stage, and in this stage also multiplication by division takes place. The amœbæ then collect together, cohering into a plasmodium; the protoplasm of the amœbæ in some cases fuses completely so that the plasmodium presents no cellular structure, whereas in others (pscudoplasmodium) the outlines of the coherent amobæ persist; but, in any case, there is no fusion of the nuclei of the constituent amœbæ, so that the plasmodium is multinucleate and syncytic.

The plasmodium creeps about, like a gigantic amoeba, by means of pseudopodia, until spore-formation begins. At this time the plasmodium comes to rest; and it either forms a single sporangium, or divides into several portions each of which forms a sporangium. The mass of protoplasm then assumes the form of the future sporangium; the external portion of it hardens to form the wall; while the internal portion, after rapid nuclear division, separates into cells each of which secretes a proper wall and becomes a spore. In most forms a portion of the internal protoplasm goes to form a number of filaments, generally tubular, either free or connected into a net-work, which constitute the capillitium. The wall dries, and eventually ruptures, and the spores are scattered by the expansion and hygroscopic movements of the 
elastic capillitium. In many cases the sporangium has a stalk, (sporophore) which is sometimes continued into the cavity of the sporangium as a columella.

In the Exosporea the spores are not formed in the interior of a sporangium, but by abstriction from the ends of filaments developed from the surface of the sporophore:

In some forms (e.g. Fuligo varians) a compound sporangium is

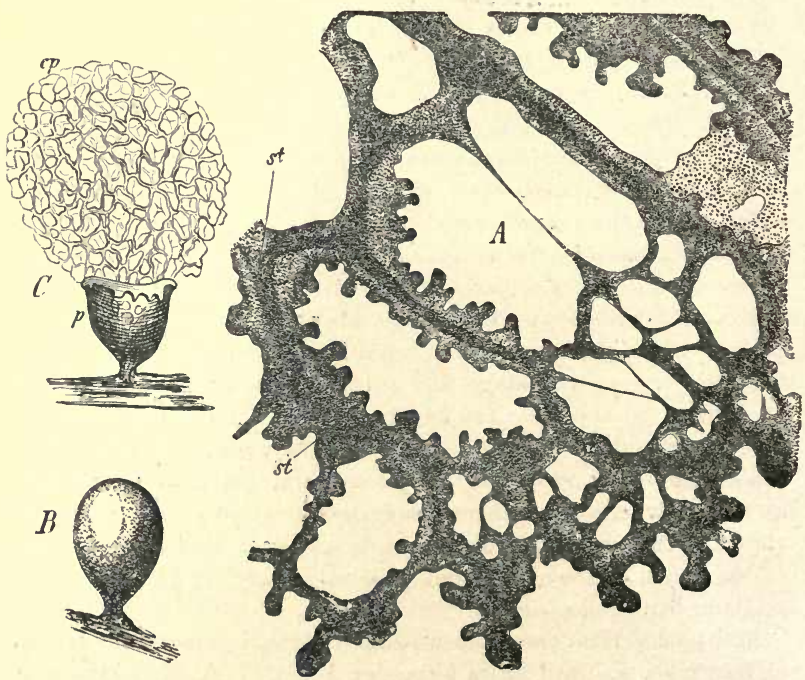

Fit. 161:-A Part of a pleismodium of Didymium leucopus ( $\times 300)$. B A closed sporanginm of Arcyria incarnata. C The same after the rupture of its wall $(p)$ and expansion of the capillitium $c p(\times 20)$. (Áfter Śachs.)

formed, termed Ethalium, by the combination of a number of plasmodia.

The sporangium-wall and capillitium give the rêactions of cuticularised cell-wall.

The life-history, as sketched above, variés somewhat in different forms. In some (e.g. Dictyosteliaceæ, Guttulineæ) the masitigopod stage is wanting; the spores giving rise directly to amoebæ. Again, the mastigopods or the amobæ may surround themselves 
with a membrane and go through a resting-stage as microcysts; or the whole or part of a plasmodium may do the same as a sclerotium.

Sub-Class III. Phycomycetes. Section A : ZZygomycetes.

The section Zygomycetes includes several orders of which, however, only the characteristic order Mucorinæ will be considered.

Order Mucorinæ. Body an unseptate mycelium, septa being only developed in connection with the formation of reproductive organs; reproduction by spores, and by zygospores formed by conjugation; mostly saprophytic, but some are parasitic on other Fungi.

The mycelium ramifies in the substratum (Fig. 165). The asexual reproductive organs are developed as simple sporophores which grow erect into the air. In the Mucoraceæ the simple sporophores are unbranched, and each
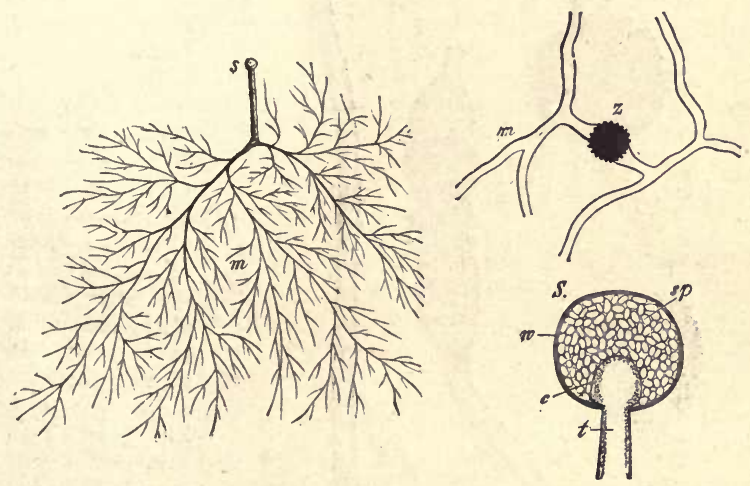

Fre. 165.-Mucor Mucedo : $m$ a mycellum bearing a simple sporophore with a terminal sporangium s; $S$ a sporangium much magnifed; $t$ the end of the sporophore dilated into the columella $c$; w the wall of the sporangium; sp the spores; $z$ zygospore formed by the fusion of the contents of two gametangia.

bears at its apex a single sporangium; the sporophore projects into the cavity of the sporangium as a columella (Fig. 165). In the Chætocladieæ and the Piptocephalideæ the sporophore is branched and more or less septate; it produces a number of spores by abstriction from the tips of its branches. On germination, the spore gives rise to a mycelium similar to that from which it was derived.

The gametophores are short swollen hyphæ; by the formation of a septum near the tip of the gametophore, a terminal cell is prodùced, which is the sexual organ or gametangium; the protoplasmic contents of the gametanginm constitute the gamete. Two gametophores from adjacent vegetative hyphæ come into contact at their tips; the walls of the two 
gametangia are absorbed at the point of contact; the protoplasmic contents (gametes) of the gametangia fuse to form the cell which surrounds itself with a coat of two layers and becomes a zygospore (Fig. 166).

In many cases the zygospore, on germination, gives rise to a small branched or unbranched mycelium, which bears a single simple sporo-

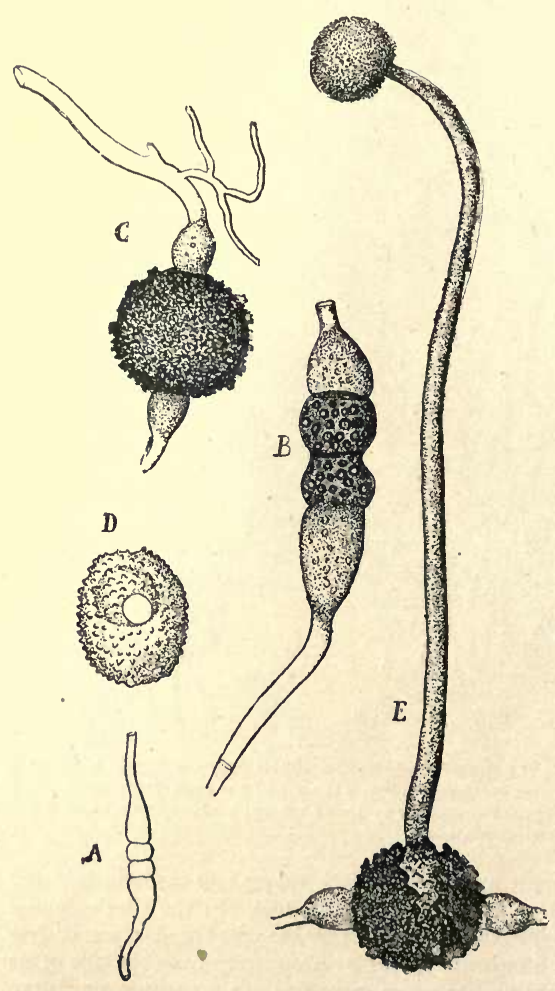

FrG. 168.-Mucor Mucedo: $A$ diagram of sexual process: two gametophores in contact; at the end of each gametophore a cell, the gametangium, has been cut off by a septum; $B$ commencing development of the zygospore from the fused gametangia; $C$ ripe zygospore, still connected with the gametophores; $D$ free zygospore, showing one point of attachment; $E$ germinating zygospore, bearing a small ipromycelium with a single sporangium (after Brefeld). phore. The spores derived from this sporophore give rise, on germination, to the ordinary mycelium. In other cases, however, the zygospore gives rise directly to a mycelium bearing sexual organs.

The mycelium, when under unfavourable conditions, gives rise to unicellular gemmæ, either chla myd ospores or oidium - cells : the latter multiply by gemmation in a yeast-like manner (e.g. Mucor racemosus) and, like Yeast, have the power of causing alcoholic fermentation; this takes place especially when the hyphæ are immersed in liquid. The hyphæ become segmented into a row of cells by the formation of transverse septa, and the cells then separate and become free. The chlamydospores ate 
thick-walled and large; the oidium-cells are smaller and thin-walled (see p. 277).

Mucor Mucedo may be obtained by keeping fresh horse-dung under a bell-jar in a warm room: it may be further cultivated by sowing the spores on slices of bread moistened and kept under a bell-jar.

\section{Section B. Oomycetes.}

This section of the Phycomycetes includes the following orders:

Order 1. Peronosporaceæ: body branched; oogonia terminal or intercalary; pollinodium functional.

Order 2. Saprolegniaceæ: body branched; oogonia generally terminal, rarely intercalary; pollinodium absent, or, if present, functionless.

Order 1.-Peronosporaceæ. The forms comprised in this order are mostly parasitic, chiefly on Phanerogams, but some species of Pythium inhabit the dead bodies of plants and animals.

The asexual reproduction of the plant is effected, in most forms, by sporangia developed at the ends of the branches of the simple sporophores (Fig. $168 A$ ) : no such organs have, however, been observed as yet in Pythium vexans or P. Artotrogus. In some forms the sporangium gives rise to zoospores either before or after it has fallen off the sporophore (Fig. $168 \mathrm{~B}, \mathrm{C}^{\eta}$ ); whilst in other forms it falls off and germinates as if it were itself a spore, growing out into a hypha, and so into a mycelium.

The oogonium is spherical, and remains closed (Fig. 167). The protoplasmic contents undergo differentiation into a single oosphere which is surrounded by the remainder of the protoplasm, the periplasm.

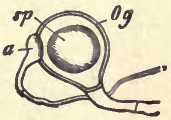

Fig. 167. - Phytophthora omnivora. An oogonium $(O g)$, containing an oospore (sp); $a$ a pollinodium which has fertilised the oosphere. (× 400.)

The pollinodium is developed terminally, either on a hypha springing from beneath the oogonium, or on an adjacent hypha, and is club-shaped. Its protoplasmic contents undergo differentiation into a male cell (aplanogamete) and into periplasm.

At the time of fertilisation, the pollinodium is closely applied to the oogonium and sends out a delicate tube which penetrates through the wall of the oogonium and reaches the oosphere. The tube then opens, and the male cell passes out of the pollinodium into the oosphere and fertilises it. The oosphere then surrounds itself with a proper wall and becomes the oospore. In some genera (Peronospora, Cystopus) an external coat, the episporium or perinium, is formed round the oospore from the periplasm.

The germination of the oospore takes place in different ways in different species. In Phytophthora omnivora and Pythium proliferum it gives rise to a small mycelium (promycelium) which produces a few spores, from 
which sexual plants are developed. In other species (e.g. Cystopus candidus) the contents of the oospore are set free as a number of zoospores. In yet other species (e.g. Pythium de-Baryanum, Pythium Artotrogus, Peronospora Valerianellce), the oospore directly gives rise to a sexual plant.

Pythium can be obtained by sowing cress in a pan of earth. When the seedlings spring up, they should be well watered and be kept covered with a bell-jar so as to keep them moist. Some of them will be seen to fall owing to the failure of the

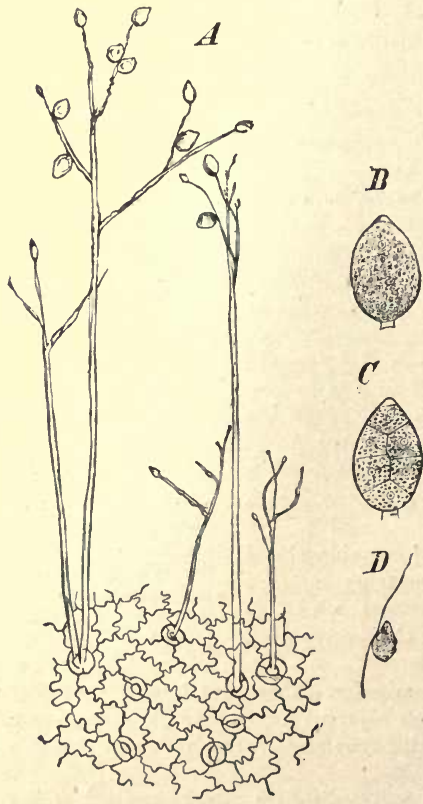

Frg. 168.-A Surface-view of the epidermis of a Potato-lesf with the sporophores of Phytophthora infestans projectiug out of the stomats $(\times 90)$. B A ripe sporangium. C Another undergoing division. D A zoospore. ( 540 : after Strssburger.) stem just above the surface of the soil; these are infected with Pythium. If an infected stem be kept in a drop of water on a slide for a day or so, and be examined from time to time, hyphæ bearing the reproductive organs of the Fungus will be seen to be developed at the surface.

In the genus Peronospora, which is represented by many species $(P$. parasitica on Capsella, $P$. calotheca on Rubiaceæ, etc.), only one sporangium is borne by each branch of the sporophore which protrudes through a stoma. In Phytophthora the sporangia are displaced laterally by branches which arise from the hyphæ bearing the sporangia, at their points of origin. To this genus belongs $P$. infestans, which produces the potato-disease. The tissues of the host undergo decomposition in the infected parts and turn black: the mycelium of the Fungus extends from the circumference of these spots, and throws up sporophores through the stomata (Fig. 168). The sporangia of the parasite are carried by the wind to healthy plants and infect them: the zoospores also penetrate through the soil to the tubers, and the mycelium which is developed from them extends into the young Potato-plant which grows from the tuber. No sexual reproductive organs have been observed in this Fungus as yet. 
Phytophthora omnivora infects and destroys the seedlings of the Beech and other plants. In Cystopus (C. candidus on Capsella and other Crucifers, C. cubicus on Compositæ) sporophores bearing numerous sporangia are formed in great numbers close together under the epidermis, and cause its rupture.

Order 2.-Saprolegniaceæ. The Saprolegniaceæ all live in water, and are mostly saprophytic, though some are parasitic; one species causes the Salmon-disease.

Asexual reproduction is effected entirely by zoospores; they are formed in terminal but not otherwise especially differentiated sporangia (Fig. 169). On coming to rest they germinate to form a mycelium. They are, in some forms, surrounded by a thin cell-wall at their first formation.

The oogonia and pollinodia (when present) resemble those of the Peronosporaceæ. The number of oospheres in the oogonium varies widely in different individuals; sometimes there is only one (Leptolegnia, Aphanomyces); but as a rule there are many, as many as $30-40$; in either case they are developed from the whole of the protoplasm of the oogonium.

The male and female sexual organs are commonly borne on the same hypha, but in some cases (e.g. Saprolegnia dioica and anisospora) this is not the case; however, it is not clear that these species are actually diocious. In some speciès (Saprolegnia Thureti, torulosa, monilifera, and Achlya stellata) no male organs are developed as a rule; in others (Saprolegnia mixta, Achlya spinosa) they are as often absent as present; in others they are frequently absent (Aphanomyces stellatus, Saprolegnia hypogyna, Aplanes Braunii); in others, finally, they are always present (Achlya racemosa and polyandra, Saprolegnia monoica).

When pollinodia are present, they are closely applied to the oogonium; sometimes several are applied to one oogonium. In some forms (e.g. Saprolegnia asterophora) the pollinodium undergoes no change, or it

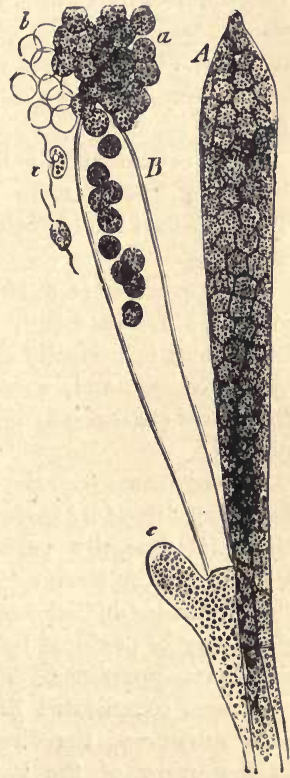

Fic. 169.-Zoosporangium of an Achlya : $A$ closed; $B$ the zoospores are escaping; $c$ a lateral branch; $a$ zoospores just escaped ; $b$ empty membranes; $e$ swarming zoospores. ( $\times 550$ : after Sachs.) sends out a short tube which enters the oogonium but does not touch the oospheres. In most others the pollinodium sends out one or more tubes which enter the oogonium and come into close contact with the oospheres. But in all cases the tubes remain closed, and no act of fertilisation has

M.B. 
been observed: the oospheres, however, all become oospores. The germination of the oospores presents the same variations as in the Peronosporaceæ.

Saprolegnia can be obtained by placing dead flies in water from a ditch or pond: in a day or two the flies will be found covered with mycelium, if the temperature has been sufficiently maintained.

Sub-Class IV.-ASCOMYCETES. This sub-class includes a vast number of forms, both saprophytes and parasites. Some of them (e.g. Penicillium glaucum, Eurotium Aspergillus) are familiar as the blue or green moulds appearing on jam, damp boots, etc. ; others (Erysipheæ) as mildew on roses, etc. : Cordyceps infests the larvæ of insects.

In some cases the life-history is complicated by polymorphism, including one or more entirely asexual conidia-bearing forms. These various life-histories are briefly illustrated by the following examples.

In some cases (e.g. Eremascus albus, Gymnoascus, most Ascomycetous Lichen-fungi, Ascobolus furfuraceus, Pyronema) the life-history is perfectly simple, presenting only the plant bearing sexual organs, and, subsequently, the ascocarp. On germination the spores (ascospores) produced in the ascocarp give rise to the plant.

In other cases (e.g. Erysipheæ, Eurotium, Penicillium) the plant reproduces itself by means of conidia ; in the Erysipheæ and Eurotium it generally produces sexual organs eventually; but in Penicillium the formation of sexual organs takes place only exceptionally under special conditions, so that many successive generations may be produced by means of conidia before a sexual plant makes its appearance. This may occur also in the Erysipheæ.

A more complicated life-history can be clearly traced in Claviceps purpurea, the Ergot of Rye. The mycelium is developed in the ovary of the Rye-flower, and forms a continuous layer of hyphæ, a compound conidiophore, at the surface, from which immense numbers of conidia are formed by abstriction, imbedded in a mucilaginous substance known as Honey-dew. This substance is eaten by insects, and thus the conidia are carried to other flowers and there reproduce the fungus. This is the Sphaceliaform. When the rye is ripening, the mycelium forms a dense sclerotium (see p. 277), fusiform, about an inch long, of a dark purple colour at the surface. This is the Ergot, and it remains dormant until the following spring. On germination the sclerotium gives 
rise to several filaments termed stromata, about an inch long, each composed of a strand of hyphæ, which bear a swollen knob at their apices (Fig. 176). All over the surface of the knob are a number of depressions, in each of which there is an ascocarp (perithecium) containing a number of asci, and in each ascus there are eight filiform ascospores. The ascospores are carried by the wind to the Rye-flowers and there give rise to the Sphacelia-form.

In some cases only conidia-bearing forms are known (e.g. Aspergillus clavatus, Botrytis Bassii, species of Isaria, Cladosporium Herbarum, etc.).

The Reproductive Organs are asexual and sexual.

The asexual organs are conidiophores, either simple or compound (see Figs. 170, 175), branched or unbranched; the conidia are formed by abstriction from short tubular outgrowths of the unbranched, or of the terminal cells of branches of the branched, conidiophore, termed sterigmata. In many cases the conidiophores are collected in to special receptacles termed pycnidia.

The sexual organs are modified hyphæ. They may be unseptate (e.g. Eremascus, Eurotium Aspergillus, Pyronema), or septate (e.g. Ascobolus, Laboulbeniaceæ); they may be quite similar (e.g. Eremascus) or more or less differentiated; they may come into close contact

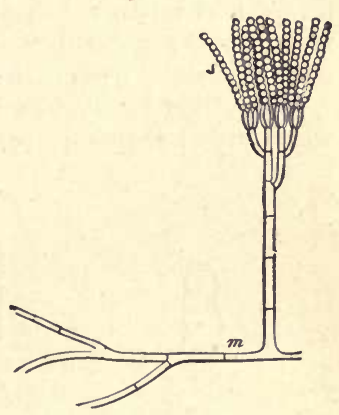

Fra. 170.-Conidiophore of Penicillium glaucum: 8 a row of conidia on a sterigma; $m$ bypha of the mycelium $(\times 150$. (e.g. Eremascus, Eurotium, Pyronema).

When, as in Eremascus, the sexual organs are undifferentiated, no special names are given to them; but when they are differentiated the female organ is termed an archicarp, and the male organ a pollinudium, when its contents do not undergo differentiation into cells, or an antheridium when (as in the Laboulbeniaceæ) male cells are formed in it.

In some forms (c.g. Laboulbeniaceæ, Pyronema) the archicarp consists of two parts; a receptive portion, filamentous in form, the trichogyne; a fertile portion, the ascogonium (compare Rhodophyceæ, p.272). In the simpler forms, the trichogyne is absent 
(e.g. Eurotium, Erysipheæ, Ascobolus), the archicarp consisting solely of the ascogonium. The form of the ascogonium is either filamentous, sometimes spirally coiled (e.g. Eurotium, Fig. 175); or, it is dilated, and spherical or oval (e.g. Pyronema, Fig. 172, Erysiphere).

The pollinodium may be filamentous (e.g. Eurotium), or dilated and club-shaped (e.g. Pyronema, Erysipheæ). The antheridium of the Laboulbeniaceæ is unilocular, and produces several nonmotile male cells (spermatia) within it.

Some of these plants bear receptacles termed spermogonia. The spermogonium consists of a wall formed of coherent hyphæ from which a number of free hyphæ, the sterigmata, grow into the interior and produce, by repeated abstriction at their apices, a number of small, rod-shaped cells, the spermatia, with a cellwall, as to the nature of which there is some doubt. These cells reach the surface through the small opening of the spermogonium.

A process of fertilisation has not been observed in all forms in which sexual organs are present; but it has been observed in the

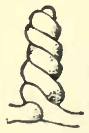

A.

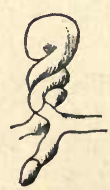

B.

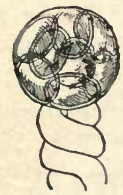

$C$.

Fig. 171.- Sexnal reproduction of Éremascus albus. A Sexual organs in contact. $B$ Fusion of the organs at the apex, with developing ascocarp. C Matnre ascocarp, consisting of a single ascus containing eight ascospores. ( $\times 1000$ : after Eidam.)

following cases which are representative of the various modes in which it may take place.

In Eremascus (Fig. 171) the apices of the undifferentiated sexual organs come into contact, and, the cell-walls being absorbed at the point of contact, the protoplasmic contents fuse.

In Pyronema the trichogyne comes into close contact with an adjacent pollinodium; the cell-walls become absorbed at the point where the apex of the trichogyne presses against the pollinodium, and the contents of the two organs fuse (Fig. 172).

In the Laboulbeniaceæ it appears that the male cells spermatia 
are brought by means of water into contact with the projecting trichogyne. One of them adheres to the trichogyne; the cell-walls are absorbed at the point of contact, and the protoplasm of the spermatium enters the trichogyne, with the result that the ascogonium developes into an ascocarp.

It is probable that, in consequence of sexual degeneration, the sexual organs are functionless in the majority of those Ascomycetes in which both kinds of them are present.

The Ascocarp. In those Ascomycetes in which there is an archicarp, the ascocarp is developed directly or indirectly from that organ: when no archicarp is present, the ascocarp is developed directly from the mycelium.

The simplest form of ascocarp is found in Eremascus (Fig. 171). After the sexual process has taken place, a large spherical cell is formed at the point of junction of the two sexual organs. This cell is an ascus, and produces within it eight ascospores. Here the whole ascocarp consists of a single naked ascus.

The ascocarp of some of the Erysipheæ (e.g. Sphærotheca) is but little more complex than that of Eremascus. Here likewise the archicarp gives rise directly to a single ascus; but an investment is formed round the developing ascus by the growth round it of hyphæ from the adjacent mycelium, which cohere to form a layer of parenchymatous tissue.

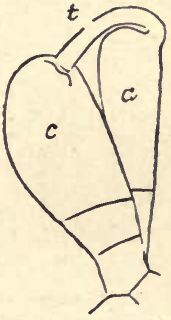

Fig. 172. - Sexual reproduction in Pyronema confluens : archicarp with trichogyne (t) which has fused with the pollinodium a. ( $\times 300$ : after Kihlman.)

In the majority of forms the development of the ascocarp is indirect. The archicarp gives rise to a greater or smaller number of filaments, branched or unbranched, the ascogenous hypho (which closely correspond to the ooblastema-filaments of the Rhodophyceæ, see p. 273), from which the asci are formed as branches, and which together form a compound sporophore. The asci are developed close together, forming a hymenial layer or group, and may or may not be enclosed, either completely or partially, by an investment formed from the surrounding mycelium. In the latter case, vegetative hyphæ grow in among the ascogenous hyphæ and terminate in a number of sterile filaments, 
the paraphyses, which are situate in the hymenial layer between the asci.

The following forms of ascocarp may be distinguished amongst those which have a cellular investment:- the cleistothecium; the investment remains closed until it decays and ruptures to permit of the escape of the ascospores (see Figs. 173, 175): the perithecium; a narrow aperture is developed opposite to the hymenial layer (see Fig. 176): the apothecium; the investment is somewhat saucer-shaped, so that the hymenial layer is fully exposed (see Fig. 177).

The ascus is in all cases unicellular. It may be either spherical (e.g. Eremascus, Eurotium), or oval, or club-shaped (e.g. Peziza) in form. In some cases the ascospores are ejected with considerable force; in others they are set free on the mucilaginous degeneration of the wall of the ascus.

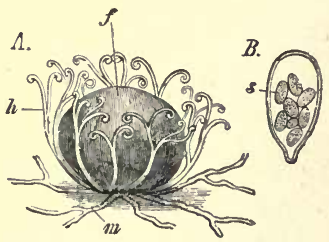

Frg. 173. - A Ascocarp of Uncinula bicornis (Erssipheæ), slightly magnifled: $m$ mycelium; $f$ cleistothecium; $h$ investing filaments, $B$ An ascns from tho cleistothecium, containing eight ascaspores (more highly magnified).

The ascopores are formed by free cell-formation (see Fig. 64, p. 86) from a portion only of the protoplasmic contents of the ascus, preceded by nuclear division. The nnused portion of the protoplasm is termed the epiplasm, and is rich in a carbohydrate called glycogen. In nearly all cases eight ascospores are formed; in some cases each of the eight spore-rudiments undergoes division to form a compound spore (e.g. Hysterium, Pleospora, etc.), the cells of which may either separate or remain coherent. The form of the ascospore is spherical, or oval, or rarely filamentous (c.g. Claviceps, Fig. 176). The wall generally consists of exospore and endospore: the protoplasm generally contains oil-drops.

The germinating ascospore usually gives rise directly to the ordinary mycelium.

The Ascomycetes may be classified as follows:-

Order I.-Gymnoasceæ: asci without any investment, or with only a rudimentary investment, either solitary, or forming a hymenial layer.

The typical members of this group are Eremascus (Fig. 171), Gymnoascus, and Exoascus parasitic on various trees.

It is now customary to place in this order the family of the SAccha- 
ROMYCETES, or Yeast-Fungi, which is familiar on account of the alcoholic fermentation of saccharine solutions which some of its members excite (e.g. Saccharomyces Cerevisiae used in brewing, and S. ellipsoideus which causes the fermentation of the grape-juice in the manufacture of wine: see p. 198). The plant is usually a single small spherical or oval nucleate cell, and multiplies rapidly by gemmation (Fig. 174: see p. 149). When budding is proceeding very rapidly, the successive cells may remain coherent for a time; but a true mycelium is only rarely found, as in S. Mycoderma, which forms a scum on decomposing wine and beer.

Under certain conditions, particularly the absence of a sufficient supply of food, the plant forms spores. Usually four spores are formed in a cell, by free cell-formation, from a portion of the protoplasm, the rest remaining as a parietal layer of epiplasm. The spores surround themselves with a membrane, and are set free by the disorganisation of the wall of the cell. The spores retain their vitality under conditions, such as desiccation, absence of food, extremes of temperature, etc., which would prove fatal to the Yeast-plants. The spores germinate, on attaining appropriate conditions of moisture and temperature, and give rise to Yeast-cells by budding.

Inasmuch as the formation of the spores in a Yeast-cell takes place in the same manner as the formation of spores in an ascus, the Yeast-cell may be regarded as an ascus. It is on this account that the Saccharomycetes are included in the Ascomycetes, and in the Gymnoasceæ on account of their naked asci. They are, however, reduced and sexually degenerate forms.

It must be borne in mind that cells very similar to those of the true Saccharomycetes, multiplying in the same manner, and often capable of exciting the alcoholic fermentation of sugar, may be formed by gemmation from the conidia of various kinds of higher Fungi (e.g. Mucor racemosus, Penicillium glaucum, some Ustilagineæ and Basidiomycetes) under special conditions. These Yeast-like cells, however, grow into mycelia-under appropriate treatment. However, it is still a question whether all the forms of Saccharomycetes may not be merely secondary conidial forms of gemmæ of mycelial Fungi.

Order II.-Pyrenomycetes: asci forming a bymenial layer, with an investment; the ascocarp is either a cleistothecium or a perithecium; a stroma is present in some families.

The ascocarp is a cleistothecium in the sub-order Perisporiaceæ, including the families Erysipheæ (the Mildews) and Perisporieæ (e.g. Eurotium and Penicillium); in these families there is no stroma.

Eurotium Aspergillus is the greenish Mould which so often attacks jam. It can be well cultivated for study on stewed prunes, by sowing conidia obtained from infected jam. The prunes soon become covered with a white, downy substance, which is the vegetative mycelium; this grad- 
ually assumes an olive-green colour as the conidiophores are developed; and finally bright yellow patches appear, indicating the formation of the ascocarps.

Specimens of Mildews can generally be obtained, in a wet summer, from the leaves of the Rose or of the Hop.

The ascocarp is a perithecium in the sub-order Hypocreaceæ, Sphæriaceæ, and Dothideaceæ (e.g. Claviceps, Cordyceps): a stroma, which varies much in form, is frequently present.
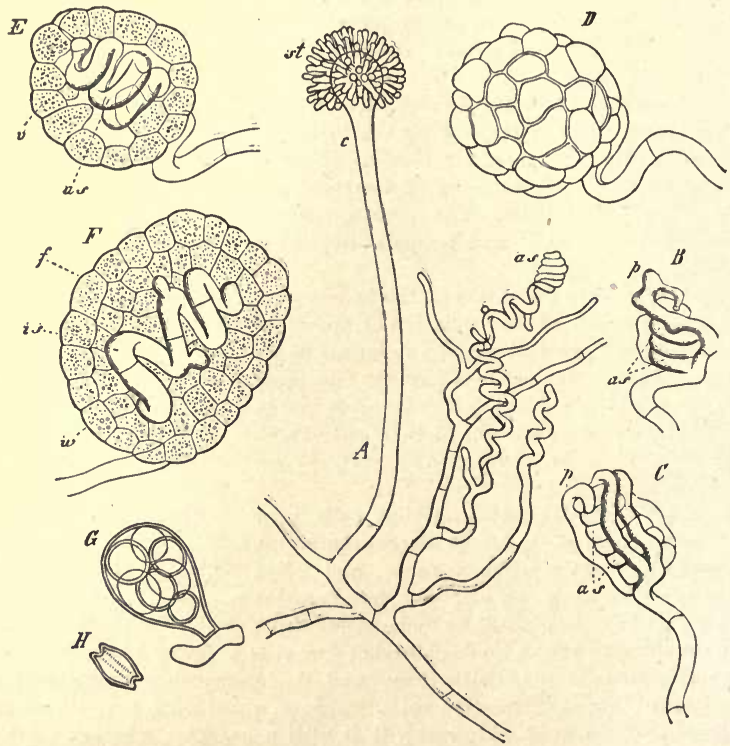

Fra. 175.-Eurotium repens. A A portion of the mycelinm with a simple conidiophore (c) beuring conidia; the conidia have already fallen off from the sterigmata (st); as, a young ascogonium. B Asoogonium (as) with a pollinodium $(p)$, C Another, with hyphæ growing up round it. $D$ A cleistothecium seen on the exterior. $E F$ Sections of unripe cleistothecia; $v$ the investment; $f$ asoogenous hyphr arising from the asoogonium, which subsequently bear the asci. $G$ An ascus. H A ripe ascospore. (Magnifled : after Sachs.)

Order III.-Discomycetes: the aseocarp is an apothecium of various form; a stroma sometimes present:

The order may be divided, according to the form of the apothecium, into the two sub-orders Pezizaceæe and Helvellaceæ. In the former the apothecium is cup-shaped, the hymenium covering the concave surface 
and is closed in the early stages of its development; in the latter the apothecium is borne on the convex, smooth, or reticulate surface of an erect stroma.

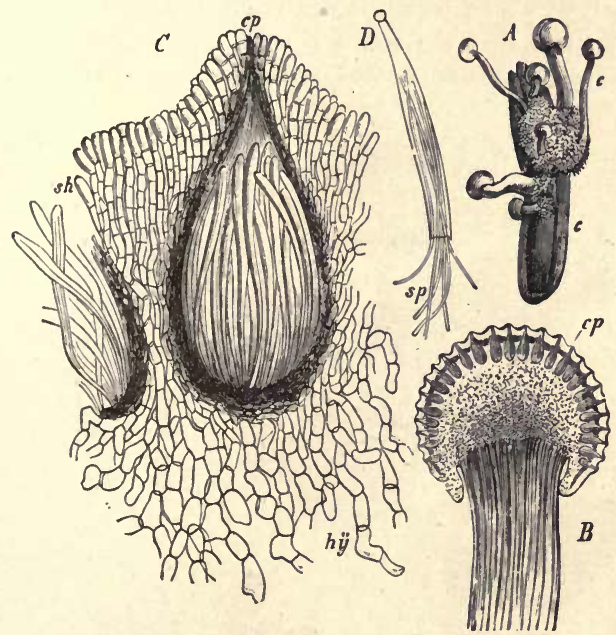

Fig. 176.-Claviceps purpurea. A A sclerotium (c) bearing stromata (x 2). B Section of a stroma; $c p$ the perithecia. $C A$ perithecinm more bighly magnified. $D$ An ascus ruptured; the elongated spores ( $8 p$ ) are escaping. (After Sachs.)

The sub-order Pezizaceæ includes several families, the Phacidieæ, Pezizeæ, Bulgarieæ, etc. As representative may be mentioned Rhytisma Acerinum, the mycelium of which infests the leaves of the Maple, but the development of the apothecium does not take place until after the leaves have fallen; and other similar forms which inhabit the leaves of the Silver Fir, Spruce, and other trees: Ascobolus, which grows on dung: the various species of Peziza, with brightlycoloured apothecia, growing on rotting wood, etc.: Bulgaria, with a gelatinous apothecium, growing on dead branches of the Oak.

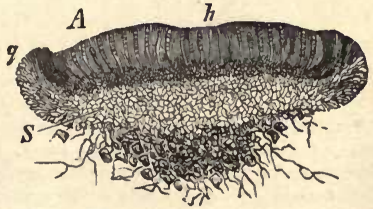

FrG. 177. - Longitudinal section of the apothecium of Pexiza convexula: $h$ the hymenium. (After Sachs.)

The sub-order Helvellaceæ includes the genera Morchella (the Morell, esculent), Gyromitra, Helvella, etc. 
Sub-Class V.- Ecidiomycetes. This sub-class includes a considerable number of parasitic plants known as Rusts and Smuts. They are characterised by their remarkably complex life-history, due to polymorphism, presenting two or more spore-bearing forms : and by the fact that the spores are not developed in the interior of a sporangium, but are formed by abstriction.

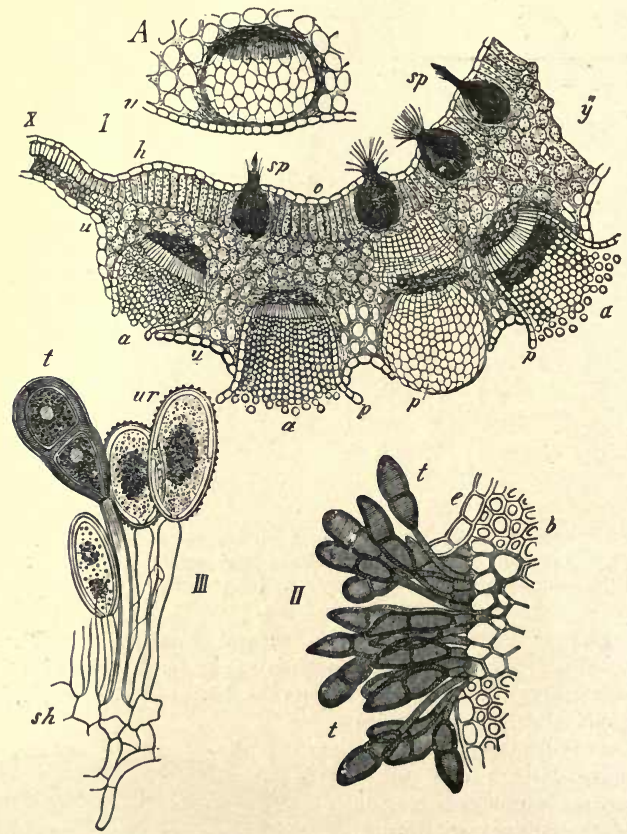

Frg. 178.-Puccinia Graminis. I Transverse section of a leaf of Barberry, with æcidia (a); $p$ the wall of the recidium; $u$ lower, o npper surface of the leaf, which has become thickened at $u, y$, in consequence of the presence of the parasite; on the apper surface are spermogonia (sp). A A yonng æcidinm which has not yet opened. II Sorus of telentospores $(t)$ on the leal of Triticum repens; 6 its epidermis. III Part of a sorus of uredospores on the same plant; $u$ r the uredospores; $t$ a telentospore. (After Sach8.)

The sub-class is divisible into two orders:-

Order 1. Uredineæ: have an æcidium-form, as a rule.

Order 2. Ustilagineæ : never have an æcidium-form. 
Order I.-Uredineæ. This order comprises those parasites which are generally known as Rusts, on account of the rusty appearance which they give to their host-plants at a certain stage of their life-history, when they bear at the surface a great number of orange-coloured spores.

Puccinia Graminis affords an example of the most complex life-history with heterocism : that is, that the different forms inhabit-different hosts. It infests Wheat, Rye, and other Grasses, and developes its mycelium in the tissues of the young plants. During the summer it produces groups of simple sporophores, at the apex of each of which a single oval spore, termed a uredospore, of an orange colour, is formed by abstriction (Fig. $178, I I I)$; in consequence of the great development of cells at these points the epidermis of the host is ruptured, and the groups of uredospores are visible on the surface as rusty spots. These uredospores are scattered by the wind, and infect other Grassplants; on reaching a leaf, the uredospore germinates at once, forming a hypha which enters through a stoma into the interior of the leaf, where it developes into a mycelium bearing uredospores. This stage in the life-history is termed the Uredoform.

Later in the season, when the tissues of the hosts are becoming hard and dry, the Uredo-form no longer produces uredospores, but dark-coloured often compound spores, known as teleutospores (Fig. 178, II), developed in the same way as the uredospores. The teleutospores remain quiescent during the winter. When they germinate in the following spring, one or both of the cells gives rise to a small, free, nonparasitic mycelium (promycel-

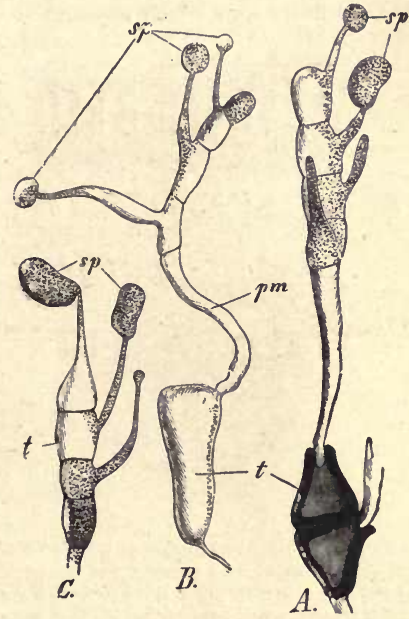

FiG. 179.-Germination of teleutospores of various Uredineæ: : A of Puccinia Graminis (x $406) ; B$ of Melampsora (x 300); C of Coleosporium $(\times 230) ; t$ teleutospore; pm promy. celium; sp sporidia.

ium), from each of the cells of which a delicate conidiophore is produced, which developes a small conidium (termed a sporidium) by abstriction at its apex (Fig. 179).

The sporidia are scattered by the wind, and if they fall on the leaves of the Barberry they germinate, giving rise to a hypha which pierces the epidermis of the leaf, and then forms a dense mycelium in the intercellular spaces of the mesophyll. At certain points the tissue of the leaf is hypertrophied, forming cushions which project on the under surface. 
Towards the upper surface of the cushion there are formed on the mycelium small receptacles, the spermogonia (Fig. $178 \mathrm{sp}$ ), each of which contains a number of unseptate hyphæ, radiating from the wall towards the centre, which are termed sterigmata; each of these produces at its apex by abstriction a small cell, the spermatium, which escapes from the spermogonium; spermogonia are formed, though less frequently, on the under surface: the significance of the spermogonia and spermatia is not known. Large spherical structures are formed on the under surface of the cushion (Fig. 178); these are the acidia. This form of the fungus is known as Ecidiun Berberidis. Each æcidium consists of a hymenial layer of simple unseptate sporophores at its base, from the apices of which a number of spores (accidiospores) are formed by successive abstriction; the æcidium has a definite wall which ruptures at the surface to set free the spores.

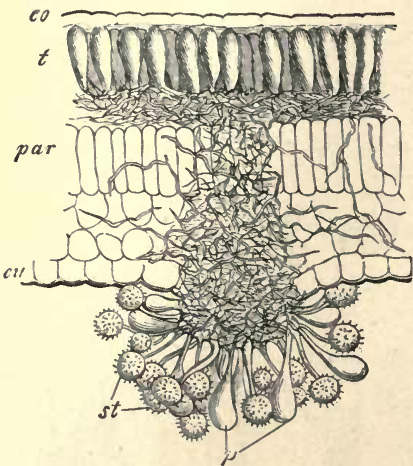

FIG. 180.-Transverse section of a Willow-leal infested by Melampsora salicina: par mesophyll of leaf: co upper, eu lower epidermis. On the under side a sorus of uredospores (st) with paraphyses $(p)$ has broken through the epidermis; beneath the upper epidermis is a sorus of young telentospores $(t) .(\times 260$.

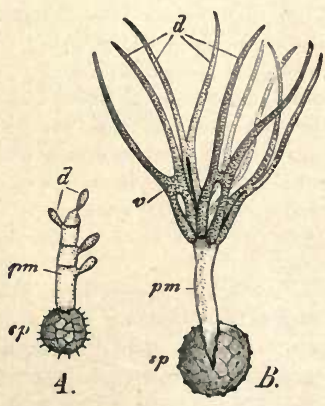

FIG. 181. - Germinating restingspores: A of Ustilago receptaculorum; $B$ of Tilletia Caries $(x 460): s p$ the spore; $p m$ the promycelium; $d$ the sporidia : in $B$ the sporidis have coalesced in pairs at $v$.

The æcidiospores are conveyed by the wind to Grass-plants, on the leaves of which they germinate, putting out hyphæ which penetrate into the interior through the stomata, giving rise to the mycelium which bears the uredospores, and subsequently the teleutospores.

Order 2.-Ustilagineæ. This order comprises those parasites which are known as Smuts. The life-history of most of the members of this order is briefly as follows. The plant produces numerous thick-walled, often black (Smut) resting-spores, the development of which is usually intercalary (resembling that of chlamydospores) on more or less specialised mycelial branches (conidiophores). On germination, the resting-spore 
forms a number of reproductive cells, sporidia, of various form; the sporidia are usually developed on a small promycelium, which may be either multicellular (Fig. $181 \mathrm{~A}$ ), or unicellular (Fig. $181 \mathrm{~B}$ ). In most forms these sporidia then coalesce in pairs; but in any case they germinate, either producing at once the mycelium which will bear the restingspores (e.g. Protomyces), or a second promycelium bearing secondary sporidia, from which the mycelium bearing resting-spores is developed (e.g. Tilletia Caries).

In some species (e.g. Entyloma Ranunculi, Tuburcinia Trientalis) the mycelium, before it produces the resting-spores, developes conidia; these are small, thin-walled, somewhat spindle-shaped cells, developed by abstriction from the ends of unbranched simple conidiophores.

The sporidia, when cultivated in nutrient solutions, may be made to multiply actively by gemmation, producing a number of yeast-like cells.

The most important and the most common species are Ustilago Carbo, which especially attacks Oats, but other Cereals and Grasses as well: $L$. Maidis, which produces large tumours in the Maize, filled with restingspores: Urocystis occulta, which fructifies in the leaves and haulms of the Rye: Tilletia Caries, the Smut of Wheat; this is dangerous because the grains filled with resting-spores remain closed, and are therefore harvested with the sound ones. Many other species and genera infest wild plants.

Sub-Class VI.-BASIDIOMYCETES. This sub-class includes a large number of plants, both saprophytes and parasites, the fructifications of which are well known as Mushrooms, Toad-stools, and Puff-Balls; they are the most highly organised of the Fungi.

The body is a branched septate mycelium, growing in the substratum, and bearing the reproductive organs which come to the surface. That of the common edible Mushroom is generally termed "mushroom-spawn."

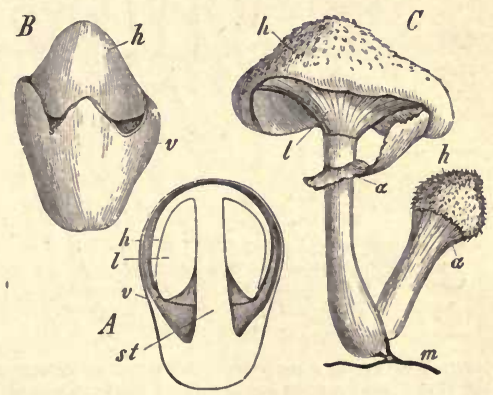

Fre. 182. $-A$ Section of young componnd sporophore of Agaricus (Amanita) vaginatus: v the velum nnirersale; st the stipe; $h$ the pileus; $l$ the lamella: $B$ the same somewhat older; the velum 0 is ruptured. C Agaricus melleus: $m$ the mycelinm (Rhizomorpha); in the smaller specimen to the right the hymenophore is still covered by the velum partiale $a$; in the larger specimen the velum is almost completely ruptured, and remains attached to the stipe as the ring, a. ( $\frac{1}{2}$ nat. size.) 
The reproductive organs are of two kinds, compound and simple. Of these the compound sporophore is universal, and is characteristic of the sub-class; it constitutes the fructification commonly known as a Mushroom, a Toadstool, etc. The structure of this fructification may be illustrated by reference to the common Mushroom (Agaricus campestris). It consists of a stalk, termed the

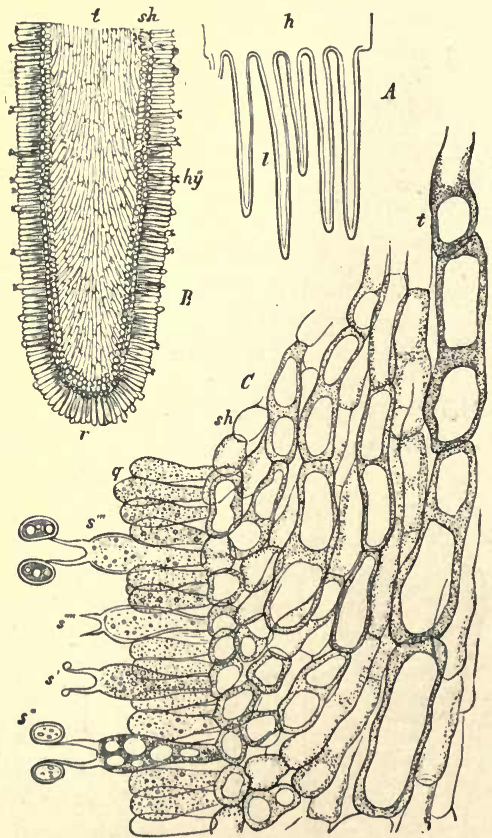

Fra. 183.-Agasicus campestris. A Tangential section of the pileus, showing the lamellm $(l)$ of the bymenophore. B A similar section of a lamella more highly mag nified $h y$ the hymenium; $t$ the central tissue called the traxa. $C$ A portion of the same section more highly magnifled ( $\times$ 550): $q$ young basidia and paraphyses; $g^{\prime}$ the first formation of вpores on a basidium; $B^{\prime \prime}$ more advanced stages; at $8^{\prime \prime \prime \prime}$ the spores have fallen off. (Alter Sachs.) stipe, bearing at its apex a large circular, somewhat umbrella-shaped expansion, the pileus. On the underside of the pileus are a number of radiating plates of tissue, the lamellae (Fig. 183), covered with the spore-bearing layer of cells, called the hymenial layer or hymenium. The lamellæ collectively constitute the hymenophore. Towards the upper end of the stipe is a ring of tissue, the annulus, the torn remains of a membrane (the velum) which extended from the stipe to the margin of the pileus, enclosing the hymenial cavity (Fig. 182).

The stipe consists of a number of closely-packed branching hyphæ, which, at its apex, spreads out to form the tissue of the pileus. In the pileus the hyphæ branch repeatedly, the hyphæ 
towards the lower surface forming the lamellæ. Each lamella (Fig. $183 \mathrm{~B}$ ) consists of a mass of hyphæ, constituting the trama; as the hyphæ approach the surface of the lamella, the cells become shorter. The last cells, before reaching the hymenial layer, are very short, and constitute a definite layer, known as the subhymenial layer (Fig. $183 \mathrm{~B}, C, s h$ ). The terminal cells of the hyphæ constitute the hymenial layer (Fig. $183 B$ hy). This consists of somewhat elongated club-shaped cells, some of which bear spores, and are termed basidia, whilst the others are sterile, and are termed paraphyses (Fig $183 C q$ ). Each basidium developes at its apex 2-4 delicate outgrowths, the sterigmata, and at the apex of each sterigma a single small spore $\left(C s^{\prime} s^{\prime \prime}\right)$ is formed. These spores are termed basidiospores, with reference to their mode of origin.

The form of the compound sporophore, as also the relation of its different parts, varies widely in the orders and families of the subclass. In some families (e.g., Auricularieæ, Tremellineæ, Clavarieæ Hydneæ, most Polyporeæ, and some Agaricinæ), the hymenium is exposed from its first development, and the sporophore is consequently said to be gymnocarpous. In Polyporus volvatus, species of Boletus, and in some Agaricinæ (e.g. sub-genera Armillaria, Psalliota, of the genus Agaricus, etc.) the hymenium is covered for some time by a membrane, termed a velum partiale, as described above (see Fig. 182); the sporophore is then termed hemi-

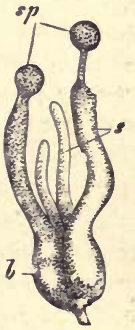

FIG. 181.-Multicellular basidium of Tremella : 8 sterigma; $8 p$ basidiospores. ( $\times 350$.) angiocarpous. Finally, the whole sporophore may be surrounded by a membrane, which is dehiscent or indehiscent, and is then said to be angiocarpous. This is due to the fact that the sporophore is developed from the internal portion of the primitive mass of hyphal tissue, the external portion constituting the enveloping membrane. This arrangement obtains in various genera of Agaricinæ, such as Agaricus (sub-genera Amanita, Fig. 182, Lepiota) and Coprinus, and generally in the order Gasteromycetes. This membrane is termed, in the case of the Agaricinæ, a velum universale; in that of the Gasteromycetes, a peridium. When it is dehiscent, and the sporophore is stipitate, a portion of it remains surrounding the base of the stipe as a volva. 
In the higher Basidiomycetes (Autobasidiomycetes) the basidia are unicellular, but in the lower forms (Protobasidiomycetes) they are multicellular, either with transverse septa (Pilacreæ, Auricularieæ), or with longitudinal septa (Tremellineæ, Fig. 184).

The number of spores borne by a unicellular basidium is usually four ; but it may be one (species of Hymenogaster), or two (Calocera, Dacryomyces, species of Octaviana and Hymenogaster), or 4-8 (Phalloideæ). In the case of the multicellular basidium, each cell bears one basidiospore.

Simple conidiophores have been discovered in several forms (e.g. Pilacre Petersii, Auricularia sambucina, Exidia, Tremella mescnterica and lutescens. In these forms the basidiospore gives rise, on germination, to a mycelium, sometimes small and unbranched, which is either itself the simple conidiophore, or bears simple conidiophores, on which conidia are formed by abstriction. The same mycelium may subsequently bear the compound sporophores; or the conidia-bearing form may reproduce itself through successive generations until at length, under appropriate conditions, the form bearing the compound sporophores occurs.

The conidia of Tremella, cultivated in nutrient solution, multiply rapidly by budding, producing yeast-like cells which have not, however, the power of exciting alcoholic fermentation.

The formation of unicellular gemmæ (see p. 277) is of common occurrence in the Basidiomycetes; either in the form of chlamydospores (e.g. Nyctalis, Oligoporus, Fistulina); or, more commonly (e.g. species of Coprinus, Clavarieæ, Polyporus, Cyathus, etc.) in the form of oidium-cells. The chlamydospores are especially developed in the basidial fructifications of the plants in which they occur: the oidium-cells are generally developed from the vegetative mycelium, either the whole of it or individual hyphæ, forming sometimes a more or less definite fructification. In some Agaricinæ (e.g. Coprinus, Clavarieæ) the oidium-cells appear to be incapable of germinating.

Sclerotia (see p. 277) are known in some cases. The mycelium (e.g. species of Typhula, Coprinus stercorarius, Tulostoma) produces sclerotia as an antecedent to the formation of the compound sporophores; the sclerotia become quite free from the mycelium, and may be kept for months without losing their vitality. On germination each sclerotium gives rise to one or more compound sporophores. The most remarkable sclerotia are those of Agaricus melleus, a Fungus which is very destructive to timber. The 
mycelium gives rise to dark-coloured compact strands of hyphæ, of the pseudo-parenchymatous structure characteristic of sclerotia ; but they are peculiar in possessing continued apical growth, and by this means they soon become long filaments, known as Rhizomorpha. It is in this way that the Fungus spreads from tree to tree: the Rhizomorpha-filaments grow underground from the roots of an infected tree to those of a healthy tree (usually a Conifer); it penetrates into them and spreads in the tissues external to the wood in the form of a white fan-shaped mycelium. The compound sporophores (Agaricus melleus) are borne either on the subterranean Rhizomorpha-filaments, or on the parasitic mycelium; in either case they come to the surface.

The Basidiomycetes are classified as follows :-

Series I. Protoвasidiomycetes : basidia multicellular, four-celled, each cell bearing a spore; simple conidiophores generally present. Principal genera; Pilacre, Auricularia, Tremella, Exidia.

Series II. Autobasidiomycetes: basidia unicellular; simple conidiophores in some forms.

This series consists of the two orders Hymenomycetes and Gasteromycetes, which are distinguished by the fac $s$ that in the former the hymenium is exposed before the maturity of the kasidiospores, whereas in the latter, the hymenium either remains altogether enclosed in the tissue, or is exposed only after the spores are ripe.

The principal genera of Hymenomycetes are, Clavaria, Hydnum, Polyporus, Agaricus (Mushrooms); and of Gasteromycetes, Lycoperdon (Puffball), Rhizopogon, Cyathus, Geaster, Phallus.

Subsidiary Group. LICHENES. A Lichen consists of a Fungus and an Alga, living in intimate connexion, and both contributing to their mutual welfare-that is,symbiotically(seep.275).

The Lichen-Fungus has always a mycelioid body, and is the constituent of the Lichen which bears the reproductive organs. From the nature of these organs the Lichen-Fungi have been found to belong chiefly to the discomycetous and pyrenomycetous Ascomycetes, but a few are basidiomycetous, belonging to the orders Hymenomycetes and Gasteromycet 3 .

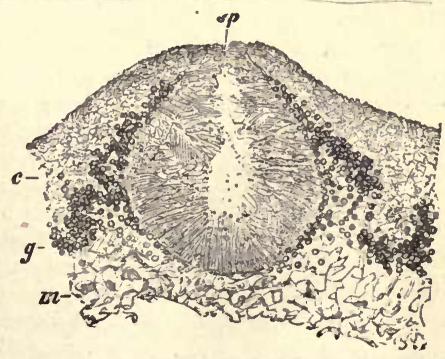

FrG. 185.- Section of a spermogonium of Ana. ptychia ciliaris: sp the aperture at the surface; $c$ cortex, and $m$ medullary portion, of the thallus; $g$ layer of algal cells. (After Strasburger.)

M.B. 
The reproductive organs of the Ascolichenes are sterigmata, producing spermatia, contained in spermogonia (Fig. 185); archicarps (in the order Collemaceæ), differentiated into a coiled ascogonium and a multicellular

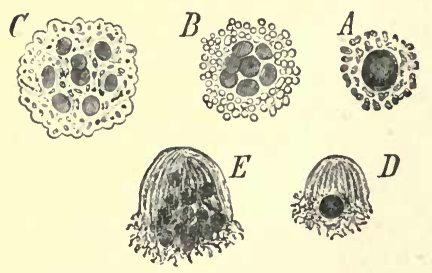

Frg. 196.-A-D Soredia of Usnea barbata. A A simple soredium, consisting of an algal cell covered with a web of hyphæ. B A soredium, in which the algal cell has multiplied by divieion. C A group of simple soredia, resulting from the penetration of the hyphæ between the algal cells. D $E$ Germinating soredia : the byphæ are forming a growingpoint, and the algal cells are multiplying. (After Bachs.)

basidiospore is produced by terminal abstriction.

projecting trichogyne; and ascocarps, which are either apothecia (discomycetous) or perithecia (pyrenomycetous); the archicarp, apparently after fertilisation by means of spermatia, gives rise to filaments which form the hymenial layer (consisting of asci and paraphyses) of the apothecium, and outgrowths from the adjacent vegetative hyphæ form the wall of the apothecium. In the fructification of the Basidiolichenes there is a hymenial layer consisting of paraphyses and basidia, the latter bearing apical sterigmata, on each of which a

Lichens are also reproduced by gemmæ, termed soredia, which consist of one or more algal cells invested by hyphæ; they are budded off from the surface of the thallus, and grow into new plants (Fig. 186).

The Lichen-Algæ belong either to the Cyanophyceæ or to the Chlorophyceæ. The algal cells or filaments may be distributed throughout the thallus, when it is said to be homoiomerous; this is usually the case in gelatinous Lichens (such as the Collemacer), in which the Alga belongs to the Cyannophyceæ, but also in some non-gelatinous forms in which the Alga belongs to the Chlorophyceæ (such as Cœenogonium, Racodium, and others, in which the Alga is Trentepohlia): or they may be arranged in a definite layer near the surface of the thallus, when it is said to be heteromerous (Fig. 188), as in the case of nearly all those Lichens of which

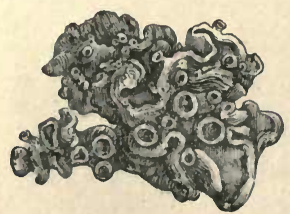

FIG. 187.-A gelatinous Lichen, Collema pulposum, slightly magnified. It is bomoiomerous, and the Alga is Nostoc. (After Sachs.) the Algæ belong to the Chlorophyceæ, and some in which the Algæ belong to the Cyanophyceæ (e.g. Peltigera, Pannaria). In some heteromerous forms (e.g. Thelidium) the Algæ are quite on the surface. Occasionally (e.g. Endocarpon) algal cells are present in the hymenium.

It may be generally stated that the form of the thallus is determined in the homoiomerous Lichens by the Alga, in the heteromerous Lichens by the Fungus. In the latter case three main forms are distinguished:- 
(a) fruticose Lichens, in which the thallus grows erect, branching in a shrub-like manner. Of this form are the various species of Usnea (Fig. $189 \mathrm{~A}$ ), and allied genera with a cylindrical thallus, which grow on trees: Roccella tinctoria grows on rocks in regions bordering on the Mediterranean; from it and other allied Lichens litmus is prepared: Ramalina and Evernia, with a ribbon-shaped flattened thallus, occur on trees and wooden fences: Cetraria islandica is the Iceland Moss, which forms a mucilaginous fluid when boiled with water: Cladonia, the Cup Moss, has a scaly decumbent thallus, from which erect branches spring bearing the apothecia; Cladonia fimbriata is common; Cladonia rangiferina, the Reindeer Moss, occurs on moors.

(b) foliaceous Lichens, in which the thallus is flattened and adheres to the substratum: the green (rarely bluish-green) algal cells form a single layer beneath the upper surface (Fig. 188). The margin of the thallus is usually lobed.

Parmeiza (or Physcia) parietina occurs, with its bright yellow thallus bearing apothecia, on treetrunks and walls, together with other species of a grey colour; Sticta pulmonacea (Fig. $189 B$ ) has a reticulated yellowish thallus, and grows on tree-trunks: Peltigera is represented by several species which grow on mossy banks in woods; the apothecia are borne on the margin of the lobes of the thallus.

(c) crustaceous Lichens, in which the thallus is usually indefinite in outline, and can often be scarcely dis-

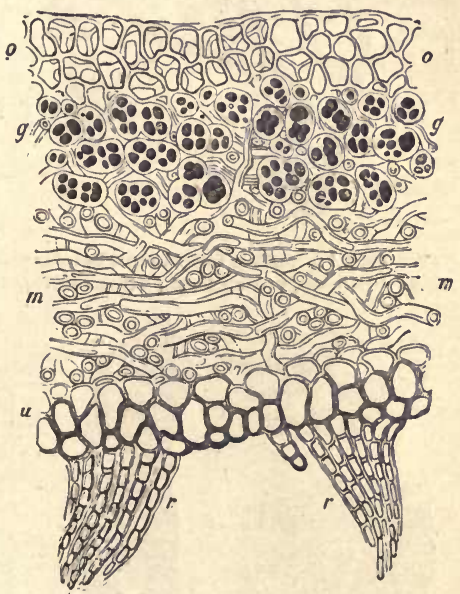

Fre. 188.-Transverse section of the beteromerous thallus of Sticta fuliginosa $(\times 500)$. o Cortex of the npper surface; $u$ under surface; $m$ network of hyphæ forming the medullary layer; $g$ algal cells; $r$ root-like outgrowths (rbizines) of the under surface. (After Sacbs.)

tinguished from the substratum, the fructification alone being conspicuous.

The Lichens of this form are extremely numerous. Among them may be mentioned the Lecanoreæ, of which Lecanora subfusca occurs on the trunks of trees: the Lecideacer, which occur mainly on earth and rocks, Lecidea geographica forming bright yellow incrustations of considerable extent on silicious rocks: the Graphideæ, of which Graphis scripta is common on the trunks of Beeches and other trees. 


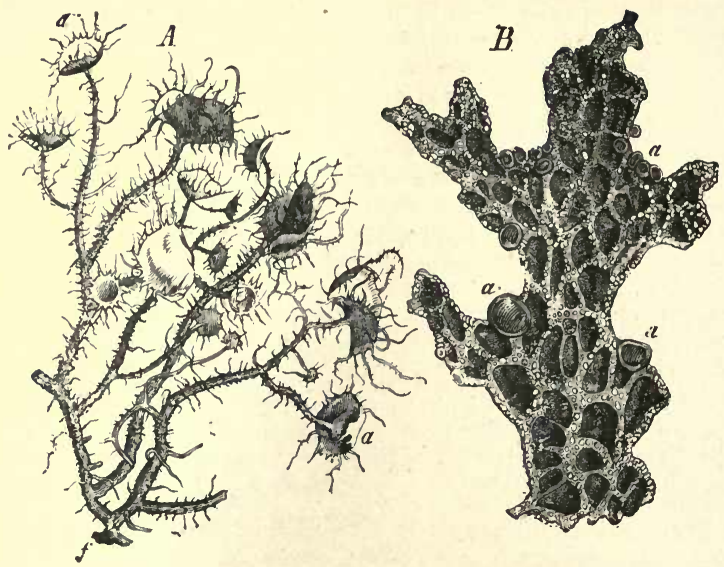

FIG. 189.-A A fruticose Lichen, Usnea barbata, with apothecia, $a . B$ A foliaceous Lichen, Sticta pulmonacea, with apothecia, $a$ (nat. size). (After Sachs.)

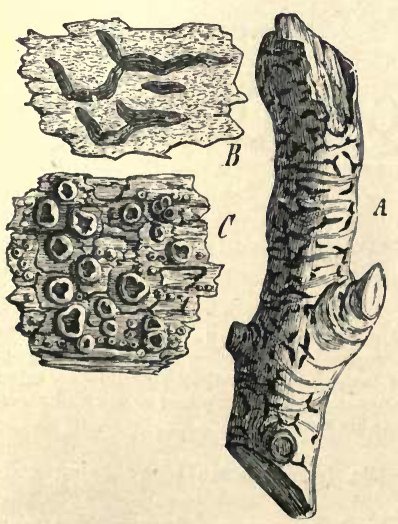

Fit. 190.-Crustaceons Lichens, $A$ and $B$ Graphis elegans: B slightly magnifled. C Pertusaria Wulfoni, slightly magnifled. (After Sachs.)
Many species of crustaceous Lichens inhabit the highest peaks of the Alps, and other lofty mountains, on which there is no other vegetation, and they contribute materially to the weathering of the rocks and to the formation of a vegetable soil. When they grow on the trunks of trees, they occur more especially upon those which have a smooth surface; the formation of a rough bark seems to interfere with their growth. Lichens may become completely dried up without losing their vitality. 


\section{GROUP II. \\ BRYOPHY'TA (Muscineæ).}

The plants forming this group, that is the Liverworts (Hepaticæ) and the Mosses (Musci), are characterised by the following distinctive features. Their life-history presents a regular and wellmarked alternation of generations: the gametophyte is the more conspicuous form, constituting "the plant": the sporophyte is a sporogonium, presenting indications of differentiation into root and shoot, but not of the shoot into stem and leaves; it never becomes an independent individual, but remains attached to the gametophyte, from which it derives all or much of its nutriment. In some of the Mosses there is an indication, in both the sporophyte and the gametophyte, of a differentiation of vascular tissue.

The GaMeTophyte. The germinating spore does not at once give rise to what is known as the "Moss-plant," but produces an embryonic body, the protonema, which consists generally of a branched filament, but occasionally of a flat layer, of cells which contain numerous chloroplastids. The protopema is generally inconspicuous and short-lived in the Hepaticæ, whilst in the Musci it is more amply developed and may, either wholly or in part, persist from year to year.

The "Moss-plant" is the adult sexual form. It does not possess any true roots, but is attached to the soil either by unicellular root-hairs (Hepaticæ), or by multicellular protonematoid filaments termed rhizoids (Musci). The body of the "Moss-plant" is essentially a shoot, which is highly developed and specialised in connexion with the functions which it performs-the development of the sexual reproductive organs and, in the case of the shoots bearing female reproductive organs, the nourishment of the attached sporophyte developed in consequence of fertilisation. The adult shoot arises as a lateral (rarely terminal) bud on the protonema : the protonema may give rise to a single shoot (Hepaticæ) or to several (generally in Musci). In the latter cases, the adult shoots may become distinct "plants" by the complete or partial dying away of the protonema. The symmetry of the shoot is, almost uniformly, dorsiventral in the Hepaticæ and radial in the Musci. It is either thalloid, as in most Hepaticæ; or it is differentiated into stem and leaf, as in the higher Hepaticæ (foliose Jungermanniaceæ) and in the Musci. 
The sexual organs are borne on the adult shoot, and are antheridia and archegonia. They are rarely borne singly or scattered; but more commonly in groups (sori) surrounded by some kind of protective investment to which the general term involucre may be applied. In some cases the portion of the shoot which immediately bears the sexual organs is more or less specialised as a receptacle, and in others special reproductive branches, gametophores, are differentiated, and may be either antheridiophores or archegoniophores. In the lower Hepaticæ the sexual organs are generally borne on the upper (dorsal) surface of the shoot, whilst in the higher Hepaticæ (Jungermanniaceæ acrogynæ) and in the Mosses they are borne at the apex.

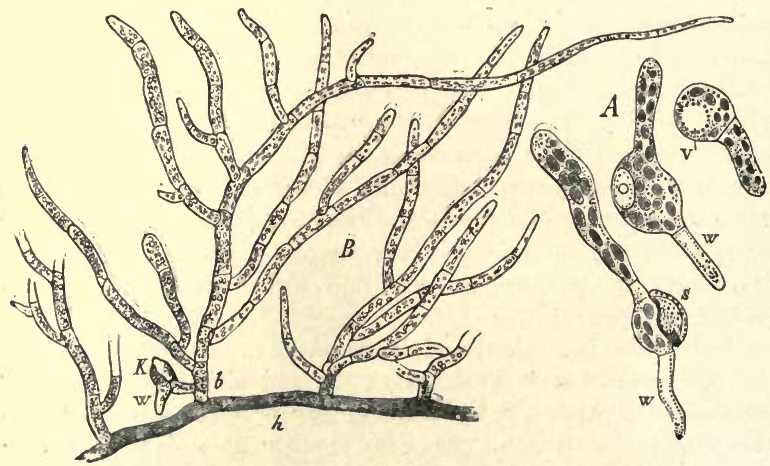

F1G. 191.-Funaria hygrometrica (Mosi). A Germinating sipores $\vdots u$ rhizoid; 8 exospore. $b$ Part of a protonema, about three weeks after the germination of the spore $: h$ a proeumbent primary shoot with brown wall and oblique septa, out of which arise the ascending branches with limited growth : $K$ rudiment of a leaf-bearing axis with rbizoid (w). $(A \times 550: B$ about 83.$)$

The distribution of the sexual organs is various: the male and female organs may be borne on distinct shoots, when they are dioecious; or on different branches of the same shoot, when they are monacious but diclinous; or together in the same sorus, when they are monoclinous. In Mosses it appears to be the rule, in diceious forms, that a protonema always bears both male and female shoots.

The sexual organs are always multicellular. The antheridium (Figs. 192, 193) is a capsule of various shape, having a longer or 
shorter stalk; its wall consists of a single layer of cells which contain chloroplastids when young; internally it consists of very numerous small cells, each of which eventually gives rise to a single spermatozoid.

The spermatozoid is a cell, consisting of a naked filament of protoplasm, spirally twisted, thickened at the posterior end where lies the nucleus, tapering at the anterior end where it terminates in two long cilia by means of which it swims (Figs. 192, 193); the spermatozoids are set free by the rupture of the antheridial wall, which usually takes place at the apex of the antheridium.

The archegonium is flask-shaped and shortly stalked (Figs. 194, 195); it consists of a slightly dilated basal portion, the venter, and of a long slender neck. The axis of the archegonium, when young, is occupied by a central row of cells; the basal cell of this row, lying in the venter, is the central cell of the archegonium; it grows considerably, and

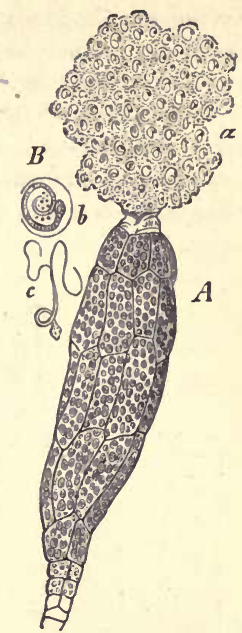

Fio. 192.-Funaria hygrometrica (Moss). A An antheridium bursting : $a$ the spermatozoids (x 350). B Spermatozoids ( $x$ 800); $b$ in the mother-cell : c free spermatozoid of Poly. trichum. eventually divides into two unequal parts, an upper and smaller, the ventral cunalcell, and a lower and larger which is the female reproductive cell or oosphere: the upper cells of the central row constitute the neck - canal-cells. At maturity the terminal cells, lidcells, of the neck separate ; the neckcanal-cells and the ventral canal-cell

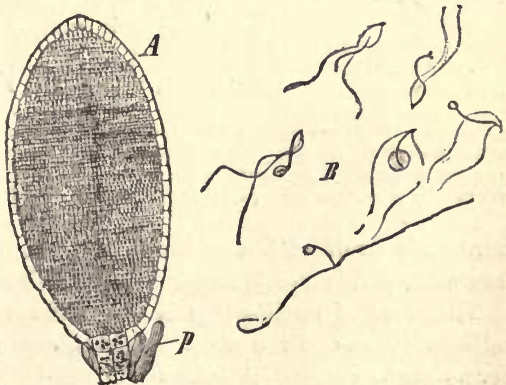

FiG. 193.-A Antheriliam of Marchantia polynorpha (Liverwort) in optical longitudinal section : $p$ paraphyses ( $\times 90)$. $B$ Spermatozoids (× 600) : (after Strasburger). 
become mucilaginous and disorganised, so that the oosphere is placed in communication with the exterior by the canal of the neck. Fertilisation takes place when the plants are more or less covered with water from rain or dew. Then the antheridia dehisce, the spermatozoids are set free, and, since the male and female organs are at no great distance, they, swimming by means of their cilia, come into the neighbourhood of the archegonia; they are

attracted to enter

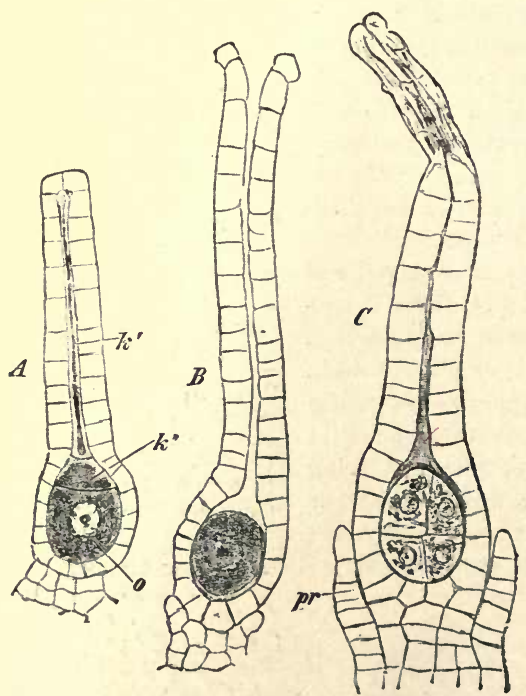

Fic. 194.-Marchantia yolymorpha. A young; $B$ mature, but unfertilised, archegoninm. C Fertilised archegoninm, with dividing oospore. $\quad k$ 'Neck-canal-cells; $k$ " ventral canal-cell; o oosphere; pr perigyniun. ( $\times$ 540 : after Strasburger.) the necks of archegonia by the escaping mucilage formed by the disorganisation of the canal-cells, which contains cane-sugar which substance has been shown to be especially attractive to them (see p. 220). One of the entering spermatozoids travels down the canal to the oosphere, which it penetrates, the nucleus of the spermatozoid fusing with that of the oosphere. Fertilisation is now complete; the fertilised oosphere surrounds itself with a cell-wall and becomes the oospore, which begins to divide and to develope into the sporophyte.

The effect of fertilisation is not confined to the oosphere. The adjacent tissue of the shoot is stimulated to growth, and in some forms (Sphagnaceæ) it grows out into a long leafless stalk, the pseudopodium, which carries np the fertilised archegonium on its apex. The venter of the archegonium also grows, forming, either 
by itself or together with the adjacent tissue of the shoot (as commonly in the Hepaticæ), an investment, termed the calyptra, which surrounds the developing embryo within and, for a longer or shorter time, keeps pace with its growth.

The gametophyte has a remarkable power, especially in the Musci, of reproducing itself vegetatively. This is effected frequently by the gemma, formed from various parts of the body: the leaves, for instance, in the foliose Hepaticæ; or in distinct receptacles termed cupules, as in the Marchantieæ and some Musci. The gemmæ are either unicellular or multicellular, and, in the latter case, may be either spherical or flattened in form. In the branched forms vegetative propagation is effected by the dying away of the main shoot or of the larger branches, the smaller branches becoming isolated and constituting independent plants. In the Musci almost any part is capable, under favourable conditions, of growing out into protonemal filaments on which new adult shoots are developed.

With regard to the histology of the adult shoot, it need only be pointed out that rudimentary vascular tissue, absent in the Hepaticæ, is to be found in the stems and the midribs of the leaves of many Musci; and, further, that the epidermis is not clearly differentiated as a tissue-system, and is destitute of stomata. It is true that in some Hepaticæ (e.g. Anthoceros, Marchantia, etc., Fig. 199) there are structures in the superficial layer which are erroneously called stomata; these are merely pores, and differ altogether in

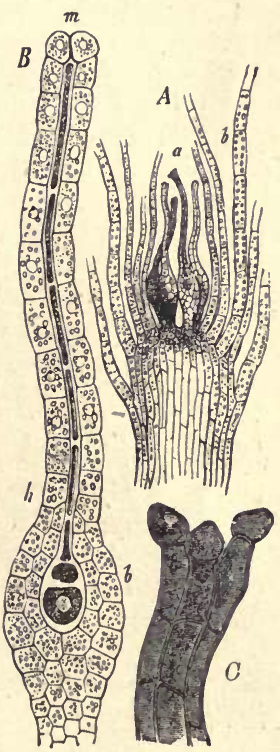

Frg. 195.-Funaria hygrometrica. A Longitndinal section of the summit of a weak female plant $(\times 100)$ : $a$ archegonia ; $b$ leaves. $B$ An archegonium $(\times 550)$ : $b$ ventral portion with the oosphere; neck; $m$ mouth still closed; the cells of the axile row are beginning to be con. verted into mncilage. $C$ The part near the mouth of the neck of a fertilised archegonium with dark red cell-walls. (After Bachs.) 
structure and development from the true stomata which are to be found on the sporophyte of Anthoceros and of most Musci, as well as on the sporophyte of the higher plants.

The Sporophyte, the asexual spore-producing form, is developed from the oospore within the venter of the archegonium (Fig. 196). The oospore divides first into two cells by a transverse wall, the basal wall, at right angles or obliquely to the long axis of the archegonium; the upper cell,

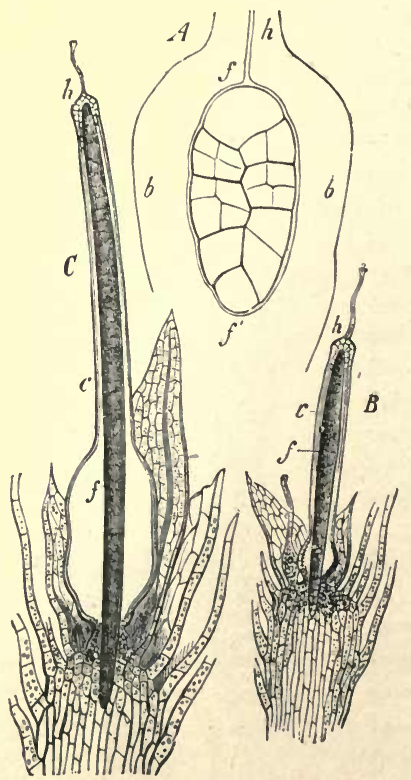

Fı. 196.-Funaria hygrometrica. A Development of the sporogonium $(f f)$ in the ventral portion $(b b)$ of the archegoninm (longitudinal section $\times 500)$. $B C$ Different farther stages of development of the sporogonium $(f)$ and of the calyptra (c); $h$ neck of the archegoninm. ( $x$ about 40.) the one next the neck, is termed the epibasal cell, the lower the hypobasal cell. This is followed in some Hepaticæ (Marchantiaceæ, Anthocerotaceæ) by the formation of two walls, at right angles to the basal wall and to each other, which are known as the quadrant and octant walls, since they respectively segment the oospore into quadrants and octants of a sphere. In other Hepaticæ, and generally in the Musci, the segmentation into octants is confined to the epibasal cell, the hypobasal cell either remaining un; divided, or dividing irregularly. With the exception of some of the lower Hepaticæ (Riccieæ), where epibasal and hypobasal cells alike contribute to the formation of the capsule in which the spores are developed, the epibasal cells alone give rise to the capsule. The hypobasal cell gives rise to the foot, which is welldeveloped in the lower forms of both Hepaticæ and Musci, but is rudimentary in the higher. The foot is essentially an em- 
bryonic organ; but it persists, acting, when sufficiently developed, as the organ of absorption and attachment, throughout the life of the Moss-sporophyte, because the sporophyte, since it does not become free and independent, does not altogether develope beyond the embryonic stage. In most forms the epibasal half of the oospore also gives rise to a longer or shorter stalk, the seta, by the elongation of which the capsule is raised up out of the calyptra. In those Hepaticæ which have a seta, its elongation, and the consequent rupture of the calyptra, takes place suddenly when the capsule is already matnre and the spores fully developed; in the Musci its elongation is gradual, whilst the capsule is still rudimentary, and the rupture of the calyptra takes place relatively early. In the Hepaticæ and some Musci (Sphagnaceæ, Phascum, Ephemerum) the whole of the ruptured calyptra remains as a sheath, the vaginula, round the base of the seta: but in the higher Musci (most Bryineæ) the calyptra is ruptured transversely into an upper and a lower half; the latter constitutes the vaginula, whereas the former is carried up as a cap on the top of the capsule. In some forms, where the true hypobasal foot is rudimentary (some Jungermanniaceæ and Bryineæ) and is functionless, the base of the seta becomes dilated to form a false foot (epibasal), which performs the functions of attachment and absorption.

The body developed from the oospore, which constitutes the asexual generation or sporophyte of the Bryophyta, is termed the sporogonium. With regard to its general morphology it may be considered (except in Riccieæ) to present differentiation into root and shoot; the foot, however rudimentary, developed from the hypobasal half of the oospore, represents the root; the capsule and the seta (when present), developed from the epibasal half of the oospore, represent the shoot. The shoot is in no case differentiated into stem and leaf. In the Riccieæ the products of the hypobasal and epibasal cells are quite similar, so that the whole thalloid sporogoninm consists only of a capsule. Hence, whilst it is the rule in the Bryophyta that sporogenous cells are only developed in the shoot-portion of the sporophyte, that is, are derived only from the epibasal cell, in the Riccieæ the derivatives of the hypobasal cells are also sporogenous.

The sporogonium is not an independent sporophyte, but remains attached to the gametophyte, obtaining from it either the whole or a portion of its food. It must, however, be clearly understood 
that there is no continuity of tissue between the two generations; the sporophyte is simply inserted into the tissue of the gametophyte. In the Hepaticæ (except Anthoceros) the sporophyte is short-lived, and is entirely dependent upon the gametophyte for its nutrition. In Anthoceros, and in most of the Musci, the capsule possesses more or less well-developed assimilatory tissue, and its epidermis is provided with stomata, so that the sporophyte is capable of using the carbon dioxide of the air as its carbonaceous food, and is dependent upon the gametophyte only for its supply of water and salts. In many of these forms the seta has a central strand of rudimentary vascular tissue through which the water and salts, absorbed from the gametophyte, can travel to the region of the capsule where assimilation and transpiration are carried on.
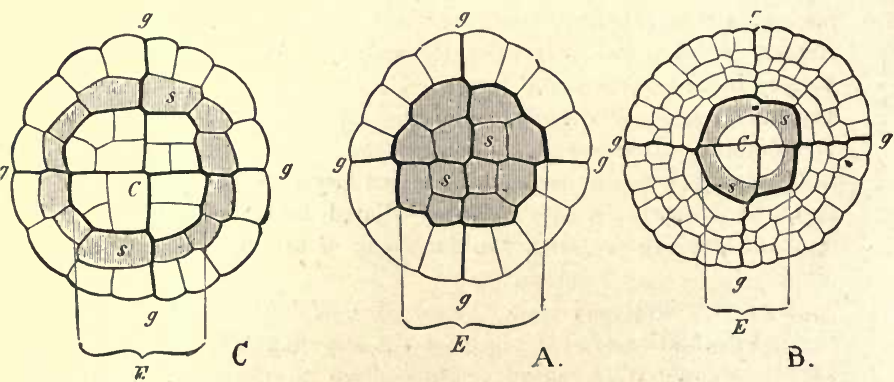

B.

FiG. 197.-Comparative morphology of the sperogonium in the Bryophyta : diagrammatic transverse sections of the young capsule. $A$ Sphærocarpus (t5pical Liverwort); $B$ Ceratodon (typical Moss); $C$ Anthoceros (aberrant Liverwort). $E$ Endothecium: $g-g$ primary divisions (quadrant and octant walls); $s$ (shaded) archesporium; $C$ columella. ( $A$ and $C$ after Leitgeb; $B$ after Kienitz-Gerloff.)

The tissue of the developing capsule becomes differentiated into an external layer (or layers) of cells, termed the amphithecium, which, in nearly all cases (except Anthocerotaceæ and Sphagnaceæ) forms only the wall of the capsule; and an internal solid mass of cells, the endothecium. The spores are developed from a mass or a layer of cells termed the archesporium. In the Hepaticæ the archesporium (Fig. $197 A$ ) includes the whole of the endothecium (except in Anthocerotaceæ, Fig. $197 C^{\prime}$ ), and the archesporial cells are either all sporogenous (Riccieæ) or, as is more frequently the case, some of them are sterile and generally become spirally thickened and elongated in form when they are termed elaters. In the Antho- 
cerotaceæ and in nearly all Musci the archesporium is a layer of cells : it is generally the external layer of the endothecium, but in most of the Anthocerotaceæ and in the Sphagnaceæ it is the innermost layer of the amphithecium. In those forms where the archesporium is a layer of cells, the internal sterile tissue of the endothecium constitutes what is termed the columella. The archesporial cells are either themselves the mother-cells of the spores, or they undergo division to form these cells. Each mother-cell gives rise to four spores; the nncleus divides into two, and each of these divides again; the protoplasm aggregates round the four nuclei, constituting four cells which surround themselves with a proper wall and which are the spores. They do not usually all lie in one plane, but are placed tetrahedrally. The mature spore is a cell, consisting of a mass of protoplasm, with a nucleus, and containing chloroplastids, starch-grains and oil-drops; the wall consists of two layers of the usual structure (see p. 50). During the formation of the spores the mother-cells become isolated from each other, floating freely in a mucilaginous liquid in the interior of the capsule.

The escape of the spores from the capsule is effected in various ways. In some cases the wall of the capsule simply decays (e.g. Riccieæ, Phascum); or it splits into valves (e.g. Jungermanniaceæ); or the upper part is thrown off as a lid or operculum (e.g. some Marchantieæ, Sphagnaceæ, most Bryineæ).

On being set free, the spores germinate, when the conditions are favourable, giving rise to the protonema. The brittle exospore being ruptured, the contents, covered by the endospore, then generally grow out in the form of a filament, which is the beginning of the protonema. In some rare cases (e.g. Pellia) celldivisions take place within the spore before the exospore is ruptured, so that the protonema is from the first a mass or a layer of cells.

The Bryophyta (Muscineæ) are divided into two classes, the distinctive characters of which are as follows:-

Class III.-HePaticE (Liverworts).

Gametophytic Characters. Protonema, generally short-lived, inconspicuous, a flattened expansion.

Adult shoot, generally dorsiventral; thalloid in many forms; has unicellular root-hairs; no trace of vascular tissue; leaves (when present) destitute of a midrib.

Sporophytic Characters. The sporogonium remains within the 
calyptra until the spores are ripe; the ruptured calyptra remains as a vaginula, no portion of it being raised as a cap on the sporogonium; the elongation of the seta (when present) is sudden; the growth of the sporogonium is not effected by a two-sided apical cell.

The archesporium (except in the Anthocerotaceæ) is a mass of cells co-extensive with the endothecium; in all cases (except Riccieæ) some of the archesporial cells are sterile, being frequently developed into elaters; a columella is present only in the Anthocerotaceæ.

There is no trace of vascular tissue in the sporophyte, nor are there any stomata in its epidermis (except Anthocerotaceæ).

Class IV.-Musci (Mosses).

Gametophytic Characters. Protonema frequently persistent, well-developed, generally filamentous. Adult shoot, radial or isobilateral; always differentiated into stem and leaf; no roothairs, but branched multicellular rhizoids; stem frequently with a central strand of rudimentary vascular tissue; leaves generally with a midrib.

Sporophytic Characters. The sporogonium escapes from the calyptra at an early stage; a portion of the calyptra (with certain exceptions) is carried up as a cap on the sporogonium; the elongation of the seta is gradual; the growth of the sporogonium is (except Sphagnaceæ) effected by a two-sided apical cell.

The archesporium is not co-extensive with the endothecium, and is generally a layer of cells; the archesporial cells are all sporogenous, none being sterile or forming elaters; there is usually a well-developed columella in the capsule.

The seta frequently has a central strand of rudimentary vascular tissue; the epidermis of the capsule is generally provided with stomata.

Class III.-Hepaticas (Liverworts).

A. The Gametophyte. The spore gives rise, on germination, to a small protonema which is sometimes filamentous, but more generally a flattened cellular expansion.

The Adult Shoot springs from the protonema. Its symmetry is generally dorsiventral. It is commonly thalloid, but is differentiated into stem and leaves in some forms (e.g. foliose Jungermanniaceæ). Its growth is effected by an apical growing-point in 
which there is either a group of initial cells (Marchantiaceæ, Anthocerotaceæ), or a single apical cell (Jungermanniaceæ). The branching is commonly dichotomous, taking place in the plane of expansion; but the development of branches from the ventral surface is constant in several genera.

The dorsiventral shoot bears numerous unicellular root-hairs on its ventral (lower) surface; when thalloid it also bears multicellular scales (ventral scales) on the same surface; when foliose, it bears on this surface a row of small rudimentary leaves, termed amphigastria, the fully developed foliage-leaves being borne in two lateral rows, one on each flank of the shoot.

In the great majority of Hepaticæ, the sexual organs are borne on the dorsal (upper) surface, either scattered or in groups; and sometimes upon a specially modified portion of the shoot, termed the receptacle, either sessile or stalked; in the latter case the shoot (e.g. higher Marchantieæ) may be more or less clearly differentiated into a vegetative and a reproductive part (gametoplore). It is only in some of the Jungermanniaceæ (Jungermanniaceæ acrogynæ) that the sexual organs are developed at the apex of the branches of the shoot, a feature in which they approach the Musci.

The protonema bears but a single adult shoot; and this, owing to the transitory nature of the protonema, soon becomes an independent plant. The plant is generally monøcious, but sometimes diocious.

B. The Sporophrte is developed from the fertilized oosphere (oospore) in the archegonium (see p. 312). It is a sporogonium, which may consist merely of a capsule (Riccieæ); or it may be differentiated into a capsule and a foot (e.g. Anthoceros); or into a capsule, a longer or shorter seta, and a foot (e.g. Marchantieæ); or into a capsule, a seta, and a rudimentary (hypobasal) foot (some Jungermanniaceæ), a false foot (epibasal) being in some cases developed from the lower part of the seta. It never grows by means of a two-sided apical cell as it does in the Mosses.

The internal differentiation of the capsule presents the following varieties:-It is in all cases differentiated into amphithecium and endothecium; in all, except most Anthocerotaceæ, the archesporium is co-extensive with the endothecium; in the Anthocerotaceæ, the whole or part of the endothecium constitutes a columella, a feature in which the Anthocerotaceæ resemble the Musci.

In the Riccieæ, as a rule, the whole archesporium is sporogenous; whereas in all other forms some of the archesporial cells are 
sterile, and in many they are developed into elaters, elongated cells with spirally thickened walls, generally becoming free from each other.

The sporogonium remains enclosed in the calyptra until the spores are mature when, if a seta be present, it suddenly elongates and ruptures the calyptra, which persists as a vaginula at its base. The capsule opens either by the decay of its wall, or more generally by the splitting of the wall from the apex downwards into valves; in some Marchantieæ a lid, the operculum, is formed and the capsule is opened by the throwing off of the lid.

The Hepaticæ are classified as follows :-

Order I. Marchantiaceæ. Order II. Jungermanniaceæ. Order III. Anthocerotaceæ.

Order I. Marchantiaceæ.

A. The GaMetophyte. The spore gives rise on germination to a short unbranched filamentous protonema which developes at its apex into a flattened cellular expansion, from the margin of which the adult shoot (commonly known as the plant) springs as a lateral branch.

The Morphology of the Adult Shoot. The adult shoot is undifferentiated into stem and leaf. Its symmetry is dorsiventral; on the lower (ventral) surface it bears numerous root-hairs, and also scales which are arranged in one or two rows, or irregularly.

Growth is effected by an apical growing-point, situated in a depression, possessing a transverse row of initial cells from which segments are cut off dorsally and ventrally; the initial cells also undergo longitudinal division, and thus increase in number.

The normal mode of branching is that which takes place in the plane of expansion; it is dichotomous, and is effected in the manner described on p. 132.

The sexual organs are in all cases developed on the dorsal surface, each antheridium or archegonium arising from a single superficial cell. In the simpler forms they are arranged in a continuous median row, developed in acropetal succession; in the higher forms they are borne on a special structure termed a receptacle.

The receptac'e. In the higher Marchantieæ the adult shoot is frequently differentiated into a vegetative and a reproductive portion, the gametophore; the gametophore is a branch (or a branch-system) bearing a terminal receptacle, in which either the male (antheridiophore) or the female (archegoniophore) organs are developed.

In the simpler forms the archegoniophore is simple, that is unbranched; the stalk presents a single furrow which represents the ventral surface of the shoot. In Marchantia the stalk has two ventral furrows, showing that it consists of the two coherent branches of the first dichotomy. The receptacle itself is repeatedly branched: thus in Marchantia there are eight groups of archegonia, corresponding to eight branches. The receptacle is more or less distinctly lobed, thus showing its compound 
nature: each group of archegonia is situated between the bases of two adjacent lobes. The complete elongation of the stalk does not take place until the archegonia are fully developed, or even until one of them has been fertilised.

It is only in a few of the higher Marchantieæ that there is a highly developed antheridiophore. In Marchantia a definite terminal receptacle is formed; it is discoid in form, and it is elevated on an erect stalk (see Fig. $198 \mathrm{~A})$; it is compound, having several growing-points, each of which gives rise to antheridia in acropetal succession, and then ceases to grow ; the stalk has two ventral furrows, showing that it consists of two coherent branches.

In Marchantia the venter of each archegonium becomes surrounded by a sac-like membraue, developed from the stalk-cell of the archegonium, which is termed the perigynium (Fig. 194). The development of the perigynium begins when the archegonium is nearly mature.
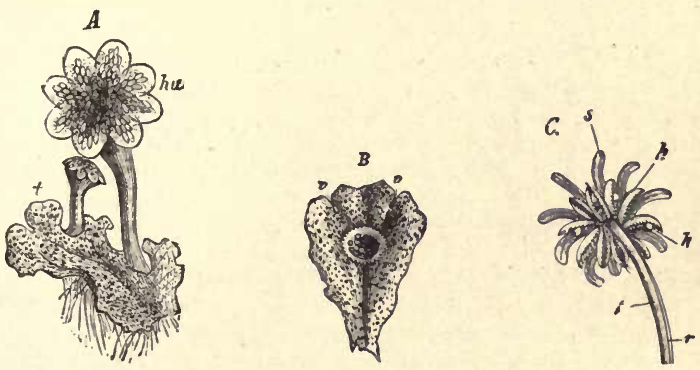

Frg. 168. - $d$ rurtiun of a plant of Marchantia polymorpia $(t)$, with antheridiophores. $B$ Portion of a plant with a cnpule containing gemma; $v$ apices of the two branches. (After Sachs.) C $\mathbf{\Delta n}$ archegoniophore with a doubly furrowed $(r)$ stalk $t$, bearing a terminal branched receptacle of which $s$ is one of the rays; $h$ perichrtinm; $k$ sporogonia.

The distribution of the sexucl organs is various: the plants may be monœcious or diœcious (Marchantia).

The Structure of the Adult Shoot. The dorsal portion of the shoot consists in all the Marchantiaceæ, of parenchymatous tissue, made up of cells containing chloroplastids, which includes a number of air-chambers, giving it an areolated appearance, whence it is termed the air-chamber-layer. The chambers are formed by the unequal growth of the cells near the growing-point, in consequence of which the surface presents alternating elevations and depressions. In Marchantia the primary air-chambers become completely closed in; at the central meeting-point the growth of the superficial cells take place vertically, leading to the formation of vertical rows of cells which subsequently separate, leaving a canal between them. This structure is distinguished as a compound pore. Compound pores of

M.B. 
this sort are found in the receptacles of other Marchantieæ, the regetative parts of which have simple pores.

In many forms, the cells containing chloroplastids (assimilatory tissue) are simply those which form the walls of the air-chambers; in Marchantia (Fig. 199) the cells forming the floor of the air-chamber, or the sides, or even the roof, grow out into branched or unbranched filaments which fill most of the air-cavity, thus largely increasing the assimilatory tissue.

Beneath the air-chamber-layer is a compact tissue, consisting of several layers of cells elongated in the direction of the long axis of the branch, which is without intercellular spaces, and contains but few chloroplastids. In the Marchantieæ the walls of these cells are generally thickened and pitted ; some of the cells contain mucilage, and in Fegatella the mucilagecells form continuous rows; other cells contain a dark-coloured oil-drop, though such cells also occur in the air-chamber layer.

The ventral surface is formed by a layer of cells which, in the simpler
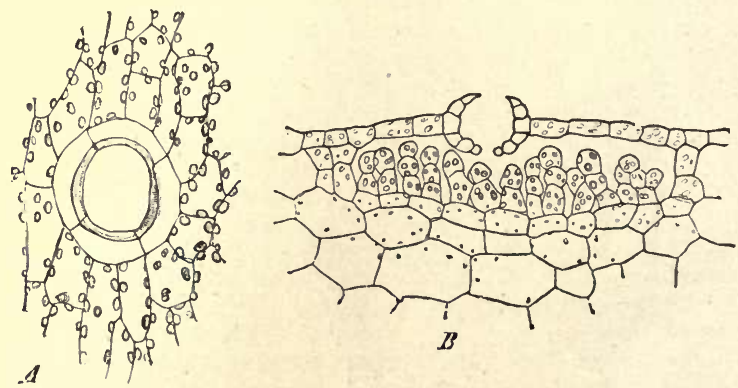

Fig. 199.-Marchantia polymorpha. A A pore seen in surface view. B Section of a portion of the dorsal region of the thallus, showing the air-chamber containing assimilatory tissue, and the compound pore. ( $\times 210$ : after Strasburger.)

forms, is not specially differentiated, but in some the cells of this layer are remarkable for their small size; in Marchantia and Preissia there are several layers of these small cells, forming a sort of ventral cortex.

The ventral scales consist of a single layer of cells, the walls of which generally assume a violet colour; each scale is developed from a single superficial cell, or, as generally in the Riccieæ, from a transverse row of cells. In Marchantia polymorpha, in addition to the scales which arise from the midrib, there are others which spring from the surface of the lamina.

Unicellular root-hairs are produced in all Marchantiaceæ; the commonest form has thin walls; in the Marchantieæ a second form occurs, in which peg-like thickenings of the wall project into the cavity of the cell : the simple root-hairs are developed mainly on the midrib, the thickened hairs mainly on the lamina. 
Ge.nme are produced in Lunularia and Marcliantia in special receptacles, termed cupules, borne on the dorsal surface of the shoot; in Lunularia the cupule is crescent-shaped, in Marchantia it is circular (Fig. 198B). The cupule is formed by an outgrowth of the air-chamber layer, and in Marchantia its margin is prolonged into laciniæ. The gemmæ spring from single cells of the floor of the cupule, which elongate upwards and divide transversely into a stalk call and a terminal cell, which, by repeated growth and division, forms a flattened plate of tissue, several layers of cells thick at the middle, thinning out to a single layer at the margin, with a growing-point in a depression on each lateral margin. The symmetry of the gemmæ is isobilateral; but when they fall on to the soil and begin to grow, the undermost surface becomes the ventral, and the uppermost the dorsal. Some of the superficial cells have no chloroplastids; those of the surface next the soil grow out into root-hairs.

B. The Srorophyтe. The degree of morphological and histological differentiation of the sporophyte presents wide divergences in the different groups. In the Riccieæ, the whole embryo simply forms a spherical capsule: in the Marchantier, the capsule is developed entirely from the epibasal cells, whilst the hypobasal cells give rise to a bulbous foot, which attaches the embryo to the parent, and to a short stalk which bears the capsule, and is formed at a relatively late stage by intercalary growth.

The differentiation of the tissue of the capsule into amphithecium and endothecium is well-marked, except in the Riccieæ. The archesporium is coextensive with the endothecium.

In the Riccia the whole of the archesporial cells are sporogenous; in Corsinia, some of the archesporial cells are sterile, but these undergo no special differentiation; in the Marchantieæ the sterile cells assume an elongated form, and their walls undergo spiral or annular thickening: these specially modified sterile cells are the elaters, and, being very hygroscopic, they assist in the scattering of the spores. Each sporogenous cell gives rise to four spores.

The wall of the capsule, which consists generally of a single layer of cells, is but slightly developed in the Riccieæ, and becomes entirely disorganised during the development of the spores. In the Marchantieæ the cells of the walls are generally thickened and the thickenings fibrous, in which case the capsule opens by the splitting of the wall longitudinally into a number of teeth.

The spores are generally tetrahedral, with two coats, the outer of which (exospore) is tuberculate or reticulate on the surface. On germination the exospore of the tetrahedral spore ruptures at the point of junction of the three projecting angles. The spores of Lunularia and Marchantia are small and spherical; the exospore is feebly developed, and presents a granular thickening. In consequence of the thinness of the exospore, the whole spore is enabled to enlarge considerably on germination, and it does not rupture at any special point. In Fegatella, cell-divisions take place in the spores before they are scattered.

The venter of the archegonium keeps pace with the growth of the developing embryo, forming the calyptra, and encloses it until the spores 
are ripe. In the Riccieæ the spores are set free by the gradual disorganisation of the calyptra and of the tissue of the thallus in which the calyptra is embedded; in the other Marchantiaceæ the capsule is forced ont of the calyptra by the elongation of the short stalk.

The order Marchantiaceæ includes the families Riccieæ (Riccia, Oxymitra), Corsiniex (Corsinia, Boschia), and Marchantieæ (Marchantia, Lunularia, Fegatella, etc.).

Orter II. Jungermanniaceæ.

A. The Gametophyte. On germination the spore gives rise to a protonema which may be a solid ellipsoidal mass of cells (as in Pellia) with a root-hair at one end; or a flattened plate of cells (Radula, Frullania); or

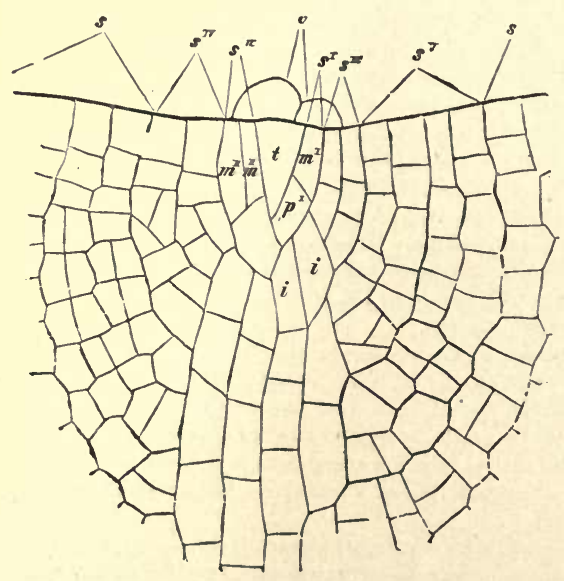

Fre. 200.-Growing-point of thallus of Metrgeria furcata : $t$ apical cell ; $s^{\prime}$ etc., successive segments; $m^{\prime} m^{\prime \prime}$ marginal cells ; $p^{\prime}$ superficial cell ; $i$ i cells of the midrib; $c$ clavate hairs. ( $\times 540$ : after Strasburger.) a filament, sometimes branched (Lophocolea, Chiloscyphus); however, the differences in form of the protonema are not of great morphological i m portance since, in many cases, flattened and filamentous forms have been found to be produced from spores of the same plant.

The protonema gives rise to the adult shoot by the formation, either from a marginal cell, if it is flat, or from the terminal cell, if it is filamentous, of a growing-point with a $\mathrm{s}$ ingle apical cell.

The Morphology of the Adult Shoot. The adult shoot may be differentiated into stem and leaf, as in the foliose forms; or undifferentiated, as in the thalloid forms. Its symmetry is generally dorsiventral; the only radially symmetrical, erect-growing forms being Haplomitrium and some species of Riella (e.g. R. helicophylla and Prrisii).

Most of the thalloid forms have a distinct midrib. The shoot bears numerous unicellular root-hairs, as also club-shaped glandular hairs which secrete mucilage, on its ventral (under) surface. In the dorsiventral foliose forms, the stem bears a row of leaves on each flank, and 
generally a row of amphigastria on its ventral surface. In the radial foliose forms, the leaves are borne in three rows in Haplomitrium, and in two rows in the radial species of Riella; here there is no distinction of amphigastria.

The growth of the shoot is effected by an apical growing-point which possesses a single apical cell. The apical cell of the thalloid forms is most commonly two-sided (Fig. 200); the base is directed outwards, the ayex inwards, and from the two sides segments are cut off alternately right and left. But in Pellia the cell is bounded by four surfaces-an external free surface, an internal, and two lateral; segments are successively cut off along the internal and the two lateral surfaces. The apical cell of the foliose forms, with the exception of Fossombronia and Riella which have a two-sided apical cell, is a three-sided pyramid; its base is directed outwards, its apex inwards, one side is ventral and the other two are dorsolateral; this latter statement does not, of course, apply to Haplomitrium, which is radial.

The normal mode of branching in the dorsiventral forms is that which takes place at the growing-point in the plane of expansion. In the thalloid forms, as also in the foliose Fossombronia and Blasia, it may be described as dichotomous (see p. 132) although the apical cell does not undergo division so as to form the apical cells of two branches; the apical cell of the parent shoot persists, and that of the branch is developed from an adjacent segment, either before or after further division. When the two shoots develope with equal vigour, the resulting branch-system resembles a dichotomy; but when the parent shoot grows the more vigorously throughout, the branches are lateral upon it and the branch-system is a monopodium (see p. 19). In the foliose forms the mode of normal branching is generally monopodial. The apical cell of a lateral branch is developed from the lower (ventral) half of a dorso-lateral segment cut off from the apical cell; either from the whols of the segment, or from the posterior (basiscopic) portion of it.

In some of these plants there is a formation of gemmx. In Aneura certain cells of the margin and of the dorsal surface of the shoot each become divided into two, an 1 the two cells thus formed are set free as a bicellular gemma, with probably a proper wall of its own, by the rupture of the enclosing wall. In Blasia, the gemmæ, which are solid multicellular nearly spherical bodies, are developed in special receptacles (cupules) situated on the dorsal surface of the apex of the shoots; their mode of origin resembles that of the gemmæ of Marchantia. In most foliose forms the gemmæ are developed from marginal cells of the leaves (e.g. Jungermannia ventricosa) or from cells near the growing-point of the stem (e.y. .Jungermannia bicuspidata). In these forms the gemmæ are usually uni- or bi-cellular, but in Radula complanata (where they are formed on the leafmargin) they are flat multicellular plates of tissue.

The leaves are developed, generally speaking, one from each segment formed from the apical call. In the typical Acrogynæ each dorso-lateral segment gives rise to a lateral leaf, and each ventral segment to a ventral leaf (amphigastrium); though, as already mentioned, the amphigastria 
are wanting in many species. A characteristic feature of the leaves of this group is that they are distinctly bilobed, at least when young; this is due to the fact that the mother-cell of the leaf is divided into two which give lise to the two lobes. The leaves are sessile, and their insertion is at first transverse to the long axis of the stem, so that one lobe is superior or lorsal, the other inferior or ventral; but by subsequent displacement it becomes oblique. Since the leaves are situated close together, they thus com to overlap each other, and this overlapping presents two forms: either the posterior edges of the leaves overlap the anterior edges of those next behind them (Fig. 201), when the leaves are said to be succubous; or the anterior edges of the leaves overlap the posterior edges of those next in front of them (Fig. 202), when the leaves are said to be incubous. The growth of the leaf is generally apical at first, and subsequently basal.

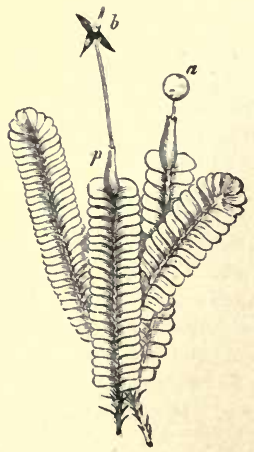

Fie. 201.-Brnnches of one of the acrof:Tnnus Jungermanniaceæ, Plagiochila asplenioides, seen from above: the leaves are succubnus; at the apex, two of the sbonts hear sporogon's, the one (b) having delisced, the other (a) being still closed; $\boldsymbol{p}$ the involucre.

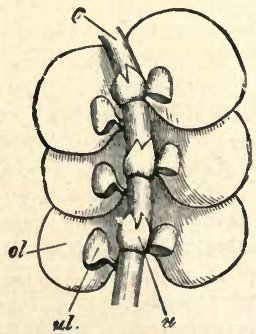

Fre. 202 -Part of a shoot of Frullania dilatuta seen from below $(\times 20)$ : $\mathrm{nl}$ auriculate lower leaf-lobes; ol upper lesf-lobe; the lesves sre incubous; $u$ amphigastrium.

The sexual organs are generally borne on the main axis and its normal branches, but in many cases they are confined to more or less specialised ventral branches (gametophores). The place of development of the archegonia affords the basis for the classification of the Jungermanniacer into the two main groups, Acrogynæ and Anacrogynæ. In the former, which includes nearly all the foliose forms, the archegonia are produced from the apical cell and its youngest segments at the growing-point; hence when the formation of the archegonia takes place on a shoot its further elongation is arrested. In the latter group, which includes all the thalloid forms and some exceptional foliose forms, the archegonia are 
produced laterally, on the dorsal surface in the dorsiventral forms, on all sides in the radial forms (species of Riella, Haplomitrium); hence the growth in length of the shoot is not necessarily arrested.

The archegonia of the Acrogynæ are borne either singly or in groups of two or more. Each archegonium is developed from a single cell; when the archegonium is single it is developed from the apical cell; when there are several archegonia, the development of them begins in the youngest segment-cells of the growing-point. The archegonia are surrounded by the leaves of the apex; and in most cases the leaves of the last whorl are coherent, forming an involucre, surrounding the single archegonium or the group of archegonia.

The archegonia of the thalloid Anacrogynæ are borne in median dorsal groups: in the radial Anacrogynæ (Riella helicophylla, Haplomitrium) they are borne singly, scattered over the whole length of the stem as in the former, or confined to the apical region as in the latter. They are in all cases provided with some sort of protective organ. Among the thalloid Anacrogynæ the group of archegonia is surrounded, in Metzgeria, Aneura, and Pseudoneura, by an involucre consisting of the short modified gametophore (ventral in Metzgeria); in Pellia, Symphyogyna, and Sphærocarpus a group (or each archegonium as generally in Sphærocarpus) is surrounded by an involucre developed as an outgrowth of the tissue of the fertile branch.

The antheridia are borne, in all Jungermanniaceæ (except Haplomitrium) on the dorsal surface of the shoot; in Haplomitrium they are borne in three rows on the sides of the apical region.

The antheridia are shortly stalked and are in all cases provided with a protection. In Metzgeria the group of antheridia is invested by an involucre which consists of the short modified ventral gametophore: in the other thalloid Anacrogynæ (e.g. Pellia) each antheridium is invested by an involucre which grows up around it, so that it appears to be sunk in the tissue of the shoot. In the Acrogynæ the antheridia are borne, singly or several together, in the axils of leaves; and in some forms (e.g. Scapania, Lejeunia, Frullania) the upper lobe of the protecting leaf is modified in form.

The distribution of the sexual organs varies even in the species of some of the genera. Some of the Anacrogynæ (e.g. Metzgeria, Pseudoneura, Sphærocarpus, Haplomitrium, etc.) are diøecious; whereas others (e.g. Pellia, some species of Aneura, Fossombronia, Symphyogyna) are generally monœcious. In the monœeious forms the antheridia and archegonia are generally borne on distinct branches (diclinous), but sometimes on the same branch (monoclinous). When a dorsiventral shoot bears only antheridia or archegonia, they are developed in the median line; but when it bears both organs, the archegonia are median and the antheridia lateral.

The Acrogynæ are generally monøcious and diclinous.

The structure of the adult shoot of the Jungermanniaceæ is very simple. In thalloid forms which have no distinct midrib, the shoot consists of parenchymatous cells forming a single layer at the margin and several 
layers (e.g. Pellia, Aneura) in the middle line of the shoot; in those which have a well-defined midrib (e.g. Metzgeria), the midrib consists of several layers of cells, whereas the lamina consists of only a single layer. In Symphyogyna and Blyttia the midrib is traversed by a strand of elongated prosenchymatous eells having thickened and more or less pitted walls : a similar tissue occurs in the thick central portion of the shoot of Pellia.

In the Acrogynæ, the stem generally consists of an axial strand of relatively thin-walled cells, surrounded by a cortex of narrow thick-walled cells: the leaves are simply single layers of similar cells, and have no midrib.

The root-hairs are, in all cases, destitute of the peculiar thickenings so characteristic of the Marchantiaceæ.

B. The Sponophyтв. The course of the development of the sporophyte is, in its main features, essentially the same throughout the Jungermanniaceæ.

The oospore is divided by a transverse (basal) wall into two halves, epibasal and hypobasal. The epibasal cell gives rise to the capsule and its stalk (seta). It divides transversely, and the longitudinal divisions follow in both cells so that the epibasal half of the embryo consists of two tiers of each consisting of four cells. Further growth in length is effected by the cutting off; by transverse walls, of segments from the cells forming the apical tier; but this apical growth is arrested, sooner or later, by the formation of walls parallel to the free surface (periclinal) in the apical cells, and also frequently in some of those below them, which indicate the differentiation of the capsule-wall (amphithecium) from the internal mass of cells (endothecium) which give rise to the spores and elaters. The cells bolow the eapsule may, however, continue to grow and divide transversely; and by means of this intercalary growth the full length of the seta is attained:

In many of the Jungermanniaceæ (e.g. Pellia, Jungermannia, Frullania) the lower end of the seta developes into a bulbous mass of cells forming a false foot, the upper margin of which grows up so as to form a sheath round the lower part of the seta in some cases:

The development of the hypobasal portion of the embryo is comparatively insignificant; in most cases it is merely a small appendage to the lower end of the seta. The hypobasal cell enlarges somewhat, without undergöing any division (e.g. Radula, often in Pellia); or it undergoes transverse division to form a filament of two or three cells, the lowest of which becomes elongated and grows down among the cells at the base of the archegonium (e.g. Metzgeria, Aneura). In some forms, however (e.g. Fossombronia), the hypobasal cell appears to give rise to a true foot, bulbous in form, comparable to that of the Marchantieæ (see p. 323).

In the further differentiation of the capsule, the cells of the amphithecium undergo periclinal division so that the wall eventually consists of two or more (up to six) layers of cells. In the wall-cells transverse annular thickenings are usually developed. The planes of dehiscence of the capsule, except in those forms which dehisce irregularly (Riella, 
Sphærocarpus), are marked out by four longitudinal rows of small-celled tissue which correspond in position with the walls between the four apical cells of the growing embryo.

The archesporium, which is co-extensive with the endothecium, presents various degrees and forms of differentiation. In the Rielleæ it comes to consist of a number of cubical cells, some of which become the mothercells of the spores, whereas the others persist as unaltered sterile cells. In all the other Jungermanniacer some of the cells of the endothecium are sterile, but they develope into elaters, becoming elongated in form and spirally thickened, having sometimez two spirals, or only one. The relative arrangement of the sterile and fertile cells, dependent upon the growth of the capsule along different diameters, varies somewhat. In the lower forms, the elongated archesphorial cells are arranged more or less longitudinally, either quite straight (e.g. Frullania, Lejeunia), or radiating from the apex of the capsule (Metzgeria, Aneura), or radiating from the base of the capsule (Pellia, Radula): whereas in the higher forms (Lepidozia, Calypogeia, Jungermannia), these cells are placed horizontally round a central longitudinal axis, except at the apex where they radiate. In most cases the sterile and fertile archesporial cells are mingled together, but in some cases certain parts of the archesporium give rise especially to spores and others to elaters. Thus, in Pellia, the cells towards the base and those in the longitudinal axis of the capsule form only elaters, whereas in Jungermannia the formation of elaters is confined to the cells near to the wall.

Whilst the development of the embryo is taking place, growth is also) proceeding in the archegonium and the adjacent tissue, giving rise eventually to the calyptra. Several of the archegonia of a group may be fertilised, but generally only one gives rise to a fully developed sporogonium, and itself takes part in the formation of the calyptra. The. calyptra is sometimes developed from the venter of the archegonium alone (e.g. generally in the Acrogynæ); in the Anacrogynæ the adjacent tissue of the shoot frequently takes part in its formation, as is shown by the fact that the unfertilised archegonia of the original group are found on the sides, or even on the top of the calyptra (e.g. Aneura, Pellia). The wall of the calyptra consists of one or more layers of cells, and keeps pace with the growth of the embryo which it encloses until the spores are mature. The cells of the seta then rapidly elongate, causing the rupture of the calyptra, and the capsule is exposed. The capsule then dehisces, generally into four valves, sometimes irregularly, and the spores are set free.

The Jungermanniaceæ may be classified as follows :-

Series I. Axacrogyxe: growth in length not necessarily arrested by the development of archegonia.

Section A. Anelatereæ: the sterile cells in the capsule do not develope into elaters.

This section consists of the family Riellece: including the two genera Riella (foliose) and Sphærocarpus (thalloid). 
Section B. Elatereæ: the sterile cells in the capsule develope into elaters.

a. Thalloid Forms: Metzgeria, Aneura, Pellia, etc.

$\beta$. Foliose Forms : Fossombronia, Blasia, Haplomitrium (with radial symmetry), etc.

Series II. AсRоGгх: : growth in length arrested by the development of archegonia; all foliose.

This series includes a number of families of which the more familiar genera are Plagiochila, Jungermannia, Scapania, Lepidozia, Radula, Lejeunia, Frullania; etc.

\section{Order III. Anthocerotaceæ.}

A. The Gaмkтонт. The protonema developed from the germinating spore is a flattened plate of cells; in Anthoceros the formation of the flattened plate is sometimes preceded by the outgrowth of the contents of the spore, covered by the endospore, into a filament at the apex of which the plate of cells is developed. The adult shoot is developed as a lateral out-growth from the flattened protonema.

The Morphology of the adult shoot. The adult shoot is thalloid, and its symmetry is dorsiventral. It is semi-circular, or nearly circular, in out-

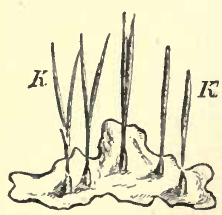

Fig. 203.-Anthoceros lavis (nat. size): $\boldsymbol{K}$ the capsules, some as yet unopened. line in Anthoceros. There are no ventral scales on the under surface, but numerous unicellular root-hairs.

The growth of the shoot is effected, in Anthoceros, by a series of marginal growing-points. In the growing-point there is a row of initial cells, each of which acts as an apical cell; their form is wedge-shaped in Anthoceros, dorsal and ventral segments being alternately cut off by the formation of oblique walls.

Branching, or at least the formation of new growing-points, takes place in the manner described for the Marchantiaceæ (p. 132).

The sexual organs are developed from the dorsal segments formed in the growing-point, and are situated in the middle line behind each growingpoint in Anthoceros. The antheridia are developed endogenously, and remain enclosed in the tissue until maturity; they are developed either singly (some species of Anthoceros) or in groups. The archegonia are sunk in the tissue, the apex of the neck reaching to the dorsal surface of the shoot. The shoots are monœeious; the sexual organs are sometimes intermingled in the same group (frequently in Anthoceros).

The structure of the adult shoot. The adult shoot of Anthoceros consists of several layers of cells in the middle line, thinning out to a single layer of cells at the margins. The tissue in the middle line consists of longitudinally elongated cells, the walls of which, especially in the older parts of the shoot, frequently present reticulate or even spiral thickening.

The chloroplastids of the Anthocerotaceæ are peculiar, on account of their relatively large size, and of the fact that they occur singly in the cells and contain a prenoid (see p. 71). 
B. The Sponophre. The early stages in the derelopment of the sporophyte of the Anthocerotaceæ appear to be much the same as in the case of other Liverworts. The oospore divides transversely into an epibasal and a hypobasal half : and each of these divides by two perpendicular walls so that the embryo consists at this stage of eight cells. The cells of the epibasal half divide transversely several times, and then further apical growth in length is arrested by the formation of periclinal walls, marking the differentiation of amphithecium and endothecium, first in the four apical cells, and subsequently in those below them. By the repeated formation of periclinal walls, the amphithecium comes to consist of several layers of cells. The hypobasal cells undergo but few divisions, giving rise to a bulbous foot, the superficial cells of which grow out into papillæ and penetrate between the cells of the adjacent tissue of the gametophyte.

As regards the differentiation of the epibasal portion of the embryo, in Anthoceros (Fig. 197) the archesporium is developed from the innermost layer of cells of the amphithecium, a peculiarity, the only other instance of which, in the Muscineæ, is to be found in the Sphagnaceæ: the endothecium gives rise to an axial strand of sterile tissue, termed the columella, which is completely invested (except at the base, where it is continuous with the tissue of the foot) by the archesporium.

In all the genera some of the cells derived from the archesporium are sterile. In some species of Anthoceros (e.g. vicentianus, giganteus, etc., constituting the subgenus Anthocerites) these cells develope into elaters with spiral thickening, each elater consisting of a row of cells with an apparently continuous spiral band: in other species (c.g. tuberculatus, glandulosus) the elaters have the same form, but they have no spiral band; in others (lavis, punctatus) the sterile cells do not form distinct elaters, but a network of short cells, with spiral thickening, in the meshes of which lie the mother-cells of the spores.

The sporogonium of Anthoceros has no seta; when the apical growth has ceased, the capsule continues to elongate by basal growth, and hence does not ever become fully mature throughout. The pod-shaped capsule splits from the apex into two valves (Fig. 203). Stomata occur in the. epidermis of the capsule in most species of Anthoceros, but they appear to be wanting in the other genera.

Since the archegonia are sunk in the tissue of the shoot, the calyptra, which invests the developing embryo, is developed mainly from the surrounding tissue, and only to a sinall extent from the wall of the archegonium. 


\section{CLASS IV. MUSCI (Mosses).}

A. The Gametophyte. The protonema is more conspicuous in the Nusci than in the Hepaticæ: it sometimes persists until the sporogonia are developed and the spores are ripe (e.g. Ephemerum), and in many cases the subterranean portion persists from year to year. It is generally filamentous and much branched; but in some forms it is a flattened expansion (e.g. Sphagnum), or cylindrical branched and shrubby, or it bears lateral flattened expansions which are assimilatory organs (e.g. Tetraphis, etc.). The filamentous protonema consists of a subaërial and of a subterranean portion, which differ in that the cells of the former contain chloroplastids, their walls are colourless, and the septa are transverse; whereas those of the latter do not contain chloroplastids, and their walls are brown and their septa oblique. The protonema presents, in fact, a certain differentiation into shoot and root, the term rhizoids being applied to the root-like filaments. This differentiation is, however, of little morphological value, since the differences between the shoot- and root-filaments depend entirely on external conditions : thus, if the rhizoids be exposed to light they assume the characters of the subaërial filaments. The flattened protonema of Sphagnum bears rhizoids on its margins and under surface.

The growth in length of the protonemal filaments is apical: the terminal cell behaves as an apical cell from which segments are successively cut off by transverse or oblique walls.

The Adult Shoot arises as a lateral bud on the subaërial portion of the protonema. In some cases (Bryinex) the subterranean portion gives rise to lateral buds: these are small, spherical or lenticular, multicellular bodies of a brown colour, filled with reserve materials, and are termed bulbils; when they are brought to the surface they give rise to adult shoots, either directly or with the intervention of protonema.

The adult shoot is in all cases differentiated into stem and leaves, and may be branched or unbranched. Its symmetry is commonly radial or isobilateral, less commonly dorsiventral. In the former case it is attached to the soil by rhizoids springing from its basal portion; in the latter, by rhizoids developed on its under surface. In Sphagnum, rhizoids occur only on young shoots. 
The growth of the adult shoot and its branches is effected by means of an apical growing-point with a single apical cell which is generally a three-sided pyramid.

Each segment cut off from the apical cell gives rise to a leaf: hence the arrangement of the leaves, and the symmetry of the shoot, is generally determined by the form of the apical cell. Thus in Fissidens, the leaves are arranged in two rows and the symmetry of the shoot is isobilateral: in other cases (c.g. Fontinalis) the leaves are in three rows, and the symmetry of the shoot is radial.

Branching is confined to perennial shoots, and is lateral, never dichotomous. When the growth of the main shoot is arrested by the formation of sexual organs at the apex (acrocarpous), one (or more) of the lateral branches (termed innorations) close behind the apex assumes the characters of the main shoot and carries on the growth: the resulting branchsystem is cymose, either sympodial or dichasial according to the number (one or more) of the innovations at each branching. When the growth of the main stem is not thus arrested, the sexual organs be-

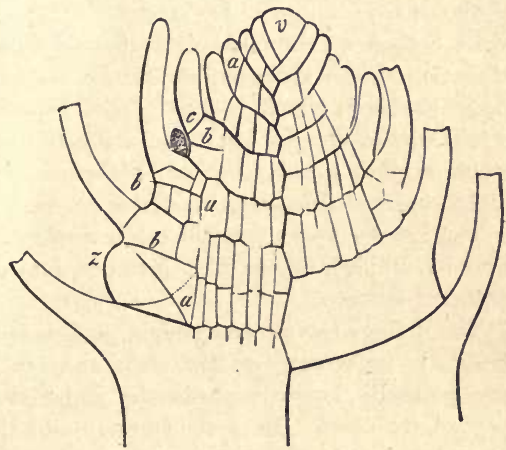

Frg. 204.-Longitudinal section through the apical region of a stom of Fontinalis antipyretica, a Moss growing in water (after Leitgeb) : $v$ the apical cell of the shoot, producing three rows of segments which sre at first oblique and afterwards placed transversely (distinguished by a stronger outline). Each egment is first of all divided by the wall $a$ into an inner and an outer cell; tho former produces a part of the inner tissue of the stem, the latter the cortex of the stem and a leaf. Leaf-forming shoots arise beneath certain leaves, a triangular apical cell $(x)$ being formed from an outer cell of the segment, which then, like v, produces three rows of seg. ments; and each segment here also forms a leaf. ing borne on lateral branches (pleurocarpous), the branch-system is monopodial and racemose.

The branches (except the innovations) frequently differ in various ways from the primary shoot. Thus, in Sphagnum and other pleurocarpous Mosses, the leaves of the branches differ in 
size and shape from those of the primary shoot: in other forms (e.g. Thuidium) the lateral branches have limited growth.

The development of the branches, though never axillary, is intimately connected with the arrangement of the leaves, since the apical cell of a branch is developed from the same segment as the corresponding leaf. Each branch is developed beneath the corresponding leaf, either in the median line (e.g. Fontinalis), or on one side of it (e.g. Sphagnum). However, a branch is not developed in connexion with each leaf.

In most cases the adult shoot does not present any differentiation into a vegetative and a reproductive portion (gametophore), but such a differentiation is to be found in certain forms. Thus, in Splachnum, the male organs are borne upon a leafless prolongation of the shoot.

In Sphagnum the apex of the female shoot grows out, after fertilisation of the archegonium, into a long leafless shoot termed a pseudopodium, which bears the sporogonium (here destitute of a seta) at its apex. In Aulacomnium and Tetraphis there is a somewhat similar terminal shoot, likewise termed a pseudopodium, which bears at its apex a cluster of gemmæ.

The Leaves present considerable variety in size and form: they may be divided, in the first instance, into foliage-leaves and involucral leaves.

The foliage-leaves are simple and sessile; they are usually inserted transversely on the stem, and are closely packed. They are geuerally larger towards the upper than towards the lower part of the shoot. In most pleurocarpous Mosses the leaves of the lateral branches differ more or less from those of the main stem. In some forms (e.g. Bryum roseum, Climacium, etc.), where the branches take the form of creeping runners or stolons, the leaves of these branches are reduced to scales (cataphyllary leaves).

The involucral leaves are arranged in one or more whorls, forming an involucre round the sexual organs. Those surrounding a group of male organs are commonly larger than the foliage-leaves, and in some cases (e.g. Polytrichaceæ) are coloured red or yellow. Those surrounding a group of female organs differ but little from the foliage-leaves: the more internal leaves are smaller than the external: the innermost leaves, distinguished as perichatial leaves, are quite rudimentary when the archegonia are mature, but after fertilisation has taken place they grow up round the base of the seta of the sporogonium. 
The Sexual Organs are borne in groups (rarely singly) at the apex either of the main shoots (acrocarpous), or of lateral branches (pleurocarpous), surrounded by involucral leaves, each group with its involncre constituting a receptacle. Generally speaking the growth of the shoot or branch ceases with the development of the sexual organs, the apical cell itself giving rise to an antheridium or an archegonium; but in some male receptacles (e.g. Polytrichaceæ and some other Bryineæ, also Sphagnum) the apical cell persists as such; consequently the elongation of the shoot or branch is not necessarily arrested by the development of the antheridia, and appears to grow through the receptacle.

Among the sexual organs there are usually present multicellular hairs, teimed paraphyses: they are often filamentous, but in some cases (e.g. male receptacle of Funaria) the terminal cells are large and rounded; they are hyaline, or coloured red or yellow, sometimes brownish, and the cells frequently contain chloroplastids. They are more numerous and more highly developed in the male than in the female receptacles; they are rarely absent in plants which grow in dry situations, but frequently in those forms which grow in water or in damp places. Their function seems to be that of serreting water to prevent the drying-up of the sexual organs.

The antheridia are generally club-shaped (spherical in Sphagnum), and are shortly stalked (see Fig. 192). The antheridia generally open at the apex to allow the spermatozoids to escape. The archegonia are stalked; the neck is long, and the venter is but slightly dilated (Fig. 195).

The distribution of the sexual organs is various. The plant may be monœcious (i.e. may bear both kinds of sexual organs), or it may be diœcious: amongst the monocious forms may be distinguished those which are monoclinous, that is, which have both male and female organs in the same receptacle (c.g. Bryum lacustre, cuspidatum, etc.), the archegonia being in the middle; and those which are diclinous, that is, which bear the male and female organs in distinct receptacles: sometimes (e.g. Bryun pendulum, arcticum, etc.) the plants are heteroclinous or polygamous, that is, some receptacles are hermaphrodite, whilst others are unisexual. In the diøcious species the male plant is usually the smaller, and is short-lived. In some species the plants are sometimes monøcious (either monoclinous or diclinous) and sometimes diøecious.

The Structure of the Adult Shoot. The stem presents more or 
less well-marked histological differentiation. The outer portion consists of an epidermal layer, followed by one or more layers of elongated prosenchymatous cells, with thickened walls which are yellow or brown, forming the cortex which passes by gradual transition into thin-walled parenchymatous ground-tissue; in the subterranean shoots of the Polytrichaceæ, however, the cortex is parenchymatous and thin-walled, whilst the ground-tissne is thickwalled.

In species which live under such conditions that both transpiration and the absorption of water may be actively carried on, a central strand is differentiated in the longitudinal axis of the stem, the structure of which presents two principal varieties; it may be simple, consisting of a group of thin-walled tracheides, destitute of protoplasmic cell-contents (e.g. Funaria, etc.); or it is compound, consisting of a group of thick-walled tracheides, or of several groups of thin-walled tracheides with intervening parenchymatous or prosenchymatous cells, surrounded by several layers of thin-walled elongated cells with oblique ends, containing abundant protoplasm and starch-grains (e.g. Polytrichum). This central strand is, in fact, a rudimentary vascular stele: the tracheides, though unlignified, represent the wood or xylem: in the simple form, the phloem is unrepresented; in the compound form it is represented by the elongated cells which surround the xylem.

The structure of the leaves shows considerable variety. Most commonly the leaf-blade consists of a single layer of cells, containing chloroplastids, with or without a midrib. In the midrib of those forms which have a central strand in their stems, there are one or more rudimentary vascular bundles of a structure corresponding to those in the stem. These bundles enter the stem as leaf-traces, and either end blindly, or join the central strand of the stem. The rest of the midrib is made up chiefly of thick-walled prosenchymatous cells. It must not be overlooked that the absorption of water is effected, in the Mosses, mainly by the leaves.

The most remarkable deviations from the usual structure of the lamina are those offered by the Sphagnaceæ and the Polytrichaceæ. In the Sphagnaceæ the constituent cells are of two kinds: large empty cells with perforated walls (see p. 94, Fig. $73 A$; and small cells containing chloroplastids. In the Polytrichaceæ, the assimilatory tissue is borne on the surface of the broad midrib in the form of numerous longitudinal plates, one cell thick.

The rhizoids which spring from the shoot are essentially similar 
to those of the protonema: in the Polytrichaceæ they become wound together into strands.

The gametophyte of the Musci possesses a remarkable capacity for vegetative propagation. Thus the perennial protonema of many species serves year by year to produce new adult shoots which, not unfrequently, become distinct plants. In the pleurocarpous forms (e.g. Sphagnum, Hypnum) the main axes gradually die away from behind, the lateral branches becoming isolated, and constituting the main axes of new plants. In probably the majority of the Musci almost any portion of the body, a piece of stem or a leaf, will, under proper conditions, grow out into protonemal filaments, which give rise to adult shoots in the usual manner. In certain species, belonging to the Bryineæ (Aulacomnium palustre, A. androgynum, Tetraphis pellucida), multicellular gemmæ are produced at the apex of the stem, either free or enclosed in a cupule (Tetraphis). In Aulacomnium palustre the gemmæ appear to be modified leaves; in $A$. androgynum and in Tetraphis the gemmæ are smaller, and consist of but few cells; in Tetraphis they are borne on long stalks. On being placed under favourable conditions, the cells of the gemma grow out into protonema.

$B$. The Sporophyte. The oospore divides into two by a wall (basal wall) transverse to the long axis of the archegonium: from the epibasal half is developed the capsule (theca) and its long or short stalk (seta), whilst the hypobasal half gives rise to a more or less well-developed foot: the whole being termed the sporogonium.

The segmentation of the onspore into octants (see p. 314) is confined to the epibasal cell, and even this can only be traced in Sphagnum, which in this respect resembles the Liverworts. In the other Mosses, the epibasal cell undergoes one or more transverse divisions, after which two oblique walls, cutting each other at an acute angle, are formed in the terminal cell; the cell marked out by these two oblique walls is a two-sided apical cell by the growth and segmentation of which the further development of the embryo is effected.

At an early stage in the differentiation of the capsule (see Fig. 197 ) the amphithecium, consisting of one or more layers of cells, can be distinguished from the endothecium. The amphithecium constitutes eventually the wall of the capsule; the internal tissues being formed for the most part from the endothecium.

The archesporium becomes differentiated in various positions within the young capsule. It is differentiated, in the Sphagnaceæ,

M.B. 
from the innermost layer of the amphithecium; in the Bryineæ, from the external layer of the endothecium. The cells which bound the archesporium on each side constitute the spore-sac. The endothecial tissue which lies internally to the archesporium constitutes the columeila. In the Sphagnaceæ the archesporium is a hollow hemisphere covering the top of the columella like a cap; in the Bryineæ the archesporium is a hollow cylinder surrounding the columella which extends to the apex of the capsule. In the Bryinex a large intercellular space is developed in the amphithecium, between its outer and its two inner layers; in most Polytrichaceæ a similar intercellular space is developed in the endothecium internally to the spore-sac, between it and the central portion of the columella.

At maturity the internal cells of the capsule become dry and disorganised, so that it simply contains the spores which now lie loose in its cavity. It dehisces by the throwing off of its apical portion as a lid or operculum in Sphagnaceæ and the higher Bryineæ (Stegocarpæ); or it ruptures irregularly or simply decays, as in the lower Bryineæ (Cleistocarpæ). In the higher Bryineæ the mouth of the dehisced capsule bears a fringe, the peristome, the development and structure of which will: be described subsequently (p. 344).

The basal portion of the capsule, where it joins the seta, is termed the neck. In the Polytrichaceæ the neck is considerably dilated, as also in various species of Splachnum; whilst in other species of Splachnum it grows out into an umbrella-shaped structure. When the neck is thus markedly developed it is termed the apophysis.

The histological differentiation of the sporogonium is wellmarked. There is a well-defined epidermis, in which, on the capsule, stomata of various forms are generally present; either scattered all over, as in the Sphagnaceæ; or confined to a particular region of the capsule, generally the neck or the apophysis, in the Bryineæ. The operculum and the peristome (Bryineæ) show considerable complexity of structure. The structure of the seta in the higher Bryineæ, where alone it is elongated, very much resembles that of the stem: in many forms, even in such in the stem of which no central strand is present, there is a central strand in the seta, marked off from the ground-tissue by one or two layers of sheath-cells. In the Bryineæ also, the structure of the neck (or apophysis) is generally characterised by the 
presence of loose assimilatory tissue, rich in chloroplastids, the intercellular spaces of which communicate with the outer air by means of the stomata.

The hypobasal cell undergoes relatively few divisions. In the Sphagnaceæ it gives rise to a bulbous foot. In the Bryineæ (e.g. Orthotrichum, Barbula, Atrichum where the hypobasal cell undergoes a single division by a transverse wall) the true foot is rudimentary, but it is functionally replaced (e.g. Phascum, Ephemerum, Polytrichum) by the dilated lower end of the seta which constitutes a false foot.

After fertilisation, the venter of the archegonium developes into the calyptra which, for a time, keeps pace with the growth of the contained embryo, but is eventually ruptured by the gradual elongation of the seta. In Sphagnaceæ, and in some of the lower Bryineæ, the whole of the ruptured calyptra remains as a sheath, the vaginula, round the base of the short seta; in the higher Bryineæ the lower portion remains as the vaginula, whilst the upper portion is raised up like a cap (still called calyptra) on the top of the elongating sporogonium. The floor of the receptacle (i.e. the apex of the sexual shoot) is also stimulated to growth, forming in most cases a conical projection on which are borne the paraphyses and the unfertilised archegonia, whilst in Sphagnaceæ it elongates into the long pseudopodium (see p. 312). The perichætial leaves also grow up round the lower part of the seta or of the psendopodium.

The sporogonium, possessing, as it usually does, assimilatory tissue and stomata, can assimilate the carbon dioxide of the air, and can transpire actively. The supply of water necessary to meet the loss by transpiration is obtained, together with salts in solution, from the gametophyte, being absorbed from it by the true (hypobasal) or the false (epibasal) foot, and travels to the capsule through the rudimentary xylem-tissue of the central strand present in the seta of the higher forms. It is a point of considerable physiological interest that the absorption of water in the first instance by the gametophyte is apparently effected for the most part by the leaves rather than by the rhizoids.

The remarkable capacity for vegetative propagation manifested by the gametophyte is shared by the sporophyte. It has been ascertained that if portions of the capsule or of the seta, whilst the cells are still living, be kept under favourable conditions, the superficial cells will grow out into protonemal filaments. In 
this way the gametophyte may be derived from the sporophyte by budding, without the intervention of spores.

The principal orders of Mosses are the Sphagnaceæ and the Bryineæ.

\section{Order I. Sphagnaceæ (Bog-Mosses).}

A. The Gaмkторнхте. The spore gives rise on germination to a filamentous protonema; when germination takes place in water, the protonema remains filamentous and branches, but when it takes place on a solid substratum the protonema assumes the form of a branched cellular expansion attached to the substratum by root-like protonemal filaments. In either case adult shoots are developed as branches upon the protonema.

The Morphology of the Adult Shoot. The shoot is radially symmetrical, and is differentiated into stem and leaves. It consists of a main axis bearing numerous lateral branches.

Growth is effected, in both the main axis and the lateral branches, by means of a growing-point in which there is a three-sided apical cell.

The Sexual Organs are borne on specially modified lateral branches (gametophores), the antheridia and archegonia being borne on distinct branches, and in some species on distinct shoots.

The branch which bears antheridia (antheridiophore) is elongated and is corered with small, closely packed, imbricate leaves, by the side of each of which an antheridium is developed. The antheridium, which is raised upon a long stalk, is spherical; it opens by the splitting of the wall into valves from the apex downwards.

The branch which bears archegonia (archegoniophore) is short; it bears at its apex a group of (1-5) archegonia, surrounded by rather large involucral leaves with rudimentary perichætial leaves.

The Structure of the Adult Shoot. The main axis has no central strand; it consists of a mass of elongated thin-walled parenchymatous cells, which gradually passes over into an external zone of prosenchymatous cells, the walls of which are thick and brown; externally to this is a cortex, consisting of 1-5 layers of cells which are usually empty, and have large holes in their walls (except the Sphagna cuspidata); in some cases (Sphagna cymbifolia) the cortical cells have spiral thickenings.

The leaves vary in form according to their position; thus stem-leaves, branch-leaves, small scaly leaves, and involucral leaves may be distinguished. They are sessile, and have a broad insertion; in most cases the leaf is connected with the prosenchymatous tissue of the stem, the leaf-tissue extending through the cortex. The stem-leaves have, at the base, a pair of lateral appendages, the auriculæ.

The leaf consists of a single layer of cells, and has no midrib. It is made up of two kinds of cells: large empty cells of various forms with perforated walls frequently with spiral or some similar form of thickening (Fig. 73, $C$ ): small cells, arranged between the preceding, containing protoplasm and chloroplastids. The relative arrangement of these two kinds of cells affords a means of classification. Nostoc and other Algæe are frequently found in the large empty cells. 
The Sphagnaceæ have no special organs for vegetative propagation; but they multiply vegetatively by the dying away of the main stems so that the lateral branches become separate and constitute distinct plants; consequently these plants are found in considerable masses. They inhabit damp, boggy spots, and retain a considerable quantity of water in the open cells of the branches and leaves. Masses of Sphagnum thus saturated with water form peat-mosses or peat-bogs, the water being raised to the surface by means of the capillary system formed by the open cells.

B. The Sporophyte. The oospore, as in other Mosses, is divided by the transverse basal wall into an epibasal and hypobasal half. The epibasal half gives rise to the capsule: it grows at first apically, segments being formed by transverse walls, each segment being divided into four cells (quadrants) by walls at right angles to each other: after six or eight

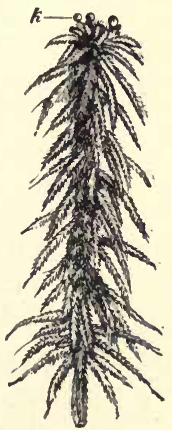

Fig. 205.-Part of shoot of Sphagnum acutifolium (nat. size). $k$ Capsules.

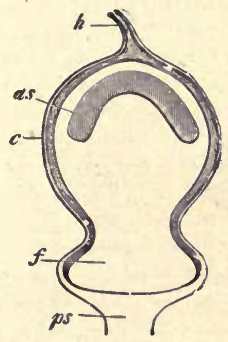

Fre. 206. - Longitudinal section (diagram. matic : $\times 19$ ) of the sporogonium of Sphagnum : $p s$ pseudopodium; $f$ foot; $c$ calsptra with neck of archegonium $h$; as archesporium.

segments have been formed, apical growth ceases, the further growth being intercalary. The cells of each segment become differentiated each into an external and an internal cell; the external cells constitute the amphithecium, the internal cells the endothecium. The amphithecium comes to consist of several layers by periclinal divisions, the first formed and most irternal layer constituting, in its upper half, the archesporium; the endothecium constitutes the columella. Thus the archesporium is a hollow hemisphere which covers the columella as a cap. There is no intercellular cavity formed in the capsule.

The hypobasal half of the oospore undergoes but few divisions, forming a bulbous foot, the superficial cells of which grow out into short papillæ.

The fully developed sporogonium consists of a capsule attached to the foot by a-very short seta; the wall of the capsule consists of a single 
layer of cells, and has numerous stomata. The capsule opens by the throwing off of the apical portion of the wall as an operculum. There is no peristorne.

When the calyptra is ruptured, it remains as a vaginula round the base of the capsule. No part of it is carried upon the top of the capsule.

The growth of the archegoniophore is stimulated by fertilisation. It grows (Fig. $206 \mathrm{ps}$ ) out at its apex into a long leafless stalk, the prendoporlium, expanded at the top into a cushion of cells in which the foot of the sporogonium is embedded; the perichretial leaves grow and surround the base of the stalk.

The order consists of the single genus Sphagnum, of which there are very many species.

Order II. Bryineæ.

A. The Giметорнтте. The protonema is filamentous, though in some cases (e.g. Tetraphis pellucida) it developes flattened cellular appendages which are assimilatory organs. The subaërial portion of the protonema is generally short lived, though in some cases it persists (e.g. Ephemerum) at least until the sporogonium has been developed and the spores are ripe: the subterranean portion frequently persists from year to year. The subaërial portion gives rise to the gametophores as lateral buds; in some forms the subterranean portion produces lateral buds in the form of bulbils (p. 332) which, when they are brought to the surface, give rise to gametophores either directly or indirectly with the intervention of protonema. It is commonly the case that, when protonema is kept dry, some of the cells grow larger and their walls thicker, whilst the other cells perish ; the persistent cells, when moistened, develope into filaments.

The Adult Shoot does not present, with regard either to its morphology or its histology, any especially characteristic features; it varies in size from a mere bud in such forms as Phascum and Ephemerum, where it is annual, to a shoot several inches long in such forms as Fontinalis and Polytrichum where it is perennial. In the latter case there is generally a central strand, and frequently leaf-traces, in the stem. It may be either acrocarpous or pleurocarpous, a feature which is important in the classification of the group. The leaves have commonly a midrib; the lamina generally consists (e.g. Funaria, etc.) of a single layer of cells. The leaves of Leucobryum resemble those of Sphagnum in that they consist of two kinds of cells, an internal layer of small living cells with chloroplastids, and external layers of dead cells with perforated walls; the peculiar structure of the leaves of Polytrichum has been already described (p. 336).

B. The Sporophrte presents features, both as to its morphology and histology, which are characteristic of the group. It is differentiated into a true hypobasal foot, a seta, and a capsule. The true foot is rudimentary. The seta is relatively short in the lower forms; a false (epibasal) foot is frequently developed from the lower portion of the seta. The neck of the capsule has nearly always stomata in its epidermis, and is developed into a distinct apophysis in some forms (e.g. Splachnum, Polytrichum). Part of the external layer of the endothecium becomes 
the archesporium, which forms a hollow cylinder round the columella, but does not extend over the top of it: an air-chamber is developed in the amphithecium round the spore-sac, and is generally traversed by strands of cells (containing chloroplastids) stretching from the wall of the capsule to the spore-sac. In the lower forms the capsule is either indehiscent, its wall becoming eventually disorganised, or it ruptures irregularly; in the higher forms, the apical portion of the wall is thrown off as an operculum, and a peristome is generally developed round the aperture thus formed. In all cases a portion of the calyptra is carried up as a cap on the top of the developing sporogonium.

The Bryineæ are classified as follows:

\section{Tribe I. Cleistocarpæ. Tribe II. Stegocarpæ.}

Tribe I. Cleistocarpx. The adult shoots are generally minute, unbranched, annual, and always acrocarpous; there is generally a central strand in the stem, and a mid-rib in the leaf.

With regard to the sporogonium, the seta is generally short, sometimes expanded at the base into a false (epibasal) foot (e.g. Phascum, Ephemerum), without any central strand in some forms. The capsule does not open by means of an operculum, nor has it any peristome; it either ruptures irregularly, or the wall simply decays.

Tribe II. Stegocarpx. The characteristics of this tribe are to be found in the sporogonium, which is distinguished by the formation of an operculum and, generally, of a peristome.

The operculum is developed from the apical portion of the capsule, either from the epidermis alone (e.g. Georgiaceæ), or

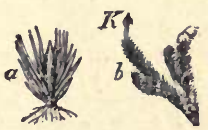

Fig, 207. $-a$ Ephemerum serratum ( $\times 3): b$ shoot of Andreaca nivalis, with (K) capsule (nat. size).

from it and one or more of the subjacent amphithecial layers. The cellwalls become cuticularised and assume a yellow or brown colour. The outline of the operculum is circular; its form cap-like, more or less flattened in some cases, more or less conical in others, sometimes apiculate.

The limit between the developing operculum and the rest of the capsule (urn) is generally marked by a slightly prominent zone, consisting of one or more rows of rather large epidermal cells, with cuticularised outer walls, termed the ring or annulus: its position is just above the level of the top of the spore-sac and of the air-chamber.

The peristome is developed within the operculum, from the innermost layer or layers of the amphithecial cells; the entire walls, or only portions of the longitudinal and transverse walls, of larger or smaller plates of these cells, become thickened, cuticularised, and coloured yellow or brown, The unthickened cell-walls, or the unthickened portions of them, break away as the capsule becomes ripe, leaving only the thickened portions forming, as it were, a skeleton attached to the urn just below the level of the annulus. The following are the principal varieties of peristomeformation. In the Georgiace» (e.g. Tetraphis) the peristome is developed from the two layers of cells beneath the epidermis which forms the 
operculum : the walls of these cells all become thickened; when the operculum falls off this plate of tissue splits from the centre into four equal

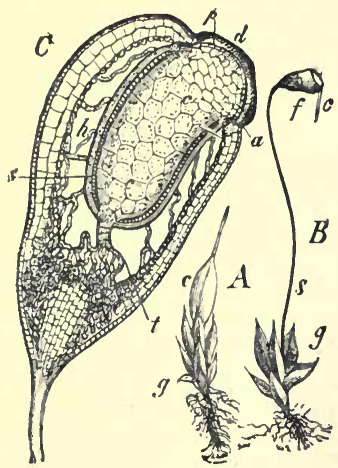

FIG. 208.-Funaria hygrometrica. A An adult shoot $(g)$, bearing a calyptra (c). B A plant $(g)$ bearing a nearly ripe sporogonium; 8 its seta; $f$ the capsule; $c$ the calyptra. C Median longitudinal section of the capsule: $d$ operculum; $a$ annulus; $p$ peristome; cc'columella; $h$ air-cavity ; the archesporium. segments which are the teeth of the peristome. In most Mosses the peristome is formed from a single layer of cells, and consists of two rows of teeth, an inner and an outer. This double peristome is dependent upon the distribution of the cuticularisation of the walls: both the internal and the external walls of the peristomial celllayer become euticularised, but the lateral and part of the transverse walls joining them remain unaltered and eventually break away, leaving the thickened internal and external walls as separate strips, which may be further divided longitudinally into teeth. The teeth of the outer peristome are generally larger than those of the inuer which are sometimes distinguished as cilia; their number is a power of two (4-8-16-32-64.) There is considerable variety in the structure and form of the peristome; this affords a means of classification. The genus Polytrichum, for instance, is characterised by the fact that the teeth of the peristome consist of strands of thick-walled fibres, the tips of which are not free, as is usually the case, but are connected by a membrane stretched over the aperture of the urn, termed the epiphragm.

A. peristome is not present in several genera (e.g. Gymnostomum,

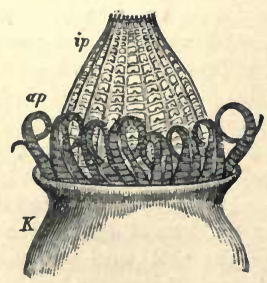

Fig. 209.- Mouth of the theca of Fontinalis antipyretic $J$, ap Outer peristome ; if inner peristoms. ( $x$ 50.)
Hymenostomum, Schistostega, etc.); nor in some species (e.g. species of Pottia and Encalypta, etc.) belonging to genera in which a peristome is usually present.

As the capsule matures, the cells (except the spores) lose their cell-contents; and those whose walls have not become thickened and cuticularised, dry up and shrink, the shrinkage being necessarily accompanied by the tearing of the thin walls in various parts. The persistent cuticularised walls are highly hygroscopic, and it is in consequence of the tensions set up by the unequal stretching and contraction of these walls, due to 


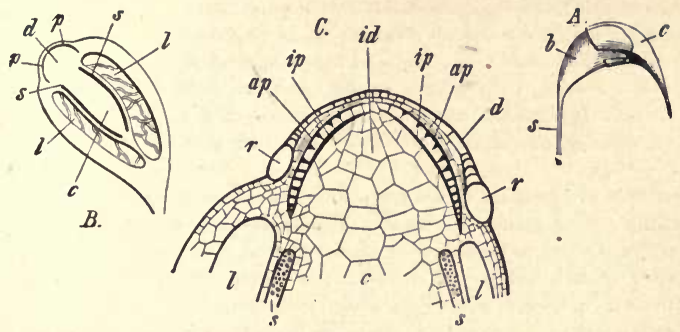

FIG. 210,-Sporogoninm of Funaria hygrometrica. A, s seta ; b capsnle; c calyptra $(\times 5)$. $B$ Section of a half-developed capsule $(\times 10)$ : c columella; $s$ archesporium; $l$ air-cavity; $d$ sub-opercular tissue; $p$ peristome. C Apical portion of the same capsnle $(x 40)$; $d$ oper. culum; id sub-opercular tissue; ap outer peristome; ip inner peristome; $r$ ring; $l$ air. єpace; $c$ columel'a; s spore-sac.

variations in their moisture, that the splitting off of the operculum is effected.

The Stegocarpæ are classified as follows :-

Sub-tribe ACROCARPA: archegonia terminal on the main shoots; but the sporogonia are sometimes apparently lateral in consequence of the growth of lateral branches (innorations) which force the apex of the main shoot to the side.

Sub-Trile PLEUROCARPA: archegonia (and subsequently the sporogonia) borne terminally on short lateral branches.

The following are among the more familiar species of acrocarpous Mosses :-

Dicranum scoparium, with sickle-shaped leaves, is common in woods. Lencobryum glaucum has leaves consisting of several layers of cells, which resemble those of Sphagnum in their structure; it occurs in Pine-woods and on moors. Ceratodon purpureus, with a red seta and a short stem, is very common in various loealities. Barbula muralis grows in patches on walls and rocks; the midrib of the leaves is prolonged into a hair, so that the patches of Moss look greyish. Telraphis pellucida has bright green leaves; it grows on decayed tree-trunks, and bears gemmæe of peculiar form. Grimmia pulvinata occurs on walls and stones in round greyish-green patches; the capsules have very short setæ. Orthotrichum affine and other species have also shortly-stalked capsules, and are common on trees. Funaria hygrometrica (Figs. 208, 210) has an oblique, pear-

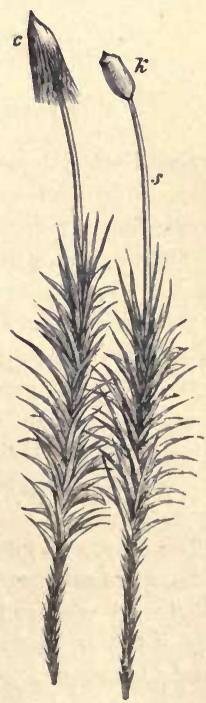

FIG. 211.-Two plants of Polytrichum formosum bear. ing sporogonis (nat. size). k The capsule; s the seta; c calyptra. 
shaped capsule; the long setæ have the peculiarity of contracting into a spiral on being wetted and dried; it is common on walls and paths. Polytrichum formosum (Fig. 211) and other species are the largest of our indigenous acrocarpous Mosses; they have large dark green leaves and long hairy calyptræ and are common in woods and on heaths.

The following are among the more familiar species of pleurocarpous Mosses:-

Fontinalis antipyretica floats in water. Neckera crispa, with flat outspreading leaves, grows on rocks. Thuidium alictinum and other species grow on banksand in woods; they have regular, pinnately-branched stems, and very small, closely-set leaves. Leucodon sciuroides is common on tree-trunks, Brachythecium rutabulum is common in woods. Eurhynchium prelongum, with long creeping stems, occurs in woods and damp gardens. Hyрпит cupressiforme is very common on tree-trunks, and $H$. cuspidatum and giganteum in bogs and ditches. Hylocomium triquetrum is very commonly used for garlands; this and $H$. splendens, with remarkably regular ramification, are both common in woods.

\section{GROUP III.}

\section{PTERIDOPHYTA (Vascular Cryptogams).}

The distinguishing characteristics of the plants forming this group are the following:-The life-history presents a well-marked alternation of generations, as in the Bryophyta; but here it is the sporophyte which is the more conspicuous form, constituting "the plant." The sporophyte becomes quite distinct from the gametophyte at an early period: it is differentiated (with but few* exceptions) into root, stem, and leaf; and in all cases it contains well-developed vascular tissue. The gametophyte, generally termed the prothallium, is a relatively small thalloid body, usually short-lived, containing no trace of vascular tissue.

The group includes the three classes, Filicinæ, Equisetinæ, Lycopodinæ.

The SPonophrte is developed from the oospore, which undergoes division, in all cases, into an epibasal and a hypobasal half, by a basal wall which is either more or less nearly parallel to the long axis of the archegonium (Leptosporangiate Filicinæ) or more or less nearly transverse to it: the epibasal half usually faces the neck of the archegonium, but in the Lycopodinæ the hypobasal half occupies this position. In the Filicinæ and Equisetinæ, the formation of the basal wall is followed by the formation of another wall at right angles to it (quadrant-uall) so that the embryo now consists 
of four cells which are quadrants of a sphere, and this is followed by the formation of a third wall (octant-wall), at right angles to both the preceding, so that the embryo now consists of eight cells which are octants of a sphere. In the Lycopodinæ the segmentation leading to the formation of quadrants and octants is confined to the epibasal half, the hypobasal half remaining undivided or undergoing a few irregular divisions. From the epibasal half, the primary stem and one or two primary leaves (cotyledons) are developed in all cases. The hypobasal half gives rise, in the Filicinæ and Equisetinæ, to the primary root and to the foot, with but few exceptions (e.g. Salvinia in which there is no primary root): in the Lycopodinæ the hypobasal half gives rise to a filament consisting of a few cells, termed the suspensor (compare Phanerogams).

The foot (as also the suspensor) is an embryonic organ, no trace of which persists in the adult. It is the organ of attachment of the embryo-sporophyte to the gametophyte; and it is also the absorbent organ by which the embryo, until it is able to absorb and assimilate food for itself, obtains its nourishment from the prothallium (compare Bryophyta, p. 314).

The development of a suspensor in the Lycopodinæ is an adaptation correlated with the fact that the nourishment of the embryo in that group depends upon its coming into direct contact with the tissue of the massive gametophyte, the cells of which are filled with nutritive substances.

A primary root, that is, a root developed from the hypobasal half of the oospore, and so situated at its origin that its growingpoint is in a straight line with that of the stem, only occurs in the Filicinæ and Equisetinæ; but even here it does not persist as a tap-root in the adult: in these plants numerous adventitious roots are developed. In the Lycopodinæ, where there is no primary root, all the roots are adventitious.

Some adult forms are altogether without roots: as Salvinia, and some species of Trichomanes, among Filicinæ; Psilotum and Tmesipteris, among Lycopodinæ. The functions of the root are discharged, in Salvinia by modified leaves, in the others by nodified branches.

The branching of the root is generally lateral in the Filicinæ and Equisetinæ; it is dichotomous in the Lycopodinæ and in Isoetes. In the former case, the lateral rootlets are developed, in the Filicinæ, from cells (rhizogenic) of the endodermis which 
are opposite to the xylem-bundles of the stele; in the Equisetinæ, from the cells forming the inner layer of the two-layered endodermis.

The stem is generally short and unbranched in the Filicinæ; generally elongated and much branched in the Equisetinæ and Lycopodinæ.

The leaves are differentiated into foliage-leaves and sporophylls in the Equisetinæ and generally in the Lycopodinæ, but not in the Filicinæ as a rule. The foliage-leaves are relatively large in proportion to the stem in the Filicinæ, relatively small in the Lycopodinæ, reduced to cataphylls in the Equisetinæ.

The grouth in length of root, stem, and leaf, is effected by an apical growing-point: the growing-point has generally a single apical cell in the Filicinæ (except root and stem of Marattiaceæ and Isoetes) and Equisetinæ; in the Lycopodinæ (as also in the exceptional Filicinæ) there is generally a group of initial cells.

The anatomy of the stem presents considerable variety. The primary stem is in all cases monostelic (pp. 102, 116): it may continue to be monostelic (e.g. Lycopodiaceæ, Isoetes, Osmundaceæ, etc.), but more commonly it becomes polystelic (most Filicinæ). The vascular tissue of the wood consists of lignified spiral (protoxylem) and scalariform tracheides, or less commonly vessels; the bast contains no companion-cells. The bundles are generally closed and cauline. The relative arrangement of wood and bast in the stele is generally concentric (see p. 124) in the Filicinæ and Selaginellaceæ, and radial in the Lycopodiaceæ: or the bundles may be conjoint and collateral as in the Equisetinæ and some Filicinæ.

The reproductive organs are sporangia, generally borne on the leaves (sporophylls) but sometimes directly on the stem (e.g. Selaginella). Each sporophyll may bear many sporangia on its inferior (dorsal) surface, as generally in the Filicinæ and Equisetinæ; or a single sporangium on its upper surface (e.g. Lycopodium, Isoetes), or in its axil (Selaginella).

When the sporophyll bears many sporangia, they are usually arranged in groups; each group is termed a sorus, and the more or less well-developed cushion of tissue from which the sporangia spring is termed the placenta. The sorus may be naked; or it may have a membranous covering, the indusium (e.g. many Filicinæ).

In the Filicinæ the sporophylls are not confined to any special 
portiou of the shoot, so as to constitute a flower: but in some cases (e.g. Osmunda, Ophioglossaceæ, Marsileaceæ) they differ in form and structure from the foliage-leaves. In the Equisetinæ the sporophylls are highly specialised, and are grouped into cones (flowers) at the ends of the fertile branches: similar cone-like flowers, with less specialised sporophylls, occur in various Lycopodinæ.

The sporangia are unilocular, though in Isoetes they are incompletely chambered by trabeculæ: they are developed singly or in groups (sori); in the latter case they are usually distinct, but in some cases they are coherent (Marattiaceæ, except Angiopteris; Psilotaceæ) forming a synangium (see p. 52): the synangium should not, however, be regarded as the result of the cohesion of originally distinct sporangia, but as a group of sporangia which have not separated. The sporangium is developed either from a single superficial cell (leptosporangiate); or from a group of superficial cells (eusporangiate), and sometimes from deeper cells as well: the mother-cells of the spores are derived from an archesporium which is either a single hypodermal cell or a group of hypodermal cells.

The spores produced in the sporangia, are single cells, with generally two coats, endospore and exospore. Many of the Pteridophyta produce spores which are all quite alike, whence they are said to be homosporous; whereas others produce spores of two kinds, small spores (microspores) and large spores (macrospores or megaspores), and are said to be heterosporous.

The sporangia of the heterosporous forms are distinguished as microsporangia and macrosporangia, according to the kind of spores which they develope: and when the sporophylls bear either only microsporangia or only macrosporangia they are distinguished as microsporophylls and macrosporophylls. The number of macrospores produced in the macrosporangium is generally small, thongh they are numerous in Isoetes: thus there are four in Selaginella, only one in the Hydropterideæ.

The spores are generally set free by the dehiscence of the sporangia: but in Salvinia the whole sporangium falls off and the spores germinate within it.

B. The Gametophyte. The spore, on germination, gives rise to a prothallium which is the gametophyte. It is very small and inconspicuous, as compared with the sporophyte; its body is, generally speaking, thalloid; there is no vascular tissue in its 
structure, and in many cases it does not become free from the spore. It usually lives through but one short period of growth.

In any one of the homosporous forms, the prothallia developed from the spores are all essentially alike; generally speaking, any one prothallium bears both male and female reproductive organs. The morphology of the prothallium varies widely in these forms: it may be a branched cellular filament (some Hymenophyllaceæ), or a flattened expansion (Equisetinæ, most Ferns), containing chlorophyll abundantly; or it is tuberous (Ophioglossaceæ, Lycopodiaceæ), either wholly or in part destitute of chlorophyll. It becomes entirely free from the spore.

In the heterosporous forms the gametophyte is represented by two individuals-a male and a female prothallium; the former is the product of the germination of a microspore, the latter of the germination of a macrospore. As compared with those of the homosporous forms, the prothallia of the heterosporous forms are relatively small; moreover they do not become independent of the spores from which they are developed. The male prothallium is reduced to little more than a single male organ (antheridium); the female prothallium is a small, usually green, cellular body projecting more (e.g. Salvinia) or less (e.g. Selaginella) through the ruptured outer coat of the macrospore.

Generally speaking, the symmetry of the prothallium is dorsiventral; in the free-growing forms, the under surface generally bears numerous unicellular root-hairs. The distribution of the sexual organs on the prothallium varies; they are frequently confined to one surface, but are occasionally scattered over the whole surface. The number of the sexual orgaus on a prothallium is in some cases only one, in others it is considerable.

The sexual organs are antheridia (male) and archegonia (female). The structure of the antheridium is simple; it cons:sts of a wall, a single layer of cells, enclosing the mother-cells of the spermatozoids. The antheridia are developed from single superficial cells of the prothallium; when the prothallium is thin, the antheridia project on the surface; when the prothallium is tuberous, the antheridia become sunk in the tissue.

The archegonium consists of a venter and a neck. As the venter is, in all cases, sunk in the tissue of the prothallium, it, has no proper wall of its own, and is, in fact, simply a cavity in the tissue; the short neck consists of a single layer of cells 
in four rows. The mature archegonium contains, in the venter, the female cell (oosphere).

The archegonium is developed from a single superficial cell of the prothallium. This cell divides transversely into two, an upper and a lower; the former, by growth and division, forms the neck of the archegonium; the lower cell projects into the developing neck, and the projecting portion becomes cut off, constituting the neck-canal-cell which sometimes divides again into two (Marattiaceæ, Lycopodium); the remainder, now termed the central cell of the archegonium, divides transversely into two unequal parts, the upper and smaller being the ventral canal-cell, the lower and larger being the ousphere. As the archegonium becomes mature, the canal-cells become mucilaginous, the neck opens by the separation of the cells at the apex, and the archegonium is ready for fertilisation.

The male cell is a naked motile cell, a spermatozoid; it is a spirally coiled filament, pointed at the anterior end which bears the cilia, becoming thicker towards the opposite end: the cilia are numerons in Filicinæ and Equisetinæ; two in Lycopodinæ.

Each spermatozoid is developed singly in a mother-cell in the antheridium. The whole of the contents of the mother-cell are not, however, devoted to the spermatozoid: a portion remains unused, and is discharged together with the spermatozoil, to which it adheres for a time as a protoplasmic vesicle containing, amongst other constituents, a portion of the nuclear substance of the mother-cell (see Fig. 222).

The female cell, or oosphere, is a naked spherical cell lying in the venter of the archegonium. Its development is described above.

Fertilisation is effected by the entrance of spermatozoids into the open neck of the mature archegonium, and the subsequent fusion of one of them with the oosphere. When, as is usually the case, numerous prothallia are developed near together on the ground, and become wetted by rain or dew, the ripe antheridia burst and set free the spermatozoids which, swimming actively in the water, are attracted to the mature archegonia by means of an acid excretion which is discharged from the neck of the archegonium when it opens. The effect of fertilisation on the oosphere is that it at once surrounds itself with a cell-wall becoming the oospore, and then begins to develope into the young sporophyte.

In a few cases (e.g. species of Trichomanes and Lycopodium) the 
gametophyte (prothallium) multiplies vegetatively by means of gemmæ, which are short spindle-shaped rows of cells in the one case, and globular multicellular bodies in the other.

The Life-History of the Pteridophyta presents in all cases, a perfectly clear alternation of generations, the sporophyte and the gametophyte being completely distinct. The oospore developes in to "the plant," be it Fern, Equisetum, or Lycopod, which bears the sporangia and spores, and is the sporophyte. The spores, when shed, germinate to form the gametophytes (prothallia) bearing the sexual organs.

The Pteridophyta are classified as follows :-

Class V. FILICINÆ. The sporophyte is characterised by having relatively large and few leaves; the sporophylls are generally similar to the foliage-leaves and are not aggregated into flowers; the sporangia are numerous on the sporophyll (except Isoetes) and are arranged in sori; the archesporium is a single cell (except Isoetes); the embryo has a primary root (except Isoetes, Salvinia, and possibly some species of Trichomanes) but no suspensor.

The characters of the gametophyte vary widely. The spermatozoids are multiciliate.

Sub-Class Eusporangiatæ. Each sporangium is developed from a group of superficial cells.

\section{HOMOSPOREA.}

Order 1. Ophioglossacea. Order 2. Marattiacea.

\section{HETERosPoreA : Order 1. Isoetaceæ.}

Sub-Class Leptosporangiatæ. Each sporangium is developed from a single superficial cell, (Filices in limited sense.)

\section{HOMOSPOREE.}

Order 1. Osmundacere. "2. Schizaасељ.

"3. Gleicheniaceo.
Order 4. Polypodiacea.

"5. Cyatheaceo.

$"$ 6. Hymenophyllacea.

\section{HETEROSPOREA.}


Class VI. EQUISETINÆ. The sporophyte is characterised by the well-developed branched stem, with small whorled leaves forming a sheath at each node; the small peltate sporophylls are aggregated into a cone-like flower at the apex of each fertile shoot, and bear a few sporangia on the inner (inferior) surface; the archesporium is a single cell; the embryo has a primary root and no suspensor. All the existing forms are homosporous and eusporangiate.

The gametophyte is a free, green, membranous prothallium, generally diœeious; the spermatozoids are multiciliate.

\section{Order 1. Equisetacea.}

Class VII. LYCOPODIN E. The sporophyte is characterised by the well-developed branched stem with numerous small scattered leaves; the sporangia are borne singly either on the upper surface of a sporophyll, or on the stem; the sporophylls resemble the foliage-leaves, but are sometimes aggregated into cone-like flowers; the archesporium is multicellular; the embryo has a suspensor, but no primary root. All the existing forms are eusporangiate.

The characters of the gametophyte vary widely. The spermatozoids are biciliate.

Sub-Class Homosporex: the sporophyte produces spores of one kind only; the prothallia are free, more or less tuberous, monœcious.

Order 1. Lycopodiacea.

Order 2. Psilotacece.

Sub-Class Heterospores: the sporophyte produces microspores and macrospores; the former give rise to male, the latter to female, prothallia; the prothallium does not become free from the spore.

\section{Order 1. Selayinellacea.}

The relations of these various groups may be simply expressed as follows :-

Filicine.

Equisetind. Lrcopodina.

Homosporous - Filices

Heterosporous - Hydropterideæ -

Homosporous $-\left\{\begin{array}{l}\text { Ophioglossaceæ } \\ \text { Marattiaceæ }\end{array}\right\}-$ Equisetaceæ $\left.-\left\{\begin{array}{l}\text { Lycopodiaceæ } \\ \text { Psilotaceæ }\end{array}\right\}\right\}-$ Eusporangiale Heterosporous - - Isoetaceæ

Mr.B. -(none existing) - Selaginellaceæ

$-\}_{\text {sporangiale. }}^{\text {Lepto- }}$ 


\section{CLASS V.-FILICIN E.}

A. Homosporous Eusporangiate.

Order 1. Ophioglossaceæ. This order includes the three genera Ophioglossum, Botrychium, and Helminthostachys.

Sporophyтe. The stem is a subterranean rhizome (except in epiphytic Ophioglossums), which does not branch at all in Ophioglossum, and but little in Botrychium and Helminthostachys; it is usually short and erect. The rather thick and fleshy roots are unbranched in Ophio-

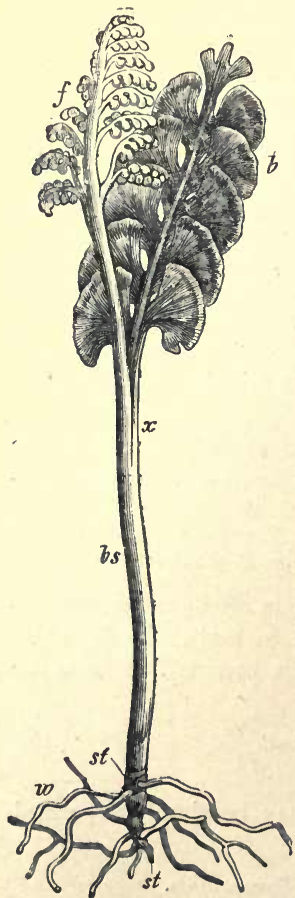

Fug. 212. - Botrychium Lunaria (nat. size): $w$ roots; st stem ;bs leaf-stalk; $x$ point where the leaf branches; the sterile lamina (b) separating from the fertile branch (f). glossum, but they give rise to adventitious buds; they are branched in Botrychium and Helminthostachys, and produce no buds. The leaves are developed close together at the apex of the rhizome, and are not circinate, or only slightly so, in vernation; their growth is so slow that a leaf does not appear above ground until the fifth year after its first development; generally, only a single leaf appears above ground each year, when more are developed some of them are sterile. The sporophylls are remarkable for their peculiar branching (see $p$. $34)$; they are petiolate, and the petiole branches into two, the one bearing a sterile and the other a fertile lamina (Fig. 212); the fertile branch being situated on the ventral surface of the sterile; the sterile lamina is leafy, whilst the fertile lamina consists of little more than the sporangia. In Ophioglossum the sterile lamina is entire, and the fertile lamina is spicate with two lateral rows of sporangia; in Botrychium the sterile lamina is pinnate, and the fertile lamina is bipinnate with marginal sporangia. The sporangia are embedded in the tissue of the sporophyll in Ophioglossum, but are free in Botrychium and Helminthostachys: they are not arranged in sori; they are globose, have no annulus, but dehisce into two equal valves by a transverse (Ophioglossum, Botrychium) or vertical (Helminthostachys) slit; the wall of the sporangium consists of several layers of cells; the spores are numerous and tetrahedral. 
Gayetophyte. The germination of the spores has not been observed, but the mature prothallium has been described in the case of Ophioglossum pedunculosum and Botrychium Lunaria. In both cases it is tuberous, subterranean, destitute of chlorophyll, monoecious; the antheridia are sunk in the tissue, and the short necks of the archegonia project but little. It appears that the prothallium is saprophytic, though possibly it may possess chlorophyll in the early stages of its development. In Botrychium it is a somewhat ovoid body not more than half a line long, with long scattered root-hairs, bearing the antheridia chiefly on its upper surface, the archegonia chiefly on the lower.

Ophioglossum vulgatum (the Adder's tongue) is the British species of this genus; $O$. lusitanicum has, however, been found in Guernsey. The epiphytic species are $O$. pendulum and $O$. palmatum, both tropical forms; the latter has palmately-lobed sterile fronds. Botrychium is represented in the British Flora by B. Lunaria (the Moon-wort) which occurs in hilly districts. Helminthostachys includes the single species $H$. zeylanica which occurs in the Eastern tropics:

Order 2. Marattiaceæ. This order includes the genera Marattia, Angiopteris, Kaulfussia, and Danæa, none of which are European, but are mainly tropical.

Sporopнyтe. In its general morphology the sporophyte agrees with that of the Ophioglossaceæ; but the leaves are more numerous, much larger, compound, and circinate in vernation, and each bears a pair of stipules. Branching of the stem occurs only in Danæa; in Kaulfussia the stem is a subterranean, creeping; dorsiventral rhizome. The roots are somewhat fleshy, and are much branched. The apical growing-point of both root and stem consists of a group of a few (four or more) initial cells. The sporophylls are not differentiated into a sterile and a fertile portion, but have the appearance of foliage-leaves. The numerous sporangia are borne in sori on the ribs of the under surface of the sporophyll; in Angiopteris the sporangia of a sorus are free, whilst in all the other genera they are coherent, forming a synangium (see p.349). The spores are numerous, and are either tetrahedral or radial:

Gametophyte. On germination the spore gives rise to a dorsiventral green prothallium resembling that of the Leptosporangiate Ferus.

\section{B. Heterosponous Eusporangiati.}

Order 3. Isoetaceæ. This order includes the single genus Isoetes which comprises about fifty species belonging to all parts of the globe. Some of these are terrestrial (I. Duricei and Hystrix), whilst others are either altogether aquatic (e.g.I. lacustris, echinospora, etc.), or amphibious (e.g. I. velata, setacea, boryana). The British species are 1 . lacustris, echinospora, and Hystrix.

Isoetes has, of recent years, been generally included among the Lycopodinæ; but it betrays a relationship to the Filicinæ in so many features, such as its general habit, its embryogeny, the absence of any cone-like fructification, the form of its spermatozoids, that it appears to be more natural to place the plant in that group. 
Sponophyte. The stem is small, unbranched, short and tuberous, with either two or three longitudinal furrows which give it a lobed appearance. It is closely covered with numerous, relatively long (1-12 in.), sessile leaves. From the furrows of the stem there spring numerous, dichotomously branched, somewhat fleshy roots.

The growth in length of the stem, which is very slow, is effected by an apical growing-point consisting of several initial cells. The growingpoint of the root consists of small-celled meristem, and presents a similar lifferentiation to that of the root of Dicotyledons (see p. 102).

The leaves are either fertile or sterile; the fertile leaves each bear a single sporangium, and are termed macrosporophylls or microsporophylls in accordance with the nature of the sporangium which they severally bear. The order of development of the leaves in each year is that first of all macrosporophylls are produced, then microsporophylls, and finally a few sterile leaves in some species. Hence, when the development is completed, the macrosporophylls are external in the rosette, the sterile leaves (when present) internal, and the microsporophylls intermediate. The sterile leares persist during the winter, and form a protection in the next spring to the young leaves developed internally to them at the growingpoint.

The fertile leaves, whether macro- or micro-sporophylls, consist of a broad, sheathing base, with membranous margins, which bears a narrow subulate lamina, flattened somewhat on the upper (ventral) surface. Close above the insertion, on the upper or inner surface of the leaf-base, is a pit, the fovea, in which the single sporangium is situated. In some species the margin of the fovea is prolonged into a membrane, the velum, which either partially (e.g. I. lacustris), or completely (terrestrial species), covers the sporangium. Above the fovea, in the middle line, is another smaller pit, the foveola, occupied by the somewhat swollen base of a projecting flattened membranous structure, the ligule, which is developed from a single superficial cell of the young foveola, and is relatively much larger in the quite young leaf than in the adult.

The sterile leaves are less highly developed than the fertile; they are smaller, especially as regards the leaf-base. In the terrestrial species they are reduced to scaly cataphyllary leaves of a brown colour.

The sporangium is developed from a group of cells in the fovea. The archesporium consists of a layer of hypodermal cells in the young sporangium. In a microsporangium all the archesporial cells grow and divide so as to form rows radiating from the free surface to the attachment of the sporangium. Some of these rows of cells soon cease to grow, and are not sporogenous, but remain as plates of tissue, termed trabecula which imperfectly chamber the cavity of the microsporangium. Of the remaining cells, the majority constitute the mother-cells of the microspores invested, towards the wall of the sporangium, by sterile cells forming the tapetum. In a macrosporangium, the fertile archesporial cells undergo but a single division, whilst the trabeculæ are formed as in the microsporangium. The large mother-cells of the macrospores are isolated, and each is invested by a tapetal layer. Each spore-mother-cell gives rise, finally, to four spores. 
Gametophyte. As Isoetes is heterosporous, the gametophyte is represented by distinct male and female individuals, which remain connected with the spores producing them : they resemble those of Selaginella and. of some Gymnosperms (q. $v$.).

The male individual is developed from a microspore. The microspore - which has the form of the quadrant of a sphere and is consequently of the bilateral or radial type-undergoes, on germination, dirision by a transverse wall,

formed near one of its somewhat pointed ends, into two cells, a large and a small: the latter is the vegetartive cell, and undergoes no further change; the former is the mother-cell of the male orgau or antheridium. The prothallium here is thus very much reduced, consisting of a single antheridium and of a single purely vegetative cell. The antheridium, developed by the growth and division of the mothercell, consists of four peripheral cells forming the wall, and of four central cells, each of which gives rise to a single spirally coiled multiciliate spermatozoid.

The female individual is developed from a macrospore. The macrospores

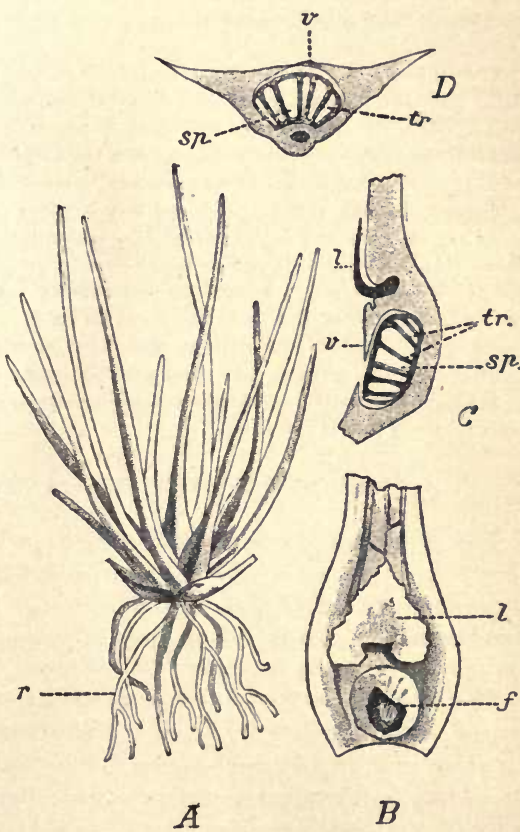

Fre. 213,-Isoetes lacustris (after Luerssen). 4 Plant, hale nat. size : $r$ dichotomonsly branched rools. B Inner (ventrsl) sarface of base of a sporophyll: $l$ ligule; $f$ foves. $C$ Longitndinal section of base of a sporophyll: $s p$ the sporanginm in the forea; $t r$ the trabecula; v the velnm; $l$ the ligule. $D$ Transverse section of the base of a spornphyll : letters as in C. are much larger than the microspores, and are nearly globular in form, though they belong to the tetrahedral type, as can be seen by the three ridges on the spore where it was in contact with the other three developed from the-same mother-cell. On germination, the nucleus of the macro- 
spore undergoes repeated division; this is followed by free cell-formation in the apical region (the pointed end where the three ridges meet) of the macrospore, the result being the formation of a small-celled tissue; subsequently cell-formation extends into the basal portion of the spore, a tissue being formed there consisting of relatively large cells with coarsely grannlar contents. Thus the macrospore becomes completely filled with a mass of cellular tissue which constitutes the female prothallium: the npper small-celled tissue is the essentially reproductive portion, whilst the lower large-celled tissue simply serves as a depository of nutritive substances.

The female organ, the archegonium, is developed from one of the superficial cells of the small-celled prothallial tissue, after the manner described on page 351. It appears that two or three archegonia are usually formed : but if none of these primary archegonia are fertilised, a small number of additional archegonia may be subsequently developed.

The archegonia are exposed, for the purpose of fertilisation, by the splitting of the coats of the macrospore along the three ridges already described: the prothallium does not, however, project from the spore, nor does it become green. After fertilisation, the gospore developes into the embryo: the foot of the embryo grows down into the large cells of the basal portion of the prothallium, absorbs the nutritive substances which were stored up in them, and thus supplies the embryo with food until such time as its leaves and roots are sufficiently developed to enable it to nourish itself in the uṣual way.

\section{HOMQSPOROUS LEPTOSPORANGIATE (Filices).}

The orders constituting this group have so much in common that they may be advantageously considered all together.

SporophyтE. The body is differentiated into stem, leaf, and root (generally): the leaves are large in proportion to the stem, and are relatively few in number.

The stem has either radial or dorsiventral symmetry. In the former case it is commonly short and straight; it grows into the air erect, or at any degree between the vertical and the horizontal; its surface is generally completely covered by the insertions of the spirally arranged leaves, and by adventitious roots: it becomes, however, elongated, to a considerable height sometimes, in the TreeFerns. In the latter case, the stem grows as a rhizome either on or in the soil, or on the surface of some tree upon which the plant lives as an epiphyte: the leaves are borne on its dorsal surface, either in two rows (e.g. species of Aneimia and Polypodium), or in a șingle row (e.g. Lygodium palmatum, Polypodium Heracleum and $P$. quercifolium): from the lower (ventral) surface, spring the adventitious roots. 
The growth in length of the stem, is effected by a growing-point with a single apical cell (with the occasional exception of Osmunda): the apical cell is, as a rule, a three-sided pyramid with its spherical base at the surface: but in Pteris aquilina it is usually a two-sided lenticular cell, with its longer axis in the dorso-ventral plane.

The radial stems branch but little, least of all when the stem is elongated, as in the Tree-Ferns; and such branching as there is appears to be mainly adventitious, the buds springing from the bases of the leaves. In the dorsiventral stems there is normal lateral branching, which takes place in the transverse plane: the branches are borne on the flanks of the stem, and are frequently (e.g. some Hymenophyllaceæ) axillary in their origin.

The leaves are for the most part foliage-leaves, though scaly leaves are found on the subterranean rhizomes of Onoclea Struthiopteris and Osmunda regalis, and in some cases the sporophylls are more or less differentiated from the sterile leaves.

The foliage-leaves are relatively large, sometimes entire (e.g. Scolopendrium), but generally more or less deeply and repeatedly pinnately lobed or branched; sometimes dichotomously branched (c.g. Platycerium, species of Schizæa).

The leaves in all cases have apical growth; the growing-point has, in most of the orders, a two-sided apical cell, whilst in the Osmundaceæ the apical cell is tetrahedral. In Lygodium, where the leaf is a climbing organ, the apical growth is long continued.

The leaf arises from a single superficial cell of the growingpoint of the stem. When young it is strongly hyponastic (see p. 211), so that, as it elongates and branches, both the main axis of the leaf (phyllopodium) and the lateral branches becomp inrolled upon themselves like a crosier; in other words, the vernation is circinate: as it grows older the growth becomes epinastic, and thus the leaf becomes expanded.

In the great majority of these Ferns the sporophylls are simply foliage-leaves bearing sporangia on the dorsal surface, but in certain cases they are more or less specialised. Thus, in Onoclea Struthiopteris, the sporophylls are smaller than the foliage-leaves, and have narrower pinnæ: in the Hard Fern, Blechnum boreale, the sporophylls are longer and have narrower pinnæ than the foliage-leaves: in Osmunda regalis the pinnæ of the upper branches of the sporophyll are reduced to little more than the midrib, the pinnules being represented by clusters of sporangia; in Aneimia 
(e.g. A. Phyllitidis) generally the lowest pair of pinnæ of the sporophyll alone bear sporangia; these pinnæ consist merely of the nervature bearing numerous sporangia, and are erect on much elongated secondary petioles: in Platycerium alcicorne there is a curious instance of specialisation; the foliage-leaves are broad, and closely appressed to the substratum, whereas the sporophylls are erect, narrow, and branched.

The sporangia are but rarely borne on the superior (ventral) surface of the sporophyll (e.g. Olfersia cervina); more commonly
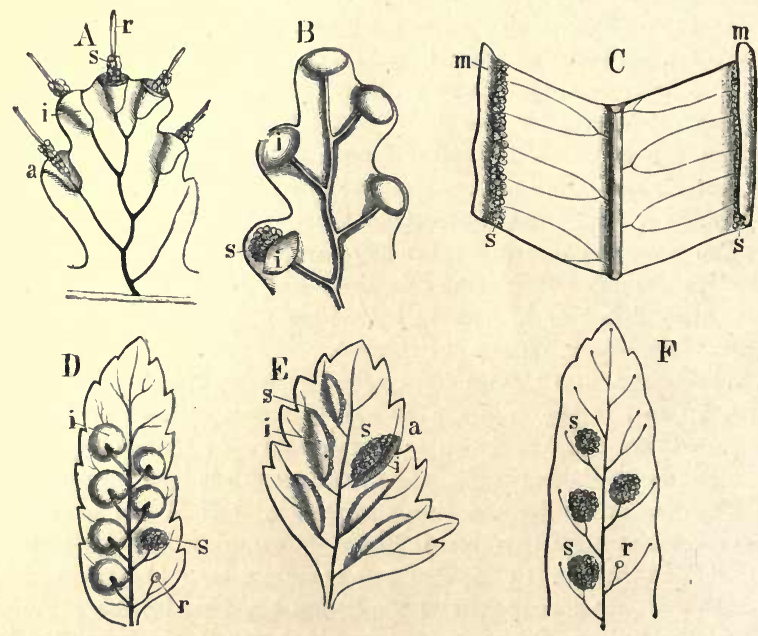

Frg. 214.-Sori (s) of the most importunt groups of Leptosporangiate Ferns, all seen from balow. A Pinna of Trichomanes sinuosuin, one of the Hymenophyllaceæ: $r$ projecting placenta; 8 sporangia; $i$ indusium; at $a$ half of the indusium is removed. B Pinna of Davallia (Leucostegia) - at 8 the one-valved indusium (i) is turned back. $C$ Part of a leaf of Pteris serrulata : 8 the sporangia; $m$ the inverted margin. D Pinnule of Nephrodium-at 8 the indusium is removed, and at $r$ the sporangia also. $E$ Pinnule of an Asplenium-at $a$ the indusium is tnrned back. F Pinna of Polypodium vulgare with naked sori-at $r$ the sporangia are removed. (All a:0 $\times 3$ to 6 .)

on the margin (e.g. Hymenophyllaceæ, Dicksonia, Davallia); but as a rule, on the dorsal surface, either near to the margin (e.g. Pteris, Adiantum), or distant from it (e.g. Asplenium, Aspidium, etc). They are usually developed in connexion with the nervature of the sporophyll, but sometimes also from the intervening tissue 
of the lamina (Acrosticheæ, such as Polybotrya, Chrysodium): in the former case they occur in gromps, termed sori, which are commonly isolated, but occasionally (e.g. Pteris) a continuous marginal sorus is formed.

The sorus generally consists of a large number of sporangia : in the Gleicheniaceæ, however, the number is small (2-8); and in some cases (e.g. Lygodium) there is only a single sporangium. The sporangia of the sorus are borne on a projection of tissue, the placenta or receptacle, which presents various forms : it may be a slight rounded elevation (e.g. Aspidium); or more elongated and conical (e.g. Cyathea, Hymenophyllum); or very long and filiform, bearing sporangia only at its base (e.g. species of Trichomanes, Fig. $214 A$ ); or a ridge (e.g. Pteris, Blechnum).

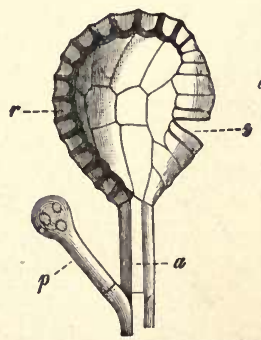

Fra. 215.-A dehisced sporangium of Aspidium Filix-mas $(\times 90)$ : $a$ the stalk, with a glandular hair $p$; $r$ the annulus; sthe stomium.

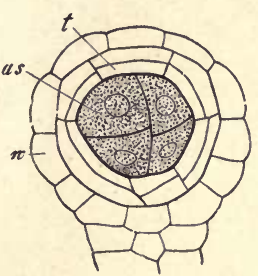

A.

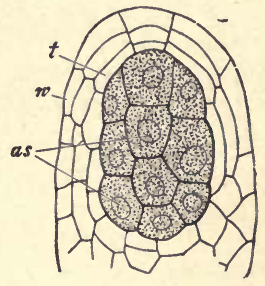

B.

FrG. 216,-Sections of young sporangia; $A$ of a Fern (Mohria), $B$ of Equisetum $(\times 150)$ : $w$ wall; $t$ tapetum; as archesporium.

The sorus is quite bare in many forms (Gleicheniaceæ; Osmundaceæ; Alsophila among Cyatheaceæ; Schizæaceæ, except Lygodium; Polypodieæ); in others it is more or less covered by a protective membrane, the indusium, which is an outgrowth of the tissue of the leaf, generally of the epidermis alone. When it springs from the placenta below the sorus, it is somewhat cupshaped: thus it is urceolate and entire in Trichomanes (Fig. 214 A), Lygodium, Cyathea, Davallia. When it springs from the apex of the placenta, above the sorus, the indusium has the general appearance of a peltate scale, either orbicular in outline (Aspidium) or reniform (Nephrodium, Fig. $214 D$ ). When it is developed on one side of the sorus, the indusium is a long narrow scale, attached 
along its length, and overlying the sorus (e.g. Asplenium [Fig. 214 $E$ ], Blechnum, Scolopendrium [Fig. 217]). In some cases, where the sori are near the margin, they are protected by a false indusium, which is merely the incurved margin of the leaf (e.g. Cheilanthes, Adiantum, some species of Pteris [Fig. 214 $C$ ]). In Pteris aquilina, and some other species, in addition to the false indusium, there is also a membrane along the inner side of the

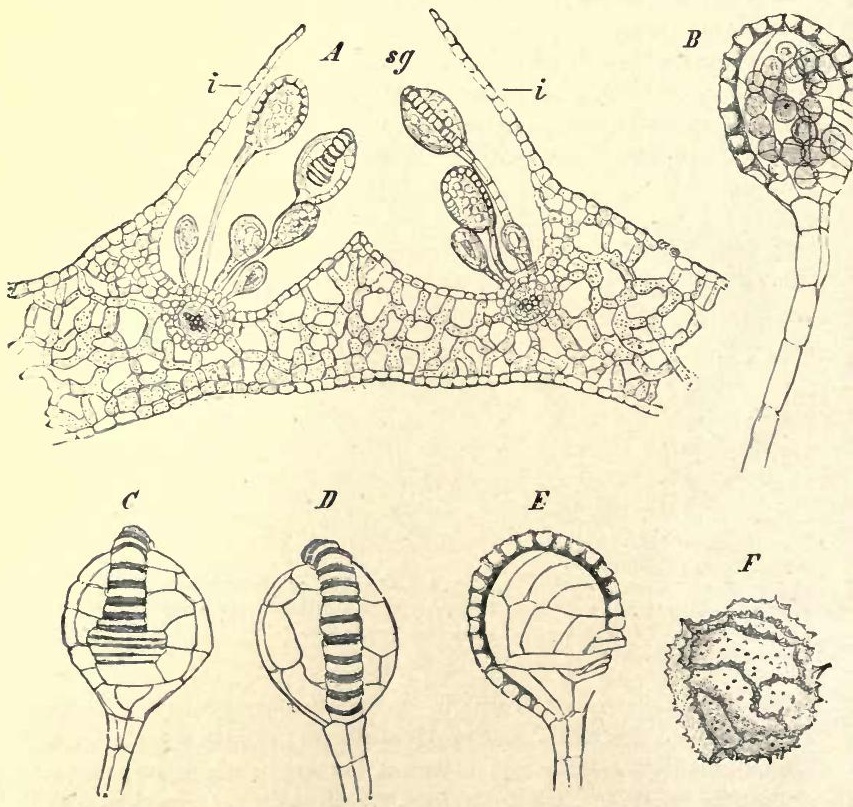

Fia 217.-Scolopendrium vulgare (Hart's-tongue Fern). A Transverse section of \& sorus; $i$ indusinm; $8 g$ sporangis. $B$ - $E$ Sporangis ; $B$ and $E$ seen sideways; $C$ in front ; $D$ from the back; $F$ a spore. ( $A \times 50 ; B-E \times 145 ; F \times 510$ : after Strasburger.)

sorus, which is a kind of lateral indusium, adapted to protect a continuous marginal sorus.

In some forms (e.g. Aspidium Fiiix-mas, Fig. 215) the stalks of the sporangia bear glandular hairs; sometimes eren the sporangia themselves. 
With the possible exception of the Osmundaceæ, each sporangium is developed from a single superficial cell. The cell grows so as to project more or less: it is then divided into two cells-an outer, the mother-cell of the sporangium; an inner, the stalk-cell-by a horizontal wall. As the mother-cell of the sporangium grows, it undergoes division by the successive formation of three oblique walls, intersecting one another below at an angle of about $60^{\circ}$, and reaching above to the wall of the mother-cell; at this stage the sporangium consists of three latero-basal external cells surrounding the pointed lower end of a tetrahedral cell, the spherical base of which occupies the summit of the sporangium. A wall is now formed in the tetrahedral cell, parallel to its spherical free surface, and intersecting the three oblique walls; so that the sporangium now consists of four peripheral cells, forming the wall, and a central cell. From the central cell are cut off, by successive walls parallel to its sides, four cells which give rise to the tapctum by subsequent growth and radial, and sometimes tangential, division; the remaining internal tetrahedral cell constitutes the unicellnlar archesporium from which the spores are derived.

As the young sporangium grows, it gradually assumes its definitive form, which is moșt commonly oval-lenticular: The four primary peripheral cells undergo repeated radial division, and form the wall of the sporangium, which ultimately consists of a single layer of cells with cuticularised walls : a portion of the wall is in all cases developed to form the ring or annulus, by means of which the dehiscence of the sporangium is effected, the walls of which are specially thickened and cuticularised, coloured yellow or brown, and are elastic. The form and position of the annulus varies in the different groups: thns in the Polypodiaceæ (Fig. 217), where the sporangium is attached to the stalk by the margin, the incomplete annulus is a projecting row of cells with their longer axes. transverse, extending round the margin in the plane of the stalk, with which it is connected on one side, but not quite reaching it on the other.

As the development proceeds, the formation of the spores takes place in the interior of the sporangium. The archesporial cell undergoes repeated division, with the result that usually sixteen cells are formed, which are the mother-cells of the spores (Fig. 216). At this stage the tapetal cells undergo disintegration, so that the mass of spore-mother-cells floats freely in the liquid thus produced. Each mother-cell then undergoes division to form four spores. 
The sporangium may be sessile (Gleicheniaceæ, most Schizæaceæ, Hymenophyllaceæ); or shortly stalked (Lygodium, Cyatheaceæ, Osmundacex : or it may have a nsually rather long slender stalk consisting of two or three longitudinal rows of cells (Polypodiaceæ); this is dependent upon whether the originally-formed stalk-cell developes further or not.

The spores are set free by the dehiscence of the sporangium; this takes place at a certain part which, though different in the various forms of sporangia, is always closely connected with the annulus and is termed the stomium (see Fig. 215); dehiscence begins by a split between (not through) the cells of the stomium. In the Polypodiaceæ the plane of dehiscence is at right angles to the long axis of the sporangium, and the stomium is situated on the margin between the end of the annulus and the stalk.

A striking feature in the general morphology of these plants is the presence on the stem and the bases of the leaf-stalks, especially when young, of numerous scaly hairs (ramenta or palea), which consist usually of a single layer of cells, with more or less thickened brown walls; they are of various shape, and frequently have marginal glandular hairs secreting tannin or mucilage, the latter generally in the neighbourhood of a growing-point or stem or leaf. Less commonly, glandular hairs are developed on the leaves, as in species of Gymnogramme (Gold and Silver Ferns), in which the under surface of the leaves is corered with a yellowish dust, consisting of minute needles of resinous and waxy substances, secreted by the hairs. Root-hairs occur on subterranean stems and leaf-stalks.

A primary root is developed, probably in all forms, but in no case does it persist in the adult. In the full-grown plant all the roots are adventitious; they spring in great numbers from the stem or the leaf-stalks. The roots are small and branched; the branching is lateral, and the growing-points of the young roots are developed each from a single cell of the endodermis, termed a rhizogenic cell, situated opposite to a xylem-bundle of the central cylinder. In most cases the growing-point of the ront has a single pyramidal apical cell (see Fig. 86) with three flat sides and a spherical base directed outwards.

Adventitious buds, subserving vegetative propagation, are commonly produced; they arise most frequently on the subterranean portions of leaf-stalks (as in Pteris aquilina, Aspidium Filix-mas), and sometimes, as in Onoclea Struthiopteris, the bud grows into 
a subterranean stolon which eventually throws up at its apex a whorl of green leaves, thus constituting a new plant; but also frequently from the lamina, as in Asplenium (Diplazium) celtidifolium, A. bulbiferum, and other species. The bud originates from a single epidermal cell.

General Histology.-The structure of stem, petiole, and root, is characterised throughout by the presence of hypodermal layers, and, generally, of scattered strands of sclerenchymatous tissue, consisting of more or less elongated ground-tissue cells with more or less thickened brown-coloured walls; and by the predominance of scalariform vascular tissue in the xylem which consists, with but few exceptions, of tracheides.

The stem is, at its first development, monostelic, with a single axile stele: in some forms this structure obtains (with or without pith) throughout the whole stem (e.g. Hymenophyllaceæ, Lygodium, Schizæa): in the Osmundaceæ also the stem is monostelic throughout, the stele eventually consisting of a ring of bundles enclosing a pith: in the other families the stem becomes polystelic.

In the monostelic stem the bundles are sometimes conjoint and collateral (e.g. Trichomanes among Hymenophyllaceæ, Osmundaceæ) : in all other cases the arrangement of the bundles in the stele is concentric, or, more strictly speaking, bicollateral (p. 123), since the phloem does not quite completely surround the xylembundles. The concentric steles are cauline and usually consist of two wood- and two bast-bundles, with usually an endodermis and a pericycle: in some cases, however, where the stele is small (e.g. some species of Polypodium) there is no pericycle, its place being taken by a layer of cells formed by the division of the primitive endodermis (p. 115) into two layers.

In the polystelic stem the course of the steles is such that they form a meshwork, each mesh corresponding to the insertion of a leaf: the bundles of the leaf join those forming the corresponding mesh in the stem. The form of the mesh is determined by the number and insertion of the leaves: when the leaves are numerous and closely arranged, the meshes are relatively short and broad; when the leaves are fow and scattered, the meshes are long and narrow.

In a monostelic stem, such as that of Osmunda, though the bundles are numerous, no such meshwork is formed. The bundles are here common. A single bundle enters the stem from each leaf, runs straight through several internodes, and then curves to join 

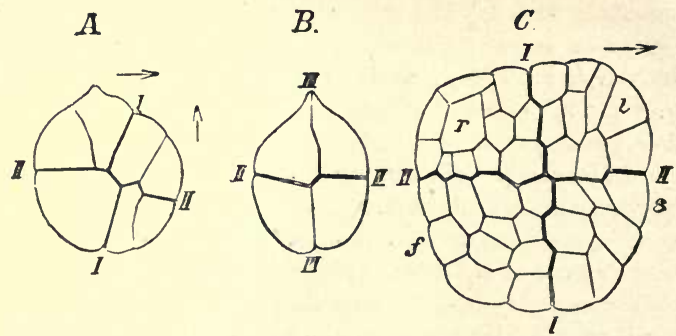

Fig. 218.--Embryogeny of the sporophyte of Pteris ssrrulata ( $\times 235$ : after Kienitz-Cerloff). $A$ In longitudinal section : $B$ transverse section, at right angles to the preceding : $C$ older embryo in longitudinal section. The vertical arrows indicate the long axis of the archegonium, pointing to the neck : the horizontal arrows indicate the longitudinal axis of the prothallium, pointing to its organic apex. I-I Basal wall; II-II transverse wall; III-III median wall : $r$ apical cell of root; $l$ apical cell of cotyledon; $s$ apical cell of stem; $f$ foot.

with the bundle of an older leaf, seven leaves intervening between the two.

Embryogeny of the Sporophyte. The sporophyte is developed from the fertilised female cell, the oospore: the development has only been studied in species of Polypodiaceæ, and has been found to be as follows. The oospore is first of all divided into two cells

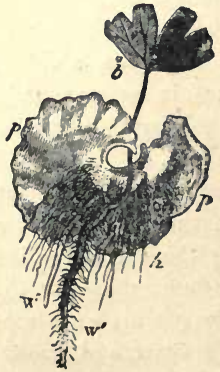

F16. 219.-Adiantun Capillus. Veneris. The prothallium $(p p)$ seen from below with young Fern attached to it by its foot ; $b$ its first leaf or cotyledon; $w^{\prime}$ its primary, w" secondary, roots; $h$ root-hairs of the prothallium (x about 3). (After Sachs). by the formation of a wall, the basal vall, which nearly coincides with the long axis of the archegonium: a second wall is then formed, the transverse vall, at right angles to the preceding, with the result that the spherical embryo now consists of four cells or quadrants : then a third wall, the median uall, is formed in a plane at right angles to both the preceding walls, the embryo now consisting of eight equal cells or octants. Of these octants, four belong to one half of the embryo, which is termed the epibasal half; and four to the other half, the hypobasal half: from these octants the primary organs of the sporophyte are developed. Beginning with the four epibasal octants, the two apical octants (i.e. nearest to the neck of the arche- 
gonium) give rise to the growing-point of the first leaf or cotyledon: of the two deeper (towards the venter of archegonium) octants, the one constitutes the growing-point of the stem, whilst the other gives rise to nothing beyond possibly some hairs. Of the four hypobasal octants, one of the two apical octants gives rise to the growing-point of the primary root, which is diametrically opposite to the growing-point of the stem; whilst the other gives rise to no special member: the two deeper hypobasal octants give rise to the embryonic absorptive organ, the foot. The gradual development of these members is dependent upon growth and corresponding cell-division, and at an early stage histological differentiation into cortical and stelar tissues is apparent in them. For a time the tissue of the venter of the archegonium keeps pace by growth with the increasing size of the embryo: but eventually the primary root and the cotyledon become free, and ultimately also the stem (Fig. 220). In the meantime the embryo is

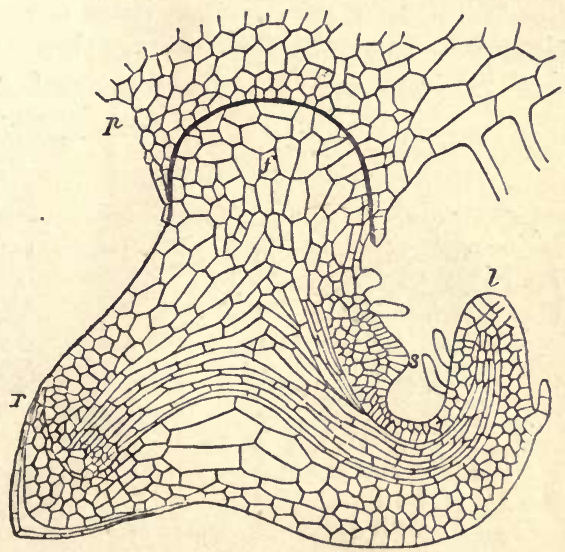

Fig. 220. - Section of young plant of Pteris aquilina still attached to the prothallium by its foot: $p$ prothallium; $f$ foot; $r$ primary root; $s$ growing-point of primary stem; $l$ primary leaf or cotyledon. (Magnified : after Hofmeister.)

nourished by means of the foot which has become a mass of tissue filling the venter of the archegonium : it absorbs from the adjacent cells the organic substances formed in the prothallium by means of the chloroplasstids which most of the cells contain. The primary root and the cotyledon are both small and short-lived: the former is succeeded by the numerous adventitious roots, the latter by the true foliage-leaves. The foot is a merely embryonic organ : it disappears when the young sporophyte has become firmly attached 
to the substratum, and is capable of independently absorbing and assimilating food.

Gametophrte. The gametophyte is a prothallium, always containing chloroplastids, generally a dorsiventral, flattened, cellular expansion, or sometimes filamentous, which is developed from a spore, but which becomes completely free from the spore. In the dorsiventral prothallium the reproductive organs, as also the root-hairs, are confined to the inferior (ventral) surface.

The prothallium is typically monøcious: the male organs, or autheridia, are developed first, and are consequently situated towards the posterior or basal end of the prothallium; the laterformed archegonia lie towards the anterior or apical end. It sometimes happens, however, that, owing to imperfect nutrition, the growth of the prothallium does not proceed beyond the stage

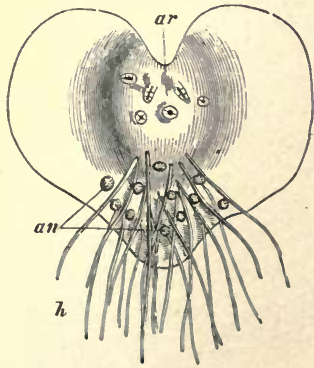

Fie. 221.-Dirgram of the prothallium of a Leptosporangiate Fern : under side ( $\times 10)$. or Archegonia; an antheridia; $h$ root.hairs.

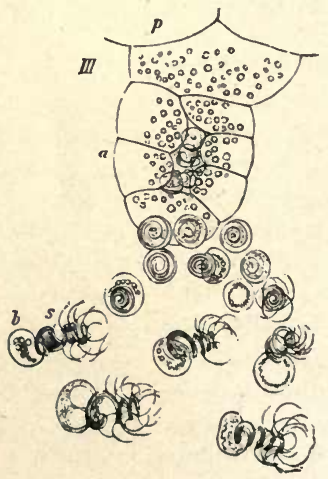

Fig. 222. - Antheridium of Adiantum Capillus.Veneris $(\times 550) . \quad p$ Prothallium; $a$ sntheridium; 8 spermatozoid; $b$ the vesicle containing starch-grains.

necessary for the formation of the antheridia, so that exclusively male prothallia may be sometimes found; less commonly, wellnourished prothallia fail to produce antheridia, and consequently exclusively female prothallia are found. The practical result of this successive formation of the antheridia and archegonia is that but few of them can possibly mature at the same time on one and the same prothallium; and, consequently, cross-fertilisation is almost certainly ensured. 
The development of the prothallium commences with the rupture of the outer coat (exospore) of the germinating spore, which takes place either along three lines meeting at an angle, when the spore is tetrahedral, or by a longitudinal slit when the spore is bilateral, the contents covered by the inner coat (endospore) being exposed. Most commonly this cell grows out into a filament, cell-divisions taking place in the transverse plane only, so that the prothallium consists of a longitudinal row of cells. At length a longitudinal wall is formed in the terminal cell of the filament; cell-division then proceeds in two planes, giving rise to a flattened plate of cells, further growth being effected by means of a two-sided apical cell. After a time the activity of the apical cell ceases, a periclinal wall being formed in it; whatever further growth takes place is effected by the marginal cells. At this stage the prothallium becomes somewhat heart-shaped, the anterior depression indicating the posi-

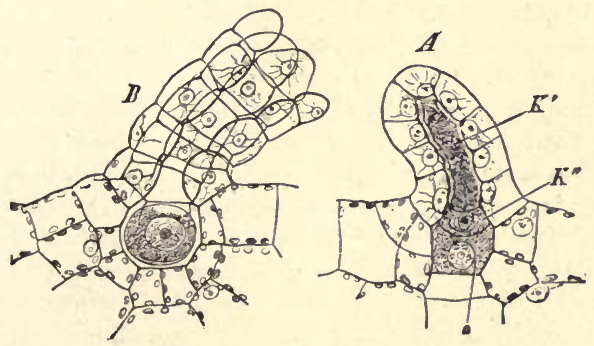

F10. 223.-Polypodium vulgare. $A$ Young archegonium, not jet open: $K^{\prime}$ neck-canalcell; $K^{\prime \prime}$ ventral canal-cell : o young oosphere. B Mature archegoniam open. ( 240 after Strasburger.)

tion of the organic apex (Fig. 221). The cells lying anteriorly in the middle line now begin to divide in a plane parallel to the surface, with the result that the prothallium becomes thickened in this region, and eventually a "cushion" of tissue, several layers of cells in thickness, is produced, which projects on the lower (ventral) surface, and bears the archegonia.

The sexual organs. The antheridium is developed from a single superficial cell. The free surface of this cell grows out into a blunt protuberance, which is cut off by a transverse wall. The projecting cell thus formed generally undergoes division by the formation of a transverse wall near its base, so that it comes to

M.B. 
consist of two cells, the lower of which is the stalk-cell, the upper, the antheridial cell. The latter grows, becoming more or less spherical, and undergoes repeated cell-divisions which result in the formation of a wall, consisting of a single layer of cells, surrounding a large central cell from which, by further division, the mother-cells of the spermatozoids are formed. When mature, absorption of water causes the rupture of the antheridium; the mother-cells of the spermatozoids are now set free, and the spermatozoids soon escape from the mother-cells as coiled ciliated filameuts, each having usually attached to it posteriorly a vesicle of granular protoplasm, the remains of the contents of the mothercell (see Fig. 222).

The archegonium. The general description given above (p. 351) of the development and structure of the archegonium, and of the process of fertilisation, will suffice for this group of the Pteridophyta. It should, however, be mentioned that only a single neckcanal-cell is developed.

The root-hairs retain in all cases their typical unicellular structure. They arise as tubular outgrowths from single cells, having, at first, colourless walls, which eventually become thickened, and assume a brown colour; the cavity of the hair is cut off by a septum from that of the cell from which it springs; their form is most commonly elongated and cylindrical, but sometimes (e.g. Hymenophyllaceæ) they are short and slightly branched. The development of the root-hairs begins at the earliest stage in the formation of the prothallium. Generally speaking, the roothairs are developed laterally, and as the prothallium assumes the flattened expanded form, the development extends inwards from the margin, over the inferior surface, and forwards as far as the posterior part of the cushion.

The life of the gametophyte is, as a rule, short, being limited by the fertilisation of an archegonium. If, however, fertilisation does not take place, the prothallium continues to grow for several months, or even years in the case of Osmunda.

Propagation of the gametophyte by means of a gemmæ is common in the Hymenophyllaceæ, but it has also been observed in certain Polypodiaceæ (Vittaria, Monogramme). In Hymenophyllum, the gemmæ are small flat plates of cells; in species of Trichomanes, Vittaria, and Monogramme, they are short spindle-shaped filaments, consisting of a single row of (6-9) cells, borne on a unicellular stalk or sterigma ; in Trichomanes, the gemma is attached at its 
centre to the stalk, so that its long axis is at right angles to the stalk; in Vittaria and Monogramme, the gemma is attached to the stalk by one end. The sterigmata are developed either singly or several together, from a single cell of the prothallium; and the gemmæ may be borne singly or several together on one sterigma.

It will have been observed that the gametophyte of the homosporous leptosporangiate Ferns presents, in its development, its root-hairs, its propagation by gemmæ, remarkable and suggestive resemblances to the gametophyte of the Hepaticæ. In the general morphology, too, of the gametophyte, there are striking correspondences between the two groups: thus, in both groups (with certain exceptions in both) the first stage in the life of the gametophyte is a filamentous protonema, which is, however, relatively small and short-lived, except in the Fern Trichomanes where the gametophyte does not develope beyond the protonematous stage. The protonema in both groups gives rise to a single flattened, expanded shoot, the adult sexual shoot of the Hepaticæ, the prothallium of the Ferns, bearing the sexual organs.

Order 1. Hymenophyllaceæ; this order contains the simplest forms The leaf-blade almost always consists of a single layer of cells; the sorus is always marginal (Fig. $214 A$ ) and indusiate, the sporangium sessile or shortly-stalked, and the annulus entire and horizontal.

Almost all the species are tropical. Trichomanes radicans and Hymenophyllum Tunbridgense and unilaterale (or Wilsoni) alone occur in Britain. Some species of Trichomanes have no true roots.

Order 2. Polypodiaceæ. The annulus of the stalked sporangium is incomplete and vertical (Fig. 215 r), that is to say, it is not continuous at the base: indusium present or absent. Almost all our native Ferns belong to this order, which is exceptionally rich in genera.

The following are the chief families :-

(a) Pteridece. Sori coalescent along the margin of the leaf (Fig. $214 \mathrm{C}^{\prime}$ ), with a spurious indusium. Pleris (Pteridium) aquilina, the Bracken, has a stem which grows at some depth below the surface of the soil, and throws up every year a single large, much-segmented leaf (frond): it has also a true lateral indusium. Adiantum, the Maiden-hair Fern, belongs to this group, as also Cheilanthes.

(b) Aspleniece. The sorus, which is situated on the under surface of the leaf, is elongated or linear, and the lateral indusium springs from the vein to which it is attached (Fig. 214 E). Aspienium Ruta muraria, the WallRue, is not uncommon on walls and rocks; $A$. Trichomanes is also abundant, with simple pinnate leaves and a shining black rachis. Athyri:m Filix fomina, the Lady Fern, is common in damp woods. Scolopendrium vulgare, the Hart's-tongue, with entire leaves, is common in damp hedgerows and woods (Fig. 217). Blechnum (Lomaria), the Hard Fern, as also 
Ceterach, may be included here, though the indusium may be rudimentary or absent.

(c) Aspidiex. Sorus on the lower surface of the leaf, orbicular in form and coverel by a peltate or reniform superior (Fig. $214 \mathrm{D}$ ) or inferior indusium. Nephrolium (Lastraca) Filix mas, the male Fern, and other species resembling it, with a thick tufted crown of leaves, are not rare in wools. Aspidium is the Shield-Fern: A. (Polystichum) Lonchitis is the Holly-Fern : Woodsia, Onoslea, and Cystopteris (Bladder-Fern), with an inferior indusium, also belong to this group.

(d) Polypodiece. The sorus, which is on the under surface of the leaf, is naked (Fig. 214 F). In the section Polypodium the leaves are articulated to the stem, so that when they die and fall off they leave a roundish scar : the leaves are usually borne in two rows on the dorsal surface of the rhizome. Polypodium vulgare, with simple pinnate leaves, is common on tree-trunks, rocks, etc. In the section Phegopteris the leares are not articulated to the stem, so that when they die, fragments of the leaf-stalks remain attached to it: Cryptogramme crispa is the Parsley-Fern: Phegopteris Diryopteris and polypodioides are the Oak- and Beech-Ferns.

Order 3. Cyatheaceæ. Distinguished from the Polypodiaceæ only by the presence of a complete annulus.

The Tree-Ferns belong to this family. Cibotium and Dicksonia have marginal sori with two-valved inferior indusia: Cyathea, Hemitelia, and Alsophila have their sori on the under surface of the leaf: Alsophila alone has no indusium; in Cyathea it is cup-shaped, and in Hemitelia onevalved.

Order 4. Gleicheniaceæ, including the genus Gleichenia with a horizontal annulus; no indusium : all tropical.

Order 5. Schizæaceæ, including the genera Schizæa Aneimia, Mohria and Lygodium, with a projecting apical annulus to the almost sessile sporangium, occur only in the tropics. Lygodium is the most remarkable genus; its piunate leaves grow to a great length, and twine round supports by means of their midribs: it alone has an indusium, and the sorus is usually unisporangiate.

Order 6. Osmundaceæ. The shortly-stalked sporangia have a rudimentary annulus consisting of a group of cells just below the apex; they burst open by a longitudinal slit on the side opposite to this.

Osmunda regalis, the Fern-Royal, is a not very common but well-known Fern. Only the upper pinnæ of the leaves are fertile, and develope little or no mesophyll; the sori are marginal, and consist of a great number of sporangia; they have no indusium. The only other genus is Todea, belonging mainly to Australasia. 


\section{HETEROSPOROUS LEPTOSPORANGIATA.}

(Hydropterideæ or Rhizocarpæ.)

This group includes the four genera, Salvinia, Azolla, Marsilea, Pilularia; of these the two former constitute the order Salviniacere, the two latter the order Marsileaceæ. They are all more or less aquatic in habit, Salvinia and Azslla being free-floating fugacious plants, whilst Marsilea and Pilularia are perennials growing in bogs and marshes.

SPOROPHYTE.-The stem is a horizontal dorsiventral rhizome. It generally bears foliage-leaves in alternating longitudinal rows (four rows in Salvinia ; two rows in the other genera) on the dorsal (superior) surface; and roots in one (Marsileaceæ) or two (Azolla) longitudinal rows on the ventral (inferior) surface. In Salvinia, however, there are no roots, but the stem bears in place of them two rows of submerged leaves on its ventral surface. The lateral branches, sometimes very numerous, are borne on the flanks.

The foliage-leaf presents a considerable variety of form. In Salvinia it is broad and flat, sessile and entire, with a wellmarked midrib; in Azolla the leaf is small and two-lobed, the lower lobe being submerged, whilst the upper floats on the surface of the water: in Marsilea the leaf has a long erect petiole bearing a paripinnate bijugate compound lamina of four leaflets: in Pilularia the leaf is cylindrical and erect.

Circinate vernation obtains in the Marsileacer, but not in the Salviniaceæ: in Salvinia the vernation is conduplicate, and in Azolla the lamina is expanded from the first.

In Salvinia the leaves are borne in a whorl of three at a node, two being a pair of opposite foliage-leaves, and the third a submerged leaf (p. 17); in the other genera the phyllotaxis is alternate.

The submerged leaf of Salvinia consists of a number of long filamentous branches, springing from a short petiole, and densely covered with multicellular hairs.

The sporangia are of two kinds, microsporangia and macrosporangia: they are borne in sori enclosed in structures termed sporocarps. The morphology of the sporocarp is, however, altogether different in the two orders, and the same term ought not to be applied to both: it would be well to restrict the term "sporocarp" to the more complex fructifications of the Marsileaceæ. 
In the Salviniaceæ the so-called sporocarp is simply a sorus of sporangia, either microsporangia or macrosporangia, but not both, surrounded by an inferior indusium (Fig. 224). In Salvinia the sori are borne at the apices of the basal branches of a submerged leaf, and may be comparatively numerous (4-20) on one leaf: in Azolla the sori are borne at the apices of the segments of the lower (rentral) submerged lobe of a leaf, and that leaf is always the first (basal leaf of a fertile branch which is sometimes less vigorously
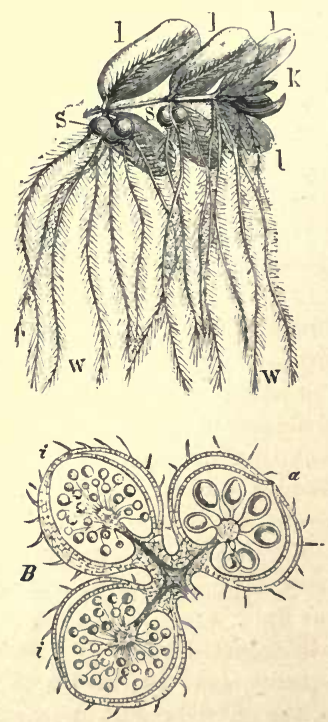

Frg. 224.-A Apical portion of the stem of Salvinia natans, seen cbliquely from below (nat. size) : $l \imath$ aerial leaves ; $v v$ aquatic leaves, with sori, ss; $k$ terminal bud of the stem. $B$ Longitudinal section through three fertile teeth of an aquatic leaf $(\times 10)$, forming two sori with microsporangia, (a) one with macrosporangia; $i$ indusium. (After Sachs.)

In the Marsileacer the sporocarp consists of a leaf-branch enclosing a number of sori, and each sorus includes both micro-and macrosporangia. In Marsilea the fertile leaf-branches spriug from developed than the purely vegetative branches; each leaf usually bears only two sori, but in $A$. nilotica there are four. In Salvinia the sori are all of the same size, whereas in Azolla the sori containing microsporangia are considerably larger than those containing macrosporangia. In both genera the tip of the fertile leaf-segment expands into a cellular cushion, the placenta, from the superficial cells of which the sporangia are developed : the indusium is developed as an annular outgrowth from the base of the placenta, becoming cupshaped, and eventually closing over the sorus : it consists of two layers of cells which, in Salvinia, are separated by large air-chambers and are connected by longitudinal cellular trabeculæ. In both genera the microsporangia of a sorus are numerous (about 40 in Azolla, more in Salvinia): the macro-sporangial sorus consists, in Salvinia, of many (up to 25) macro-sporangia, whereas in Azolla there is but one. Both kinds of sporangia are borne by the same plant. 
the ventral surface of the petioles of the foliage-leaves (compare Ophioglossaceæ), and each bears a sporocarp at the end of a longer or shorter stalk: the petiole bears a single fertile leaf-branch near its base in some species, or two or more adnate branches springing from the same point; or it bears (e.g. M. polycarpa) a series of $10-$ 20 branches, one above the other, each bearing a single sporocarp. In Pilularia the fertile leaf-branches appear to be also developed from the ventral surface of the foliage-leaves : each leaf has at its base a single almost sessile sporocarp.

The sporocarp of Marsilea (Fig. 225) is dorsiventral, somewhat pod-shaped, with its dorsal margin directed upwards; the stalk is continued along the dorsal margin as a midrib: the sporocarp may, in fact, be regarded as being developed from the laminar portion of the leaf-branch. The sporocarp of Pilularia is globular, though it is slightly pointed at the apex : it may be likewise regarded as being a leafbranch, four (usually) leaflets or segments being concerned in its construction. In both genera, especially in Marsilea, the wall of the sporocarp is composed of several layers of cells with thick hard walls: vascular bundles, springing from the stalk, are distributed in the wall.

The number of sori in the sporocarp of Marsilea varies from five to twenty-three in the different species : they are developed in tubular cavities, extending from the ventral margin of the sporocarp for some distance towards the dorsal margin, which are disposed in two longitudinal rows, one row on each side of the middle line; when young, these cavities are open at the ventral

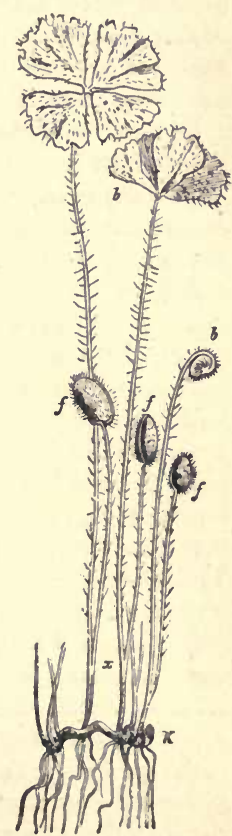

Fre. 225.-Stem of Marailea Salvatrix with leaves (reduced one-half). $K$ Terminal bud; $b$ b lesves; $f f$ sporocarps borne on petioles. margin, but the apertures become closed as the sporocarp matures; the external wall of each cavity developes into a projecting ridge of tissue, the placenta, which bears the sorus, consisting of a single median row of macrosporangia and a double row of microsporangia 
on each flank. The cavities are surrounded by parenchymatous tissue.

The globular sporocarp of Pilularia contains four (sometimes two or three) cavities, extending longitudinally from the base to the apex, enclosed by parenchymatous tissue. The placenta is a ridge of tissue on the external wall of the cavity, bearing the sorus which consists, in its upper part, of microsporangia, and in its lower of one or more macrosporangia. The cavities at first communicate with the onter air at the apex of the sporccarp, but eventually become completely closed.

In their development, the sporangia of the Heterosporous Leptosporangiatæ resemble those of the Homosporous Leptosporangiatæ (see p. 363) in all essential points : but no annulus is developed. In each sporangium sixteen spore-mother-cells are developed from the single tetrahedral archesporial cell, and each of these mother-cells undergoes division to form four spores: but whereas in the microsporangia all these sixty-four spore-rudiments develope into microspores, in the macrosporangium only one developes into a macrospore, the others being abortive.

The development of the spores in this group, is remarkable on account of the important part played by the multinucleate protoplasmic mass (epiplasm), derived from the disorganisation of the tapetal cells, in which the free spore-mother-cells are embedded at the time when the development of the spores is commencing. Taking first the Salviniaceæ: the microsporangium of Salvinia contains, when mature, a number of microspores embedded in a spongy mass of a substance, which gives some of the reactions of corky cell-walls and is derived from the protoplasm of the tapetal cells: in Azolla the microspores are likewise embedded in this substance, but in more than one group or massula (2-8) according to the species; each massula is surrounded by a membrane, bearing in some species a number of anchor-like hairs, the glochidia. In Salvinia the macrospore also is invested by a layer of this spongy substance, constituting the epispore or perinium. This is also the case in Azolla, but here the perinium is remarkably developed: over the rounded dorsal surface of the radial macrospore, the perinium is a thick membrane, firm at the surface, spongy within, with warty projections bearing filaments of the same substance: on the three flattened surfaces of the ventral aspect of the macrospore the perinium forms three or more large spongy masses which constitute the so-called floats of the spore; at the pointed apex of the spore, 
between these masses, the perinium usually terminates in a tuft of delicate filaments.

In the Marsileaceæ the spores become invested by a perinium, secreted by the epiplasm, consisting of an inner layer made up of prisms placed with their long axes perpendicular to the surface of the spore, and of an outer layer which is homogeneous in the case of the microspore; but in the case of the macrospore it is stratified, swells up enormously on being wetted, and gives the cellulosereaction.

In all cases the spore has its own proper coats, the exospore and the endospore, of the usual constitution. It contains a mass of granular protoplasm, with a nucleus, and encloses numerous starchgrains, oil-drops, and proteid granules.

The root is altogether absent in Salvinia; in the other genera the primary root is of but short duration, and the root-system consists of numerous adventitious fibrous rootlets which have an apical growing-point with a tetrahedral apical cell. In Azolla the rootcap is but imperfectly developed, and in A. caroliniana it is completely thrown off after a time.

General Histology. In the Salviniaceæ the stem is monostelic ; in the Marsileaceæ it is polystelic.

On the whole the histology of these plants generally resembles that of the allied homosporous Ferns, though in consequence of their more or less aquatic habit the intercellular spaces of these plants are more conspicuous, especially in Salvinia and in the root of Pilularia where they form large air-chambers.

The Embryogeny of the Sporophyte. The early divisions of the oospore are essentially the same as in the allied homosporous Ferns. The individual peculiarities of subsequent development are briefly as follows. In Salvinia the whole of the hypobasal half goes to form the foot, no primary root being developed; of the four epibasal octants, one gives rise to the growing-point of the stem, and two to that of the first leaf or cotyledon, and from the basal region of these octants a transverse layer of cells is cut off which eventually elongates forming a cylindrical hypocotyl, sometimes termed the caulicle; the cotyledon is termed the scutiform leaf on account of its form and mode of attachment; the young stem first produces one or two isolated foliage-leaves, and then the regular development of the whorls of two foliage-leaves and one water-leaf (see p. 373) begins. In the other three genera, two of the epibasal octants give rise to the first cotyledon, one to the growing-point of 
the stem, and the fourth to a second cotyledon, so that here there are two cotyledons : the hypobasal octants give rise to foot and root in the usual manner.

The Ganetophyte. As these plants are heterosporous, the gametophyte is represented by distinct male and female individuals : these remain connected with the spores producing them.

The male individual is developed from a microspore: it consists of a rudimentary prothallium, represented by a single cell, bearing a single male organ (antheridium).

In Salvinia the germination of the microspores takes place within the microsporangium; the inner coat (endospore) of the spore grows oit as a longer or shorter tube through the ruptured outer coat (exospore), and eventually makes its way through the wall of the sporangium so that its free end is in the water outside : a transverse wall is formed within it which cuts off the apical portion of the tube as the fertile portion of the prothallium.

In Azolla the microspores germinate within the massula. The exospore of the tetrahedral spore ruptures along the three edges, and the endospore protrudes as a papilla at the apex. A transverse wall is formed across the base of the papilla, which now becomes the mother-cell of the single antheridium. The spermatozoids probably escape from the massula on the deliquescence of its substance.

In the Marsileaceæ the-male prothallium is formed altogether within the microspore; the spore divides iuto two cells : a small basal vegetative cell and a larger one which is the mother-cell of the antheridium. In all cases the prothallium has no chlorophyll.

The male organ, or antheridium, is developed from the antheridial mother-cell mentioned above. It generally undergoes divisions so as to form a central cell surrounded by a single layer of cells forming the wall of the antheridium. But Salvinia is peculiar in that the central cell of each antheridium is not completely surrounded by a parietal layer of cells, but comes to the surface of the antheridium. The central cell then undergoes further divisions to form the mother-cells of the spermatozoids, of which there are eight in the Salviniaceæ and thirty-two in the Marsileaceæ.

The male cells are spermatozoids, which resemble those of the homosporous leptosporangiate Ferns in all essential features of their form and development, as also in their extrusion from the antheridium. In the Marsileaceæ, the male prothallium is enclosed within the microspore until the antheridium is mature, when the 
spore-walls are ruptured by the swelling of the cells of the contained prothallium, and the spermatozoids are set free.

The female individual is a small multicellular prothallium of a green colour, and is developed from a macrospore to which it remains attached. The development of the prothallium begins inside the macrospore at its pointed apical end, where there is an aggregation of protoplasm in which the nucleus lies. The nuclens divides, and this is followed by the formation of a cellwall between the two nuclei, cutting off the apical portion of the spore, as a small cell, from the basal larger portion; this first wall is termed the diaphragm, and it marks off that portion of the macrospore which gives rise to the prothallium from that portion which takes no part in the process. The small cell then undergoes repeated division to form the prothallium which consists, in the Salviniaceæ, of several layers of cells (at least in the middle region), and in the Ziarsileaceæ of two layers only. As the prothallium developes, the coats of the macrospore split into three valves at the apex, so that now the prothallium is in direct relation with the exterior. Whilst in the Marsileaceæ the prothallium projects but little from the spore, in the Salviniacer (especially Salvinia), where it is larger, the greater part of it is outside.

No cell-formation takes place in the larger basal portion of the macrospore below the diaphragm, though nuclear division has been observed in Azolla. This eventually becomes filled with

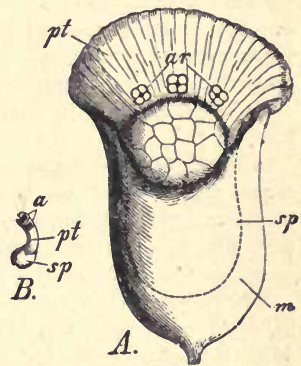

Fig. 226.-Gametophyte of Salvinia $(\times 60)$. A Macrosporanginm $m$ with a germinated macrospore $s p$ (dotted ontline); pt female prothallinm projecting from the apex of the spore; ar archegonia, B A microspore isolated from a microsporangium; $8 \rho$ spore; $p t$ male pro. thallium; $a$ antheridia.

starch and other nutritive substances for the nutrition of the embryo.

The female organ, or archegonium, differs in no essential feature of structure or development from that of the homosporous leptosporangiate Ferns. In the Marsileaceæ, only a single archegonium is developed; it arises from a cell in the middle of the upper surface of the prothallium: in Azolla, if the archegonium does not become fertilised, a few more archegonia may be subsequently developed : in Salvinia, at least three archegonia are always formed, 
the first anteriorly in the middle line, the second and third one on each side of the first. If none of these become fertilised, the prothallium resumes its growth both in breadth and length, and a second row of archegonia is formed in front of the first. Similarly a third and a fourth row, with an increased number of archegonia in each (seven or more), may be successively produced. In Pilularia also the prothallium grows to a considerable size if the archegonium is not fertilised, though no more archegonia are formed.

The female rell, or oosphere, developed in each archegonium, does not require any special description.

Order 7. Salviniaceæ : microsporangia and macrosporangia in distinct sori, each sorus being covered by an indusium; the spores are surrounded by spongy mucilage, forming an episporium or perinium round the individual macrospores, and holding all the microspores together within the sporangium (Salvinia) or in several groups or massulæ (Azolla); the female prothallium is relatively large and bears several archegonia.

No species of Azolla is European: Salvinia natans occurs in Southern Europe.

Order 8. Marsileaceæ: microsporangia and macrosporangia in the same sorus, a number of sori being enclosed in the specially modified sporophyll-segment, the whole forming a sporocarp; each spore is invested by a mucilaginous prismatic perinium: the female prothallium is relatively small, and bears but a single archegonium.

Pilularia globulifera is the one British species belonging to this order. The European species of Marsilea are M. pubescens, which occurs in the Mediterranean region, and $M$. quadrifoliata, in Central Europe.

\section{CLASS VI. EQUISETINE.}

This class includes, among existing plants, only the homosporous order, Equisetaceæ; but there are many extinct fossil forms, some of which are undoubtedly heterosporous.

Order 1. Equisetaceæ. This order includes the single genus Equisetum (Horsetail). Of the twenty species of this genus, about half are British ( $E$. arvense, maximum, silvaticum, palustre, limosum, hyemale, trachyodon, variegatum, pratense, litorale).

The Sponophyte. The stem consists of a horizontal, subterranean, muchbranched rhizome; some of the branches come to the surface, and are the sub-aerial shoots. The rhizome and its branches are very distinctly seg- 
mented into nodes and internodes. At each node is borne a whorl of scaleleaves forming a continuous sheath. The branches, as also the adventitious roots, spring from the nodes, a bud being developed in the axil of each leaf, and an adventitious root from the base of each bud; but in the sub-aerial shoots the rudimentary roots do not grow out, whilst in the subterranean shoots relatively few of the buds grow into branches. In certain species (E. arvense, silvaticum, maximum, palustre, etc.) some of the subterranean branches become tuberous.

The sub-aerial shoots generally live for one season only, and are herbaceous in texture, but in some species they persist (e.g. E. hiemale, trachyodon, variegatum). They are generally green in colour, and their surface is more or less strongly ribbed. Some of these shoots aresterile, whilst others are fertile, bearing the sporangia. In most species the sterile and fertile shoots are alike (Equiseta homophyadica), but in the four species $E$. arvense, maximum, silvaticum, pratense (Equiseta heterophyadica) they are more or less widely different. Thus in $E$. arvense and maximum, the fertile shoots are developed early in the spring, and are unbranched, whereas the copiously branched sterile shoots are not developed till the summer; moreover the fertile shoots are not green. In $E$. pratense the difference between the

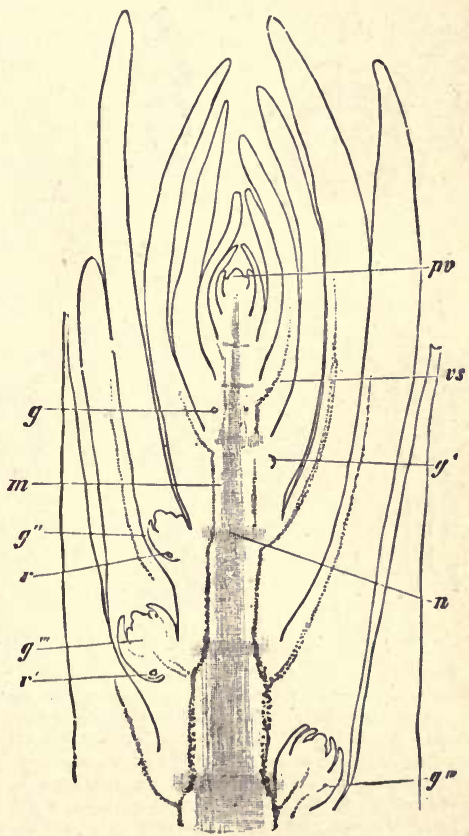

Fra. 227. Median longitndinal section of the aplcal portion of a vegetative shoot of Equiset um arvense; pv apical growing-point; $g$ bud-rudiment; $g^{\prime}-g^{\prime \prime \prime}$ stages in the development of lateral buds; $r$ developing adventitious roots on the buds; $m$ central ground tissue; vs developing (common) vascular bundle; $n$ nodal diaphragms. ( $\times 26$ : after Strasburger)

fertile and sterile shoots is less marked, the former bearing a few whorls of simple branches. In $E$. silvaticum the fertile shoot has no branches at first, but after the shedding of the spores the terminal cone dies off, the 
shoot throws out branches, and thus comes to be a sterile shoot. In some species the sub-aerial shoots are generally unbranched (e.g. E. hiemale trachyodon, variegatum).

The leaves are either cataphylls or sporophylls. The catophylls, representing the foliage-leaves, are borne in whorls at the nodes, baving a common attachment, so that they form a leaf-sheaf at each node. They are sinall and brown in colour.

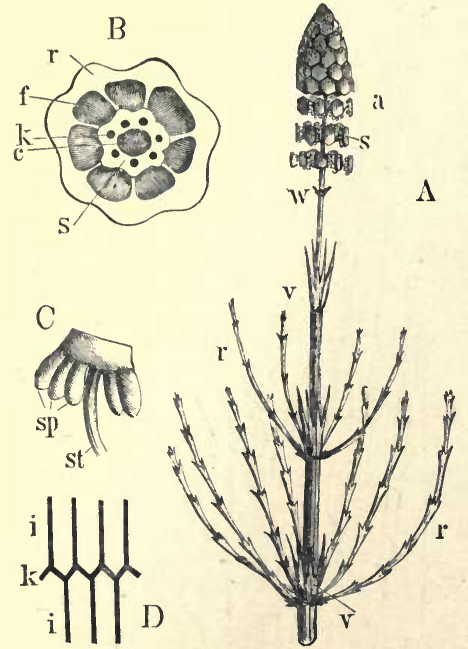

FrG. 228. -A Upper portion of a fertile branch of Equisetum palustre. v Leaf-sheaths, below which the branches $(r)$ spring; $w$ the uppermost sterile sheath (ring); $a$ the flower; 8 the peltate sporophylls. $B$ Transverse section of the stem $(\times 6)$ : c central cavity; 8 the vascular bundles arranged in a circle, each having a carinal cavity, $k$; $f$ the vallecular cavities; $r$ the ridges. C Sporophyll with sporangia $(\times 10): s t$ the stalk; $s p$ the sporangia. D Diagram of the course taken by the vascular bundles where two internodes meet; $i$ i the internodes; $k$ the node.

The sporophylls, like the cataphylls, are developed in whorls, but owing to the fact that the internodes between the whorls do not elongate, the sporophylls are aggregated into a cone-like flower situated terminally on the shoot (Fig. 228), or less commonly (e.g. E. palustre) on some of the lateral branches. The leaf-sheath below the cone, marking off the reproductive from the vegetative region of the shoot, is peculiar, being generally very much reduced, and is termed the ring (see p. 57).

Each sporophyll has a small hexagonal lamina which is inserted on the axis of the cone by a short stalk attached to the centre of the inner surface of the lamina. Thus the sporophyll is peltate. It bears on its inner (dorsal) surface a small number (5-10) of sporangia arranged round the leafstalk.

The sporangia are somewhat elongated in form, and are sessile. The wall of the sporangium consists of a single layer of cells with spiral thickening. Dehiscence takes place longitudinally on the side facing the leaf-stalk. The archesporium is usually a single cell from which are derived the mother-cells of the spores, each of which give rise to four spores.

The spores, which are all of one kind, are developed tetrahedrally, but 
are nearly spherical when ripe. Each spore has two coats, exospore and endospore, and originally a perinium is present. The perinium, as it developes, becomes irregularly thickened in such a way that, when the thin portions are destroyed, the thickened portions remain as four filaments, the elaters, all attached at one point only to the spore. These elaters are very hygroseopic. When the air is dry they expand, and stand out stiffly from the spore; when moistened, they suddenly roll up spirally round the spore. The spores become entangled by their elaters, so that when set free from the sporangium a number of the spores fall to the ground and germinate near together.

The roots are all adventitious, though a short-lived primary root is developed. They are developed at the nodes of the rhizome.

\section{General Histo-} logy. A striking feature in the anatomy of the stem is the presence of large, mainly lysigenous, air-cavities: thus, in some species, the rhizome has a large central cavity in each internode (Fig. $230 \mathrm{C}$, a); a similar cavity is present in the internodes of the aerial shoots of nearly all the species (Fig. $230 A, a$ ); the central cavities of successive internodes are

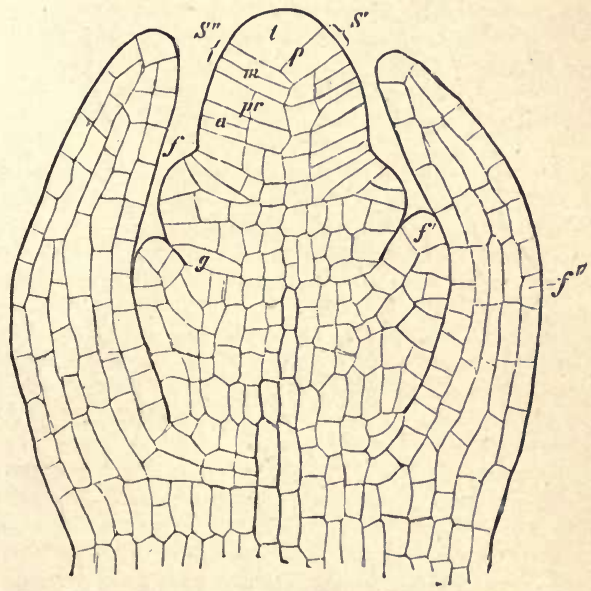

Frg. 229.-Growing-point of the stem of Equisetum arvense, in longitudinal section; $t$ apical cell; $s^{\prime} s^{\prime \prime}$ successive segments; $p$ anticlinal segment-wall; $m$ wall dividing the segment into an upper and a lower cell; pr periclinal wall dividing the segment into an inner and an outer cell ; $f f^{\prime} f^{\prime \prime}$ successive whorls of leaves ; $g$ initial cell of a lateral bud. (After Strasbnrger: $\times 240$.)

shut off from each other by diaphragms at the nodes (Fig. $227 n$ ): a series of similar eavities occurs always in the cortex, alternating with the vascular bundles internally and with the surface-ribs externally, hence termed vallecular cavitzes (Fig. $230 \mathrm{~b}$ ); finally, in connexion with each vascular bundle, there is a large cavity, the carinal cavity (Fig. 230 c), extending, like the others, from one node to another.

The growing-point of the stem, and of its branches, is apical, and has a tetrahedral apical cell (Fig. 229).

In the aerial shoots (except specialised fertile shoots of $E$. arvense, etc.) 
there is a considerable development of assimilatory tissue in the cortex, strands of this tissue corresponding in position with the furrows on the surface in which the stomata are developed; whilst opposite the ridges on the surface there are cortical strands of sclerenchyma. The development of assimilatory tissue in the shoots and branches is correlated with the absence of foliage-leaves, the functions of foliage-leaves having therefore to be discharged by the shoots and branches. The epidermal cell-walls are impregnated with silica.

Within the cortex, and almost abutting upon the large central cavity, is a ring of distinet vaseular bundles which run down the internode from
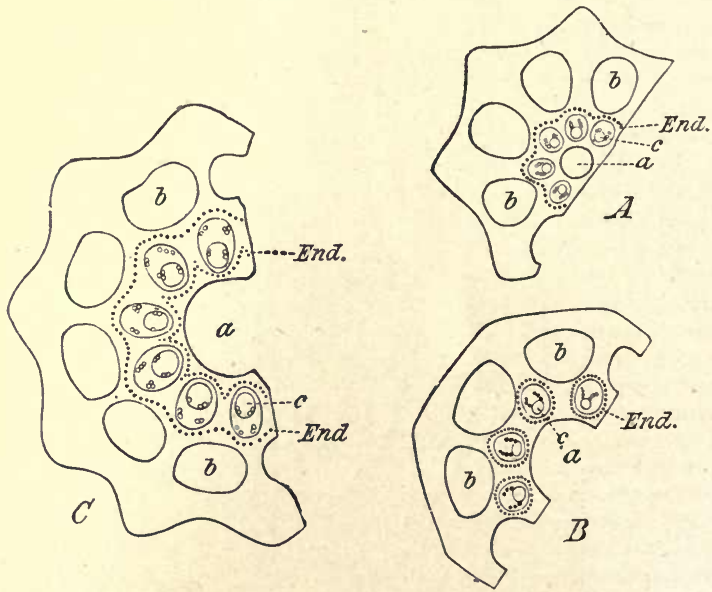

Fig. 230.-Portions of transverse sections of stems of species of Equisetum (after Pfitzer: $\times 36$ ). B rhizome of $E$. litorale; $C$ rhizome of $E$. silvaticum; $A$ serial stem of $E$. palustre, in which the structure is the same as in $C$, but the markings of the internal endodermal layer are not developed; $a$ central cavity ; $b$ vallecular cavities in the cortex; $c$ carinal cavities in the vascular bundles; End. endodermis.

the leaves at the node. Each bundle is collateral, closed and common, with very rudimentary xylem consisting of the few annular vessels of the protoxylem and of two small groups of scalariform tracheids.

The root grows in length by means of a tetrahedral apical cell; in its mode of growth, development of root-cap, etc., it essentially resembles that of the Ferns. Its structure is rather peculiar:-the vascular cylinder consists (usually) of three wood-bundles and three bast-bundles, and is invested by two layers of sheathing-cells, the outer of which has the characteristic marks of an endodermis, whilst the inner appears to be a pericycle and gives rise to the growing-points of the lateral roots; however, the inner layer is, as a matter of fact, not a pericycle, but the inner- 
most layer of the cortex, the endodermis being the last layer but one of the cortex (p. 115). Hence it appears that here, as in the Ferns, the lateral roots spring from the innermost layer of the cortex. There is no pericycle in the root of Equisetum.

Embryogeny of the Sporophyte. The oospore is divided by a transverse basal wall, and then becomes segmented into octants, as in the Filicinæ. Of the four epibasal octants, one gives rise to the growing-point of the primary stem; two to the first cotyledon; and the fourth to the second cotyledon: the two cotyledons cohere to form a leaf-sheath round the young primary stem. Of the four hypobasal octants, one gives rise to the growing-point of the primary root, and two to the foot.

The primary stem grows erect, and its leaf-sheaths are three-toothed, the three leaves corresponding to the three segments cut off from the apical cell of the stem; it branches at its base; stouter shoots with an increasing number of teeth in the leaf-sheaths are successively produced, and eventually a branch is produced which becomes the perennial subterranean rhizome.

The Gлметорнуте is a green, dorsiventral, lobed prothallium which becomes quite free from the spore. The prothallia are generally dioecious, the female prothallia being larger than the male; but the distinction of sex is not absolute, for the female prothallia may eventually bear male organs, and the male prothallia female organs; it appears to depend largely on conditions of nutrition.

The germinating spore divides into two cells: one of these contains no chloroplastids, and grows out into a root-hair, the other contains chloroplastids, and grows and divides to form the first lobe of the prothallium, which branches as its development proceeds, some of the branches of the female prothallia growing erect. On its under surface the prothallium bears numerous root-hairs.

At first the prothallium consists throughout of a single layer of cells; in the female prothallium, however, one of the lobes becomes thick and fleshy, consisting of several layers of cells formed by repeated horizontal cell-division, and this constitutes the archegoniophore.

The male organ, or antheridium, is developed from a single cell of the margin of the male prothallium: this cell undergoes repeated division, with the result that a wall, consisting of a single layer of cells, is formed surrounding a central cell from which, by subsequent divisions, the numerous mother-cells of the male cells are developed: the antheridium eventually dehisces by the separation of the cells forming the roof, in consequence of the swelling-up of the contents of the antheridium. The male prothallium bears several antheridia, one being developed terminally on each lobe, and others in succession on the lateral margins.

The male cell is a spermatozoid, which is larger than that of any other Pteridophyta; it has only two or three coils, and bears a tuft of short cilia at its anterior pointed end.

The female organ, or archegonium, resembles, in all essential features of its structure and development, that of the typical Filicinæ: a distinctive peculiarity-is afforded by the long recurved terminal cells of the neck,

I.B. 
and by the relatively small neck-canal-cell. Each prothallium bears a number of these organs: they are developed each from an anterior marginal cell, and, as the prothallium continues to grow, the organs come to lie on its upper surface.

The female cell is an oosphere, and calls for no special remark.

\section{CLASS VII.-LYCOPODINA.}

\section{SUB-CLASS HOMOSPOREE.}

Order 1. Lycopodiaceæ. This order contains the two genera Lycopodium and Phylloglossum: the former is a large genus, six species being

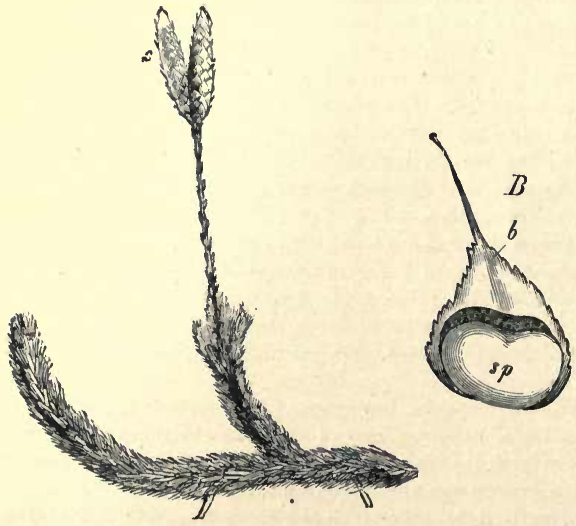

FIG. 231.-Portion of Lycopodium clavatum, somewhat smaller than nat. size : 8 , the cone-like fower. $B$ a single sporophyll (b) from the cone, bearing a sporangium $8 p$, which has debisced $(\times 10)$.
British (L. Selago, inundatum, annotinum, clavatum, alpinum, complanatum) and commonly termed Club-mosses: the genus Phylloglossum has a single species (P. Drummondii) found in Australia and New Zealand.

The Sporophyte. The stem. In Lycopodium the stem is slender and much branched, erect (e.g. L. Selago), or growing horizontally on the surface of the ground (e.g. L. clavatum [Fig.231]

annotinum), or beneath the surface as a rhizome (e.g. L. alpinum, complanatum): the branching is in some cases dichotomous, in others monopodial; it may take place in all directions, or in one plane only ( $L$. complanatum).

The leaves. In some species of Lycopodium all the leaves are alike (e.g. L. Selago); but in most species the foliage-leaves and the sporophylls are more or less widely different.

The foliage-leaves are small and very numerous in Lycopodium; their arrangement is various, whorled, or spiral, or in decussate opposite pairs (L. complanatum, etc.): in the last case there is heterophylly (p. 41), as the decussate leaves on the flattened sterile shoots vary in size, those on the lateral 
margins of the shoots being larger than those on the flattened surfaces. The leaves are sessile, simple, and have a rudimentary midrib.

The sporophylls present considerable variety. In $L$. Selago and its allies they are quite like the foliage-leaves; in most species of Lycopodium (e.g. L. inundatum, clavatum, Phlegmaria, etc.) the clearly differentiated sporophylls are aggregated into terminal cone-like flowers, and in some cases the branch bearing the cone grows out into a long peduncle ( $L$. clavatum, complanatum, etc.).

The sporangia are borne singly on the upper surface of the sporophylls near their base. The archesporium consists of a single row or of a few rows of cells which, by their division, give rise to the mother-cells of the spores. The sporangia are unilocular, somewhat reniform in shape, and (in Lycopodium) seated on a short broad stalk; they dehisce by a longitudinal slit.

The spores are all of one kind, and are tetrahedral in form; they have the ordinary structure.

The roots are all adventitious. In the erect species of Lycopodium they spring as a tuft from the basal end of the stem : in the procumbent species they are born singly on the under surface of the stem. The roots branch dichotomously in alternate planes.

General Histology. The growing-point of stem and root alike consists, in Lycopodium, of small-celled meristem, no apical cell being present. Both stem and root have an axial vascular cylinder consisting of alternating bundles of wood and of bast arranged radially (p. 125): thus the stem is monostelic, and its structure only differs from that of the stouter roots in respect of the larger number of bundles present: in smaller roots there is only one wood- and one bast-bundle. In the stem the bundles frequently anastomose, more especially in the erect-growing species, so that transverse sections taken at different levels present diverse pictures. The wood-bundles consist of scalariform tracheids, with the exception of the protoxylem. Neither stem nor root grows in thickness. In both stem and root there is an endodermis, the cells of which have the characteristic marking when young, but eventually become thick-walled and corky.

The leaves of Lycopodium are of vers simple structure; they usually have stomata on both surfaces.

Embryogeny of the Sporophyte. The early stages have only been observed in L. Phlegmaria, where the oospore is divided by a transverse basal wall, the cell next to the neck of the archegonium being the hypobasal cell, and the lower cell the epibasal. The hypobasal cell developes into a short, cylindrical, usually nnicellular, suspensor (p. 347). The somewhat hemispherical epibasal cell becomes segmented into four octants by two walls at right angles to each other and to the basal wall; and then the octants are divided transversely, by a wall at right angles to the two preceding, into two tiers or stages of four cells each. Of these two tiers the lower forms a sbort hypocotyl (as in Salvinia, see p. 377) which is commonly (but erroneously) called the foot, though it is morphologically quite different from the foot of the Filicinæ and Equisetinæ. The upper tier of cells gives rise to the first leaf or cotyledon, and to the primary stem. The 
first root eventually springs adventitiously from cells belonging to the upper tier, below the cotyledon: its origin is exogenous. (Compare embryogeny of Selaginella, p. 393).

Vegetative Propagation. In the creeping forms, as the main stems die off, the younger branches become independent and constitute new individuals. In some speeies there are gemmæ, as in $L$. Selago, where they are borne on the stem, and are modified leafy branches; and as in $L$. cernuum, where they are small tubercles borne on the roots.

The Gанеторнутк. In so far as the gametophyte has been investigated, it is a monœeious prothallium, either containing chlorophyll ( $L$. inundatum and cermum), or destitute of chlorophyll (L. annotinum and Phlegmaria) and saprophytic.

The morphology of the prothallium offers considerable variety. In some species (e.g. L. innudatum) the prothallium is tuberous; its base is embedded in the soil, and bears root-hairs; its apex projects above the surface and bears a tuft of green leafy lobes: the sexual organs are developed in a zone from a layer of tissue which long remains merismatic and which is situated just below the apical tuft of lobes; occasionally some antheridia are developed on the lobes. Whilst in these species the prothallium is very small and simple, in $L$. Phlegmaria and some other species it is considerably larger and more complex. It consists here of a cylindrical, monopodially-branched body, with apical growing-points similar in structure to those of the sporophyte. The superficial layer of cells, representing an epidermis, gives rise to a number of root-hairs. The sexual organs are developed on special branches, gametophores, though antheridia sometimes occur on the vegetative branches; the gametophores are shorter and thicker than the vegetative branches, sometimes even tuberous, and on the upper surface bear the sexual organs surrounded by stout multicellular hairs, paraphyses.

The male organs (antheridia) are sunk in the tissue of the prothallium: they resemble those of the Eusporangiate Filicinæ. Their development precedes that of the female organs.

The male cells are spermatozoids, oval in shape, and have two cilia.

The female organs (archegonia) have short necks which project but little above the surface of the prothallium; they have the structure usual among Pteridophyta.

The female cell (oosphere) requires no special description.

In consequence of its position and of its mode of development, the embryo is forced downwards into the tissue of the fleshy prothallium, being anchored, as it were, at one end by the suspensor (see p. 347). As it grows it destroys the cells of the prothallium with which it comes into contact, and absorbs the nutritive substances stored in these cells by means of the so-called foot, the superficial cells of which grow out into short papillæ. In its further growth the embryo becomes more and more curved until it regains the surface of the prothallium and projects. In L. Phlegmaria the embryo remains for some time enclosed in a sac, the calyptra, formed by active growth of the prothallial tissue.

The life of the prothallium is short and closes, in most cases, with the 
development of an embryo from the oospore, but in $L$. Phlegmaria it seems to persist from one season to another. In the latter species the prothallia are multiplied vegetatively by the isolation of branches, as also by small multicellular bulbils.

Order 2. Psilotaceæ. This order consists of the two genera Psilotum and Tmesipteris; of these the former is widely distributed in the tropics; the latter is confined to Australia, New Zealand, and Polynesia, and lives epiphytically, and perhaps parasitically, on the trunks of TreeFerns.

The Sporophyte. The most striking feature in the morphology of these plants is the total absence of roots, the functions of these organs being performed by specially adapted stem-branches bearing minute scaleleaves, and covered with root-hairs.

The sten. In Psilotum the subterranean shoots have unlimited apical growth: they are much branched, apparently dichotomously, but it seems probable that the branching is really lateral. The subaerial shoots generally arise as lateral branches on the subterranean shonts: they have limited apical growth; they are branched, the mode of branching being probably the same as that of the subterranean shoots; and they bear small scattered leaves.

The stem of Tmesipteris appears to agree in all essential morphological points with that of Psilotum; but with this conspicuous difference, that it is much less branched.

The leaves. In both genera the leaves of the subaerial shoots are of two kinds. In Psilotum the vegetative leaves are minute scales, whereas in Tmesipteris they are relatively well-developed as foliage-leaves: they are simple and sessile. The sporophylls, on the contrary, are petiolate and bilobed in both genera, a single sporangium being borne on the upper surface of each sporophyll just at the junction of the basis of the two lobes : they are not borne in cones.

The sporangia are synangia (p. 52); that is, they are not unilocular, but multilocular capsules: in Psilotum the synangium is generally trilocular (sometimes 2-4 locular), in Tmesipteris bilocular. Each loculus opens by a longitudinal slit. The origin of the archesporium has not been fully traced: but it appears probable that it consists primarily of a layer of cells, some of which become the mother-cells of the spores, whilst the rest are sterile and form the tissue of the walls separating the loculi.

The spores are developed in tetrads from the mother-cells; bilaterally, as in Tmesipteris; or either bilaterally or tetrahedrally, as in Psilotum. They have the typical structure.

The Gametophyte. No observations have as yet been made on the gametophyte of either genus, and consequently the embryogeny of the sporophyte is also unknown.

\section{SUB-CLASS HETEROSPORE,E.}

Order 3. Selaginellaceæ. This order consists of the single genus Selaginella, of which the numerous species are very widely distributed, but only one, S. spinosa (selaginoides), is British. 
The Sporophyte. The primary stem is slender and elongated, erect, or more commonly procumbent; its symmetry is bilateral, isobilateral when erect, dorsiventral when procumbent; the branches spring from the flanks of the primary stem, and, as this is subsequently repeated, the resulting branch-system lies in one plane; the mode of branching is lateral, though it appears to be dichotomous. In some few species, however, the branches have radial symmetry (e.g. S. spinosa).

At the points at which the normal branching takes place, leafless branches, termed rhizophores, are in some species developed in a plane at right angles to that of the normal branching; thus in S. Kraussiana they arise singly on the upper surface of the stem at the points of normal branching, whilst in $S$. Martensii two are developed at each such point, one on the upper and one on the lower surface. The direction of growth of the rhizophore is such that the apex eventually penetrates into the soil, when routs arise from it and it ceases to grow.

These organs have been regarded as roots, and are sometimes so designated still. But in view of the important morphological facts that the

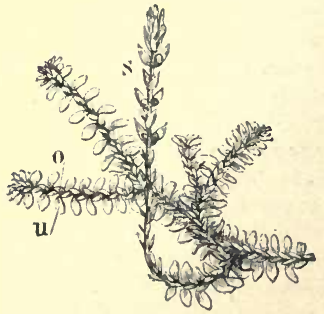

FiG. 232.- Selaginella helvetica (nat. size) : 8 the upright fertile shoot, with sporangia in the axils of the leaves. On the procumbent sterile shoota, the leaves on the under side $(u)$ ar'e larger than those on the upper side $(o)$. rhizophore is of exogenous origin like the leafy branches; that it has no root-cap, whilst the true roots of Selaginella have one; and finally, that sometines a rhizophore will develope leaves and even cones, the probability is that they are modified branches comparable with the root-like branches of the Psilotacer.

The leaves can be readily distinguished as either foliage-leaves or sporophylls. A characteristic feature in their morphology is the development of a small ligule on the upper surface of each leaf near its base.

The foliage-leaves are simple, small, sessile, and rather numerous. Those borne on the radial branches are all alike, and are arranged spirally; the bilateral branches show remarkable heterophylly, there being leaves of two sizes in decussate pairs, each pair consisting of one large and one small leaf; when the branch bearing these two kinds of leaves is dorsiventral, the four rows of leaves show displacement, with the result that the two rows of small leaves are borne on the upper surface of the branch, and the two rows of larger leaves are borne infero-laterally (Fig. 232).

The sporophylls are generally collected into more or less distinct conelike flowers; they do not differ materially from the foliage-leaves, and, like them, may be all of one size or of two sizes.

The sporangia are shortly stalked and unilocular; they arise singly from a group of superficial cells of the stem just above the insertion of each sporophyll; the wall, when mature, consists of two layers of cells; 
the archesporium probably consists of a single row of cells, and is entirely sporogenous.

There are two kinds of sporangia, macrosporangia and microsporangia, distinguished by the kind of spores which they produce, and by their size. The macrosporangia each give rise to generally four (sometimes 2 or 8 ), relatively large macrospores; the microsporangia each give rise to a considerable number of microspores.

The relative distribution of the two kinds of sporangia presents some variation. As a rule both kinds of sporangia are present in the same cone, so that, like the flower of most Angiosperms, it contains both microsporophylls and macrosporophylls; in this case there may be several macrosporophylls at the lower part of the cone, or only a single one.

The spores are developed in fours from the mothercells resulting from the growth and multiplication of the archesporial cells. They are developed tetrahedrally: but in the macrosporang i u m usually only one of the mother-cells undergoes division to form spores. The structure of the spores is normal.

The roots are all adventitious and endogenous. In some species (e.g. S. cuspidata and Wildenovii) they spring directly from the

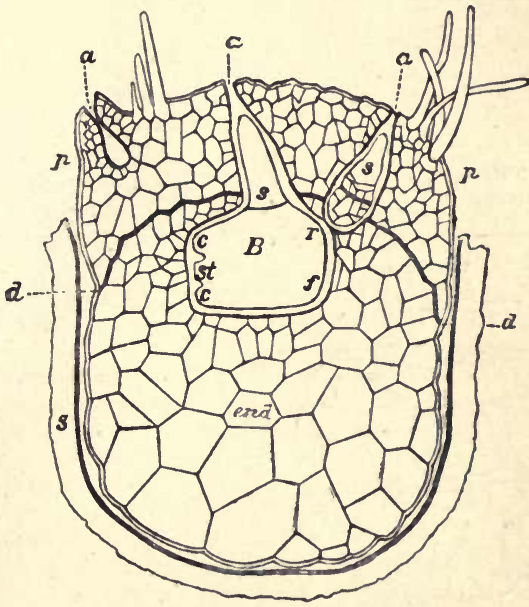

FIG. 233.-Prothallium and embryo of Selaginella Martensii ( $\times$ 65: after Pleffer) 8 coat of macrospore; $p$ prothallinm; $a$ archegonium; $d$-d diaphragm; ond so-called endosperm: $B$ an embryo (there is a smaller one to the righr): suspensor; c $c$ rleveloping cotyledons; st stem; $r$ origin of the root; $f$ soca'led foot. lower surface of the stem at the points where branching takes place. In other (e.g. S. Martensii and Kraussiana) cases they spring from near the apex of the rhizophores after the rhizophores have reached and entered the soil. The roots branch monopodially.

General Histology. The stem is, in some species (S. spinulosa and denticulata), monostelic, but in most species it is polystelic (two or three). The epidermal and the ground-tissues of the stem are prosenchymatous, with- 
out intercellular spaces. In correlation with this each stele is suspended, by delicate trabecular cells developed from the endodermis, in an airchamber: each vascular bundle going to a leaf is in a similar chamber which communicates in the lamina with the external air through the stomata. Each stele is surrounded, towards the air-chamber by a pericycle consisting of one or sometimes two layers of cells. The stele is circular or oval in transverse section, it usually consists of two or more bundles arranged concentrically, the bast forming a peripheral layer and the wood-bundles joining in the centre.

Rhizophore and root are both monostelic, and without air-chambers : the stele contains but one bast- and one wood-bundle.

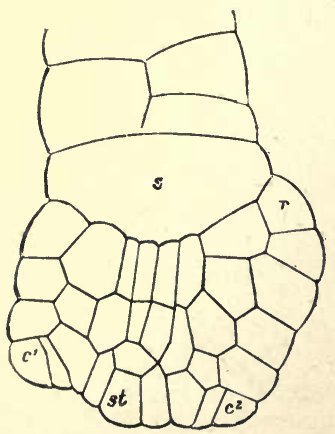

A

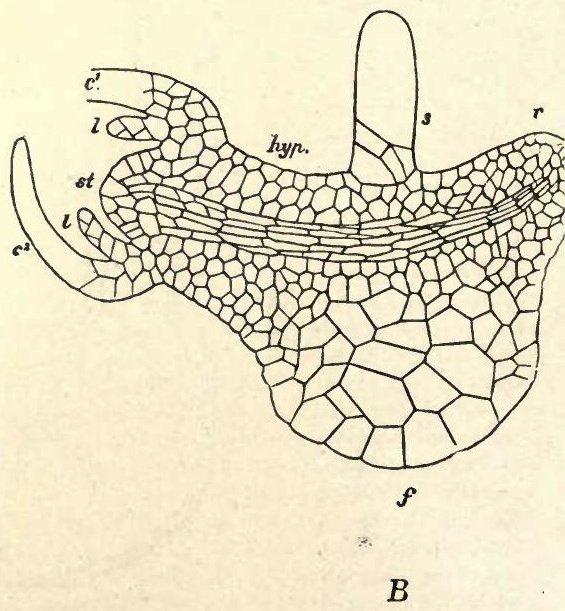

Fra. 234.-Embryogeny of Selaginella Martensii (after Pfeffer). Two isolated embryos at different stages, $A$ Younger embryo $(\times 510) B$ older $(\times 165): 8$ suspensor; $c^{1} c^{2}$ cotyledons; st stem; $l$ young foliage-leaves; hyp hypocotyl; $r$ root; $f$ so-called foot.

The bundles are all closed; there is no secondary growth in thickness.

The leaves are very simple in structure; they have a midrib with a single vascular bundle: the epidermal cells contain chloroplastids which, like those in the other cells, are large and are present in small numbers (sometimes only one) in the cells. The stomata are usually confined to the under surface, on the sides of the midrib.

The growth in length of the stem is effected by an apical growing-point which has, in some species (e.g. S. Martensii), a two-sided or three-sided apical cell; whilst in others (e.g. S. Lyalli, Pervillei, etc.) it consists of 
small-celled stratified meristem. The structure of the growing-point of the rhizophore agrees with that of the stem in the varions species: but the apical cell, when present, is a four-sided pyramid at first, becoming eventually two-sided. The growing-point of the root has a tetrahedral apical cell.

Embryogeny of the Sporophyte(p. 347). The embryogeny of Selaginella closely resembles that of Lycopodium. The oospore undergoes division, a transverse basal wall being formed : the upper or hypobasal cell developes into a unicellular or few-celled suspensor : the lower or epibasal cell appears to undergo division into four octants, which eventually form two tiers of cells: from the basal tier of cells the hypocotyl is developed; from the apical tier the growing-point of the stem and those of the two cotyledons. The hypocotyl elongates, and curves so as to escape from the prothallium and the spore; the convexity of the curve becomes somewhat protuberant and is usually (but erroneously) termed the "foot," though it doubtless acts as an organ of absorption; morphologically it cannot be a foot since it is epibasal in origin; it would more appropriately be termed a feeder. The first root eventually springs, endogenously and adventitiously, from the posterior portion of the convex surface of the hypocotyl; it is not a true primary root because it is epibasal in origin (Figs. 233, 234).

The Gametophyte.

Selaginella being heterosporous, the gametophyte-generation is represented by distinct male and female individuals, which are rudimentary prothallia bearing the male and female organs respectively : the sexual organisms resemble those of Isoetes (p. 357) and of Gymnosperms.

The male prothallium is developed inside the microspore: the germination of the spore begins with the formation of a wall across the pointed apical end of the spore, cutting off a small cell, the vegetative cell: the rest of the spore goes to form the single antheridium which consists of a layer of parietal cells enclosing the mother-cells of the spermatozoids. When the development of the spermatozoids is completed, the coats of the microspore burst, as also the wall of the antheridium, and the spermatozoids are set free.

The male cell is a spermatozoid; it is a somewhat club-shaped slightly twisted body, bearing two cilia at its pointed anterior end.

The female prothallium is developed inside the macrospore (Fig. 233): germination begins with the formation of a wall, termed the diaphragm, across the apical end of the macrospore: in the smaller upper cell thus cut off cell-division proceeds, resulting in the formation of the meniscusshaped prothallium consisting of compact small-celled tissue: the larger portion of the spore, below the diaphragm, is rich in reserve materials; here cell-formation goes on but slowly, a large-celled loose tissue (sometimes called endosperm) being produced which serves to nourish the embryo which is forced down into it by the elongation of the snspensor.

The walls of the spore eventually split along the angles, thus forming an apical aperture by means of which the upper surface of the prothallium which now becomes green, is exposed. 
The female organ or archegonium is dereloped from a single superficial cell at the centre of the upper surface of the prothallium (here several cells thick); it does not call for any special description; if the first archegonium fails to become fertilised, nthers may be subsequently formed.

The fenale cell or oosphere is contained in the venter of the archegonium.

\section{SUB-KINGDOM.}

\section{PHANEROGAMIA (OR SPERMAPHYTA).}

The Grmnosperms and Angiosperms are all heterosporons plants, having a definite alternation of generations, which is, however, not readily perceived on account of the great reduction of the sexual generation, and of the fact that the female gametophyte remains enclosed in the macrospore, that the macrospore remains enclosed in the macrosporanginm, and that the macrosporangium remains for a long time attached to the sporophyte, the result being the development of a seed. The reduction of the gametophyte and the formation of the seed are the features which essentially distinguish the Phanerogams from the higher heterosporous Pteridophyta such as Selaginella and Isoetes.

A. The Sporophyte. As in the Pteridophyta, so here, the plant itself is the sporophyte or asexnal generation.

It is unnecessary to go into detail at present with regard to the morphology of the vegetative organs, an account of which is given in the section on General Morphology, and subsequently in the description of the classes and orders.

The Reproductive Organs of the sporophyte are sporangia of two kinds, microsporangia and macrosporangia, which are usually borne on sporophylls, but sometimes directly on the axis: the modified shoots bearing the sporangia constitnte flowers; and often bear, in addition to the sporophylls, other floral leaves (hypsophylls, see p. 57), protective or attractive in function, some of which usually constitute a perianth.

The flowering shoot constitntes an inflorescence, which may consist of one or many flowers, according to the extent to which the shoot branches.

The Flouer (see p. 55) is a sporanginm-bearing shoot or sporophore, of limited growth, with usually undeveloped or feebly developed internodes, so that the sporophylls and hypsophylls which it bears are closely aggregated together. Most commonly the flower includes both kinds of sporangia, that is, it is monoclinous 
or hermaphrodite; but it frequently contains but one kind of sporanginm (unisexual): in the latter case there are two kinds of flowers, microsporangiate and macrosporangiate, which may be borne by the same individnal, when they are said to be diclinons and monoecious; or by two distinct individuals, when they are dioecious (see p. 61). Occasionally the same plant prodnces both monoclinous and nnisexual flowers, when it is said to be polygamous. The microsporangiate flowers are frequently termed staminate, and the macrosporangiate flowers carpellary (p. 56): the former are indicated by the sign $\delta$, the latter by the the sign $q$, and monoclinons flowers by the sign $\varnothing$. In the Gymnosperms the flower always has bnt one kind of sporangium; in the Angiosperms it generally, though by no means always, has both kinds. The flower of the Gymnosperms is nearly always destitute of a perianth.

The special morphology of the Perianth is dealt with under the Angiospermæ, in which class it attains its highest development.

The Sporophylls are of two kinds: microsporophylls, otherwise known as stamens; and macrosporophylls, otherwise known as carpels: the former bear exclusively microsporangia, the latter exclusively macrosporangia. The sporophylls present considerable variety of form, and are on the whole more highly specialised than in any of the Pteridophyta.

The microsporophyll, or stamen (see p. 56), in its most highly specialised form, consists of a stalk of varying length, the filament bearing a terminal structure, the anther, which is a sorus of one or more microsporangia embedded in more or less placental tissue. In the less highly organized Phanerogams (e.g. most Gymnosperms), the microsporophylls are morphologically simpler, haring the general character of sessile or shortly-stalked scaly leares.

The macrosporophyll, or carpel, bears (usually) macrosporangia see p. 56). In the Angiosperms the carpel, either by itself or by cohesion with others, forms a closed cavity, the ovary, which is frequently prolonged at its apex into a longer or shorter process, the style, bearing at its summit a glandular surface, the stignia: sometimes the style is absent, so that the stigma is sessile on the orary; within the orary the macrosporangia are developed. In the Gymnosperms, the macrosporophylls (when present) do not cohere, either individually or several together; so that in this group there is no ovary, style, or stigma; they are thus distin- 
guished from the Angiosperms, in which there is always an ovary and a stigma.

The Sporangia are of two kinds, microsporangia or pollen-sacs, and macrosporangia or ovules. The development of the sporangium is, in both, eusporangiate (see p. 53). The sporangia are, as a rule, borne on the sporophylls; but in some few cases (microsporangia rarely, e.g. Naias; macrosporangia of Taxus, Polygonum, Primulaceæ, etc.) they are borne on the axis.

The microsporangia, or pollen-sacs, may be developed either singly or in a sorus of two or more; they may be very numerous on the sporophyll, as in the Cycadaceæ. When borne on the sporophylls, they are developed on the lower (dorsal) surface of the microsporophyll in the Gymnosperms; whereas in the Angiosperms they are usually developed both on the upper (ventral) and the lower surfaces.

The microsporangia either project freely or are embedded in the placental tissue of the member bearing them. The multicellular hypodermal archesporium is either a row or a layer of cells. The archesporial cells undergo, as a rule, division, giving rise to the sporogenous cells together with a more or less extensive transitory layer of investing cells, the tapetum, which is eventually disorganised. The microsporangium is, with few exceptions, unilocular.

The microsporangium eventually dehisces, generally by a longitudinal slit, less commonly by a transverse slit or by a pore. The dehiscence is mainly effected by a layer of tracheidal cells, differentiated as part of the wall, which are highly hygroscopic.

The microspores, or pollen-grains; are developed from the sporogenous mother-cells of the sporangium. As a rule each mothercell divides so as to give rise to four microspores, all of which develope. As a rule, also, the microspores eventually become quite free from each other, but to this there are exceptions, thus, in the Mimoseæ, while the pollen-grains are isolated in some species, in other species they cohere in groups of $4,8,12,16$, or 32 , derived from one, two, three, or more mother cells; again, in the Orchidaceæ, whilst Cypripedium has isolated pollen-grains, in most genera the pollen-grains are in groups of four (tetrads), and cohere into a mass (or 2-8 masses), the pollinium, of varying consistence.

The microspore has, as a rule, the ordinary structure of a spore (see p. 50); it is a nucleated cell, with a certain amount of granu- 
lar nutritive material in its cytoplasm, and has two coats, an intine and an exine, the structure of the latter being elaborate in many cases. The spore has not, however, always two coats. In some cases there is no exine, and only a single thin coat, as in the cells of the pollinia of Orchids and Asclepiads, and in certain plants whose flowers develope under water, such as certain Naiadaceæ. In others, again, there is but one coat, but it is thick and is cuticularised externally (e.g. Senecio),

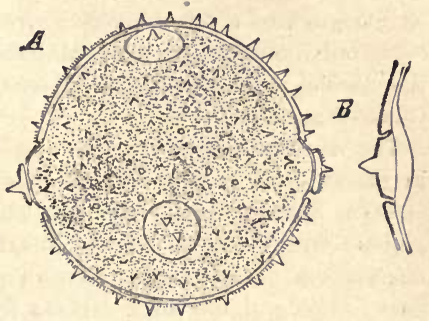

Fra. 235.-A Pollen-grain of Cucurbita Pepo, showing the lid-like areas through which the pollen tubes will protrude $(\times 240)$. B Section of one of these areas $(\times 510)$ (after Strasburger). or the two coats are only distinguishable at those points at which the pollen-tubes will be eventually protruded (e.g. Onagraceæ).
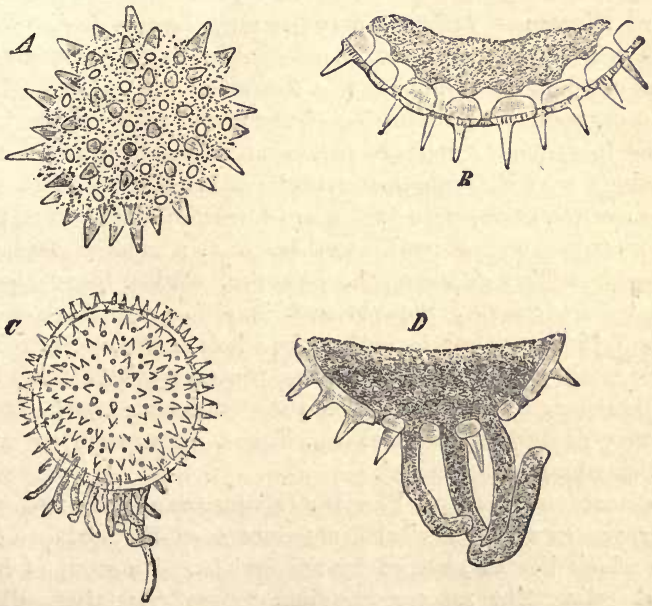

Fra. 236.-Pollen-grains of Malva crispa. A Grain seen from surface; B section of wail, showing the exine with its alternate spines and pores, the latter closed internally by the delicate innermost layer of the exine; $C$ germinating pollen-grain with pollen-tnbes $; D$ the same in seetior, showing the protrusion of the pollen-tubes through the pores. $(A, B, D$ $\times 510 ; C \times 210$ : after Strasburger.) 
The exine is frequently highly differentiated with special reference to the protrusion of the pollen-tubes: it may be porous (e.g. Malvacer, Fig. 236) ; or there may be thin areas at certain points; or (Onagracer) much-thickened areas where the pollen-tubes are eventually developed; or, again, areas are marked off here and there which come off like lids under the pressure of the developing pollen-tube (Fig. 235).

The development of the microspores has already been dealt with in general (see p. 85), so that it will be only necessary here to mention certain special points. The mother-cells of the microspores either remain coherent during the development of the microspores, or (as in many Monocotyledons) they become free and float in the granular fluid, derived from the disorganisation of the tapetum, which fills the pollen-sac. The walls of the mother-cells usually become very much thickened, especially in the planes of the future divisions. The division of the mother-cell is either successive (Monocotyledons, Cycads), or simultaneous (most Dicotyledons and Conifers); in the former case the microspores are usually bilateral, in the latter tetrahedral. The form of the mature microspore varies widely; it may be spherical, etc.; in plants in which pollination takes place under water, the microspore becomes elongated and filiform (e.g. Zostera).

In some cases the germination of the pollen-grain begins before it is set free from the dehisced pollen-sac, so that it consists of two (sometimes more in Gymnosperms) cells at the time of pollination.

The macrosporangia, or ovules, are developed singly, or in pairs, or more commonly several together, from a more or less welldeveloped cushion of tissue, the placenta. When the ovules are borne on sporophylls, the placenta is either marginal, or less commonly, it is ventral, including the whole of the upper or inner surface of the carpel with, sometimes, the exception of the midrib (e.g. Butomus, Nymphæa). When the ovules are borne on the axis, they are either terminal (e.g. Taxus, Polygonum) or lateral (e.g. Primulaceæ, Compositæ).

The macrosporangium, like the microsporangium, makes its appearance as a small cellular prominence on the surface of the organ which bears it, formed by the division of a group of hypodermal cells. The macrosporangium proper (sometimes distinguished as the nucellus) is invested by one or two coats, which grow up from the base, but do not completely close over the apex, leaving there a narrow channel termed the micropyle; the base of 
the macrosporangium, where the coats and the tissue of the sporangium proper become indistinguishable, is termed the chalaza. The macrosporangium is not, as a rule, embedded in the placental tissue, and is sometimes borne on a longer or shorter stalk, the funicle. The point of attachment of the macrosporangium, whether it be sessile or stalked, to the placenta, is termed the hilum.

The form of the macrosporangium presents many varieties, of which the following are the more common (Fig. 237). When the micropyle, the chalaza, and the funicle (or the hilum) all lie in one and the same straight line, the ovule is said to be orthotropous : when the micropyle and the chalaza lie in the same straight line, but not the funicle, the ovule being bent back against the funicle (termed the raphe along the line of contact), the ovule is anatropous; when

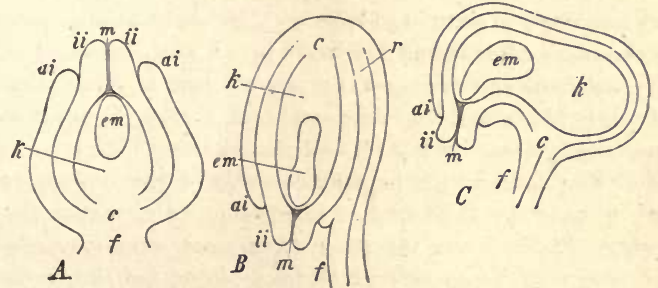

FrG. 237.-Diagrams of the Ovale: $\boldsymbol{A}$ orthotropous (Polygonum); $B$ anatropous (Lils); $C$ campylotropous (Bean): $f$ funicle; ai the outer integument; $i i$ the inner integument; $m$ micropsle; $k$ nucellus; $m m$ embryo-sac: $r$ the raphe; $c$ chalaza.

the ovule itself is curved, so that the micropyle and the chalaza do not lie in the same straight line, the ovule is campylotropous. Various intermediate forms occur which may be easily imagined.

The archesporium (see p. 53), which here, as elsewhere, is hypodermal, consists generally of one cell. In some cases the archesporial cell undergoes no division (e.g. Tulipa Gesneriana, Lilium bulbiferum) but directly developes into the mother-cell of a macrospore; but, as a rule, the archesporial cell (or cells) undergoes more or less frequent division. Thus, in most Phanerogams, the division of the archesporial cell begins with the cutting off, by a periclinal wall, of a sterile cell towards the organic apex (micropylar end) of the macrosporangium-or sometimes two such sterile cells-which, with or without further division, represent a tapetal layer. The large remaining cell now undergoes division 
into two by a transverse wall, and owe or both of these cells may divide in a similar manner. Thus a longitudinal row of large cells, two to four in number, is formed, all of which are potentially mother-cells of macrospores. In a few plants (Cycads and some Coniferæ among Gymnosperms; some Amentales, among Angiosperms) the growth of the archesporial cells is more extensive, leading to the production of a considerable mass of sporogenous tissue, as in the macrosporangia of the Pteridophyta.

Generally speaking, only one of the cells of the sporogenous tissue shows any sign of developing into a macrospore; and in the normal Angiosperms, this cell is generally the lowest (nearest the chalaza) of the longitudinal row described above. The growth of the fertile mother-cell of the macrospore is vigorous. It canses the displacement and absorption of the sterile cells of the sporogenous tissue.

The macrosporangium is indehiscent, and only becomes detached from the plant after it has developed into a seed.

The macrospore (megaspore) or embryo-sac is, as a rule, developed singly in the macrosporangium; and, further, it is always developed singly from its mother-cell without any indication of that division into four. which is characteristic of the development of spores in general. It is in fact impossible, as a rule, to fix upon any stage at which the transition from macrospore-mother-cell to macrospore may be considered to take place; for the mother-cell simply grows and becomes the macrospore without any special differentiation. However, in the Cycadaceæ, the wall of the mother-cell undergoes that differentiation which is characteristic of spores, so that the wall of the macrospore consists of two layers the outer of which is cuticularised. The macrospore is simply a large cell, containing vacuolated protoplasm in which lies a nucleus, and having, as a rule, a wall of cellulose.

In the course of its growth, the macrospore frequently causes the absorption of more or less of the tissue of the nucellus, more especially towards the micropylar end. It commonly attains such a size that little or none of the nucellar tissue remains: in some cases, however (e.g. Gymnosperms, Scitamineæ, most Nymphæaceæ), the macrospore does not grow to such an extent, so that a considerable mass of nucellar tissue is left, which persists to some extent in the seed as perisperm, its cells being then filled with nutritive substances.

General Histology. The following are the principal characteris- 
tic features:-The apical growth of shoot and root is only exceptionally effected by means of a single apical cell; the small-celled meristem of the growing-point of the stem is inore or less distinctly differentiated into dermatogen, periblem, and plerome; stem and root are monostelic, with but few exceptions (p. 102); the vascular bundles of the stem are generally collateral; both root and stem generally present secondary growth in thickness (except Monocotyledons and a few other cases) by means of a normal cambiumring; the growing-points of the lateral roots are developed from the pericycle of the parent root (see p. 134).

The Embryogeny of the Sporophyte. The sporophyte is developed from the fertilised oosphere in the ovule. The development of the embryo is not continuous, but is in two stages, which may be conveniently distinguished as the intra-seminal and the extra-scminal. The intra-seminal stage includes the whole of the development which the embryo undergoes during the conversion of the ovule into the ripe seed-that is, during what is known as the "ripening of the seed." The extra-seminal stage includes the development of the embryo which follows the sowing of the seed;that is, the escape of the embryo from the seed, and the gradual development of the characters of the adult plant. The interval between these two stages may be brief, or it may extend over many years if the seed be kept dry. The "germination" of the seed when sown is simply the resumption of development by the embryo in consequence of exposure to the necessary conditions of moisture, warmth, etc.

In most Phanerogams, each oospore gives rise to a single embryo; but in most Gymnosperms each oospore gives rise to more than one embryo (four or many), thus exhibiting polyembryony.

Generally speaking, the oospore divides into two by a transverse wall: the upper of the two cells remains coherent to the micropylar end of the embryo-sac and developes into a suspensor, which bears at its lower end the other cell, termed the embryo-cell, from which the whole or a considerable part of the body of the embryo is developed (cf. Lycopodinæ, pp. 387, 393).

The suspensor is for the most part a temporary organ of the embryo, but it frequently contributes the primary root to the embryo. It commonly becomes a filament of a single row of cells. Its function is, chiefly, to place the embryo in such a position within the developing seed that it can easily avail itself of the nutritive materials stored in the adjacent cells.

M.B. 
The embryo-cell divides, as a rule, into two by a longitudinal wall, then transversely, and then in a plane perpendicular to both the preceding, into octants; but while the four anterior octants are octants of a sphere, this is not the case with the four truncated pos-

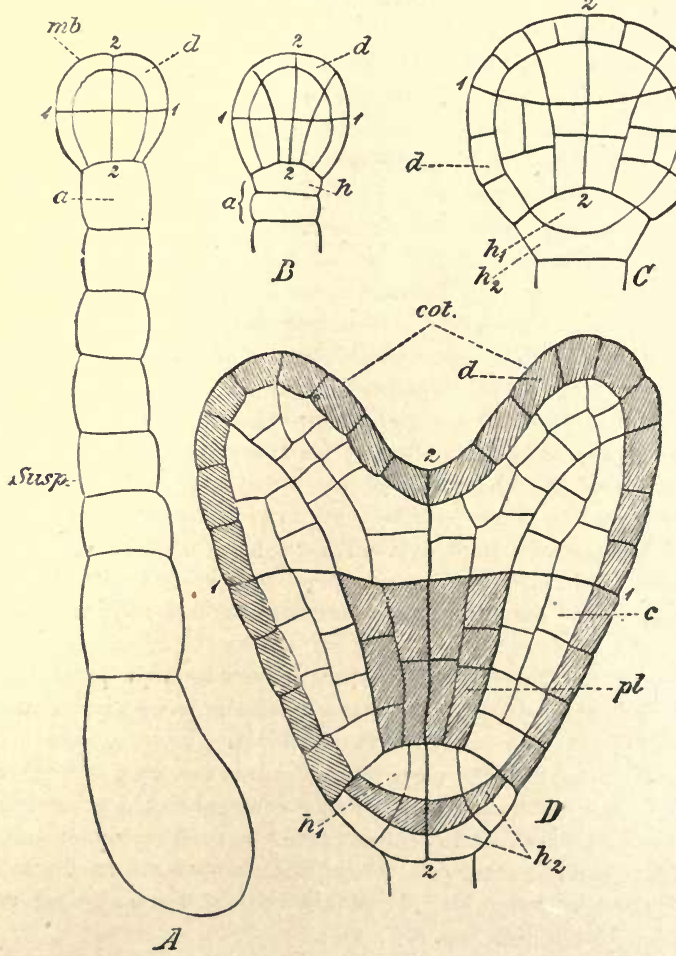

FrG. 233.-Embryogeny of Dicotyledons as represented by Capsella Bursa-Pastoris (diagrammatic, after Goebel and Hanstein). A-D Successive stages : susp. suspensor; emb. cmbryo; 1-1, 2-2, octant-walls; $a$ lowest cell of suspenser, dividing in $B$ to form the hypophysial cell $h$; in $C$ the hypophysial cell bas divided into two, $h_{2}$ and $h_{2}$, the former constituting the periblem, the latter the dermatogen, of the growing-point of the primary root ; in $D, h$, has undergone a periclinal division to form the primitive root-cap : $d$ dermatogen; $c$ periblem; pl. plerone; cot. cotyledons, between which lies the growing.point of the primary stem. 
terior octants abutting on the suspensor. In some cases, the transverse division precedes the longitudinal. From the anterior octants are developed, in Dicotyledons generally (Fig. 238), the two cotyledons and the growing-point of the primary stem, but the growingpoint of the primary root is supplied from the last cell of the suspensor (Fig. $238 \mathrm{~A}, a$ ) which divides transversely into two (Fig. $238 \mathrm{~B}$ ) and contributes the cell $h$, the hypophysis, to complete the

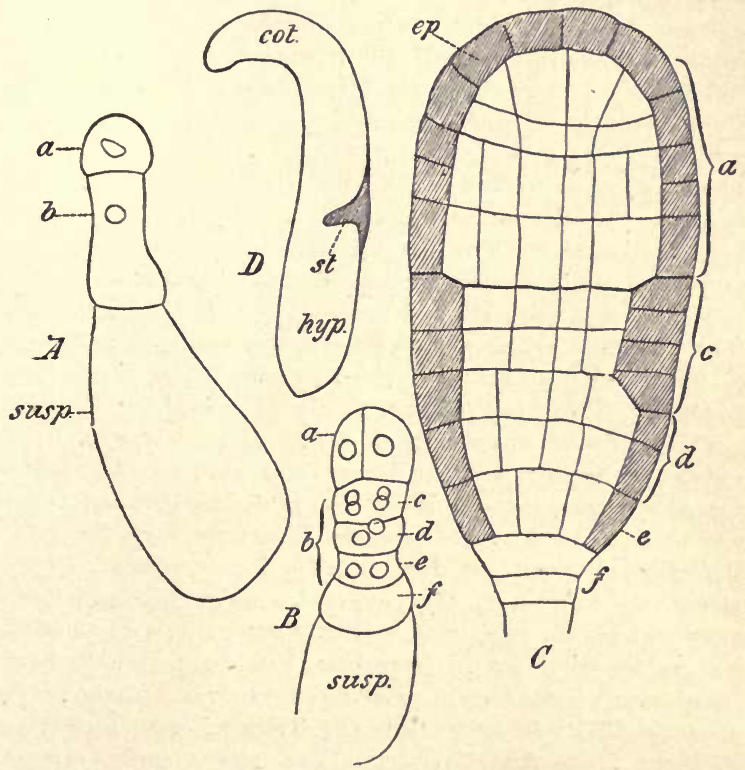

FrG. 239.-Embryogeny of Monocutyledons, as represented by Alisma Plantago (diagrammatic, after Goebel, Hanstein, and Famintzin). A-C Saccessive stages : a embryo-cell; 3 lowest cell of suspensor, susp. : the products of the repested tratsverse division of $b$ are indicated $(c, d, c, f)$ in $B$ and $C$. In $C, a$ has given rise to the single terminal cotyledon : $c$ to the growing point of the primary stem; $d$ and e form the bypocotyl; the growingvoint of the root is developed from $f_{\text {; }}$ op dermatogen. $D$ is a mature embryo, less highls msgnified : cot. cotyledon; st. growing-point of stem; h3p. bypocotyl. The nuclei of the cells are indicated in $A$ and $B$.

root-end of the embryo. In Monocotyledons, on the other hand, the embryo cell gives rise, as a rule (Fig. $239 A$ and $C, a$ ), only to the single terminal cotyledon; whilst the last cell of the 
suspensor (Fig. $239 A, b$ ) gives rise to the growing-point of the stem, which is here lateral (Fig. $239 C, c ; D, s t$ ), and to that of the root by a hypophysial cell $(f)$.

With regard to the histological differentiation of the embryo, the first step, after the division into octants, is the formation of periclinal walls marking off a superficial layer, which is the dermatogen (Figs. 238, 239); this differentiation proceeds from the anterior end, or apex, backwards towards the posterior end of the embryo. In those plants in which the root-end of the embryo is formed by a hypophysial cell contributed by the suspensor (Fig. $238 \mathrm{~B}, \mathrm{~h})$, the dermatogen-layer is completed by the periclinal division of the hypophysial cell, the inner cell forming the periblem of the growing-point, the outer forming the dermatogen which undergoes further periclinal division to form the primitive root-cap. In the meantime, anticlinal and longitudinal walls have also been formed, so that the embryo, as it increases in size, consists of an increasing number of cells. The degree of histological differentiation attained varies widely: in the highest forms (Fig. $238 D$ ) a cylinder of plerome is differentiated in the axis of the embryo, so that the three primary tissue-systems, dermatogen, periblem, and plerome, are clearly defined.

The degree of morphological differentiation attained by the embryo in its intra-seminal development also varies widely, as does also the size of the embryo. In the ripe seed of most Orchids and parasitic plants (e.g. Orobanche, Monotropa, etc.), the body of the embryo presents no differentiation into members. In most plants, the embryo, in the ripe seed, consists of the following members: ( $a$ ) one, two, or several cotyledons; (b) a primary stem bearing the cotyledon or cotyledons, but not projecting beyond them, termed the hypocotyl, passing posteriorly into (c) the primary root or radicle. In some plänts (e.g. Triticum and other Grasses, Phaseolus, Vicia, Amygdalus, etc.) the primary stem has elongated beyond the insertion of the cotyledon or cotyledons, and bears the rudiments of future foliage-leaves; this portion of the primary shoot is termed the plumule or epicotyl.

The size and texture of the cotyledons vary with the functions which they have to perform. When, as in exalbuminous seeds, such as peas and beaus, the cotyledons are themselves the storehouses in which food is deposited for the nutrition of the embryo during its extra-seminal development, they are relatively large, thick, and fleshy; but when, as in albuminous seeds (e.g. Ricinus, 
Grasses, etc.), the food is stored in the endosperm, the cotyledons are absorbent organs and, though still relatively large, are not thick and fleshy.

In a few Phanerograms (e.g. Utricularia, which never developes any root, Ruppia rostellata, Wolffia arrhiza) no primary root is developed or even indicated.

The extra-seminal development of the embryo may be briefly described as follows:-The first event is the elongation of the hypocotyl, with the result that the radicle passes, through the micropyle, out of the seed into the soil, where it becomes firmly attached. The other members then escape from the seed, the coat of which becomes more or less split. In those cases in which the growth of the hypocotyl is active, the cotyledons appear above the surface of the soil, that is, they are epigean (e.g. Cucurbita, Ricinus, Radish, Sunflower, Scarlet Runner, etc., most Gymuosperms), either leaving the seed-coat in the soil, or carrying it up to the surface. In those cases in which the growth of the hypocotyl is comparatively slight, the cotyledons do not reach the surface of the soil, that is, they are hypogean (e.g. Vicia Faba, Pea, Grasses, etc.): here it is the epicotyl (plumule) which grows rapidly, and is the first member to appear above ground. The part which first appears above ground, whether it be hypocotyl, epicotyl, or cotyledon, usually does so in the form of an arch, so that the apex is not exposed to injury whilst the member is forcing its way up through the soil.

Epigean cotyledons become green in colour, and in many cases (e.g. Sunflower, Radish) assume the appearance, and discharge the functions, of foliage-leaves ; but they do not ever precisely resemble, either in size or form, the true foliage-leaves of the plant to which they belong.

Vegetative Propagation is common among Phanerogams, by means of bulbs (e.g. Lily, Onion, and many other Monocotyledons), tubers (Potato), tuberous roots (Dahlia), etc.

B. The Ganetophyte. As all Phanerogams are heterosporous, the sexual generation is represented by two individuals, a male and a female, developed respectively from the microspore and the macrospore.

The Male Prothallium is, in all cases, filamentous and relatively small, consisting of but few cells. The first indication of its development is the division of the nucleus of the microspore, which may take place even before the microspore escapes from the micro- 
sporangium, and this is followed by cell-formation. In the Angiosperms the cell-formation is simple, consisting in the aggregation of protoplasm round one of the two nuclei, without any formation of cell-wall, so that a small primordial cell, the generative cell, is formed, floating freely in the protoplasm of the microspore which, with the other nucleus, constitutes the vegetative cell. In the Gymnosperms the process is rather more complicated. In the simplest case (e.g. the Yew), the microspore divides into two cells, separated by a cell-wall; of these the one, the antheridial cell, undergoes division into two, a stalk-cell, and a generative cell;
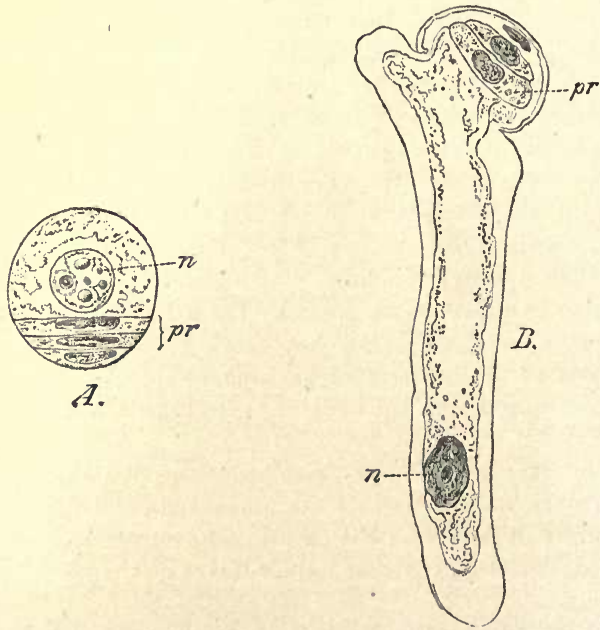

Fra. 240, - Development of the male prothallium of Ginkgo biloba (Gymnosperm). $A$ Pollen-grain in which cell-division is proceeding whilst still in the pollen-sac: $n \mathrm{nu}$ cleus of the vegetative cell; $p r$ three prothallial cells, the innermost of which is the antheridial cell. $B$ older pollen-grain developing a pollen-tube; $p r$ prothallial cells; $n$ nucleus of vegetative cell ( $\times 540$ : after Strasburger.)

whilst the other remains as an undivided vegetative cell. In some cases, however (e.g. Larch, Ginkgo, Fir), generally three cells are successively cut off by parallel septa (Fig. 240): of these the two first formed are merely vegetative cells, and undergo disorganisation, whilst the last is the antheridial cell, and undergoes division into a generative cell and a stalk-cell. 
In both Angiosperms and Gymnosperms, the pollen-tube is formed by the outgrowth of the large vegetative cell: in both cases the generative cell (after being set free when necessary) enters the pollen-tube together with the vegetative nucleus; the vegetative nucleus becomes disorganised, whilst the generative cell undergoes division into two; either into two equal generative cells, as is generally the case, or in two unequal cells only one of which is generative (e.g. Taxus). More than one pollen-tube may be developed from the microspore (Fig. 236).

Thus the male individual in the Phanerogams is a prothallium consisting of but few cells, and the antheridium is at most twocelled.

The male cell is usually a small nucleated primordial cell in the pollen-tube, and is either the original generative cell itself, or a product of its division ; but in sorne Gymnosperms (Cycas, Zamia, Ginkgo) it is a large spirally-coiled multiciliate spermatozoid. It is eventually extruded through the apex of the pollen-tube.

The Female Prothallium is developed in the interior of the macrospore (embryo-sac) in a similar manner to that of the heterosporous Pteridophyta: but, in the Phanerogams it does not at any period project from the macrospore as it does in the Pteridophyta, though this occurs exceptionally in the Cycadaceæ.

The development of the prothallium (or endosperm) is simple in the Gymnosperms. The nucleus of the macrospore divides; repeated nuclear division takes place, until a large

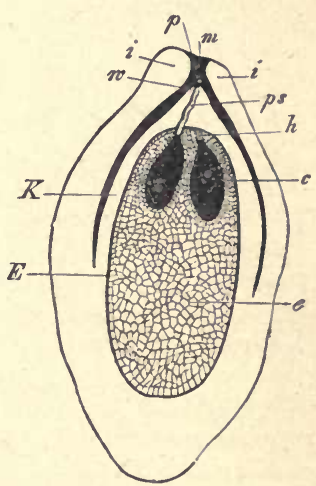

Fig. 241.-The female prothallinm of Gymnosperms (e.g. Pinus), shown in a longitudinal section of the ovale ( $x$ about 15; disgrammatic) : $i i$ inte zument; $\boldsymbol{m}$ micropyle; $\boldsymbol{K}$ nucellus (macrosporangium); $E$ embryo-sac (macrospore); e female prothallium (endosperm), in which sre situated, towards the micropyle, $t$ wo archegonia, $c$, with neck $h$; $p s$ pollen-tube entering the neck of the left archegonium : $p$ pollen.grain seated on the apex of the nucellus.

number of nuclei are formed which lie in the protoplasm round the wall of the macrospore; between these nuclei cell-walls are developed, so that a cellular tissue is produced, the cells of which grow and multiply by division until the cavity of the macro- 
spore is entirely filled with this tissue which constitutes the prothallium.

In the Angiosperms the development of the prothallium is more complicated in that it generally takes place in two stages, the one preceding, the other following, fertilisation. The nucleus of the macrospore divides into two: of these the one travels to the micropylar pole, the other to the chalazal pole of the macrospore; each nucleus then divides, and each of the four so formed divides again, so that eight nuclei are formed, four at the micropylar, and four at the chalazal pole of the macrospore; one nucleus is then conveyed

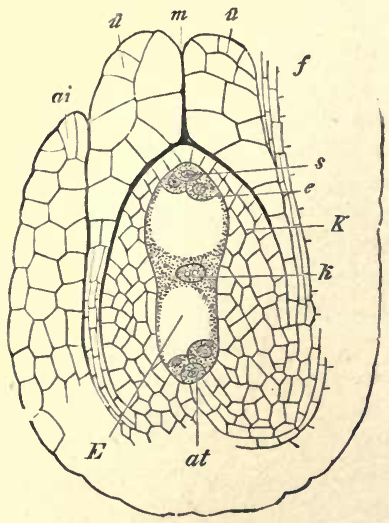

Fig. 242,-The female prothallium of Angiosperms, shown in a longitndinal section of the ovnle, before fertilisation $(\times 70)$ : ai nuter, $i$ inner, integument; $m$ micropyle; $f$ fnnicle. K Macrosporangium (nucellus). E Macrospore (embryo-sac). $k$ Definitive nucleus of the embryo-sac. The female prothallinm consists of the egg-apparatus at the micropslar end of the macrospore, and of the group of antipodal cells at at the chalazal end. The egg-appsratus consists of two synergidæ $s$, and an oosphere 6. from each pole toward the centre of the macrospore, where the two nuclei meet and fuse into one which is termed the definitive nucleus of the macrospore or embryo-sac. Three nuclei now lie at each pole, and around these aggregation of protoplasm takes place, so that cells are formed: those at the chalazal pole soon acquire a cell-wall, and are termed antipodal cells: those at the micropylar end do not form any cell-wall; one of them is the female reproductive cell or oosphere, the other two are sterile (though in rare cases they are fertile), and are termed the synergida, the three together constituting the egg-apparatus. This is the extent to which the development of the female prothallium takes place previously to fertilisation (Fig. 242.) In most Angiosperms the structure of the prothallium is completed by the formation, after fertilisation has taken place, of additional cellular tissue: this process is initiated by the division of the definitive nucleus of the macrospore, nuclear division is repeated, cell-formation takes place in the manner described above for the Gymno- 
sperms, and the macrospore becomes more or less completely filled with cellular tissue, commonly termed endosperm.

The degree of development attained by the endosperm in Angiosperms is various. Whilst, as a rule, it completely fills the embryo-sac, leaving room, however, for the embryo, in some cases it occupies but a portion of the embryo-sac, as in the Coco-nut, where it forms a thick parietal layer; or, as in Nymphæa, Viscum, Lathræa, Thesium, Rhinanthus, etc., where the development of endosperm is confined to the npper half of the embryosac. In some cases the endosperm is rudimentary, being represented merely by a number of nuclei, as in Tropæolum, Alismaceæ, Orchidace ; and in Canna even this rudimentary development is wanting.

The antipodal cells do not, as a rule, undergo any further development, but in some cases (e.g. some Graminaceæ) they have been observed to divide and give rise to a considerable mass of cells.

The female organ is essentially an archegonium. In most Gymnosperms it is actually an archegonium, like that of the Pteridophyta ; it is developed from a single superficial cell of the prothallium at the micropylar end, and has a neck containing a canal-cell, leading to the ventral cavity in which lies the female cell or oosphere. In the Angiosperms the female organ is reduced to a single naked cell: the three cells constituting the eggapparatus represent each an archegonium reduced to a single cell; but one cell only is a true fertile oosphere, the other two (the synergidæ) being sterile as a rule.

Pollination. In view of the fact that the female cell (oosphere), and the prothallium bearing it, remain (as a rule) permanently enclosed in the macrospore, and that the macrospore remains enclosed in the indehiscent macrosporangium, it is clear that the process of fertilisation can only be effected when the microspore germinates in immediate proximity to the macrosporangium. The bringing of the microspore into such close relation with the macrosporangium is what is termed pollination (see p. 232). When the pollen of any one flower is brought into relation with the macrosporangium of the same flower, the case is one of self-pollination; when the pollen of any one flower is brought into relation with the macrosporangium of another flower (whether on the same plant, or on another plant of the same species), the case is one of crosspollination.

The microspores when so brought are placed under conditions of moisture and nutrition favourable to their germination. In Gymnosperms, where there is no ovary and no stigma, the microspore is 
brought into direct contact with the macrosporanginm (Fig. 241). In the Angiosperms, where there is an ovary and a stigma, the microspores cannot come into direct contact with the macrosporangium; they fall upon the stigma and germinate on its moist surface; the pollen-tubes then grow into the ovary, down the style if there is one, and finally enter the ovules.

In certain cases flowers are so modified as to ensure self-pollination: instances of this are afforded by species of Viola, Lamium amplexicaule, Oxalis Acetosella, and others, where the plant (in addition to the ordinary flowers) bears inconspicuous flowers which do not open, and in which self-fertilisation is perfectly effected by the pollen; these peculiar flowers are said to be cleistogamous.

In the great majority of Phanerogams, however, cross-pollination is the rule. In the case of diclinous or diøecious plants (e.g. Gymnosperms) it is clear that pollen must be conveyed from a staminate to a carpellary flower. It is also known that in a great number of monoclinous flowers, pollination is effected by the transfer of pollen from one flower to another: in some of these cases it has been demonstrated that it is only the pollen of another flower which can effect fertilisation; in other cases, that the pollen of the same flower, though not absolutely useless, has less fertilising power than that of another flower; and in yet other cases, that though the pollen of the flower itself has sufficient fertilising effect, yet the progeny is less vigorous than when pollen is supplied from another flower.

The conveyance of pollen from one flower to another is effected, in the case of a number of plants with inconspicnous flowers (e.g. Gymnosperms, Grasses, many Dicotyledonous Forest-trees), by the agency of the wind, when they are said to be anemophilous; but in the case of flowers which are conspicnous by their size, colour, perfume, or by their secretion of honey, the conveyance is effected by the insects which are attracted to visit the flowers; such flowers are said to be entomophilous.

Among the contrivances for the prevention of self-pollination in monoclinous flowers, one of the simplest is the arrangement of the anthers and stigma in such positions that the pollen cannot possibly reach the stigma of the same flower, e.g. Aristolochia (Fig. 243). Or secondly, the abortion of all the microsporangia in some flowers and of all the macrosporangia in others; in such flowers the organs in question are present, but they are not functional: this is an apprach to the diclinous condition; it 
occurs in the Tiger-Lily, in which the anthers are commonly abortive in some flowers and the ovaries in others. Thirdly, dichogamy frequently occurs, that is, that the stigmas and stamens attain their functional activity at different times: flowers in which this occurs are either protandrous, that is, the anthers are first developed and have already shed their pollen when the stigma of the same flower is capable of receiving it ; or they are protogynous, that is, the stigma is fully developed before the anthers of the same flower are ready to shed their pollen: in the latter case self-pollination is obviously only excluded if the stigma is withered before the pollen is shed; there are, however, protogynous flowers in which the stigma remains fresh for a long time and which may be pollinated by their own pollen. As examples of protandrous flowers, those of the Umbelliferæ, and most of the Compositæ, Lobeliaceæ, and Campanulaceæ may be mentioned; and of protogynous flowers, Aristolochia, Arum, Scrophularia nodosa, and some species of Plantago, but this condition is less common than the preceding.

Among the contrivances which lead to the cross-pollination of flowers by the agency of insects, the means of tempting insects to visit the flowers, such as bright colours, odours, and the secretion of honey, must first be mentioned. The peculiar marking of the flower serves in many cases the purpose of guiding insects to the nectary. The form of the flower, the situation of the honey, the position of the stamens, and their relation to the other parts of the flower, particularly to the stigma, the relative development in point of time of the different parts, all these circumstances combine and co-operate to secure cross-pollination, and sometimes to allow of the visits of particular insects only, as, for instance, of butterflies with long probosces: though there are also cases in which the insects must occasionally convey the pollen to the stigma of the same flower. A simple arrangement of this kind known as heterostylism or dimorphism, and which occurs in species of Primula, Pulmonaria, Linum, Polygonum, etc., may be mentioned here. These plants have two forms of flowers; in one form the stamens are short and the style much longer, so that the stigma projects above the anthers; in the other form, on the contrary, the anthers are on long filaments above the stigma; they are both so constructed that the anthers of one form stand on the same level as the stigma of the other. From the position of the nectary, and the form of the rest of the flower, an insect 
visiting it is obliged to take up the same position at each visit ; consequently after it has visited a flower of the one form, when it visits a flower of the other form, it touches the stigma of the latter with the same part of its body with which in the first flower it brushed the anthers, and thus the pollen which it carried away with it from the anthers of the one flower is trans-

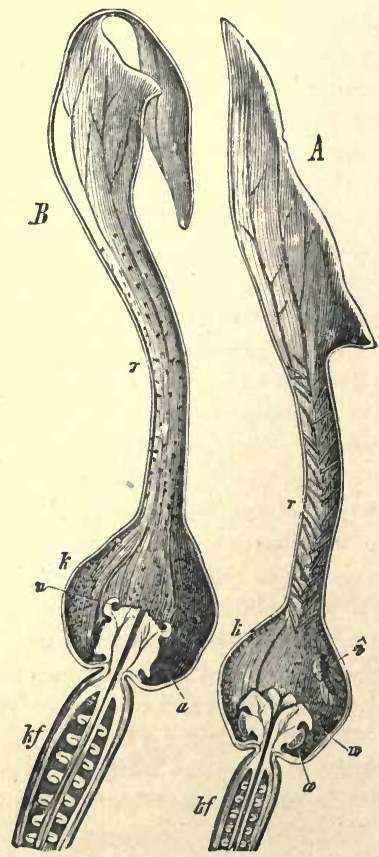

FIg. 213.-Flower of Aristolochia: $A$ before, and $B$ after fertilisation; $r$ the tube of the perianth; $k f$ the cavity below; $n$ stigma; $a$ anthers; $i$ an insect ; $k f$ ovars. (After Sachs.) ferred to the stigma of the other. Observations made by artificially transporting the pollen have shown that fertilisation is most complete when the pollen of stamens of a certain length is conveyed to the stigma of a style of the same length. The same is the case with trimorphic plants, e.g. Oxalis, Lythrum Salicaria: in these, three forms of flowers occur with three different lengths of styles and stamens.

The flower of Aristolochia Clematitis (Fig. 243) is protogynous; insects can penetrate without difficulty down the tube of the perianth, which is furnished on its internal surface with hairs which point downwards, and they thus convey to the stigma the pollen they have brought with them from other flowers ; the hairs, however, prevent their return. When the pollen has reached the stigma, its lobes (Fig. $243 A$ and $B n$ ) spring upwards, and thus the anthers, which now begin to open, are made accessible to the insects; these, in their efforts to escape (Fig. $243 i$ ), creep round the anthers and some of the pollen adheres to them; by this time the hairs in the tube have withered, and the 
insect escapes, dusted over with pollen which, in spite of experience, it proceeds to convey in like manner to another flower. Those flowers which are ready for pollination have an erect position, and the tube of the perianth is open above so that the insect can readily enter; after pollination the peduncle bends downwards and the tube is closed by the broad lobe of the perianth, so that it is impossible for insects to enter flowers which have been fertilised.

In the flower of Epipactis (one of the Orchidaceæ), the anther is situated above the stigma and does not shed its pollen in isolated grains: but when a certain portion of the stigma (the abortive anterior lobe), known as the rostellum (Fig. $244 h$ ), is touched, the two pollinia (p. 396), together with a mass of sticky substance (retinaculum) derived from the rostellum, are removed from the pollen-sacs, adhering to the foreign body (Fig. 244 $F, h)$. The insect creeps into the flower to obtain the honey which is secreted in the cavity of one of the leaves of the perianth, the labellum (Fig. $244 l$ ); as it withdraws from the flower, it carries away the pollinia on its head, and on entering the next flower, deposits them upon the stigma.

Fertilisation. As in other plants, so here, the process of fertilisation consists in the fusion of the male and female reproductive cells. The male cell (see p. 407), whether it be a spermatozoid or not, escapes from the pollen-tube and enters the oosphere; the nucleus of the male cell (male pronucleus) and that of the female

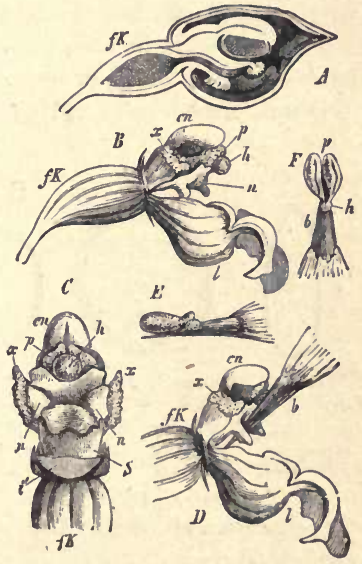

Fre. 241.-Epipactis lntifolia : $A$ longitudinal section through a flower-bud; $B$ open flower after removal of the perianth, with the exception of the labellum, $l ; C$ the reproductive organs, aner the removal of the perianth, seen from below and in front; $D$ as $B$, the point of a lead-pencil (b) is inserted after the manner of the proboscis of an insect; $E$ and $F$ the leadpencil with the pollinis at ached; $f K$ ovary ; I labellum, its sac-like depression serving as a nectary; $n$ the brosd stigma; $c n$ the connective of the single fertile anther; $p$ pollinia; $h$ the rostellum; $x x$ the two lateral staminodes; $i$ place where the labellum has been cut off; $s$ the gynostemium. (After Sachs.) 
cell (female pronucleus) approach each other and fuse into one the two protoplasms likewise fusing. Fertilisation is now complete; in consequence, the oosphere surrounds itself with a cellwall, becoming the oospore, and begins to develope into the embryosporophyte. Further details are given in the sections on Gymnosperms and Angiosperms respectively.

The Results of Fertilisation. The most direct result of fertilisation is the development of the embryo (see p. 401) from the oospore, a process which involves the conversion of the ovule into the seed. But the effect of fertilisation is not limited to this : a process of growth is initiated in various other parts of the flower so that they undergo marked changes in structure, accompanied by considerable increase in size, the product being the structure known as the fruit (p. 61). In some cases the carpels only are affected, besoming either fleshy and succulent (e.g. Plum), or dry and hard
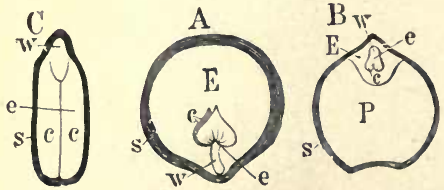

FIG. 245.-Sections of ripe seed. A Nux vomica, showing $\boldsymbol{E}$ endosperm. $\boldsymbol{B}$ Piper, showing both endosperm $E$, and perisperm $\boldsymbol{P}$. C Almond, devoid of endosperm; s the testa; 6 embryo; $w$ its radicle; c c its cotyledons. (e.g. Poppy); in others, the floral axis becomes fleshy (e.g. Strawberry); in others again the perianth-leaves also (e.g. Mulberry). It is convenient to regard as true fruits only those which are developed from the gynæceum alone; and as false fruits, or pseudocarps, those in the formation of which other parts of the flower or of the inflorescence take part.

The seed (p. 62) is produced from the ovule, as a consequence of the fertilisation of the female cell contained within the ovule: its characteristic feature is that it contains an embryo. The seed (Fig. 245) may contain little or nothing but the embryo, in which case it is said to be exalbuminous (e.g. Pea, Bean, Sunflower, Almond, Oak): or it may contain, in addition to a small embryo, a considerable portion of the female prothalliam (endosperm), when it is termed albuminous (e.g. Grasses and other Monocotyledons, Ranunculaceæ): in a fow rare cases the albuminous seed contains, in addition to the embryo and endosperm, some of the nucellar tissue of the macrosporangium which is termed perisperm (e.g. Nymphæaceæ, Zingiberaceæ): in Canna, Chenopodiaceæ, etc., 
there is perisperm but no endosperm in the ripe seed, though it has been ascertained in some cases that endosperm is originally formed.

A formation of endosperm takes place in nearly all seeds, even exalbuminous seeds: but in these latter it is more or less disorganised and absorbed by the growing embryo, so that little or none remains in the ripe seed.

Whether the seed be albuminous or exalbuminous, it contains (except in some parasitic or saprophytic plants, such as Orchids, etc.) a supply of organic substances for the nutrition of the embryo during its extra-seminal period of development. These substances may be mainly stored in the cells of the cotyledons, as in exalbuminous seeds; or in the cells of the endosperm, or in the cells of the perisperm, when present, as in albuminous seeds. The substances are nitrogenous and non-nitrogenous. The nitrogenous substances are proteids, deposited in the solid form as aleuron (see p. 80), and are present in all seeds. The non-nitrogenous substances are starch, in the form of starch-grains (see p. 78), in starchy seeds (c.g. Peas, Beans, Cereals, etc.); or fat, in the form of oil-drops (see p. 80), in oily seeds (e.g. Linseed, Rape, Castor-Oil seed, etc.).

The seed is generally enclosed in a single integument, the testa, derived from the outer integument of the ovule, the inner integument of the ovule having been absorbed; sometimes, however, the seed has two integuments derived from those of the ovule, an outer testa, and an inner endopleura (e.g. Euphorbiaceæ, Rosaceæ) : in others again neither of the ovular integuments persists into the seed, in which case the wall of the embryo-sac is in direct contact with the wall of the ovary.

In a few cases additional integuments or appendages are developed in connexion with the seed, such new growths being designated by the general term aril. The aril may be developed from either the funicle or the hilum ; or from the micropyle, when it is distinguished as an arillode. Good examples of a funicular aril, which grows up round the seed like an additional integument, are afforded by the Nutmeg, where it forms the Mace; (Fig. 246), the Yew, -Water-Lily (Nymphæa), Passion-

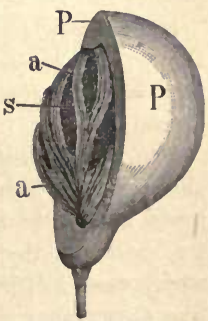

Fre. 216-Fruit of the Nutmeg-tree, Myristica moschata : $\boldsymbol{P}$ pericarp, half of it removed; the seed; $a$ arillus (uat. size). 
Flower. The Willow has a funicular aril in the form of a tuft of woolly hairs. The most striking example of a membranous micropylar aril is the Spindle-tree (Euonymus): in Euphorbia and Polygala the micropylar aril is a small mass of tissue, and in Asclepias it is a tuft of hairs. Other excrescences, not especially connected with either the hilum or the micropyle (sometimes distinguished as caruncles or strophioles), occur in certain plants; thus in the Violet and the Celandine (Chelidonium) an elevated ridge marks the course of the raphe, and in the Willow-herb (Epilobium) a tuft of hairs springs from the chalaza.

The most important point to be considered is, however, that of the structural conditions which determine the production of a seed in the Phanerogams, the feature which sharply defines this group of plants from all others. The structural conditions are briefly as follows:- the macrospore (embryo-sac) is not set free from the macrosporangium (ovule), as is the case in the heterosporous Pteridophyta; nor does the macrosporangium itself separate from the plant producing it until it has ripened into the seed: this being so, the macrospore germinates inside the macrosporangium, producing there the female prothallium with its reproductive organs: fertilisation of the oosphere, as also the development of the embryo from the oospore, takes place inside the macrospore; and thus the seed is formed. If the macrospore were set free from the macrosporangium, no seed would be formed; but in that case the condition of things would be that which actually exists in the higher heterosporous Pteridophyta, such as Selaginella and Isoetes.

Some seeds can germinate as soon as they are shed: but, for the most part, they only do so after a peri d of quiescence, though they may lose their germinating power if this period be too prolonged.

The Dissemination of the Seed. Fruits are either dehiscent, so that the seeds escape, or they are indehiscent : in the former case the seeds, and in the latter case the fruits, present various adaptations for ensuring their dispersal. The most conspicuous are those which ensure dispersal by the wind: of this nature are the winglike appendages of the fruit in the Maple, Ash, Elm, etc.; and of the seed of Pinus, Catalpa, etc.: also the hairy appendages of fruits (e.g. the pappus of Compositæ, the feathery style of Clematis, etc.), and of seeds (e.g. on those of Gossypium the Cotton-plant, Willow, Poplar, etc.). Other adaptations ensure dispersal by 
animals ; such are the hooks on fruits (forming burrs), as in various Boraginaceæ, Compositæ, Galium, etc.: the succulence and agreeable taste of many indehiscent fruits also promotes the dispersal of the seeds, the fruits being eaten by animals and the seed being protected from digestion by hard protective tissue either in the fruit (endocarp) or in the seed-coat (testa). In some cases (e.g. Ecballium Elaterium, the Squirting Cucumber; Impatiens nolime-tangere; Oxalis Acetosella; Hura crepitans) the fruit dehisces suddenly, ejecting and scattering the seeds with considerable force. Some fruits, provided with a long appendage (awn), bore their way into the soil (e.g. Stipa pennata, Erodium).

The Life-history of the Phanerogams is essentially similar to that of the heterosporous Pteridophyta, though, on account of the structural peculiarities which bring about the formation of a seed, it is not quite so easy to trace. The sporophyte, or asexual generation, is represented by the plant itself, bearing macro- and microsporangia and macro- and micro-spores. The gametophyte, or sexual generation, is represented by the male and female prothallia developed respectively from the microspore and the macrospore; though it is here very much reduced, even more so than in the highest heterosporous Pteridophyta. Thus there is a definite and regular alternation of generations, since the male and female prothallia can only be developed from the spores of the sporophyte; and, on the other hand, the sporophyte can only be developed from the immediate product of fertilisation, the oospore.

The life-history of these plants is made clear by a morphological consideration, as indicated in the following table, of the structure of the seed :-

$\left.\begin{array}{l}\text { Seed-coats . . . } \\ \text { Perisperm (if present) }\end{array}\right\} \begin{aligned} & \text { macrosporangium of parent- } \\ & \text { sporophyte. } \\ & \text { Endosperm. }\end{aligned}$
$\begin{aligned} & \text { gametophyte: female pro- } \\ & \text { thallium. }\end{aligned}$
Embryo . . . $=$ young sporophyte.

When a plant perishes after once producing flowers and seeds, it is said to be monocarpous. In rare cases (e.g. Agave americana) several or even many years elapse before the plant blooms: more common are annual plants (indicated by the sign $\odot$ ), i.e. such as complete the whole course of their development in a single 
year, as the Wheat; and biennials, which do not blossom until the second year of their life, when they perish, as the Turnip, Carrot, Beetroot, etc. By polycarpous plants are meant such as produce flowers and fruit year after year; such are trees and shrubs, as also many herbaceous plants which have underground rhizomes, tubers, etc.

The sub-kingdom Phanerogamia falls into two natural divisions; the one containing but a single class; the other, two classes.

\section{GROUP IV. GYMNOSPERME.}

Sporophytic Characters. The ovule is not enclosed in an ovary, nor is there any style or stigma: in pollination, the pollen-grain enters the micropyle and comes into direct contact with the nucellus: the flowers are never monoclinous, and are generally without a perianth: there are no companion-cells in the phloem, and the secondary wood does not (except Gnetaceæ) contain true vessels.

Gametophytic Characters. The female prothallium is completely formed before fertilisation: the female organ is generally a well-developed archegonium : the male cell is sometimes a spermatozoid.

\section{Class 8.-GyMNosPERMe}

\section{GROUP V. ANGIOSPERME.}

Sporophytic Characters. The ovule is enclosed in an ovary, and there is always a stigma: the pollen-grain does not come into direct relation with the ovule, but falls upon the stigma and germinates there: the flowers are commonly monoclinous and possess a perianth: there are companion-cells in the phloem, and the secondary wood generally includes true vessels.

Gametophytic Characters. The female prothallium is only partly formed before fertilisation: the female organ is a reduced unicellular archegonium: the male cell is never a spermatozoid.

Class 9.-Monocotyledones. Class 10.-Dicotyledones. 


\section{GROUP IV. GYMNOSPERME.}

The plants of this class are all perennial trees and shrubs, for the most part evergreen: they are classified into the three natural orders, Cycadaceæ, Coniferæ, and Gnetaceæ.

\section{The Sporophyte.}

General Morphology of the Vegetative Organs. The body is distinctly differentiated into stem, leaf, and root.

The Stem grows above ground, usually erect, but climbs in several species of Gnetum : it is woody, and is generally branched monopodially: the symmetry of the main stem is radial, whilst that of the branches is frequently bilateral, either isobilateral (e.g. Thuja, phylloclades of Phyllocladus) or dorsiventral (e.g. species of Abies, Taxus, and many other Coniferæ in which the branches are horizontal). The branches in many Coniferæ (e.g. Pinus, Larix, Cedrus, Ginkgo) are dimorphous, being either long shoots or dwarfshoots (see p. 23): in the other forms the dwarf-shoots bear foliageleaves and fall off, sooner or later, with the leaves which they bear: in Pinus the dwarf-shoots alone bear foliage-leaves, whilst in the other genera the long shoots bear foliage-leaves as well.

The Leaves are either foliage-leaves or scale-leaves. The foliageleaves are either small and numerous, as in the Coniferæ; or large and few, as in the Cycadaceæ, and as in Welwitschia where there are only two foliage-leaves: they are branched only in the Cycadaceæ: they are sessile in the Coniferæ and in Welwitschia: their growth is basal: their form varies considerably, one of the most peculiar forms being that characteristic of certain Coniferæ (Abietineæ) where the leaf is needle-like (acicular) and either flattened or prismatic and angular. The leaves fall annually in only a few forms (e.g. Larix, Ginkgo); in the others the leaves persist for two to ten years, or, as in Welwitschia, throughout the life of the plant.

Scale-leaves, destitute of chlorophyll, occur in nearly all the Cycadaceæ, in most Conifers (absent in most Cupressineæ) and in Ephedra (Gnetaceæ).

The Primary Root always persists as a tap-root.

General Histology. The Stem. The growing-point of the stem, whilst generally conforming to the structure characteristic of Phanerogams (see p. 102), does not present a clearly-marked differ- 
entiation into dermatogen, periblem and plerome. The stem is monostelic: the primary vascular bundles are collateral, are open, and have the usual general structure; they are generally arranged in a single circle round the pith. Secondary growth in thickness takes place as a rule by means of a normal cambium-ring. In the Cycadaceæ and Coniferæ, the secondary wood consists exclusively of tracheides with rounded or elongated bordered pits and of parenchymatous medullary rays, but true vessels are formed in the Gnetaceæ; the secondary bast has generally the normal structure, but in soine cases (Abietineæ) it has no bast-fibres.

The Foliage-leaf is characterised by its well-developed epidermis the cells of which are fibrous (Pinus, Torreya): the stomata are always depressed below the surface, and are borne usually on the under surface only, when the leaf is flat (e.g. Abies, Taxus, Ginkgo, etc.), or on the upper side only (Juniperus), but on all sides when the leaf is acicular (e.g. Pinus, Picea, etc.): the epidermis is supported by a hypodermal layer of fibrous sclerenchymatous cells: when the leaf is flat, the mesophyll is more or less clearly differentiated into palisade and spongy tissue, but when it is acicular, the mesophyll is uniform throughout, consisting of parenchymatous cells with curiously infolded walls (Fig.93, p. 114): the acicular leaves (Abietineæ) have a single central vascular strand enclosing two bundles which give off no branches: in the flattened leaves there may be several ribs which either do (e.g. Ginkgo) or do not branch in the lamina, and in all these cases the bundles end blindly. A remarkable feature in the structure of the leaf is the presence, in all the genera, of a tissue, termed transfusion-tissue (p. 118), which consists of parenchymatous cells, some of which contain no protoplasm and have pitted walls, being in fact tracheides, whilst others contain protoplasm and have unpitted walls. The use of the transfusion-tissue is to compensate for the absence of a much-branched vascular system in the leaf, the tracheidal cells serving to distribute water from the xylem of the bundles to the mesophyll, the other cells serving to convey organic substances formed in the mesophyll to the phloem of the bundles.

The Root grows in length by means of a growing-point differentiated into dermatogen, plerome and periblem, and root-cap as in Dicotyledons (see p. 103); there are commonly two xylem-bundles in the stele: the cambium-ring is formed in the usual way: the phellogen is derived from the pericycle. 
General histological peculiarities. In all the Coniferæ, except Taxus, resin-ducts (see p. 98) are present: they are always to be found in the leaves and in the cortex of the stem, sometimes also in the pith of the stem (Ginkgo), in the primary wood (Pinus, Larix), or in the primary bast (Araucaria) : they are absent from the root in many genera, and when present they never occur in the cortex, but are situated in the primary wood (Pinus, Larix), in the primary bast (Araucaria), or as a single canal in the centre of the conjunctive tissue (Cedrus, Abies): they are formed also in the secondary wood (Pinus, Picea, Larix) or in the secondary bast (Cupressus, Thuja), of both stem and root. Mucilage-ducts resembling the resin-ducts of the Coniferæ, occur in the cortex of the stem in the Cycadaceæ.

The bast of the Gymnosperms resembles that of the Pteridophyta, and differs from that of the Angiosperms, in that it contains no companion-cells (see p. 96), the function of these cells being performed by certain cells belonging either to the medullary rays (Abietineæ, some Cupressineæ) or to the bast-parenchyma.

\section{The General Morphology of the Reproductive Organs.} The reproductive organs are microsporangia (pollen-sacs) and macrosporangia (ovules) : the microsporangia are borne on sporophylls, but (except Gnetum) the macrosporangia are sometimes borne directly on the axis (e.g. macrosporangia of Taxeæ and of the Gnetaceæ): they are developed on distinct shoots, and frequently on distinct plants (e.g. Cycadaceæ: some Coniferæ, such as the Taxeæ; Gnetaceæ generally).

Certain shoots are more or less clearly differentiated as flovers; the only exception being Cycas in which there is no proper macrosporangiate flower. The flower is always unisexual: its structure varies widely; it may consist merely of a terminal sporangium invested by a few small bracts (e.g. macrosporangiate flower of Taxeæ); of a terminal sporangium with a rudimentary perianth (macrosporangiate flower of Gnetaceæ); of one or more sporophylls borne on a short axis and surrounded by a perianth (microsporangiate flower of Gnetaceæ) ; or of a larger or smaller number of sporophylls arranged on an elongated axis, the whole forming a cone.

The Sporophylls are of two kinds, distinguished by the nature of the sporangia which they respectively bear, as microsporophylls and macrosporophylls. When the flower is a cone, the sporophylls have a general resemblance to scaly leaves: in other flowers 
(Taxeæ, Cycas, Gnetaceæ) they have various and specialised forms.

The microsporophyll (stamen) occurs in its simplest form in the Cycadacex, where it is a large stout scale bearing usually an indefinite number of microsporangia on its under surface. In some of the Coniferæ (c.g. Pinus), the microsporophyll essentially resembles that of the Cycadaceæ, though it is much smaller (in proportion with the smaller flowers) and bears only two microsporangia. In the other Coniferæ the microsporophylls, bearing 2-15 sporangia, show more or less distinct differentiation into a stalk bearing a terminal leafy expansion, until, in Taxus, a stage is reached where the microsporophyll consists of a stalk

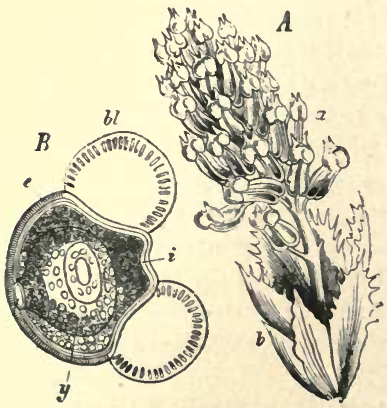

FIG. 217, - A Microsporophyllary (or staminal) flower of Abies pectinata; $b$ aculy bracts; $a$ microsporophyll with two microsporangia (pollensacs). B Microspore (pollen-graiu) (bighly mag.); ( e exine expanded into two hollow vesicles b); y male prothallium. (After Sachs.)

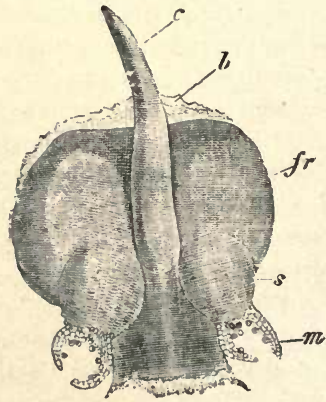

F16. 248.-Pinus sylvertris ( $\times$ 7: after Strasburger) : Macrosporophyll $b$, bearing on its upper surface the placental scale $f i$, which bears two ovules $s$ at its base; $c$ spophysial projection of the placental scale; in micropyle of the ovule within which pollen-grains have lodged.

bearing a peltate lamina, on the under surface of which the sporangia are developed. In other words, the microsporophyll consists of a filament bearing a sorus of sporangia which constitutes an anther (see p. 395). In all cases the microsporangia are developed on the morphologically under (dorsal) surface of the sporophyll.

The gradual differeutiation of the microsporophyll, which can be traced in the Coniferæ, leads on to the more complete differentiation and specialisation which obtains in the Gnetaceæ and in 
the Angiosperms. In Gnetum, however, there are no microsporophylls.

The macrosporophyll (carpel) appears in a simple, yet typical, form in Cycas (see Fig. 253), the one Gymnosperm which has no distinct macrosporangiate flower. Here the carpels are essentially similar to the foliage-leaves, though they are smaller, of a yellow colour, and of a somewhat different form: they are, in fact, developed at the growing-point of the stem in the place of a whorl of foliage-leaves. The few sessile macrosporangia are borne laterally on the lower part of the sporophyll.

In the other Cycadaceæ, the macrosporophyll is a stout scaly leaf, thickened at its outer end, bearing usually two lateral ovules, one on each side.

In the Coniferæ, the simplest form of macrosporophyll is a scaly leaf bearing a single macrosporangium on its upper surface: in other forms the superior surface of the macrosporophyll is clearly marked out, by outgrowths of various kinds, into an apical and a basal half, the latter alone bearing the (1-7) macrosporangia (e.g. Cupressineæ): in the Abietineæ (Pinus, Larix, etc.) the sporangiferous structure of the preceding families is developed from the base of the carpel as a placental scale, which is much larger than the carpel itself, and bears the two macrosporangia on its upper surface. In the Taxeæ the macrosporophylls are rudimentary (e.g. Phyllocladus, Cephalotaxus) or absent (e.g. Torreya, Taxus) : even when present they do not bear the macrosporangia.

In the Gnetaceæ there are no macrosporophylls.

The microsporangia (pollen-sacs) are borne, in nearly all cases, on the lower (dorsal) surface of a sporophyll; they may be numerous (abont 1,000) as in some Cycadaceæ; or few (2-15) in the Coniferæ and Gnetaceæ: scattered (some Cycads), or more commonly grouped into one or more sori, with more or less welldeveloped placental tissue; either imbedded in the tissue of the sporophyll (e.g. Abietineæ), or freely suspended (eg. Ginkgo): in the Cupressineæ, the sporangia, when young, are covered by an outgrowth of the under surface of the sporophyll which is comparable to the indusium of Ferns. In Gnetum, as there is no microsporophyll, the two microsporangia are borne on the apex of the floral axis.

The structure of the microsporangium is simple: it is unilocular; it contains, at an early stage, a mass of spore-mother-cells derived from the archesporium, surrounded by a layer of tapetal 
cells also derived from the archesporium, and by a wall consisting of one, two, or more, layers of cells : each spore-mother-cell gives rise to four microspores, which are usually tetrahedral, but bilateral in the Cycads. The dehiscence is generally longitudinal.

The microsporcs (pollen-grains) present no special features beyoud the fact that in some genera of Coniferæ (e.g. most Abietineæ) the exine is dilated into two hollow expansions which lighten the pollen-grains and facilitate their dispersal by the wind.

The macrosporangia (ovules) are borne either terminally on a floral axis (e.g. Taxeæ, Gnetaceæ), or on the upper surface of a macrosporophyll; on the floral axis they are borne singly, on the sporophylls their number varies $(1-7)$ : they are orthotropous and sessile, the micropyle being directed either towards the axis of the cone (in Abietineæ), or away from it (Cupressineæ): they have a single integument, though in some genera (most Taxoideæ) an arillus is eventually developed.

The macrospore (embryo-sac) is developed singly in the macrosporangium, by the growth and maturation of the mother-cell which does not undergo division into four as in the Pteridophyta. In the Cycadaceæ the wall of the macrospore, like that of spores generally, is differentiated into two layers, the outer of which is cuticularised.

Pollination. The microspores are conveyed by the wind from the microsporangiate to the macrosporangiate flowers, the Gymnosperms being anemophilous, and they come into direct relation with the ovule. In the case of cone-flowers, the scales separate at the time of pollination, to permit of the pollen-grains being blown in between them. The micropyle of the ovule secretes a mucilaginous liquid which catches one or more of the pollen-grains: by the gradual evaporation of this liquid, the pollen-grain is drawn down the micropyle and is lodged on the apex of the nucellus, where it germinates.

Embryogeny of the Sporophyte. The Gymnosperms are remarkable in that they are frequently polyembryonic (most $\mathrm{Cu}$ pressineæ, Abietineæ, and Gnetaceæ), though the ripe seed eventually contains only a single embryo (see p. 401).

In the Coniferæ (except Ginkgo) the type of development is essentially the same throughout, though with slight variations. In the Abietineæ the nucleus of the oospore descends towards the lower end of the cell, and divides into two, and each of these again into two; cell-formation takes place, walls being formed in two 
planes at right angles to each other, so that the lower end of the osspore is occupied by a group of four cells lying in one plane; these cells then divide by transverse walls, so that three tiers of four cells each are formed; of these, each cell of the middle tier grows out into a long unicellular suspensor; those of the upper tier
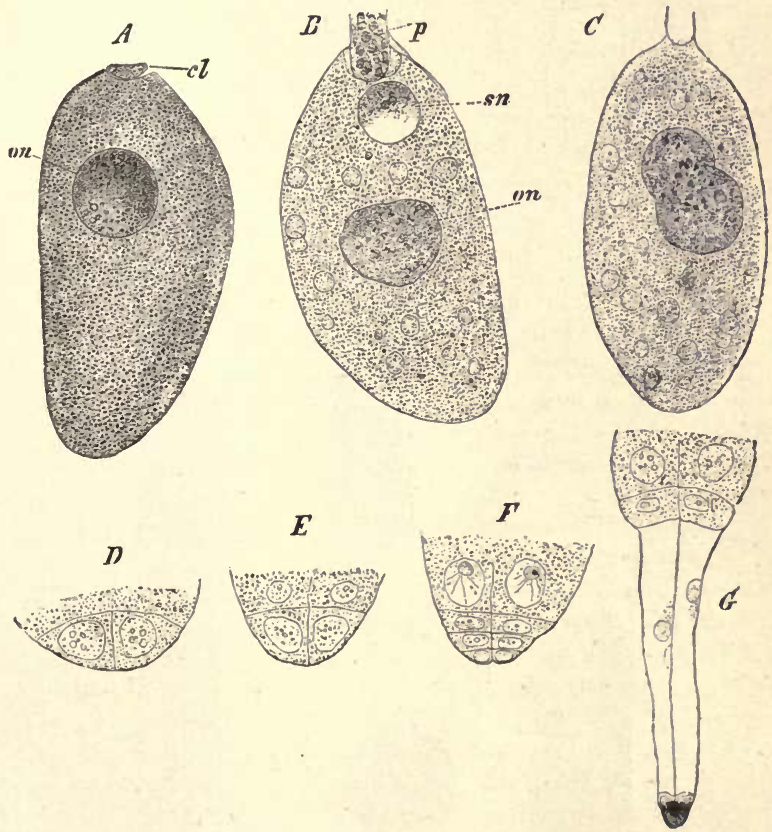

Fig. 249.-Fertilisation, and early stages in the embryogeny, of Picea excelsa ( $\times 90$; afer Strasburger). A Oosphere, with nuclens on, sud canal-cell cl. B Fertilisation in progress : $p$ pollen-tnbe; $s n$ nucleus (male pronucleus) of the male cell now in the oosphere on female pronucleus. C Fusion of male and female pronnclei. D Commencing cell-formation at the chalazal end of the oospore; $E$ a further stage: $F$ three tiers of four cells each have been formed: $G$ the cells of the middle tier have elongated into suspensors, bearing the single embryo at their lower end.

simply maintain the connexion of the suspensors with the rest of the oospore; those of the lowest tier, whilst also contributing to the suspensors, each give rise to an embryo: from the cells at the base 


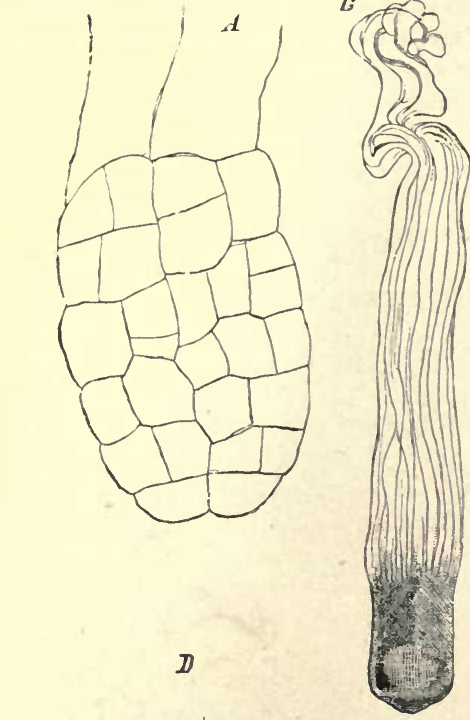

b
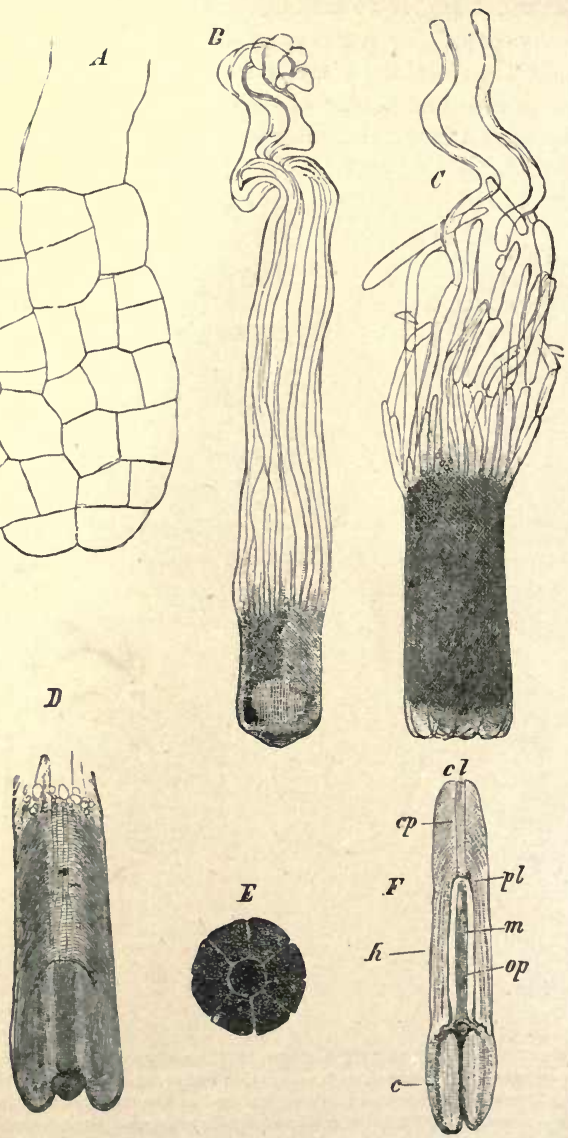

Fic. 250.-Later stages in the embryogeny of the sporophyte of Picea excclsa (after Strasburger). A Optical section of yonng embryo borne on the end of the suspensors $(\times 240)$ : $B$ older embryo, with suspensor and embryonal tnbes; at this stage the growing-points of primary root and stem are already differentiated: $C$ balf-grown embryo in surface-view: $D$ longitudinal section of a half-grown embryo: $E$ surface-view of the apex of the shoot of this embryo $(\times 27): F$ longitudinal section of a fully developed embryo in a ripe seed; $c$ cotyledons; $h$ bypoctyl; $p l$ apex of the plerome in the root; $c p$ root-cap; $m$ pith; op pros cambial ring. 
of the embryo, one or more embryonal tubes are developed which grow backward along the suspensor. Picea excelsa departs from this type in that the suspensors remain coherent, bearing at their end the cells of the lowest tier which develope into but a single embryo, whereas in the typical Abietineæ four embryos originate from each oospore (polyembryony). Only a single embryo is developed from the oospore in Thuja (Cupressineæ) and in the Taxeæ.

The cotyledons vary in number: one, in Ceratozamia, and sometimes in other Cycadaceæ; two, in the Cycadaceæ generally, in the Cupressineæ generally, in the Taxoideæ, and in the Gnetaceæ; in the Cupressineæ sometimes $3-5$; in the Abietineæ 5-15. The cotyledons are generally epigean, but they are hypogean in the Cycadaceæ.

The growing-point of the root is in all cases differentiated endogenously, at some distance from the posterior end of the embryo.

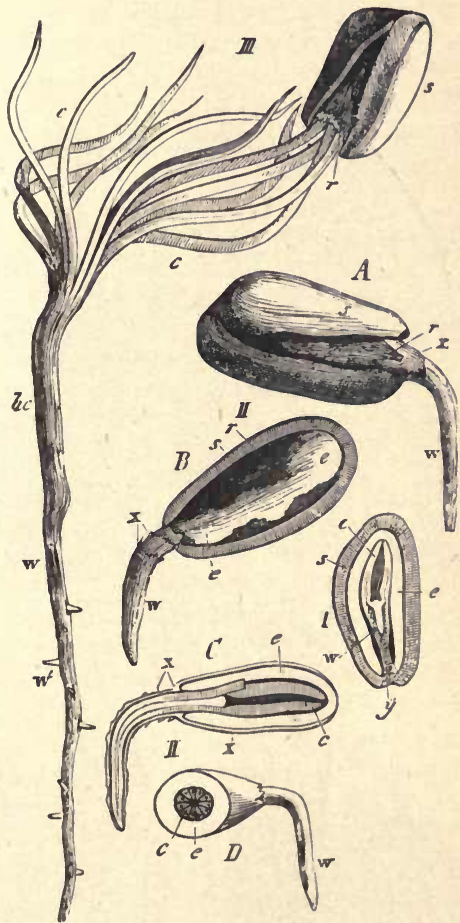

Frg. 251.-Germinating seods of Pinus Pinea: I first stage, in longitudinal sectlon: II second stage, with protruding radicle; $A$ external view; $B$ view after removal of half the seed-coat; $C$ longitndinal section, withont seedcoat; $\boldsymbol{D}$ transverse section, without seed-cost; III germination is here completed, the cotyledons having expanded, and the hypocotsl elongated : - seed-coat; $c$ endosperm; wo radicle; $c$ cotyledons; y micropyle; $r$ rell membrane (remains of nucellus); $\approx$ the embrso-sac. 
ThE GaмeтоPнтTE.-As the Gymnosperms are heterosporous, the sexual generation is represented by a male and a female individual.

The Male Individual is a prothallium developed from the microspore as described on p. 405 . It consists of two or more cells, one of which grows out into a pollen-tube (see Fig. 240).

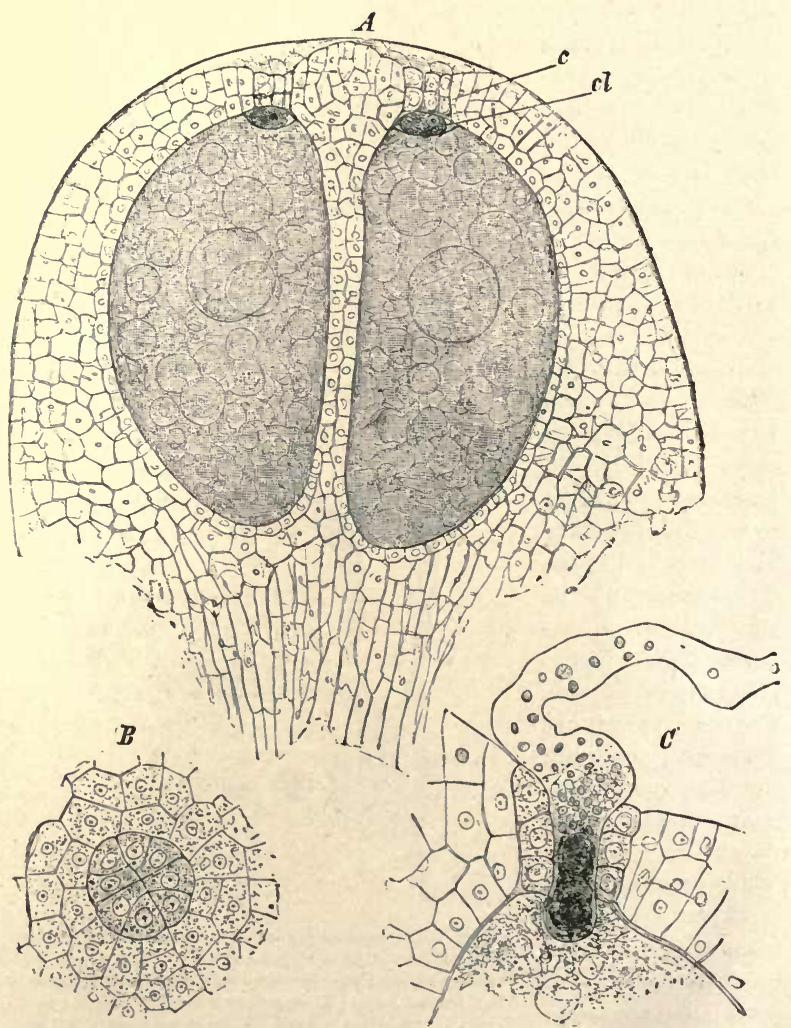

FiG.252. - 1 Longitudinal section of the mioropylar portion of the female prothallium of Pice excolsa snowing two archegonia $(\times 100)$ : c neck of archegonium; cl canal-cell. $B$ Surface-view of nuopened neck of an archegonium $(\times 250)$. C Pollen-tube penetrating to the oosphere through the neck of the arohegonium ( $\times 250)$. (After Strasburger.) 
The male organ is a rudimentary antheridium consisting of two cells, the stalk-cell and the generative cell.

The male cell is derived from the generative cell of the antheridium which travels into the pollen-tube; this cell undergoes division into two similar cells, near the apex of the pollen-tube, both of which are, as a rule, functional male cells. In Cycas, Zamia, and Ginkgo, each of these two cells actually developes into a large multiciliate spermatozoid; whilst in those forms in which the male cell is not a spermatozoid, it is of somewhat spherical or oval form. When, as in Juniperus, and other Cupressineæ, several archegonia are'fertilised by means of a single pollen-tube, repeated cell-division takes place in the pollen-tube.

The Female Individual is a prothallium (sometimes called endosperm) developed within the macrospore. The germination of the macrospore begins with the division of its nucleus ; nuclear division is repeated until a large number of nuclei are formed, lying in the parietal protoplasm of the spore; free cell-formation then takes place, walls being formed between the cells so that the interior of the macrospore is lined by a layer of cells which grow and divide until the cavity of the macrospore is entirely filled. It is characteristic of Gymnosperms that the development of the prothallium is uninterrupted, and that it is completed before the female organs are developed and, consequently, before fertilisation can have taken place.

The female prothallium is a mass of parenchymatous tissue, which does not, as a rule, protrude to any extent from the spore, and which, in consequence of the exclusion of light, is destitute of chlorophyll; the only exception to this rule is offered by the Cycadaceæ where, if the female organ is not fertilised, the prothallium, resuming its growth, protrudes through the micropyle and turns green in the light.

The female organ is an archegonium, and is developed from a single superficial cell of the female prothallium at its micropylar end. The mother-cell generally divides transversely into two; an upper, the neck-cell; a lower, the central cell: the neck-cell usually divides, by two vertical walls, into four cells, which form the neck; the central cell grows, and divides transversely at its upper end so as to cut off a small cell, the canal-cell, which lies in the canal formed by the separation of the neck cells, and a large cell which is the female cell or oosphere (Fig. 252).

The number of archegonia developed on the female prothallium 
varies from a small number (3-5) in the Abietineæ, to a large number $(20-60)$ in Welwitschia and Gnetum. The archegonia are either scattered (Abietineæ), or in a group (Cupressineæ): when scattered, the central cells are surrounded by a layer of small cells belonging to the prothallium; when in a group, the central cells are in actual contact and have a common investment of small cells.

The female cell or oosphere is a relatively large nucleated cell, the protoplasm of which is so highly vacuolated that it presents a frothy appearance.

Fertilisation. When the microspore has reached the apex of the nucellus, it developes a pollen-tube which penetrates the tissue of the nucellus, making its way to the archegonia which have been, or are being, developed on the prothallium inside the macrospore. Generally speaking, the pollen-tube, on reaching the macrospore, pierces its wall, and enters the neck of an archegonium (when scattered), or spreads out over the necks of a group of adjacent archegonia; a male cell is forced out through the mucilaginous tip of the pollen-tube into the oosphere, or into each of the oospheres of a group of archegonia so that one male organ fertilises several archegonia; the act of fertilisation is completed by the fusion of the male pronucleus with the female pronucleus, to constitute the nucleus of the oospore (Fig. 249).

With regard to those forms in which the male cell is a spermatozoid, in Cycas and Ginkgo the pollen-tube does not approach the archegonia, but by its growth causes the absorption of much of the micropylar portion of the nucellus, so that a cavity containing liquid is formed, into which the spermatozoids are discharged. In Zamia the pollen-tube comes into contact with the neck of the archegonium, into which it discharges the two spermatozoids tygether with a drop of liquid. In all cases the spermatozoids swim down the neck of the archegonium to the onsphere, and one of them enters it and fertilises it.

The Results of F'ertilisation.

1. The fruit. In all the Gymnosperms which have a cone-like macrosporangiate flower (Cycadaceæ, except Cycas; Coniferæ, except Taxeæ), one effect of fertilisation is to cause more or less considerable growth in the macrosporophylls, or in the placental scales, as also tissue-change resulting in their becoming woody (e.g. Pinus, Abies, etc.) or fleshy (e.g. Juniperus), the product being the fruit. 
The fruit-cone, in most cases, sets free the seed by the separation of the macrosporophylls, or of the placental scales, which fall off from the axis of the cone, leaving it bare (most Cycadaceæ, also Abies, Cedrus); or they merely separate enough to let the seeds fall out, and then the cones either remain on the tree (e.g. Larix), or, as is more commonly the case, drop off entire. However, where the fruit is a berry-like cone (e.g. Juniperus), the macrosporophylls do not separate, and the dispersal of the seed depends on the fruit being eaten by animals.

2. The seed is albuminous in all Gymnosperms, the single straight embryo being imbedded in the endosperm (see Fig. 251 I) in all cases, also, some portion of the nucellar tissue persists as perisperm, amounting, in the Cycadaceæ and Coniferæ, to little more than a membranous layer.

The development of the seed-coats varies widely. In the Cycadaceæ the testa consists of two layers, an outer fleshy and succulent, and an inner hard and woody, so that the seed bears a superficial resemblance to a fruit such as a plum. In those Coniferæ in which the seeds are produced in a cone-fruit, the testa is hard and tough; but in those in which the seed is exposed from the first, the testa is either fleshy (e.g. Ginkgo, Cephalotaxus), being developed after the manner of that in the Cycadacex, or it is hard, and is invested by a succulent aril (e.g. Taxus). In those Coniferæ with woody cones (e.g. Abietineæ, most Cupressineæ) the seed is usually winged, either by means of a membranous outgrowth of the testa, or (Abietineæ) by the adhesion to the seed of a thin strip of tissue, split off from the surface of the placental scale.

\section{Classification of the Gymnosperma.}

The group contains the following three orders:-

1. CyCADACE.s: the trunk is generally unbranched: the leaves are large and branched: no vessels in the secondary wood.

2. CoNIFERA: trunk much branched: leaves many, small, and unbranched: no vessels in the secondary wood.

3. GNeTACEe: habit various: flowers have a rudimentary perianth : there are vessels in the secondary wood.

Order 1. Cycadaceæ. The Cycadaceæ are plants which, in many respects, show affinity with the Ferns, while, on the other hand, they resemble the Palms in external appearance. The stem is tubercular or cylindrical. The vegetative leaves are of two kinds; scaly leaves, brown and dry, closely covering the surface of the stem; foliage-leares, pinnate, 
of a leathery consistency, produced annually or at a longer interval, forming a crown at the top of the stem; the foliage-leaves are generally developed expanded, but in Cycas the pinnæ are circinate in vernation, as is also the phyllopodium in Stangeria and Zamia.

The diœeious flowers are produced, either singly or several together, at the apex of the stem; they are cones (except Cycas). The development of the cones does not arrest the growth in length of the stem: hence the stem may be regarded as a sympodium, its growing-point being maintained by either dichotomous or lateral branching (p. 18). The macrosporophylls of Cycas do not constitute a true flower, since they are not borne, as in the other genera, on a special axis, but simply take the place of a whorl of foliage-leaves. The cones consist of an elongated axis, bearing

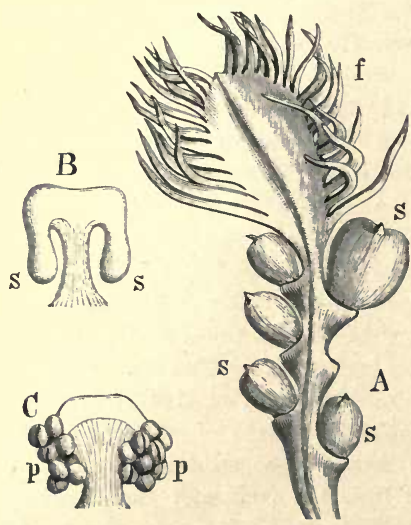

Frg. 253.-Sporophylls of Cycads. A macrosporophyll of Cycas revoluta (k nat. size): $f$ pinnæ; ovules. $B$ Macrosporophyll of Zamia muricata, with two ovnles (s); C microsporophyll of this species with numerous microsporangia $(p)$.

numerous spirally-arranged scaly sporophylls, which vary in number from 30 to 600 . The microsporophylls bear on the under surface usually numerous (2 to 1000 ) microsporangia, either scattered or in sori (Cycas, Stangeria, Zamia). The macrosporophylls bear two orthotropous macrosporangia, one on each flank, developed upon the peltate terminal lamina; but the exceptional macrosporophylls of Cycas (see Fig. 253) may bear as many as 5-6 macrosporangia.

The macrosporangia are all sessile, and have a single integument, and are of considerable size; those of Cycas are as large as a plum before fertilisation.

In the coniferous genera, the macrosporangiate flower becomes the fruit; that is, a dry cone, the sporophylls of which fall away, and so set free the seeds. In Cycas, the sporophylls bend outwards and drop off, bearing the seeds. The seed is covered by a testa, developed from the integument of the ovule, which is succulent externally and stony internally. It contains a single straight embryo, on a coiled suspensor, lying in the endosperm. The embryo has generally two cotyledons(one in Ceratozamia, and occasionally in other genera also), which are hypogean.

The Cycadaceæ, of which there are nine genera, and about seventy-five species, are all tropical or subtropical.

Order 2. Coniferæ. This order includes the Pines, Firs, Cypresses, Yews, etc., which, for the most part, are extra-tropical, inhabiting more especially the northern hemisphere. 
The conspicuous features of their morphology are the regular monopodial branching of the stem, the small (often acicular) simple leaves, and the tap-root. In their histology, these plants resemble the Dicotyledons in that the stem grows in thickness by a normal cambium-ring; but the vascular tissue of the wood consists entirely of tracheides with bordered pits. The presence of resin-ducts is another characteristic feature.

The flowers are never monoclinous; some genera are dioecious. The microsporangiate flower is a cone, consisting of an elongated axis bearing microsporophylls (Fig. 254), which are generally somewhat peltate in form. Each microsporophyll bears two or more microsporangia on its under (dorsal) surface. The macrosporangiate flower is also a cone in certain cases (Pinoideæ, Fig. 255), in which case the macrosporophylls bear the macro-
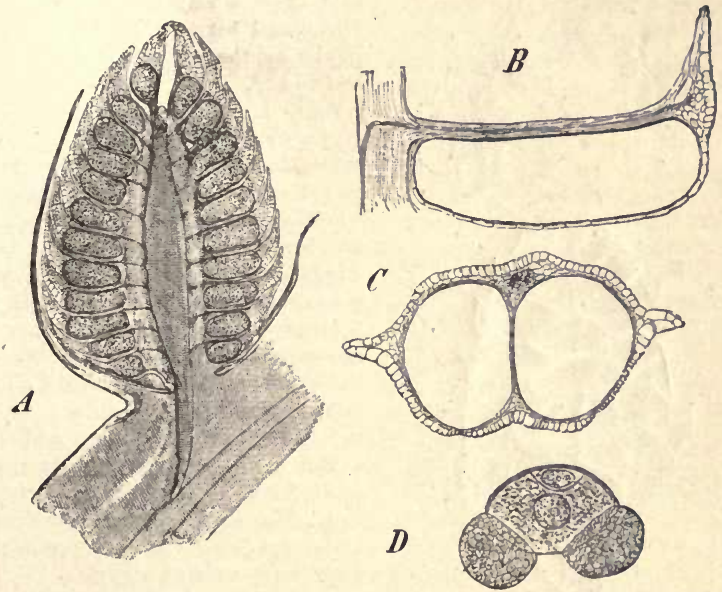

Fra. 25 b.-Pinus montana (Pumilio). A Longitudinal section of a microsporangiate flower ( $\times 10)$. B Lorgitudinal section of a microsporophyll, showing the cavity of one pollen-sac (x 20). C Transverse section of a microsporophyll, showing the cavities of both pollensacs. $D$ Germinating two-celled microspore of Pinus sylvestris, showing the expansions of the exine $(\times 400)$. (Aftor Strasburger.)

sporangia; in other cases there is a less perfect cone, or none at all (Taxoideæ, see Fig. 258), the macrosporophylls are either rudimentary or absent, and the macrosporangia are generally borne on the axis.

In some genera (e.g. Pinus, Juniperus) the seed takes two years to ripen; in the first year, pollination takes place, and the pollen-tube begins to grow through the tissue of the nucellus; in the second year, after a period of rest, the pollen-tube completes its growth, reaches the archegonium, and fertilises the oosphere; as a consequence, the embryo is developed, and the ovule is changed into a seed.

M.B. 
In spite of the fact that so many of the Coniferæ are polyembryonic (see p.424), and that each ovule contains several archegonia, the ripe seed con-, tains only a single embryo, though occasionally two are found (e.g. Ginkgo). The embryo has two, or more, cotyledons, which are usually epigean.

The order, which includes 34 genera and about 350 species, may be naturally divided into the two sub-orders, Pinoideæ and Taxoideæ, based upon the structure of the macrosporangiate flower; each of these sub-

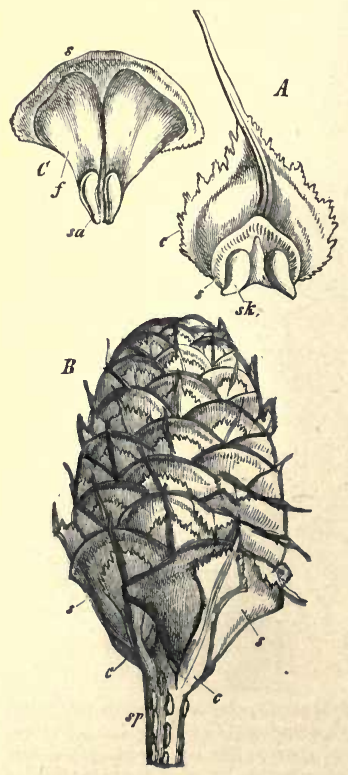

Frg. 255.-Abies pectinata. A Carpel $c$, seen from above (ventral surface), show. ing $s$ the placental scale, and $s k$ the two ovules (mag.) B Mature cone (nat. size); sp axis; c carpel; 8 enlarged placental scale. C Ripe placental scale (s) isolated, seen from above; $s a$ the two seeds, each with a wing $(f)$. (After Sachs.) orders includes several families, the chief of which are described below.

Sub-order I. Pinoidex. The macrosporangiate flowers are cones; the seed has a woody or leathery testa, is enclosed between the macrosporophylls or the placental scales, and has no aril.

Fam. 1. Abietinex: monœcious; on its upper surface at the base, the macrosporophyll bears a large placental scale on the upper surface of which two inverted macrosporangia are borne. The ripe seed has two wings derived from tissue of the placental scale; the microsporophyll bears two microsporangia; microspores usually have expansions of the exine; all leaves arranged spirally ; cotyledons, more than 2 , commonly 5 , sometimes as many as 15 .

The more important genera may be distinguished as follows:-

$A$. No dwarf-shoots; placental scales flat; seed ripens in one year ; stem bears whorled branches.

1. Fruit-cones erect, falling to pieces when ripe; foliage-leaves flat, cylindrical at the base, and not decurrent; placental scales about the same length as the macrosporophylls . Abies.

2. Fruit-cones pendent, falling off entire; foliageleaves with decurrent projecting base.

Leaves 4-angular; placental scales much longer than the macrosporophylls . . - Picea.

$B$. Long and dwarf-shoots. 
1. Placental scales flat; foliage-leaves borne on both long and dwarf-shoots; branching of the stem irregular.

(a) Leaves annually deciduous; seed ripens in one year . Larix.

(b) Leaves persistent; seed ripens in two years. . . Cedrus.

2. Placental scales thickened externally into an apophysis:

foliage-leaves confined to the dwarf-shoots: branches whorled. Pinus. 1. Abies, the Silver Firs. The foliage-leaves are flat, marked on the under surface with two longitudinal white streaks, and show in section two lateral resin-ducts: the macrosporangiate cone is developed in the axil of a leaf borne on a shoot of the previous year, at some distance from its apex, and when ripe falls to pieces so that the naked axis remains. To this genus belongs $A$. pectinata $(A$. alba), the Silver Fir, the emarginate leaves of which stand out in a comb-like manner from the branches.

2. Picea, the Spruce Firs. The foliage-leaves are quadrangular, and have two lateral resin-ducts: the macrosporangiate cone is borne terminally on a shoot of the previous year, becomes pendent after fertilisation, thus enabling the seeds to drop out, and then falls off entire. To this genus belong $P$. excelsa, the Norway Spruce, the leaves of which are compressed laterally.

3. Larix, the Larches. The deciduous leaves are arranged spirally on long shoots, and also in clusters on dwarf-shoots developed in the axils of the leaves of the long shoots of the previous year: the microsporangiate cones are borne terminally on leafless $\mathrm{d}$ warf-shoots, the macrosporangiate cones terminally on leafy dwarf-shoots. $L$. europoca is the common Larch, a native of the Alps and Carpathians.

4. Cedrus, the Cedars. This genus differs from Larix in that the leaves, which are arranged in the same way, persist for more than one year, and in that the seed takes two years to ripen. The genus includes three species: $C$. Libani, in Asia Minor; $C$. allantica, in the Atlas mountains of North Africa: C. Deodara, in the Himalayas.

5. Pinus, the Pines. The thick placental scales are expanded at their free end into a flattened rhombic surface, the apophysis : the seed takes two years to ripen : the foliage-leaves persist for several years and are confined to dwarf-shoots which bear cataphyllary leaves at their bases, and are borne in the axils of the cataphyllary leaves of the long shoots of the same year: the primary branches are arranged in false whorls near the apex of the shoot of any one year, and the branches of a higher order are developed in the same manner: the microsporangiate cones take the place of dwarf-shoots at the base of a long shoot of the same year, and are closely packed : the macrosporangiate cones also occupy the place of $d$ warf-shoots near the apex of long shoots of the same year.

In the section Pinaster, the apophysis has a rhombic free surface with a central projection (umbo): it includes the sub-genus Pinea, characterised by the fact that each dwarf-shoot bears two leaves, with about twenty species, including Pinus sylvestris, the Scots Pine; P. Laricio, the Black Pines; P. Pinaster, the Cluster Pine of South Europe; $P$. montana, the Mountain Pines of Europe; $P$. Pinea, the Stone Pine of the South of Europe, the seeds of which are large and edible. 
Fam. 2. Cupressinea: monœcious, sometimes diœcious: macrosporophylls with a projecting placental outgrowth: seeds axillary, erect, often winged: microspores without expansions of the exine: leares always arranged in whorls.

In the sub-family Cupressinc, including the genera Cupressus and Chamæcyparis, the ripe cone is woody and consists of 2-6 pairs of peltate macrosporophylls coherent by their margins in a valvate manner. The genus Cupressus, the Cypress, has several seeds on each macrosporophyll : in Chamæeyparis each macrosporophyll bears only two seeds.

The sub-family Juniperince, including the single genus Juniperus, is distinguished from the other sub-families in that the flowers are, as a rule, diøecious ; the ripe cone is somewhat fleshy, resembling a berry or a drupe; it usually consists of one whorl of macrosporophylls each bearing one or two wingless seeds.

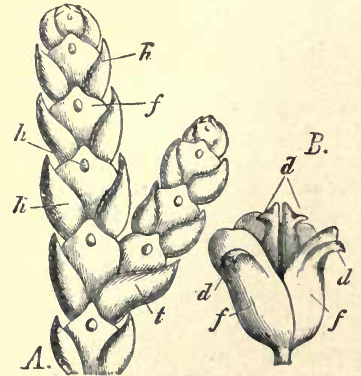

Fig. 256.-A Branch of Thuja occidentalis $(\times 6)$ showing heterophylly: $k$ fiank-leaves ; $f$ surface-leaves; $h$ resinreceptacle. $B$ Fruit of Biota orientalis (nat. size) : $f$ macrosporophylls with ventral ontgrowths $d ; d$ (in the midale line) sterile sporophylls.
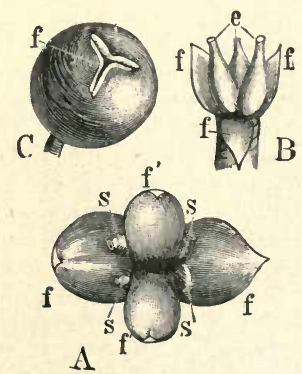

Fra. 257.- A Macrosporangiate flower of Juniperus Sabina, seen from above : $f f$ fertile macrosporophylls, bearing macrosporangia $s$; $f f^{\prime}$ upper part of sterile sporophylls (mag.). $B$ and $C$ Juniperus communis. B young fruit: $f f f$ macrospornphylls, of which the anterior is turned down : o the ovules. $C$ ripo fruit; the limits of the three carpels are only distinguisbable at the aper.

In the section Oxycedrus (including Juni/erus communis, the Juniper; $J$. Oxycedmus, J. macrocarpa, and other species), the cone consists of 1-2 whorls; and in the section Sabina (including J. Sabina, J. virginiana, etc.), it consists of $2-3$ whorls ; the innermost or uppermost whorl alone is fertile as a rule in Oxycedrus, but is sterile in Sabina : the (2-3) seeds are free in most forms: in Sabina the flowers are generally monoecious, and the leaves (including sporophylls) are usually in whorls of 2, whilst in the other sections they are in whorls of 3 .

Sub-order II. TAxombs: the macrosporangiate flowers are, as a rule, 
not cones; the seed usually projects beyond the macrosporophylls (when present) and has a succulent testa or an arillus: flowers generally diceious.

Fam. 1. Taxea: the macrosporophylls are usually rudimentary or absent, and the macrosporangia are borne on the axis: the seed has an arillus in some forms, while in others it has a succulent testa: microsporophylls with 2-9 microsporangia: microspores without expansions of the exine.

Phyllocladus, remarkable for its rudimentary leaves and for the development of its dwarf-shoots into phylloclades, has thick persistent macrosporophylls; in the axil of each there is a single erect macrosporangium with an arillus: flowers sometimes monœcious. Ginkgo biloba (Salisburia adiantifolia), the Maiden-hair Tree, is characterised by its fanshaped deciduous leaves with furcate venation: the macrosporophylls are rudimentary : the macrosporangia are borne in an opposite pair at the end of a short stalk: no arillus, but the testa of the seed becomes succulent. Taxus (the Yew) has only long shoots: nor has this genus any macrosporophylls, the macrosporangia being borne singly at the end of short lateral shoots, and the seed has a fleshy arillus: there are no resin-ducts in the tissues: the microsporophyll is peltate, bearing 5-9 microsporangia on its under surface.

Order 3. Gnetaceæ. This order includes but three genera, Ephedra, Gnetum, and Welwitschia. Though they differ widely from each other in many respects, they agree in that they have opposite leaves; flowers which are not cones and which have a rudimentary perianth, but have no macrosporophylls

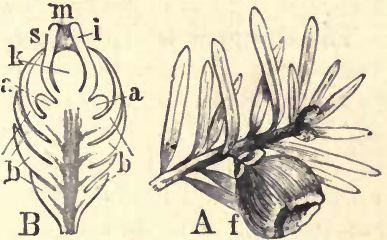

Fig. 258.-A Branch of Taxus baccata bearing a fruit $f$, which consists of a fleshy arillus en. closing a seed. $B$ Longitudinal section of the end of a branch terminating in a macrosporangiate flower: $b$ kcsly bracts; $k$ terminal macrosporangium (nucellus); ithe integument; $m$ the micropyle : a the rudiment of the arillns ( $\times 20)$.

as the macrosporangia are borne on the axis; an albuminous erect seed; a dicotyledonous embryo; and secondary wood which contains true vessels. They are generally diøecious.

Ephedra is a genus of shrubby plants, with rudimentary leaves, somewhat resembling an Equisetum. It is especially remarkable on account of its peculiar embryogeny. Habitat, warmer temperate zone.

Gnetum is a genus of shrubs or trees, for the most part climbers, but some erect-growing (Guetum Gnemon) : with its broad well-developed foliage-leaves, with pinnate venation, it resembles the Dicotyledons in habit. Habitat, the tropics.

Welwitschia includes the single species W. mirabilis : it is remarkable for its short thick stem, prolonged below into a tap-root, with a broad flat somewhat circular bilobed upper surface, a single long persistent foliage- 
leaf being borne at the margin of each lobe: the inflorescences are borne in dichotomous cymes, usually in the axil of each of the two leaves. Habitat, Damaraland, Western South Africa.

\section{GROUP V.-ANGIOSPERMA.}

The plants of this group are to a large extent herbaceous annuals, biennials, or perennials; but it also includes a great number of shrubs and trees.

The Sporophyte.

The General Morphology of the Vegetative Organs is so raried that it cannot be dealt with in a general way. The reader is referred to the treatment of the subject in Book I., and to the descriptions given in the systematic account of the group.

The General Morphology of the Reproductive Organs. The reproductive organs are pollen-sacs (microsporangia) and ovules (macrosporangia), borne generally on sporophylls, but sometimes directly on the floral axis (e.g. microsporangia of Naias, etc.; macrosporangia of Polygonum, Primulaceæ, etc.): they are developed on special shoots differentiated as flowers, and the flowers are arranged in a more or less complex branch-system, the inforescence.

The Inflorescence (see p. 54). It is only in comparatively few cases that the primary axis of the plant terminates in a flower; such plants are said to uniaxial: it is usually not until the secondary or tertiary branches, or even those of a higher order, are developed, that a flower is formed. Such plants are said to be bi-, tri-, or poly-axial.

The floral axis of the Angiosperms frequently forms an elaborate branch-system which is usually sharply defined, as a sporophore, from the vegetative shoots, and which bears leaves which are either sporophylls or hypsophylls (p. 55).

In the inflorescence, as usually in all parts of the shoot of Angiosperms, the branching is almost always monopodial and axillary. Some apparent exceptions may be easily reduced to this type: thus, in the racemes of most of the Cruciferæ the bracts at the bases of the individual lateral branches are abortive, and the same occurs in many of the Compositæ. In the Solanaceæ and Boraginaceæ the braet often undergoes displacement, so that it 
appears to be inserted laterally upon the axillary branch; on the other hand, it sometimes happens that the axillary branch is adherent to the main shoot for some distance.

The flowers of an inflorescence are either sessile or stalked, the stalk being termed a pedicel.

In accordance with the principles of branching laid down on p. 18 , the different forms of inflorescences may be classified as follows :-

A. Racemose Inforescences consist of a main axis (rhachis, peduncle), bearing a number of lateral branches developed in acropetal (or centripetal) succession, constituting a monopodial branch-system. The lateral branches do not usually grow longer than that portion of the main axis which lies above their points of origin. If the lateral shoots of the first order terminate in a flower without again branching, the inflorescence is said to be simple; but if they branch, it is compound.

These inflorescences are also termed indefinite, not because the apical growth of the main axis of its branches is unlimited, but because, owing to the acropetal succession in the development of the flowers, the growth of branches of a high order is arrested, by the development of a terminal flower, earlier than that of branches of a lower order: for instance, the growth of the secondary branches is arrested before that of the main axis, that of the tertiary branches before that of the secondary branches, and so on; hence these inflorescences are sometimes termed centripetal.

\section{Simple racemose inflorescences:}

(a) With an elongated main axis: the lateral shoots spring from the axis at some distance from each other. The three following forms may be distinguished:

(1) The spike, in which the lateral branches are flowers which are sessile on the main axis, or have very short pedicels (Fig. 259 A); e.g. the inflorescence of the Plantain (Plantago). The small spikes of the Glumales are termed spikelets.

(2) The spadix, which differs from the spike only in having a thick and fleshy axis; a large bract forming a sheath, called a spathe, commonly grows at the base of the inflorescence and envelopes it more or less; e.g. Arum and Richardia.

(3) The raceme, in which the lateral branches are flowers with pedicels of nearly equal length, e.g. the Cruciferæ, as the Radish, Cabbage, ete. ; in these the bracts of the individual flowers are not developed; also Berberis and others.

( $\beta$ ) With a short main axis; the lateral branches are set closely together on the short or flattened main axis.

(4) The capitulum (head) in which the short main axis is conical or discshaped or even hollowed out, and is closely covered with lateral branches in the form of sessile flowers (Fig. 259 D), e.g. the Compositx, as Dandelion, Sunflower; also the Scabious. The bracts (paleæ) of the individual 
flowers (Fig. $259 \mathrm{Dp}$ ) are sometimes wanting; but the whole head is surrounded at the base by a number of bracts forming an involucre (Fig. $259 \mathrm{Di}$ ) which gives the inflorescence the appearance of being one single flower.

(5) The umbel, composed of a number of lateral branches, in the form of pedicillate flowers, springing together from a very short axis which commonly terminates in a flower (Fig. 259 Cd); e.g. the Umbelliferæ and the Iry. The bracts of the separate pedicels forming the rays are usually present in diminished number; they form an involucre.

II. Compound racemose inforescences are formed when the lateral shoots which bear flowers, as described above, are again branched; or, in other words, when inflorescences of the types above enumerated are united to form a larger inflorescence; for instance, when several capitula are arranged on the main axis in the same way as the flowers of a raceme. The same terms are applied to the first ramification of the compound inflorescence as to the simple ones described above; the above-mentioned

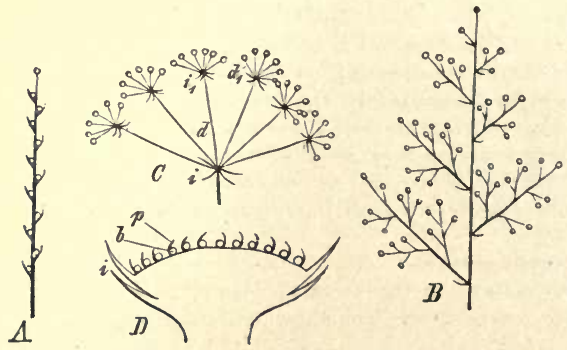

Fig. 259.-Diagrams of the varieties of racemose inflorescences. $A$ Spike. B Compound raceme. C C mmpound nmbel; $d$ rass of the umbel; $i$ involucre; $d_{1}$ secondary rays of the umbellules; $i_{1}$ involucel. D A capitulum; $i$ involucre; $b$ flower; $p$ bracteoles. example, for instance, is a raceme of capit ula, and is termed a capitulate raceme. Compound inflorescences may be classified as follows :

(a) Homogeneously compound; in these the branches of the first and second (or higher) orders are of the same character.

(6) The compo:and spike; in this form many sinple spikes are arranged on the main axis of the inflorescence in the same way as the flowers in a simple spike, or, in other words, the main axis of the spike bears secondary spikes instead of single flowers, e.g. the inflorescence of Wheat, Rye, etc.

(7) The compound racome; in this case smaller racemes grow on the main axis of the raceme; the ramification is in many cases still further repeated in such a way that it is more complex at the base of the primary raceme than towards the apex, e.g. the Grape-vine (Fig. $259 \mathrm{~B})$.

(8) The compound umbel (Fig $259 \mathrm{C}$ ). This is far more common than a simple umbel, and is in fact usually called an umbel ; the separate simple umbels (Fig. $259 \mathrm{C} d$ ) are then called umbellules, and their respective involucres are involucels.

( $\beta$ ) Heterogeneously compound inforescances; in these the branches of the 
different orders are dissimilar. In consequence of this so many complicated forms arise that it is impossible to enumerate and name all the combinations. As examples, the following will only be mentioned: the capitulate raceme, which consists of a number of capitula arranged in a raceme; it occurs in many of the Compositæ, e.g. Petasites: the spicate capitulum, which consists of several spikes forming a capitulum, as in the Scirpoideæ: the spicate raceme, whiç occurs in many Grasses, in which the last branches of a compound raceme are spikes.

B. Cymose Inflorescences; the main axis produces one, two, or more lateral branches-rarely several-at the same level below its apex, which grow more vigorously than the main axis, and repeat the same type of branching.

These inflorescences are also termed definite because the growth of each axis is arrested, by the development of a terminal flower, before that of the lateral branch or branches which it bears. The simplest kind of definite inflorescence is that in which the axis (peduncle) does not branch but bears a single terminal flower.

Cymose infloresences are also termed centrifugal, because the development and expansion of the flowers begins with the primary axis, and occurs successively in the axes of the second, third, and higher orders.

I. In the simple cyme the ramification in the secondary and higher orders follows the same type.

(a) Without a pseud-axis.

The cyme: beneath the terminal flower spring several-three or morelateral shoots of equal vigour, e.g. many Euphorbias. This inflorescence greatly resembles the true umbel, and in fact cannot be distinguished from a true umbel which has a terminal flower. The identification of an inflorescence as belonging to the cymose type depends in many cases on the fact that in the higher orders of branching the cymes are reduced to dichasia.

The dichasium (Figs. 10 and 11C) consists of only two equal lateral shoots arising at the same level below the terminal flower, and branching in a similar manner. The successive false dichotomies commonly decussate, e.g. Valerianella and the weaker inflorescences of many Euphorbias.

(B) With a pseud-axis.

The scorpioid cyme (cincinnus and rhipidium): in this the lateral branches occur alternately on opposite sides (Fig.11 $A$ and $B$ ) : Boraginacere, Crassulaceæ, Iridaceæ, Commelynaceæ, etc.

The helicoid cyme (bostryx and drepanium): the lateral branches of the successive ramifications always occur on the same side (Fig. $11 D$ ): this is frequently found in Monocotyledons, such as Hemerocallis, Ornithogalum, Alstrœmeria, Juncaceæ.

It has been ascertained, however, that in many cases (various Solanacer and Boraginaceæ) the so-called scorpioid cymes are monopodial; the axis is therefore not a pseud-axis but a true one, and the inflorescence must be regarded as a unilateral raceme.

II. Compound cymose inflorescences arise on the one hand from the reduc- 
tion of the ramification in the higher orders, as, for instance, when the secondary members of a cyme are not cymes, but dichasia; these are dichasial cymes; they occur in many Euphorbias: again, when dichasia terminate in scorpioid or helicoid cymes. On the other hand it sometimes occurs that helicoid cymes are combined to form scorpioid cymes, as in Geranium.

C. Compound racemose and cymose inflorescences. It may occur that a compound inflorescence changes in type in the different orders of ramification. Thus the branches of the first order may exhibit a racemose arrangement, and those of the second a cymose arrangement, as in the dichasial racemes of many Euphorbias (e.g. E. Esula, amygdaloides), in the scorpioid racemes of the Horse-Chestnut, and in the helicoid capitula of many species of Allium. On the other hand the branches of the first order may have a cymose, and those of the second a racemose arrangement; for instance, the helicoid cymes of capitula in Cichorium.

Finally, there are certain terms used in describing inflorescences which refer only to the general external appearance rather than to the mode of formation of the inflorescence: thus, the panicle is a pyramidal inflorescence generally of the racemose type, at least in its first ramification : the corymb is a racemose inflorescence of which all the ultimate ramifications lie in one plane and bear flowers, e.g. the Elder, many Cruciferæ: the amentum (catkin) is a simple or compound spicate inflorescence, usually pendulous and elongated, bearing inconspicuous unisexual flowers, which falls off entire from the plant when the flowering is over. Of cymose inflorescences there is the fascicle, consisting of a number of flowers on pedicels of equal length (Sweet William); the glomerule (Nettle and Box) or verticillaster (many Labiatæ), consisting of a few sessile or shortly pedicillate flowers; and the anthela, which is a compound inflorescence, in which the branches of the first order are gradually shorter from below upwards (or rather from without inwards), as in Juncaceæ.

To a floral axis arising from the ground, with no leaves, or with only a few bracts, bearing a single flower or a more or less complex inflorescence, the term scape is applied.

The Bracts (p. 43) are leaves borne on the inflorescence, in the axils of which the flowers are developed: there may be a single large bract, termed a spathe, enclosing the whole inflorescence, as in Palms and in the Arum Lily (Richardia athiopica) where the bract is white; or the bracts may be brightly coloured (petaloid), as in Poinsettia and other Euphorbiaceæ where they are red, and in Leycesteria formosa, Melampyrum, etc.; or the bracts may be scaly, forming an involucre round the inflorescence as in the Compositæ: the glumes of the Grasses are scaly bracts. The bracts are frequently not very unlike the foliage-leaves, differing from them inainly in form and size. 
The portion of the floral axis below the flower (i.e. the peduncle or the pedicel) commonly bears one or more bracteoles or prophylla. In most Monocotyledons there is a single posterior prophyllum, whilst in most Dicotyledons there are two lateral prophylla.

In some cases several bracteoles are arranged in a whorl, forming an epicalyx, either close beneath the flower (as in Malva, Anemone Hepatica, Dipsacus, or at some distance below it (other species of Anemone). In some plants (Nyctaginaceæ) the epicalyx may become an involucre enclosing several flowers; this is due to the fact that flowers are developed in the axils of some of the bracteoles of the terminal flower. Though they are generally green, the bracteoles are sometimes brightly coloured, as in some Amarantaceæ and Nyctaginaceæ; or scaly, as the lodicules of Grasses.

The Flower (p. 5̃) is a shoot of limited growth, with undeveloped or but slightly developed internodes, bearing, as a rule, both perianth-leaves and sporophylls on the somewhat shortened and expanded terminal portion of the axis which is the receptacle or torus.

The perianth-leaves are generally differentiated into two series: an outer, of usually rather small green leaves, the sepals, constituting the calyx : an inner, of usually conspicuous brightly coloured leaves, the petals, constituting the corolla.

The flower is usually monoclinous (hermaphrodite); but is

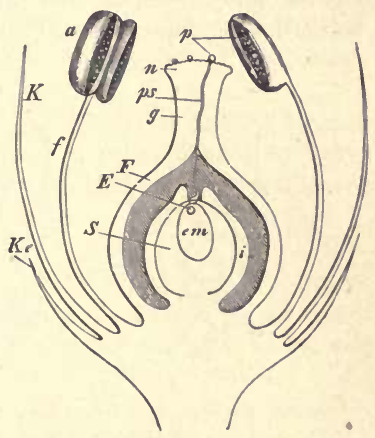

Fig. 260.-Diagram of an angiospermons flower: $K_{e}$ calyx; $K$ corolla; $f$ flament of stamen; $a$ anther with two pollen-8acs in each half which are opened, showing the pollengrains (p). On the stigms $(n)$ are pollen. grains $(p)$ which have germinated; the pollen-tube (ps) penetrates the style $(g)$ as far as the cavity of the ovary $(F)$, reaching the ovule (S); $i$ the integument of the ovnle; $\mathrm{em}$ the embryo-sac; $\boldsymbol{E}$ the oosphere. not infrequently unisexual, when it is diclinous, or even dioecious. The sporangia, with but few exceptions, are borne upon sporophylls (see p. 56): the microsporophylls (stamens) constitute the androcium, the macrosporophylls the gynoceum, of the flower.

It occasionally happens, that one or more of the internodes within the flower may be developed to some extent: for instance, 
the internode (termed anthophore) between the calyx and the corolla, as in Lychnis and some other Caryophyllaceæ; that (termed gonophore) between the corolla and the androecium, as in the PassionFlower, and in Orchids where the styles adhere to it forming the gynostemium or column; that (termed gynophore) between the andrœeium and the gynæceum, as in some Gentians and some Cruciferæ.

When the axis grows, as is usually the case, equally in all parts, the gynæceum, being nearest to its apex, is the uppermost part of the flower. When this is the case its insertion is above that of the androcium and perianth (Fig. $261 H$ ), and the ovary is said to be superior and the flower hypogynous, as in Ranunculus, Papaver, Lilium, and Primula. But in a great number of plants the perianth and andrœcium are raised by the intercalary growth of a
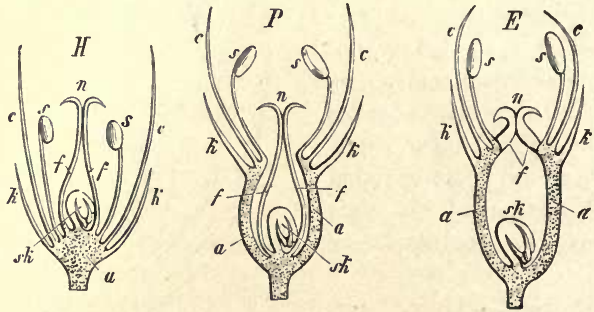

FIG. 261.-Diagram of $H$ hypogsnous; $P$ perigynous; $E$ epigynous flowers; $a$ axis $k$ calyx ; $c$ corolla ; s stamgns ; $f$ carpels; $n$ stigma; sk ovule.

lower portion of the axis (as represented by the outer portion of the torus) and stand on a circular rim surrounding the apex of the axis which lies at a lower level. Of this condition two different forms occur:-in the one, the carpels are inserted in the depression at the apex of the axis (Fig. 261 P), and there form one or more ovaries free from it, primarily at least, though they may subsequently become adherent to it; in such cases, as in the Rose and Apple, the flower is said to be perigynous : in the other, the carpels spring from the upper rim of the cavity which is formed by the axis itself and simply cover it in at the top; such flowers are said to be epigynous, and the ovary to be inferior, e.g. Gourds and Umbelliferæ (Fig. $261 E$ ). Many transitional forms between these two extremes are found.

Stipules are sometimes developed in connexion with the floral 
leaves; thus in sume Rosaceæ (Potentilla, Comarum, Geum, Alchemilla) the stipules of the sepals form a calyculus or epicalyx : stipules are developed in connexion with the petals of some Sapotaceæ (Dipholis, Mimusops); and in connexion with the stamens of Allium, Ornithogalum, some Zygophyllaceæ, etc.

The Phyllotaxy of the Flower. The floral leavas, like the foliage-leaves on the stem (see p. 10), are frequently arranged spirally, (e.g. Calycanthus, Anemone, Trollius) when the flower is acyclic. The most common divergence is $\frac{2}{5}$, but higher divergences also occur, especially in the androcium, when numerous small organs are inserted upon an expanded axis (e.g. Ranunculus). In the spiral or acyclic flower there is either no well-marked distinction of the various series, that is, the members of the calyx, corolla, and androcium, are connected by intermediate forms (e.g. Nymphæa); or the various series are sharply defined, each series taking up one or more turns of the spiral.

In most cases the floral leaves are arranged in whorls, that is, the flowers are cyclic. Cyclic flowers are connected by intermediate forms with the acyclic, especially through pentamerous forms. Thus some pentamerous flowers are hemicyclic, that is, some of their floral leaves are arranged spirally, and the others in whorls. Instances of a spiral perianth combined with cyclic sporophylls are afforded by those flowers in which the members of the perianth, calyx, or corolla are developed in $\frac{2}{5}$ succession, and the prefloration is quincuncial (see p. 43); the perianth is spiral in the flowers of the Cannabinaceæ and Chenopodiaceæ; the calyx is spiral in the flowers of the Bindweed (Calystegia Sepium), the Rose, some Boraginaceæ (Cerinthe, Echium, etc.), Geraniaceæ, Oxalidaceæ, Linaceæ, Caryophyllaceæ, and many other dicotyledonous orders; both calyx and corolla are spiral in Camellia, though the phyllotaxy is not $\frac{2}{5}$. In other cases, the sporophylls are spirally arranged, whilst the perianth-leaves are cyclic. For instance, in Magnolia, Ranunculus, and Helleborus, both stamens and carpels are spirally arranged; and in Delphinium and Aconitum, the stamens only.

Closely related to the foregoing cases of $\frac{2}{5}$ phyllotaxy-occurring in fact not only in flowers of closely allied species, but also in flowers of the same species-are certain of the typical forms of cyclic arrangement in which each series (whether perianth, calyx, corolla, or androecium), instead of consisting of five floral leaves, taking up two turns of a spiral with a divergence of ${ }_{3}^{2}$, consists of 
four or six leaves arranged in two whorls, consisting respectively of two or three leaves.

For purposes of comparative description, it is convenient to regard each turn of the spiral in an acyclic or a hemicyclic flower as equivalent to a whorl: thus a well-defined series with $\frac{2}{3}$ arrangement would represent two whorls.

As in the case of the foliage-leaves (see p. 9), so in that of the floral leaves, the order of development is as a rule acropetal: hence each whorl of the flower is developed later than the one external to it, and earlier than the one internal to it. When, however, a series of floral organs is becoming degenerate, its development is retarded; for instance, in the Compositæ, Valerianaceæ, and Umbelliferæ, the degenerate calyx is developed after the corolla, or even after the andrœcium. The members of each whorl may be developed either simultaneously or successively.

In their arrangement, also, the floral leaves resemble the foliageleaves. When, in an acyclic or hemicyclic flower, the spiral is continuous with the same divergence from one series of floral organs to another, the members of the successive series lie on the same radii drawn from the centre of the flower, that is, they are directly superposed. A good example of this is afforded by the terminal flower of the inflorescence of Berberis (Fig. 262 ; occasionally in Epimedium, and also in Gagea among Monocotyledons), where the stamens, petals, and sepals are all directly superposed. When, on on the other hand, the divergence varies from one series to another, direct superposition does not occur, but some form of alternation, as is generally the case in acyclic flowers: for instance, the calyx of certain (pentamerous) forms of Anemone and other Ranunculaceæ is arranged with a $\frac{2}{5}$ divergence, whereas the divergence of the stamens is $\frac{5}{13}$ or $\frac{8}{21}$. In hemicyclic flowers with a simple spiral perianth and cyclic stamens (e.g. Cannabinaceæ, Chenopodiaceæ), the stamens are superposed on the perianth-leaves.

When the floral leaves are in whorls consisting of equal numbers of members, the general rule is that the members of the successive whorls alternate with each other: thus, in a flower with calyx, corolla, androcium, and gynæceum, each consisting of a single whorl of five members, the petals alternate with the sepals, the stamens with the petals, and the carpels with the stamens; and if radii be drawn from the centre of the flower, it will be seen that the stamens are opposite to the sepals and the carpels to the petals, or more briefly, that the stamens are antisepalous and the carpels 
are antipetalous. This is not, however, a case of direct superposition, since the corolla intervenes between the androecium and the calyx, and the andrœcium intervenes bettween the gynæceum and the corolla.

There are, however, certain cases in which this law of alternation does not prevail, in which, that is, the members of successive whorls are directly superposed. For instance, the (4-5) stamens are directly antipetalous in several natural orders (Primulaceæ, Plumbaginaceæ, Ampelidaceæ, Rhamnaceæ); again, in some Campanulaceæ (e.g. Campanula Medium, Fig. 263) the (5) carpels are directly superposed on the stamens.

The Floral Diagram.-These various arrangements of the floral leaves, like those of the foliage-leaves, are most clearly represented

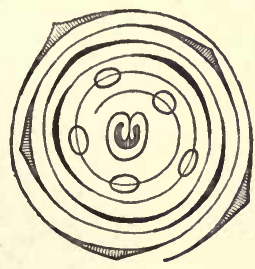

Fig. 262.-Floral diagram (ground-plan) of an acyclic flower, with $\boldsymbol{t}$ divergence in the calyx, corolla, and androcium (terminal flower of Berberis: after Eichler).

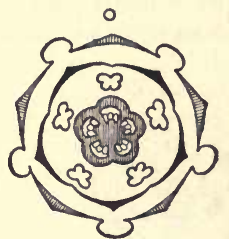

Fre. 263.- Thoral diagram of Campanula Medium: the five carpels are directly superposed on the stamens. (After Eichler).

by means of diagrams (see p. 13). In a floral diagram, the calyx lies externally, and the gynæceum, as being the uppermost series of organs (even in epigynous flowers) lies most internally. In order to be able readily to distinguish the various series, symbols are used which recall some peculiarity of their form: thus the mid-rib of the sepals is indicated, and, in the case of the stamens, the anthers.

If only such relations of position as can be actually observed in a flower are indicated in the diagram, a simple empirical diagram is the result. If, however, the results of the investigation of the development of the flower and of the comparison of it with others be borne in mind, a general plan of arrangement will be detected, and the individual peculiarities of arrangement, quite apart from any variation in the form of the organs, will be seen to be due either to the suppression of one or more whorls or of one or more 
members of a whorl, or, more rarely, to a multiplication of the whorls or of their members. If, however, the organs which are absent, but which should typically be present, be indicated in the empirical diagram by dots, it becomes a theoretical diagram. In this way it is possible to arrive at general types on which large numbers of flowers are constructed. Fig. 264, for instance, is the empirical diagram of the flower of the Lily, and it is at the same time the type on which the flower of Grasses (Fig. 265) is constructed in which certain members are suppressed.

In constructing a floral diagram the position of the main axis should be indicated by a dot placed above the diagram : the bract, which would of course be exactly opposite to it, may or may not be indicated: the side of the flower toward the main axis is said to be posterior, and that toward the subtending bract, anterior. A plane which passes through the flower and also through the main stem and the median line of the bract is termed the median

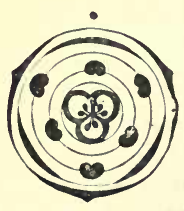

Fre.264.-Floral Diagram of a Lily.

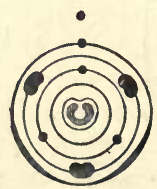

FrG. 265.-Floral Diagram of a Grass.

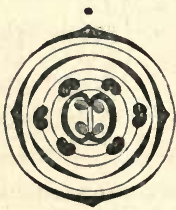

FrG. 268.-Floral Diagram of a Crucifer; the median stamens are duplicated.

plane or section of the flower: the plane which cuts the median plane at right angles is the lateral plane or section: and the plane which bisects the angles made by the intersection of the median and lateral planes is the diagonal plane or section: any plane other than these is said to be oblique. By means of these conceptions the position of the parts of a flower may be accurately indicated: thus, in describing the flower of the Cruciferæ (Fig. 266), the two external sepals lie in the median plane; the two inner sepals, the two outer stamens, and the two carpels, in the lateral plane; whilst the petals and the four inner stamens lie in the diagonal planes.

The number and the relations of the different parts of the flower may be indicated not by diagrams only, but also by formulæ in which, as in the diagrams, for the sake of clearness, all the 
peculiarities of form are overlooked. Thus the diagram Fig. 264 may be expressed by the formula $K 3, C 3, A 3+3, G^{(3)}$, which means that the calyx $K$, and the corolla $C$, each consist of a single whorl of three members, the androecium of two whorls each of three members, and the gynæceum of one whorl of three members, all in regular alternation. When one whorl is superposed on another, the superposition is indicated in the formula by a line | between the whorls. If the number of members in any whorl is variable, the letter $\mathbf{n}$ is used instead of a number. Thus, for instance, $K n, C n, A n+\mathrm{n}, G \mathrm{n}$ is the theoretical formula' of most Monocotyledons. The absence of a whorl is expressed by a cypher 0 , and of individual members by the number of those actually present. Thus the formula for the flower of a Grass (Fig. 265) is $K 0, C O, A 3+0, G^{1}$. Superior and inferior ovaries are indicated by a stroke below or above the corresponding figure, and duplication by the exponent 2 ; thus the diagram Fig. 266 is represented by the formula $K^{2}+2, C \times 4, A 2+2^{2}, G^{(2)}$, the $\times$ after $C$ indicating that the position of the petals is diagonal, i.e. that the four petals alternate with the four sepals, as if the latter all belonged to the same whorl. The bracket in which the number of the carpels of the gynæceum $G$ is enclosed, indicates that the members thus bracketed are coherent. Staminodia may be distinguished by a + before the figure. When the perianth is not differentiated into calyx and corolla, it is expressed by the letter $P$ : thus the formula for the flower of Chenopodium is $P 5 \mid A 5$ $G^{(2)}$.

The Number of Members in a Whorl shows considerable variation : thus, in Monocotyledons it is generally three (rarely two or five), whereas in Dicotyledons it is frequently five, less frequently two or four, rarely three (e.g. Berberis, Rheum, Polygonum). The number of members in a whorl is indicated by the terms di-tritetra-penta-merous, etc. Whorls containing the same number of members are said to be isomerous; or, when the number of members is not uniform, heteromerous. Flowers having isomerous whorls are said to be eucyclic or isocyclic, whereas when the whorls are heteromerous the flowers are said to be heterocyclic. Of these two conditions the latter is the more common, though the former is frequently realized (e.g. many Monocotyledons). The heterocyclic condition is due either to the number of members in one or more of the whorls being smaller (oligomery) or greater (pleiomery) than that which is the typical number. The com-

M.B. 
moner cases of oligomery are to be found in the whorls of sporophylls, especially in the gynæceum: for instance, the typically pentamerous flower of the Saxifragaceæ is heterocyclic because of the oligomerous (dimerous) gynæceum ; similarly, in the Scrophulariaceæ, the androcium is generally, and the gynæceum is always, oligomerous, the former consisting of but two or four stamens, the latter of but two carpels. Pleiomery is of less frequent occurrence: however in the Cruciferæ (Fig. 266) the whorls of the calyx, the outer whorl of stamens, and the gynæceum, are dimerous, but the corolla and the inner whorl of stamens are tetramerous and hence pleiomerous: similarly, one or more whorls of the androcium in the Papaveraceæ and Polygonaceæ are pleiomerous: and probably in other cases where the number of the stamens is twice that of the petals or sepals, that is, where the flower is diplostemonous, the condition is due rather to pleiomery (duplication) of a single whorl than to the development of two whorls as is usually assumed (see below, under pleiotaxy). Pleiomery of the corolla is common in double flowers.

Heteromery necessarily affects the alternation of the floral leaves of the successive whorls. Thus, in the Cruciferæ, where the calyx consists of two alternating dimerous whorls, and the corolla of a single tetramerous whorl, the four petals alternate with the four sepals just as if the sepals all belonged to a single whorl. When, as is very frequently the case, the gynæceum is oligomerous, the carpels (or carpel) present do not appear to occupy any definite position with regard to the preceding organs.

The Number of Whorls in the Flower. The simplest case is that in which each series of floral organs-calyx, corolla, androcium, gynæceum-occupies a single whorl, or is monocyclic: this is realized in a few natural orders, either accompanied with regular alternation (e.g. Caprifoliaceæ generally, Iridaceæ, Orchidaceæ), or with antipetalous stamens (e.g. Rhamnaceæ, Ampelidaceæ). In this case the flower is tetracyclic.

More commonly one or more of the series may occupy two whorls, or be dicyclic. This is generally the case when the whorls are dimerous (e.g. both corolla and androecium of Oleaceæ and Fumariaceæ; corolla of Papaver; calyx and androecium of Cruciferæ; perianth of Urtica and Morus). Where the whorls are trimerous the dicyclic condition is frequent: thus in the majority of Monocotyledons there are two whorls of stamens whilst all the other series of the flower are monocyclic, so that the flower is 
diplostemonous with regular alternation: in the comparatively few trimerous flowers of Dicotyledons the dicyclic condition may be observed in the androecium (Rheum, Polygonum, Berberis), or in calyx, corolla, and androecium. The $\frac{2}{5}$ calyx, which is to be found in very many Dicotyledons, may be regarded as equivalent to a dicyclic calyx (see p. 446). A dicyclic gynæceum is to be found in a few Monocotyledons (e.g. Alisma, Butomus) and Dicotyledons (e.g. Malvaceæ such as Malva, Althæa, Lavatera).

The conclusion to be drawn from these facts is that in the complete dichlamydeous monoclinous flowers of Angiosperms there are, as a general rule, five whorls of floral leaves; the flowers are pentacyclic. In most Monocotyledons the five whorls belong, one to the calyx, one to the corolla, two to the androecium, and one to the gynæceum: in most Dicotyledons they belong, two to the calyx, one to the corolla, one to the androecium, and one to the gynæceum.

If, now, such a pentacyclic flower with regularly alternating whorls be taken as a type or standard of comparison, it will be observed that many flowers deviate from it by having either a larger or a smaller number of whorls, the deviation being combined in some cases with direct superposition.

Pleiotaxy, or an increase in the number of the whorls in a flower, is characteristic of a number of genera belonging to various natural orders. Instances have been mentioned above of Monocotyledons and of Dicotyledons having flowers with a dicyclic gynæceum, and of Dicotyledons with a dicyclic corolla or androcium: but the number of whorls is sometimes much greater (15 in Aquilegia), when the flowers, as also the special series, are said to be polycyclic. Thus, the calyx is polycyclic in Nandina

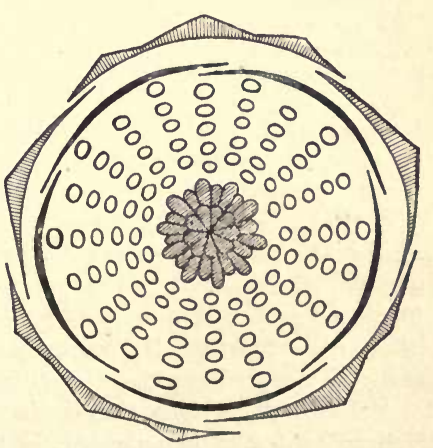

FiG. 267,-Floral diagram of Rosa tomentosa, showing the polycyclic andrœcinm and gynæceum. (After Kichler.) (Berberidaceæ); the androcium, in Aquilegia, Rosa, and Papaver- 
acer; the gynæceum, in some Alismaceæ and Butomaceæ. In some cases, one series becomes polycyclic at the expense of another: thus in the acyclic flowers of Clematis, Anemone, and Caltha, the petals are replaced by stamens so that the number of turns of the spiral ( = whorls) in the androcium is increased whilst the corolla disappears. The "doubling" of flowers is commonly due to the polycyclic derelopment of the corolla, the additional whorls being either new formations, or the result of the more or less complete replacement of the sporophylls by petals.

An important case is that to be found in several Dicotyledonous orders Ericaceæ, Crassulaceæ, Saxifragaceæ, some Caryophyllaceæ, Onagraceæ Fig. 270, Geraniaceæ," Oxalidaceæ, Rutaceæ Fig. 268 where the flower is diplostemonous, and the androecium is apparently dicyclic: but the flower is not simply diplostemonous (as in the Moncotyledons), because the whorls do not alternate

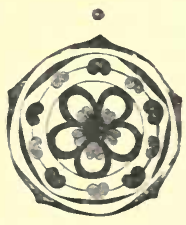

FiG. 268.-Diagram of obriplostemonous flower of Dictamnus. regularly; the stamens of the apparently outer whorl are directly antipetalous, consequently the stamens of the inner whorl are antisepalous, and the carpels (in eucyclic flowers) are antipetalous. Such flowers are said to be obdiplostemonous.

Oligotaxy, or a decrease in the typical number of whorls in a flower, is frequently due to suppression. For instance, owing to the suppression of one whorl of stamens in some Monocotyledons, either the outer (some Hæmadoraceæ, also Cypripedium), or the inner (Iridaceæ, most Orchidaceæ), the androecium is monocyclic. In some cases a whole series is suppressed: for instance the corolla may be absent (e.g. Glaux, among the Primulacer; Alchemilla, Sanguisorba, among the Rosacex: some Caryophyllacex, such as Sagina apetala, Scleranthus, etc.): or the androecium or gynæceum (diclinous or diøcious flowers, such as those of Sedum Rhodiola, Rhamnus cathartica, Hydrocharidaceæ, ray-florets of Compositæ, etc.): or the whole perianth (Fraxinus excelsior).

Althongh it is true that both oligotaxy and oligomery are frequently due to suppression, in the one case of one or more whorls, in the other of one or more members of a whorl, it must not be assumed that this is the only possible explanation. On the contrary, it is very probable that the simple structure of the flower in some plants (e.g. Urticales and Amentales among 
Dicotyledons is not the result of suppression, but is itself typical : in other words, these flowers are probably to be regarded, not as reduced, but as primitive, belonging to plants which are, it may be, of a relatively low type among Phanerogams, but which are on the "p-grade, and not on the doun-grade of organisation.

The Symmetry of the Flower. The flower presents all the varieties of symmetry which are discussed in Part I. (p. 4); these are mainly determined by the number and the relative development of the floral leaves, and in a few cases by the development of the floral axis or receptacle.

The symmetry may be radial or actinomorphic. When an eucyclic flower is also regular, that is, when the members of each whorl are similar to each other in size and form, it can be divided into symmetrical halves by sections made in two or more planes, the halves produced by section in one plane being similar to those produced by section in one or more other planes. Such a flower is polysymmetrical (see p. 6). The number of these planes of symmetry depends upon the numerical constitution of the flower. Thus a regular eucyclic trimerous flower (e.g. many Monocotyledons) can

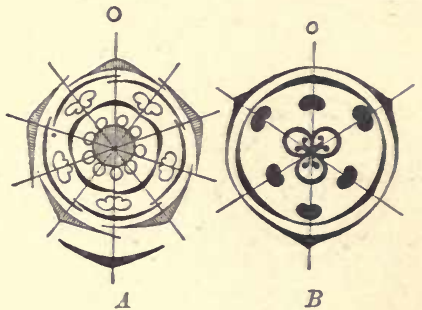

FIG. 239.-A Diagram of the pentsmerous flower of Primala, showing the five planes of symmetry; the stamens are antipetalous; there are no prophylla. $B$ Diagram of the trimerous flower of Lilium, showing the three planes of 85 mmetry. (After Eichler.)

be so divided in three planes, the median and the two diagonals, that all the three pairs of resulting halves are exactly alike (Fig. 269 B). Similarly, the pentamerous flower of Primula, Geranium, species of Campanula, is divisible in five planes (Fig. 269 A). But where the flower is tetramerous (e.g. Fuchsia, Euonymus europaus), there are but two planes of section, the median and the lateral, which will give exactly similar halves, though the flower is also symmetrically but diversely divisible in the diagonal planes (Fig. $270 \mathrm{~A}$ ); or, again, where the flower is hexamerous (e.g. species of Sedum) it is symmetrically divisible in twelve planes, but the halves produced by the section in six of the planes are unlike those produced by section in the other six planes. 
The symmetry may be isobilateral; in this case the flower is divisible into symmetrical halves in two planes, but the halves produced by section in one plane are unlike those produced by section in the other plane. Thus, a regular eucyclic dimerous flower (e.g. Circaea lutetiana, Fig. 270 B; Fraxinus dipetala), is symmetrically divisible in the median and lateral planes, but the halves produced by the median section differ from those produced by the lateral section. This is true also of some regular heterocyclic flowers, such as those of the Cruciferæ, Jasminum, Olea europeea, Cornus, Hamamelis, the whorls of which are 2- or 4-merous, and of the somewhat peculiar flower of Dicentra.

The symmetry may be zygomorphic, that is, the flower may be monosymmetrical, there being only one plane in which it is symmetrically divisible. Monosymmetry is characteristic of irregular
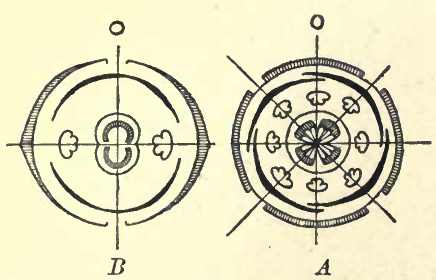

Fig. 270 -A Diagram of the tetramerous flower of Fuchsia, showing the four planes of symmetry. $B$ Diagram of the dimerous flower of Circæa, showing isobilateral symmetry. flowers, whether eucyclic or heterocyclic; of flowers, that is, in which the members of one or more whorls differ in various respectsamong themselves, accompanied frequently by a reduction in the typical number of members in one or other of the whorls, frequently of the androecium: it is, in fact, to irregular flowers that the term zygomorphic is specially applied in Descriptive Botany. Such a flower usually presents a clear distinction into two diverse portions, an anterior and a posterior, separated by the lateral plane, whilst the two lateral halves about the median plane are symmetrical; hence it is clearly dorsiventral (Fig. 271).

Dorsiventrality is presented by some flowers which, so far as their early development is concerned, or even so far as is shown by their floral diagram, are actinomorphic, isobilateral, or simply zygomorphic, the dorsiventrality being due to the subsequent irregular development of some of the floral leaves; as in some eucyclic flowers (e.g. among Monocotyledons, Amaryllis, Gladiolus ; among Dicotyledons, Dictamnus, and other Ruteæ, species of Impatiens, Pelargonium), and in some heterocyclic flowers (e.g. some Scrophu- 
lariaceæ, Labiatæ, some Caprifoliaceæ, Violaceæ, Echium, Lobelia, Orchidaceæ, the marginal flowers of the inflorescences in some Umbelliferæ and the ray-florets of some Compositæ). The degree of irregularity in these flowers varies widely; the irregularity may be very slight, due to the more active growth of the leaves (perianth-leaves only, or stamens also) of one half of the flower, either the posterior (e.g. Gladiolus), or the anterior (e.g. Amaryllis), which causes an upward or a downward curvature; this is more marked in Dictamnus where the calyx and corolla tend to form two lips, an upper and a lower; this bilabiate form of flower is more fully developed in the calyx and corolla of the Labiatæ, the corolla (personate, the lips being closed) of the Scrophulariaceæ, and of the Orchidaceæ and Lobelia. In not a few cases the irregularity of the flower is increased by the development of spurs from some portion of the perianth (e.g. among Monocotyledons, Orchis, Rhinopetalum, from the corolla; among Dicotyledons, Linaria, Viola, from the corolla ; Pelargonium, from the calyx). A remarkable morphological feature is offered by the flowers of Orchis and of Lobelia which

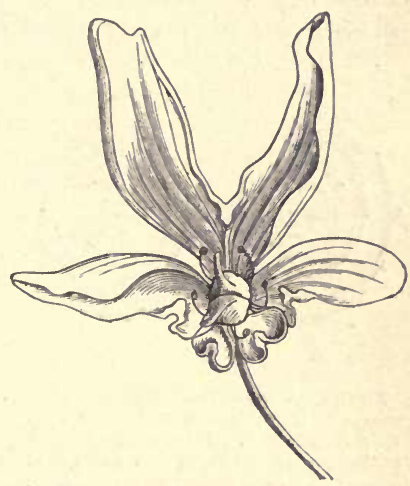

FIG. 271.-Dorsiventral flower of a Heracleum (mag.) are resupinate; that is, in consequence of torsion of the pedicel, the posterior side of the flower becomes anterior. The plane of symmetry is generally median in these flowers.

In some few cases the irregularity, leading to dorsiventrality, is due, not to the unequal development of the floral leaves, but to the configuration of the floral receptacle, so that the floral leaves are not developed in a radially symmetrical manner (e.g. Reseda, Papilioneæ, Fig. 272).

When in irregular flowers the single plane of symmetry is the median plane, the flower is dorsiventral : but there are other cases (e.g. flowers of some Fumariaceæ, Fumaria, Corydalis) in which the single plane of symmetry is the lateral; these flowers are 
therefore not dorsiventral, that is, they have not antero-posterior, but lateral, asymmetry. The zygomorphic symmetry of a flower is indicated in its floral formula by symbols; when the plane of symmetry coincides with the median plane the symbol $\downarrow$ is used, and when it coincides with the lateral plane the symbol $\rightarrow$.

Sometimes regular flowers are developed by plants which usually produce irregular flowers: these exceptional flowers are termed peloria. This is due in some cases to the fact that the primitive number and arrangement of the floral organs is not disturbed by the irregular development of the parts which usually takes place: such cases are distinguished as regular peloria (e.g. Viola, Gloxinia, Labiatæ, etc.). In other cases the peloric flower is to some extent the result of the symmetrical development of the irregularity

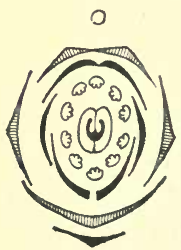

$A$

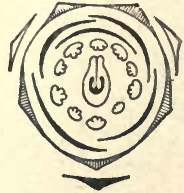

$B$
Fig. 272.-Diagram illustrating dorsiventral symmetry in leguminons flowers: $A$ Vicia Faba (Papilioneæ): B Cercis Siliquastrum (Cæsalpinieæ): in both cases the odd sepal is anterior : the plane of symmetry is median. (e.g. the development of five spurred petals and five stamens in Linaria). Dorsiventral flowers are, generally speaking, such as are borne laterally on the inflorescence; whilst the terminal flowers (which may be regarded as peloric) are frequently regular. Peloric lateral flowers are, however, known to occur.

There remain to be considered those flowers which cannot be symmetrically di-

vided in any plane: such flowers are asymmetric. Amongst these are to be included most of the acyclic or hemicyclic flowers in which the number of members is high and the divergence variable (e.g. Calycanthus, some Ranunculaceæ, etc.): the asymmetry of most of these is approximately, though not quite accurately, actinomorphic, but in some it is dorsiventral (e.g. Delphinium, (Fig. $273 A$,) Aconitum). Asymmetry is rare in cyclic flowers, but is to be found in some heterocyclic flowers: for instance, in Tropæolum, (Fig. 273 B, Canna and other Marantaceæ, Valeriana and other Valerianaceæ, where the asymmetry is dorsiventral and is due to oligomery and irregularity combined, whilst in other cases (e.g. some Paronychieæ), it is due merely to oligomery. 
The Floral Organs.

The Perianth is completely absent, that is, the flower is achlamydeous, in a few families (e.g. Piperaceæ, Araceæ, Graminaceæ, many Cyperaceæ, Salicaceæ). When present, it is usually differentiated into calyx and corolla, the flower being termed dichlamydeous or biseriate: when the calyx and corolla clearly differ from each other in colour, texture, etc., the flower is said to be heterochlamydeous; for instance, when the calyx is green and the corolla highly coloured (as in most Dicotyledons, and in some Monocotyledons such as Tradescantia and Commelyna); or when the calyx is coloured (petaloid) and the petals reduced to nectaries (as in Helleborus and other Ranunculaceæ). When the perianth-leaves are all alike, the flower is said to be homochlamydcous. This condition may be due to different causes in different cases: the flower is sometimes homochlamydeous, even though calyx and corolla are differentiated, because the sepals and petals are very similar, as in most Monocotyledons where the sepals are often petaloid: in other cases the flower is homochlamydeous, because only one series of perianthleaves is developed; that is, because the flower is monochlamydeous. The flower may be monochlamydeous, because, though typically dichlamydeous, either the calyx or the corolla is suppressed (e.g. calyx suppressed in some Umbelliferæ and Compositæ; corolla suppressed in most Thymelæaceæ, Paronychieæ, Glaux, some Rosaceæ such as Alchemilla and Sanguisorba); where the corolla is suppressed or rudiment-
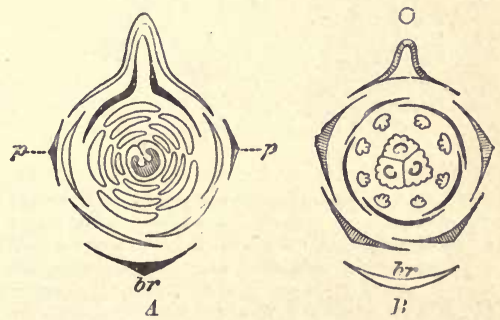

F1G. 273.-Floral diagrams illustrating asymmetry. $A$ Dorsiventrally asymmetrical hemicyclic flower of Delphinium Ajacis : $B$ Dorsiventrally asymmetrical heterocyclic flower of Tropaolum majus: $b r$ subtending bract; $p \cdot 1$, prophylla. (After Eichler.) ary the calyx is frequently petaloid (e.g. Clematis, Anemone, Caltha, and other Ranunculaceæ): or the flower may be monochlamydeous merely because the perianth is undifferentiated (simple), and is then generally sepaloid (e.g. Urticaceæ, Betulaceæ, Chenopodiaceæ, etc.), or petaloid-(e.g. some Amarantaceæ). 
The individual leaves of the perianth may be either perfectly separate (eleutheropeialous or polypetalous corolla, eleutherosepalous or polysepalous calyx), e.g. Ranunculus; or they may cohere from the base upwards, so as to form a longer or shorter tube, which divides at its upper end into as many teeth or lobes as there were originally leaves (gamosepalous calyx, gamopetalous corolla) (Fig. $274 A B C c$ and $B k$ ); e.g. the Primrose and the Tobacco plant. In Dianthus (the Pink) the sepals alone are coherent, as also in Daphne (Fig. $274 \mathrm{D}$ ) where the corolla is absent. More rarely all the leaves of the perianth cohere to form one tube, e.g. the Hyacinth and allied genera; the six lobes of the tube corre-

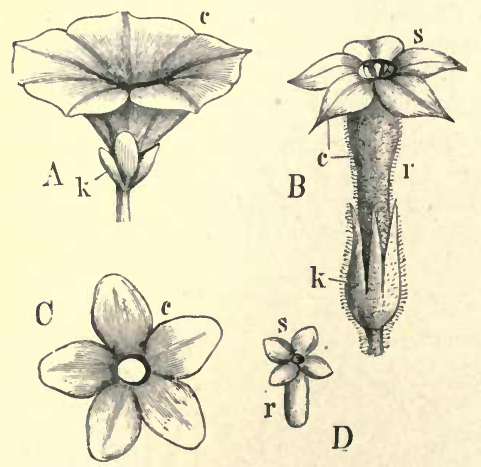

Fig. 274.-Cohesion of sepals and petals. A Flower of Convolvulus arvensis, with a funnel-shaped corolla (c); and a 5-partite calyx (k). B Nicotianu Tabacum, with a 5-cleft calyx (is) ; tubular corolla ( $r$ ), with a distinct 5 -toothed limb (s). C The rotate corolla of Sambncus. D Gamosepalous calyx of Daphne Mezereum; $r$ the tube; $s$ the limb. spond to the three sepals and the three petals. The simple perianth also may consist of separate leaves (eleutherophyllous or polyphyllous perianth), e.g. Amarantus, or the leaves may be coherent (gamophyllous), e.g. Aristolochia.

The degree of division presented by gamophyllous perianths into teeth or lobes is indicated by the same terms which are used in describing the incision of the leaf-blade (page 37). The form of the gamopetalous corolla may be campanulate, as in the Campanula; funnel-shaped (or infundibuliform), as in the Bindweed (Fig. $274 \mathrm{~A}$ ); rotate, as in the Elder (Fig. 274 $C$ ). The upper and lower portions may frequently be distinguished, the lower as the tube (Fig. $274 B r$ ), the upper expanded part as the limb (Fig. 274 $B$ s). Other peculiarities of form are connected with the symmetry of the flower (page 453).

The petal frequently consists of two parts, the claw and the limb, as in the Pink (Fig. 275 $A B$ ). The Corona (paracorolla) in the Narcissus and Lychnis is formed by ligular outgrowths 
from the claws (Fig. $275 B l$ ). Anj segmentation of the petal, as in the Pink (Fig. $275 A$ ) is unusual; emarginate or obcordate petals are more common. In many cases the petals have spurshaped appendages (Violet, p. 455), or they are prolonged at the base into tubes, as in Helleborus and Aconitum. This peculiarity is connected with the secretion of the nectar

The Reproductive Organs of the Flower are sporangia of two kinds, microsporangia and macrosporangia, borne usually on sporophylls, though sometimes directly on the floral axis. The flower is usually monoclinous ( $\not$, hermaphrodite, see p. 395); but it is not infrequently unisexual, in which case the flowers are either microsporangiate ( $\delta$, staminal) or macrosporangiate $(q$, carpellary). The plants which have unisexual flowers may be either
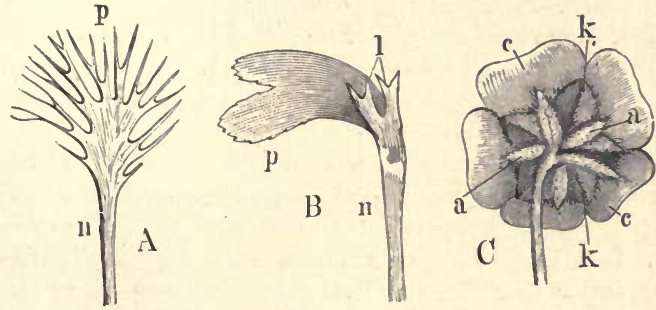

Frg. 275. $-A$ Petal of Dianthus superbus, with $(n)$ the claw and $(p)$ the limb, mnch divided. $B$ Petal of Lychnis : $n$ claw; $p$ limb; $l$ ligula. $C$ Flower of Potentilla, seen from below : c corolla; $k$ calyx ; $a$ epicalyx.

monœcious (e.g. Zostera, Arum, Carex, Typhaceæ, Zea, Betulaceæ, Euphorbia, Buxus, Juglans, Quercus, etc.): or diøcious (e.g. some Palms, Vallisneria, Cannabinaceæ, Salicaceæ, Mercurialis, Viscum, etc.): or polygamous. Of polygamy there are several varieties: thus, the plant may bear monoclinous flowers and staminate flowers (e.g. Veratrum, Asculus Hippocastanum, Celtis); or monoclinous flowers and carpellary flowers (e.g. Thymus vulgaris and T. Serpyllum, Parietaria diffusa and P. officinalis): or it bears monoclinous flowers and both staminate and carpellary flowers $(e . g$. Fraxinus excelsior, Saponaria ocymoides).

Some flowers are probably primarily unisexual; that is, there is no reason to believe that the unisexual condition is due to the suppression of either micro- or macrosporangia (e.g. Hemp, Oak, Walnut, Poplar, Willow). Others are secondarily unisexual; that is, there is reason to believe, either from their development 
and structure, or from their relation to allied hermaphrodite forms, that they are typically monoclinous, but have become unisexual by suppression: thus, in the Cucurbitaceæ some genera (e g. Cucurbita, Cucumis, Bryonia, etc.) have unisexual flowers, whilst in others the flowers are always hermaphrodite; similarly, in the Caryophyllaceæ, the flowers are generally hermaphrodite, but in the species Lychnis vespertina and $L$. diurna they are unisexual. In some unisexual flowers traces of the missiug organs are to be found, such as staminodes in carpellary flowers (e.g. Feuillea among the Cucurbitaceæ; Laurus nobilis), or rudimentary pistils in staminate flowers (e.g. Rhamnus cathartica, Lychnis vespertina and diurna).

It sometims happens that typically diøcious plants become exceptionally monœsious (e.g. development of $q$ flowers on $\delta$ plants of Cannabis sativa; or of $\delta$ flowers on $q$ plants of Cannalis sativa and Mercurialis annua): or that a typically monœious diclinous plant bears some monoclinous flowers (e.g. Ricinus).

The Androecium comprises the microsporophylls (one or more) of the flower, the stamens. Euch stamen usually consists of two parts; a slender stalk called the filament (Fig. $276 \mathrm{~s}$ ), and a placental portion which bears the pollen-sacs (Fig. $276 \mathrm{D} p$,) known as the anther (Fig. 276a). The anther consists of two longitudinal halves, termed thecee, each of which usually contains two pollen-sacs; these two halves are united by the placental portion of the filament which is known as the connective (Fig. $276 \mathrm{c}$ ). This is oacasionally very narrow, so that the two halves of the anther lie close together (Fig. $276 A_{1} a$ ): in this case it may be that the anther is not sharply marked off from the filament, and is attached throughout its whole length to the filament (adnate, Fig. $277 C$ ): when the anther is sharply marked off from the filament, it may be attached to the filament by its base, when it is said to be innate or basifixed (e.g. Tulip); or the filament is inserted in the middle of its dorsal surface, when it is dorsifixed (Fig. $277 A$ ); in the last case it may be articulated as by a joint, so that the anther with the connective can oscillate on the apex of the filament (versatile anther, Fig. $276 C$ ), as in Grasses and some other plants. But the connective is often broader, so that the two halves of the anther are widely separated (Fig. $276 \mathrm{~B}$ ): it may be much elongated (distractile) and very delicate, so that with the filament it forms a T-shaped body (Fig. $276 \mathrm{C}$ ); in this 
plant, the Sage, the further peculiarity is exhibited that onehalf of the anther is abortive and is modified for another purpose. It is only rarely, as in Herb Paris (Fig. $277 C$ ), that the connective is prolonged beyond the anther into a point, or into a bristle as in the Oleander.

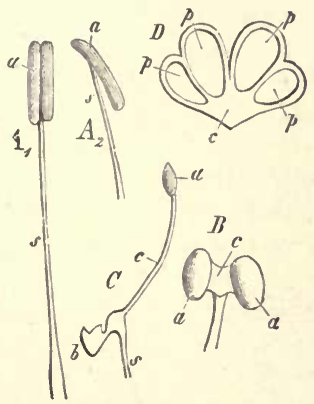

Frg. 276.-Stamen : $A_{1}$ Of Lilium : 8 fila. ment; $a$ the dorsifixed anther. $A_{2}$ Side view. $B$ Of Tilia : $c$ connective. $C$ O Salvia, with dorsifixed versatile anther: $b$ is the half of the anther that has been modifled. I) Transverse section of the anther of Hypericum (mag.): $p$ the 4 pollen-sacs; $c$ connective.

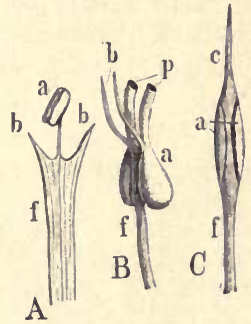

Frg. 277.-A Stamen of Allium. $B$ of Vaccinium Myrtillus. C of Paris quadrifolia (mag.) : $f$ fllament; $c$ connective: $a$ anther; $b$ appen. dages; $p$ the pores by which the anther opens.

The filament is usually round and stalk-like, of a delicate coloured or colourless tissue, with a central vascular bundle; it is occasionally flattened; when it is very short or absent the anthers are sessile.

In some plants, e.g. Allium (Fig. 277 A), the filament has what appear to be stipular appendages; in others, e.g. Erica (Fig. $277 \mathrm{~B})$, the anther is furnished with appendages, such as spurs and so forth: in Viola. the spurs borne by the two anterior stamens are glandular. In certain plants the stamens, that is to say the filaments, branch; either, like most leaves in a plane perpendicular to the median plane, as in Myrtacem and Fumariaceæ, or in various planes, as in Ricinus (Fig. 278) and Hypericaceæ; an anther is borne on each of the branches of the filament.

Somewhat similar in appearance, but essentially different in structure are the coherent stamens of the Papilioneæ and other 
plants. The stamens of each flower may be coherent into one or more bundles. The arrangement becomes complicated when the filaments are at the same time coherent and branched as in the Malvaceæ. When the filaments are all coherent into a single bundle (e.g. Malvaceæ), they are said to be monadelphous; when in two bundles (e.g. some Papilioneæ, Fumariaceæ), they are diadelphous; when in several bundles (e.g. Hypericaceæ), they are polyadelphous. In the Compositæ (e.g. Sunflower and Thistle), though the filaments are free, the anthers become coherent or syngenesious. When the stamens are quite free from each other they are said to be polyandrous.

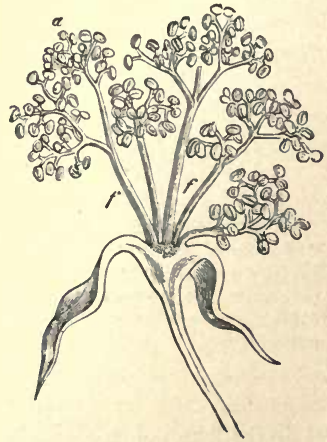

FrG. 273.-Part of a staminal flower of Ricinus communis cnt through lengthways : $f f$ the basal portions of the compoundly-branched stamens; $a$ the anthers. (After Sachs.)

Besides these varieties of cohesion, adhesion frequently occurs; that is the filaments adhere to other portions of the flower, particularly of the perianth, so that they-or when they are very short, the anthers-appear to be inserted not upon the axis of the flower, but upon the leaves of the perianth (epipetalous or epiphyllous): this condition is most frequently present when the petals themselves are connate and form a tubular corolla, e.g. Primula. The adhesion of the stamens to the carpels is of rarer occurrence (e.g. Orchidaceæ, Aristolochia); the flower is then termed gynandrous.

In many flowers it happens that certain filaments, occupying a definite position with regard to the other parts of the flower, are longer than the others; thus, of the six stamens of the Cruciferæ (e.g. Wallflower), four are much longer than the other two; of the four stamens of the Labiatæ, (e.g. Lamium), two are longer than the other two. In the former case the stamens are said to be tetradynamous, in the latter didynamous.

Stamens which bear no anthers are termed staminodes: they are frequently petaloid (e.g. Canna). In many acyclic flowers (e.g. Nymphæa), the stamens and the petals are connected by intermediate structures, of which it is difficult to say whether 
they are to be regarded as petaloid stamens or as staminoid petals.

The Microsporangia or Pollen-Sacs are borne on the anther. There are commonly four of them (quadrilocular anther), two forming a sorus in each longitudinal half (or theca) of the anther, situated usually side by side, but sometimes (Lauraceæ) one above the other ; in the former case the typical arrangement seems to be that of each pair of pollen-sacs one belongs to the anterior or inner surface of the anther, the other to the posterior or outer surface.

In some cases, however, there are but two pollen-sacs-(bilocular anther); this may be due to the non-development of one longitudinal half of the anther (e.g. Cucurbitaceæ, Salvia, Canna); or to branching (c.g. Adoxa, Malvaceæ); or to the abortion of one pollen-sac, generally the posterior one, of each pair (e.g. Asclepiadaceæ); or (some Lauraceæ) of the upper or lower one of each pair; or, finally, to the early fusion of the archesporia of two adjacent pollen-sacs (some Orchidaceæ). In the Araceæ the process of fusion is carried to such an

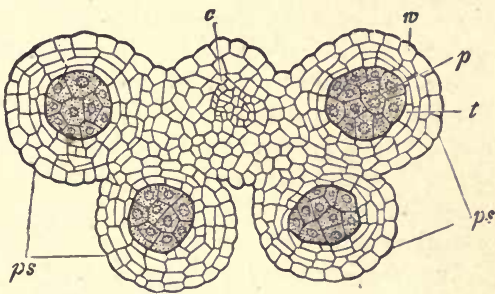

Fre. 279.-Transverse section of a young anther of Sambucus racomosa $(\times 80)$ : $c$ the connective with the vascular bnndle; $p$ the four pollen-facs (microsporangia); $p$ the mother-cells of the pollen; $t$ tapetal layer; $x$ the wall of the pollen-sac. extent that all four archesporia fuss, so that the anther is unilocular.

Each pollen-sac encloses an archesporium from which the mother-cells of the microspores (pollen-grains) are developed by division; each group of spore-mother-cells is invested by a layer of granular cells, the tapetum (Fig. $279 \mathrm{t}$ ), which eventually becomes disorganised: externally to this is the wall of the pollen-sac consisting of one or more layers of cells with usually reticulately thickened walls, followed by the epidermis at the surface.

The pollen-sacs dehisce usually by a longitudinal slit which, when the anther is quadrilocular, is generally so situated that it at once opens into both the pollen-sacs of each half of the anther, and frequently the tissue separating each pair of pollen-sacs be- 
comes dried up and ruptured whilst the anther is ripening : sometimes the dehiscence of the pollen-sac is transverse (Alchemilla); sometimes it is valvular (Berberidaceæ); or by apical pores (Ericaceæ, Polygalaceæ). Though in a quadrilocular anther the pollen-sacs typically belong, two to the inner (ventral), two to the outer (dorsal), surface of the anther, it frequently happens that in the course of their development they become somewhat displaced, so as to appear all to belong to either the inner or the outer surface; hence, when dehiscence takes place, the pollen is shed, in the former case, towards the centre of the flower, when the anthers are said to be introrse ; and, in the latter case, towards the periphery of the flower, when the anthers are said to be extrorse. These terms are similarly applicable in the case of bilocular anthers. Introrse anthers are the more common; extrorse anthers occur in the Aristolochiaceæ, Iridaceæ, Juncagineæ, Araceæ, and in various genera of other orders. In rare cases some of the anthers of the flower are introrse, and others extrorse, as in some species of Polygonum ( $P$. Bistorta, tataricum, aviculare, etc.), where the anthers of the outer whorl are introrse, and those of the inner whorl extrorse; and as in most Lauraceæ, where the anthers of the innermost staminal whorl are extrorse, whilst those of the outer whorls are introrse.

The Microspores or Pollen-grains. The essential features in the structure and development of the microspores have been already fully described (see pp. 85 and 396).

The shapes of the pollen-grain are very various : it may be spherical, oval, triangular, etc., or

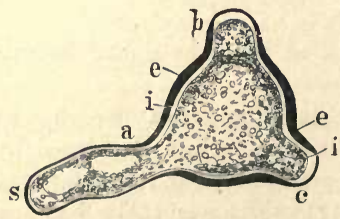

FIG. 250.-Germinating pollen-grain of Epilobium (bighly mag.) bearing a pollen-tube 8 ; $e$ exine; $i$ intine; $a b c$ the three spots where the exine is thicker in anticipation of the formation of the pollen-tube developed in this case at $a$. long and cylindrical (confervoid) as in the Naiadaceæ.

On germination the pollengrain gives rise to one or more pollen-tubes, which consist of outgrowths of the intine: these penetrate the exine (when present), either rupturing it irregularly, or at determinate points where the exine is thinner and less resistent (e.g. Onagraceæ, Malvaceæ), or where there are lid-like areas which are easily removed (e.g. Cucurbitaceæ, Fig. 235). These points are definite in number $(1,2,3,4$, or more), sometimes very numerous (Malvaceæ). 
The Gynceceum or Pistil is always the terminal structure of the flower, occupying the apex of the floral axis. It consists of the macrosporophylls or carpels, which, in the Angiosperms form the whole or part of the ovaries, that is, closed cavities containing the ovules. If in a flower where there are several carpels, each of them closes by the cohesion of its margins, they form so many ovaries; the gynæceum is then said to be apocarpous (Fig. $281 \mathrm{~A}$ ), e.g. Ranunculus, Pæonia, and Butomus : if there is only one carpel (Fig. $281 B$ ), the pistil is said to be apocarpous and simple: if several carpels in one flower cohere and form a single ovary (Fig. 281 $C)$, the gynæceum is said to be syncarpous, e.g. Poppy and Lily. Intermediate forms occur in that the carpels may cohere by their lower ends whilst their upper ends remain free (Fig. $281 \mathrm{D}$ ).

The ovary is said to be nonomerous when it is formed of only
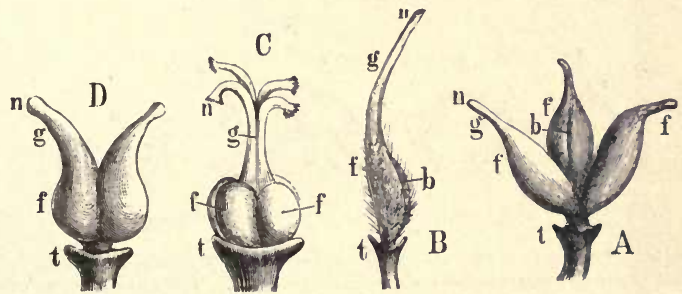

FIG. 281.-A Apocarpous gynæcenm of Aconite. B Simple apocarpous gynæceum of Melilotus. C Tetramerons syncarpons gynæcenm of Rhamnus cathartica. D Ovary of Saxifrage, formed of two carpels which diverge towards the top: $t$ torus; $f$ ovaries; $g$ style; $n$ stigma; $b$ ventral suture.

one carpel (Figs. $281 B$ and $282 A$ ), the margins of which cohere on the side opposite to the midrib. The outer side along which the midrib runs is the dorsal surface (Fig. $282 A r$ ), and the midrib itself is the dorsal suture; opposite to it is the line of cohesion, the ventral suture, which runs therefore along the ventral surface. The cavity thus enclosed (loculus) is not usually divided by dissepiments, but it is a simple cavity, as in the Vetch; such an ovary is said to be unilocular. False or spurious dissepiments, formed by growths on the inner surface, occur in some few instances, as in Astragalus.

When, on the other hand, several carpels cohere to form a syncarpous ovary, it is polymerous (di-tri-or tetra-merous, etc). The syncarpous ovary is unilocular (Fig. $282 B$ ) when the individual

M.B. 
carpels cohere simply by their edges without any portion of them projecting inwards; but if the margins project into the cavity so as to form incomplete longitudinal dissepiments, the ovary is chambered (Fig. 282 C), e.g. Poppy; but since the chambers are open towards the centre, the ovary is still unilocular. When the margins form dissepiments which meet in the middle, the ovary is multilocular (Fig. 282 D) ; sometimes the margins turn outwards again towards the circumference. In the last case the individual loculi are completely separated; but there are others in which the margins of the carpels do not extend so far towards the centre at the upper part as at the lower, but the two margins of each carpel simply cohere together above; consequently the lower part of the ovary is polymerous and multilocular, while the upper part is composed of a number of monomerous ovaries, e.g. Saxifraga (Fig. $281 \mathrm{D}$ ). In all these cases the floral axis may grow up into the
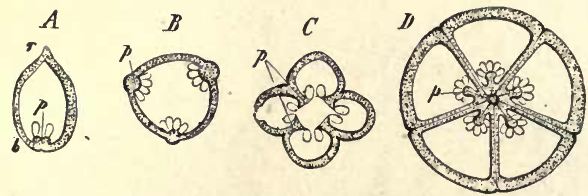

Frg. 282.-Transverse section of ovaries; $p$ placenta. A Monomerous and unilocular; $r$ dorsal suture: $b$ ventral suture; placentation marginal. $B$ Polymerous and unilocular; placentation parietal. $C$ Polsmerous and many-chambered, but unilocular; placentation parietal. D Polymerous and multilocular; placentation axile.

interior of the cavity of the ovary, and when the ovary is multilocular the axis may coalesce with the dissepiments.

False dissepiments may be formed in polymerous ovaries by ingrowths from the internal surface of the carpels; thus the ovary of the Boraginaceæ and Labiatæ is originally bilocular, but each loculus becomes divided into two by a false dissepiment, and when the fruit is ripe the four loculi separate completely; similarly, the unilocular ovary of the Cruciferæ becomes spuriously bilocular.

The inferior ovary of epigynous flowers (see p. 444) is commonly polymerous, but it may be either unilocular or multilocular.

In some bases the axis is prolonged between the carpels, constituting a carpophore, as in the Geraniaceæ and Umbelliferæ (Fig. 287).

The Style (Figs. 281 and 283) is the prolongation of the upper part of the carpel: it is commonly a slender cylinder, but some- 
times it is leafy and pataloid (e.g. Iris). Monomerous ovaries have but one style; polymərous ovaries have as many styles as there are carpels, which may cohere throughout their whole length, or at their lower parts only, the uppor parts remaining distinct; or they may remain quite free, and they may even branch. The style originally arises from the apex of the ovary, but it is frequently displaced forwards, by the vigorous development of the dorsal portion of the carpel, on to the inner side, so as to appear to be a prolongation of the floral axis (gynobasic style): this is conspicuous in the Boraginaceæ and Labiatæ, where it is surrounded by the four rounded loculi of the ovary which have been already mentioned (p. 466). The style is sometimes very short, and appears only as a constriction between the ovary and the stigma, as in the Poppy. In some rare cases it is hollow, but it is usually filled with a loose tissue, called conducting tissue, through which the pollen-tube can easily penetrate.

The Stigma (Figs. 281 and $283 n$ ) is usually terminal, but it may be lateral (e.g. Iris); it is distinguished by being covered with papillæ, or frequently with hairs, and by the secretion of a sugary fluid which retains the pollen-grains which fall upon it, and which promotes the development of the pollen-tubes. The stigma is often evidently distinct from the style, appearing as a lobed expansion; in other cases it seems to be merely a portion of the style at its end or sometimes on its side. In the Poppy it is a sessile disk-shaped

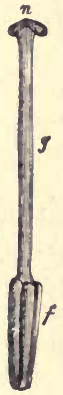

Fra. 283.-Gynæceum of the Lily : $f$ ovary ; $g$ style; $n$ stigma (nat. 8ize). expansion on the upper surface of the ovary; more rarely it is represented by bands of papillæ on the ovary itself, when it is said to be pleurogynous.

The number of the stigmata often affords a means of ascertaining whether the ovary is monomerous or polymerous; for instance, the ovary of the Compositæ seems, at first sight, to be monomerous; but the two short branches of the style, each bearing a stigma, show that it is dimerous. On the other hand, this character may be misleading: for instance, in various Grasses the ovary bears two or three stigmata, either directly, or springing from the style; hence it might be inferred that the ovary is di-or tri-merous, whilst as a matter of fact it is monomerous. In this respect some few 
other plants, belonging to the Naiadaceæ and other families, resemble the Grasses.

The Macrosporangia or Ovules are always enclosed in the cavity of the ovary, either singly or in larger or smaller number. Usually they may be readily seen to be developed on the carpels (Fig. 284 $A, B, C)$, but in many cases they appear to be developed from the floral axis (Fig. $284 D, F, G$ ). However, from careful comparative examination, it seems that the apparently axial ovules may be regarded in some cases as having been developed on the carpels, their position on the axis being merely the result of a more or less considerable subsequent displacement. due to the coalescence of the carpels with the axis. That portion of the ovary which bears the ovules is called the placenta.

The ovules, when borne by the carpels, are but rarely developed over the whole surface of the carpel, but are confined to the margin: in other words the placentation is rarely superficial but generally marginal. Superficial placentation (Fig. $284 C$ ) is to be found in Butomus, Nymphæa, and Nuphar, the dorsal suture (midrib) of the carpel being the only sterile portion of its internal surface. Of marginal placentation there are two varieties: in the one the ovary is syncarpous but unilocular, and the contiguous placental margins of the carpels constitute so many placentæ on the wall of the ovary, that is, the placentation is parietal (Fig. $282 \mathrm{~B}, \mathrm{C}$ ), as in the Violaceæ, Cruciferæ, Papaveraceæ, Ribesieæ, Orchidaceæ, etc. ; in the other the ovary is syncarpous and multilocular, the margins of the carpels meeting in the centre and there bearing the ovules, so that each placenta is at the inner angle of each loculus, that is, the placentation is axile or axillary (Fig. $282 \mathrm{D}$, and Fig. 284 B): in a monomerous ovary (Fig. $282 \mathrm{~A}$, and Fig. $284 \mathrm{~A}$ ) the placentation is essentially parietal, but it is simply termed marginal.

The position of attachment is a point of descriptive importance, more especially where the number of ovules is small, or where there is but one, in the loculus. When the ovule is attached to the roof so that it down hangs into the loculus, it is said to be pendulous; when it is attached high up, but at the side, it is suspended (Fig. $284 E$ ); when it is attached to the side and projects straight, it is horizontal; when it is attached at the side, but towards the base and stands up into the loculus, it is ascending.

When the ovules are borne, either actually or apparently, by the axis, the placentation is said to be axial. When many ovules are borne on the axial placenta (as in the Primulaceæ, Santalaceæ, etc., 
Fig. $281 G$ ), the placentation is termed free central. When there is but a single ovule in the loculus, the placentation is basilar or basal, and the ovule is erect: in this case the ovule is borne either terminally at the apex of the floral axis (e.g. Polygonum, Piper, Naias, Fig. $284 F^{\prime}$ ); or laterally, below or behind the actual apex (e.g. Compositæ, Fig. 284 D).

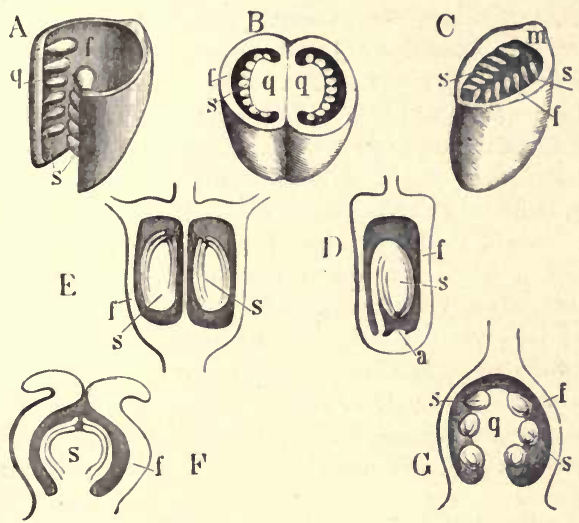

Fig. 231.-Diagrams of the different modes of Placentation. A Monomerous ovary of Helleborus, opened along the ventral sutare; the ovules on $(q)$ the margiual placenta. $B$ Transverse section of the ovary of Nicotians : $f$ wall of the ovary; $q$ placenta, largely developed by the nnion of the margins of the carpels (axile placentation). C Transrerso section of the ovary of Butomus. The ovnles are scattered over the whole of the inner surface, except the midrib, $m$ (superficial placentation). D Longitudinal section of an ovary of one of the Compositæ : $f$ the wall; the erect, anatropous ovale (s) grows from the base by the side of the apex of the axis, a. $B$ Longitndinal section of the ovary of one of the Umbelliferæ; in each chamber an anatropons ovale is suspended. F Longitudinul section of Rhenm; a single erect orthotropous ovnle grows at the apex of the floral axis. $G$ Longitndinal section of the ovary of one of the Primalacea; the ovules grow on a prolongation of the axis (free central placentation). Fig. $282 B$ represents parietal placentation.

For other descriptive terms relating to the ovule, refer back to p. 398 .

The macrosporangium, or ovule, consists primitively of a mass of cellular tissue, the nucellus, invested by one or two integuments, with a micropyle at the apex (see p. 398): generally speaking, two integuments are present in the Monocotyledons, in most polypetalous Dicotyledons (with exceptions such as some Umbelliferæ and Ranunculaiceæ), and in the Cucurbitaceæ among Gamopetalæ; 
whereas there is only one integument in the Gamopetalæ (except Cucurbitaceæ) and in the polypetalous orders, Umbelliferæ and Ranunculaceæ. In some few cases (e.g. Santalaceæ, Loranthaceæ), where the development of the ovule is degraded in correlation with the parasitic habit of the plants, the ovule has no integument.

The Macrospore or Embryo-sac. The structure and development of the macrospore are described on p. 400.

Accessory Organs of the Flower. The most common of these is the Nectary, a glandular organ secreting odorous or sweet liquid, and thus attracting insects. The nectary is sometimes borne on some other organ-which is not thereby materially modified (e.g. petals of Ranunculus, stamen of Viola); or on a specially modified perianth-leaf (e.g. petals of some Ranunculaceæ, as Helleborus, Eranthis, Delphinium), or on staminodes (e.g. a whorl in Parnassia): in some cases it is borne on the carpels, in the septa of a multilocular ovary (septal glands of many Monocotyledons, Liliaceæ, Amaryllidaceæ, and Iridaceæ). Generally the nectary is borne on the floral axis, when it is described by the general term disc: in the Cruciferæ there is generally a whorl of four nectaries at the insertion of the stamens; or the disc may be developed as a ring of tissue round the base of the ovary (e.g. Rutaceæ, Rhamnaceæ, Celastraceæ); or on the upper surface of the inferior ovary (e.g. Umbelliferæ).

The position of the axial nectaries or discs is various: in some flowers it is extra-staminal, and then it is situated either between the andrœcium and the corolla (e.g. Capparidaceæ, Sapindaceæ, Resedaceæ), or less commonly, between the corolla and the calyx (e.g. some Apocynaceæ, such as Nerium): in others it is intrastaminal, that is, between the androcium and the gynæceum (as in Rutaceæ, Rhamnaceæ, Celastraceæ, etc.). Again, the disc is generally hypogynous, but sometimes epigynous (Umbelliferæ).

Generally speaking, when the nectaries, of whatever kind, are towards the outside of the flower, the anthers are extrorse (e.g. Ranunculaceæ); and when towards the centre of the flower, the anthers are introrse.

The General Histology of the sporophyte is sufficiently treated of in Part II., and in the general account of the Phanerogams (p. 400).

The Embryogeny of the sporophyte is considered on p. 401 .

The Gametophyte is considered on p. 405.

Fertilisation. After reaching the stigma (see p. 409) the pollen- 
grains protrude the polien-tubes which penetrate through the tissue of the style into the cavity of the ovary, and through the micropyle of each ovule to its nucellus (Fig. $285 P n$ ). The time required by the pollen-tube for this process depends partly on the distance of the pollen-grain from the ovule and partly on the specific peculiarities of the plant; thus the pollen-tube of the Crocus takes only from one to three days to traverse the style, which is from five to ten centimetres in length; but in the Orchids, where the length of the style varies from two to three millimetres, several days, weeks, or even months are needed, and it is during this process that the ovules are formed in the ovary.

The Results of Fertilisation. The Seed is described on p. 414.

The Fruit. In view of the variety in the structure and morphology of the fruit of Angiosperms, a somewhat detailed account of it is necessary.

The word fruit, in its strictest sense, means the whole product of the development of the gynæceum as a result of fertilisation (p. 61). If other parts of the flower take part in the formation of the

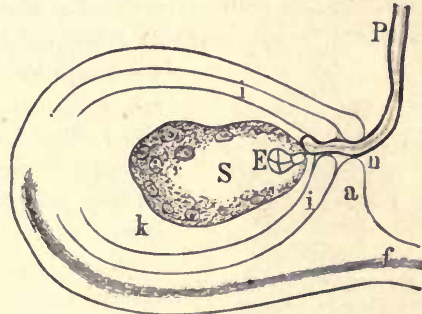

Fro. 235.-Diagram of an orule shortly after fertilisation; $a$ nnter, and $i$ inner Integnments ; 1 funicle: $k$ nucellns. $S$ Embryo-sac in which $E$ is the embryo developed from the fertilised oosphere. The sac also contains the endosperm-cells which are heing formed by free cell-formation. P The pollentnhe, paxsing throngh the micropyle, $n$. organ which is formed in consequence of fertilisation, and which contains the seed (of what, in short, is commonly called the fruit), it is termed a spurious fruit or pseudocarp. The apple, for instance, is such a spurious fruit, for the outer fleshy part belongs to that part of the axis of the perigynous flower which surrounds the ovaries and which still bears the sepals (Fig. ' $A$ ). What are called the pips of the apple are the seeds. This kind of spurious fruit is termed a pome. The strawberry also is a spurious fruit: in it the receptacle, which belongs of course to the axis, developes largely and becomes fleshy and bears the true fruits (achenes) in the form of small hard grains. The fig is another example of a spurious fruit; it is, in fact, a fleshy receptacle (i.e. an axis) which bears 
a multitude of distinct flowers sitnated inside the cavity of the receptacle, and the individual fruits appear as hard grains; such a fruit is termed a syconus. Again when the ovaries and floral envelopes of closely crowded flowers, as in the Mulberry and the Pine-Apple, become succulent, a kind of spurious fruit is formed which is termed a sorosis.

In other cases, a husk, called the cupule, is formed, which contributes to the formation of a spurious fruit: this is formed by the bracteoles and is not developed until after fertilisation; it may surround either a solitary distinct fruit, like the acorn-cup, or several distinct fruits, like the four-valved spiky husk of the Beech-tree or the prickly husk of the edible Chestnut.

When the fruit consists of one or more monomerous ovaries, it is said to be apocarpous : examples of this occur in Ranunculus, in

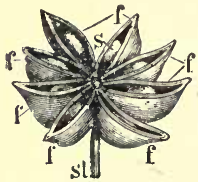

FIG.286.-Frait of Illicium anisatum : st pedunele; $f f$ the separate fruits, each with a seed (s) forming an apocarpous fructification. the Raspberry, where the individual ovaries are succulent, and in the Star-Anise (Fig. 286). The individual fruits may be developed in very different ways; they may be dehiscent or indehiscent, dry or succulent.

When the fruit consists of a single polymerous ovary, it is said to be syncarpous. When the carpels of such a fruit separate septicidally during the process of ripening, so that it ultimately appears as if a number of distinct fruits were present, it is termed a schizocarp : it may thus split into only two distinct fruits, as in the Umbelliferæ (Fig. 287 ); or, as in the Geraniaceæ and many Malvaceæ, into several distinct fruits : each of them is termed a coccus or mericarp; the individual coccus is generally indehiscent (dehiscent in most Euphorbiaceæ).

In various multilocular ovaries only one loculus becomes fully developed and bears seeds, as in Valerian, the Coco-Nut, and the Oak ; the others are abortive. It sometimes happens in cultivated plants that the fruit becomes perfectly formed without any development of seed, as in a particular seedless variety of Grape, the Banana, the Pine-Apple, etc.

In all true fruits the wall of the ovary forms the pericarp or rind. In some more or less succulent fruits, the pericarp consists of three distinct layers; the external layer is the epicarp, the middle the mesocarp, and the innermost the endocarp. 
The following varieties of true fruits have been distinguished by the character of the pericarp, whether it is dry or succulent, hard or soft:and by the dehiscence or indehiscence of the pericarp.

A. Dry Fruits. The pericarp is woody or coriaceous; when ripe, the sap has usually disappeared from all the cells.

I. Dry Indehiscent Fruits. The pericarp does not rupture, but encloses the seed until germination; the testa is usually thin, and frequently coalescent with the pericarp.

(1) One-seeded fruits:

(a) The nut (glans), e.g. Acorn, Hazel-Nut (but not the Walnut); the dry pericarp is hard and sclerenchymatous: it is inferior and syncarpous.

(b) The achene is superior and monomerous: the pericarp is thin and coriaceous; e.g. the Rose and the Buttercup. The similar fruit of the Compositæ is a cypsela; it is inferior and dimerous.

The fruit of Grasses, termed a caryopsis, is very similar to the achene; it differs from it in that the testa and the pericarp closely adhere, whereas in the achene they are not adherent.

(2) Many-soeled fruits: these (schizocarps) commonly split into one-seeded fruits, which usually enclose the solitary seeds until germination: e.g. the Umbelliferæ (Fig. 287) and Maple, with two, the Euphorbiacer with three, mericarps; the Geraniaceæ, with five mericarps; and most Malvaceæ, where the fruit is termed a carcerule, and splits into many mericarps.

The pericarp of dry indehiscent fruits is sometimes developed into a membranous wing (e.g. Ash, Elm, Birch); to such a fruit the term samara is applied: the fruit of the Maple is a double samara.

II. Dry Dehiscent Fruits. The pericarp rup-

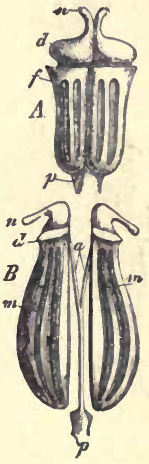

FIg. 287.-Carum Carui. nne of the Umbelliferæ. A Ovary of the flower $(f)$. $B$ Ripe schizocarp which has divided into two cocci or mericarps $(m)$, a portion of the median wall (a) forms the carpophore. tures and allows the seeds, which usually have a firm and thick testa, to escape:-they are commonly many-seeded.

(1) Dehiscence longitudinal.

(a) The fallicle, consisting of a single carpel which dehisces along the ventral suture, where also the seeds are borne, e.g. Pronia and Illicium (Fig. 286); but sometimes (e.g. Magnolia) along the dorsal suture : it is superior.

(b) The legume or pod likewise consists of but one carpel which dehisces along both the dorsal and ventral sutures (Fig. $288 \mathrm{~A}$, transverse section Fig. 282 A): e.g. the Vetch, Pea, Bean, and 
many other Leguminosæ; in some cases (Astragalus) a spurious dissepiment occurs: it is superior.

The lomentum is a modification of the legume; it is constricted between the seeds, and it is either indehiscent or it breaks across, when ripe, at the constricted parts. It occurs in the Hedysareæ.

(c) The siliqua consists of two coherent carpels. The two carpels
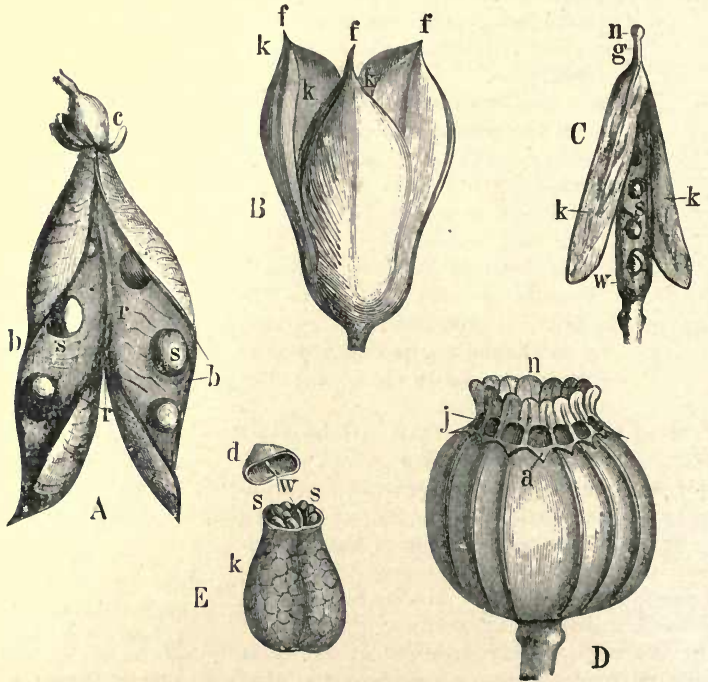

Fig. 288.-Dry dehiscent fruits. A The pod (legume) of the Pea: $r$ the dorsal suture; $b$ the ventral ; $c$ calyx; 8 seeds. B Septicidal capsule of Colchicum a utumnale : $f f f$ the three separating carpel s. C Siliqua or Brassica; $k$ the valves; vo the dissepiment and placentæ (replum); s seeds; $g$ stgle; $n$ stigma. D Capsule, opening by pores, of Papaver somniferum, the Poppy; $n$ stigms; $j$ the pores which open by the removal of the valves (a). E Psxidium of Hyовсyamus; $d$ the lid; $w$ the dissepiment; 8 seeds.

when ripe separate from the base upwards into two valves, leaving their margins (with the parietal placentæ and the spurious dissepiment) attached, as a frame or replum, to the apex of the pedicel; e.g. Rape, Mustard, and most of the Cruciferæ (Fig. $288 C^{\prime}$ ): it is superior.

When the siliqua is short and broad, it is termed a silicula, as in Thlaspi and Capsella. In some cases, as in the Radish, the siliqua is jointed and indehiscent, breaking transversely 
into one-seeded portions. It resembles the lomenturn, and is therefore said to be lonutaceous.

(d) The capsule is derived from a polymerous syncarpous ovary which may be uni- or multilocular; it splits into two or more valves, either for a short distance only from the apex downwards, or down to the very base (Fig. $288 \mathrm{~B}$ ). If the carpels become separated from each other, and in the case of multilocular ovaries this involves the splitting of the dissepiments (Fig. $289 \mathrm{~A}$ ), the dehiscence is said to be septicidal; if, on the other hand, each carpel splits along its dorsal suture, the dehiscence is said to be loculicidal (Fig. $289 \mathrm{~B}$ ). In eithe form of dehiscence in a multilocular ovary the placentæ may either adhere to the valves (Fig. $289 \mathrm{~B}$ ), or remain united into a central column which is free from the valves; in the latter case the dehiscence is further described as being septifragal (Fig. 289 C).

The capsule is usually superior, but sometimes, as in Iridaceæ and Campanulaceæ, it is inferior; a special term, diplotegi$u m$, is applied to the inferior capsule by some authors.

(2) The form of capsule known as a pyxidium has a transverse dehiscence, e.g. in Plantago, Anagallis, Hyoscyamus (Fig. $288 \mathrm{E}$ ); the upper part falls off like a lid.

(3) The porous capsule, e.g. the

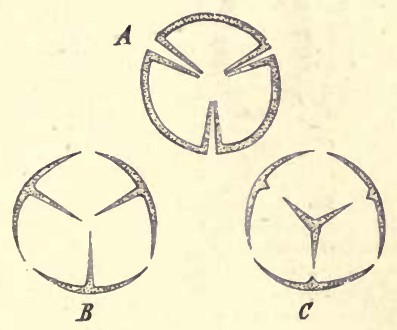

Frg. 289.-Diagrammatic sections of dehissent multilocular capsules. A Septicidal, B loculicida], dehiscence; C loculicidal septitragal dehiscence.

Poppy (Fig. $288 \mathrm{D}$ ), sheds its seeds through small holes arising from the removal of small portions of the wall in certain spots.

B. Succulent Frurts. In these the pericarp is usually differentiated into layers, and some portion of it retains its sap until it is ripe, and usually becomes fleshy at that stage; it is indehiscent.

(1) The drupe (Fig. 290) is superior and monomerous, e.g. the Plum, Cherry; or syncarpous, e.g. the Walnut and Coco-Nut. The most internal layer, the endocarp, is very hard and sclerenchymatous (Fig. $290 e$; it is commonly known as the stone in Plums, Peaches, etc., and encloses the seed until germination: the mesocarp is generally succulent, and the epicarp is a delicate membrane: when the fruit consists of several drupes, they are commonly termed drupels (e.g. Raspberry).

(2) The berry (bacca): the endocarp is soft and juicy as well as the mesocarp, so that the seeds are imbedded in the pericarp: there may be one seed only, as in the Date; or many, as in the Gourd, Currant and Grape : 
the fruit may have one loculus, as in the Grape and the Gourd, or several loculi, as in the Orange; and further, it may be superior, as in the Grape, Orange, and Lemon; or inferior, as in the Currant, the Gooseberry, and the Gourd; it is, as a rule, developed from a syncarpous ovary, but a monomerous berry occurs in Actæa (Ranunculaceæ).

When the fruit is apocarpous and consists of many achenes, drupels, or follicles, it is termed an etario; for instance, the fruit of the Buttercup, the Rose, and the Strawberry is an etærio of achenes; that of the Raspberry and the Blackberry is an etærio of drupels; that of the Tulip-Tree and

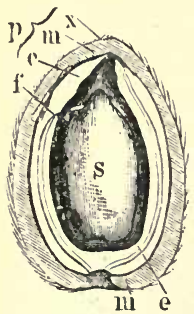

Frg. 290,-Longitudinal section of the drupe of the Almond: $s$ the seed attached by the funicle $(f)$; $\theta$ the hard endocarp; $m$ the mesocarp; and $x$ the epicarp-these con-titute the pericarp (p). of the Magnolia is an etærio of follicles.

The Angiosperms are subdivided as follows :-

Class IX. Monocotyledones: the embryo has usually a single terminal cotyledon, and the growing-point of the primary stem is developed laterally: the vascular bundles of the stem are closed : the leaves commonly have parallel venation; the flower belongs usually to the pentacyclic trimerous type.

Class X. Dicotrledones: the embryo has usually two opposite cotyledons, and the growing-point of the primary stem is developed terminally: the vascular bundles of the stem are usually open : the leaves commonly have reticulate venation: the structure of the flower varies, but it frequently belongs to the pentacyclic pentamerous type.

\section{Class IX.-MONOCOTYLEDONES.}

Although the seed frequently contains endosperm, it contaius none in certain orders; namely, the Orchidaceæ, most aquatic Monocotyledons (Alismales, Hydrocharidaceæ), and in some genera of Araceæ. In the Scitamineæ perisperm is always present in the seed, either together with endosperm (Zingiberaceæ), or without endosperm (Musaceæ, Marantaceæ). In the albuminous seeds, the embryo is usually small in proportion to the endosperm (Fig. $291 \mathrm{I}, e, c)$

Whilst the single cotyledon of the embryo is, as a rule, terminal, 
and the growing point of the stem lateral, in some forms the growing-point of the stem is terminal (apical) on the longitudinal axis of the embryo (e.g. Dioscoreaceæ). The growing-point of the primary stem frequently developes into a plumule. The axis of the embryo terminates posteriorly in a short radicle.

On germination, the upper end of the cotyledon commonly remains in the seed and absorbs the nutritious substances deposited in the endosperm (Fig. $291 I I .-I V$.); the lower part of the cotyledon elongates and pushes the rest of the embryo out of the seed. In Grasses the cotyledon has a peculiar shieldlike form, and is termed the scutellum (Fig. 292 $s c)$ : in the ripe seed it almost entirely encloses the embryo, and is in contact by its outer surface with the endosperm ; during germination the cotyledon absorbs the nutritious matters contained in

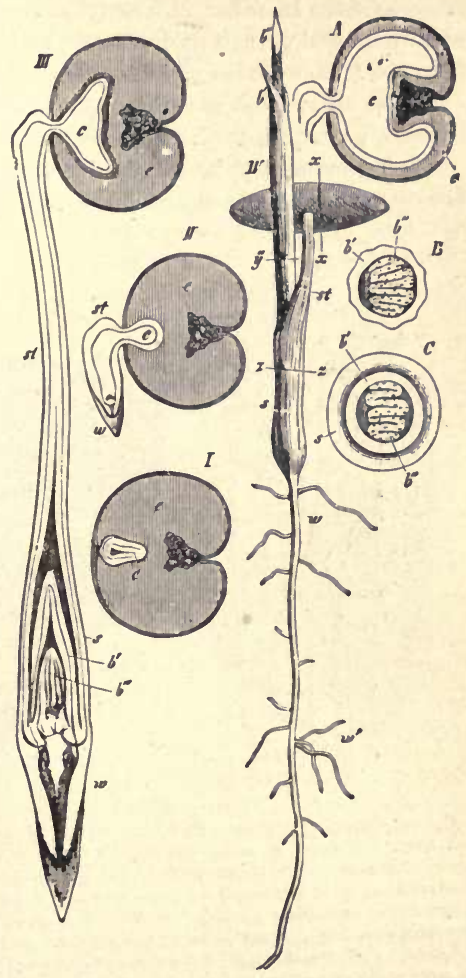

Fra. 291.-Germination of Phanix dactylifera, the Date. I. Transverse section of the dormant seod. II, III, $I V$, Different stages of germination (IV. the natural size). 4 Transverse section of the seed at $x \neq$ in $I$. $B$ Transverse section of the seedling at $z y: C$ at $z$. - The horny endosperm; sthe sheath of the cotyledon; st its stalk; $c$ its apex developed into an orgsn of abnorption which gradnally consumes tioe endosperm and at length occupies its place; $w$ the primary root; $w^{\prime}$ secondary roots; $b^{\prime} b^{\prime \prime}$ the lesves which succeed the cotyledon; $\left(b^{\prime \prime}\right)$ becomes the first foliage-leaf, in $B$ and $C$ its folded lamina is seen cut across. (After Sacbs.) the endosperm, while the stem with the other leaves grows ont 
of the seed. In other Monocotyledons either the cotyledon is a sheathing scale, or it is the first green leaf differing but little from the foliage-leaves which are subsequently developed.

The primary root usually remains small and inconspicuous: in Grasses generally, the radicle begins to branch before it escapes through the micropyle on germination, so that the root is then fibrous; when this is the case the inadequate root-system is sup-
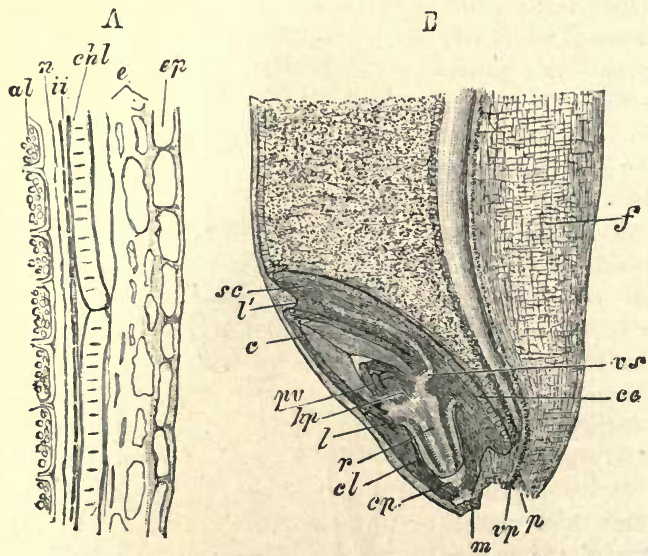

Fro. 392.-Grain of Triticum vulgare, the Wheat. A Cross-fection through the pericarp and testa. Of these, op is the epidermis, o the onter layers, and chl the chloropluyll. layer, of the pericarp: ii remnants of the ovular integument, and $n$ the outermost thickened layer of the nucellus; these together constitute tho testa: al the aleuron. layer of the endosperm (x 210). B Median longitndinal section through the lower part of a ripe grain, in the plane of the furrow. At the bottom of this to the left is the embryo: the scutellum, sc; $l^{\prime}$ the ligule of the scutellum; vs its vascular bundle; co its layer of cylindrical epithelium: $c$ the sheath of the plnmule (colcoptile); pv the growing-point of the stem; $h p$ the hypocotyl; $l$ the cpiblast; $r$ the radicle; $c p$ the root-cap of the radicle; ol the root-sheath (coleorbiza); $m$ place of exit of the radicle, corresponding with the micropyle of the ovule; $p$ the funicle; vp vascular bundle in the funicle: $f$ lateral surface of the furrow ( $\times 11)$. (After Strasburger.)

plemented by the development of adventitious roots in succession at higher and higher levels upon the stem.

The stem of Monocotyledons is traversed longitudinally (Fig. 99, p. 122) by scattered closed vascular bundles (Fig. 103); it has therefore no growth in thickness by the means of cambium. In a few genera only, as Yucca and Dracæna, it grows subsequently 
in thickness by the formation of meristem in the pericycle from which additional closed vascular bundles are developed (see p. 148, Fig. 117).

The axis of the embryo in many cases continues to be the main axis of the plant; at first it is thin and weak, and since no secondary growth in thickness of the stem takes place, and since the successive portions of the stem are thicker and more vigorous, the whole stem gradually assumes the appearance of an inverted cone; but when the plant has reached a certain height it may then grow cylindrically: this is the reason why in Palms, in the Maize, and other similar erect stems, there is a diminution in thickness at the lower end. Frequently, however, the primary axis of the plant perishes when it has given rise to lateral shoots.

The arrangement of the leaves is at first alternate: when the stem is well developed this alternate arrangement often passes over into complex spiral arrangements, as in Fritillaria and in Palms, in which plants a crown of leaves is conspicuous. In the Grasses, and a few other families, the phyllotaxis is permanently alter-

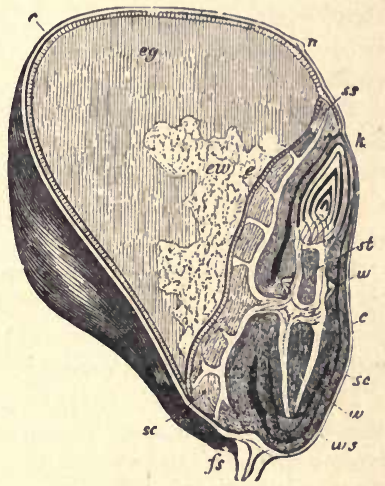

FrG. 293.-Iongitudinal section of thegrain of Zea Mais ( $x$ about 6 ): $c$ pericarp; $n$ re. mains of the stigma : $f 8$ hase of the grain ; eg hard yellowish part of the endosperm; ew whiter less dense part of the endosperm; sc scutellum of the embryo; $s s$ its apex; 6 its epidermis; $k$ plumule; $w$ (below) the primary root; $v s$ the coleorhiza : $w$ (above) secondary ronts springing from the epicotyl (st). (After Sachs.)

nate. A whorled arrangement of the foliage-leaves occurs but rarely.

The leaves commonly have a well-developed sheathing leaf-base: they may be described as exstipulate. The lamina is usually entire, simple in outline, often long and narrow, linear or ensiform, more rarely orbicular, cordate or sagittate. Branched leaves occur only in a few of the Araceæ: the pinnate or palmate leaves of the Palms acquire this form by the splitting of the originally entire laminæ, and the same is the case with the perforated leaves of many Araceæ (see p. 37). 
The venation of the leaves is characterized by the fact that the weaker veius do not usually project on the under surface. In linear leaves. and in such as are inserted by a broad base, the stronger veins run almost parallel; in broader ones, e.g. Lily of the Valley Convallaria majalis), they describe a curve which is more or less parallel to the margin; the weaker veins usually run at right angles between the stronger ones. In the Scitamineæ and a few other plants, a number of parallel transverse veins are given off at various angles (sometimes acute, and sometimes nearly right angles from the midrib. Reticulate venation of the leares is uuusual; but it occurs in Aroids, in Paris quadrifolia, etc. (see p. 39$)$.

The flower of Monocotyledons consists typically of five alternating and isomerous whorls, two belonging to the perianth, two to the androcium and one to the gynæceum. Thus the typical formula is $k \mathrm{n}, C \mathrm{n}, A \mathrm{n}+\mathrm{n}, G \mathrm{n}$, where $\mathrm{n}$ in most cases $=3$, more rarely $=2,4$ or $\tilde{5}$.

The perianth-leaves are generally all much alike, and petaloid in both series: sometimes they are all sepaloid (e.g. Juncaceæ); more rarely those of the external whorl are sepaloid, those of the internal petaloid (e.g. Alismaceæ).

This type is most closely adhered to in the Liliaceæ. The simplest departure from it is exhibited in the suppression of the inner whorl of stamens in the Iridacex, and in the inferior position of the ovary. This latter character occurs also in the Scitaminex and Orchidaceæ, which are further characterized by the zygomorphism of their flowers and the considerable reduction of the androecium. Other various and considerable deviations by reduction from the Liliacesus type of flower occur among the Araceæ, and in the Glumales, and Typhaceæ, and in certain water-plants (e.g. Naiadaceæ, Lemnaceæ). On the other hand, the deviation may be due to increase in number, more especially of the members of the gynæceum and to some extent of the androecinm (e.g. Alismaceæ). 
GROUP V.-ANGIOSPERMLE: MONOCOTYLEDONES.

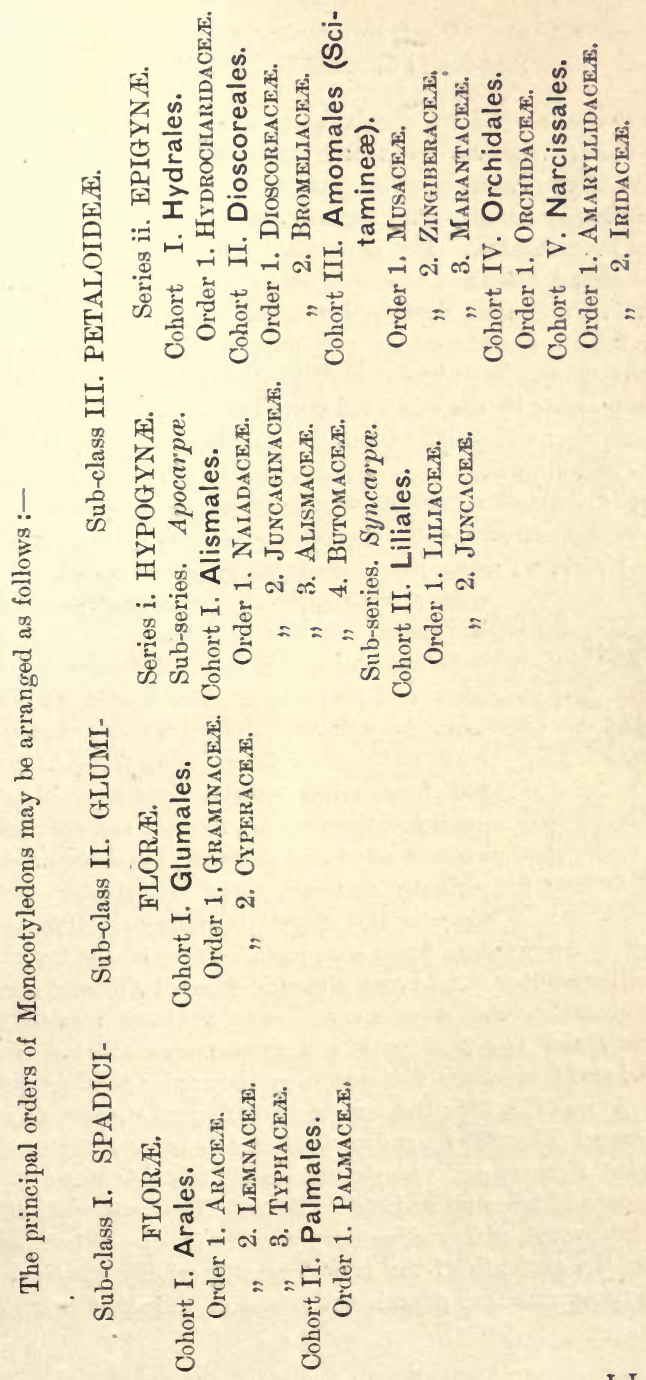




\section{Sub-Class I. SPADICIFLORÆ.}

Inflorescence usually a spadix with a spathe, but flower sometimes solitary : flowers frequently unisexual, sometimes diœcious: perianth, often wanting, never petaloid: anthers usually extrorse, or dehiscing by pores: ovary superior.

Cohort I. Arales. The flowers are small and numerous; the inflorescence a spadix or a panicle with thick branches, commonly enclosed in a greatly developed spathe; the bracts of the individual flowers are frequently wanting; perianth 0 , or polyphyllous; the flowers are usually diclinous, but both kinds of flowers frequently occur in the same inflorescence: gynæceum apocarpous or syncarpous: the seeds have a large endosperm: the embryo is straight and minute.

Order 1. ARACEE. Flowers monœcious or $\not{q}:$ perianth 0 or of $4-6$ leaves : stamens $1-8$, frequently coherent into a synandrium in the $\delta$ flowers : ovary monomerous, or polymerous and multilocular: fruit a berry: seed sometimes exal-

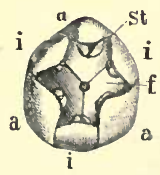

FIG. 294.-Flower of Acorus Calamus (mag.) : $a$ outer, $i$ inner perianth: st stamens; $f$ ovars. buminous. Mostly tropical.

In many of the genera the flowers are complete and conform to the monocotyledonous type, $K \mathrm{n}, C \mathrm{n}, A \mathrm{n}+\mathrm{n} G\left({ }^{\mathrm{n}}\right)$, where n may stand for 2, or 3, as in Acorus (Fig. 294), in which the flowers are exactly typical. In other genera, however, the flowers are reduced in various ways and degrees; not only does the perianth disappear, but the number of the stamens and carpels is frequently diminished.

In many $q$ flowers staminodia are present, either in the typical or in a smaller number. An extreme case is offered by those diclinous flowers of which the $\delta$ consists of only a single stamen (e.g. Arisarum), and the $q$ of only one monomerous ovary. These much-reduced flowers are disposed in regular order on the spadix : thus in Arum (Fig. 295) the numerous of flowers, consisting each of one carpel (Fig. 295 $f$ ), are inserted on the base of the spadix; and the $\delta$ flowers, each consisting merely of 3-4 stamens, are closely packed higher up on it (Fig. $295 a$ ). The upper part of the spadix is covered with rudimentary flowers $(b, c)$. When, as in this case, the perianth of the true flowers is wholly wanting, the whole inflorescence may assume the aspect of a single flower; but 
irrespectively of the numerous intermediate forms which are to be found, such a view is untenable when it is bərne in mind that here the ovaries are invariably situated below the stamens, while in a flower they are invariably above them.

The usually sympodial stem may be underground, a tuber, or a rhizome, or it may be aerial; in the latter case it often climbs, clinging to trees by means of aerial roots. The leaves are either alternate and distichous or, more often, spiral with a divergence of $\frac{2}{5}$. They are rarely narrow, linear, or ensiform, and commonly consist of leafbase, petiole, and blade; the venation is reticulate, and the leaf often exhibits a more or less complicated segmentation. Laticiferous sacs or cells (see p. 99) occur in some families of the order, as do also sclerotic cells (see Fig. 98A, p. 120).

The principal families are :-

Fam. 1. Pothoidea: without either laticiferous or sclerotic cells: flowers usually $\wp$, with or without a perianth. This family includes a

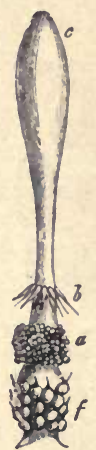

FiG. 295.-Spadix of Arum maculatum (nat. size): $f$ macrosporangiate, a microsporangiate, and $b$ rudimentary flowers; $c$ the up. per club-shaped end of the spadix. number of genera, such as Pothos, Anthurium, Acorus. The only member which occurs in Britain is Acorus Calamus, the Sweet Flag, which grows on the margins of ponds and rivers: its subterranean rhizome bears long ensiform alternate leaves, crimped at the edges; its flowering-shoot is triquetrous, bearing a terminal spadix which is, however, displaced to one side by the spathe which developes so as to form a continuation of the long axis of the flowering-shoot: the spadix is densely covered with flowers (Fig. 294).

Fam. 2. Calloidex: with straight rows of laticiferous cells: flowers usually $\Varangle$, with or without a perianth: leaves never sagittate. No member is indigenous in Britain : Calla palustris occurs in the marshes of Northern Europe; it has a white spathe and parallel-veined leaves.

Fam. 3. Philodendroidec: with straight rows of laticiferous cells: flowers diclinous, without a perianth: stamens usually connate: leaves generally parallel-veined. Zantedeschia (Calla or Richardia) athiopica, with a white spathe, is commonly cultivated under the name of the Trumpet Lily.

Fam. 4. Aroidex: with straight rows of laticiferous cells: flowers diclinous: usually without perianth. Arum maculalum, the Cuckoo-pint or Lords and Ladies, is a British plant, common in wood and hedges; the 
large green spathe completely envelopes the spadix (Fig. 295). Dracunculus and Arisarum are also European genera.

Order 2. Lemnaces. Stem leafless. Each inflorescence consists of two $\delta$ flowers and one $q$ flower borne on a lateral branch of the stem: the $\delta$ flowers consist of a

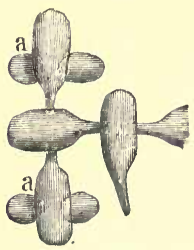

Fig. 296,-Part of a plant of Lemua trisulca, seen from above: $a$ the soung lateral branches (nat. size). single stamen, and the $q$ flower of one carpel.

Lemna trisulca, L. (Spirodela) polyrhiza, minor and gibba, are known as Duck-weed; they are common in tanks and ponds, floating on the water. The stem, which is leafless, is almost flat, resembling a thallus : it bears two rows of branches (Fig. 296), as also roots on its under surface which are suspended in the water. Roots are, however, absent in Wolffia arrhiza, which is also devoid of vascular bundles; its flower has no spathe, and it bears only one row of branches: it is the smallest known flowering plant.

Order 3. TYPHACEE. Flowers diclinous; the perianth represented only by scales, or 0 . Stamens usually 3 . Ovary usually monomerous, containing one ovule. Inflorescence a spadix, without a spathe, elongated or compact.

In Sparganium, the Bur-Reed, the inflorescences are spherical spikes which are borne terminally and laterally in two rows on the upper part of the stem. The lower spikes bear only + , and the upper only $\delta$ flowers; the perianth consists of 3-6 scales; stamens 3-8, free; gynæceum sometimes dimerous with an ovule in each loculus. Sparganium simplex and ramosum are not rare in ditches.

Typha, the Reed-Mace or Bulrush, bears its flowers on a long terminal spadix; the flowers are borne directly on the upper and thinner portion of the main axis; on the lower and thicker portion are borne the $q$ flowers, partly on the main axis and partly on very short lateral shoots; the perianth is replaced by long hairs; stamens $1-5$, monadelphous. Typha angustifolia and latifolia occur in bogs and wet places.

Cohort II. Palmales. Order 1. Palmaces. The diœcious or monœcious, rarely moncclinous or polygamous, flowers are inserted, with or without bracts, on the spadix or on the thick axis of a spicate or paniculate inflorescence (Fig. 297): they generally

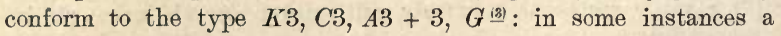
larger or a smaller number of stamens are present: anthers sometimes introrse: carpels rarely more or less than 3, either free or connate; when the gynæceum is apocarpous, the ovary is unilocu- 
lar: when syncarpous, the ovary has from one to three loculi. Each loculus contains, typically, a single basal ovule; but in trimerous ovaries, two of the ovules are generally abortive: frequently not more than one of the carpels (whether the gynæceum be apocarpous or syncarpous) developes into the fruit: the fruit is generally baccate or drupaceous, one-seeded: the seed is large, and the contained endosperm is horny.

Their mode of growth is somewhat various. Most Palms bear their leaves closely arranged in a crown at the top of a tall or of a quite short stem, which is clothed for some distance below its apex with the remains of the older withered leaves. But in some genera, e.g. Calamus, the stems creep or climb and the leaves are inserted at some distance from each other. The blade of the leaf commonly splits in the course of its growth, assuming a compound palmate or pinnate form. The inflorescence is invested by bracts: there is usually a large bract (spathe) which envelopes the whole inflorescence when young, and other, inner, bracts which either partially invest it or (when branched) its branches.

Palms chiefly inhabit the tropics, particularly the Moluccas, Brazil, and the region of the Orinoco, and the different genera belong exclusively (at least originally) either to the Old or to the New World.

Phanix dactylifera (the Date Palm) a native of Asia and Africa, has pinnatifid leaves. Of the three ovaries, one only developes to form the fruit which is known as the Date (p. 475, Fig. 291); the stone of the Date consists of a very thin testa enclosing the large mass of hard endosperm in which

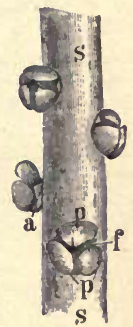

Fig. 297. - Part of the panicle of $\%$ flowers of Cham mdore a: s the thick axis; a the external; and $p$ the iuternal whorl of the perianch; $f$ ovary $(x 3)$. the embryo is imbedded. Chamarops humilis is a frequently cultivated ornamental plant, with fan-like leaves, which belongs to the Mediterranean region. Metroxylon (Eu-Sagus) Rumphii and lave, growing in the Moluccas, are the plants from which Sago is obtained; it consists of the starch-grains obtained from the parenchyma of the trunk. The stems of species of Calamus, in the East Indies, supply Malacca-cane. Areca. Catechu (Fig. 298 J) is the Betel-Palm of tropical Asia. Cocos nucifera (the. Coco-nut Palm) has, as is well known, many uses. The fruit itself is a gigantic drupaceous fruit; the mesocarp is traversed by an immense number of vascular bundles, which are used to make ropes, etc. Inside the excessively hard innermost layer of the pericarp, the endocarp, lies a single large seed. When the fruit is mature, the endosperm forms a 
layer only a few millimetres in thickness, which lines the hard shell; the rest of the space (the remaining cavity of the embryo-sac) is filled with fluid, kuown as coco-nut milk. The embryo, which is small, is imbedded in the firm tissue of the endosperm, under the spot where there is a hole
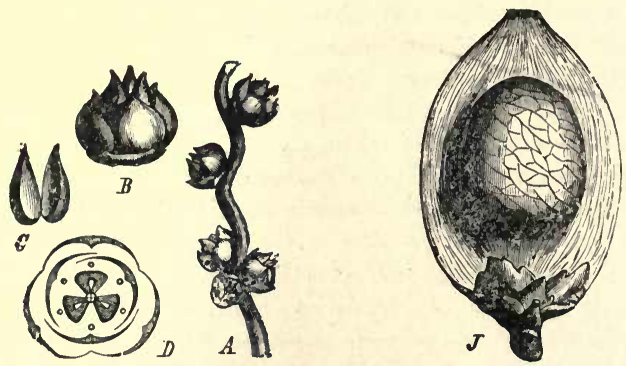

F'tG, 298. $-A$ Part of the $f$ inflorescence of Phanix reclinata (nat. size): $B$ single $q$ flower: $C$ two carpels : $D$ floral diagram. $J$ Fruit of Areca Catechu: one half of the fibrous pericarp has been removed.

(corresponding in position to the style of the single fertile loculus of the ovary) in the endocarp. Elais guineensis is the Oil Palm of West Africa; the mesocarp of the plum-like fruit yields the oil. Phytelephas grows in tropical America: the hard endosperm is known as vegetable ivory.

\section{SUB-CLASS II.-GLUMIFLORÆ.}

Flowers monoclinous, or unisexual and then mostly monœcious, usually in heads or spikelets invested by imbricate bracts: perianth absent, or scaly : ovary superior, uni- or multilocular, with one ovule in the loculus: seeds with endosperm.

Cohort I. Glumales. Ovary unilocular : ovule erect.

Order 1. Graminace.s. True Grasses. The leaves are alternate on the stem, which is known as the haulm; the embryo lies
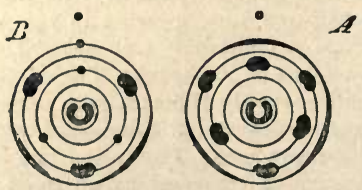

FIG. 299,-Diagrams of Grass flowers. A Bambusa. $B$ Common type of Graminaceæ. In $A$ there are three, in $B$ two lodicules. on the side of the endosperm (Figs. 292-3). The usually monoclinous flowers generally have the formula $K 0, C O$, $A 3+0, G 1$; they are enclosed by bracts here termed palea, and are arranged in complicated inflorescences; the monomerous unilocular ovary 
contains only one ovule; the grain is the fruit, a caryopsis, to which one (the inferior) or, less commonly, both, of the paleæ sometimes adhere, e.g. Barley and Oats.

The flower is sessile in the axil of a bract, which is termed the inferior or outer palea, sometimes also called the flovering-glume (Fig. $301 b_{1}, b_{2}, \ldots$ ), and there is also a bracteole opposite to and somewhat higher than this which is termed the superior or inner palea (Fig. 301 ps). The two paler completely enclose the flower.

Within the inferior palea are usually two small (antero-lateral) scales, the lodicules (sometimes only a single anterior one, Melica),

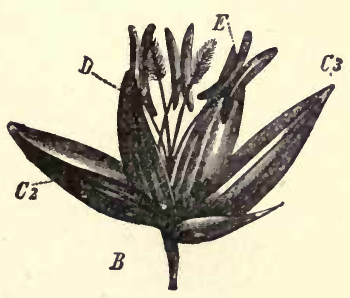

Fig. 300.-Single-flowered spikelet of Panicum miliaceun (mag.); $C_{2}$ and $C_{3}$ second and third glumes: $D$ inferior palea: $E$ superior palea.

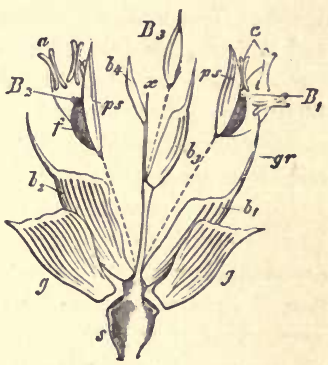

FrG. 301.-A spikelet of Wheat dis. sected (mag.): $z$ axis of the epikelet; 9 glnmes; $b_{1} b_{2} b_{3} b_{4}$ inferior palem bear. Ing $(g r)$ the awn; $b$, is sterile. $B_{2} B_{2} B_{4}$ the flowers raised (as indicated by the dotted lines) out of the sxils of the in. ferior palex; ps superior palea; $a$ an. thers; fovaries.

and occasionally (e.g. Stipa, some Bambuseæ, Fig. 299 A), there is a third scale situated posteriorly within the superior palea. These lodicules are frequently regarded as rudimentary perianthleaves, but it is more probable that they are bracteoles, the two antero-lateral lodicules representing the two halves of a single bracteole, present, as such, in Melica. They grow and become succulent at the time of flowering, thus forcing apart the paleæ and the glumes. Usually two or more flowers, thus enclosed by paleæ, are present on an axis (Fig. $301 x$ ), and constitute the spikelet of the Grass, and beneath the lowest flower there are usually two (or more) bracts which bear no flowers in their 
axils and are known as the glumes (Fig. $301 \mathrm{~g}$ ). Thus a spikelet consists of a main axis bearing two rows of bracts of which the two first and lowest are barren, while the succeeding ones bear each a flower in its axil, and beneath each flower there is also a bracteole (superior palea) belonging to the floral branch itself. The inferior paleæ often have, either at the apex or else borne on the midrib, a spinous process called the arista or awn (Fig. 301 gr).

The number of flowers in each spikelet varies, however, according to the genus; often there is but one, the lowest, with rudiments of others above it; if, however, only one of the upper flowers is developed, then the lower paleæ bear no flowers in their axils and are regarded as glumes, several being therefore present in such a case. The spikelets themselves are in many genera, e.g. Rye and Wheat (Fig. $302 \mathrm{~B}$ ), arranged in two rows on a main axis; the inflorescence may then be designated a compound spike (see p. $440)$; in most of the other genera the main axis of the inflorescence bears lateral branches which are slender, of various length, and often branched again, and which bear the terminal spikelets; in this way a panicle is formed, as in the Oat (Fig. $302 \mathrm{~A}$ ). This may be either loose and spreading, with long lateral branches, or compressed, with very short branches, e.g. Alopecurus. The position of the branches of the panicle is more or less bilateral; dorsiventral, when (e.g. Festuca) the branchlets of the main branches of the panicle all arise on the same side (unilateral or secund panicle).

The androecium consists commonly of one (Fig. $299 \mathrm{~B}$ ) or two (A) whorls of 2-3 stamens; when there is but one whorl of stamens, it corresponds to the outer whorl in those flowers in which two whorls are present. Sometimes (e.g. Luziola, Ochlandra, Pariana) the stamens are numerous (about 18-20), or there may be but one or two. When there are normally only two stamens, they are usually situated in the median plane (e.g. Anthoxanthum), sometimes in the lateral plane (e.g. Coleanthus); but where this is the result of suppression (Diarrhena, Orthoclada) they are postero-lateral, the anterior stamen being suppressed: when there is only a single stamen, this is generally the anterior stamen (e.g. species of Festuca and Andropogon), the two postero-lateral stamens being suppressed.

The monomerous gynæceum consists of a single median carpel (Fig. 299), bearing 1-3 styles (see p. 467): the single, somewhat campylotropous ovule is sessile on the ventral suture of the carpel. 
The stem is generally characterised by swollen or tumid nodes, to which the sheathing leaf-bases contribute. The long internodes are hollow: the sheathing leaf-bases are largely developed, and frequently extend over several internodes. A membranous ligule is developed at the junction of leaf-base and lamina (see p. 32; Fig. 19 A).

The more common Grasses are classified as follows:-

Series $A$. PAniconnex: spikelet one-flowered, or sometimes two-flowered and then the lower flower is imperfect; articulated so that it falls off entire after flowering; no prolongation of the axis beyond the flower.

Tribe 1. Panicece : spikelets dorsally compressed, in compound spikes: glumes 3, of which the lowest is the smallest: inferior palea without an awn.

Panicum glabrum (Digitaria humifusa), P. (Echinochloa) Crus-galli, and $P$. (Setaria) viride occur occasionally on cultivated land. $P$. miliaceum yields Millet (Fig. 300).

Tribe 2. Maydea: the diclinous flowers are in distinct spikelets; the two kinds of spikelets usually form distinct infloresences, but sometimes they occur in different parts of the same inflorescence : the lowest glume is the largest.

Zea Mais, the Maize Plant, cultivated in warm countries, is a native of Tropical America: the of spikelets form a loose panicle at the apex of the haulm, and the of flowers are borne laterally on a thick spadix, which is ensheathed by leaves.

Tribe 3. Andropogonece: flowers monocious or polygamous : glumes 3, of which the lowest is the largest.

Saccharum Officinarum, the Sugar-cane, is a native of the East Indies. Andropogon Sorghum, in different varieties (vulgaris, Durra, eto.), yields a kind of Millet seed: the flour of this is known in Arabia and India as Durra.

Tribe 4. Oryzéa : spikes laterally compressed: glumes 2-4, often represonted only by bristles: stamens generally 6 . Oryza sativa is the Riceplant, from the East Indies; cultivated in marshy regions of Southern Europe. Leersia oryzoides, the Cut-grass, is found in ditches in the South of England.

Series $B$. Poondex : spikelet one- or many-flowered, with distinct internodes between the flowers: when one-flowered, the axis of the spikelet is prolonged beyond the flower: the ripe fruits fall, leaving the glumes behingd.

Tribe 5. Phalaridece: spikelets pedicillate in panicles, laterally compressed, 1-flowered: glumes 4, the inner pair being smaller. Phalaris arundinacea, the Reed-Grass, is common on the banks of streams, etc.: a variety with white-streaked leaves is cultivated in gardens. Anthoxanthum odoratum, Vernal-Grass, which has only two stamens and a paniculate inflorescence, is common in meadows : it gives the peculiar odour to fresh hay: 
Tribe 6. Agrostideae: spikelets 1-flowered, in panicles: glumes 2.

In Agrostis, the Bent-Grass; the axis of the spikelet is glabrous, or it baars short hairs; A. vulgaris and alba are common in meadows: Apera Spica Venti is common in fields : in Calamagrostis, the Small Reed, several species of which occur on the banks of rivers and in woods, the axis of the spikelet is covered with long hairs. Stipa pennata, the Feather-Grass, has a long hairy awn. Milium effusum, Millet-Grass, without an awn, is common in woods. Amongst the forms with dense cylindrical panicles, Alopecurus, the Fox-tail Grass, has the glumes coherent at the base, and one rudimentary palea. Phleum, the Cat's-tail Grass, has free glumes and two distinct paleæ. Phleum pratense is commonly known as TimothyGrass.
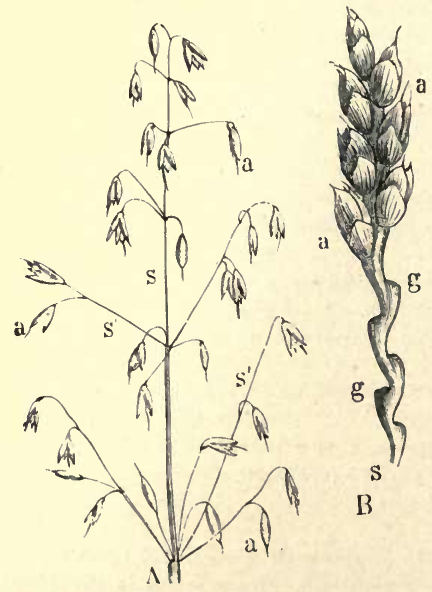

B

Fre. 302.-A Panicle of Oat, dvena sativa : 8 main axis; $s^{\prime}$ lateral axes; $a$ spikelet ( $\frac{1}{3}$ nat. size). $B$ Spike of Wheat: 8 axis; $g$ the depressions in which the spikelets $(a)$ lie. These are removed at the lower part.

Tribe 7. Avenex: the paniculate, or rarely spicate, spikelets consist of several (usually two) flowers one of which is sometimes $\delta$; the glumes (or one of them at least) are as long as the whole spikelet, longer than the inferior paleæ, which usually have a long twisted or bent awn.

Avena, the Oat-Grass, has loose panicles, and a twotoothed inferior palea; of this genus there are many species; A. fatua (Wild Oats, or Havers), pratensis and pubescens, are common in cornfields and meadows. The following species are cultivatéd: $A . s a-$ tiva, the Oat (Fig. $302 \mathrm{~A}$ ), with its panicles in various planes; $A$. orientalis, with its panicles in one plane; A. strigosa, with a hairy floral axis; and $A$. $n u d a$, the spikelets of which usually consist of three flowers. Trisetun (Avena) flavescens, the yellow Oat-Grass, with a free fruit, occurs in pastures. Aira (Deschampsia) caspitosa, and flexuosa, Hair-Grasses, have truncate inferior paleæ, and are common in meadows and woods. Holcus, the Honey-Grass, has spikelets consisting of two flowers, the upper of which is usually $\delta$, and the leafsheaths are covered with silky hairs; it is common in damp meadows. In Arrhenatherum, the False Oat-Grass, the lower of the two flowers is $\delta$.

Tribe 8. Festucea: the spikelets are usually many-flowered, and the glumes shorter than the inferior paleæ which either have no awn or a straight terminal awn. Melica, the Melic-Grass, has sometimes spikelets 
consisting of a single flower only: the glumes are long; it is common in woods. Molinia carulea has a very long haulm, consisting for the most part of a single internode; its spikelets are in loose purplish panicles; it occurs on moors. Briza, the Quaking-Grass, has spikelets which are compressed laterally and are cordate at the base; it is common in meadows. Koeleria cristata has dense panicles; it is common in dry meadows. Dactylis glomerata, the Cock's-foot Grass, has dense panicles divided into parts which have longer stalks; it is common in meadows. Pox pratensis, trivialis, etc. (Meadow-Grass), are common in meadows; their spikelets are compressed laterally; the glumes have a sharp keel; $P$. annua is common by the roadside. Other Meadow-Grasses are Glyceria aquatica and fluitans, with obtuse unequal glumes, and a lower palea with 5-7 prominent parallel veins, growing in ditches; and Schlerochloo maritima, distans, etc., growing in salt-marshes and by the sea-shore, with acute unequal glumes. In all the Meadow-Grasses, the fruit is free from the paleæ. Festuca elatior, and others, the Fescue-Grasses, are common in meadows. Bromus, the Brome-Grass, of which there are several species, is common in fields ( $B$. secalinus), in meadows (B. racemosus and others), by the roadside ( $B$. sterilis and nollis). Brachypodium, with shortly-stalked spikelets in a simple raceme, and unequal glumes, is common in woods ( $B$. sylvaticum) and on heaths ( $B$. pinnatum). In Phragmites the axis of the spikelet is coverel with long silky hairs; Phragmites communis, the Roed, cesurs abundantly in marshes. Sesleria carulea, the Moor-Grass, has laterally compressed spikelets in dense panicles. Gynerium, the Pampas-Grass, also belongs here; it is diocious. The upper flowers in the spikelets of plants belonging to this tribe are often unisexual, and $\delta$; Phragmites is peculiar in that the lower flower of the spikelet is $\delta$.

Tribe 9. Chloridect: spikelets laterally compressed, usually 1-flowered, sessile, in compound spikes: glumes 2. Cynodon Dactylon, the Dog's-tooth Grass, is often abundant on waste ground. Spartina stricta occurs in saltmarshes.

Tribe 10. Hordece: spikelets solitary, or 2 or $\mathbf{3}$ together, 1- or manyflowered, situated in depressions on the main floral axis nearly always in two opposite rows, forming the so-called spike: glumes 1-2. In Lolium, the Rye-Grass ( $L$. perenne, Darnel, is common everywhere), the posterior surface (that is, the middle line of the posterior glume) is directed towards the main axis, and this glume is usually rudimentary. In all the other genera the side of the spikelet is directed towards the main axis, and there are two glumes. In Agopyrum, the paleæ adhere to and fall off with the fruit: $A$. repens, the Couch-Grass, is common everywhere, and is a troublesome weed on account of its spreading rhizome. Secale coreale, the Rye, has 2-flowered spikelets and narrow awl-shaped glumes. In Nardus stricta, the Mat-Grass, the two rows of spikelets converge laterally; the glumes are rudimentary; there is but one stigma; the leaves and haulms are rough; it grows on moors. Triticum, the Wheat, has 3 - or more flowered spikelets, with ovate glumes. Three species are cultivated, $T$. monococcum, $T$. sativum and $T$. polonicum; in the first species the terminal spikelet is abortive. The following varieties of $T$. sativum are cultivated; 
T. vulgare, the common Wheat, with long glumes, which have no keel, and T. turgidum, English Wheat, with short keeled glumes; $T$. comspactum, the Dwarf Wheat, with short, stout spikelets; and T.durum, the Hard Wheat, known by its long rigid awns; all these varieties have a wiry floral axis (hence sometimes described as T. sativum tenax), and the fruit easily falls out of the glumes, and in all but $T$. durum there are awned and un-awned (beardless) forms: $T$. spelta, the Spelt, which has an almost quadrangular spike, and $T$. dicoccum; with a compact spike, have a brittle floral axis, and the fruit is firmly enclosed by the glumes. In all the species the length of the awn varies very much. Hordeum, the Barley, has 3 single-flowered spikelets inserted together in one depression on the floral axis. H. murinum is common on the roadside and on walls. The following varieties of $H$. sativum are cultivated: $H$. vulyare and $H$. hexastichum, with only fertile spikelets; in the latter species the spikelets are all equally distant, and are therefore arranged in six rows; in the former species the median spikelets are nearer together, and the lateral ones more distant, so that they are described as being in four rows : further, $H$. distichum is the two-rowed Barley, the lateral spikelets of which are $\delta^{*}$, so that the fruits are arranged in two rows. The fruit usually adheres to the palea. The genus Elymus, the Lyme-Grass (E. arenarius, British) belongs to this tribe, as also Pariana, a tropical genus remarkable for its numerous stamens.

Tribe 11. Bambusece:'spikelets 2- or many-flowered, rarely 1-flowered, in racemes or panicles, clustered at the nodes of the, branches of the inflorescence: glumes 2 or many, becoming larger upwards, but shorter than the nearest palea: stamens generally 6 (see Fig. 299 A). Large Grasses, known as Bamboos, having perennial aerial shoots with often shortly petiolate leaves, growing mostly in the Tropics. The most familiar genera are Arundinaria and Bambusa.

Order 2. Cyperacex. The leaves are arranged in three rows on the stem: perianth 0 , or of $3-6$ or more bristles or scales: the androeium consists typically of two trimerous whorls, though one whorl (the inner) is absent in some genera: the gynæceum is typically trimerous, though it is sometimes dimerous: ovary unilocular : ovule erect, anatropous: the embryo is enclosed in the endosperm.

Tribe 1. Scirpoidea : flowers $\Varangle ;$ perianth 0 , or of bristles: glumes distichous: the odd carpel is anterior. The spikelets are often arranged so as to form spikes, panicles, umbels, or capitula : the flower has the formula $\mathrm{K} 3, \mathrm{C} 3, \mathrm{A3}+0$ or $3, \mathrm{G} 3 \mathbf{3}$.

Cyperus, the Galingale, has many-flowered compressed spikelets with deciduous bracts or glumes: Schœnus, the Bog-Rush, has few-flowered (1-4) spikelets with persistent glumes: C. longus and fuscus, and S. nigricans, occur in England. Cyperus Papyrus (Papyrus Antiquorum) is an Egyptian species from which the Papyrus of the ancients was made. 
Scirpus, the Club-Rush, has a bristly perianth, cylindrical spikelets, and the glumes are imbricate on all sides; in some species the spikelets are solitary, as in Scirpus caspitosus, in others there are lateral spikelets, in addition, on short stalks, as in S. lacustris (the true Bulrush), or on long stalks, as in S. sylvaticus. Eriophorum polystachium and other species (Cotton-Grass) are common on boggy moors; the hairs of the perianth, after flowering, grow to a considerable length.

Tribe 2. Caricoidece: spikelets cylindrical; flowers unisexual ; perianth 0.

These plants have diclinous (sometimes diœcious) flowers. In the genus Carex the $\delta$ flowers have the formula $K 0, C 0, A 3+0, G 0$; they are situated in the axils of bracts (glumes) (Fig. $304 B$ and $D$ ) and form simple spikes. The $q$ flowers have the formula $K 0, C 0, A 0+0, G^{(3)}$ or ${ }^{(2)}$ and are not sessile in the axils of the glumes ( $b$ in Fig. $304 A$ and $C$ ), but a short branch springs from the axil of each of these leaves bearing a second bract ( $s$ in
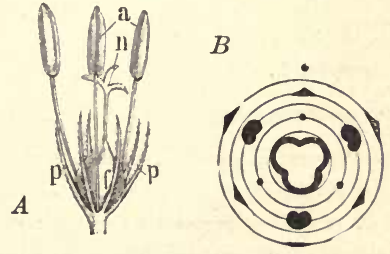

Fit. 303.-A Flower of Scirpus (magnifed): $p$ the bristly perianth; $a$ the three stamens; the ovary: $n$ the three stigmata. B Its floral diagram.

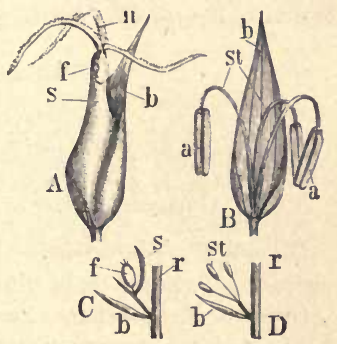

Fig. 304.-Flower of Carex (mag.). $A$ o lower with (b) bract (alume); 8 second bract (utriculus); $f$ ovary; $n$ stigms. $B$ of flower: st the threo stamens; $a$ anthers. C Diagram of the $q$ and $(D)$ of the $\delta$ flower: $r$ axis of the spike; $b$ bract (glume); s second bract.

the Fig.) and it is in the axil of this second bract that the of flower, which consists of a trimerous, or more rarely, dimerous (in Carex dioica and pulicaris, etc.) ovary, is situated. The second bract increases greatly and invests the fruit (and the short branch which sometimes projects beyond the fruit as a seta), forming the so-called utriculus: this structure has been regarded as a perianth, and termed the perigynium. In Kobresia (Elyna) the second bract is not tubular, and therefore does not completely invest the ovary. In consequence of there being a second bract, the odd carpel of the trimerous gynæceum is posterior: when the gynæceum is dimerous, the two carpels are lateral.

The genus Carex, the Sedge, contains numerous. species which grow mostly in damp localities; they have stiff leaves with sharp or saw-like edges. Only a few of them are diœcious (C. dioica, scirpoidea): in most 
the $\delta$ and $q$ inflorescences occur on the same axis. In one large section of them the two kinds of flowers occur on the same spike which is either $\delta$ at the base and $q$ at the top, or vice versa. When this is the case the axis bears either only one terminal spike, as in Carex pulicaris and $C$. panciftora, or several spikes forming a capitulum at the apex, as in $C$. cyperoides, or a spike or a panicle, as in C. muricata, arenaria, and paniculata. In a second section, on the other hand, each spike is unisexual, and then the $\delta$ spike is almost always terminal on the axis and the $q$ lateral, as in Carex acuta, glauca, procox, digitata, flava, and paludosa.

\section{Sub-Class III. PETALOIDEX.}

Flowers rarely unisexual; perianth rarely wanting, usually biseriate, the corolla usually petaloid, and sometimes the calyx also.

\section{SERIES I. HYPOGYNÆ.}

\section{Ovary superior.}

\section{Sub-series. Apocarpa.}

\section{Gynæceum more or less completely apocarpous.}

Cohort I. Alismales. Marsh- or water-plants; flowers frequently unisexual; seeds without endosperm.

Order 1. NaIADACEx. Perianth 0 , or of 2-4 segments ; stamens 1-4: ovaries $1-4$, with usually a single erect or suspended ovule. Water-plants.

In the genus Naias the flowers are solitary or in spikes, and are either monœcious or diocious: perianth of one or two gamophyllous series: $\delta$ flowers with 1 stamen, $q$ flowers with one carpel : ovule erect. $N$. flexilis is the only British species. In Zostera, the Grass-wrack, the flowers are diclinous, and without a perianth; they are borne in two rows on one side of a flattened spike; stamen 1, carpel 1. Zostera marina and nana are the British species living in the brackish waters of estuaries. In Zannichellia, the Horned Pondweed, the flowers are diclinous, and are solitary or in spikes: of flower, perianth 0 , stamen 1 ; $f$ flower, perianth bell-shaped, carpels 4-6. Z. palustris is the only British species.

In Potamogeton, the Pondweed, the flowers are monoclinous and in spikes: general formula $P 0, A 2+A 2, G \times 4$ : the extrorse stamens have a broad leafy connective. This genus is represented in Britain by many species: in some ( $P$. pusillus) the stem bears only submerged leaves which are narrow and linear; in others the leaves are somewhat broader $(P$. densus), and in others again it bears a few broad leaves which float on the water $(\boldsymbol{P}$. natans). In Ruppia, the Tassel Pondweed, the flowers are gener- 
ally two on a spike; formula $P 0, A 2, G 4$. $R$. maritima is the British species.

Order 2. Juncaginacex. Flowers sometimes diclinous; both perianth-whorls are sepaloid and inconspicuous; anthers extrorse ; carpels sometimes coherent; the outer whorl of carpels is occasionally abortive; ovules 1-2, anatropous, embryo straight.

Triglochin palustre, the Arrow-Grass, is common in marshes and on the margin of pools: carpels coherent till mature. The monoclinous flowers are disposed spirally in a long loose spike without bracts. Scheuchzeria palustris is rarer; it occurs in bogs; the flowers are set in the axils of distichous bracts: carpels free.

Order 3. AlisMace.e. Flowers sometimes monœeious; floral formula $K 3, C 3, A 3^{2}+0$ or 3 , or $\infty, G 3+3$ or $\infty$ : perianth heterochlamydeous; the sepals are often coherent at the base; the petals

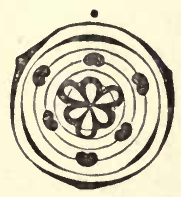

FIG. 305.-Diagram of the Flower of Trigloshin.

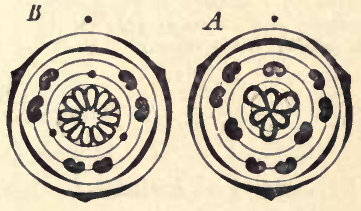

Fig. 326.-Flora diagrams. A of Butomus. B Of Alisma.

are white or violet; anthers extrorse or introrse ; carpels sometimes partially coherent; ovules 1-3, campylotropous, embryo curved.

Alisma Plantago (Water Plaintain, Fig. 306 B), has the floral formula $K 3, C 3, A 3^{2}+0, G 6$ or more ; the numerous, monomerous, one-seeded ovaries are crowded on the broad receptacle. The main axis of the inflorescence bears whorls of branches which have a helicoid ramification. It is rather common in damp spots. Damasonium stellatum, the Star-fruit, is found in ditches in the South of England: it has two-seeded ovaries.

Sagittaria sagittofolia, the Arrowhead, has diclinous flowers with the formula $K 3, C 3, \delta A \infty, q G \propto$. The flowers are disposed in trimerous whorls, the $\delta$ in the upper and the $f$ in the lower whorls. The anthers are extrorse. The ovaries, which are very numerous and one-semded, are inserted on a fleshy receptacle. Only the sagittate leaves and the inflorescence appear above the water.

Order 4. Butomacex. Flowers never unisexual; general floral formula the same as in Alismaceæ; anthers introrse; carpels distinct; ovules numerous, with superficial placentation; embryo straight or curved. 

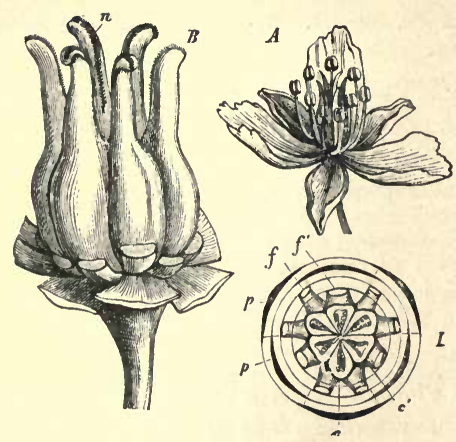

Fig. 307.-Butomus umbellatus. A Flower (nat. size). $B$ Gynæceum (mag.); $n$ stigmata. $I$ Diagram : $p \quad p$ periauth; $f$ stamens of the outer whorl duplicate : $f^{\prime}$ stamens of the inner whorl; $c$ outer, and $c^{\prime}$ inner whorl of carpels. (After Sachs.)
Butomus umbellatus is the Flowering Rush (Figs. $306 A, 307$ ). The flowers, which have violet petals, have the following formula: $K 3, C 3$, $A 3^{2}+3, \mathrm{G}^{3+3}$; they are arranged in an umbellate helicoid cyme at the apex of the scape, which is about 3 feet high; this and the leaves, which are of about the same length, spring from an underground rhizome. The ovules, which are numerous, are borne on the inner surface of the carpels (Fig. $284 C$ ): the embryo is straight.

\section{Sub-series. Syncarpa.}

Gynæceum syncarpous.

Cohort I. Liliales. Perianth homochlamydeous, usually petaloid; seeds with endosperm; general floral formula $K 3, C 3$, $A 3+3, G^{(3)}$.

Order 1. Liliaces. The flowers conform generally to the above formula, but 3 is replaced sometimes by 2 or 4 : they are not zygomorphic : endosperm oily ; fruit a capsule or a berry. Mostly rhizomatous or bulbous plants: rarely trees or shrubs.

Sub-order 1. Liliomex, with a loculicidal capsule, introrse anthers, and united styles. Bulbous plants.

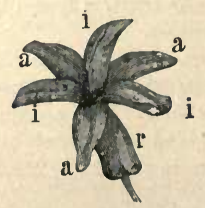

Fra. 308 . - Flower of the Hyacinth: $a$ a $a$ the three outer; $i$ i i the three inner segments of the perianth, which is tubular at the lower part (nat. size).

The family Tulipece includes the following genera : Lilium, Fritillaria, Tulipa, Erythronium, Lloydia.

Many species are cultivated. Lilium candidum is the white Lily ; L. bulbiferum, producing bulbils in the axils of the upper leaves; I. Martagon, the Turk's Cap Lily ; L.tigrinum, the Tiger-Lily; L. speciosum, auratum, etc. Fritillaria imperialis is the Crown Imperial, the flowers of which are surmounted by a crown of leaves. Tulipa Gesneriana is the Tulip. Erythronium Dens-Canis is the DogTooth Violet. The following occur wild in 
Britain : Lilium Martajon; Tulipa sylvestris, wild Yellow Tulip; Fritillaria Meleagris, the Snake's Head; Lloydia serotina.

The Scillea includes the following genera amongst others: Galtonia, Hyacinthus, Muscari, etc., in which the segments of the perianth cohere more or less (Fig. 308); Scilla, Camassia, Ornithogalum, etc., with freeperianth-leaves. The following occur wild in Britain: Byaeinthus nonscriptus, the Blue Bell; Muscari racemosum, the Grape-Hyacinth; Scilla
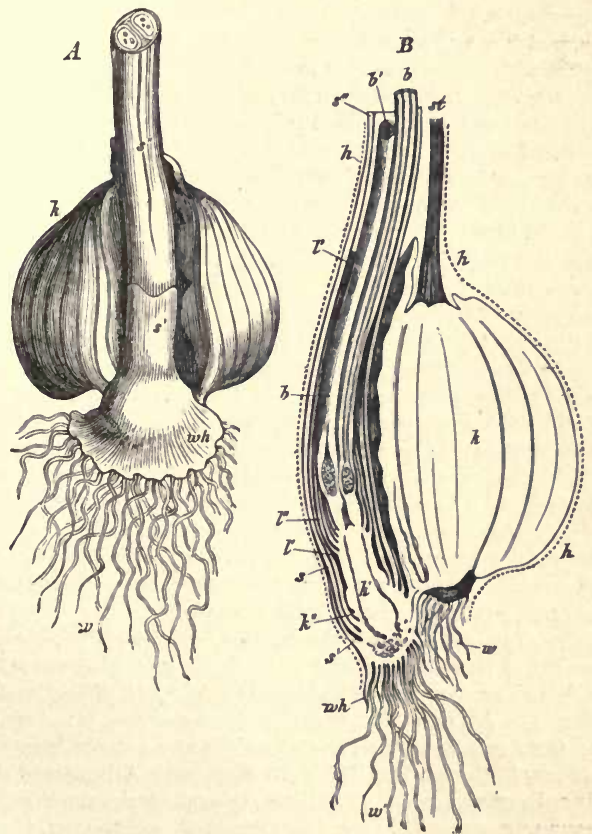

F1G. 309.-The undergronnd part of a flowering plant of Colchicum autumnale. 4 Seen in front; $k$ the corm; $~_{\prime}^{\prime \prime}{ }^{\prime \prime}$ cataphyllary leaves embracing the flower-stalk; wh its base from which proceed the roots, w. B Longitudinal section: $h \boldsymbol{h}$ a brown membrane which envelops all the nuderground parts of the plant; st the flower-shoot of the previons jear which has died down, its swollen basal portion $(k)$ only remaining as a reservoir of food-materials for the new plant now in flower. The new plant is a lateral shoot from the base of the corm $(k)$, consisting of the axis, from the base of which proceed the roots $\left(20^{\prime}\right)$, and the middle part of which $\left(k^{\prime}\right)$ swells $\mathrm{np}$ in the next year into a corm, the old oorm $(k)$ disappearing; the axis bears the sheath-leaves $\left(s s^{\prime} s^{\prime}\right)$ and the foliage-leaves $\left(l^{\prime} l^{\prime \prime}\right)$; the flowers $\left(b b^{\prime}\right)$ are placed in the axils of the nppermost foliage-leaves, the axis itself terminating amongst the flowers. (After Sachs.).

M.B. 
verna and autumnalis, the Squills; Ornithogalum nutans, the Star of Bethlehem.

Sub-order 2. Melanthioidex or Colchicoides, with a usually septicidal capsule, usually extrorse anthers, and separate styles. Mostly rhizomatous plants.

Not many genera are common in cultivation; among these Gloriosa, Uvularia, and Veratrum may be mentioned; Veratrum album and nigrum have broad ovate leaves.

Tofieldia palustris, the Scottish Asphodel, has ensiform radical leaves; the flowers, which are pale green, are disposed in a raceme on a scape; it occurs in Scotland, in wet places on mountains, but it is rare. Narthecium ossifragum, the Bog-Asphodel, somewhat resembles Tofieldia, but the flowers are yellow and the capsule is loculicidal; common in Scotland and in the north of England.

The Colchicea are bulbous plants and have introrse anthers. Colchicum autumnale is the Autumn Crocus or Meadow Saffron; when it is flowering in the autumn, the stem is underground; it is at this time short and slender (Fig. $309 \mathrm{k}^{\prime}$ ), attached laterally to the corm of the previous year's growth $(k)$, and bears a few imperfectly developed leaves $\left(l^{\prime} l^{\prime \prime}\right)$ as well as one or two flowers $\left(b^{\prime} b^{\prime \prime}\right)$ : the ovaries of the flowers are also subterranean; the six leaves of the perianth cohere and form a tube of some centimetres in length, which grows far beyond the ovaries and above the surface of the soil, terminating in a petaloid six-partite limb; the stamens are attached in the upper portion of the tube. In the spring the underground stem swells at its base $\left(k^{\prime}\right)$ into a corm, and grows upwards, so that the developing leaves $\left(l^{\prime} l^{\prime \prime}\right)$ and the capsule rise above ground; a lateral shoot is formed at its base, which, in the autumn, produces the flower.

Sub-order 3. Asphodelondes; rhizomatous plants, with usually radical leaves, but the leaves are sometimes borne on an aerial rarely branched stem; inflorescence usually a terminal spike or raceme: perianth-leaves free or connate; anthers introrse ; fruit capsular.

Asphodelus, Eremurus, Anthericum, Hemerocallis, Phormium (Phormium tenax is the New Zealand Flax), Kniphofia and Aloë, are cultivated. The only British species is Simethis bicolor in the south of England.

Sub-order 4. Alcroides; generally bulbous plants: inflorescence umbellate, more or less completely enclosed by two or more bracts.

Agapanthus, Nothoscordum, Milla, Brodiæa, and Allium are the more commonly cultivated genera. Of Allium, several species are in cultivation for culinary purposes, as A. Cepa, the Onion; $A$. ascaionicum, the Shalot; A. Schoenoprasum, Chives; A. Porrum, the common Leek; A. sativum (vulgare), Garlic. Some species (Wild Garlic) are wild in Britain, such as $A$. oleraceum, vineale, ursinum, and triquetrum in Guernsey. The leaves of the various species of Allium are generally tubular and hollow; the flowers are disposed in spherical heads or umbels; bulbils are occasionally produced among the flowers. Gagea lutea is also British.

Sub-order 5. Drac zNoidex, stem erect, usually arborescent, with secondary growth in thickness (see p. 148).

Species of Yucca are commonly cultivated in gardens; Cordyline and 
Dasylirion in greenhouses. Dracana Draco is the Dragon's Tree of the Canary Islands, yielding a red gum-resin (Dragon's blood).

Sub-order 6. Asparagordes, with a subterranean rhizome bearing aerial leafy stems: fruit baccate.

Asparagus officinalis is the Asparagus; the young shoots, which spring from the underground rhizome, are eaten. Convallaria majalis is the Lily of the Valley. Maianthemum bifolium has a dimerous flower. Polygonatum is Solomon's Seal. Ruscus aculeatus (the Butcher's Broom), and other species, are small shrubs, with leaf-like branches (phylloclades, see p. 28), on which the diclinous flowers are borne in the axils of minute leaves. Paris quadrifolia (Herb Paris) is poisonous : the flowers are tetramerous, or exceptionally trimerous or pentamerous: they are terminal, and the stem beneath bears four (or three or five) leaves in a whorl benesth the flower (Fig. 310); the venation of the leaves is reticulate.

Maianthenum bifolium, Paris quadrifolia, Ruscus aculeatus, Convallaria majalis, Polygonatum verticillatum, multiflorum, and officinale, are wild in England.

Sub-order 7. SMILACO1DEe, scrambling shrubs, having 3-5 ribbed leaves with reticulate venation. The roots of species of Smilax constitute Sarsaparilla.

Order 2. JUnCacex. Floral formula, $K 3, C 3, A 3+3, G_{\overline{(3)}}$. Plants of a grass-like aspect; they differ from the preceding order in the dry and glumaceous character of the perianth, and in the starchy endosperm. The leaves are linear or tubular; the

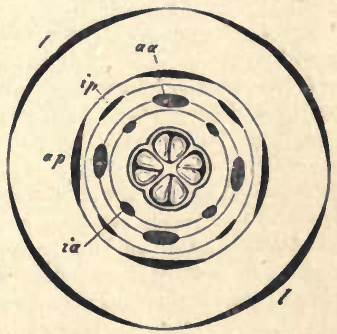

Fig. 310.-Diagram of the flower of Paris quadrifolia; $l$ the foliage-leaves; ap the outer; ip the inner whorl of the perianth; a outer; ia Inver whorl of stamens. (After Sach8.) inflorescence is an anthela (see p. 442).

The species of Luzula, which has a unilocular three-seeded ovary, multiflora, pilosa, campestris, and sylvatica, are common in woods and on heaths. Juncus has a trilocular many-seeded ovary; plants of this genus are called Rushes; J. glaucus and effusus have a tubular stem and leaves, and a terminal inflorescence which is displaced laterally by a tubular bract which appears to be a prolongation of the stem; they are common in wet fields; $J$. bufonius, by waysides. 


\section{SERIES II. EPIGYNE.}

Ovary inferior.

Cohort I. Hydrales. Order 1. Hydrocharidaces. The inflorescence is at first enclosed in a spathe formed of a single bract, or more commonly of two connate bracts. The flowers have a perianth, the inner whorl being petaloid, and usually conform to the monocotyledonous type, but with pleiotaxy in the androecium and gynæceum; formula $K 3, C 3, A 3+3+, \mathrm{G}_{\overline{(3+\ldots) .}}$ The flowers are usually unisexual and diœcious; the $f$ flowers have staminodia; the $\delta$ flowers have no gynæceum but an increased number of whorls in the androcium. Seeds generally numerous; without endosperm. Water-plants.

Fam. 1. Hydrillex. Ovary unilocular. Stem elongated, with whorls of small leaves.

Elodea (Anacharis) canadensis came originally from North America and has spread in our waters so as even to impede navigation in canals.

Fam. 2. Vallisneriea. Ovary unilocular. Stem short, with crowded leaves.

Vallisneria spiralis inhabits the lakes and ditches of the warmer parts of Europe. The leaves are long, narrow, and linear. The $q$ flowers are raised above water on long peduncles; the $\delta$ inflorescences break away from their peduncles and float about on the water to fertilize the $q$ flowers; the fruit ripens under water.

Fam. 3. Stratiotece. Ovary 6- (or more) chambered. Stem short, with crowded leaves.

Stratiotes aloides (Water-Soldier) has stiff narrow leaves. Hydrocharis Morsus Rance is the Frog's Bit; the plant is small and floats on the water, with small roundly-cordate leaves.

Cohort II. Dioscoreales. Flowers regular: floral formula $K \dot{3}, C 3, A 3+3, G_{(\overline{3})}$ : fruit a berry or a capsule : endosperm oily.

Order 1. Diosconeacex. The ovary is trilocular, with one or two ovules in each loculus: the flowers are diœcious. They are climbing plants, with twining stems, having large above- or underground tubers, and usually triangular leaves with reticulate venation.

Dioscorea sativa, Batatas, and others, known as Yams, are largely cultivated in the tropics, their tuberous roots yielding a food rich in starch. Tamus communis, the Black Bryony, is common in England.

Order 2. Bromeliace.e. $K 3, C 3, A 3+3, G(3)$. The ovary is superior, inferior, or semi-inferior, trilocular, with many seeds. 
Perianth heterochlamydeous. The leaves are usually long and narrow, sharply serrate; the stem is generally very short. The flowers are $\not$, and form spikes or panicles with bracts.

Ananas sativa is the Pine-apple. The fruit is a berry, and the berries of each inflorescence coalesce into a spurious fruit (sorosis), above which the axis of the inflorescence extends and bears a crown of leaves (Fig. 311 ; see p. 472). In a state of cultivation the berries contain no seeds. It is a native of America, and is cultivated in all warm countries and in hothouses.

Cohort III. Amomales (Scitamineæ). The flowers are irregular, zygomorphic or asymmetrical: general formula, $\downarrow K 3, C 3, A 3+3, \mathrm{G}_{\overline{(3)}}$, occasionally with a great reduction in the androecium. Perianth wholly petaloid, or clearly heterochlamydeous : ovary usually trilocular:

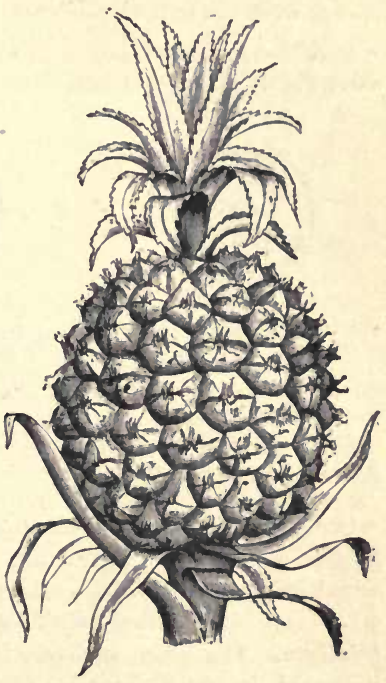

F. .. 311.-Fruit of the Pine-apple (reduced). fruit, a capsule or a berry. Usually no endosperm, but abundant perisperm. They are tall herbaceous plants; the leaves are large and have pinnate venation.

Order 1. Musaces. $\downarrow K 3, C 3, A 3+2+1$ or $0, G^{(3)}$. Flower dorsiventral ; the anterior external member of the petaloid perianth is usually very large, and the posterior always very small. In thr family Museæ the odd sepal is anterior; the sepals are usually free; as are also the petals in Ravenala; but in Strelitzia the two lateral petals are connate, and in Musa the five anterior members of the perianth are connate, forming a tube which is open posteriorly: the posterior stamen is sterile or absent, and the others are not always fertile. The flower of the family Heliconieæ differs from this type in that the odd sepal is posterior, and the abortive posterior stamen belongs to the outer whorl. Seeds, one (Heliconia), or many, in each loculus, without endosperm. They are 
all shrubs of colossal growth, with enormously long leaves: the flowers are usually arranged in spicate inflorescences in the axils of large and often coloured bracts; sometimes several flowers spring from the axil of one bract.

Musa paradisiaca (Plantain), M. Sapientum (Banana), and M. Ensete are natives of the tropics of the Old World; the two former are now distributed

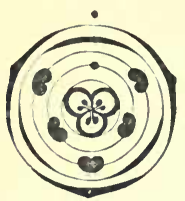

F1G. 312.-Diagram of flower of Musa.

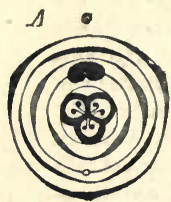

F1G.313.-Diagrams of the two types of flower in the Zingiberaceæ. $A$ Hedychium. B Alpinir.

throughout America and applied to a great variety of purposes; the fruit, which is of the nature of a berry, is an article of food, and the vascular bundles are used for making textile fabrics. The other genera are Ravenala, Strelitzia, Heliconia.

Order 2. Zingiberaces. $\downarrow K 3, C 3, A+2$ or $0+1+2, G_{(3)}$. Flower dorsiventral: calyx not always distinct. Of the inner whorl of stamens the posterior alone bears a perfect anther, the other two being transformed into a usually petaloid body, the labellum. The outer whorl of stamens is absent, or but slightly indicated, in the Zingibereæ (Fig. $313 \mathrm{~B}$ ); but is represented in the Hedychieæ and Globbeæ by two postero-lateral petaloid staminodes (Fig. $313 \mathrm{~A}$ ). There is a small amount of endosperm in the seed, in a depression in the perisperm.

The commoner genera are Curcuma, Hedychium; Zingiber, Alpinia ; Globba, having a unilocular ovary with three parietal placentæ.

The starch which is prepared from the rhizome of Curcunca angustifolia and leucorrliza is known in commerce as East Indian arrowroot ; Turmeric is obtained from the rhizome of $C$. longa. Cardamoms are the fruits of Eletteria Cardamonum. The dried rhizomes of Zingiber officinale are the common ginger.

Order 3. Marantaces or Cannaceas. $K 3, C 3, A 0+1+1,0$, or $A+2,0+1+2, G_{(3)}$. Flower asymmetric, often heterochlamydeous. The androcium is represented by a number of petaloid bodies, of which one only, the posterior stamen of the inner whorl, bears a bilocular anther (Fig. 314st, an); of the staminodia one is larger than the others, and is reflexed, forming a labellum (Fig. $314 l$ ); 
the narrow ones vary in number in the different species (Fig. $314 a$ and $\beta)$ : seed without endosperm ; seeds numerous in Canna, single in each loculus in other genera.

Camna indica and other species are commonly grown as ornamental plants.

Amylum Marantæ, the starchy meal prepared from the rhizome of Maranta arundinacea, is true or West Indian arrowroot.

Cohort IV. Orchidales. Flower irregular, dorsiventral, zygomorphic, gynandrous (see pp. 455,462 ), reduced in the androcium : perianth petaloid. Seeds very small, without endosperm or perisperm; the embryo a minute undifferentiated mass of cells.

Order 1. ORChidaces. The flowers of most of the genera have the formula $\downarrow k 3, C 3, A 1++2, G_{(3)}$ : those of the Cypripediinæ, however, have the formula $\downarrow K 3, C 3, A+1+2, G_{(3)}$ (Fig. $315 A, B$ ). The flower is generally so placed, in consequence of

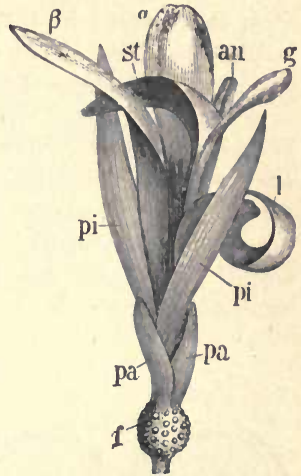

Fig. 314.-Flower of Canna indica (nat.size) : $f$ inferior ovary; pa the outer; pi the inner whorl of the perianth; $g$ style; st the fertile stamen, with (an) the anther; $l$ labellum; $\alpha$ and $\beta$ the two staminodia. (Afver Eichler.) torsion of the ovary, that the posterior side of the flower, instead of being uppermost, as is normally the case, comes to lie inferiorly (resupinate), but there are exceptions (e.g. Liparis, Nigritella, Epipogum). The posterior segment (petal) of the inner whorl called the labellum (Fig. 316, see also Fig. $244 l$ ), is always larger than the others, and varies greatly in form; it frequently has a spur (Fig. $316 s p$ ) or a sac-shaped cavity (Fig. 244). The androecium and the three stigmata are, in most Orchids, borne on a prolongation of the floral axis the gynostemium (Fig. $244 \mathrm{~s}$; Fig. $318 \mathrm{~B}$ and $\mathrm{Cgs}$ ). In the androecium usually three stamens are represented: in the monandrous Orchids there is a fertile anterior stamen belonging to the outer whorl (Fig. $315 \mathrm{~A}$ ), and often two staminodes, which are sometimes petaloid (e.g. Diuris) or small tooth-like prominences (auriculæ, stelidia) on the gynostemium (e.g. Orchis, Epipactis, Fig. $244 x$ ), belonging generally to the inner androecial whorl, but sometimes apparently to the outer: in the diandrous Orchids (e.g. Cypripedium, Fig. 315 B) there are, generally, two fertile stamens belonging to the inner whorl; the outer whorl being only 
represented by an anterior staminode. The anther usually has four pollen-sacs, but may have two (e.g. Collabium) or eight (e.g. Calanthe, Bletia). In some genera the pollen-grains are separate from each other; in the majority they are united into a mass, pollinium, which fills an entire pollen-sac (Fig. $244 E, F, p$ ). The pollinium may consist of tetrads with a common exine (e.g. Neottia); or of larger groups of cells, termed massula (e.g. Orchis), when it is said to be sectile; or of uniform tissue. In those Orchids which have pollinia, it is frequently the case that the tissue of the pollensac is prolonged, according to the position of the anther, either to the lower (basitonous, c.g. Ophrydinæ) or to the upper end of the anther (acrotonous, e.g. Phajiinæ, Oncidiinæ), and here almost. exclusively gives rise to a mucilaginous filament, the caudicle,
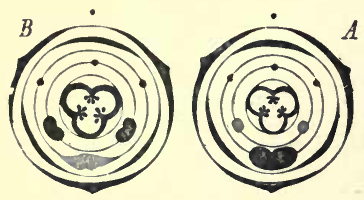

F16. 315.-Disgram of Orchidaceous flowers, neglecting resupination. $A$ The monandrous type. $B$ The diandrous type (Cypripedinm): the shaded stamens are staminodia.

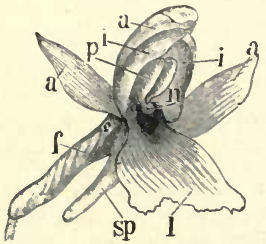

Fra. 316. -F orrer of Orchis mascula $(\times 2)$ $f$ the tristed ovary; $a$ a a the three outer perianth-leaves; $i i$ two of the inner, $l$ the third inner perianth-leaf, the labellum, with $(s p)$ the spur; $n$ stigma; $p$ pollen-sacs.

attached to the pollinium (or to the two or more pollinia of each half of the anther) below or above.

The ovary is unilocular (rarely trilocular as in some Cypripediinæ), and contains numerous anatropous ovules on three parietal placentæ. In all the monandrous Orchids, the anterior lobe of the trilobate stigma is not susceptible of pollination, and is either rudimentary or develops into an organ termed the rostellum (Fig. 244h), which is situated either above or below the anther, and in the tissue of which one or two small masses of sticky mucilage (retinacula) are formed, and are frequently enclosed in one or two pouches (bursicula) formed by the rest of the tissue of the rostellum. The pollinia adhere to the retinacula by the caudicle, when present, and are removed, in pollination, by the adhesion of the retinacula to the proboscis of the insect (see p. 413). 
Most of the indigenous species have underground rhizomes or tubers. In the latter case, two tubers are usually present: the

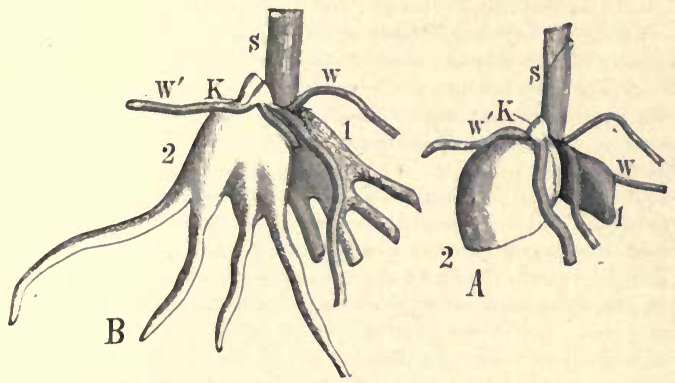

Fre. 317.-Tubers (A) of Orchis Morio; B of Gymnadenia Conopsea : s the peduncle; 1 this Jear's tuber; 2 next jear'* tuber; $k$ the bad; $w$ and $w$ ' roots (nst. size).

older one, which, at the time of flowering, becomes flaccid (Fig. 317 $A$ and $B, 1)$, throws up the flowering scape $(s)$ or, in young plants, a short underground stem which produces only leaves above ground. At the upper end of this tuber another much firmer taber is formed (Fig. 317, 2), bearing at its apex the bud of the next year's stem $(K$ ). The tuber is to be regarded as a lateral bud which coalesces with its first root (or more than one, Fig. $317 B$ ) and then increases in bulk: the lower end of an undivided tuber, as well as the ends of palmate tubers, has, in the young state at least, the same structure as the apex of a true root.

The genera of Orchidaceæ are so numerous and so diverse that it is impossible to give more than a summary of those which are British.

Diandra: two fertile stamens, belonging to the inner whorl: all three lobes of the stigma are susceptible of pollination: pollen-grains cohering but slightly.

Fam. 1. Cypripediince. Cypripedium Calceolus, the Lady's Slipper, now very rare, occurs in woods in the north of

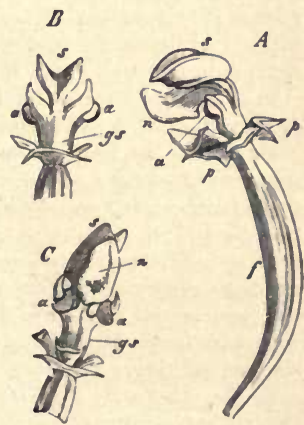

Fro.318.-Floxer of Cypripedium Calceolus : $p$ p the leares of the peri. anth hare been cut away. $A$ Side view. B Back view. C Front view; $f$ ovary; ge grnosteminm; a a the two fertile stamens; s staminode; $n$ ntigma. (After Sach8.) 
England: it has a creeping rhizome and broad ovate leaves: the perianth is of a reddish-brown colour, except the labellum which is yellow and forms a shoe-like sac (Figs. 315, 318).

Moxaxpre: one fertile stamen, the anterior, belonging to the outer whorl: only the two lateral lobes of the stigma are susceptible of pollination; the anterior lobe is rudimentary, or is developed as the rostellum: pollen-grains coherent into pollinia.

Fam. 2. Oplerydina: anther short and broad; the waxy pollinia are basitonous; a rostellum, forming retinacula to which the caudicles of the pollinia allhere.

To the sub-family Serapiadece, which is characterized by the short gynostemium and the erect anther belong the genera Ophrys, Orchis, and Aceras. In Ophrys there are two distinct bursiculp and retinacula, and the pollinia remain distinct: the flowers resemble insects: O. apifera the Bee Orchis, O. aranifera the Spider Orchis, and O. muscifera the Fly Orchis, occur in chalk pastures. In Orchis there is but one bursicula, but there are two retinacula, so the pollinia may be removed separately, and the labellum is spurred: Orchis Morio, mascula, and militaris, have round or oval tubers; whilst $O$. latifolia, maculata, and pyramidalis have palmate tubers. In Aceras (Aceras anthropophora is the green Man-Orchis) the 3-lobed lip is not spurred, and there is but one retinaculum.

To the sub-family Gymnadeniece, characterized by the absence of a bursicula, and consequently bare retinacula, belıng the British genera Gymnadenia, Habenaria, Neotinea, Herminium (as also other interesting European genera, such as Chamæorchis and Nigritella). In Gymnadenia (G. Conopsea, the fragrant Orchis) the retinacula are contiguous : in Habenaria (H. albida, bifolia, viridis, Butterfly Orchis) the retinacula are distant: in Neotinea ( $N$. intacta) the pink perianth-segments are connivent: whilst in the preceding genera the labellum is spurred, it is not spurred in Herminium (H. Monorchis, the green Musk Orchis).

Fam. 3. Neottiince: pollinia usually soft and granular, either acrotonous or altogether without caudicles.

To the sub-family Cephalantherea, in which the labellum is transversely segmented, belong the genera Cephalanthera, Epipactis, and Epipogum. Cephalanthera (C. grandiflora, C. ensifolia, C. rubra) and Epipactis (E. latifolia and E. palustris), the Helleborines, are rhizomatous leafy plants with well-developed leaves on the peduncles: the labellum is not spurred, and the rostellum is rudimentary. Epipogum Gmelini is a saprophyte, has no roots, and its leaves are scaly and not green; it has granular pollinia with acrotonous caudicles, a rostellum producing a retinaculum, and a spurred labellum; the flower is not resupinate.

To the sub-family Spiranthece, characterized by a rostellum as long as the anther, producing a retinaculum to which the granular pollinia (without caudicles) adhere, belong the genera Spiranthes, Listera, and Neottia. Spiranthes, Lady's tresses (S. autumnalis, cestivalis, and gemmipara) has a spike unilateral by torsion, perianth-segments connivent, no spur. Listera, Tway-blade (L. cordata and ovata), has only two foliageleaves, and spreading perianth-segments, no spur. Neottia Nidus-Avis, the 
Bird's-nest Orchid, is a saprophyte, with scaly leaves, which do not contain chlorophyll; labellum not spurred.

To the sub-family Physurea, characterized by the structure of the pollinium, which is sectile, belongs the genus Goodyera (G. repens) in which the labellum has no spur, and the pollinia have acrotonous caudicles; the inflorescence is, like that of Spiranthes, a unilateral twisted spike; the plant is rhizomatous.

Fam. 4. Liparidince: the anther produces four waxy pollinia without caudicles. Liparis (Siurmia) Loeselii, has only two foliage-leaves and a psendo-bulb; the flower is not resupinate; there are two retinacula, to each of which a pair of pollinia become attached. Malaxis (M. paludosa, Bog Orchis) has a short gynostemium and a single retinaculum; reproduced by pseudo-bulbs. Corallorhiza ( $C$. innata, the spurless Coral-root) is a saprophytic plant, without roots or foliage-leaves.

There are many other families, including a large number of genera which are mainly tropical and commonly epiphytic with aerial roots. Many of these are cultivated in hot-houses such as Oncidium, Vanda, Dendrobium, Angræcum, etc. Vanilla is the dried fruit of Vanilla planifolia, a climbing species.

Though pollination is usually dependent upon the visits of insects (see p. 413), self pollination is by no means uncommon. For instance, among British Orchids, Ophrys apifera and Neotinea intacta are probably always self-pollinated, and Neottia Nidus-Avis, Epipactis ovalis and E. latifolia, are frequently self-pollinated, simply by the falling of the pollen on to the stigma. Cephalanthera rubra is commonly pollinated whilst in the bud, by the germination of the pollen-grains, the pollen-tubes making their way to the stigma.

Cohort V. Narcissales. Flowers regular or irregular: not less than three stamens in the androecium: perianth petaloid: seeds with oily endosperm.

Order 1. Amaryllidaces. $K 3, C 3, A 3+3$ or 12 to $18, G_{\text {(3) }}$, The flower is occasionally zygomorphic and narrowly funnelshaped : anthers usually introrse. The fruit is usually a trilocular loculicidal capsule, sometimes a berry.

The principal of the numerous genera are arranged in the following families:-

Fam. 1. Amaryllidoidece: subterranean stem, bulbous: scape leafless, bearing a single terminal flower, or an umbellate inflorescence, invested by one or more bracts. Amongst the genera without a corona (see p. 458) are Annaryllis (A. Belladonna, the Belladonna Lily), Vallota (V. purpurea, the Searborough Lily) with zygomorphic flowers; Galanthus (G. nivalis, the Snowdrop), and Leucojum (L. vernum, the Spring Snowflake; L. aest $i$ vum, the Summer Snowflake) with actinomorphic flowers. Amongst the genera with a corona are the many species of Narcissus; $N$. (Corbularia) Bulbocodium, the Hooped Petticoat Daffodil; N. (Ajax) Preudo-narcissus, the 
common Daffodil; N. (Queltia) Jonquilla, the Jonquil, and N. incomparabilis the Star Daffodil ; $N$. poeticus, the Poet's or Pheasant's Eye Narcissus ; $N$. Tazetta, the Clnster Narcissus.

Fam. 2. Agavoidea : stem not subterranean, short or elongated into a trunk. Here belongs the genus Agave. Agave americana, commonly known as the false or American Aloe, is a native of Mexico but has been naturalised in Southern Europe. The short stem bears a rosette of large thick prickly leaves: when it has attained sufficient vigour-in Southern Europe in from 10 to 20 years-it throws up a scape 20-30 feet high, which branches ard bears a large number of flowers in a pyramidal panicle.

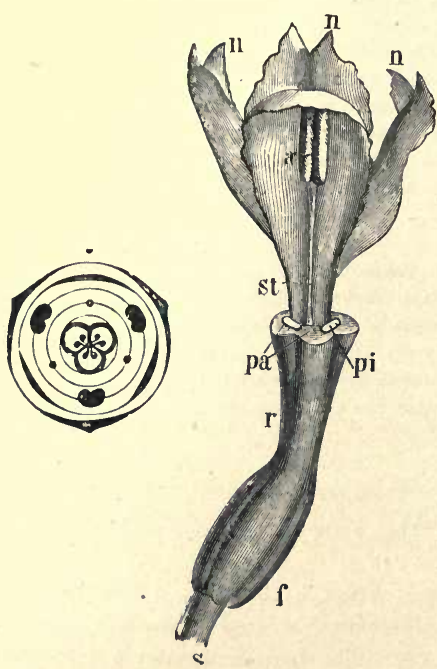

Fig. 319.-Diagram of the flower of Iris, and view of the arme after the removal of the perianth : 8 peduncle; $f$ inferior ovary; $r$ tubular portion of the perianth; $p a$ the insertion of the onter, $p i$ of the inner leaves of the perianth; st stamen; $a$ anther; $n n n$ the three petaloid stigmata (nat. size).

The British species of the order are the common Daffodil, the Snowdrop, and the Snowflakes.

Order 2. IRIDACEA. K3, C3, A3+0, $G_{(3)}$. The flower is sometimes zygomorphic: the anthers are extrorse. the fruit is usually a trilocular loculicidal capsule.

Fam.1. CRocoldex: flowers actinomorphic, terminal, single, with sometimes other axillary flowers, each invested by a spathe: stem, a corm.

To this family belong, amongst others, the genera Crocus and Romulea. Many species of Crocus (e.g. C. aureus, biflorus, speciosus, ver$n u s$, etc.) are cultivated; $C$. rativus is the Saffron Crocus, the dried stigmata of which are termed Saffron : the only indigenous British species is C. nudiflorus which is autumnflowering. Romulea (Trichonema) Columna occurs in the Channel Islands.

Fam. 2. IRIDIOIDEx: flowers mostly actinomorphic, forming manyflowered inflorescences of various form with spathes, each of which invests more than one flower: stem bulbous or rhizomatous.

Iris, the Flag, is the principal genus. The species of this very large genus may be divided into two groups based upon the bulbous or the rhizomatous character of the stem. The most familiar of the bulbous Irises are, I. xiphioides (or Xiphion latifolium, or Iris anglica) the so-called 
English Iris; I. Xiphium (Xiphion vulgare) the Spanish Iris; I. reticulata and persica. The rhizomatous Irises are classified, according to the presence or absence of hairs (beard) on the perianth-segments, into bearded (e.g. Iris germanica, florentina, etc.) and beardless forms (e.g. Iris Pseudacorus, the Yellow Flag, and fotidissima, both of which are British).

Fam. 3. IxIoldes: the flowers, which are frequently zygomorphic, are each invested by a spathe: stem, usually a corm.

In the Gladiolea, the zygomorphism of the flower is well-marked, but the flower may be either straight and erect (e.g. Tritonia, Montbretia, Sparaxis), or curved (e.g. Gladiolus). Gladiolus illyricus (communis), the lesser Gladiolus or Corn-Flag occurs in England.

\section{Class X.-DICOTYLeDONES.}

The ripe seed (Fig. 245) may be albuminous, containing a mass of endosperm and a relatively small embryo, as in the Umbelliferæ and Euphorbiaceæ; but sometimes the embryo is relatively large and the endosperm occupies only a small space, as in the Labiatæ: more commonly the seed is exalbuminous, the endosperm being wholly absent, and then the embryo, which has large and fleshy cotyledons, fills the entire cavity of the testa, as in the Rosaceæ, the Leguminosæ (Fig. 320), and the Compositæ. Perisperm is rarely present, either together with endosperm (e.g. some Piperales and Nymphæaceæ), or alone (Chenopodiales, Caryophyllales).

The embryo (see p. 401) usually has distinct members, consisting of an axis and two opposite cotyledons; in rare cases, e.g. Corydalis, only one cotyledon is present, or abnormally three may occur, as is occasionally the case in the Oak, the Sycamore, and the Almond. In parasites and saprophytes which are devoid of chlorophyll and which have very small seeds, such as Monotropa and Orobanche, the embryo is quite undifferentiated, and it consists of only a small number of cells.

The axis of the embryo frequently persists as the main axis of the plant which grows in length and produces numerous less vigorous lateral shoots; but it often happens that some of these lateral branches subsequently grow as vigorously as the main axis: when this is the case, and when also the lower and feebler shoots die off, a head, such as is common in forest-trees, is the result; in the case of shrubs, vigorous branches are formed quite low down on the main stem. The branching of the stem is almost invariably axillary and lateral: it is frequently monopodial (p. 19), but in many forest-trees the stem (trunk) and branches form a sympo- 
dium, the uppermost lateral bud growing each year in the direction of the main axis, which does not itself develop any further (p. 21).

When the axis of the embryo continues to be the main axis of the plant, the primary root also develops greatly, and forms a tap-root from which the lateral roots grow in acropetal succession. In cases in which the growth in length of the tap-root is limited, numerous adventitious roots spring from its older portions; these may again give rise to lateral roots, and by a repetition of this process an elaborate root-system is formed.

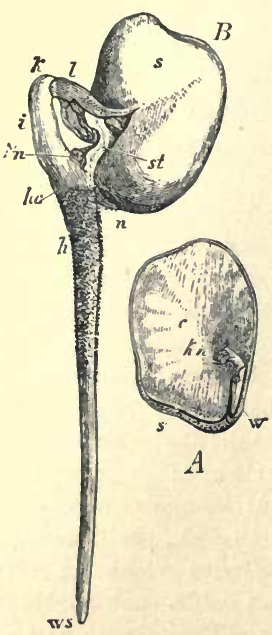

FIG. 32?-Vicia Faba, the Bean. A Seed with one of the cotyledons removed; $c$ the remaining cotyledon; w radicle; $k n$ plumule; stesta. $B$ Germinating seed; s testa; $l$ a portion of the testa torn away; $n$ hilum; $s t$ petiole of one of the cotyledons; $k$ curved epicotyl; he the very short hypocotyl; $h$ the primary root; ws its apex; $k n$ bud in the axil of one of the cotyledons.

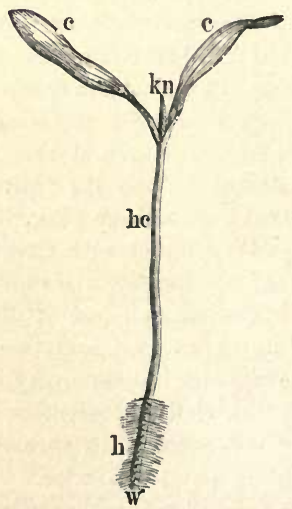

Frg. 321.-Seedling of the Maple (nat. size): $c c$ the cotyledons; $k n$ the plumule; he the hypocotyl; vo primary root; $h$ root hairs (the lower part is cut off).

The stem is almost always monostelic (see p. 117). The vascular bundles of the stem are almost always conjoint, collateral, and open, and the stem grows in thickness by the activity of the cambium-ring which is formed (p. 137). When the stem grows in thickness, the root does so also. 
The leaves exhibit infinite variety both in their relative position and in their form. The foliage-leaves almost always consist of petiole and blade; amplexicaul leaf-bases are comparatively rare, but stipules, on the contrary, are very common. Branching or segmentation of the leaves is common, and is frequently indicated by the incision of the margin. The usually reticulate venation of the leaves is characterized by the presence of a large number of veins which project on the under surface, except in thick, fleshy leaves, and which frequently anastomose; a midrib is almost always present, giving off lateral branches to right and left.

The flowers, when they are lateral, are usually furnished with two prophylla or bracteoles (see p. 443): they differ very considerably in their structure, and cannot be referred to any one type. The following are the principal forms:

1. In a considerable number the perianth, which is simple, and the androecium are isomerous, consisting of four, five, or six members; their arrangement is either spiral $\left(\frac{2}{3}\right)$, or whorled so that the stamens are always superposed on the leaves of the perianth; the latter are all similar and are sepaloid. Formula $P 5 \mid A 5$, or $P \mathrm{n}+\mathrm{n}, A \mathrm{n}+\mathrm{n}$, where $\mathrm{n}=2$ or 3 . This structure prevails in some of the Monochlamyder (Urticales, Amentales).

2. In a second group, all the parts of the flower are arranged in a continuous spiral, the stamens, and sometimes the carpels, being generally more numerous than the leaves of the perianth: the perianth may consist only of a calyx, or a corolla may be developed in place of the external stamens; when this is the case the corolla alternates with the calyx, provided that it is isomerous with it, as in most Ranales.

3. With these two types are connected by many intermediate forms those flowers in which the biseriate perianth and the stamens are in whorls: their formula is $K \mathrm{n}, C \mathrm{n}, A \mathrm{n}+\mathrm{n}$, where n usually $=5$ or 4 . This is the most common type of structure of the flower; it occurs in most Polypetalæ and Gamopetalæ; it may be modified either by the suppression of one (usually the inner) whorl of stamens, or by their multiplication, their branching, or their cohesion, or by the suppression of the corolla.

4. Finally, there remain certain flowers which cannot be directly referred to any one of the above types, and they must therefore be left unexplained for the present, and the relationships of their families must remain uncertain. 
In all cases the structure of the gynæceum is variable: it is frequently oligomerous.

The sub-divisions in which the Dicotyledons are arranged in the following classification are especially characterized by peculiarities in the structure of the flower. It is impossible, however, to draw sharp distinctions between the sub-classes, the cohorts, the orders, and sometimes even between the families, for the position of a plant in the system depends, not upon any one character, but upon the aggregate of its characters.

The principal orders of Dicotyledons may be arranged as follows :-

\section{SUB-CLASS I. MONOCHLAMYDEÆ.}

Cohort I. Urticales.

Order 1. URTICACEE.

, 2. MoRacei.

, 3. Cannabinaces.

"4. Ulmaces.

Cohort II. Amentales.

Order 1. Betulacez.

"2. Corylace..

"3. Fagace..

9

,

4. Juglandaces.

5. SalicaceE.
Cohort III. Chenopodiales.

Order 1. Chenopodiacex.

2. Polygonacees.

Cohort IV. Asarales.

Order 1. ARISTOLOCHIACEA: Cohort V. Santalales.

Order 1. SaNTalace玉.

2. Loranthace.e.

Cohort VI. Euphorbiales.

Order 1. EupHORBIACEA.

\section{SUB-CLASS II. POLYPETALÆ.}

SERIES I. THALAMIFLORE.

Cohort I. Ranales.

Order 1. Ranunculacee.

$"$

$"$

",

2. Magnoliacee.

3. NYMPHEACEE.

4. Berberidace.e.

Cohort II. Caryophyllales.

Order 1. Caryophyllace.. Cohort IV. Guttiferales.

Order 1. HyPERICACEE.

Cohort V. Malvales.

Order 1. TiliaceE.

2. Malvaces. 
SERIES II. DISCIFLORA.

Cohort I. Geraniales.

Order 1. Geraniaces.

2. Linacee.
$"$ 3. Oxalidace.e.
$"$ 4. Balsaminace.e.
$"$ 5. Rutace.e.

"2. Linacee.

"3. Oxalidaces.

$"$ 5. Rutaces.
Cohort II. Sapindales.

Order 1. SAPINDaCE

"2. ACErace.e.

"3. Polygalacef.

Cohort III. Celastrales.

Order 1. Celastrace.e.
"2. Rhamiace.
$"$ 3. Ampelidace.e.

Cohort I. Umbellales.

Order 1. UMBELLIFERE.

"2. Araliacex.

Cohort II. Passiflorales.

Order 1. Cucurbitacez.

Cohort III. Myrtales.

Order 1. ONAGRACEE.

$"$ 2. LYTHRaces.

" 3. Mrrtace.e.

\section{SUB-CLASS III. GAMOPETALA.}

\section{SERIES I. HYPOGYNE.}

Cohort I. Lamiales.

Order 1. Labiate.

Cohort II. Personales.
Cohort IV. Gentianales.

Order 1. Gentianacex. "2. Oleaces.

Order 1. Scrophulariace环. Cohort V. Primulales.
",
2. Plantaginaced.
Order 1. Primulaces.
3. Orobanchacee. $"$
2. Plombaglnace
$"$
4. Lentibulariacez. Cohort VI. Ericales.
Cohort III. Polemoniales.
Order 1. Convolvulace.e.
"2. Polemoniacee.
$"$ 3. Solanacee.
"4. Boraginacee.
Order 1. Ericaces.
"2. Pyrolacee.
3. Vaccinracex.

SERIES II, EPIGYNE.

Cohort I. Campanales.

Order 1. Campanulacee. Cohort II. Rubiales.

Order 1. Rubiaces.

2. Caprifoliacee.
Cohort III. Asterales.

Order 1. Valerianacex.
$"$
2. Dipsace.e.
9
3. COMPOSITE. 


\section{SUB-CLASS I. MONOCHLAMYDEE.}

The flowers have a simple, usually sepaloid, perianth, or it may be absent; they are commonly unisexual.

Cohort I. Urticales. Flowers usually diclinous, in inflorescences of various forms: perianth usually present, simple, sepaloid, consisting typically of five $\left(\frac{2}{5}\right)$ or reduced to four $(2+2)$ segments; stamens equal in number and opposite to the segments of the perianth, in consequence, apparently, of the essentially spiral arrangement of the floral organs (see p. 446); ovary superior, monomerous, unilocular, or sometimes dimerous with two styles, and then rarely bilocular: ovule solitary, in different positions. Seed commonly containing endosperm. The inflorescences in orders 1-3 are usually situated two together at the base of a leafy dwarf-shoot which springs from the axil of a leaf, and they are cymose (Fig. 322). The leaves are generally hirsute. Cystoliths (p. 78) are commonly present.

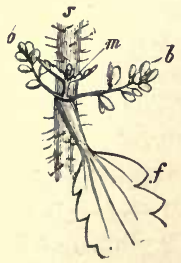

Fro. 322.-Part of the stem of Urtica urens, with a leaf $(f)$ in the axil of which is the branch $(m)$, at the base of which are the inflorescences $(b)$, without any bracts (nat. size).

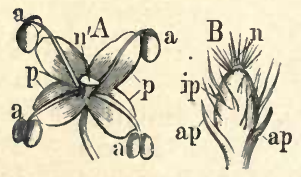

Fig. 323. $-A$ staminal ơ ; $B$ carpellary of flowers of the Stinging Nettle, Urtica : $p$ perianth; $a$ stamen; $n^{\prime}$ rudimentary ovary of the of flower; ap outer; ip inner whorl of the periantb; $n$ stigma of the of flower (mag.).

Order 1. URTICACE.e. Ovary monomerous: ovule central, orthotropous. Seed containing endosperm. They are mostly herbs or shrubs without milky juice and frequently provided with stinging hairs : leaves alternate, stipulate. Flowers polygamous, monœcious, or diøcious, in paniculate or glomerulate inflorescences.

Urtica urens and dioica (Stinging Nettles) are known by the stinging hairs which are distributed over their whole surface: perianth $2+2$; the two outer segments of the perianth of the $q$ flower are larger than the inner segments (Fig. $323 \mathrm{~B}$ ). In the former species the $\delta$ and $q$ flowers are contained in the same panicle, and the floral axis is but feebly developed; in the latter they are on different plants, and the axis is well 
developed and bears leaves. Böhneria nivea, a native of China and Japan, has strong bast-fibres used for weaving the material known in England as Grass-cloth. Parietaria officinalis, Wall-Pellitory, having polygamous flowers with a gamophyllous perianth, and destitute of stinging hairs oceurs occasionally on walls, by roadsides, ete.

Order 2. MoRACEe. Ovary generally dimerous, and sometimes bilocular (Artocarpus) : ovule suspended, anatropous or campylotropous, more rarely basal and orthotrobpous: seed with or without endosperm; the fruit is enveloped by the perianth (usually $2+2$ ), which becomes fleshy, or by a fleshy floral axis. Trees and shrubs with milky juice, scattered leaves and caducous stipules.

Morus alba and nigra (Mulberry) come from Asia; the flowers are disposed in short catkins; the catkins are borne singly on shoots, which, at the time of flowering are still buds, and they contain the diclinous flowers; the $q$ flowers give rise, as ripening take place, to a spurious fruit (sorosis, p. 472), consisting of spurious drupes formed mainly by the perianths. The leaves, particularly of the former species, are the food of the silkworm. Broussonetia papyrifera (Paper Mulberry) has flowers like the preceding, but they are diocious: the bark is made into paper in China and Japan. Maclura tinctoria, in Central America, yields Fustic, a dye. Ficus Carica is the Fig-tree of Southern Europe; the fig itself (termed a syconus) is the deeply concave axis of the inflorescence, on the inner surface of which the flowers and subsequently the fruits, in the form of hard grains (achenes), are borne (Fig. $324 m f)$; the cavity is closed above by small bracts (Fig. 324 b). Ficus e?astica is the Indiarubber tree; it is frequently cultivated in rooms.

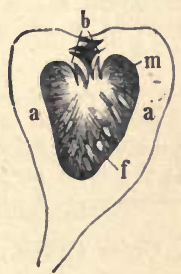

Fig. 32t.-Longitudinal section of a Fig (nat size): a a fleshy axis of the in. florescence; $f$ \&, $m \delta$, flowers; $b$ brscts.

$F$. religiosa and other East Indian species yield Caoutchouc, which is their inspissated milky juice (latex). Ficus indica is the Banyan. Arlocarpus incisa is the Bread-fruit tree of the South Sea Islands; the large spurious fruit (sorosis) of this tree is roasted and eaten as bread. Galactodendron utile, the Cow-tree of Columbia, has a nutritious latex, while that of Antiaris toxicaria (Java) is poisonous.

Order 3. Canvabinacee. Ovary dimerous, unilocular: ovule suspended, campylotropous: seed with endosperm. Flowers diocious : the $\delta$ flowers (Fig. $325 \mathrm{~A}$ ) have a 5-partite perianth and 5 short stamens; the $q$ flowers have a tubular entire perianth (Fig. $325 B, p$ ), enclosed in a bracteole (Fig. $325 B, d$ ). Herbs with decussate leaves-at least the lower ones-and persistent stipules; devoid of latex. 
Cannabis sativa, the Hemp, a native of Asia, is cultivated throughout Europe. The $\delta$ inflorescences are panicled dichasia or scorpioid cymes, and are disposed on both sides of a rudimentary shoot at the apex of the

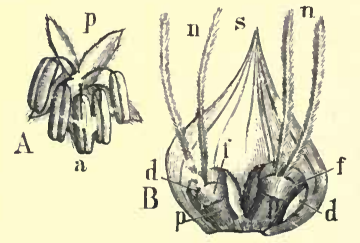

Fig. 325.-A of flower of the Hop: $p$ the perianth; $a$ stamens. $B$ Part of + inflorescence $: p$ perianth; $f$ ovary, with two stigmata $(n)$; each flower is enclosed in its bracteole $(d) ; 8$ scale, i.e. one of the two stipnles, from the common axil of which the branch bearing the flowers springe.

plant; the of flowers are placed singly on both sides of a similar shoot, which bears secondary shoots in the axils of its leaves, each having two flowers. The tough bast-fibres are used in weaving and for ropes; the seeds contain a great deal of oil. Humulus Lupulus, the Hop, is both cultivated and found wild. The stem, which has the peculiarity of twining to the right, bears its leaves in pairs; each leaf has a pair of membranous stipules. In the inflorescence the leaves (bracts) are placed singly, and are finally represented only by their stipules. In the $f$ inflorescence, which somewhat resembles a fir-cone, a rudimentary shoot is present in the common axil of each pair of stipules, and bears two flowers on each side; it seems at first sight as if two flowers were developed in the axil of each stipule (Fig. $325 B$ ). All the scales and bracts are covered, especially on the upper surface, with numerous yellow glands. In the of inflorescence the shoot which bears the flowers is well developed.

Order 4. Ulmaces. Ovary dimerous, sometimes bilocular, but generally unilocular by abortion. Ovule suspended and solitary. Flowers mostly monoclinous, with a 4-6-partite perianth (Fig. 326 A). Woody plants devoid of milky juice: leaves alternate, with caducous stipules. The inflorescences (glomerules) are borne directly in the axils of the leaves.

In the genus Ulmus the compact dichasial inflorescences are developed in the axils of the leaves (either persistent or deciduous), of the previous

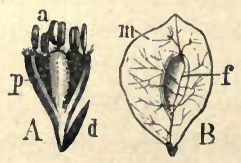

FIG. 326. $-A$ Flower of Ulmus montana (mag.): $d$ bract : $p$ perianth; $a$ stamens. B Fruit (samara) (nat. size) : $m$ membranous margin (wing). year, and they are invested by bud-scales; one or more flowers are developed in the axil of each of the more internal scales (bracts), and they open before the unfolding of the leaves. The ovary is sometimes bilocular. The fruit is a samara, that is, an achene with a broad membranous wing (Fig. $326 \mathrm{~B}$ ). The leaves are alternate, and always oblique (p. 33). The annual shoots have no terminal bud, and so they form a sympodium (see p. 21). Two species of Elm are indigenous in England: Ulmus campestris, the common Elm, and Ulmus 
montana, the broad-leafed Wych, or Scottish, or Mountain Elm. Celtis australis, from Southern Europe and $C$. occidentalis, from North America, are often cultivated as ornamental trees; their flowers are polygamous and are placed singly or several together in the axils of the oblique acuminate leaves: the fruit is drupaceous.

Cohort III. Amentales. The flowers, which are either diclinous or diøeious, are arranged in catkins (amenta). The perianth, when it is present, consists typically of $5\left(\frac{2}{5}\right)$ segments ; or it may deviate from the type so as to consist of four, (i.e. $2+2$ ), or six (i.e. $3+3)$ segments : the stamens, when their position can be determined, are superposed on the segments of the perianth for the reason given in the case of Urticales (see p. 514). The ovary is either superior or inferior, di- or tri-merous, with few ovules. The fruit (with the exception of the Salicaceæ) becomes by abortion one-seeded, and is indehiscent: the seed has no endosperm. The flowers are furnished with bracts which often form investments for the fruit: their arrangement in most of the orders is as follows: in the axil of a scaly bract (the bracts being arranged spirally in the amentum) is a flower (b) with two bracteoles $\alpha$ and $\beta$, in the axil of each of which is another flower with two more bracteoles $\alpha^{\prime}$ and $\beta^{\prime}$ (Fig. 327). The plants are trees and shrubs.

Order 1. Betulaces. The flowers are monocious, but in different catkins. The $q$ flowers have no perianth: the ovary is bilocular, with two ovules: the fruit is one-seeded, indehiscent,

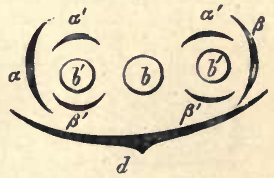

FIG. 327.-Typical diagram of a group of flowers in the Amen. tales : $d$ bract; $b$ the median flower with its bracteoles, $\alpha$ and $\beta ; b^{\prime} b^{\prime \prime}$ the two lateral flower3, with the ir bracteoles $\alpha^{\prime}$ and $\beta^{\prime}$. without any investment: the bract is coherent with the two or four bracteoles (the bracteoles $\alpha^{\prime}$ are always absent) to form a three-or five-lobed scale, which does not adhere to the fruit.

Alnus, the Alder. In the $\delta$ amenta three flowers with four bracteoles $\left(a, \beta, \beta^{\prime}, \beta^{\prime}\right)$ occur in the axil of the bract, each flower having a perianth of four segments, and four unbranched stamens. In the $q$ amenta the median flower is absent; the four bracteoles coalesce with the primary bract (Fig. $328 B, v s$ ) to form a five-lobed woody scale which persists after the fall of the fruit which is not winged. The of catkins are borne terminally, and the $q$ laterally on the highest lateral branch, on the shoots of the previous year; they are not enclosed by bud-scales during the winter, and blossoming takes place before the unfolding of the leaves. The leaves have usually a $\frac{1}{3}$ arrangement : in $A$. incana, the White Alder, the leaves 
are acuminate and gray on the under surface; in A. glutinosa, the black or common Alder, they are obovate or even emarginate, and green on both surfaces. In Alnus viridis, the Mountain Alder, only the of catkins are destitute of bud-scales in the winter: the fruit is winged,

Betula, the Birch. In both kinds of catkins the three flowers have only the bracteoles $\alpha$ and $\beta$. In the $\delta$ flowers the perianth is usually incomplete, and there are only tivo stamens, the filaments of which are forked. In the $q$ catkins, the two bracteoles cohere with the bract to form a threelobed scale which falls off together with the winged fruit. The $\delta$ catkins are borne terminally on the shoots of the previous year, and are not covered with bud-scales during the winter; the $q$ catkins are borne terminally on lateral dwarf-shoots which have only a few leaves, and they are enclosed by bud-scales during the winter; as a consequence, flowering takes place after the unfolding of the leaves. The shoots of successive years form sympodia, and the leaves are arranged spirally. B. verrucosa has white glands on the leaves and young shoots: B. pubescens has no glands, but the shoots are hairy; it is a northern form : $B$. fruticosa and $B$. nxna are shrubs occurring in high latitudes: $B$. alba is the common Birch.
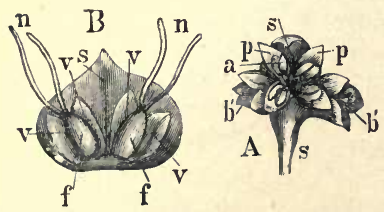

Fig. 328.-A Scale from a $\delta$ catkin of Alnus incana: the axillary branch adberes to the scale (s), it besrs four bracteoles and three flowers: two of the flowers are seen laterally $\left(b^{\prime} b^{\prime}\right)$, the median one from above; $p$ perianth; $a$ stamens, $B$ Bract (s) of a 9 catkin of the same plant : its axillary branch bears two lateral branches, each of which bears two bracteoles $(v v)$ and one flower ; $f$ the ovary; $n$ the stigmata (magnified and diagrammatic).
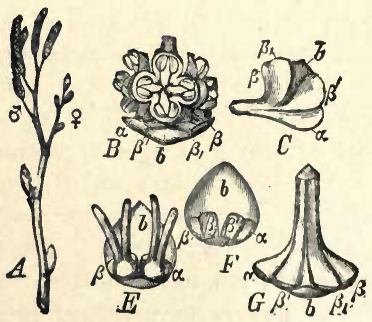

Frø. 329.-Alnus glutinosa, $A$ Branch bearing catkins (in winter). $\boldsymbol{B}$ a group of of flowers (from above). C The same after removal of flowers (lateral view). $E$ Gronp of $q$ flowers, seen from within. F The same after the removal of the flowers. $G$ a scale from the $q$ catkin : $b$ bract; $a, \beta, \beta^{\prime}$ bracteoles.

Order 2. CoRylace . Flowers monœcious, in $\delta$ and $q$ catkins. The $\delta$ flowers have no perianth; that of the $q$ flower is rudimentary. The inferior ovary is bilocular; one loculus is sterile, the other contains two suspended anatropous ovules: the fruit is one-seeded and indehiscent (a nut). Two flowers are borne in the axil of the bract of the $q$ catkin, the median flower being absent. The one-seeded fruit is surrounded by a leafy investment

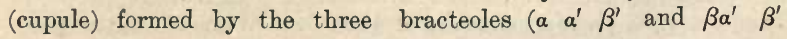


respectively, Fig. 327) of each side. In the $\delta$ catkin the median flower only is developed: the filaments of the stamens are deeply forked.

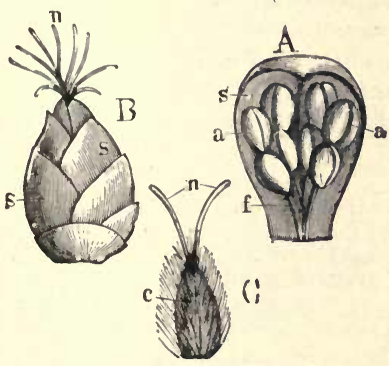

FrG. 330.-Corylus Avellava. A Bract (s) of a $\delta$ catkin, with a of flower: stamens $(f)$, and anthers (a). B o catkin: the lower bracts (s) have no flowers : the stigmata $(n)$ project above. C A single of flower surrounded by the cupule (bracteoles) (c), with two stigmata (n) (mag. and diag.)

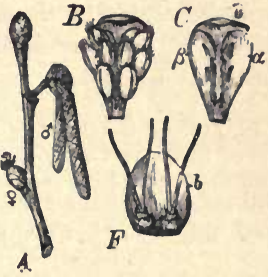

Fre. 331.-Corylus Arellana. A Flowering branch. $B$ \& flower with its bract. $C$ Bract after the removal of the anthers. $F$ Group of $\$$ flowers seen from within: 3 bract.

In Corylus, the Hazel, the $q$ catkin resembles a bud, since the external sterile bracts have the same structure as the bud-scales (Fig. $330 B$ ); the red stigmata project at the top; the investment of the fruit is irregularly cut; a small projection is formed on the fruit, the nut, by the remains of the epigynous perianth. Each bract of the $\delta$ amentum bears two bracteoles $\alpha$ and $\beta$, and a flower consisting of four forked stamens (Figs. 330-1). Both kinds of amenta are placed in the axils of the leaves of the previous year, and are not enclosed by scales during the winter; hence flowering takes place before the unfolding of the leaves. Leaves distichous. C. Avellana is the common Hazel ; a variety of $C$.tubulosa, with red leaves, the Purple or Blood Hazel, is cultivated as an ornamental shrub.

In Carpinus, the Hornbeam, the fruit has a three-lobed cupule (Fig. 332), the fruit is ribbed and is surmounted by the perianth. The bract of the o catkin beurs 4-10 deeply forked stamens; there are no bracteoles. The catkins of both kinds are borne at the apex of short leafy shoots of the same year, hence flowering takes place after the unfolding of the leaves. Leaves distichous. The annual shoots form sympodia. C. Betulus has an irregular stem and serrate leaves which are plicate along the lateral veins.

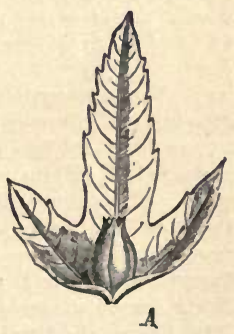

Fro. 332. - Fruit of Carpinus Betulus witb tbreelobed capsule. 
In Ostrya (Southern Europe) the investment of the fruit is an open tube.

Order 3. FAGACE. Flowers monœeious, with a perianth of five or six segments. Ovary inferior, trilocular, with two ovules in each loculus ; ovules anatropous, ascending or suspended; the fruit is one-seeded and indehiscent (a nut); it is invested by a cupule formed probably by the connate bracteoles $\alpha^{\prime} \beta^{\prime} \alpha^{\prime} \beta^{\prime}$ (Fig. 327), and having its surface covered with scales, prickles, etc. The filaments are not forked.

In Quercus, the Oak, the $\delta$ catkins are loose; each bract bears a single Hower in its axil without bracteoles: the perianth is $5-7$ lobed, and the stamens from $5-10$ or indefinite (Fig. $333 A$ ). There is a single flower, the median one, in the axil of each bract of the $\&$ catkin; thus the cupule inrests only a single fruit, and forms the so-called cup at its base. The

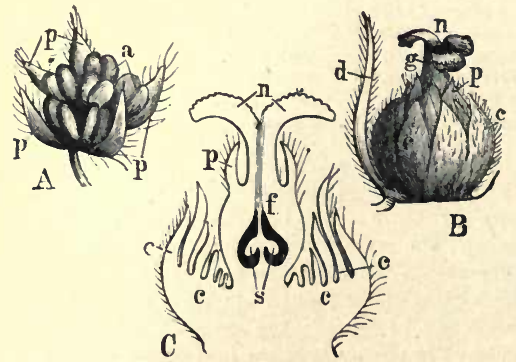

Frg. 332.-Quercus pedunculata, $A\}$ flower magnified: $r$ perianth; $a$ stameus. $B$ \& flower magnified $: d$ bract ; $c$ cupule; $p$ the epigynous perianth; $g$ the style; $n$ the stigma. $C$ The same, still more magnified, in longitudinal section; $f$ ovary ; s orules. leaves are developed in $\frac{2}{5}$ order, and are aggregated towards the apices of the annual shoots; the annual shoots are always terminal. The of catkins are borne in the axils of the uppermost budscales (pairs of stipules) on both long and dwarf - shoots of the same year; the $q$ catkins in the axils of the foliage-leaves of the terminal shoots : flowering takes place shortly after the unfolding of the leaves. The ovules are ascend-

ing. The hypogean cotyledons remain enclosed in the testa during germination. Quercus Robur is the English species, of which there are two varieties, Quercus pedunculata and Quercus sessiliflora: the former has elongated $q$ catkins, so that the fruits are widely separated from each other, and its pinnately lobed leaves are shortly stalked and cordate at the base: the latter has compact $q$ catkins, so that the fruits form a cluster, and its leaves have longer petioles, and are narrowed at the base. Quercus Suber is the Cork-Oak of Southern Europe. There are also several North American species.

In Fagus, the Beech, the catkins of both kinds are stalked dichasial clusters, borne each in the axil of a foliage-leaf. The flowers have no bracts, or bracteoles, except the cupule of the $q$ flower, The flowers of 
the pendulous of catkin are closely packed: they have a perianth of 4-7 segments, and 8-12 stamens. The erect + catkin consists of two flowers only, which are invested by a tetramerous cupule. The cupule is covered with hard bristles, and when ripe splits into four valves to allow the two triquetrous fruits to escape; each fruit bears at its apex a brush-like remnant of the perianth. The ovules are suspended. The $q$ inflorescences are borne on erect axes in the axils of the leaves of the apical shoot of the same year, the $\delta$ on pendulous axes springing from the axils of the lower leaves of the shoot. Leaves distichous, approaching each other on the under surfaces of the shoots, their axillary buds approaching each other on the upper surface: the winter-buds are elongated and pointed. The epigean cotyledons escape from the seed on germination. Fagus sylvatica is the common Beech: varieties with tinted leaves, such as the Purple Beech and the Copper Beeh, are commonly cultivated.

In Castanea, the edible or Spanish Chestnut, some of the catkins consist at their lower part of $q$ flowers and at their upper of $\delta$ flowers, whilst others have only $\delta$ flowers. In the axil of each bract there are usually either seven $\delta$ or three $\&$ flowers: the latter are invested by the bracteoles $a$ and $\beta$, and by a cupule formed by the other four bracteoles; the cupule, which is covered with prickles, completely encloses the fruit until it is ripe, when it splits into four valves. Both kinds of catkins are formed in the axils of leaves of shoots of the same year, the mixed catkins being nearer to the apex than the $\delta$ ones. The ovules are suspended. The leaves are arranged spirally on vigorous shoots; they are distichous on the less vigorous lateral shoots. C. vulgaris, from Southern Europe, is cultivated in parks; it has undivided toothed leaves.

Order 4. Juglandacex. Flowers monocious, the two kinds of flowers being contained in distinct catkins. Each bract bears in its axil a single flower with two bracteoles. The $q$ flower has usually a perianth: the inferior ovary is dimerous, and encloses a single erect orthotropous ovule. The $\delta$ flowers are usually borne on the bract; they may or may not have a perianth, and the stamens are indefinite (Fig. 334 A). The fruit is drupaceous; the

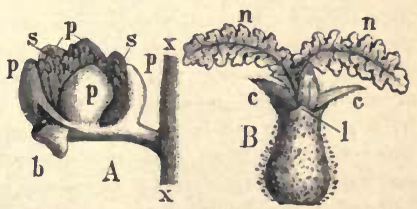

Fig. 334.-A Bract of the $\delta$ catkin of Juglane nigra bearing a flower: $p$ perianth and bract. eoles; stamens; $x$ axia of the catkin. $B$ ? flower of the same plant: $l$ bracteoles; e perianth; $n$ stigmata (magnited). leaves are pinnate, and, like the flowers, they are aromatic.

In Juglans the $\delta$ catkins are borne on the apices of the leafless shoots of the previous year, and the few-flowered \& catkins on the apices of the leafy shoots of the same year. The bracteoles of the $q$ flowers (Fig. $334 l$ ) 
grow up around the orary. The succulent mesocarp is thin, and ruptures irregularly; the hard endocarp opens on germination along the line of junction of the two carpels, and then the incurved margins of the carpels are seen as an incomplete longitudinal septum projecting between the two cotyledons of the embryo which is closely invested by the endocarp. $J$. regia, the Walnut Tree, is a native of Southern Europe: in North America, $J$. cinerea and nigra occur; also various species of Carya, the Hickory, remarkable for its very hard wood.

Order 5. SAlicace.e. The diøecious flowers are arranged in amenta, and are borne in the axils of the bracts without any bracteoles. There is no perianth, but each flower contains a glandular disc or nectary. The ovary is dimerous and unilocular, and contains a number of parietal ovules. The dehiscence of the fruit is loculicidal; the numerous seeds are furnished with a pencil of silky hairs at their bases (p. 416). The catkins are developed at

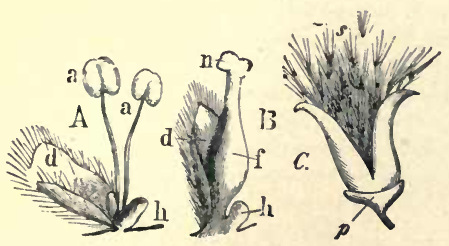

Fig. 335.-A $\delta, B$ ㅇ flower of Salix : $d$ bract; $h$ disc; $a$ stamens; $f$ ovary; $n$ stigmata (enlarged). $C$ Dehiscent fruit of the Poplar; $s$ seeds ; $p$ disc.

the ends of lateral dwarfshoots which always bear scales or even a few foliage-leaves.

Salix, the Willow or Sallow, has entire bracts, a oneor two-toothed nectary in each flower, and usually two stamens, entire shortlystalked leaves, and its winter-buds are covered by a scale which is formed by

the coalescence of two. Some species, such as S. alba, fragilis, and babylonica, the Weeping Willow, have pendulous branches, and are arborescent : most of them are shrubby, and some, such as S. reticulata, retusa, and herbacea, are small decumbent shrubs occurring in the Alps and in high latitudes. In S. purpurea and incana the two stamens are connate: S. triandra has three stamens. Most of the species grow on the banks of rivers; S. aurita and caprea in forests, and $S$. repens and others on moors.

Populus, the Poplar, has toothed or lobed bracts, a cup-shaped nectary (Fig. $335 \mathrm{C}, p$ ), and numerous $(4-30)$ stantens ; the leaves are often lobed and have long petioles; the winter-buds are enclosed by a number of scales; the shoots have a terminal bud.

Cohort III. Chenopodiales. Flowers usually monoclinous ; perianth sepaloid or petaloid: ovary monomerous or polymerous; ovule usually solitary; embryo coiled or curved.

Order 1. Chevopodacex. Flowers small, united to form a dense inflorescence: the bracteoles are frequently suppressed. 
Stamens typically equal in number to and superposed on the usually four $(2+2)$ or five $\left(\begin{array}{l}2 \\ 3\end{array}\right)$ free or connate sepaloid perianth leaves for the same reason as in the Urticales (p. 514) (Fig. 336). Ovary usually medially dimerous and unilocular, with a single campylotropous, erect or horizontal, basal ovule: seed contains perisperm, but no endosperm. Stipules wanting.

Chenopodium album, the Goose-foot, and c: Bonns Henricus, the All-good, are common weeds on garden-ground and waste land.

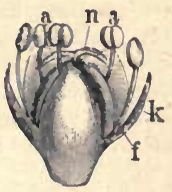

Fig. 330.-Flower of Chenopodium (enlarged); $k$ reriar.th ; a stamens; $f$ ovary ; $n$ stigma. Spinacia oleracea is Spinach, cultivated as a vegetable. Beta vulgaris is cultivated under the var. Cicla (Mangold); B. altissima is the species used in the manufacture of sugar, and $B$. rubra is the red Beetroot; B. maritima is the wild Beet. Salsola, the Salt-wort, and its allies, Sureda, the Sea-blite, and Salicornia, the Marsh-Samphire or Glass-wort, with fleshy stems and leaves, are conspicuous in the vegetation of the sea-shore. Atriplex, the Orache, is the other British genus.

Order 2. Polygonaces. The flowers have a simple 4, 5, or 6-leaved perianth which may be either sepaloid or petaloid, and usually the same number of superposed stamens; but occasionally the stamens are more numerous or some of them are suppressed. Ovary usually trimerous, unilocular, with a single basal orthotropous ovule; the fruit is frequently more or less enveloped by the persistent perianth. The leaves have well-developed sheaths (Fig. $337 A v$ ) and connate stipules forming an ocrea (Fig. $337 \mathrm{Ao}$ : see p.31) which embraces the stem for somedistance above the leaf-sheath.
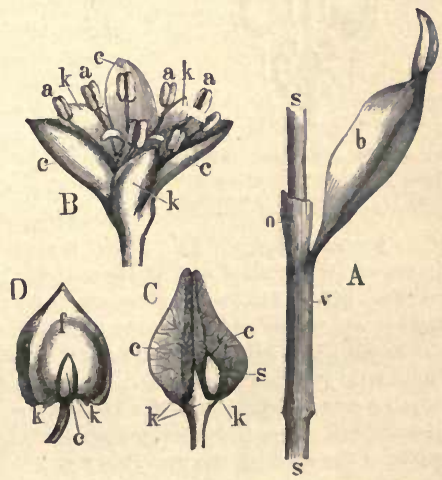

Fig. 337. $-A$ Pcrtion of the stc $m$ (s) of Pulggonum, with a leaf $(b)$, its sheath $(v)$, and the ocrea $(0)$ (nat. size). B Flower of Rhenm; $k$ external, c internal perianth-whorl; a the stamenk. C Fruit of Rumex, enclosed by the inner whorl of the periantb; s base of one of the perianth-leares; $k$ external rerianth-leaves, $D$ Fruit of Rbeum $(f)$; $k$ outer, $c$ inner perianth-whorl (enlarged). 
Rheum, the Rhubarb, has six (three internal and three external) perianth-leaves and two whorls of stamens, the outer containing six, and the inner three; Rheum undulatum and other species are cultivated. Rumex, the Dock, has flowers of similar structure, but the inner whorl of stamens is absent; the triquetrous fruits are completely enveloped by the inner whorl of perianth-leaves (Fig. $337 \mathrm{Cc}$ ); the leaves contain a large quantity of oxalic acid. Polygonum has usually five petaloid perianthleaves and a varying number of stamens $(5-8) ; P$. Fagopyrum, the Buckwheat; is cultivated for the sake of its mealy seeds.

Cohort IV. Asarales. Affinities doubtful. Flowers monoclinous or unisexual : ovary inferior: ovules numerous.

Order 1. ARISTOLOCHIACE. Flowers 3-6-merous, monoclinous : perianth of three connate petaloid segments forming a three-lobed tube: stamens 6 or 12, with extrorse anthers: ovary usually 6-locular, with numerous ovules in two longitudinal rows along the inner angles of each loculus. The

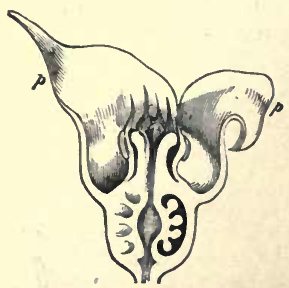

Fig. 339. - Asarum europceum. Longitudinal section of the flower (mag.); $p$ perianth. (After Sachs.) minute embryo is enclosed in the copious endosperm. They are herbs or shrubs, often climbing, with large leaves.

In Asarum europoum (Asarabacca) the three lobes of the perianth are equal; alternating with them are three scales which probably represent a corolla: the twelve stamens (apparently in two whorls) are free, and the connective is produced (Fig. 338). The annual shoots of the creeping stem bear four eataphyllary leaves. two large petiolate reniform foliage-leares, and a terminal flower. The lateral branches spring from the axils of the uppermost foliage-leaf and of the scales. In Aristolochia, the Birthwort (see Fig. 243, p. 412), the limb of the perianth is obliquely lipped; the six anthers are sessile and adnate to the short style (see p. 462). A. Sipho is a climber frequently cultivated: A. Clematitis, though not indigenous, is found wild in Britain, generally on ruins; the flowers of the latter occur usually several together in the axils of the leaves, and those of the former in pairs, one above the other, together with a branch, in the axils of the leaves of the shoot of the previous year.

Cohort V. Santalales. Parasitic plants: leaves, when present, entire: stamens equal in number to the leaves of the perianth and superposed upon them: ovary inferior, unilocular; ovules usually devoid of integument.

Order 1. Saxtalace.e. Parasites provided with chlorophyll: 
flowers generally monoclinous: ovules $1-4$, suspended, upon a free central placenta: perianth 3-5-lobed; fruit a nut or drupe: seed with endosperm.

Thesium linophyllum, the Bastard Toad-flax, is an indigenous plant which is parasitic on the roots of other plants. The leaves are narrow and linear. The bracts of the flowers, which are disposed in racemes, are usually placed high up on the pedicels, close under the flowers, and in most of the species constitute with the bracteoles a three-leaved epicalyx. The stamens are filiform, inserted at the base of the lobes of the perianth. The perianth is persistent, remaining curled up at the apex of the indehiscent fruit (Fig. $339 \mathrm{~B}$ ). Santalum albun, an East Indian tree, yields Sandal-wood.

Order 2. LoRAnthaces. Parasites provided with chlorophyll: flowers monoclinous or diclinous; sometimes diøcious: perianth of 4,6 , or 8 leaves: ovary 1-2-merous: in the free central placenta, which becomes more or less closely adherent to the wall of the ovary, are developed several embryo-sacs, each of which probably represent an ovule, but usually one only is fertile: fruit a berry : seed generally with endosperm.

Viscum album, the Mistletoe, is parasitic on various trees, forming conspicuous evergreen bunches. The stem bears a pair of opposite leaves (Fig. $340 b b$ ), from the axils of which new branches spring, each bearing a pair of cataphyllary leaves and then a pair of foliage-leaves, while the main axis ceases to grow, or produces a terminal inflorescence consisting of three flowers (Fig. $340 h f$ ): branches or inflorescences may also spring from the axils of the cataphyllary leaves. The flowers are diœcious. The fruit is a one-seeded berry with a viscid pericarp, by means of which the seeds become attached to trees, and thus effect the distribution of the plant. The $\delta$ flowers have multilocular sessile anthers which are inserted (Fig. $340 B$ a) upon the leaves of the perianth.

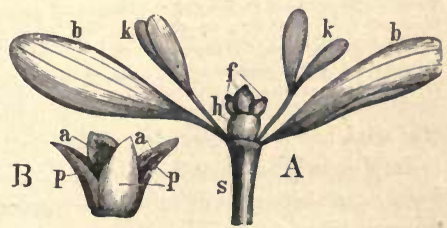

Fro. 3๒. $-A$ Terminal shoot of a \& plant of the Mistletoe, Viscum album: stem; $b$ b leaves; $k k$ axillary buds; $f$ three o tlowers with the fruit set; $h$ bracts. $B$ \& flower (mag.) $p$ perianth; a anthers adherent to the leaves of the perianth.

Cohort VI. Euphorbiales. Flowers usually diclinons; the 
perianth sometimes consists of calyx and corolla, sometimes it is simple, and occasionally it is absent: the ovary is usually trilocular, with one or two anatropous and generally suspended ovules in each loculus; the seed contains endosperm: the structure of the flowers is very various.

Order 1. Euphorbiaces. The fruit is usually dry and dehiscent, a schizocarp splitting into cocci. The micropyle of the solitary suspended ovule is directed outwards. They are plants of very various habit and floral structure, and they mostly contain milky juice.

The geuus Euphorbia has cymose umbels or dichasia, the brauches of which terminate in what were formerly regarded as hermaphrodite flowers, but are really inflorescences, each one being termed a cyathium. The cyathium consists of a tubular involucre

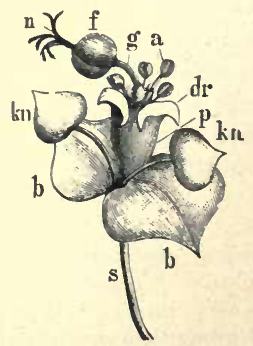

FrG. 311.-Part of an inflorescence of a Euphorbia: $b$ b bracts in the axils of which are the flower bnds $(k n) ; p$ is the involucre of the cyathium; $d r$ the g'ands; $a$ the male flowers; $g$ the nericel of the female flower $(f)$; $n$ the stigmas (enlarged). (Fig. $341 p$ ), between the five lobes of which glandular appendages, often of a semilunar form, are situated (Fig. $341 d r)$. Within this involucre are numerous staminate flowers in five groups, each of which consists of a single stamen (Fig. $341 a$ ) and is terminal on a long pedicel, and one carpellary flower (Fig. $341 \mathrm{~g}$ ), consisting of a trilocular ovary (Fig. $341 f$ ), at the base of which an indication of a perianth may in some cases be detected. That the cyathium is an inflorescence and not a single flower is most clearly visible in some foreign genera (e.g. Monotaxis), in which a perianth is distinctly developed round each stamen. There is a single ovule in each loculus of the trilocular ovary : the seed has a peculiar appendage (arilode, p. 416).

In Mercurialis the inflorescence is racemose: the staminate flowers have a three-leaved perianth and numerous stamens; the carpellary flowers have a similar perianth and a bilocular ovary. The juice is not milky.

Ricinus bears its monœcious flowers in a compound inflorescence, in which the staminate flowers are placed below and the carpellary flowers above. The perianth is simple and five-lobed, the stamens numerous and much branched (Fig. 278). 
Of Euphorbia, the Spurge, a number of species are anuual herbs, as E. Peplus and helioscopia (the common Sun Spurge) occurring in gardens and by roadsides; some South European forms are small shrubs, as $E$. dendroides and fruticosa. In Africa and the Canary Islands the genus is represented by species which much resemble Cacter in appearance; their stems are thick and cylindrical or angular or sometimes spherical, producing small leaves which usually soon fall off. Mercurialis annua and perennis (Dog's Mercury) are weeds; the first common in cultivated ground, the second in woods; their flowers are diøcious. Ricinus comsmunis (the Castor-oil plant) is a native of Africa, now frequently cultivated. Some species of Phyllanthus have phylloid branches which bear their small flowers in the axils of minute bristle-like leaves situated in indentations at the edge of the phylloclade. Manihot utilissima, a South American plant, yields the starchy meal known in commerce as tapioca. From Hevex guianensis, a species growing in Central America, most of the caoutchouc is obtained.

\section{SUB-CLASS II. POLYPETALE.}

Flowers usually monoclinous: perianth usually consisting of calyx and corolla, the petals being free.

\section{SERIES I. THALAMIFLORÆ.}

Sepals usually free : petals of ten indefinite : stamens hypogynous, often indefinite: gynæceum apocarpous or syncarpous.

Cohort I. Ranales. Flowers generally acyclic or hemicyclic : perianth consisting of calyx only, or of calyx and corolla : stamens usually indefinite: gynæceum apocarpous, sometimes reduced to a single carpel; very rarely syncarpous, with a multilocular ovary. Seed with or without endosperm.

Order 1. Ranunculace.e. Perianth either consisting of a petaloid calyx, or of calyx and corolla, usually spiral: stamens numerous, occupying several turns of the spiral, or arranged in several alternating whorls: anthers nsually with lateral dehiscence, sometimes extrorse or introrse : carpels numerous, spirally arranged ; rarely one only; the ovules are disposed on the connate margins of each carpel, that is, in two rows down the ventral suture; in several genera the number of the ovules in each ovary is reduced to one, which then originates from either the upper or the lower end of the cavity of the ovary: seed with endosperm. They are almost all herbaceous plants, and are either annuals or they have perrennial rhizomes; they have no stipules, but they have amplexicaul leaves.

Tribe 1. Anemonea. Petals generally replaced by stamens: sepals fre- 
quently petaloid : ovaries numerous, each containing a single suspended or ascending anatropous ovule; fruit consists of a number of achenes.

The genus Clematis consists of shrubs which creep, or climb by their petioles, and have opposite leaves, and a petaloid usually valvate calyx. Clematis Vitalba, the Old Man's Beard, is common in hedges; it has a greenish-white calyx, and fruits with long feathery styles; C. Viticella, patens, and others are cultivated as decorative plants. Atragene alpina, occurring in the Alps and in Siberia, has its external stamens converted into petaloid staminodes.

Thalictrum; the species of this genus, as T. majus, minus, flavum, and
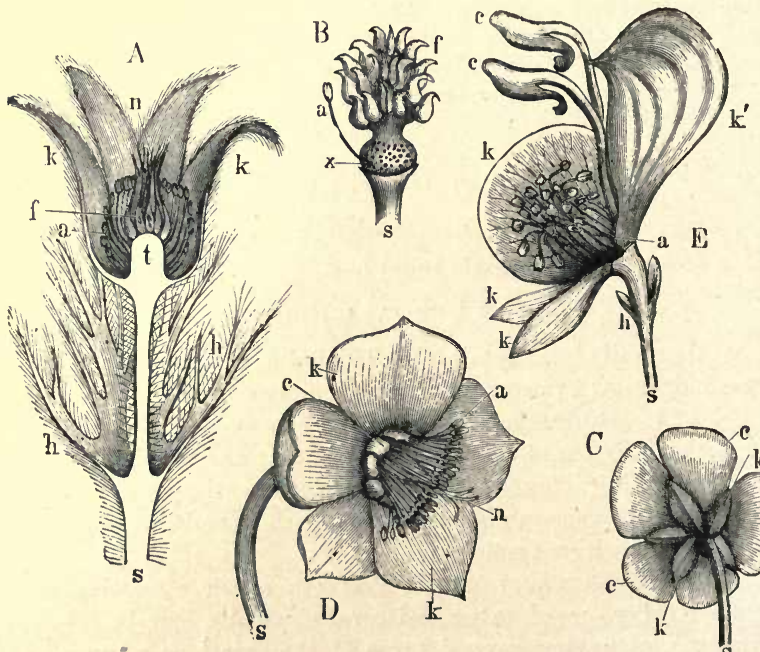

Fig. 312.-Flowers of Ranunculaces: 8 peduncle; $k$ sepals; $c$ petals; a stamens; $f$ carpels; $n$ stigma (all of natural size or slightly magnifled). A Flower of Anemone $P$ ulsatilla in longitudinal snetion; $h$ epicalyx; $t$ receptacle. $B$ Gynæcenm of Ranunculus : $x$ receptacle with the points of insertion of the stamers which have been removed: $C$ flower seen from below. D Flower of Hellsborus viridis. E Flower of Aconitum Napellus: $h$ bracteoles; $k$ hoodel posterior sepal-the lateral sepal on this side is removed.

alpinum, the Meadow-Rues, have stems well covered with leaves, and flowers with an inconspicuous, fugacious, 4-5-leaved calyx, and a flat receptacle.

Anemone has an hemispherical receptacle (Fig. $342 \mathrm{~A} t$ ), and a petaloid, usually 5-6-leaved calyx. In most of the species the underground rhizome elongates into an erect scape which bears a single whorl of three bracteoles forming an epicalyx ( $\mathrm{p}, 443)$, beneath the terminal flower. In 
A. nemorosa, ranunculoides, and others, these bracteoles resemble the foliageleaves, and often bear flowers in their axils; but in A. Pulsatilla, and others, they differ from the foliage-leaves in that they are palmatifid (Fig. 342.4 h); in A. Hepatica, in which the scapes spring from the axils of cataphyllary leaves, the three bracteoles are simple and lie so closely under the petaloid calyx that at first they appear to be the calyx of the flower.

Myosurns minimus (Mouse-tail) has a very long eylindrical receptacle, bearing the indefinite spirally arranged carpels: stamens $4-14$; the 5 sepals are spurred. Adonis, the Pheasant's Eye, has completely acyclic flowers; sepals 5, petals 8 or more, not glandular at the base ; stamens and carpels indefinite, arranged in $\frac{5}{15}$ order: $\boldsymbol{A}$. autuntnalis is the species which occurs in England.

In Ranunculus, the ealyx, which is not petaloid, consists of $\tilde{5}\left(\begin{array}{l}\text { g } \\ \xi\end{array}\right)$ sepals, and the corolla of $\tilde{5}$ imbricate petals which alternate with the sepals and have a nectary at their base: the stanens and carpels are arranged spirally; anthers extrorse; the ovule is ascending, whereas it is suspended in all the preceding genera. The genus includes water-plants with finelydivided leaves and white flowers, as $R$. aquatilis, Water Crowfoot, fluitans, etc.; and land-or bog-plants, usually with a yellow corolla, as $R$. acris, the Buttercup, repens, bulbosus, and sceleratus (all known as Crowfoot), and Lingua and Flammula (the Greater and Lesser Spearworts); they are all more or less poisonous. R. Ficaria (the Lesser Celandine) has 3 sepals and usually 8 petals.

Tribe. 2. Helleborece. Perianth generally consisting of calyx and corolla, the latter being occasionally suppressed; the petals are glandular at the base: ovaries usually fewer in number than the leaves of the perianth; ovules numerous, borne on the ventral suture; fruit usually consists of several follicles.

(a) With regular, generally actinomorphic, flowers :

Helleborus, with acyelic flowers; sepals more or less petaloid in $\frac{2}{5}$ arrangement; the petals, which are small and tubular, in $\frac{9}{8}$ or $\frac{5}{15}$; stamens in $\frac{5}{13}$ or $\frac{8}{2}$; ovaries usually 3-5 (Fig. $342 D$ ); H. Niger is the Christmas Rose; $H$. viridis and fotidus are not rare. Nigella has 5 petaloid sepals and usually 8 (superposed if 5) small glandular petals: its carpels cohere partially or completely, forming a septicidal capsule. Trollius, the Globeflower, has 5-15 petaloid sepals, and a similar number of small petals which, like the stamens and carpels, are all arranged spirally : T. europaus occurs in sub-alpine regions. Caltha, the Marsh-Marigold, has 5 yellow petaloid sepals, but no corolla : $C$. palnstris is common in damp places. Eranthis, the Winter Aconite, has a 3 -leaved epicalyx, and small petals with long claws. Actæa has a petaloid calyx and an alternating (sometimes suppressed) corolla; it has a single carpel which becomes a baccate fruit: A. spicata, the Baneberry or Herb Christopher, occurs in woods. Aquilegia, the Columbine, has a cyclic fiower (Fig. 313): it has o petaloid sepals, and petals with long spurs; there are several whorls of stamens: A. vulgaris, atrata, Aklei, and others occur wild, or are cultivated as decorative plànts. 
(b) With irregular dorsiventral flowers.

Delphinium, the Larkspur, has the posterior of the 5 petaloid sepals prolonged into a spur : there are typically 5-8 petals, of which only the 2 (D. Ajacis; see Fig. $273 \mathrm{~A}$ ) or 4 (D. Staphisagria) posterior are developed;

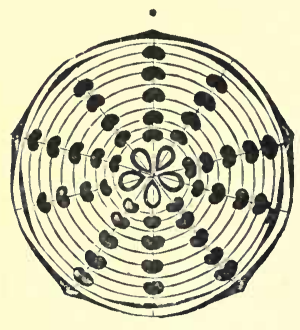

Fig. 343.-Diagram of flower of Aquilegia. the spurs of the two posterior petals project into that of the posterior sepal: $D$. Staphisagria has $3-5$ carpels; $D$. Consolida and D. Ajacis, common garden plants, have usually but one carpel. In Aconitum, the Wolf's-bane or Monk's-hrood, the posterior of the 5 petaloid sepals is large and hooded; the two posterior of the 8 petals have long claws and are covered by the posterior sepal, the others being inconspicuous (Fig. $342 E, c$ ).

Tribe 3. Poconiex. The perianth consists of calyx and corolla, and the petals are not glandular : ovaries with numerous ovules, surrounded by a disc: fruit of several follicles.

In Pæonia, the Peony, the flower is acyclic: the calyx consists of 5 sepals which gradually pass into the foliage-leaves; the petals are $\mathbf{5}$ or more. $P$. officinalis, corallina, and others are cultivated as decorative plants ; P. Moutan has a woody stem and a tubular disc.

Order 2. Magnoliacex. Perianth cyclic, consisting usually of three alternating trimerous whorls, one of sepals and two of petals, stamens and carpels numerous, arranged spirally: seed containing endosperm. Woody trees or shrubs.

Tribe 1. Magnoliece. Carpels very numerous on an elongated cylindrical receptacle: flowers invested by a spathoid bract; stipules connate. Magnolia grandiflora and other species, and Liriodendron tulipfera, the Tuliptree, from North America, are ornamental trees.

Tribe 2. Illiciece. Carpels in a single whorl on a flat receptacle (Fig. 286). Illicium anisatum, the Star-Anise, is a native of China.

Order 3. Nyмrнжacex. Flowers usually acyclic without any sharp demarcation between the petals and the stamens: pistil either apo- or syn-carpous. Water-plants, generally with broad floating leaves.

Tribe 1. Nymphaina. Carpels connate, forming a polymerous multilocular ovary which may be either superior or inferior. Ovules numerous, placentation superficial: seeds numerous, containing both endosperm and perisperm, sometimes arillate (p. 415). ' The rhizome grows at the bottom of the water and throws up broad, flat, cordate leaves with long petioles which float on the surface. The flower also reaches the surface, borne on a long peduncle. 
Nymphcea alba, the white Water-Lily, has four green sepals, a great number of white petals which, together with the very numerous stamens, are arranged spirally, and a semi-inferior ovary. Nuphar luteum, the yellow Water-Lily, has a calyx consisting usually of five greenish-yellow sepals; the petals, which are smaller and yellow, are usually 13 in number, and form a continuous spiral with the indefinite stamens; the ovary is superior. Victoria regia, a Brazilian species, has peltate leaves of more than a yard in diameter.

Tribe 2. Nelumbiea. Ovaries numerous, distinct, imbedded in the fleshy receptacle: seeds solitary, exalbuminous.

Nelumbium speciosum is the Lotus of Egypt and Asia.

Tribe 3. Cabombece. Flowers cyclic. Calyx and corolla each threeleaved. Stamens 3-18 or $\infty$. Ovaries 3-18, monomerous, each with two or three ovules attached to its walls or to the dorsal suture of the carpel. Seeds containing endosperm and perisperm. The submerged leaves are much divided, the floating leaves peltate. Cabomba occurs in tropical America : Brasenia is widely distributed.

Order 4. Berberidace.e. The calyx, corolla, and androcium, each consist of two di- or tri-merous whorls. Gynæceum monomerous; ovary with numerous marginal ovules. Fruit capsular or baccate. Seed with endosperm.

Berberis vulgaris is the Barberry; its floral formula is $K 3+3, C 3+3$, $A 3+3, G^{\prime}$; the flowers are in pendent racemes, nsually without terminal flowers; when a terminal flower is present it is acyclic and its formula is K5 | C5 | A5 (see Fig. 262, p. 447). Fruit an oval berry. The leaves of the ordinary shoots are transformed into spines (Fig. 29), in the axils of which are dwarf-shoots bearing the foliage-leaves and the inflorescences. Epimedium has a dimerous flower; calyx of 4-5 whorls; petals spurred. In Berberis, sub-genus Mahonia, there are 3 whorls of sepals, and in Nandina many whorls, the inner of which gradually become petaloid. Podophyllum has sometimes 3 whorls of petals (though the number of petals varies in consequence of oligomery), and shows duplication of the stamens of the inner whorl. The anthers usually dehisce by valves, but in Podophyllum and Nandina the dehiscence is longitudinal.

Cohort II. Caryophyllales. Flowers cyclic, generally actinomorphic and pentamerous, sometimes monochlamydeous: calyx often gamosepalous: stamens usually definite: ovary unilocular, with basal placenta: seed with perisperm.

Order 1. Caryophyllaces. Flowers generally pentamerous, with calyx and corolla, though the latter is suppressed in some cases; sepals distinct or coherent: stamens in two whorls of which the inner is often wanting; ovary 2-, 3-, or 5-merons, unilocular; or multilocular at the base, with a central placenta 
or with a single basal orule: fruit usually a capsule: leaves opposite, decussate : stems usually tumid at the nodes.

Tribe 1. Alsinese. The corolla and the inner whorl of stamens are usually present; the calyx is eleutherosepalous; fruit a capsule; usually no stipules.

The British genera are Sagina (Pearl-wort), Arenaria (Sand-wort), Cerastium, Stellaria (Chick-weeds and Stitch-worts), Spergula (Spurrey), Lepigonum, Holosteum, Mœnchia; they are mostly small herbaceous plants with white petals, occurring in meadows, on roadsides, etc., but species of Lepigonum (Spergularia), the Sandwort-Spurrey, and Arenaria (Honckeny/a) peploides, Sea-Purslane, grow on the sea-coast; they are distinguished from each other principally by the number of carpels present, and by the mode of dehiscence of the fruit.

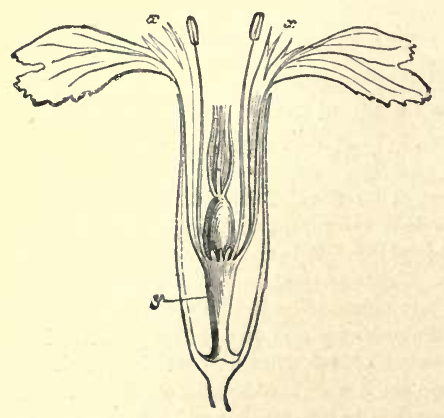

FrG. 34.-Longitudinal section of the flower of Lychnis Flos Jovis: y prolonged axis (anthophore; see p. 444) between the calyx and the corolla; $x$ ligular appendages or corona. (After Sachs.)
Tribe 2. Silenece. The corolla and the inner whorl of stamens are always present: the calyx is gamosepalous; stamens 10 , filaments connate at base: the fruit is a capsule (in Cucubalus a berry): the leares have no stipules; the floral axis often elongated between the calyx and the corolla (Fig. $344 y$ ): the petals (as in Lychnis and Saponaria) often have ligular appendages (Fig. $344 x$ : see p. 459).

The species of Dianthus, the Pink, which commonly occur wild are $D$. deltoides, D. cersius and D. Armeria; D. Caryophyllus, the Carnation, and $D$. chinensis, are well-known garden flowers; there are two styles, and the calyx is surrounded at its base by bracteoles. The genus Saponaria has two styles but no bracteoles; $S$. officinalis, the Soap-wort, occurs on the banks of rivers. The genus Silene (Catchfly) has three styles; $S$. inflata, nutans, and others, are common in meadows. The genus Lychnis (Campion) has five styles; the species alla (vespertina) and diurna are diøcious; L. Githago, the Corn-cockle, is common in fields.

Tribe 3. Polycarpece. Leaves with scarious stipules: calyx eleutherosepalous; the corolla is present, but the inner whorl of stamens is wanting: style 3-fid. This group includes the British genus Polycarpon (Allseed) and others.

Tribe 4. Paronychiea. Sepals distinct or coherent: the corolla and the 
inner whorl of stamens are usually wanting: style usually bifid: ovary unilocular, with 1-4 ovules: fruit generally indehiscent.

The British genera are Scleranthus (Knawel), Herniaria, Corrigiola (Strap-wort), and Illecebrum: they are small inconspicuous herbs, with scarious stipules (except Scleranthus).

The Paronychieæ have also been placed, as a distinct natural order, Illecerraces, among the Monochlamydeæ. There is no doubt that they have affinities with the Chenopodiales, and that they thus connect that cohort with the Caryophyllaceæ.

Cohort III. Parietales. Flowers cyclic, with calyx and corolla: sepals free: stamens definite or indefinite: gynæceum of two or more carpels : ovary unilocular, sometimes many-chambered, with parietal placentation: seed with or without endosperm.

Order 1. Papaveraces. Flowers usually actinomorphic, $K 2$, $C^{2}+2, A x, G^{(2)}$ or $(\propto)$, or rarely with trimerous whorls: calyx sepaloid, corolla petaloid: the numerous whorls of stamens alternate: ovary of two lateral carpels or of more (Fig. 345 a), twoor more-chambered : ovules numerous, attached to the more or less infolded edges of the carpels: endosperm abundant, embryo small. The sepals commonly fall off before the flower ex-
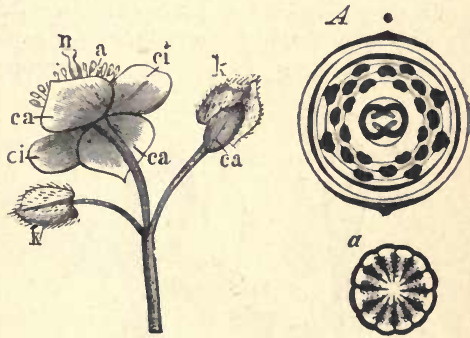

Fig. 315.-Flower of Chelidonium majus (nat. size) : $k$ calyx ; ca onter, ci inner petals; a stamens ; $n$ stigma. A Diagram of the flower of Chelidonium. a Manychambered ovary of Papaver. pands (Fig. 345̌). Plants with abundant milky latex.

Papaver, the Poppy, has a many-chambered ovary; the fruit is a porous capsule (Fig. $288 D$ ): P. somniferum is cultivated for the sake of the oil contained in the seeds, and for the latex obtained from its capsules, which when inspissated, constitutes opium; several species are British, such as. P. Rhreas, the Field Poppy; P. Argemone, the Pale or Long Pricklyheaded Poppy ; P. hybridum, the Round Prickly-headed Poppy; P. dubium, the Long Smooth-headed Poppy; and Meconopsis cambrica, the Yellow Welsh Poppy. Chelidonium majus, the Celandine, has two carpels, a siliquose fruit, and orange-coloured milky latex. Glaucium, the Horned Poppy, has a siliquose fruit which is generally spuriously bilocular

Order 2. Fumariacex. Flowers isobilaterally symmetrical, 
or zygomorphic with lateral symmetry : floral formula $K 2, C 2+2$, $A 2+2, G^{(2)}$. The three whorls of the perianth alternate; one of the outer petals (rarely both) is usually furnished with a spur : in most genera there are three stamens on each side, a central one, with a perfect anther (the stamen of the outer whorl, Fig. $346 \mathrm{~B} \mathrm{a}$ ), and two lateral stamens, each with only half an anther (apparently the halves of the stamens of the inner whorl; Fig. $\left.346 B a_{1} a_{l}\right)$. The fruit is siliquose and many-seeded, or one-seeded and indehiscent. Herbaceous plants without milky latex, sometimes climbing by means of their petioles which act as tendrils (Adlumia, Fumaria). Seeds containing endosperm.

The flowers of Adlumia, Dicentra, and Hypecoum are isobilaterally symmetrical. Dicentra spectabilis is a favourite ornamental plant; both the outer petals are spurred, the two inner petals are hollowed at their apices, so that they completely enclose the anthers. In Hypecoum the petals are not spurred, and there are four stamens, two lateral forming the outer whorl, and two antero-posterior forming the inner whorl: fruit usually indehiscent. In Corydalis and Fumaria only one of the outer
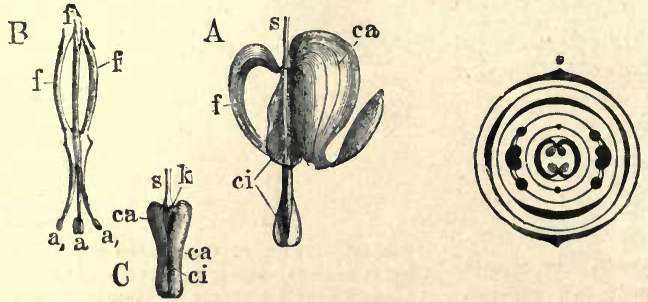

Frg. $346-A$ Flower of Dicentra spectabilis: one of the outer petals is remorea: $s$ pedicul; $c a$ the outer, $c i$ the inner petals; $f$ stamens. B The three stamens of one side, seen from within: $f$ filaments; $a$ the middle complete antber; $a, a$, the lateral half-anthers. $C$ Flowerbud, with the sepals, which soon fall off, still adhering $(k)$; (nat. size). Diagram of Fumitory.

petals is spurred, and consequently the flower is irregular and laterally zygomorphic (p. 455). In Corydalis the fruit is a two-valved capsule with numerous parietal seeds: some species, e.g. C. cava and solida, have a tuberous rootstock; others, as C. lutea and aurea, have rhizomes. Fumaria officinalis, and others (Fumitories) are common in fields; the ovaries contain but few ovules, and of these only one ripens to a seed; fruit globose, indehiscent.

Order 3. CRUCIFER F. Flowers regular, isobilateral : floral formula $K 2+2, C \times 4, A 2+2^{2}, G^{(2)}$. The four petals form a whorl, alter- 
nating with the four sepals as if the latter formed one whorl; there are, however, three perianth-whorls, as in the two preceding families; but whereas in them only the outermost whorl is sepaloid, in this family the two outer whorls are sepaloid, and the innermost, which alone is petaloid, is a whorl consisting of four instead of two members. The two outer stamens are lateral, as in those families; the two inner ones, which in most Fumariaceæ are apparently divided, are here duplicate, having longer filaments (Fig. $348 B \quad b \quad$ ) than the outer

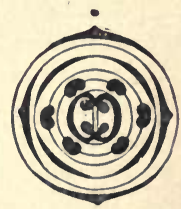

Fia. 317.-Diagram of the flower of Cruciferæ. ones $(a)$; hence they are tetradynamous. There are usually four, sometimes more, hectaries at the base of the stamens (Fig. $348 \mathrm{Bd}$ ). The ovary consists of two carpels with the ovules in two longitudinal rows on the connate margins of the carpels; these two parietal placentæ are connected by a membranous growth which, as it is not formed of the margins of the carpels, must be regarded
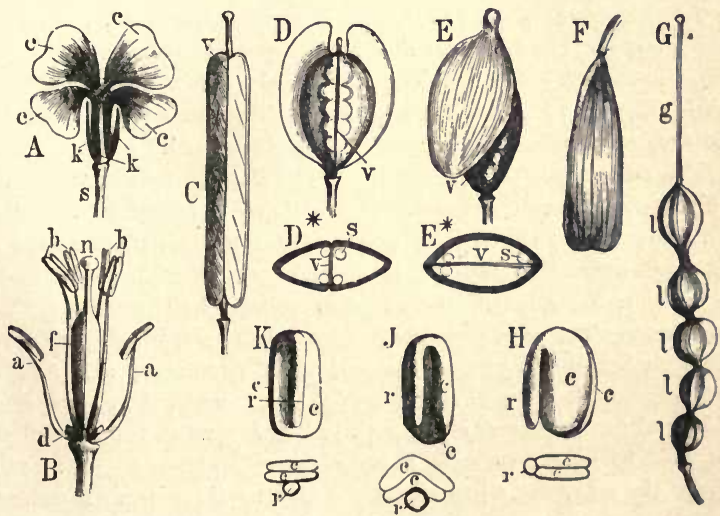

$F_{\text {I }}$ 349.-Flowers, fruits, and embryos of various Cruciferæ. A Flower of Brassica (nat. size; 8 pedicel; $k k$ calyx; $c$ corolla. $B$ The same after removal of the perianth (much mag.): $a$ a the two outer short stamens; $b$ the four longer inner ones; $f$ the ovary; $u$ the stigma ; $d$ gland. C Siliqua of Brassica ; $v$ dissepiment. D Angustiseptal siliculs of Thlasp:. $E$ Latiseptal silicula of Draba. $D^{*}$ and $E^{*}$ Diagrammatic transverse section of the preced. ing: $v$ dissepiment; s seed. $F$ indehiscent silicula of Isatis. G Jointed siliqua of Raphanus Raphanistrum: $g$ style; $l l l$ separate segments. $H-K$ Diagrams of differentls-folded embryos, with transvere sections: $r$ radicles; $c$ c cotyledons. 
as a spurious dissepiment (Figs. $348 D^{*} E^{*} v, 288 C w$ ). When the fruit opens, the pericarp splits into two valves corresponding to the carpels, leaving their margins, as a frame or replum, bearing the placentæ with the spurious dissepiment attached: the seeds remain attached to them for some time (Fig. $288 C$, p. 474).

The flowers are in racemes in which the bracts are suppressed; when the lower pedicels are longer than the upper ones, the raceme becomes a corymb, and then the lower flowers are usually zygomorphic, the petals turned towards the periphery being larger than those directed towards the axis of the inflorescence, as in Iberis.

The form of the fruit is of importance in the subdivision of this order. In some genera it is much longer than it is broad, when it is termed a siliqua, (Figs. $288 C, 348 C$ ); in others, it is not much longer, or about as long as it is broad, when it is॰termed a silicula (Fig. $348 D$ and $E$ ). The latter is commonly somewhat compressed in one direction; either parallel to the dissepiment, that is to say laterally (Fig. $348 E$ and $E^{*}$ ), so that the dissepiment lies in the direction of the greatest diameter, when it is latiseptal; or perpendicularly to the dissepiment, that is in the median plane, so that the dissepiment lies in the narrowest diameter, when it is angustiseptal ( $D$ and $\left.D^{*}\right)$. Fruits with only one or a few seeds, and which are indehiscent, are confined to only a few genera, such as Isatis (Fig. $348 \mathrm{~F}^{\prime}$ ). So likewise is the jointed siliqua, which has transverse dissepiments between the seeds; when they are ripe it divides transversely into segments, as in Raphanus (Fig. $348 G$ ).

The seed is exalbuminous. The embryo is folded in the seed in various ways; the radicle may lie in the same plane as one of flat cotyledons (Fig. $348 \mathrm{~K}$ ), when the cotyledons are said to be incumbent, Notorhizea (the diagram being $\bigcirc \|$ ); or the radicle may occupy the same position, the cotyledons being folded (Fig. $348 J$ ), when the cotyledons are said to be incumbent and folded, Orthoplocece (diagram of section $\bigcirc \gg$ ); or, thirdly, the radicle may be lateral to the two cotyledons (Fig. $348 H$ ), when the cotyledons are said to be accumbent, Pleurorhizea (diagram $\bigcirc=$ ): more rarely the cotyledons are spirally rolled so that in a transverse section they are cut through twice, Spirolobece (diagram $\bigcirc\|\|$ ); or, finally, they may be doubly folded, and be seen four times in a section, Diplocolobere (diagram $\bigcirc\|\|\|\|$ ). The seeds contain much fatty oil.

Sub-odder 1. Sruquos $x$. Fruit a siliqua, much longer than it is broad. 
Tribe 1. Arabidex. $\bigcirc=$. Cheiranthus Cheiri, the Wall-flower, and Matthiola annua and incana, the Stocks, are cultivated as garden-plants. Nasturtium officinale is the Water-cress. Barbarea vulgaris is the Yellow Rocket. Cardamine (incl. Dentaria) also belongs to this tribe.

Tribe 2. Sisymbriea. O\|. Sisymbrium officinale, the Hedge-Mustard, is common on rubbish heaps; and Erysimum, the Treacle-Mustard, on walls, etc. Hesperis is the Dame's Violet.

Tribe 3. Brassicea. $\bigcirc \gg$ The species and varieties of Brassica are much cultivated. Brassica oleracea is the Cabbage, with the following varieties; acephala, Scotch kale, Cow-cabbage or Borecole; bullata, the Savoy-cabbage; capitata, the red and white Cabbage; caulorapa, with the stem swollen at base, is the Kohl-rabi; Botrytis, with connate fleshy peduncles and abortive flowers, is the Broccoli (asparagoides) and the Cauliflower (cauliflora); gemnifera, with numerous lateral leaf-buds, known as Brussels-sprouts. Brassica campestris is the wild Navew; it includes the following sub-species: Rapa, the wild Turnip, with bright green hispid leaves and flat corymbs of flowers, among the cultivated varieties of which is the var. depressa, the Turnip: Napus, the wild Rape, with glabrous glaucous leaves and long racemes of flowers, several varieties of which are cultivated for their oily seeds, and one (var. esculenta, the Teltow Turnip) for its fleshy root: Napobrassica, the Turnip-cabbage, including Rutabaga, the Swedish Turnip. B. campestris oleifera is the true Colza or Coleseed, from the seeds of which colza-oil is obtained. Brassica (Sinapis) nigra and alba are the black and white Mustard. Brassica Sinapis (Sinapis arvensis) is the Charlock or Corn-Mustart. To this tribe belongs also the genus Diplotaxis.

Sub-order 2. Siliculos 2 . Fruit a silicula.

A. Latisepto. The dessepiment is in the longest diameter of the silicula.

Tribe 4. Alyssinece. $\mathrm{O}=$. Cochlearia officinal is is the Scurvy-grass; $C$. Armoracia, the Horse-radish, has a thickened root. Alyssum calycinum and Draba (Erophila) verna, the Whitlow-grass (Fig. $348 \mathrm{E}$ ), are common weeds : Lunaria biennis is Honesty.

Tribe 5. Canelinea. O\|. To this tribe belong Camelina (Gold-ofpleasure), and Subularia, the Awl-wort, an aquatic plant.

B. Angustiseptoe. The dissepiment is in the shortest diameter of the silicula.

Tribe 6. Lepidinece. O\|. Capsella Bursa Pastoris, the Shepherd's Purse, is common, as also various species of Senebiera and Lepidium (Cresses).

Tribe 7. Thlaspidea. $\bigcirc=$. Various species of Thlaspi, the PennyCress, are common. To this tribe belong also the British genera Iberis (Candytuft), Teesdalia, and Hutchinsia.

Sub-order 3. Nucumentacex. Silicula indehiscent, few-seeded.

Tribe 8. Isatidea. Isatis tinctoria, the Woad, has compressed, pendulous, unilocular, one-seeded fruits (Fig. $348 F^{\prime}$ ): the leaves yield a blue dye.

Sub-order 4. Lomentaces. Fruit a siliqua or silicula, constricted into one-seeded segments (lomentaceous) (Fig. $348 \mathrm{G}$ ). 
Tribe 9. Cakilinea. Silicula two-jointed. This tribe contains the genera Cakile, the Sea-Rocket, and Crambe, the Sea-Kale.

Tribe 10. Raphanece. Silicula more or less moniliform. Raphanus sativus is the Radish; R. Raphanistrum, the wild Radish or White Charlock, is a common weed.

Order 4. Cistace.e. Flowers usually actinomorphic and pentamerous: the two external of the five sepals are generally smaller, and sometimes they are absent: stamens numerous, in consequence of multiplication: carpels 3-10, forming a uni- or multilocular ovary; ovules or thotropous; seed with endosperm. Trees or shrubs with generally opposite stipulate leaves.

Cistus has $\check{-}-10$ carpels forming a chambered or completely mutilocular ovary. Cistus ladaniferus, creticus, and other species, grow in the south of Europe; a balsam is derived from them. Helianthemum has a unilocular trimerous ovary: Helian-

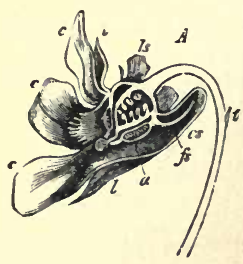

Fig. 349-Viola trucolor. A Longitudinal section of fiower: $v$ bracteule on the peduncle; $l$ sepals; is ap. pendage; $c$ petals; cs spur of the lower petals; $f s$ glandulur appendage of the lower stamens; a anthers (after Sachs). $B$ Ripe fruit: $k$ calsx. $C$ After lehiscence; $p$ parietal placentr; $x$ reeds. (Mag.) themum vulgare, the Rock Rose, is an under-shrub which grows wild on dry soils.

Order 5. VIOLACEx. Floral formula $K \tilde{5}, C \tilde{5}$, $A 5, G^{(3)}$ : flowers always borne laterally: ovules anatropous : fruit a lcculicidal capsule (Fig. 349 C): seed with endosperm. The indigenous species have irregular dorsiventral flowers; the anterior inferior petal is prolonged into a hollow spur (Fig. $349 \mathrm{~A} \mathrm{cs}$ ) in which the nectar secreted by the spur-like appendages of the two lower stamens collects (Fig. $349 \mathrm{Afs}$ ). The sepals are produced at the base (Fig. 349 A $l s$ ).

Viola is the Violet, Pansy, or Heart's-ease :-many species, as V.odorata, the Sweet Violet, have only an underground stem which bears cataphyllary leaves, and which throws up petiolate foliage-leaves, and bracteolate peduncles each bearing a single flower: V. odorata has runners, but lirta and collina have none:-in others, as $V$. canina, the Dog-Violet, the main stem is above ground and bears the foliage-leaves:-in V. mirabilis these two forms are so combined that, in the spring, flowers are developed from the rhizome which have large blue petals but are always sterile; it is not 
till later that inconspicuous (cleistogamous, p. 410) flowers with minute petals appear on the leafy stem, and these only are fertile:-in $V$.tricolor and its allies the stipules are leafy and pinatifid.

Cohort IV. Guttiferales. Flowers usually cyclic, generally actinomorphic, and pentamerous: sepals usually free, with imbricate æstivation: stamens usually indefinite: gynæceum syncarpous, ovary uni- or multi-locular: seed exalbuminous.

Order 1. HYPericaces. Formula usually $K 5, C 5, A 0+5 \infty$. $G^{(5)}$; or $A 0+3 \infty, G^{(3)}$. Sepals sometimes united at the base : stamens usually indefinite and polyadelphous; when in five bundles, the bundles are superposed on the petals; this position of the stamens is generally attributed to the suppression of an outer whorl of stamens which is indicated by staminodes in species of all the genera : ovary uni- or multi-locular, or many-chambered; capsule septicidal; ovules numerous, anatropous; placentæ parietal or axile. Herbs or under-shrubs with decussate entire leaves,

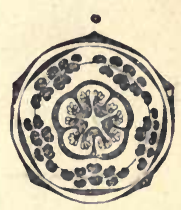

Fig. 350,-Dingram of Hypericum calycinum. which are dotted over with translucent oil-glands ; exstipulate.

The following are examples of the different relative numbers of staminal bundles and of carpels:-

Staminal bundles 5, carpels 5: Hypericum calycinum.

Staminal bundles 3, carpels 3: H. Humifusum, hirsutum, nontanum, perforatum, undulatum, barbatum.

Staminal bundles 5, carpels 3: H. Androsomum, hircinum, elatum.

Staminal bundles 3, carpels 5: H. peplidifolium.

All these species, except the last (St. John's Worts, or Tutsans), nceur wild in Britain.

Cohort V. Malvales. Flowers cyclic, generally pentamerous and actinomorphic: calyx often gamosepalous, with valvate restiration: corolla with usually contorted æstivation: stamens typically in two whorls, frequently obdiplostemonous (p. 452), sometimes branched, and often connate: carpels usually five and then antipetalous, often forming a multilocular ovary: seed usually with endosperm.

Order 1. Trliaces. Sepals usually free: stamens 10 or indefinite, sometimes polyadelphous; in the indigenous species the staminal whorl opposite to the sepals is suppressed, and there are 5 antipetalous staminal bundles; anthers 4 -locular, opening by pores or valves: gynæceum usually completely syncarpous; style 1 ; 
ovary usually 5-locular, each loculus containing two ovules; but the fruit is generally only one-seeded. Mostly trees or shrubs : leaves alternate, stipulate.

The only indigenous genus is Tilia, the Lime-tree. It has oblique leaves with deciduous stipules; the annual shoots have not a terminal bud. The inflorescence is cymose, few-flowered : the peduncle is adnate to the leafy bracteole; this is brought about in the following manner: in the axil of the leaves there is usually a bud, together with an inflorescence (Fig. 351):

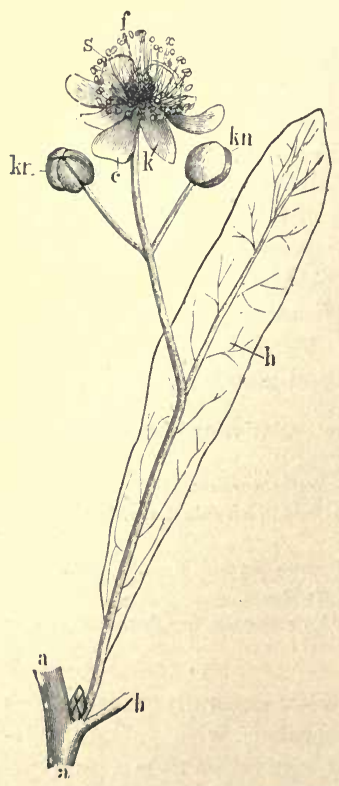

FrG. 351.-Inflorescence of the Lime : $a$ branch; $b$ petiole subtending an inflorescence and $\mathbf{a}$ bnd. Attached to the peduncle is the large bracteole $(h): k$ $k n$ flower-bud (nat. size). calyx ; c corolla; 8 stamens; fovary;

the large bracteole $(h)$ and a bud-scale, which is opposite to it, are the first two leaves of the axillary shoot which is terminated by the infloresence, the peduncle of which is adnate to the large bracteole for some distance: the bud is a winter-bud developed in the axil of the above-mentioned bud-scale. The inflorescence itself terminates in a flower; other flowers are borne in the axil of two upper bracteoles which soon fall off, and other flowers again may be developed in the axils of their bracteoles, and so on. T. platypliyllos, the large-leafed Lime, has a few-flowered inflorescence, and leaves which are bright green and downy on the under surface: $T$. cordata has an inflorescence which consists of a large number of flowers, and has small leaves which are bluish-green and pubescent with red hairs on the under surface. T. vulgaris is the common Lime. Corchorus, in the East Indies, yields Jute, which consists of the bast-fibres.

Order 2. Malvacee. Calyx usually gamosepalous, frequently invested by an epicalyx (p. 443); the corolla is adnate at the base to the androecium: the typically obdiplostemonous androecium is a long tube (Fig. $352 \mathrm{~A}$ ) consisting of five monadelphous usually branched stamens which are opposite to the petals, each branch bearing a bilocular anther; there is sometimes an inner series of staminodes opposite to the sepals: carpels $5-\infty$; styles many, connate; the gynæceum is sometimes 
almost apocarpous (Malopeæ); usually syncarpous with a maltilocular ovary, splitting into cocci (Fig. $352 C D$ ), with usually one ovule in each coccus (p. 473), or a loculicidal capsule (Hibisceæ). Under-shrubs or herbs: leaves stipulate and generally palmately veined.

Malva, the Mallow, has an epicalyx of three bracteoles, Hibiscus has one of many bracteoles, and Althæa has one of 6-9 brocteoles: Althera rosea is the Hollyhock, and A. officinalis is the Marsh-mallow: several species of Malva are indigenous, M. sylvestris, rotundifolia, and moschata : Gossy-

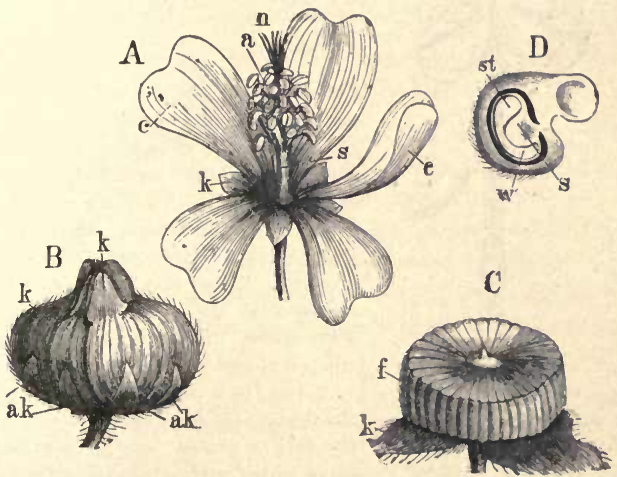

FIG. 352. -A Flower of Malva Alcea (nat. size) : $k$ cslyx; c corolla; 8 connate stamens, with the anthers (a); n stigmata. B Fruit of Althae rosea enclosed in (k) the calyx : ak epicalyx. C The same after the removal of the calyx. D A single coccns of the same in longitudinal section: s seed; w radicle; st cotyledon of the embryo (mag.).

pium herbaceum (with the vars. religiosum and hirsutum) and G. arboreum in Egypt and the East Indies, and G. barbadense (with var. peruvianum) in America, yield Cotton, which eonsists of the long hairs on the testa of the seed.

\section{SERIES II.-DISCIFLORA.}

Flowers typically eucyelic and generally pentamerous, often obdiplostemonous : sepals free and coherent : petals in a single whorl : stamens usually definite, and hypogynous: a dise is usually present: gynæceum generally syncarpous.

Cohort I. Geraniales. Flowers usually pentamerous throughout ; formula $K 5, C 5 \mid A 5+5, G^{(5)}$; generally obdiplostemonous; the carpels are opposite to the petals : ovary usually 5 -locular, with 
1 or 2 suspended ovules; the micropyle is directed inwards: disc various or wanting.

Order 1. Geraniaces. Disc usually represented by a gland at the base of and outside each of the antisepalous stamens: flowers usually actinomorphic: stamens connate at the base: the carpels are prolonged into a carpophore (Fig. $353 \mathrm{~A}$ a); two ovules in each

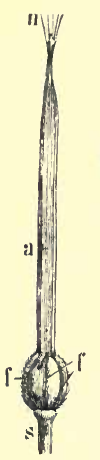

A

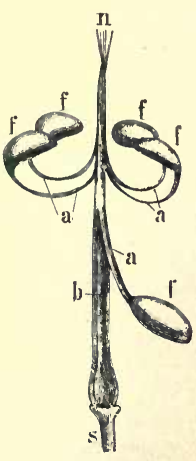

B
Frg. 353.-Fruit of Geranium. A Before, $B$ after splitting into cocci; $s$ pedicel; $f$ losuli of the ovary : $a$ iu $B$ the awn; $n$ stigma; $a$ and $b$ carpophore (mag.).

loculus; the fruit is septicidal from below upwards, the awns of the separating carpels (cocci, see p. 473) rolling up (Fig. $353 \mathrm{~B}$ ). Seed devoid of endosperm. Herbs; leaves simple, stipulate.

Geranium has 10 stamens: in most species the seed is expelled on the rolling up of the awn: Geranium pratense, sylvaticum, sanguineum, columbinum, and other species, the Crane's.bills, are wild in England; G. Robertianum, Herb-Robert, is universally distributed. Erodium, the Stork's-bill, has the 5 stamens which are opposite to the petals transformed into staminodes; E. cicutarium is common in waste places. Pelargonium, in many varieties, is a well-known garden-plant; the flowers are irregular and dorsiventral; the dise is absent, but the posterior sepal is provided with a glandular spur which adheres to the pedicel. The cocci of Erodium and Pelargonium are indehiscent, and are forced into the ground by the movement of the hygroscopic awn.

Order 2. Linaces. Disc generally a whorl of 10 small extrastaminal glands : formula $K 5, C 5,(\mid A+5+5), G^{(5)}$ : flowers actinomorphic, rarely all the whorls are tetramerous: stamens monadelphous at the base; the whorl of stamens opposite to the petals is replaced by staminodes. each loculus of the ovary contains two ovules, and is often divided into two by a more or less complete false dissepiment : seed usually contains ezdosperm : capsule septicidal. Herbs or shrubs; leaves simple, entire, with or without stipules.

Linum usitatissimum is the Flax: the strong bast-fibres are used in weaving linen; the seeds contain oil; the walls of the outer cells of the testa are mucilaginous. There are several British species of Linum. Radiola, the other British genus, has tetramerous flowers. 
Order 3. Oxalidaces. Disc present as small glands at the base of the antipetalous stamens, or of all of them : flowers actinomorphic; formula $K \tilde{5}, C \tilde{5},(\mid A 5+5), G^{(5)}$; the antipetalous stamens are sometimes staminodial; those which are opposite to the sepals are the longest: ovules numerous; fruit a capsule, or more rarely a berry; seed containing endosperm. Herbs, with compound (ternate), generally exstipulate leaves.

Oxalis Acetosella, the Wood-Sorrel, is frequent in woods; it contains much potassium oxalate. The tuberous roots or underground stems of some American species, as $O$. esculenta, crenata, and Deppei, contain much mucilage, and are used as food. Some species (e.g. O. gracilis) show trimorphic heterostylism (p. 411): others (e.g. O. Acetosella), have cleistogamous flowers (p. 410). The leaves of Oxalis and Averrhoa show sleepmovements : those of Biophytum are sensitive to touch.

Order 4. Balsaminacex. Disc 0: flowers irregular, dorsiventral; formula $K 5, C 5, \mid A 0+5, G^{(5)}$ : the posterior sepal is spurred, and the two anterior are small or absent: the anterior petal is large: ovary 5-locular; ovules numerous; the fruit is loculicidally septifragal, the valves separate elastically and roll upwards, so that the seeds are projected to some distance; seed without endosperm. Herbs, with simple exstipulate leaves.

Impatiens Noli-me-tangere, the yellow Wild Balsam, occurs in damp and shady spots; the ripe fruit flies open with violence at a touch. Impatiens Balsamina, an Indian species, is cultivated.

Order 5. Rutaces. Disc usually annular: flowers usually actinomorphic: gynæceum sometimes partially apocarpous, but the styles are usually connate: seed with or without endosperm. There are numerous oil-glands on the leaves and stems.

Sub-order. Rutex. The placentæ project into the loculi of the ovary; each bears 3 or more ovules: fruit a loculicidal capsule: seed with endosperm. Ruta graveolens, the Rue, has pentamerous terminal flowers, and tetramerous lateral flowers. Dictamnus Fraxinella has an irregular dorsiventral flower.

Sub-order. Arrantiex. Gynæceum syncarpous : calyx gamosepalous: fruit a berry (p. 476): seed without endosperm.

The genus Citrus has an indefinite number of bundles of connate stamens (polyadelphous) (Fig. $355 \mathrm{~A}$ ), all belonging apparently to the autise-

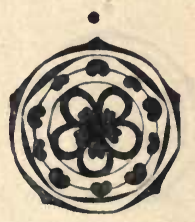

FiG. 351.-Diagram of the flower of Dictamnus. palous inner whorl: the carpels are usually more numerous than the petals, and during ripening they become filled with a succulent tissue de- 
derived from their walls; the various parts of the flower and the fruit (p. 97) contain much ethereal oil : the leaf, which is typically pinnate, is reduced to its terminal leaflet which is articulated to the winged petiole (Fig. $23 G$ ); the leaf is sometimes spinous.
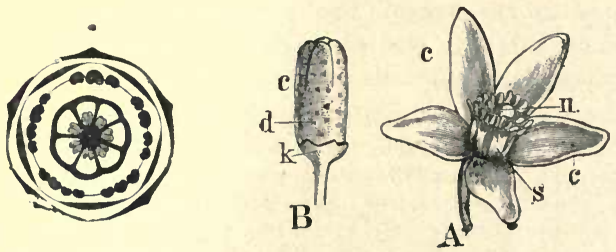

FIG. 355.-Filower and floral diagrnm of Citrus, $A$ Open flower ; $c$ corolla ; 8 the partially connate stamens; $n$ the stigma. B Bud; $k$ calyx; $c$ corolla; $d$ oil-glands.

(itrus nedica is the Citron; C. medica var. Limonum, is the Lemon; $C$. medica var. Limetta, is the Lime; Citrus Aurantium var. Bigaradia (or C. vulgaris) is the Bitter or Seville Orange, and C. Aurantium sinense is the Sweet Orange; Citsus nobilis is the Mandarin Orange; and Citrus decumana is the Shaddock: all originally derived from tropical Asia.

Cohort II. Sapindales. Flowers typically pentamerous and obdiplostemonous but with reduction in the androecium, actinomorphic or zygomorphic, sometimes unisexual: gynæoeum oligomerous, usually syncarpous. Mostly trees.

Order 1. SAPINDACEE. Flowers usually irregular, obliquely zygomorphic or asymmetric, in that the two petals of one side are larger and of somewhat different form to the three others; of these, one, which lies in the plane of symmetry, is sometimes wanting

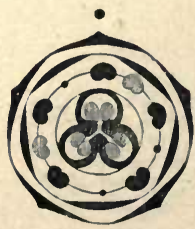

FrG. 350.-Floral disgram of Asculus: but the missing stamens should be represented ns antisepalous.

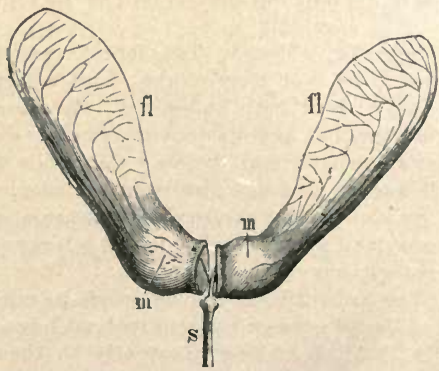

Fre. 357.-Fruit of $A$. platanoides, dividing into two mericarps $m$; s pedicel ; $f$ wings (nat. size). 
two or three of the antisepalous stamens are usually suppressed, so that the number is eight or seven; they are inserted within the disc : the ovary is trilocular; ovules two in each loculus: seed without endosperm.

Esculus has opposite, palmately compound, exstipulate leaves; the flowers are in terminal scorpioid racemes; the fruit has a loculicidal deliscence : $E$. Hippocastanum is the Horse-Chestnut, derived from Asia; $\mathbb{E}$. carnea, E. Pavia, and other species are frequently cultivated. A great number of genera and species grow in warm climates; they have generally scattered pinnate leaves: often climbers with branch-tendrils. The fleshy fruit of Sapindus Saponaria makes a lather with water like soap.

Order 2. ACERACE.E. Flowers regular: stamens commonly eight, in consequence of the suppression of the two median.ones, variously inserted : disc annular, rarely absent, extrastaminal or intrastaminal : ovary bilocular; ovules two in each loculus; when ripe the fruit splits into two one-seeded winged mericarps (samaras, p. 473, Fig. 357): leaves opposite, palmately lobed, sometimes compound, exstipulate: flowers in terminal racemes, sometimes in corymbs with an apical flower: seed without endosperm.

The principal species of Acer, the Maple, are A. Pseudoplatanus, the Sycamore, having leaves with crenate margins, flowers in elongated pendulous racemes, blooming after the unfolding of the leaves, and parallelwinged fruits; $A$. platanoides, having leaves with serrate margins, flowers in short erect racemes blooming before the unfolding of the leaves, and fruits with widely diverging wings (even more than in Fig. 357); A. campestre, the common Maple, which is sometimes shrubby, with a trilobate leaf, short erect racemes of flowers which bloom after the unfolding of the leaves, and fruits with wings which are diametrically opposite. Some North American species are often cultivated, such as A. rubrum, with five stamens opposite to the sepals, and a rudimentary disc; $A$. dasycarpum, with the same number and position of the stamens, without any corolla, and having diocious flowers; $A$. Negundo, with compound 3-5 foliolate leaves, and diøecious flowers like those of the preceding species. Sugar is prepared from the sap of A. saccharinum and dasycarpum especially.

Order 3. Polygalacex. Flowers irregular, dorsiventral; the two lateral sepals conspicuously large and known as "wings" (Fig. $\left.358 A k^{\prime}\right)$ : petals three, the two lateral being absent; the anterior petal is very large and carinate : stamens usually eight, forming a tube open posteriorly, to which the corolla, or at least the anterior petal, is adnate (Fig. $358 \mathrm{~B}$ ): disc rudimentary: carpels two, median, forming a bilocular ovary, each loculus containing a single suspended ovule: fruit usually a capsule. The flower somewhat

M.B. 
resembles that of the Papilioneæ, but it must be borne in mind that here the two "alæ" or wings belong to the calyx.
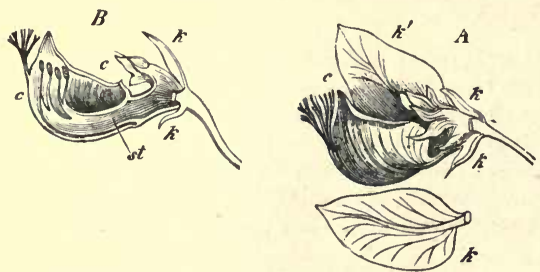

Frg. 358.-Flower of Polygala grandiflord. A Seen from outside after the removal of the wing-sepal $k$. $B$ Longitudinal section: $k$ calyx : $k^{\prime}$ wing; $c$ corolla ; 8 tube of stamens. (After Sacbs.)

The flower of the Polygalaceæ resembles that of the Aceraceæ in the suppression of two stamens in the plane of the two carpels.

Polygala vulgaris, amara, and others, the Milkworts, are herbs, woody at the base, occurring in woods and meadows.

Cohort III. Celastrales. Flowers regular, frequently actinomorphic, 4-5-merous; only one whorl of stamens, which either alternates with or is opposite to the petals, is usually present: disc usually within, sometimes external to, the androcium: ovules usually erect: the seed nearly always contains endosperm. Trees or shrubs.

Order 1. Celastrace E. Formula, $K \mathrm{n}, C \mathrm{n}, A \mathrm{n}, G(\mathrm{n})$ or less, $\mathrm{n}=4$ or 5 : sepals imbricate: stamens and carpels inserted on a flattened disc: stamens alternate with the petals: usually two

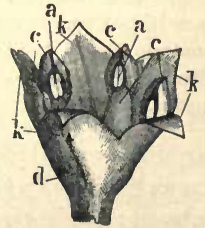

Fra.359.-Flower of Rhamnus Frangula (mag.): $k$ sepals connate at the hase into a tube (d); $c$ hood-shaped petals enclosing the stamens (a). ovules in each loculus of the ovary: leaves scattered, entire, stipulate.

In the genus Euonymus, the Spindle-tree, the loculicidal capsule contains seeds invested by an orange-coloured arillode (p. 416); E. europoea occurs both cultivated and wild.

Order 2. Rhamnacex. Formula, $K \mathrm{n}$, $C \mathrm{n}, \mid A \mathrm{n}, G^{(2-4)} ; \mathrm{n}=4$ or 5 : calyx usually gamosepalous, valvate; petals usually small and often hood-shaped (Fig. 359 c), enclosing the stamens which are opposite to them: flowers sometimes diclinous: usually a single ovule in each loculus of the ovary which is in- 
vested by a dise: leaves usually scattered, entire, stipulate : fruit a drupe or a capsule.

Rhamnus cathartica, the Buckthorn, has opposite leaves and thorny twigs: the berries of $R$. infectoria, in Southern Europe, yield a green or yellow dye : $R$. Frangula has scattered leaves; its wood produces a particularly light charcoal.

Order 3. Ampelidace E. Formula same as in Rhamnaceæ: sepals small; the corolla is often thrown off before it opens (Fig. $360 \mathrm{~A} \mathrm{c})$ : a glandular disc between the androcium and the gynæceum : ovules one or two in each loculus : fruit baccate. Climbing plants, with stem-tendrils; leaves palmate, exstipulate or stipulate.

Vitis vinifera, the Grape-Vine, probably derived from the East, is cultivated in endless varieties; other species, such as V.vulpina and Labrusca, as also Ampelopsis hederacea, the Virginian Creeper, are also frequently cultivated. The tendrils of the Vine (Fig. $15 \mathrm{~A}$ ) are branches bearing sealy leaves in the axils of which other branches arise: their peculiar position opposite to the foliageleaves may be explained as follows: the ordinary shoots are sympodia, and each tendril is the terminal segment of a member of the sympodium; the following member is a
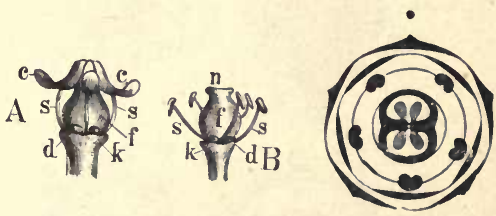

FIG. 360.-Flower of Vitis vinifera, and diagram. A $\Delta t$ the moment of opening. $B$ Open; $\mathbf{k}$ calyx; c corolla; $d$ glands ; 8 stamens; $f$ ovary; $n$ stigma (slightly mag.).

shoot springing from the axil of the foliage-leaf which is opposite to the tendril. Every third leaf has no tendril opposite to it, that is to say, the members of the sympodium alternately bear nne or two leaves. The inflorescences occupy the same positions as the tendrils. Each leaf has also a bud in its axil, which either remains undeveloped or gives rise to a dwarf-shoot: from the axil of the cataphyllary leaf of the dwarf-shoot an ordinary shoot is developed. In some species of Ampelopsis (e.g. A. Veitchii and Roylei) the tendrils attach themselves to flat surfaces by means of discoid suckers developed at their tips.

\section{SERIES III. CALYCIFLORE.}

Flowers epigynous or perigynous : calyx usually gamosepalous: stamens definite or indefinite: gynæceum syncarpous or apocarpous.

Cohort. I. Umbellales. Flowers regular, sometimes actinomorphic, epigynous, with generally a single whorl of stamens 
opposite to the sepals: calyx inconspicuous: ovary bilocular, with one ovule in each loculus: a disc between the stamens and the styles: inflorescence usually umbellate: seed containing endosperm: leaves exstipulate.

Order 1. UMBelLifere. Flowers generally regular, but with oligomery in the gynæceum; formula, $K \tilde{5}, C \tilde{5}, A \tilde{5}, G_{(\overline{2})}$ : the calyx is generally very small, often hardly visible, though sometimes well developed (e.g. Eryngium, Astrantia): the corolla consists of five rather small white or yellow petals; occasionally the outermost petals of the flowers at the circumference of the umbel are larger than the others, and the umbel is then termed radiant: stamens five; ovary inferior, bilocular: the base of
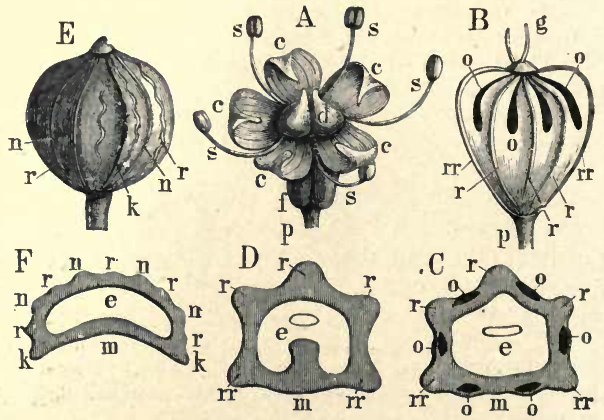

Fig. 361.-A Flower of Fœniculum (mag.) : $f$ ovary; $c$ corolla ; s stamens; $d$ disc. $B$ Fruit of Heraclean : $p$ pedicel; $g$ style; $r r r$ ridges (costæ) : $r$ marginal ridges; 0 oilducts (vittæ) (mag.). C Transverse section of mericarp of Carum Carui (Orthospermea): $m$ surface that comes into contact with the other mericarp; 0 vittæ; 6 endosperm. $D$ Transverse section of mericarp of Conium (Campylospermea). E Fruit of Coriandrum. (Colospermea) : $k$ margin of the surface along which the two mericarps are in contact; $r$ ridges; $n$ secondary ridges : $F$ section of a mericarp. (Mag.)

the two styles is fleshy and thickened, forming an epigynous disc (Fig. $361 A d$ ); one suspended ovule in each loculus of the ovary (Fig. $284 E$ ): the fruit, when ripe, splits into two mericarps, each loculus of the ovary being permanently closed by a median septum (Fig. $362 B a$; see p. 473). The structure of the pericarp is an important characteristic for the classification of the family. The fruit is commonly either oval in form, or compressed (Fig. $361 \mathrm{~B}$ ), or nearly spherical (Fig. $361 \mathrm{E}$ ): its surface generally bears longitudinal ridges (costce or juga primaria) euclosing vas- 
cular bundles, five generally on each mericarp; of these, two run along the margins (Fig. $361 B, C, D, r r$ ), and the other three along the dorsal surface (Fig. $361 B, C, D, r$ ). In the spaces between the ridges which form furrows, lie oil-ducts or receptacles (vittoe) (Fig. $361 \mathrm{~B}, \mathrm{C}, \mathrm{o}$ ), and sometimes other secondary ridges (juga. secundaria) (Fig. $361 E, F, n$ ), which do not enclose vascular bundles. The mericarp when ripe is filled by the seed, which consists of the abundant endosperm (Fig. $361 C, D, F, e$ ) enclosing a small embryo. According to the form assumed by the endosperm, the following groups may be distinguished: the Orthospermea, in which the surface of the endosperm, which is directed towards the plane of junction of the two mericarps, is flat or convex, as in Carum (Fig. 361C): the Campylospermea, in which the endosperm is concave towards the same plane, as in Conium (Fig. $361 \mathrm{D})$, and the Coelospermea, in which the whole endosperm is curved, so that it is seen to be concave towards this plane both in longitudinal and in transverse section, as in Coriander (Fig. $361 \mathrm{~F}$ ).

The flowers, with few exceptions (Hydrocotyle, Astrantia, Eryngium, where the umbels are simple), are in compound umbels (p. 440); in some few cases, as in Daucus, the umbel has a distinct terminal flower which is black in colour: an involucre and involucels are largely developed in some species, in others they are wholly wanting. The hollow stem bears large leaves with generally well-developed sheathing bases and much divided laminæ: rarely the leaves are simple, as in Hydrocotyle and Bupleurum.

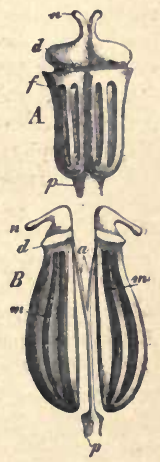

Fre. 362.-Fruit of Carnm Carui. 4 Ovary of the flower (f). B Ripe Frait. The two carpels have separated so as to form two mericarps $(m)$. Part of the septum constitutes the carpophore (a).

The British genera are arranged as follows:Sub-order I. Orthosperme.s.

A. Umbels simple.

Tribe 1. Hydrocotylex. Fruit laterally compressed. The genus Hydrocotyle consists of marsh-plants with peltate leaves (Fig. 22).

Tribe 2. Saniculea. Fruit nearly cylindrical. This group includes the genera Astrantia, Eryngium, and Sanicula.

B. Umbels compound.

Tribe 3. Amminece. Fruit without secondary ridges, laterally com- 
pressed: Ammi, Bupleurum, Petroselinum, Apium, Egopodium, Carum (Figs. 361 C, and 362), Cicuta, Sium, Pimpinella, Trinia, Conopodinm, Sison.

Tribe 4. Seselinew. Secondary ridges absent, or if present (Siler) not so prominent as the primary: fruit not compressed: Fthusa, Fœniculum, Enanthe, Seseli, Meum, Ligusticum, Silaus, Crithmum, Siler.

Tribe 5. Angelicere. Fruit without secondary ridges, dorsally compressed, the lateral primary ridges winged, the wings of the two mericarps divergent; Angelica, Archangelica.

Tribe 6. Pencelanee. Fruit without secondary ridges, dorsally compressed, the lateral primary ridges winged, the wings of the two mericarps apposed: Peucedanum (incl. Imperatoria), Pastinaca, Heracleum, Tordylium.

Tribe 7 . Daucinee. The secondary ridges are spinons: Daucus.

Sub-order II. Camprosiprmes.

Tribe 8. Caucalinea. Secondary ridges spinous: Caucalis (incl. Torilis).

Tribe 9. Smyrniece. Fruit without secondary ridges: Anthriscus, Myrrhis, Conium (Fig. $361 D$ ), Smyrnium, Physospermum.

Sub-order III. Ceelospermez.

Tribe 10. Scandicea. Fruit sub-globose, without secondary ridges: Scandix, Chærophyllum, Echinophora.

Tribe 11. Coriandrea. Fruit spherical; secondary ridges more prominent than the wavy primary ridges: Coriandrum (Fig. $361 F, E$ ).

Anthriscus silvestris, the Cow-Parsley; Carum Carui, the Caraway; Heracleum Sphondylium, the Cow-Parsnip; Egopodium Podagraria, the GontWeed; Pastinaca sativa, the Wild Parsnip, are common in meadows and woods: Crithmum, the Samphire, grows on rocks by the sea : Echinophora, the Prickly Samphire, growing on sandy sea-shores, has been exterminated in Britain. The following are cultivated: Apium graveolens, Celery; Petroselinum sativun, Parsley; Daucus Carota, the Carrot; Pastinaca oleracea, the Parsnip; Anthriscus Cerefolium, the Chervil. The following are poisonous: Conium maculatum, the Hemlock; Cicuta virosa, the Water-Hemlock; Ailhusa Cynapium, Fool's-Parsley.

Order 2. Araliacex. Flowers generally pentamerous; stamens sometimes more numerous; carpels more or less numerous: fruit, a berry or a drupe. Shrubs, sometimes root-climbers, with scattered palmate leaves.

Hedera Helix, the Ivy, does not blossom till it is some years old: the mbels are borne on erect branches, the leaves of which are entire. Fatsia papyrifera is used in Japan for making a kind of paper known as ricepaper; it is made from the pith.

Cohort II. Passiflorales. Flowers frequently unisexual, regular; epigynous, perigynous or hypogynous; pentamerous: stamens in one or two whorls, or indefinite : gynæceum syncarpous ; 
ovary usually trimerous and unilocular; ovules numerous, on parietal placentæ.

Order 1. Cucurbitaces. Flowers diclinous or polygamous, often irregular : corolla of five petals, often gamopetalous : stamens epipetalous, five, but they frequently cohere, either in pairs, so that there appear to be but three (Fig. 363, diagram), or all completely into a single continuous ring (Cyclanthera); the anthers are commonly long and sinuous: ovary inferior, unilocular, becoming spuriously multilocular, with one or (more often) many ovules; it is, however, often described as multilocular (usually 3) with projecting axile placentæ: fruit baccate, a pepo or a succulent berry (p. 476), often of great size, with a relatively thick and solid pericarp: seed without endosperm. Herbs with scattered leaves, mostly climbers, with tendrils growing by the side of the leaves.

There is considerable difference of opinion as to the morphological nature of the tendril in this order, but it appears to be essentially a leaf, in fact the first leaf of the flowering-shoot which arises in the axil of the related foliage-leaf : the vegetative branch, which is always developed by the side of the flowering - shoot, seems to spring from the axil of the

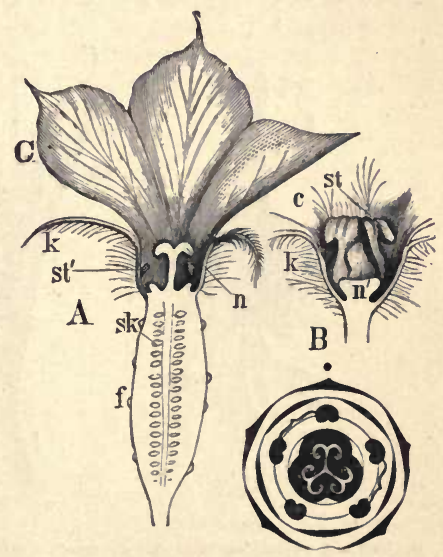

F1G. 363.-A Longitudinal section of $q$ flower of Cucumis : $f$ ovary; sk ovules , $k$ calyx; $C$ corolla 3 n stigma ; st' rudimentary stamens. B Longitudi. nal section of $\delta$ flower; st stamens ; $n^{\prime}$ rudimentary ovary; the corolla (c) is not all shown (somewhat mag.). Floral diagram of Cucurbita.

tendril. The tendril often bears a number of branches at its distal end, but whether simple or branched, its structure shows that the proximal portion corresponds in structure to a petiole, whilst the distal irritable portion (including the branches) has a bilateral structure which suggests correspondence with a lamina.

Cucurbita Pepo is the Pumpkin: the genus Cucumis has free stamens; Cucumis sativa is the Cucumber, and Cucumis Melo is the Melon: Citrullus vuigaris is the Water Melon. The genus Bryonia has a small white corolla : the loculi of the ovary are 2-seeded, and the fruit is a succulent berry; $\dot{B}$. dioica is common in shrubberies and hedges. 
Cohort III. Myrtales. Flowers usually actinomorphic, eucyclic, epigynous or perigynous, with usually two whorls of stamens, typically obdiplostemonous : gynæceum syncarpous, with usually a single style: leaves usually opposite.

Order 1. ONAGRACEE. Flowers usually tetramerous throughout, generally epigynous: antipetalous stamens sometimes suppressed: ovary multilocular, with generally numerous ovules on axile placentæ: fruit a berry or a capsule; seed without endosperm. Calyx often petaloid, forming a long tube (Fig. $364 \mathrm{~A}, \boldsymbol{r}$ ).
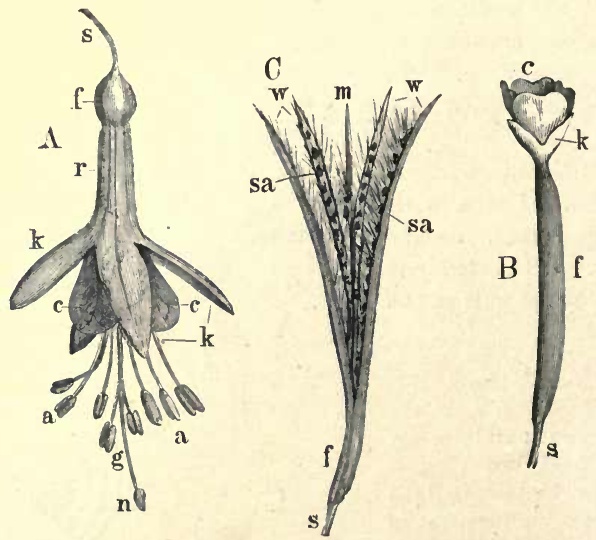

Fre. 364.-A Flower of Fuchsis : $s$ pedicel; $f$ inferior ovary; $k$ sepals, connate at the base, forming a tube $(\mathrm{r})$; $a$ atamens; $g$ style; $n$ stigma. B Flower of Epilobium hirsutum (letters as before). $C$ Fruit of Epilobium after dehiscence; $v$ outer wall; $m$ columella formed by the septa; sa seed with tufts of hairs (nat. size).

Enothera biennis, the Evening Primrose, occurs on river banks; the seed has not a tuft of hairs, and the flowers are yellow. Epilobium is the Willow Herb, of which many species are common; $E$. angustifolium, hirsutum, and montanum occur in fields, hedges, and ditches; the seeds have a tuft of long hairs (see p. 416); flowers red; fruit a septifragal capsule. Circac lutetiana (Enchanter's Nightshade) has dimerous flowers $K_{2} \mathrm{C} 2, A 2, G_{(2)}$ (Fig. $270 \mathrm{~B}$ ); common in damp and shady spots. Isnardia palustris has no corolla; its fruit is a septicidal capsule. Fuchsia (Figs. $364 A, 270 A$ ), many species of which are cultivated as ornamental plants, is a native of South America; fruit a berry.

Trapa natans, the Water-Chestnut, a not very common water-plant of Central Europe, has a stem bearing a rosette of leaves which float 
on the surface of the water; in the axils of these leaves the flowers are borne singly : their formula is $K 4, C 4, A 4, G^{(2)}$, and they are perigynous: the fruit is indehiscent, and the sepals remain adherent to it in the form of four horns: it contains two seeds.

Order 2. Lythracee. Flowers perigynous, with usually both whorls of stamens : formula $K \mathrm{n}, \mathrm{Cn}, \mid A \mathrm{n}+\mathrm{n}, G^{(2-8)}$, where $\mathrm{n}=3-$ 16: ovary free in the hollow receptacle: an epicalyx formed by connate stipules is often present: seed without endosperm.

Lythrum Salicaria, the Loosestrife, occurs in bogs and ditches: flower usually pentamerous or hexamerous: the stamens of the two whorls are unequal in length, and the length of the style also varies; three forms of flowers are thus produced (trimorphism; see p. 412). The other British genus is Peplis; P. Portula is the Water-Purslane; it has usually hexamerous flowers and an indehiscent fruit: gynæceum dimerous in both genera.

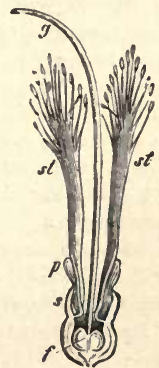

Fie. 365.-Longitudinal section of the flower of Calo:hamnns; fovary; s calyx; $p$ corolla; st antipetalons bundle of stamens; $g$ style. (After Sachs).

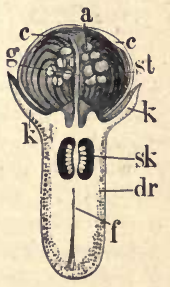

Fig. 366.-Flower-bud of Jambosa Caryophyllus, the Clove, in longitudinal section; $f$ the infericr ovary, with the oil-glands $(d r)$; $s k$ the ovales; $k$ calyx; $c$ corolla; st stamens; $a$ anthers; $g$ style (enlarged).

Order 3. Myrtaces. Flowers 4- or 5-merous, epigynous : stamens often very numerous, free, or connate in usually antipetalous bundles (Fig. 365); sometimes few and obdiplostemonous: ovary $1-\infty$-locular; seeds $1-\infty$ in each loculus, without endosperm: placentation and fruit various: leaves usually opposite, dotted with oil-glands. Shrubs or trees.

Myrtus communis is the Myrtle of Southern Europe; the genus Eugenia includes a number of ornamental shrubs, among which is $E$. (Jambosa) Caryophyllus, the buds and flowers of which yield the spice known as cloves (Fig. 366). Eucalyptus Globulus, from Australia, is much planted 
in marshy districts, which it tends to dry up by its active transpiration. Bertholletia excelsa grows in tropical America; its seeds are known as Brazil nuts.

Punica Granatun, the Pomegranate, grows in Southern Europe; flowers 5-8-merous; receptacle petaloid; stamens indefinite; in the ovary there are two whorls of loculi, an external superior of which the loculi are as numerons as and are opposite to the petals, and an internal inferior consisting of three loculi.

Cohort IV. Rosales. Flowers actinomorphic or zygomorphic, usually monoclinous and perigynous: stamens rarely fewer in number than the petals or equal to them, generally indefinite in numerous whorls: gynæceum more or less completely apocarpous : ovules anatropous, suspended or erect: seed generally without endosperm.

Order 1. ROSACEe. Flowers actinomorphic, rarely zygomorphic, perigynous: gynæceum generally apocarpous; carpels $1-\infty$; ovules 1 or few, anatropous : fruit various; seed generally without endosperm: leaves scattered, stipulate; the odd sepal is posterior (see Fig. 267).

Tribe 1. Rosece. Carpels numerous, attached to the base and sides of the hollow receptacle, which is narrow above (Fig. $367 \mathrm{C}$ ); each contains a singie suspended ovule; when ripe, they are achenes enclosed in the Heshy receptacle: the sepals are frequently persistent at the top of it. Shrubs with imparipinnate leaves; the stipules are adnate to the petiole.

Many species of Rosa, the Rose, are wild, such as $R$, arvensis, canina, and rubiginosa (Sweet-Briar or Eglantine); and many others are cultivated, as $R$. centifolia, damascena, indica, gallica, etc.

Tribe 2. Spirceece. Carpels usually 5, each containing two or more suspended ovules; they are inserted upon the floor of the flat open receptacle, and become follicles; the calyx is persistent till the fruit is ripe.

Spircea Ulmaria, Meadow-sweet, and S. Filipendula, Dropwort, occur in woods, meadows, etc.; Sp. sorbifolia, media, ulmifolia, and other species, Kerria japonica, and Rhodotypus (with drupes), are ornamental shrubs.

Tribe 3. Prunece. The single carpel, containing two suspended ovules, is inserted on the floor of the receptacle (Figs. $367 A$ and $368 A$ ); the receptacle and the calyx fall off when the fruit is ripe: stamens usually in three whorls of 5 or 10; fruit a drupe (p. 475, Fig. 290); only one seed is usually present.

Prunus is the principal genus of the tribe. In the sub-genus Amygdalus the fruit has a furrowed coriaceous endocarp; Prunus Amygdalus (A. communis), the Almond-tree, and nana, are trees of Southern Europe; $P$. Persica is the Peach. In the sub-genus Prunophora, the fruit has a smooth, stony endocarp; $P$. communis (spinosa) is the Sloe or Blackthorn; 
$P$. Armeniaca is the Apricot; $P$. domestica is the Wild Plum, it has an ovoid fruit and glabrous shoots: $P$. insititia is the Bullace, it has a globoid fruit and hirsute shoots. In the sub-genus Cerasus, $P$. Cerasus, the Dwarf or Morello Cherry, has foliage-leaves at the base of its umbellate inflor-
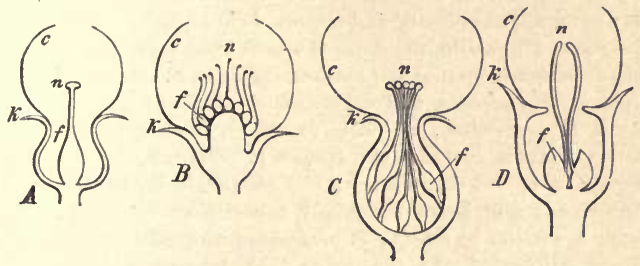

Fig. 367.-Diagrammatic longitudinal sections of Rosaceous flowers. A Pruneæ. $B$ Potentilleæ. $C$ Rовеæ. $D$ Poiner : $k$ calyx ; $c$ corolla; $f$ ovaries; $n$ stigmata.

escences; P.Avium, the Wild Cherry or Gean, has only scales at the base of its inflorescences. In the sub-genus Laurocerasus, $P$. Mahaleb, the Damson, has fragrant bark; $P$. Padus, the Bird-Cherry, has elongated racemose inflorescences; $P$. Laurocerasus, the Cherry-Laurel, has evergreen leaves which somewhat resemble those of the true Laurel; $P$. lusitanica is the Portugal Laurel.

Tribe 4. Poteriea. Flowers often diclinous: corolla often absent: ovaries few, often but one, monomerous, enclosed in the cavity of the receptacle : ovules solitary, suspended: fruit, a dry receptacle bearing one or more nut-like achenes.

The genus Alchemilla has tetramerous flowers destitute of a corolla the stamens ( 4 or fewer) alternate with the sepals; an epicalyx is present: A. vulgaris, the Lady's Mantle, and A. arvensis, are common. In the genus Poterium, the flowers of the sub-genus Sanguisorba ( $P$. officinale, the great Burnet), have no corolla, the four stamens are opposite the sepals, and they have no epicalyx : the flowers of the sub-genus Poterium ( $P$. Sanguisorba, the Salad Burnet), resemble those of the preceding, but the stamens are indefinite, and they are polygamous. The flower of Agrimonia is pentamerous; it has a corolla and indefinite stamens; the outer surface of the receptacle is beset with bristles.

Tribe 5. Potentillea. The ovaries, which are numerous, are inserted upon a prolongation of the axis into the cavity of the receptacle (Figs. $367 B$ and $368 B$ ); each usually contains one ovule. The calyx is often surrounded by an epicalyx formed by the connate stipules of the sepals (Fig.
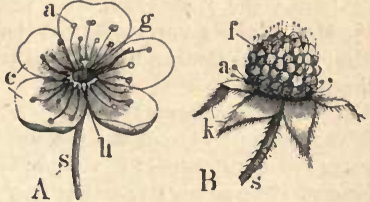

Fig. 368.-A Flower of the Cherry: $s$ peduncle; $c$ corolla; $a$ stamens; $g$ style, pro. jecting ont of the cavity of the receptacle. $B$ Fruit of the Blackberry. Rubus fruticosus : k calsx; $f$ teshy ovaries. 
$275 C$ ). The stamens are usually indefinite, each whorl consisting of as many or twice as many stamens as there are petals. These flowers are distinguished from those of the Ranunculaceæ, which they somewhat resemble, by the whorled arrangement of the stamens and by the presence of the hollow receptacle; for in Ranunculaceous flowers the stamens are arranged spirally and the sepals are quite free.

Of the genus Potentilla, the fruit of which is an etærio of achenes on a dry receptacle, many species are common, such as $P$. anserina, the Silverweed, reptans, Tormentilla, and others: the sub-genus Sibbaldia includes the species $P$. procumbens, which is found on Scottish mountains: the sub-genus Comarum includes the species $P$. Comarum, the Marsh Cinquefoil. Fragaria is the Strawberry; the receptacle becomes succulent as the fruit ripens and bears the small achenes on its surface; $F$. vesca and elatior are found in woods; $F$. virginiana and other North American species are cultivated. In the genus Rubus there is no epicalyx, the ovary contains two ovules, and the fruit is an etærio of drupels; Rubus Idcus is the Raspberry; its fruits separate from the dry receptacle when they are ripe: in $R$. fruticosus, the Blackberry, and $R$. ccesius, the Dewberry, the upper part of the receptacle separates together with the fruits when ripe. Dryas octopetala, the Mountain Avens (without epicalyx) is a procumbent Alpine shrub with an oval long-tailed fruit (resembling that of Clematis Vitalba). An epicalyx is present in most species of Geum; Geum urbanum and rivale (Avens) occur in woods and damp fields; the long style is hooked.

Tribe 6. Pomea. Ovaries five or fewer, contained in the cavity of the receptacle, connate, and adnate to the wall of the receptacle (Fig. $367 D$ ). The spurious fruit is surmounted by the calyx. The individual fruits either become hard and are like small drupes imbedded in the fleshy receptacle, or they have only a thin wall, so that they are more like capsules and seem to be loculi of the whole fruit, as in the apple for instance, where the succulent portion is derived from the receptacle, and the core consists of the fruits enclosing the seeds, which are basal, generally two in each carpel. Stamens indefinite: no epicalyx. Shrubs or trees with deciduous stipules.

I. With stony fruits.

In the genus Cotoneaster, the fruits project above the receptacle: in Cratægus, the Hawthorn, they are completely enclosed; C. Oxyacantha, the May, and its var. monogyna, the common White Thorn, are common: Mespilus, the Medlar, has a large fruit which is surmounted by the five large sepals.

I. With coriaceous fruits.

The genus Cydonia, the Quince, has numerous ovules on the ventral suture of each carpel; the outer layers of cells of the testa are mucilaginous. The genus Pyrus has two basal ovules: P. communis and others are the Pear-trees; the loculi of the spurious frait, seen in transverse section, are rounded towards the exterior; the fruit is not hollowed at the base: the sub-genus Malus includes $P$. Malus and others, the Apple-trees; the fruit is hollowed at the base, and the loculi, seen in transverse 
section, are pointed towards the exterior: the sub-genus Sorbus resembles the preceding, but has pinnatifid leaves; it includes $P$. Aucuparia, the Mountain Ash or Rowan-tree, also P. domestica, the true Service-tree, and $P$. torminalis, the Wild Service-tree : the sub-genus Aria, includes $P$. Aria, the White Beam. The genus Amelanchier includes the European $A$. vulgaris, and $A$. canadensis, the June-Berry. The genera Raphiolepis and Photinia (incl. Eriobotrya, the Loquat), include well-known cultivated flowering shrubs.

Order 2. Leguminose. Flowers usually dorsiventral, perigynous, pentamerous, with calyx and corolla: stamens ten or more : ovary of a single anterior carpel; ovules borne on the ventral suture: fruit a legume or a lomentum: flowers always lateral: leaves nearly always compound.

The Leguminosæ, more particularly the Papilioneæ, are remarkable physiologically by the presence of tubercles on their roots, caused by the attack of a Fungus, and by their extraordinary faculty of flourishing in soils poor in combined nitrogen (see p. 191).

Sub-order 1. Papiliones. Flowers dorsiventral, papilionaceous (Fig. $272 \mathrm{~A}$ ). The five sepals, the odd one being anterior, are usually connate, forming a tube above the insertion of the corolla and the androcium: the five lobes are usually unequal and sometimes form two lips, the lower of three and the upper of two teeth: petals five, alternate with the sepals, imbricate so that the anterior petals are overlapped by those behind them; the posterior petal is much enlarged, and is called the vexillum (Fig. $369 \mathrm{~A}, f a$ ); the two lateral petals, which are much smaller, are termed the alce (Fig. $369 \mathrm{~A}, f$ ); the two

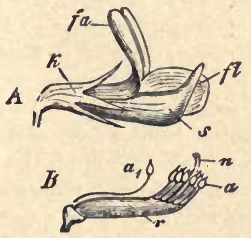

Fig. 369.-Flower of Lotus corniculatus (somewhat mag.). 4 With one ala removed; $k$ calyx; $f a$ vexillum; $f$ ala; 8 carina. $B$ With the corolla removed; $r$ tnbe formed by the nine stamens; af the free stamen; $a$ an. ther; $n$ stigma. anterior petals are connate or sometimes simply apposed, and form a hollow boat-shaped body, the keel, or carina (Fig. $369 A, s$ ). In a few cases the corolla is entirely or partially suppressed; thus in Amorpha, only the vexillum is present. The ten stamens belong to a single whorl, with direct diplostemony ; they are either connate and monadelphous, forming a tube, or the posterior stamen may be free, so that the tube consists of nine stamens, and is incomplete posteriorly (Fig. $369 \mathrm{~B}$ ), in which case the androecium is diadelphous (9-1); rarely the stamens are all free; they mostly curve upwards, and diminish in length from in front backwards. The ovary, enclosed by the staminal tube, consists of a solitary anterior carpel; it is often divided into chambers by a spurious longitudinal septum, or by transverse septa into several chambers. The fruit is usually a legume or a lomentum (Fig. $288 \mathrm{~A}$ ), rarely one-seeded, and 
indehiscent: the seed frequently contains scanty endosperm. The flowers are solitary and axillary, or in racemes. The leaves are only rarely entire, usually palmately or pinnately compound (Fig. 23), with often large stipules (Fig. $19 \mathrm{C}$ ), which are sometimes spines (Robinia). The following are the principal tribes:-

Tribe 1. Genistece. Stamens usually monadelphous: leaves simple, or compound ternate.

In Ulex the Whin, Gorse or Furze, Genista the Green-weed, Cytisus (Sarothamnus) the Broom, and Lupinus, the stamens are monadelphous; in Genista the leaves are simple; in Cytisus the leaves are ternate; in Ulex the leaves are ternate in seedlings, but in mature plants they are scaly or spinous; in Lupinus the leaves are palmately compound. Cytisus Laburnum is a well-known flowering tree.

Tribe 2. Trifoliea. The posterior stamen is usually free; leaves ternate, and leaflets with serrate margins.

In Medicago (Medick), Melilotus, and Trifolium, the stamens are diadelphous : in Ononis, the Rest-harrow, they are monadelphous. Trifolium is the Clover: the stamens are partially adnate to the corolla; the withered corolla persists and encloses the small legume: flowers in capitula; T. pratense, the Red Clover, 'T. repens, the White Clover, and $T$. hybridum, the Alsike Clover, which are common in meadows, and $T$. incarnatum, from the East, are cultivated. Medicago has usually a spirally-wound legume, and a deciduous corolla; $M$. falcata and lupulina are common; M. sativa, Lucerne, is cultivated. Melilotus (Melilot) has a globular legume; $M$. alba and altissima are common on the banks of streams. Trigonella is the Fenugreek.

Tribe 3. Lotece, Stamens diadelphous, the posterior stamen being free: leaves pinnate; leaflets sessile, entire.

Lotus corniculatus, the Bird's-foot Trefoil, with a beaked carina and nearly straight legume, is common in meadows. In Anthyllis, the Kidney-Vetch, the stamens are monadelphous at first, the posterior stamen becoming more or less separate: Anthyllis Vulneraria, Ladies' Fingers or Woundwort, is common in dry pastures.

Tribe 4. Galegece. Stamens diadelphous: leaves multijugate imparipinnate; leaflets stalked.

Indigofera tinctoria, in the East Indies, produces Indigo. Glycyrrhiza is the Liquorice. Robinia Pseudacacia, the false Acacia, is a native of North America, but it has become naturalized. Astragalus bas a legume with a spurious longitudinal dissepiment: very many species of it occur, especially in the East.

Tribe 5. Hedysarea. Leaves imparipinnate; stamens diadelphous: fruit a lomentum, with transverse septa, dividing into segments. Cotyledons leafy, epigean.

Hippocrepis, the Horse-shoe Vetch, and Coronilla arecommon in meadows; Onobrychis sativa, the Sainfoin, is cultivated. Arachis hypogaca, the Earth. Almond or Ground-Nut of tropical America, ripens its fruits in the earth. Desmodium gyrans, the Telegraph-plant, has motile leaflets.

Tribe 6. Viciece. Stamens diadelphous : legume unilocular; cotyledons hypogean; leaves paripinnate and usually cirrhose (see Fig. $19 C$ ). 
Vicia sativa, the Vetch, and V. Faba, the Bean, are cultivated; other species occur wild. Pisum sativum and arnense, the Pea, are cultivated. Lens esculenta, the Lentil, belongs to Southern Europe. Various species of Lathyrus (incl. Orobus) occur wild in woods: $L$.odoratus and others are cultivated.

Tribe 7. Phaseolece. Stamens diadelphous: legume unilocular: cotyledons usually epigean, but not leafy : leaves usually imparipinnate, frequently ternate. Mostly climbing plants with twining stems.

Phaseolus vulgaris, the French Bean, and $\boldsymbol{P}$. multiflorus, the Scarlet Runner, are cultivated. Wistaria (Glycine) chinensis is an ornamental climber. Physostigma is the Calabar Bean.

Sub-order 2. Cesalpinies. Flower dorsiventral, but not papilionaceous (Fig. $272 B$ and Fig. 370); petals imbricate so that the posterior petal is overlapped by those anterior to it; stamens ten or fewer, free, more rarely connate: the legume is frequently divided by transverse septa, and is indehiscent: flowers in panicles or racemes: seeds often albuminous.

Gleditschia triacanthos and other species are cultivated for ornament. Cercis Siliquastrum, the Judas tree, has rounded leaves. The wood of

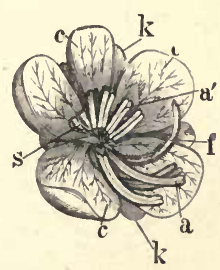

Fra. 370.-Flower of a Cassia : $k$ calyx; c corolla; $a$ stamens; $a^{\prime}$ the central shorter ones; fovary.

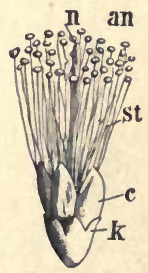

F16. 371.-Flower of an Acacia (mag.) : $k$ calyx ; $c$ corolls; st stamens, with (an) anthers; $n$ stigms.

Casalpinia braziliensis is known as Pernambuco or Brazil wood. Hæmatoxylon, Cassia, Bauhinia, Tamarindus, and Ceratonia ( $C$. Siliqua, the Carob-tree) are other well-known genera.

Sub-order 3. Miмоsex. Flowers regular; petals with valvate gestivation: stamens ten, rarely fewer, frequently very numerous, free (Fig. 371), usually much longer than the perianth: legume sometimes divided by transverse septa: seed rarely albuminous: flowers usually grouped in spikes or capitula.

Mimosa pudica, the Sensitive Plant, has irritable leaves (see Part III). Species of Acacia are numerous in Africa, Asia, and Australia. In the Australian species the leaves are represented by flattened petioles (phyllodes, p. 32) which are extended in the median plane.

Cohort V. Saxifragales. Flowers generally monoclinous and actinomorphic; hypogynous, perigynous or epigynous; eu- 
cyclic; stamens usually in two whorls, with obdiplostemony; ovary generally syncarpous, multilocular, with more than one style or stigma; ovules usually numerous in each loculus; seed with or without endosperm.

Order 1. Saxifragacex. Flowers usually 4-5-merous, epigynous or perigynous, completely actinomorphic only when there are five carpels: stamens usually in two whorls; carpels less numerous, usually connate below and free above; seeds numerous, containing endosperm.

Tribe 1. Saxifragece. Flowers perigynous or epigynous, regular, but generally with oligomery in the gynæceum: petals with imbricate æstivation, sometimes suppressed : two whorls of stamens, but one or other of the whorls is suppressed in some genera and species: carpels usually

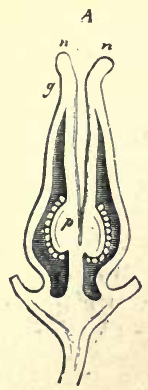

FIG. 372.-Longitudinal section of the ovary of Bergenia ; $g$ style; $n$ stigmata; $p$ placentæ (mag.). (After Sachs.)

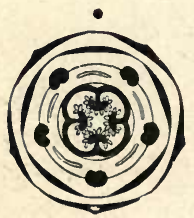

Fig. 373.-Floral diagram of Parnassia ; but the whorl of antipetalous staminodes should be represented as external to the whorl of stamens.

two, diverging above (Figs. $281 \mathrm{D}, 372$ ): inflorescence of racemose cymes: fruit a capsule : leaves alternate.

The British genera are Saxifraga and Chrysosplenium :-Saxifraga has an oblique bilocular ovary; the receptacle invests the lower connate portion of the ovary : many species occur in mountainous districts, and in several of them there is a deposit of carbonate of lime on the margins of the leaves (see pp. 96, 203); only a few species, such as $S$.tridactylites and gramulata, occur in the plains: Chrysosplenium, the Golden Saxifrage, has a tetramerous flower destitute of a corolla; the two species are small plants, somewhat resembling a Euphorbia, occurring in damp places.

Tribe 2. Parnassiece. Fowers perigynous, often actinomorphic; the five stamens opposite to the petals are transformed into glandular staminodes; petals with imbricate æstivation : ovary 4-5-merous, unilocular : fruit a loculicidal capsule : leaves alternate. 
Parnassia palustris, Grass of Parnassus, has a whorl of radical leaves, and terminal and lateral peduncles each bearing a single flower and adnate to a bracteole: it is frequently found in damp localities.

Tribe 3. Ribesiea. Flowers epigynous, incompletely actinomorphic, pentamerous (Fig. 374): stamens five, opposite to the sepals; carpels usually two, usually median, sometimes lateral: fruit a berry: leaves scattered: inflorescence racemose. Shrubs.

Several species of Ribes, the Currant, are cultivated: $R$. rubrum is the Red Currant; $R$. nigrum, the Black Currant; $R$. Grossularia, the Gooseberry : the spines of the last species are developed from the pulvinus.

Apparently allied to the Saxifragacer is the order Droseracex, which includes a number of insectivorous plants. Drosera has a scorpioid inflorescence borne on a scape without bracteoles; the leaves are radical and are fringed with glandular appendages, each of which is traversed by a fibro-vascular bundle (Figs. 33,34, p. 48). D. rotundifolia and intermedia, the Sun-dews, are found on wet heaths. Aldrovanda vesiculosa, is a floating rootless water-plant of Southern Europe; its whorled leaves fold up when stimulated ; flowers solitary, axillary. Dionoa muscipula, Venus' Fly-trap, occurs in North America; it has leaves which likewise fold to gether when touched; flowers with 10-20 stamens and basal ovules.

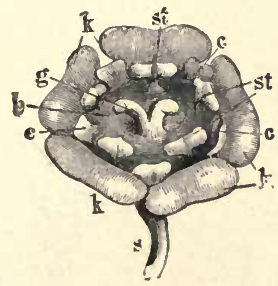

Fra. 374.-Flower of Ribes (mag.): 8 pedicel; $k$ calyx; $c$ corolla ; st stamens ; $b$ disc; $g$ styles.

Order 2. Crassulacex. Formula $K \bar{n}, C \mathrm{n}, \mid A \mathrm{n}+\mathrm{n}, G \mathrm{n}$, where $\mathrm{n}=3-30$ : flowers actinomorphic, perigynous or hypogynous, with two (rarely one) whorls of stamens: gynæceum, generally completely apocarpous; carpels opposite to the petals, with a scale (disc) external to each carpel: ovules numerous, marginal: fruit a follicle: seed with endosperm: inflorescence usually cymose. Plants with entire fleshy leaves, arranged spirally, often in rosettes.

The genus Sedum has usually pentamerous flowers; Sedum acre, the Stonecrop, is common on walls and rocks; $S$. Rhodiola has diocious flowers. S. Telephium, the Orpine and others are common. The genus Sempervivum has at least 6-merous flowers; $S$. Tectorum, the Houseleek, and other species, as also species of Echeveria, Crassula, etc., are, frequently cultivated.

M.B. 


\section{SUB-CLASS II. GAMOPETALÆ.}

Flowers usually monoclinous : perianth differentiated into calyx and corolla : calyx usually gamosepalous; corolla generally gamopetalous, in some cases suppressed : ovary usually syncarpous.

\section{SERIES I. HYPOGYNE.}

Ovary superior (except in Vacciniaceæ): stamens epipetalous, or free and hypogynous.

Cohort I. Lamiales. Flower pentamerous, usually dorsiventral: the formula is generally $\downarrow K(5)\left[C(5) A\right.$ 5] $G^{(2)}$; corolla usually bilabiate, the two posterior petals being connate and forming a frequently helmet-shaped (galeate) projecting upper lip; the anterior petal, with the two lateral petals, forming the under lip : stamens epipetalous; the pasterior stamen is usually suppressed or is a staminode; the two lateral stamens are generally shorter than the two anterior ones, so that they are didynamous: the two median carpels form a usually bilocular ovary which sometimes becomes subdivided into four loculi : leaves scattered, or opposite decussate

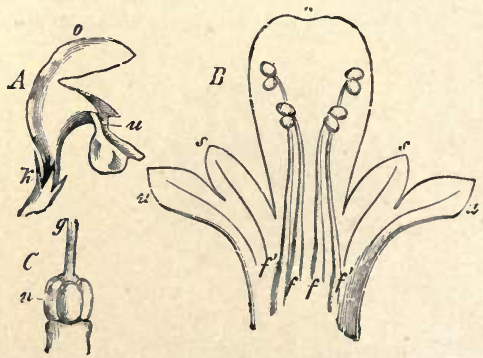

Frg. 376.- $d$ Flower of Lamium, side view : $k$ calyx ; o npper; $u$ under lip. B Flower of Leonurus opened: 0 upper; $u$ divided under lip; $s$ lateral lobes of the corolla; $f f$ short, $f^{\prime} f^{\prime}$ long stamens (mag.). C Gsnaceum; $n$ 4-lobed ovary; $g$ style (mag.). exstipulate: the leafy shoots have no terminal flower.

Order 1. Labiate. Stamens four, didynamous (Fig. $376 \mathrm{~B}$ ); rarely, as in Salvia and its allies, only the two anterior stamens stamens are developed: the bicarpellary ovary becomes subdivided by spurious dissepiments into four loculi (Fig. $376 C$ ), which part, as the seed ripens, into four nutlets (as also in the Boraginacer, səe Fig. 383); style gynobasic: the ovule in each loculus is solitary and erect: seed without endosperm. Herbs with decussate leaves and quadrangular stem. The flowers are disposed apparently in whorls round the stem, but the inflorescence is in fact made up of 
compound cymes or dichasia, termed verticillasters, developed in the axil of each of the two opposite leaves.

Tribe 1. Ocimoidece. Stamens 4, descending.

Ocimum basilicum, the Sweet Basil, from India, and Lavandula, the Lavender from Southern Europe, are cultivated as pot-herbs: several species of Coleus are cultivated.

Tribe 2. Menthoidex. Stamens 4, equal, ascending, divergent: corolla almost regular, 4- or 5-lobed.

Many species of Mentha, Mint, are common. Pogostemon Patchouli yields oil of Patchouli. Lycopus has only 2 fertile stamens, the two posterior ones being abortive.

Tribe 3. Satureinea. Stamens 4, with broad connective, ascending, either almost equal (Thymus, Origanum), or didynamous and remote at base, conniving under the upper lip.

Origanum vulgare is the Wild Marjoram; the Sweet Marjoram which is cultivated is an exotic species. Thymus Serpyllum is the wild Thyme; the garden Thyme is T. vulgaris, from Southern Europe. Satureia hortensis (exotic) is the Summer Savory. Various species of Calamintha (stamens not divergent) are common, such as $C$. arvensis, the Common Basil, and $C$. Clinopodium, the Wild Basil.

Tribe 4. Melissinece. Stamens 4, didynamous, with narrow connective, remote at base, conniving under upper lip.

Melissa officinalis, the Balm, and Hyssopus, the Hyssop, are cultivated as pot-herbs.

Tribe 5. Monardece. Stamens 2, ascending:- one theca of each anther is either wanting or it is widely separated from the other (see Fig. $276 C$ ).

Salvia verbenacen, the Wild Sage or Clary, is common. Rosmarinus officinalis, the common Rosemary, is exotic.

Tribe 6. Nepetex. Stamens 4, didynamous, ascending parallel; the posterior two are the longer.

Nepeta Cataria, the Catmint, occurs in hedges; and Nepeta Glechoma, the Ground Ivy, is very common.

Tribe 7. Stachydece. Stamens 4, didynamous, ascending, parallel; the anterior two are the longer: upper lip of corolla usually arched (ringent).

Lamium album, the Dead-Nettle, and purpureum, are very common (Fig. 376). Various species of Galeopsis (Hemp-Nettle), Stachys (Woundwort or Betony), Marrubium (Horehound), Ballota, Melittis, and Leonurus (Mother-wort) are found in England.

Tribe 8. Seutellariece. Stamens 4, didynamous, ascending, parallel; calyx closed when the fruit is ripe.

In the genus Scutellaria, the anthers of the anterior pair of stamens have but one theca; S. galericulata, the common Skullcap, and S. minor, the Lesser Skullcap, are common. In the genus Prunella each filament has a small tooth below the anther: $P$. vulgaris is common.

Tribe 9. Ajugoidece. Stamens 4, didynamous, ascending, parallel; the posterior two are the shorter: upper lip of corolla very short. 
Ajuga reptans, the Creeping Bugle, and Teucrium Scorodonia, the Wood Germander, are common.

Cohort II. Personales. Flowers pentamerous, usually dorsiventral: stamens epipetalous: the posterior stamen is usually suppressed, or appears as a staminode: carpels 2, median: ovules usually indefinite.

Order 1. Scrophulariaces. Ovary bilocular, with numerous anatropous ovules borne on axile placentæ: seed with endosperm: stamens four, didynamous, often with a rudimentary fifth posterior. stamen (Fig. $378 \mathrm{~B}, \mathrm{st}$ ); sometimes only the two lateral stamens are present; rarely all five are fertile: corolla with imbricate (cochlear) restivation : general floral formula as in Lamiales.

Sub-order 1. Psecdosolanex. Flower nearly regular: the two posterior petals are external, the anterior internal; stamens usually 5 : leaves scattered. The genus Celsia has only four stamens, whilst in the genus Verbaseum (Mullein) there are five.

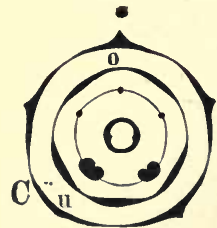

Fic. 377.-Flcral diagrams, $\boldsymbol{A}$ of most Scrophulariaceæ; $\boldsymbol{B}$ of Veronica ; $\boldsymbol{C}$ of the Lentibulariaceæ: $O$ upper, $u$ under lip.

Sub-order 2. Aktirrhoides. Flowers irregular: corolla as in the preceding, the two posterior petals forming the upper lip of the corolla : stamens 4 : leaves opposite. Antirrhinum, the Snapdragon, has a projection on the lower lip of the personate corolla, termed the palate; the corolla is gibbous at the base; stamens 4 (Fig. $378 A, B$ ): $A$. majus, the great Snapdragon, is a well-known garden plant. Linaria has a spurred personate corolla; stamens $4: L$. vulgaris, the yellow Toad-Flax, is common in fields. In Gratiola the two anterior stamens are represented by staminodes. Paulownia imperialis is an ornamental flowering tree from Japan. Limosella (L. aquatica, the Mudwort) has a sub-campanulate corolla with a short tube. Mimulus (M. luteus, the Yellow Monkey-flower) has a sub-campanulate corolla with a two-lipped limb; the two lobes of the stigma close together on being touched. Maurandia and Rhodochiton are genera of plants climbing by means of sensitive petioles. Many species of Mimulus (Musk), Calceolaria, Chelone, and Pentstemon, are cultivated.

Sub-order 3. Rhinanthoidex. Flower irregular: the two posterior petals are overlapped by the lateral petals : stamens 4, or 2. Digitalis, 
the Foxglove, has an obliquely campanulate (digitaliform) corolla; stamens $4 \cdot D$. purpurea is common in woods; the yellow $D$. grandiflora is cultivated. Scrophularia has a globose corolla; S. nodosa (Figwort) and S. aquatica are common. Veronica, the Speedwell, has only the 2 posterslateral stamens, and the two lobes of the upper lip of the rotate corolla are united; the posterior lobe of the calyx is suppressed (Figs. $377 \mathrm{~B}, 378 \mathrm{C}$ ): $\boldsymbol{V}$. Anagallis and $\boldsymbol{V}$. Beccabunga are common in ditches; $\boldsymbol{V}$. arvensis, agrestis, serpyllifolia, Chamadrys, and others in pastures and fields. Sibthorpia has a sub-rotate 5-8-fid corolla, and four stamens; $S$. europae is the Cornish Moneywort.

Pedicularis, the Lousewort, has a 5-toothed calyx, and the upper lip of the corolla is galeate: Euphrasia, the Eyebright, has a 4-toothed calyx, the upper lip of the corolla has two spreading or reflexed lobes: Bartsia has a 4-toothed calyx, upper lip of the ringent corolla entire or only

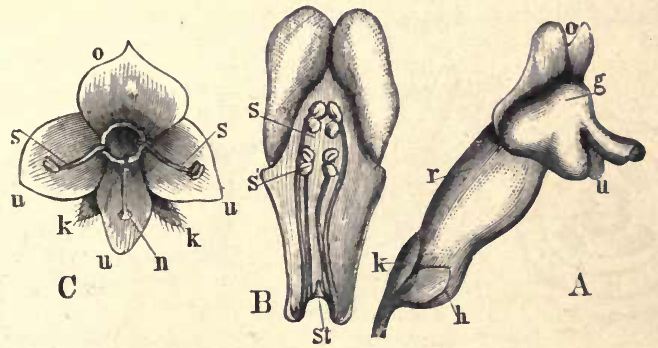

FiG.378.-Flowers of Scrophnlariacex. A Antirrhinum : $k$ cal $j x ; r$ tube of the personate corolla, gibbons at the base $(h): 0$ npper, $u$ nnder lip of the corolla; $g$ prominence (palate) of the under lip. B Upper lip of the same, seen from within: s the two longer anterior stamens; $s^{\prime}$ the short lateral ones; st rudimentary posterior one. C Flower of Veronica : $k$ calyx; $u$ u the three lobes of the lower lip of the rotate corolla : o the npper lip; s the two stamens; $n$ stigma.

notehed: Rhinanthus, the Rattle, has a four-toothed inflated calyx: Melampyrum, the Cow-wheat, has a 4-toothed tubular calyx, and the capsule is few-seeded: all these plants possess chlorophyll, but they are more or less parasitic apon the roots of other plants.

Order 2. Plantaginaces. Flowers regular, isobilateral, and apparently tetramerous, but the true interpretation of them is deduced from those of Veronica (Figs. $377 B$ and 379): the posterior sepal is suppressed, as also the posterior stamen; the two posterior petals cohere to form an upper lip which is quite similar to one of the lobes of the three-lobed lower lip (Fig. 379): stamens four, the two anterior not being suppressed: ovary dimerous, bilocular, or sometimes unilocular or spuriously 4-locular: ovules solitary and 
basal, or numerous: fruit a capsule with transverse dehiscence, or a nutlet: seed with endosperm.

Plantago lanceolata (Ribwort), major, media, the Plantains, are weeds nniversally distributed. $P$. Coronopus, the Buck's-horn Plantain, and $P$. maritima, grow in dry places and on sandy sea-shores. The leaves form a rosette just above the root, and the long scapes spring from their axils, bearing simple spikes. In P. Cynops, Psyllium, and others, the main stem is elongated: the testa of the seed is mucilaginous. In Littorella lacustris the flowers are monøecious; fruit 1-seeded, indehiscent; stamens hypogynous: it grows on the bottom in shallow waters.

Order 3. Orobanchaces. Plants which are destitute of chlorophyll, with scaly leaves, parasitic on the roots of other plants; the flower resembles that of the Scrophulariaceæ, but the ovary is unilocular with 2 or 4 parietal placentæ.

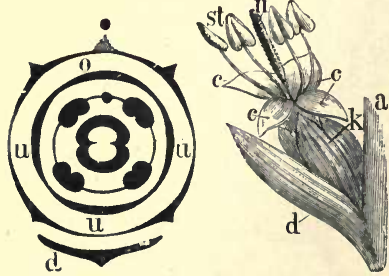

Fia. 379.-Flower of Plantago: $a$ axis of the inflorescence (scape); $d$ bract ; $k$ calyx; c corolla; st stamens; $n$ stigma (mag.). In the diagram, $o$ is the ujper, and $u$ the under lip.

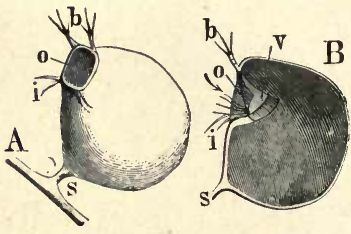

Fig. 380,-Bladders of Utricularia. A Outside view : s pedicel : 0 entrance; $i$ and $b$ bristly appendages. $B$ Section; $v$ a valve opening inwards and preventing the exit of the imprisoned animal (mag.).

The commoner species of Broomrapes, occuring in Britain, are Orobanche major and minor, parasitic on Leguminosæ, elatior on the Greater Knapweed, Hedera on Ivy, ramosa on Hemp; mostly of a brownish or whitish hue. Lathroa Squamaria, the Greater Toothwort, is generally parasitic on the roots of the Hazel: it is of a pale rose colour with slightly bluish flowers : the subterranean scaly leaves each form a kind of pitcher.

Order 4. Lentibulariacexe. Only the two antero-lateral stamens are developed (Fig. $377 C$ ): ovary unilocular : ovule numerous on a free central placenta : seed without endosperm.

The British species of Utricularia are floating water-plants with finely divided leaves bearing bladder-like appendages (modified leaflets) which serve to catch small aquatic animals (Fig. 380). Pinguicula vulgaris and alpina (Butter-worts) are small plants growing in damp 
places, with rosettes of radical leaves which catch insects by their viscid secretion.

Cohort III. Polemoniales. Flowers generally regular, but with oligomery in the gynæceum; pentamerous : stamens epipetalous: ovary of two, rarely five, carpels: leaves usually scattered and exstipulate: the inflorescence is often cymose, with a terminal flower: formula $K(5)[C(5) A 5] G^{(2)}$ to $\left(^{5-}\right)$.

Order 1. Convolvulacex. Usually two median carpels forming a bilocular ovary, with 1-2 anatropous ovules in each loculus: the corolla has usually a contorted rstivation, twisted to the right: fruit a septifragal capsule, or a berry: seed with endosperm. Commonly plants climbing by twining stems: with milky latex.

Convulvus arvensis, the lesser Bind weed (Fig. 274 A), and Calystegia Sepium, the larger Bindweed, the former with two small bracteoles, the latter with two large bracteoles which invest the calyx, and C. Soldanella. the Sea-Bindweed, are common wild plants. Batatas edulis is cultivated in Tropical America for its edible tuberous rhizome, the Sweet Potato.

The genus Cuscuta consists of parasites destitute of chorophyll, with filiform twining stems, which attach themselves to other plants by means of haustoria (see p. 48), and derive their nourishment from them: the small flowers are arranged in fascicles (Fig. 381 b): the corolla has imbricate æstivation: fruit a capsule with transverse dehiscence.

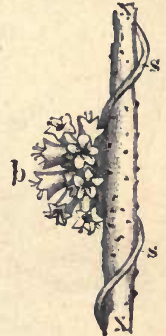

Fra. 381 - Stem of Cuscuta europaea (8), with inflorescence $(b)$ twining round a stem of Hop $(x)$.

Cuscuta europar, the greater Dodder, which occurs commonly on Nettles and Hops, is widely distributed : $C$. Epilinum is the Flax Dodder, and $C$. Epilhymum, the lesser Dodder, occurs on various low-growing plants; $C$. Trifolii attacks Clover, which it often destroys.

Order 2. Polemoniacex. Ovary usualy trimerous and trilocular, with one erect or several oblique ovules in each loculus; capsule loculicidal: seed with endosperm. Mostly herbs.

Polemonium coruleum is Jacob's Ladder; various species of Phlox and Gilia are common garden plants. Cobæa is a genus of plants climbing by means of leaf-tendrils.

Order 3. Solanacex. Ovary usually consists of two obliquely placed carpels, bilocular, with numerous ovules in each loculus: the axile placentæ sometimes project so far into the loculi that 
the ovary appears to be quadrilocular, as in Datura: ovules campylotropous; fruit a capsule with various dehiscence, or a berry: seed with endosperm. Herbs, occasionally woody plants, sometimes climbers by irritable petioles (e.g. species of Solanum); without milky latex. Inflorescence cymose, but complicated by the displacement of the bracts : Fig. $382 \mathrm{~B}$, for instance, is a diagram of the inflorescence of Atropa; the main axis which terminates with the flower 1 , bears a bracteole $1 \alpha$ and a lateral shoot terminating in the flower 2 ; this springs from the axil of a bract $1 \beta$, which, however, is not inserted at the base of its axillary shoot (the point of

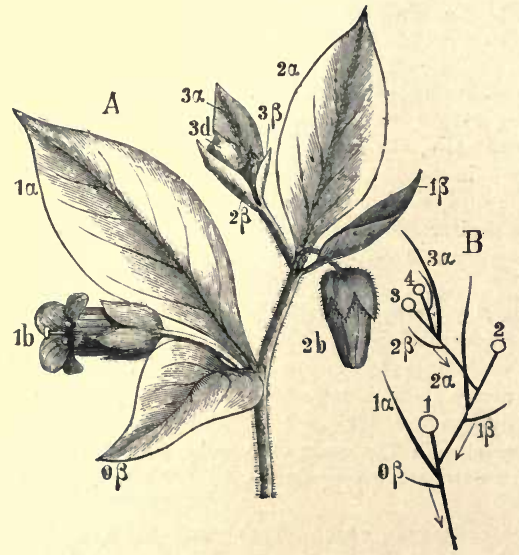

Fia. 382-A Upper portion of a flowering stem of Atropa Belladonna. $B$ Diagram of the same stem : 123 the flowers; $a$ and $\beta$ the bracteoles and bracts. From the axils of $\beta$ spring the new floral axes, along which the bract $\beta$ is displaced.

flowering-shoot springs. In other of the Solaneæ similar arrangements are found. Most plants of this order are poisonous.

Tribs 1. Solanece. Fruit a berry: embryo curved. In the genus Solanum the anthers are syngenesious: $S$. Dulcamara, the Bittersweet or Woody Night-shade, has a blue flower, and S. nigrum has a white flower; both are common: S. tuberosum is the Potato-plant. Physalis Alkekengi, the Winter Cherry, has an inflated red calyx which encloses the berry. Liycopersicum esculentum is the Tomato. The fruits of Capsicum longum and 
annuun are known as Chili Peppers. Atropa Belladonna (Fig. 382) is the Deadly Nightshade; the anthers are not syngenesious, and the corolla is campanulate; the berries are black and very poisonous. Lycium barbarum is a shrub belonging to Southern Europe which has become wild in places in the North. Hyoscyamus niger is the common Henbane: the capsule dehisces transversely (pyxidium).

Tribe 2. Dature. Capsule almost quadrilocular in consequence of the outgrowth of the placenta, 4-valved : embryo curved. Datura Stramonium is the Thorn-apple.

Tribe 3. Cestrece. Embryo straight : all five stamens fertile. Nicotiana Tabacum is the Tobacco plant (Fig. 274B): Petunia is commonly cultivated.

Order 4. Boraginacee. Ovary consisting of two median carpels, spuriously quadrilocular in consequence of a dissepiment along the dorsal suture of each carpel (Fig. $383 \mathrm{C}, r$ ): the single style usually arises from the incurved apices of the carpels (gynobasic),

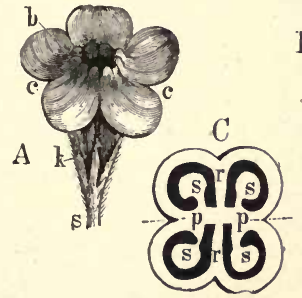

FiG. 383.-A Flower of Anchusa (slightly mag.): $k$ calyx; $c$ corolla; $b$ the scaly appendages. $B$ Fruit of Myosotis (mag.); $t$ the receptacle; $m m$ the four achania; $g$ the gynobasio style. $C$ Diagram of the quadrilocular ovary in trans. section: $r$ the dorsal sutures; $p p$ the placentæ; 8 the ovules.

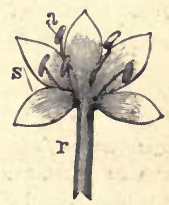

Fig. 381. - Corolla of Ery. thrcea Contaurium spreal out $r$ tube; 8 limb; $a$ stamens.

and is surrounded at its base by the four loculi (Fig. $383 \mathrm{~B}$ ): each loculus contains a single suspended anatropous ovule: when the fruit is ripe the loculi separate completely, and appear to be four nutlets: seed without endosperm: the corolla usually has five scaly ligular appendages at the junction of the limb with the tube (Fig. $383 A b$ ) : inflorescence scorpioid (see p. 441), often very complicated. Herbs or shrubs generally covered with harsh hairs and only rarely glabrous, e.g. Myosotis palustris.

Myosotis is the Scorpion-grass; M. palustris, the Forget-me-not, occurs in damp places, $M$. sylvatica in woods, and $M$. arvensis and others in fields. Lithospermum arvense (Gromwell), L. officinale, Echium vulgare (Viper's Bugloss), with an irregular flower, Symphytum officinale the Comfrey, Lycopsis 
artensis (Common Bugloss), Cynoglossum officinale (Hound's-tongue), and Borago officinalis, the Borage, are common. Anchusa officinalis, the Alkanet; Mertensia maritima, the smooth Gromwell or Sea-Bugloss; and Pulmonaria angustifolia, the Lung-wort, are rare in Britain.

Cohort IV. Gentianales. Flowers regular, but with oligomery in the gynæceum: perianth and andrœcium usually 4- or 5 -merous: corolla with frequently contorted æstivation (to the right): stamens inserted on the tube of the corolla: carpels two: leaves commonly decussate and exstipulate: formula $K(5)[C(\tilde{\mathbf{5}})$ $A 5] G^{(2)}$.

Order 1. Gentianaces. Carpels are perfectly connate, forming a uni- or incompletely bi-locular ovary: ovules parietal, numerous, anatropous: seed with endosperm. Usually herbs without milky latex: leaves almost entire.

Sub-order 1. Gentianes. Leaves decussate: corolla with contorted æstivation.

Gentiana the Gentian, has a bilobed stigma; it occurs in mountainous districts. Erythræa has a capitate stigma; E. Centaurium, the common Centaury, is common in pastures (Fig. 384). Species of Cicendia and Chlora also occur in Britain.

Sub-order 2. Menyanthez. Leaves spiral: corolla with valvate æstivation.

Menyanthes trifoliata, Buck-bean or Bog-bean, with ternate leaves, is common in marshes: Villarsia nymphceoides (or Limnanthemum peltatum) is found in ponds and rivers.

Order 2. Oleaces. Calyx and corolla usually 4-merous, sometimes wanting; stamens and carpels two, alternate: ovary bilocular: ovules 2 in each loculus: fruit a capsule, a berry, a drupe,
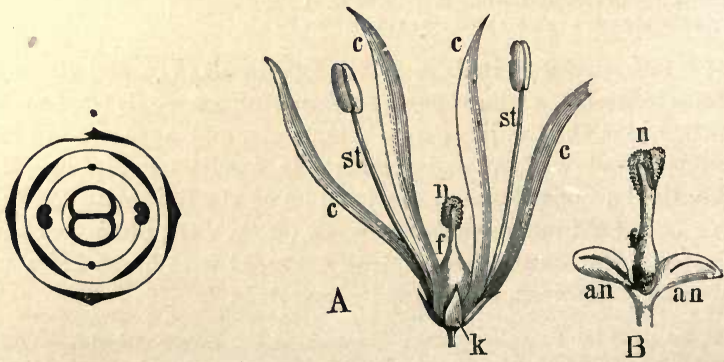

Fig. 385.-A Flower of Fraxinus Ornus (enlarged): $k$ calyx; $c$ corolla; st stamens ; $f$ ovary; $n$ stigma. $B$ ช̧-flower of Fraxinus excelsior, the common Ash; an anthers; $f$ ovary; $n$ stigma (enlarged). Floral diagram of the Oleacex. 
or a samara: seeds 1-4, usually with endosperm: stem woody: leaves always decussate.

Ligustrum has a baccate fruit; $L$. vulgare, the Privet, is a common shrub. Olea has a drupaceous fruit; O. europoea is the Olive-tree of the East and of Southern Europe. The genus Fraxinus has a winged fruit; in $F$. excelsior, the common Ash, the perianth is suppressed and the flowers are polygamous ; in $F$. Ornus, the Manna-Ash of Southern Europe, the perianth is complete, and the corolla is deeply cleft (Fig. $385 \mathrm{~A}$ ). The genus Syringa has a tubular corolla with a 4-lobed limb; S. vulgaris is the Lilac.

The flowers of Jasninum grandiflorum and other species belonging to Southern Europe, contaiu a very fragrant ethereal oil.

Cohort V. Primulales. Flowers actinomorphic, usually pentamerous : formula $K(5)[C(5) A 0+5] G^{(5)}$ : stamens inserted on the tube of the corolla and opposite to its lobes: gynæceum con-
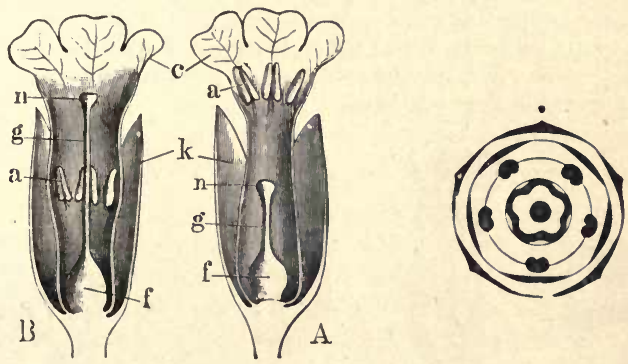

F1G. 586.-Heterostyled flowers of Primula elatior in longitudinal section. A Shortstyled, $B$ long-styled form; $k$ calyx; $c$ corolla; $a$ anthers; $f$ ovary; $g$ style; $n$ stigma. Floral diagram of Primula.

sisting of five connate carpels which are opposite to the sepals; ovary unilocular, with a free, central placenta or a single central ovule: seed with endosperm.

Order 1. Primulacex. Style single: ovales indefinite, on a free central placenta (Fig. $284 G$ ): the corolla is gamopetalous, tubular below, expanding above into a 5-lobed limb; it is suppressed in the genus Glaux: the stamens (Fig. 386 a) are generally adnate to the tube of the corolla and are opposite to its lobes; this position of the stamens is explained by assuming the suppression of an outer antisepalous whorl of stamens which is represented in some genera (e.g. Soldanella) by petaloid staminodes: fruit a capsule. Herbaceous plants with conspicuous flowers. 
The genus Primula has a 5-valved dehiscent capsule, and a 5-cleft calyx, Primula vulgaris is the Primrose; Primula elatior and $P$. veris are the Oxlip and the Cowslip or Paigle; they are remarkable in that they are heterostyled (see p. 411). The capsule of Anagallis arvensis, the Pimpernel, dehisces transversely (pyxidium). Cyclamen europceum, the Sow-bread, has an underground tuber; the lobes of the corolla are reflexed. Lysimachia, the Yellow Loosestrife, has a deeply 5-cleft calyx. Trientalis, the Chickweed Winter-green, has usually a 7-merous flower. The other British genera are Hottonia ( $H$. palustris, the Water-violet), Samolus (S. Valerandi, the Brookweed), and Glaux (G. maritima, the Sea Milk-wort).

Order 2. Plumbaginaces. Styles five: there is a single basal ovule in the cavity of the ovary, pendulous on a long funicle: flowers often small, in dense inflorescences with numerous bracts: no trace of an external antisepalous whorl of stamens.

In the genus Armeria the flowers are in capitula of scorpioid cymes, which are surrounded by an involucre formed of the lower scarious bracts with downward prolongations embracing the peduncle; $A$. maritima, the Thrift, occurs on sandy soils. Statice Limonium, the Sea-Lavender, with racemose cymes, occurs on sandy sea-shores. Plumbago occurs in Southern Europe and in the East Indies.
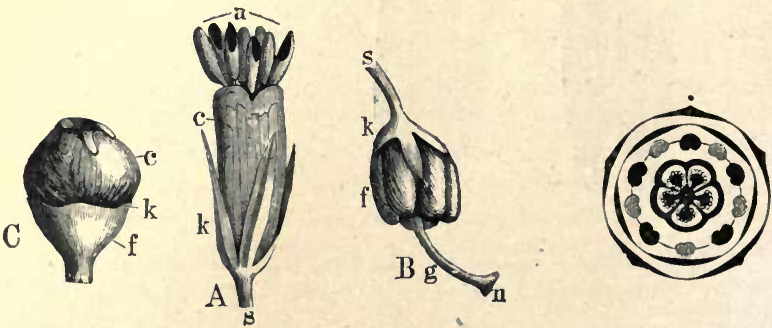

Fig. 387.-A Flower of Frica : $s$ pedicel; $k$ calyx; $c$ corolla; $a$ anthers. B Fruit of Pyrola rotundifolia : 8 pedicel ; $k$ calyx; $f$ fruit, the loculi of which alternate with the sepals; $g$ style; $n$ stigma. C Flower of Vaccinium Myrtitlus : $f$ ovary (inferior); $k$ calyx; $c$ corolla. Floral diagram of Erica : the stamens opposite to the petals are faintly shaded.

Cohort VI. Ericales. Flowers 4-5-merous, actinomorphic: stamens usually in two whorls and then obdiplostemonous, usually hypogynous: carpels opposite to the petals: formula $K(\mathbf{n}), C(\mathbf{n})$, I $A \mathrm{n}+\mathrm{n}, G(\mathrm{n})$, where $\mathrm{n}=4$ or 5 : ovary superior or inferior, multilocular, with large recurved axile placentæ: seed with endosperm : anthers sometimes appendiculate (Fig. $277 \mathrm{~B}$ ).

Order 1. ERICACE. Anthers generally opening by two pores at the top (Fig. $387 \mathrm{~A}$ ), often furnished with appendages : pollen in tetrads : fruit a capsule, or succulent: a well-developed disc. 
Sub-order 1. Rhododendrordes. Fruit a septicidal capsule, corolla fugacious : anthers without appendages.

Rhododendron ferrugineum and hirsutum, the Alpine Roses, are wild on the continent: other species of Rhododendron (incl. Azalea), from the mountains of Asia and North America, as also species of Kalmia from North America, are cultivated. Daboecia polifolia, the Irish Menziesia or St. Dabeoc's Heath, Phyllodoce taxifolia, the Scottish Menziesia, and Loiseleuria procumbens, the trailing Azalea, represent the sub-order in the British Flora.

Sub-order 2. Arbutondes. Fruit a berry, or a drupe, or a loculicidal capsule: corolla fugacious : anthers usually appendiculate.

Andromeda Polifolia, the marsh Andromeda or Wild Rosemary, occurs in peat-bogs, and Arctostaphylos Uva Ursi and alpina, the red and the black Bearberry, on the mountains of Scotland. Arbutus Unedo is the Strawberry-tree of Southern Europe, and Gaultheria is the Aromatic Wintergreen.

Sub-order 3. Ericondex. Fruit usually a loculicidal capsule : corolla persistent: anthers usually appendiculate.

Calluna Erica, the Ling or Heather, with a septicidal capsule and a deeply 4-partite coloured calyx, is common on moors: the principal British species of Erica, are $\boldsymbol{E}$. mediterranea (or carnea), the Irish Heath; $\boldsymbol{E}$. Tetralix, the cross-leaved Heath ; $E$. cinerea, the grey or fine-leaved Heath ; and $\boldsymbol{E}$. vagans, the Cornish Heath. Very many species belong to the Mediterranean region, and to the Cape.

Order 2. Pyrolacex. Sepals nnore or less distinct: petals commonly connate at the base only : anthers without appendages, dehiscing generally transversely or by pores: fruit a loculicidal capsule (Fig. $387 B$ ): seeds minute, with an extremely small embryo consisting of only a few cells, and a relatively massive integument. Saprophytes containing chlorophyll.

Pyrola rotundifolia, secunda, minor, and uniflora, the Winter-greens, are found in woods.

The Monotropes are saprophytes devoid of chlorophyll, with scale-like leaves. Monotropa Hypopitys (Hypopitys multiflora), the Bird's nest, is not very common in England.

Order 3. VACCINIACEx. Ovary inferior (Fig. $387 \mathrm{C}$ ): anthers with appendages (Fig. $277 \mathrm{~B}$ ), usually opening by two pores : fruit a berry.

Vaccinium Vitis-Idoe is the red Whortleberry or Cowberry; it usually blossoms and bears fruit twice in the year: $\boldsymbol{V}$. Myrtillus is the Bilberry, Blaeberry, or Whortleberry, with deciduous leaves: V. Oxycoccos (Oxycoccos palustris, or Schollera Oxycoccos) is the Cranberry: and $\nabla$. uliginosum, the great Bilberry or Bog-Whortleberry. They are all low shrubs occurring on moors. . 


\section{SERIES II. EPIGYNA.}

\section{Ovary inferior.}

Cohort I. Campanales. Flowers actinomorphic or zygomorphic, pentamerous ; formula $K(5) C(5) A(5) G_{(\overline{2})}$ to $\frac{(5)}{\text { : }}$ : sepals leafy and narrow : stamens usually free from the corolla, but often connate : ovary multilocular, of two to five carpels, inferior.

Order I. CAMPANulace£. Flowers regular (Figs. 263, 389) : stamens five, often connate at the base; ovary usually trilocular, with numerous ovules; placentation axile: fruit a capsule: seed with endosperm. Mostly herbs with milky latex.

The gynæceum is often oligomerous, and then usually trimerons (e.g. most species of Campanula, Fig. 389, and Phyteuma), sometimes bilocular (Jasione, species of Phyteuma): when isomerous, the carpels are either antisepalous and therefore opposite to the stamens (e.g. a few species of Campanula, Fig. 263), or antipetalous and therefore alternate with the stamens (e.g. Musschia, Platycodon).

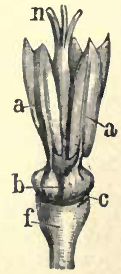

FIG. 339.-Androcinm and gynæceum cf Campanula : $f$ inferior ovary; $c$ insertion of the corolla; $a$ anthers; $b$ expanded base of the stamens; $n$ stigmata (mag.).

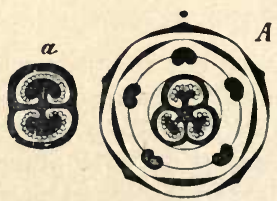

Fit. 389.- $A$ Floral diagram of a spe. cies of Campanula with a trimerous ovary (e.g. C. persicifolia) : a gynæceum of Lobelia.

Campanula rotundifolia, the Hare-bell, glomerata, and other species are common in fields, on heaths, etc., etc.: $C$. Medium is the Canterbury-bell cultivated in gardens. Phyteuma orbiculare and spicatum, the Rampions, are indigenons in parts of England; the flowers are in capitula, and the calyx is deeply 5-cleft with spreading teeth : nearly allied is the genus Jasione; $J$. montana, the Sheep's-bit, is common in England. Specularia has a rotate corolla; $S$. Speculum, Venus's Looking-glass, is cultivated.

Cohort II. Rubiales. Flowers generally regular, actinomorphic or zygomorphic : calyx generally present: stamens epipetalous : gynæceum 2-5-merous : ovary uni- or multi-locular ovules $2-\infty$ : leaves generally opposite. 
Order 1. Rubiacex. Flowers regular, 4- or 5-merous : calyx leafy or suppressed: corolla with valvate æstivation: ovary 1 - or 2-locular, consisting of 2 carpels, 1 or many-seeded : seed usually containing endosperm : leaves decussate, stipulate: stipules (see p. 30) often similar to the true leaves (Fig. $390 \mathrm{~A}$, $n n)$ : the true leaves are distinguished by the branches which arise in their axils (Fig. 390 A, $f f, s s$ ).

Sub-order 1. StrLLATE. Stipules large and leafy: loculi 1 seeded.

Galium, Bedstraw, has a rotate 4-lobed corolla and an inconspicuous calyx,

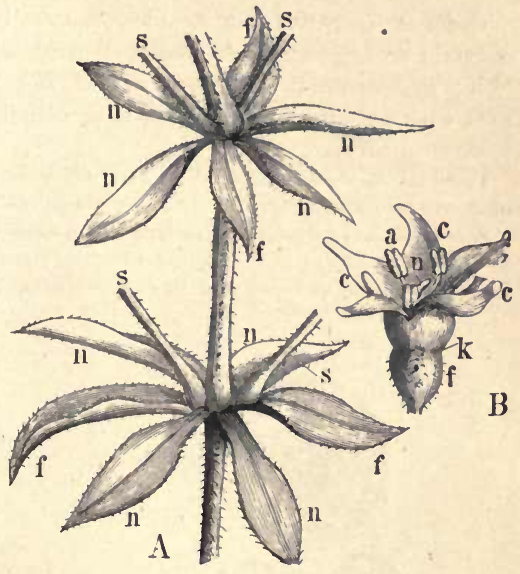

FIG. 390.-A Portion of a stem of Rubia Tinctorum: ff the decussate leaves with the young shoots $(s s)$ in their axils; $n n$ the free stipules resembling the leaves (nat size). $B$ Flower (mag.) : $f$ ovary ; $k$ calyx (rudimentary); $e$ corolla ; $a$ anthers; $n$ stigma.

usually tetramerous: G. verum, Mollugo, Aparine, and others are common in hedges and pastures. Asperula has an infundibuliform corolla, but in other respects the flower resembles that of Galium; $A$. odorata, the Wood-ruff, is common : A. cynanchica is the Squinancy-wort. Rubia Tinctorum, the Dyer's Madder, has a pentamerous flower, a rotate 5-lobed corolla, and a baccate fruit; it is used in dyeing and largely cultivated; it is indigenous in Southern Europe and the East; it is closely allied to the British species $R$. peregrina, the Wild Madder. Sherardia has a tubular 4-lobed corolla, and a conspicuous calyx with a 4-6 toothed limb which persists on the top of the fruit; S. arvensis, the Field Madder, is found in cultivated and waste places.

Sub-order 2. Cofreez. Stipules scaly: loculi 1-seeded.

Coffea arabica, the Coffee-tree of Africa, is grown in the tropics; the fruit, a berry, contains one or two seeds; the so-called coffee-bean is the seed, which consists of hard endosperm and contains a small embryo. Cephaelis yields Ipecachuana.

Sub-order 3. Crachoxex. Stipules scaly; loculi many-seeded.

Various species of Cinchona, indigenous to the eastern slopes of the 
Andes, but cultivated in Java and the East Indies, yield the cinchona bark from which Quinine is prepared. Bouvardias are ornamental greenhouse plants from Central America.

Order 2. CAPRIFoliaCe.e. Flowers usually pentamerous, actinomorphic or zygomorphic: corolla usually with imbricate æstivation; gynæceum 2-5-merous: ovules suspended: fruit baccate; seed with endosperm: leaves opposite, usually exstipulate. Mostly trees or shrubs.

Tribe 1. Sambucece. Flower regular, sometimes completely actinomorphic, corolla rotate (Fig. $274 \mathrm{C}$ ): one ovule in each loculus.

Sambucus has a 5-partite corolla, and 3-5 seeds in the berry ; $S$. nigra is the Elder; $S$. Ebulus is the Dwarf Elder or Danewort. Viburnum has a o-partite corolla, and one seed in the trimerous berry, two carpels being

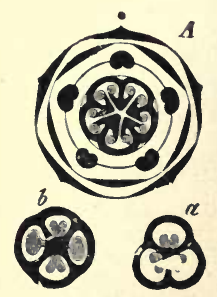

Fig. 391.-Floral diagram of Caprifoliaceæ, $A$ Leycesteria : $a$ gynæceum of Lonicera; $b$ of Symphoricarpus.

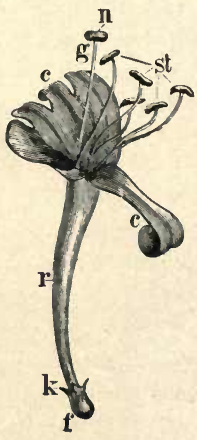

Frg. 392.-Flower of Lonicera Caprifolium : $f$ ovary ; $k$ calyx; $r$ corolla-tube ; $c$ the five lobes of the limb; st stamens; $g$ style; $n$ stigms.

abortive; $\boldsymbol{V}$. Lantana and $\boldsymbol{V}$. Opulus, the Guelder Rose, are common; a form of the last species is cultivated in which all the flowers (and not merely those at the circumference of the corymb as in the original species) have a large corolla, and are barren; V. Tinus is the Laurustinus. Adoxa maschatellina, the Moschatel, is a small plant occurring in damp woods; its flowers are 4- or 5-merous; it appears that there is no calyx, that which is regarded as the calyx being probably an involucre of bracteoles and bract; the stamens are each divided into two, so that there are 8-10 bilocular anthers.

Tribe 2. Lonicerece. Flowers more or less irregular, zygomorphic; corolla tubular : loculi containing several ovules.

Lonicera, the Honeysuckle, has a somewhat bilabiate corolla (Fig. 392), and a 2-3-locular ovary; L. Caprifolium and Periclymenum, with a climbing stem, are well-known garden shrubs; in many species the fruit of two 
adjacent flowers grow together to form a single berry (e.g. L. alpigena). Symphoricarpus racemosus, the Snowberry, has 4-5-locular ovary with white berries; it is a common ornamental shrub. Diervilla (or Weigelia) has a bilocular capsule; $D$. florida and rosea are ornamental shrubs. Linnexa borealis is a small creeping plant in Scotland; it has 4 unequal stamens, the posterior being suppressed, and a trilocular ovary.

Cohort III. Asterales. Flower either irregular or regular, pentamerous, with oligomery in the gynæceum: calyx inconspicuous, of ten wanting: stamens epipetalous, alternating with the segments of the corolla: ovary unilocular, ovule solitary.

Order 1. VAlerianace.E. Flower irregular : calyx rudimentary, sometimes eventually assuming the form of a hairy crown of ten rays, called a pappus, which is not developed until after flowering (Fig. $393 \boldsymbol{B}, p$ ); during flowering it remains short and infolded (Fig. 393 $A, k)$ : stamens $1-4$, usually three: carpels three, of which, however, usually only one developes, so that the fruit is unilocular (Diagram $A$, Fig. 393); ovule single, suspended: seed without endosperm: leaves decussate, exstipulate.

Of the geners occurring in Britain, Valeriana and Centranthus have a pappus, whilst Valerianella has not. Valeriana officinalis, and dioica, are com-

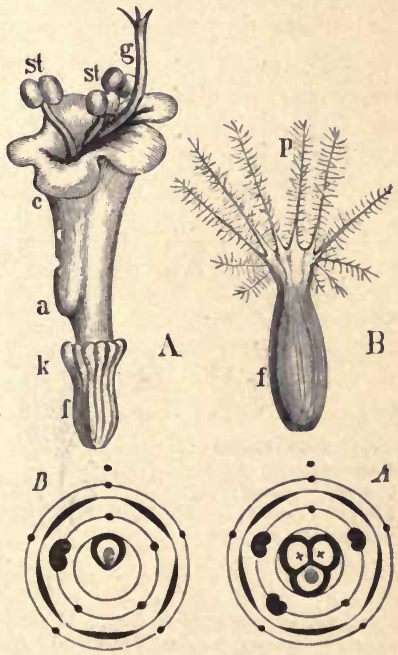

FIG. 393.-A Flower, B Fruit of Valerian: ovary; $k$ calyx; $c$ corolla ; a spur ; st stamens $g$ style; $p$ pappus. Floral diagrams, $A$ of Valerian; abortive carpels $\times \times: B$ of Cen. tranthus.

mon in damp places. Valerianella has a toothed calyx-limb; many species are common in fields: Valerianella olitoric, Corn-salad, or Lamb'slettuce, is eaten. Centranthns ruber is an ornamental plant; only one stamen and one carpel are developed (Fig. 393, Diagram B); at the base of the tube of the corolla is a spur which is indicated in Valeriana by a protuberance.

Order .2. Dipsace.e. Flower more or less dorsiventral, surM.B. 
rounded by an epicalyx (Fig. $394 k^{\prime}$ ) formed of connate bracteoles : calyx often plumose or bristly (Fig. $394 k$ ): corolla usually bilabiate: stamens only four, the posterior one being suppressed: ovary apparently dimerous, one carpel being more or less completely suppressed, unilocular, with one suspended ovule: seed with endosperm: leaves decussate, exstipulate: flowers in a dense capitulum surrounded by an involucre of bracts: the outer florets are usually ligulate: the receptacle may or may not bear scaly bracts (paleæ): fruit invested by the epicalyx which is cleft longitudinally.

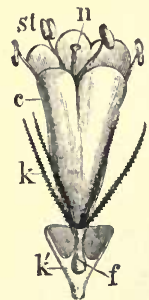

FiG. 394.- Flower of Scabiosa (mag.) : $f$ ovary; $k^{\prime}$ epiculyx (long sect.); $k$ calyx ; $c$ corolla ; st stamens; $n$ stigma.
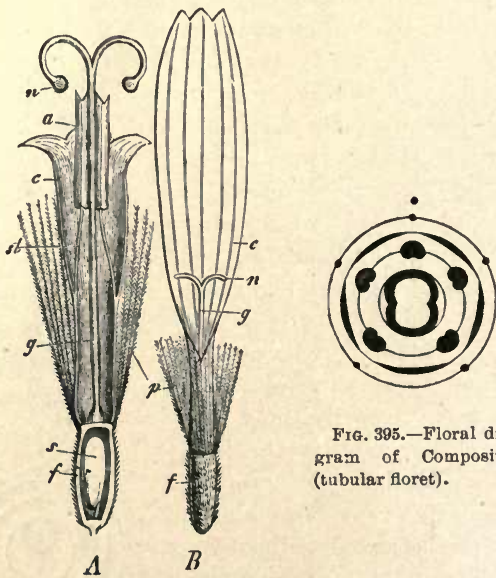

Fra. 395.-Floral diagram of Compositæ (tubular floret).

Fr6. 396.-Flower of Arnica (mag.). A Tubular floret from the centre (disc) (longitudinal sect.). B Ligulate marginal floret (ray): $f$ ovary; $p$ pappus; c corolla; $a$ anthers; st stamen; $n$ stigma; g style; sovale.

Dipsacus, the Teazle, has a calyx without bristles; the capitula of Dipsacus Fullonum are used in finishing woollen cloth, for the sake of the strong hooked spines of the paleæ: D. sylvestris is common on waste ground. In the genus Scabiosa, the paleæ, which are usually present, are not spinous: in the sub-genus Asterocephalus, the epicalyx (or involucel) is 8 -furrowed, and its projecting limb is dry and scarious; S. Columbaria, with a 5-lobed corolla, is common in dry pastures: in the sub-genus Succisa, the limb of the 8-furrowed epicalyx is herbaceous; S. succisa, with a 4-lobed corolla, occurs in damp meadows: in the sub-genus Knautia, there are no paleæ but the receptacle is hairy, and the epicaly $x$ is 4furrowed; S. arvensis is common in fields. 
Order 3. Composite. The flowers are always collected into many-flowered capitula (sometimes only 1-flowered); different kinds of flowers ( $\zeta, q$, or sterile) generally present in the same head: ovary dimerous, unilocular, with a basal, erect, anatropous ovule: the calyx is rarely present in the form of small leaves or scales (Fig. $397 D, p$ ); more commonly it is a crown of simple or branched hairs (pappus; Figs. $396 p ; 397 A, E, p$ ), and is not developed till after the flowering is over; sometimes the calyx is wholly wanting: corolla tubular, either regular, and 5-toothed (Figs. $396 A, c ; 397 C, m, c$ ), or irregular and expanded at the upper end into a lateral limb with 3 or 5 teeth (Figs. $396 \mathrm{~B} ; 397$ $B, r a ; 397 A, c)$, when it is said to beligulate: the stamens are short, inserted upon the corolla (Fig. $396 \mathrm{~A}, \mathrm{st}$ ); the anthers are elongated and syngenesious, forming a tube through which the style passes (Figs. $396 \mathrm{~A}, a$ ): this is bifid at its upper end (Fig. $396 A, n ; 397 A$ and $C, n)$ : on each of these branches the stigmatic papillæ are arranged in two rows: in the wholly $q$ flowers the styles are usually shorter (Fig. $396 \mathrm{~B}, \mathrm{~g}$ ): fruit a cypsela (p. 473), crowned by the pappus (Fig. $397 A, E, D, p$ ) when it is present (Fig. $397 F, f$ ): sometimes the fruit has its upper end prolonged into a beak, and its surface is covered with ridges or spines (Fig. $397 E$ ): seed without endosperm.

Usually herbs with scattered (more rarely decussate), exstipulate leaves, of ten with milky latex. The capitula are always surrounded by a number of bracts forming an involucre (Fig. $397 \mathrm{~B}, \mathrm{C}, \mathrm{i}$ ). The scaly bracteoles of the individual florets (paleæ) may be present or wanting (Fig. $397 C, d$ ).

The Compositæ are classified according to the form of the flowers and to the distribution of the different kinds of flowers in the inflorescence.

Sub-order I. TUBULIFLor.e. The capitula either consists entirely of $\Varangle$ tubular florets (by tubular flowers are meant those with a regular 5toothed corolla); or the central florets (florets of the disc) are tubular and ช (Fig. $396 \mathrm{~A}$ ), whereas the florets of the ray are ligulate and $q$ or sterile and form one or two rows (Figs. $396 B ; 397 B$ and $C, r a$ ).

Tribe 1. Eupatoriece. Leaves mostly opposite: flowers all tubular, ఫ the branches of style narrow ; papillæe extending to the middle.

Eupatorium cannabinum, the Hemp Agrimony, is common in damp places.

Tribe 2. Asteroidece. Leaves alternate: ray-florets $q$ or sterile, generally ligulate: branches of the style hairy above, papillæ extending to where the hairs begin. Many species of Aster, belonging chiefly to North 
America, are cultivated as ornamental plants, as also Callistephus hortensis, commonly known as the China Aster. Erigeron acre, alpinum, and canadense occur in England; the last is an imported weed. Bellis perennis, the Daisy, has no pappus. Solidago virgaurea is the Golden Rod.

Tribe 3. Senecionidece. Leaves alternate: ray-florets in one row, ligulate \& , rarely absent: branches of the style tufted at the tips.

Senecio vulgaris, the common Groundsel, has no ray-florets. Arnica niontana occurs in Alpine woods. Two species of Doronicum(D. Pardalianches and plantagineum) have become naturalized in England. Petasites vulgaris, the Butter-bur, and Tussilago Farfara, the common Coltsfoot, are common in damp fields.

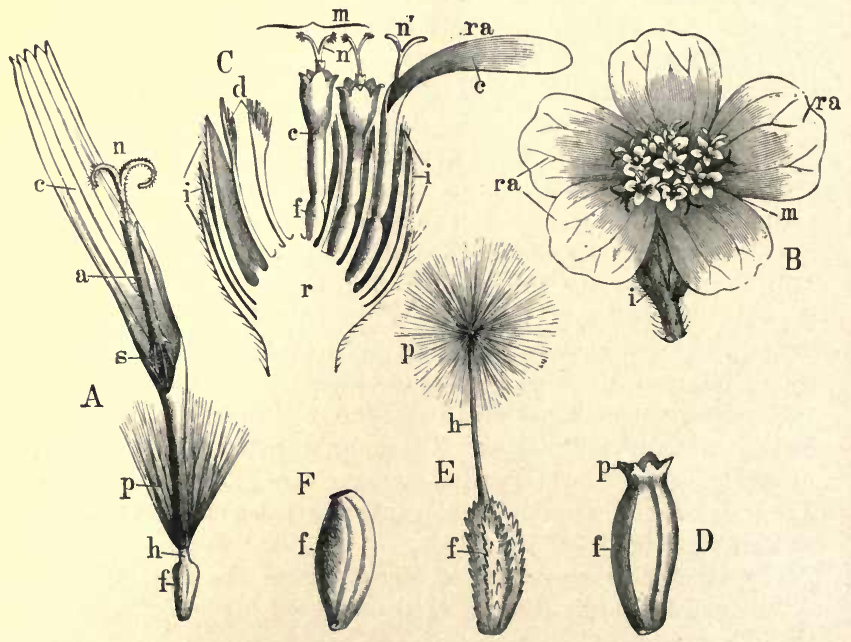

FrG. 397.-Flowers of Compositæ : $f$ fruit or ovary; $h$ its beak; $p$ pappus; $c$ corolla; $s$ stamens; $a$ anthers ; $n$ stigmata. A Ligulate Hower of Taraxacum, with a 5-toothed corollalimb, ఛ. B Capitalum of Achillea: ra floret of the ray, with ligulate 3-toothed corolla, \&; $m \not$ florets of the disc, with a 5 -toothed tubular corolla; $i$ involucre. $C$ Longitudinal section more highly magnifled; $r$ receptacle; $i$ involucre; $d$ bracteoles (paleæ); ra floret of the ray; $m$ florets of the disc; $n^{\prime}$ stigmata of the $q$ flowers. D Fruit of Tanacetam with a scaly pappus: $E$ of Taraxacum, with a hairy pappus; $h$ beak : $F$ of Artemisia without a pappus (mag.).

Tribe 4. Anthemidece. Leaves alternate: ray-florets $q$, ligulate or tubular: branches of style tufted at the tips: involucral bracts scarious : pappus 0 , or minute.

Artemisia Absinthium, Wormwood, A. vulgaris and campestris are common: Chrysanthemum Leucanthemum, the Ox-eye Daisy, is common in fields: Matricaria Chamomilla, the Wild Chamomile, has a hollow conical recep- 
tacle destitute of paleæ: Anthemis nobilis, the Common Chamomile, has a receptacle bearing paleæ, as also $A$. arvensis, the Corn Chamomile: Achillea Millefolium is the Milfoil, or Yarrow: Tanacetum vulgare is the Tansy: Diotis maritima is the sea-side Cotton-weed.

Tribe 5. Helianthoidece. Leaves opposite: ray-florets 0 or ligulate yellow, $f$ or sterile: branches of style as in Asteroideæ.

Bidens is common in wet places. Galinsoga is naturalized in England. Helianthus annuus is the Sunflower; oil is extracted from the seeds: the tubers of $H$. tuberosus, a West Indian species, are rich in inulin (p. 83), and serve as a vegetable (Jerusalem Artichoke). Species of Zinnia, Rudbeckia, Dahlia, and Coreopsis are cultivated.

Tribe 6. Helenioidece. Resemble the Helianthoideæ, but the receptacle is without paleæ. Species of Helenium, Tagetes, Gaillardia, are commonly cultivated as garden flowers.

Tribe 7. Inuloideo. Leaves alternate: ray-florets frequently ligulate, $f$, yellow : anthers appendiculate at base.

In Inula ( $I$. Helenium, the Elecampane), Pulicaria ( $P$. dysenterica, the Fleabane), and others, the ray-florets are ligulate; whereas, in other genera, Gnaphalium (the Cndweed), Filago, Antennaria, the ray-florets are fil:form; Antennaria is diøecious.

Tribe 8. Cynarea. Flowers all tubular, the outer ones sometimes $q$ or sterile: style thickened below the branches: anthers often appendiculate at base: leaves generally armed with spines, alternate.

Arctium Lappa (A. majus), the Burdock, is common by roadsides; the leaves of the involucre are hooked and spinous. Carduus nutans and crispus are the common (true) Thistles; Cnicus lanceolatus, palustris, pratensis (Plume-Thistles), are common in damp districts. Carlina vulgaris is the Carline-Thistle; the inner leaves of the involucre, which are white, fold over the flower-head under the influence of moisture, but in drought spread widely open. Onopordon Acanthium is the Scottish or Cotton Thistle. Centaurea Scabiosa and nigra, the Knapweeds, are common everywhere: $C$. Cyanus is the Corn-flower or Bluebottle, occurring in wheat-fields. Cynara Scolymus is the Globe-Artichoke; the flower-buds are eaten as a vegetable. Carthamus tinctoria, the Safflower, is used in dyeing. In Echinops, the Globe-Thistle, numerous one-flowered capitula are collected into one large spherical head. Saussurea and Serratula are the Saw-worts.

Tribe 9. Calendulea. Ray-florets $q$ and usually ligulate: disc-florets usually sterile.

Calendula officinalis, the Pot-Marigold, is a familiar garden plant.

Sub-order II. Labiatiflorx. The $\Varangle$ disc-florets have a regular or a bilabiate corolla; the ray-florets have usually a bilabiate corolla.

Tribe 10. Mutisiece. This tribe includes all the Compositæ with a bilabiate corolla: they come mostly from South America. Mntisia is one of the few climbing genera : it climbs by means of leaf-tendrils.

Sub-order III. Liguliflorx. All the florets are $\Varangle ;$ limb of the corolla 5-toothed and ligulate (Fig. 397 A).

Tribe 11. Cichoriea. Mostly herbs, all containing latex in laticiferous vessels (Fig. 80, p. 99). 
Taraxacum officinale, the Dandelion, is the commonest of wild flowers. Lactuca sativa is the Lettuce: L. Scariola, virosa, and others are common in waste places. Scorzonera hispanica is eaten as a vegetable. Tragopogon porrifolius is the Salsafy; T. pratensis, the Goat's-beard, is common. Cichorium Intybus, the Chicory, is found by roadsides; the roasted roots are mixed with Coffee: C. Endivia (Endive) is a vegetable. To this tribe belong also the British genera Hypochæris (Cat's-ear), Arnoseris (Lamb's Succory), Leontodon (Hawkbit), Hieracium (Hawkweed), Sonchus (SowThistle), Crepis (Hawk's-beard), Lapsana (Nipplewort), Picris. 


\section{INDEX.}

\section{PART I.-MORPHOLOGY, ANATOMY, AND PHYSIOLOGY.}

Abscission-layer, 156.

Absorption, 158, 177.

of gases, 178.

of liquids, 178.

Accumbent, 536 .

Achene, 473.

Achlamydeous, 457.

Acicular leaves, 32, 433.

crystals, 81 .

Acids, organic, 187.

Acrocarpous, 333.

Acropetal development of members, 9.

of tissue, 126.

Acrotonous, 504 .

Actinomorphic symmetry, 453.

Acuminate, 37.

Acute, 37.

Acyclic flower, 445 (Fig. 262), 527.

Adhesion, 21, 462.

Adnate, 460.

Adventitious members, 9, 136.

Ecidiospore, 300.

Fcidium, 300 (Fig. 178).

Aerial roots, 45, 109 (Fig. 87).

Estivation, 43.

Air-bladders, 269.

Air-cavity, 108 (Fig. 88), 115.

Air-chamber, 89, 321 (Fig. 199).

Alæ, 546 (Fig. 358), 557 (Fig. 369).

Albuminous seed, 414 (Fig. 245).

Alburnum, 143, 165.

Aleuron, 80 (Figs. 51, 55), 201.

Alkaloids, 186, 201.

Alternation of generations, 2, 234.

Aluminium, 189.

Amentum, 442, 517.

Amides, 186, 196, 199, 201.

Ammonia, 190.

Amœboid stage, 283.

Amphigastria, 319.

Amphithecium, 136, 316, 337.

Amplexicaul, 30.

Amygdalin, 187.
Amylin, 187.

Amylolytic enzyme, 198.

Amyloplastic function, 70 .

Amyloses, 187.

Anabolism, 193.

Anatomy, 63.

Anatropous ovule, 399 (Fig, 237).

Androecium, 443, 460 .

Androspore, 258.

Anemophilous, 410.

Angiocarpous sporophore, 303.

Angustiseptal silicula, 535 (Fig. 348).

Annual plants, 417.

rings, 141 (Figs. 112-3). shoots. 23.

Annular vessels, 74 (Fig. 44),

Annulus, 302 (Fig. 182), 343 (Fig. 208), 363 (Figs, 215े-7)。

Anterior, 448.

Anthela, 442.

Anther, 395, 460 (Figs. 276, 279),

Antheridial cell, 406.

Antheridiophore, 310 (Fig. 198).

Antheridium, 60, 243, 310, 350, 369 (Figs. 139, 140, 147, 148, 150, $158,160,192,193,222$ )

Anthocyanin, 83.

Anthophore, 444, 532 (Fig. 344).

Anticlinal, 102.

Antipetalous, 447.

Antipodal cells, 408 (Fig. 212).

Antisepalous, 446.

Apex, 4.

A pical cell, 101, 104 (Figs. 85, 86), 132 (Fig. 106), 133, 321 (Fig. 200).

Aplanogamete, 240.

A pocarpous, 465 (Fig. 281), 472.

Apophysis of Moss-capsule, 398. of Pinus, 435.

A postrophe, 172 (Fig. 124).

A pothecium, 294 (Fig. 177).

Aqueous tissue, 115. 
Archegoniophore, 310 (Fig. 198).

Archegonium, 60, 235, 311, 350, 409

(Figs. 191, 195, 223, 211, 252).

Archesporium, 53, 136 (Figs. 197, $206,210,216)$.

Archicarp, 60, 237, 278, 293 (Fig. 172 ).

Aril (or arillus), 415 (Figs. 246, 258 ).

Arillode, 415, 516.

Arista, 488.

Arrangement of lateral members, 10.

Ascidium, 41 (Fig. 28), 175.

Ascocarp, 62, 27\%, 280, 293 (Figs. $171,173,175)$.

Ascogenous hyphæ, 293 (Fig. 175).

Ascogonium, 278, 291, 296 (Fig. 175).

Ascospore, 290, 294 (Figs. 173, 175, $176)$.

Ascus, 278, 293 (Figs. 171, 175, 176).

Asexual formation of spores, 50 , 230.

reproductive cells, 2,50 .

reproductive organs, 2,51 .

Ash, 188.

Asparagin, 186, 199.

Assimilation, 158, 193.

Asymmetry, 456 (Fig. 273).

Auriculate, 31 (Fig. 20), 326 (Fig. 202).

Autumn-wood, 142 (Figs. 112-3).

Auxospore, 26.

Awn, 487 (Fig. 301).

Axial placentation, 468.

Axil, 11.

Axillary branching, 11.

Axile placentation, 468 (Fig. 284).

Axis, 4, 18.

Bacca, 475.

Bacterioids, 191.

Balsam, 97.

Bark, 153 (Fig. 119).

Basal wall, 314, 346.

Base, 4.

Basidiospore, 303 (Figs. 183, 184).

Basidium, 303 (Figs. 183, 184).

Basifixed anther, 460.

Basitonous, 504.

Bast, 121 (Figs. 100-5), 130, 143. hard, 143.

soft, 143.

Bast-fibres, 130, 143 (Fig. 111).

Berry, 475.

Biennial plants, 418.

Bifurcation, 19.

Bijugate, 35 .
Bilabiate, 45๊.

Bilateral Symmetry, 6.

Bilocular anther, 463.

Bipinnate, 35.

Biseriate perianth, 457 .

Bisexual, 61.

Biternate, 37.

Blade of leaf, 29, 32.

Bleeding, 182.

Bloom on plants, 107 .

Body, 1, 63.

septate or unseptate, 63.

Bordered pits, 74 (Figs. 48, 49).

Bostrychoid dichotomy, 19 (Fig. 9).

Bostryx, 441.

Bract, 57, 442.

function of, 175 .

Bracteole, 57, 443.

Branches, development of, 9, 132.

Branching, 3.

axillary, 11.

dichotomous, 18 (Fig. 9)

cymose, 19 (Fig. 11)

racemose, 19.

of leaf, 34 .

of root, 45 (Fig.30), 133(Fig.107). of shoot, 12, 132.

Branch-systems, 18 (Figs. 9-11).

Bromine, 189.

Bud, 11.

adrentitious, 136.

Budding, 229.

Bud-scales, 42.

Bulb, 25 (Fig. 13), 50.

Bulbil, 25, 50, 232 .

Bundle, vascular, 121.

bicollateral, 123.

cauline, 122.

closed, 127.

collateral, 123.

common, 122.

concentric, 123, 125 (Fig. 101).

conjoint, 121.

medullary, 123.

open, 127.

phloem-, 125.

xylem-, 125.

longitudinal course of, 122

(Fig. 99).

structure of, 129.

termination of, 130 .

Bursicula, 504.

Calcium, 188, 192.

carbonate, 78 (Fig. 52), 81, 202.

oxalate, 78 (Fig. 51), 81 (Figs. $57,58), 202$.

Callus, 137, 155 (Fig. 121). of sieve-tubes, 95 (Figs. 75, 76).

Calyculus (epicalyx), 445. 
Calyptra, 62, 313 (Figs. 196, 206, 211).

Calyx, 58, 443.

Cambium, 127, 130 (Fig. 105), 137 (Figs. 108, 109).

Cambium-ring, 137 (Fig. 110).

Campanulate, 458 .

Campylotropous ovule, 399 (Fig. 237).

Cane-sugar, 187, 198.

Caoutchouc, 167.

Capillitium, 283 (Fig. 164).

Capitate hairs, 46.

Capitulate raceme, 440.

Capitulum of Charoideæ, 261. inflorescence, 439 (Fig. 259).

Capsule of Bryophyta, 52, 314, 337 (Figs. 197, 206, 208-11).

Capsule, a fruit, 475 (Figs. 288, 289).

Carbohydrates, 186, 201.

Carbon, 189.

Carbon dioxide, absorption of, 189, 193.

evolution of, 200.

Carcerule, 473, 541 (Fig. 852).

Carina, 557 (Fig. 369).

Carinal cavity, 383 (Fig. 230).

Carpel, 56, 395, 465.

Carpellary flower, 56, 395 .

Carpogamy, 241, 277.

Carpogonium, 242, 272 (Fig. 160).

Carpophore, 466 (Fig. 287).

Carposporangium, 244, 273 (Figs. $160,161)$.

Carpospore, 274.

Caruncle, 416, 526.

Caryopsis, 473.

Catabolism, 158, 185, 197.

Cataphyllary leaves (Cataphylls), $42,175$.

Catkin, 442, 517 (Figs. 327-31).

Caudicle, 504.

Caulicle, 377.

Cauline vascular bundles, 122.

Cell, 1, 63, 66 (Fig. 36).

Cell-contents, 78 .

Cell-division, 83 (Fig. 60).

Cell-formation, 83 (Figs. $60-85$ ).

Cell-sap, 66, 82 .

Cell-wall, 63, 66, 72, 76. growth of, 73 .

Cellular structure, 61 .

Cellulose, 66, 72, 76, 187, 201.

Chalaza, 399 (Fig. 237).

Chalk-glands, 96, 202.

Chambered ovary, 466 (Fig. 282).

Chemical composition of plants, 185.

Chemical effects of light, 161 .

Chemiotaxis, 220, 232.

Chlamydospore, 277, 286, 304.
Chlorine, 188.

Chlorophyll, -corpuscle, 71, development of $161,192$.

function of, 194.

Chloroplastids, 69 (Figs. 38, 40, 41). functions of, 70 .

movements of, 172 (Fig. 124).

Chlorotic, 192.

Chromatin, 69.

Chromatophore, 69 (Figs. 41, 42).

Chromoplastid, 69 (Fig. 42).

Cincinnal dichotomy, 19.

Cincinnus, 441.

Cilium, 72, 207 (Fig. 62).

Circinate vernation, 43 .

Circulation of protoplasm, 204, 206.

Citric acid, 187.

Classification, 233.

Claw, 458 (Fig. 275).

Cleistogamous flowers, 410.

Cleistothecium, 294 (Fig. 173).

Climbing plants, 27 (Fig. 15), 212, 223.

Closed vascular bundles, 127.

Cobalt, 189.

Coccus, 472.

Cœnobium, 239, 253.

Coenocyte, 64, 100 (Fig. 81), 250 (Figs. 140-2), 252 (Fig. 143), 276.

Cohesion, 21 (Fig. 12), 462.

Coleoptile, 478 (Fig. 292).

Coleorhiza, 479 (Fig. 293).

Collateral vascular bundles, 123 (Figs. 97, 100).

Collenchyma, 91 (Fig. 69), 111.

Colleter, 101, 167.

Colony, 238.

Colouring-matters, 83, 186.

Columella, 285 (Fig. 165), 317 (Figs. $197,208)$.

Column, 444.

Combined effects of stimuli, 222.

Common bundles, 122.

Companion-cell, 95 (Fig. 74), 166.

Compound inflorescences, 439, 441.

Compound leaves, 35 (Fig. 23).

Concentric arrangement of bundles, 123 (Fig. 101).

Conceptacle, 269 (Fig. 157).

Conditions of movement, 223.

Conducting tissue of style, 467 . -sheath, 184.

Conduplicate vernation, 43.

Cone, 55, 382, 386, 421, 433 (Figs. $228,231,254,255)$.

Conical root, 45 .

Conidiophore, 279.

Coniferin, 187.

Coniin, 186. 
Conjoint bundle, 121.

Conjugation, 58, 87 (Fig. 65), 240 255, 256 (Fig. 146), 286 (Fig. 166).

Conjunctive tissue, 118, 144.

Connate, 32 (Fig. 20).

Connective, 460 (Fig. 276).

Contorted vernation, 43 .

Contractile vacuoles, 206.

Convolute vernation, 43 .

Copper, 189.

Cordate, 37.

Cork, 151 (Fig. 118).

Corm, 25, 50 (Fig. 309).

Corolla, 58, 443.

Corona, 48, 458. of Characeæ, 262 (Fig. 150).

Cortex, 111, 149, 260.

Corymb, 442 .

Costæ, 548.

Cotyledon, 28, 403 (Figs. 238, 239), 414 (Fig. 245), 476 (Figs. 291-3), 509 (Figs. 320-1).

Crenate, 37.

Cross-fertilisation, 232.

Cross-pollination, 409.

Cruciate tetraspores, 271.

Crumpled æstivation, 43.

Crystalloids, 81 (Fig. 54).

Crystals, 78 (Fig. 51), 81 (Figs. 57, 58). Culm, 28.

Cupule, 49, 313, 323 (Fig. 198), 337. of Phanerogams, 472, 518, 520 (Figs. 332, 333).

Cuticle, 106.

Cuticularisation of cell-wall, 76, 91 .

Cutin, 76.

Cyathium, 526 (Fig. 341).

Cyclic flower, 445 .

Cyclosis, 204, 205, 260.

Cyme, 441.

helicoid, 21 (Fig, 11), 441.

scorpoid, 21 (Fig. 11), 441.

Cymose branching, 19 (Fig. 11).

inflorescence, 441.

Cypsela, 473.

Cystocarp, 62, 241, 273 (Figs. 160, 161).

Cystolith, 78 (Fig. 52), 202.

Cytoplasm, 68.

Daily periodicity of growth, 214.

Day-position, 174.

Deciduous, 10.

Decussate arrangement of leaves, 13.

Definite inflorescences, 441.

Definitive nucleus, 408.

Dehiscence of anther, 396, 463. of fruits, 473 .
Dehiscence of sporangium, 54,361 .

Dehiscent fruits, $416,473$.

Dentate, 35, 37.

Dermatogen, 102 (Figs. 83, 84).

Development of body, 8 . of branches of roots, 133. of branch-systems, 18. of leaves, 133.

of secondary members, 132.

of hairs, 135 .

of emergences, 135.

of reproductive organs, 135.

of adventitious members, 136 .

Dextrin, 187, 198.

Dextrose, 198.

Diadelphous, 462.

Diageotropism, 171, 218.

Diagonal plane of flower, 448.

Diagram, floral, 447.

Diaheliotropism, 171, 215.

Diaphragm, 379, 393 (Fig. 233).

Diastase, 198.

Diastole, 206.

Dichasial cyme, 442.

Dichasium, 20 (Fig. 10), 441.

Dichlamydeous, 455 .

Dichogamy, 411.

Dichotomy, 9, 18 (Fig. 9), 132 (Fig. 106).

Diclinous, $61,310,395$.

Dicyclic, 450.

Didynamous, 462.

Differentiation of tissues, 65, 101, $125,145$.

Digestive sac, 135.

Dimorphism, 411.

Diøecious, $61,310$.

Diplotegium, 475.

Diplostemonous, 450 .

Directive effect of light, 162, 214. of gravity, 217.

Dise, 470 .

Dissected leaves, 37.

Dissemination of seed, 416 .

Dissepiment, 466.

false or spurious, 466.

Dissipation of energy, 203.

Distractile anther, 460 (Fig. 276).

Distribution of water and other substances, 181.

of organic plastic substances, 184.

Diurnal and nocturnal positions, 173 (Figs, 125, 126).

Divergence, 12.

Dorsal suture, 465 .

Dorsifixed anther, 460 (Fig. 276).

Dorsiventral arrangement, 17.

Dorsiventrality, 7 (Fig. 2), 13, 451 (Figs. 271, 272). 
Double flowers, 452.

Drepanium, 411.

Drape, 475 (Fig. 290).

Drupel, 475.

Duet, 98.

Duplication, 450 .

Duramen, 143, 165.

Dwarf-males, 258 (Fig. 147).

Dwarf-shoots, 23.

Egg-apparatus, 408 (Fig. 242).

Elater, 316, 383.

Elementary constituents of the food of plants, 188.

Eleutheropetalous, 458.

Eleutherophyllous, 458.

Eleutherosepalous, 458.

Emarginate, 37.

Embryo, 8.

Embryo-cell, 401.

Embryogeny of Bryophyta, 314, 319, 337 : of Gymnosperms, 424 (Figs. 249-251): of Phanerogams, 401 (Dicotyledons, Fig. 238 ; Monocotyledons, Fig. 239): of Pteridophyta, 346, 366 (Figs. 218-220), 377, 385, 387, 393 (Figs. 233, 235).

Embryonal tubes, 427 (Fig. 250).

Embryo-sac, 51, 400 (Figs. 241-2), 424.

Emergences, 48, 135.

Endocarp, 472 (Fig. 290).

Endodermis, 111, 115, 134 (Figs. 94, 96).

Endogenous development, 9, 44, 131 (Fig. 107).

Endopleura, 415.

Endosperm, 407 (Fig. 241), 414.

Endospore, 50.

Endothecium, 136, 316 (Fig. 197).

Energy of growth, 209.

absorption of, 194.

dissipation of, 203.

kinetic, 194.

potential, 197.

Ensiform, 32, 479.

Entire, 35.

Entomophilous, 410.

Enzyme, 189, 197.

Epibasal cell, 314, 346, 387.

Epiblast, 478 (Fig. 292).

Epiblema, 106.

Epicalyx, 57, 175, 443, 578.

Epicarp, 472 (Fig. 290).

Epicotyl, 404.

Epidermis, 106 (Figs. 87-90, 92).

Epigean cotyledons, 405.

Epigynous, 441 (Fig. 261).

Epinasty, 211 (Fig. 131).
Epipetalous, 462.

Epiphragm, 344.

Epiphyllous, 462.

Epiplasm, 294.

Epipodium, 29, 32.

Episporium (Epispore), 287, 376.

Epistrophe, 172 (Fig. 124).

Equitant, 43.

Erect ovule, 469 (Fig. 281).

Erythrophyll, 83.

Etærio, 476.

Etiolated plants, 162, 213.

Etiolin, 161.

Eucyclic, 449.

Eusporangiate, 53, 319.

Evolution of oxygen from waterplants, 195 (Fig. 128).

Exalbuminous seed, 414.

Excretion, 202.

Exine, 50.

Exodermis, 111 (Fig. 87).

Exogenous development, 9.

Exospore, 50.

Exstipulate, 30 .

External conditions, 159.

Extra-floral nectaries, 96, 166.

Extra-seminal development, 401.

Extrorse, 464.

False dichotomy, 20 (Fig. 10). foot, 315,339 .

Fascicle, 442.

Fascieular cambium, 138.

Fats, 80, 187, 201.

Fat-enzyme, 198.

Feeder, 393.

Female organ, 60. pronucleus, 414.

Ferment, organised, 198.

Fermentation, alcoholic, 198.

Fertilisation, 59.

Fibres, 92. woody, 140.

Fibrous cells, 92, 140. root, 45 .

Fibro-vascular bundle, 121.

Filament, 88, 395.

Filtration under pressure, 182.

Fixed light-position, 173. oils, 187.

Flanks, 6.

Floral diagram, 447. formula, 448 .

leaves, $55,175,445$.

organs, 456.

Flower, 25, 55, 394. accessory organs of, 470 . irregular, 454. macrosporangiate, 56,395 . microsporangiate, $56,395$. 
Flower, opening and closing of, 176. regular, 453.

reproductive organs of, 176,395 . symmetry of, 453.

phyllotaxy of, 445.

Fluorine, 189.

Foliage-leaves, 39 (Figs. 18-28), 114 (Fig. 92), 171.

Follicle, 473.

Food of plants, 188.

Foot, 314, 319, 337 (Fig. 206), 347

(Fig. 218-220), 393 (Fig. 234).

Form of leaves, 28 (Figs. 18-29).

root, 45 (Fig. 30 ).

shoots, 23 (Figs. 13-15).

stems, 27 (Figs. 16, 17).

Forms of tissue, 90 .

Formation of chlorophyll, 161.

Formation of tissue in consequence of injury, 155 .

Formative region, 208.

Fovea, 356 (Fig. 213).

Foveola, 356.

Free cell-formation, 87.

Freezing, effects of, 160 (Fig. 122).

Fruit, 61, 232, 414, 471 .

dehiscence of, 473 .

dry dehiscent, 473 .

dry indehiscent, 473.

succulent, 475 .

Frustule, 265 (Fig. 152).

Function of chlorophyll, 194.

Functions of the members, 167. of plants, 157.

of the tissues, 162.

Funicle, อ๊3, 399.

Fusiform root, 45 .

Galeate, 562.

Gallotannin, 187.

Gametangium, 58, 60, 242 (Fig. 146), 278, 285 (Fig. 166).

Gametes, 2, 58, 240.

Gametophore, 58, 310.

Gametophyte, 2, 229, 234.

Gamopetalous, 458.

Gamophyllous, 458.

Gamosepalous, 458.

Gamostelic, 117.

Gemmæ, 49, 240, 313, 337, 352.

Gemmation, 49, 276.

Generations, alternation of, 2, 234 .

Genetic spiral, 14 (Fig. 8).

Generative cell, 406, 429.

Genus, 285.

Geotropism, 217 (Fig. 132). negative, 171, 218. positive, 169, 218.

Germination of seed, 199, 401 (Figs. $251,291,320$ ).
Gibbous, ว664 (Fig. 378).

Glandular hairs, 100 (Fig. 82).

Glandular tissue, 96 (Figs. 76-79), 166.

Glans, 473.

Globoid, 80 (Fig. 54).

Glochidia, 376.

Glomerule, 442.

Glucoses, 187.

Glucoside, 187.

Glucoside-enzyme, 198.

Glume, 442, 487 (Figs. 300, 301).

Glycerin, 198.

Glycogen, 294.

Gonimoblastic filaments, 273.

Gonophore, 444.

Graft-hybrids, 229.

Grafting, 229.

Grand period of growth, 209.

Grape-sugar, 187.

Ground-tissue, 110.

Growing-point, 8 (Fig. 3), 102 (Figs. 83-86).

Growth, 8, 207.

in length, 207.

in thickness of stem and root, 137.

limited, 9.

of cell-wall, 78 .

of leaf, 29.

sliding, 147.

Guard-cells of stomata, 107 (Fig. 8S), 179.

Gum, 97, 187.

Gymnocarpous sporophore, 303.

Gynandrosporous, 258.

Gynandrous, 462.

Gynæceum, 443, 465.

Gynobasic style, 467.

Gynophore, 444.

Gynostemium, 444, 503 (Fig. 318).

Hairs, 3, 109 (Fig. 90), 135. internal, 92.

Hapteron, 48, 240.

Hastate, 37.

Haulm, 28.

Haustorium, 48, 190, 276.

Heart-wood, 143.

Heat, influence of, 160. production of, 203 (Fig. 129).

Helicoid cyme, 21 (Fig. 11), 441. dichotomy, 19 (Fig. 9).

Heliotropism, 162, 169, 171, 214. negative, 169, 216. positive, 171, 216.

Hemiangiocarpous, 303.

Hemicyclic, 445.

Herbaceous, 27.

Hermaphrodite, 61, 395. 
Heterochlarnydeous, 457 .

Heteroclinous, 335.

Heterocyclic, 449.

Heterocyst, 245 (Figs 135, 136).

Heterocism, 299.

Heterogamy, 58, 241, 277.

Heteromerous lichen-thallus, 306. floral whorls, 449 .

Heterophylly, 41,

Heterosporous, 51, 349, 394.

Heterostylism, 411.

Hilum, 79, 399.

Histological differentiation, 65.

Histology, 63.

of Gymnospermæ, 419.

of Phanerogamia, 400.

of Pteridophyta, 365, 377, 383, 387, 391.

of the development of secondary members, 132.

Homochlamydeous, 457.

Homoiomerous lichen-thallus, 306.

Homosporous, 51, 349, 380.

Hook-climbers, 171.

Hormogonium, 214 (Fig. 136).

Humus, 190.

Hybrid, 232.

Hybridisation, 232.

Hydrogen, 186, 188, 190.

Hydrotropism, positive, 169.

Hymenial layer, 293. 302.

Hymenophore, 302 (Fig. 183).

Hymenium, 302 (Fig. 183).

Hypha, 275.

Hypobasal cel], 314, 346.

Hypocotyl, 404.

Hypoderma, 111.

Hypogean cotyledons, 405.

Hypogynous, 444 (Fig. 261).

Hyponasty, 211.

Hypophysis, 403 (Figs. 238, 239).

Hypopodium, 29, 30.

Hypsophyllary leaves, 55, 57 (Fig. 27), 175.

Ice, formation of, 161 (Fig. 122).

Imparipinnate, 35 (Fig. 23).

Incubous leaves, 326 (Fig. 202).

Incumbent, 536 .

Indefinite inflorescences, 439.

Indehiscent fruits, 473,475 .

Induced movements, 211.

Indusium, 348, 361.

Inferior ovary, 444 (Fig. 261).

Inflorescence, 51, 394, 439.

Infundibuliform, 458 .

Initial cells, 101 .

Innate, 460.

Innovation, 23, 333.

Insertion-of leaves, 11.
Integument, 415.

Intercalary growth, 239 (Fig. 133).

Intercellular spaces, 89 (Fig. 67).

Interfascicular cambium, 138.

conjunctive tissue, 118, 120.

Internal hairs, 92.

Internode, 11, 261.

Interruptedly pinnate, $\mathbf{3 5}$.

Intine, 50, 397.

Intra-seminal development, 401.

Introrse, 464.

Inulin, 83 (Fig. 59), 187.

Invert-enzy me, 198.

Involucel, 440.

Involucral leaves, 334 .

Involucre, 57, 310, 334, 440 (Fig. 259), 579 (Fig. 397).

Iodine, 189.

Iron, 188, 192.

Irregular spontaneous variations in rate of growth, 209.

Irritability, 158.

conditions of, 223.

localisation of, 220 .

to differences in the degree of moisture in the surrounding medium (hydrotropism), 169, 219.

to direction of incidence of the rays of light (beliotropism), $169,171,214$.

to mechanical stimuli, 211.

to the directive influence of gravity (geotropism), 169, 171, 217 (Fig. 132).

to variations in the intensity of light, 213.

to variations of temperature, 212.

Isobilateral arrangement, 17.

symmetry, 4, 6 (Fig. $2 B$ ), 454.

Isocyclic, 449.

Isogamy, 58, 240, 277.

Isomerous, $\mathbf{1 4 9 .}$

Juga primaria, 548.

Juga secundaria, 549.

Kinetic energy, 194, 197.

Knight's machine, 218.

Labellum, 413 (Fig. 244), 503 (Fig. 314).

Lævilose, 198.

Lamella, 302 (Fig. 183).

Lamina, 29, 32.

Lanceolate, 97 .

Lateral branching, 19.

buds, 11.

members, development of, 9,132. 
Lateral plane of flower, 448.

Latex, 99, 167.

Laticiferous cœnocytes 100 (Fig. 81).

tissue, functions of, 167.

vessels, 99 (Fig. 80).

Latiseptal silicula, 536 (Fig. 348).

Leaf, 3, 28 (Figs. 18-29).

apex of, 37.

-base, $29,30,37$.

-blade, 29, 32.

cataphyllary, 42, 175 .

compound, 35 .

coriaceous, 40.

epipodium, $29,32$.

fall of, 10, 156 .

floral, 43, 55, 175, 394, 457.

foliage, 39 .

functions of, 171.

form of, 33.

herbaceous, 40 .

hypopodium, 29, 30.

margin of, 37.

hypsophyllary, 43,175 .

mesopodium, $29,32$.

minute structure of, 114 (Fig. 92).

oblique, 33.

outline of, 37.

phyllopodium, 28.

pitchered, 41 (Fig. 28), 175.

prefloration, 43.

scaly, 42, 175.

-scar, 10

segmentation of, 28, 35 (Fig. 23).

-spine, 42 (Fig. 29), 175.

sporophyllary, 43, 55, 176, 348, 395.

-stalk, 29.

succulent, 40.

-tendrils, 32, (Fig. 19), 41, 175.

-traces, 122.

venation of, 38 .

vernation of, 43 .

-wing, 29.

Leaflet, 35 .

Leafy shoot, 22.

annual, 23.

creeping, 26.

dwarf-, 23.

Legume, 473 (Fig. 288).

Lenticels, 154 (Fig. 120).

Leptosporangiate, $53,349$.

Leucin, 186, 199.

Leucoplastid, 69, 70 (Fig. 39).

Life-history, 2, 233, 309, 346, 417.

Light, chemical effects of, 161. mechanical effects of, 161 .

Light-position, 173, 215, 223.
Lignification of cell-wall, 77.

Lignin, 77.

Ligulate corolla, 579 (Figs. 396, 397).

Ligule, 32 (Fig. 19), 48, 357 (Fig. 213).

Limb, 458 (Fig. 274).

Linear, 37.

Linolein, 187.

Lithium, 189.

Lobed, 35, 37.

Localisation of irritability, 220.

Loculicidal, 475 (Fig. 289).

Loculus, 465 .

Lodicule, 487 Fig. 299).

Lomentaceous, 475, 537.

Lomentum, 474.

Longitudinal axis, 4. section, 4 .

Lysigenous, 89, 97.

Macrosporangiate flower, 56, 395.

Macrosporangium, 52, 349, 398.

Macrospore, 51, 349, 400, 438.

Macrosporophyll, 56, 349, 395, 123.

Macrosporophyllary flower, 56 .

Maguesium, 188, 192.

Male organ, 60 . pronucleus, 413 (Fig. 219). reproductive cells (gametes), 59 .

Malic acid, 187.

Maltose, 187, 198.

Mannite, 187.

Manubrium, 261 (Fig. 150).

Massula, of Azolla, 376. of Orchids, 504 .

Mastigopod-stage, 283.

Mechanical effects of light, 161.

Mechanism of movements, 224.

Median plane of flower, 448 .

Medulla, 117, 119.

Medullary bundles, 128. conjunctive tissue, 118. rays, 117, 118 (Fig. 97), 144 (Figs. 114, 115). sheath, 128.

Megaspore, 400.

Members, 1, 3, 167. development of, 8, 132.

Mericarp, 472 (Fig. 287).

Meristele, 118.

Meristem, 90.

Mesocarp, 472 (Fig. 290).

Mesophyll, 112.

Mesopodium, 29, 32.

Metabolism, 185.

Metallic elements of food, 188.

Microcysts, 277, 285.

Micropyle, 398.

Microsporangiate flower, 56, 395. 
Microsporangium, 52, 349, 396.

Microspore, כ1, 349, 396.

Microsporophyll, 56, 349, 395.

Microsporophyllary flower, 56.

Middle lamella, 88 (Fig. 66).

Midrib, 34.

Mineral matters in cell-wall, 77 (Figs. 51, 52).

Monadelphous, 462 .

Monocarpous, 417.

Monochlamydeous, 457.

Monoclinous, 61, 310, 394.

Monocyclic, 450 .

Monœecious, 61, 310, 395.

Monomerous ovary, 465.

Monopodial branch-system, 19.

Monosiphonous, 266, 271.

Monostely, 102.

Monosymmetrical, 7, 454.

Morphin, 186.

Morphology, 1.

of asexual reproductive organs, 51.

sexual organs, 58.

of the tissue-systems, 101.

Morphological differentiation, 3.

Motile region, 225.

Motility of protoplasm, 225.

Movement, 158, 204, 205. conditions of, 223. induced, 205, 211. mechanism of, 224. of cellular members, 207. of growth, 207.

of protoplasm, 206.

of variation, 207 spontaneous, 206.

Mucilage, 187. conversion of cell-wall into, 77 , 109. secretion of, 98, 101, 167.

Mucro, 36 (Fig. 23).

Mucronate, 37.

Multijugate, 35.

Multilateral symmetry, 4 (Fig. 1).

Multilocular ovary, 466 (Fig. 282).

Mycelium, 275.

Mycorhiza, 275.

Myrmecophilous plants, 166.

Myrosin, 187.

Myronate of potash, 187.

Myxopod-stage, 283.

Napiform root, 45.

Neck, of archegonium, 311 (Fig. 194), 350, 429.

Nectary, 96, 166, 202, 470.

Negative geotropism, 171, 218. heliotropism, 169, 216. pressure, 180.
Nicotin, 186.

Night-position, 173, 213.

Nitrogen, 188, 190.

Nitrogenous organic substances 186.

reserve materials, 201.

Node, 11, 29.

Non-metallic elements of food, 188.

Non-nitrogenous organic substances, 186.

reserve materials, 201.

Nucellus, 398, 469.

Nuclear division, 81.

Nucleo-hyaloplasm, 69.

Nucleolus, 66, 69.

Nucleus, 63, 66, 68 (Fig. 37).

Nut, 473.

Nutation, 211.

Nutritive properties of protoplasm, 158.

Nyctitropic movements, 173 (Fig. 125), 213.

Obcordate, 37.

Obdiplostemonous, 452 (Fig. 268).

Oblique leaf, 8, 33.

plane of flower, 448.

zygomorphy, 7 .

Oblong, 37.

Obovate, 37.

Obtuse, 37.

Ocrea, 31, 523 (Fig. 837).

Octant-wall, 314, 347, 366 (Fig. 218).

Oidium-cells, 277, 304.

Oil-drops, 80.

Oil-gland, 97 (Fig. 76).

Oils, fixed, 187.

Oily seeds, 80, 201.

Oleic acid, 187, 198.

Olein, 187, 198.

Oligomery, 449.

Oligotaxy, 452.

Ooblastema-filaments, 273.

Oogamy, 241, 277.

Oogonium, 60, 237, 241, 278, (Figs. $139,140,147,148,150,158$, 167).

Oosphere, 59, 241, 277 (Figs. 147, 242, 311 (Fig. 194), 351 (Fig. 223), 409 (Fig. 242).

Oospore, 59, 241, 277 (Fig. 167), 312, $351,414$.

Opening and closing of flowers, 176.

Operculum, 317, 320, 338, 343 (Figs. 208,210 ).

Opposite members, 13.

Optimum-temperature, 160.

Orbicular, 479.

Organs, 1, 157. reproductive, 51, 58, 394, 459. 
Organic acids, 187.

Organised ferments, 198.

Orthostichy, 13 (Figs. 7, 8).

Orthotropic members, 222.

Orthotropous ovule, 399 (Fig. 237), 169 (Fig. 281).

Osmosis, 178.

Oval, 37.

Uvary, 57, 395, 465 (Fig. 282).

Ovate, 37.

Ovule, 52, 396, 424, 468 (Fig. 285̃). anatropous, 399 (Fig. 237), 469

(Fig. 284).

ascending, 469.

campylotropous, 399 (Fig. 237). erect, 469.

horizontal, 468.

orthotropous, 399 (Fig. 237),

469 (Fig. 281).

pendulous, 468.

suspended, 468 (Fig. 284).

Oxalate, calcium, 78 (Fig. 51), 81 (Figs. 57, 53).

Oxalic acid, 187.

Oxygen, 188, 190, 197.

absorption of, 197, 200.

evolution of, 193 (Fig. 128).

Palea of Compositæ, 579.

of Ferns, 364.

of Grasses, 486.

Palisade-tissue, 112 (Fig. 92), 172.

Palmate, 33 (Fig. 21).

Palmatifid, 36 (Fig. 23).

Palmitic acid, 187.

Palmitin, 187.

Panicle, 442.

Pappus, 416, 577 (Fig. 393), 579 (Figs. 396, 397).

Paracorolla, 458.

Paraheliotropism, 174.

Paraphysis, 269 (Fig. 158), 294, 303, (Fig. 183), 385.

Parasites, 189, 275.

Parastichy, 15.

Paratonic effect of light, 162, 213.

Parenchyma, 90. functions of, 163.

Paripinnate, 35 (Fig. 23).

Partite, 37.

Passage-cells, 112, 116 (Fig. 96).

Pedate, 33 (Fig. 21).

Pedicel, 55, 439.

Pedicellate, 55.

Peduncle, 55.

Peloria, 456.

Peltate, 33 (Fig. 22).

Pentacyclic, 451.

Pentamerous, 449.

Peptone, 198.
Perfoliate, 32 (Fig. 20).

Perianth, 55, 394, 457. -leaves, 57, 175, 443, 458.

Periblem, 102 (Fig. 83).

Pericarp, 472 (Figs. 290, 56).

Perichætial leaves, 334 .

Periclinal, 102.

Pericycle, 116, 118 (Figs. 97, 107), 119.

Periderm, 150, 151 (Fig. 118).

Peridium, 303.

Perigynium of Carex, 493. of Liverworts, 312 (Fig. 191).

Perigynous, 444 (Fig. 261).

Perinium, 287, 376.

Periodicity of growth, 214.

Periplasm, 287.

Perisperm, 400, 414 (Fig. 245), 501, $523,531$.

Peristome, 338 (Figs. 208-210).

Perithecium, 291, 294 (Fig. 176).

Permanent tissue, 90.

Personate, 455.

Petal, 58, 176, 443.

Petaloid, 57.

Petiole, 29, 32.

Petiole-climbers, 175 (Fig. 127), 212.

Phelloderm, 150, 154.

Phellogen, 150.

Phloem, 121, 130.

Phosphorescence, 204.

Phosphorus, 188, 191.

Phototaxis, 214.

Phototonic effect of light, 162, 224.

Phototonus, 162, 224.

Phycocyanin, 238.

Phycoerythrin, 71. 238.

Phycophæin, 71, 238.

Phycoxanthin, 71.

Phylloclade, 28 (Fig. 17).

Phyllode, 32.

Phyllopodium, 28.

Phyllotaxis, 12. of flower, 445 .

Physiology, 1, 157.

Pileus, 302 (Figs. 182, 183).

Piliferous layer, 109.

Pinna, 35.

Pinnate, 33 (Fig. 21).

Pinnule, 35.

Pistil, 465.

Pitcher, 32, 41 (Fig. 28), 175.

Pith, 118, 119 (Fig. 97).

Pitted wall, 74 (Figs. 45-49).

Placenta, 53, 348, 398.

Placental scale, 423.

Placentation, 468 (Fig. 281). axial, 468. 
Placentation, axile or axillary, 468. basal, 469 .

free-central, 469.

marginal, 468.

parietal, 468.

superficial, 468.

Plagiotropic members, 222.

Plane of symmetry of flower, 448.

Planogametes, 59, 240, 256 (Fig. 146), 268 (Fig. 155).

Plasmodium, 63, 276, 283 (Fig 164).

Plastic products, 184, 201.

Plastid, 68, 69.

Pleiomery, 449.

Pleiotaxy, 451.

Plerome, 102 (Fig. 83).

Pleurocarpous, 333

Pleurogynous stigma, 467.

Plumule, 404.

Pod, 473.

Podium, 18.

Pollen, development of, 85 (Fig. 61). -grain, 51, 396 (Figs. 235, 236). -sac, 52, 396 (Figs. 254, 279). -tetrads, 396.

-tube, 407 (Fig. 240), 410

Pollination, 409.

Pollinium, 396, 413 (Fig. 244), כ004.

Pollinodium, 60, 278, 291 (Fig. 172), 296, (Fig. 175).

Polyadelphous, 462.

Polyandrous, 462.

Polyaxial, 438.

Polycarpous, 418.

Polycyclic, 451 (Fig. 267).

Polyembryony, 401, 427.

Polygamous, 335, 395.

Polyhedron-stage, 253.

Polymerous, 465.

Polymorphism, 2, 247.

Poly petalous corolla, 458.

Polyphyllous, 458.

Polysepalous calyx, 458.

Polystely, 117.

Polysymmetrical, 6, 453.

Polysiphonous, 266, 271.

Polytomy, 18.

Pome, 471.

Pore, 322 (Fig. 199).

Porous capsule, 475 (Fig. 288).

Positive geotropism, 169, 218.

heliotropism, 171, 216.

hydrotropism, 169, 220 .

Posterior, 448.

Potassium, 188, 192.

Potential energy, 197.

Prefloration, 43.

Prefoliation, 43.

Prickle, 48 (Fig. 32).

Primary bast, 130.
Primary bundle, 129.

differentiation of, 125.

cortex, 102.

members, 8.

meristem, 101.

vascular tissue, 121.

wood, 129.

Primordial cell, 67.

Procambium, 116, 126.

Procary, 60, 237, 272 (Figs. 160, 161).

Products of metabolism, 200.

Proliferation, 55.

Promycelium, 299 (Figs. 179, 181).

Prophyllum, 57, 443.

Prosenchyma, 90 (Fig. 68).

Protandrous, 411.

Proteids, 186, 201.

Proteid crystalloids, 81 . grains, 80 (Figs. 54-56).

Proteolytic enzyme, 198.

Prothallium, 2, 349 (Figs. 221, 226, 233), 405, 407 (Figs. 210, 241).

Protogynous, 411.

Protonema, 309 (Fig. 191).

Protophloem, 126 (Fig. 103).

Protoplasm, 1, 63, 66, 68. continuity of, 65 (Fig. 35). properties of, 158.

Protoxylem, 126 (Figs. 100-105).

Pseudaxis, 19, 441.

Pseudo-bulb, 27.

Pseudocarp, 414, 471.

Pseudo-plasmodium, 283.

Pseudopodium, 206, 283. of Bryophyta, 312, 339 (Fig. 206).

Pulvinus, 30, 220, 225.

Pycnidium, 279, 291.

Pyrenoid, 71 (Fig. 41), 252 (Fig. 143).

Pyxidium, 475 (Fig. 288).

Quadrant-wall, 314, 346.

Quadrilocular anther, 463.

Quincuncial, 43.

Quinin, 186.

Raceme, 439.

Racemose, branching, 19. inflorescences, 439 (Fig. 259).

Radial arrangement, of members, 12 (Figs. 4-8).

of bundles, 125 .

longitudinal section, 4 .

symmetry, 4 (Figs, 1 and 2), 453.

Radiant umbel, 548.

Radicle, 404.

Ramenta, 364.

Raphe, 399 (Fig. 237).

Raphides, 81 (Fig. 58), 202. 
Rate of growth, 208.

Receptacle, 54, 271, 310, 443.

Receptive spot, 241.

Region of elongation, 208.

Regular flower, 453.

Rejuvenescence of cells, 87 (Fig. 62).

Replum, 474 (Fig. 288), 536.

Reproduction, 49, 227.

Reproductive organs, 49, 459.

asexual, 51.

sexual, 58.

property of protoplasm, 158.

Reserve materials, 201.

Resin-ducts, 98 (Fig. 77), 421. -sac, 98 (Fig. 79 ).

Respiration, $197,200$.

Resupinate, 455, 503.

Retardation of grow th by light, 162 .

Reticulate vessels, 74 .

Retinaculum, 413, 504 .

Rhachis, 54 .

Rhipidium, 441.

Rhizine, 276, 307 (Fig. 188).

R hizogenic cells, 135, 347, 364 .

Rhizoid, 309.

R hizome, 26 (Fig. 14).

Rhizophore, 390.

Rib, 34.

Ricinolein, 187.

Ring, 57, 302 (Fig. 182), 343 (Figs. 208, 210), 363 (Fig. 215), 382 (Fig. 228).

Ringent, 563.

Rise of temperature in germinating seeds, 203 (Fig. 129).

Roots, 3, 44 .

adventitious, 9, 136.

aerial, 45, 106 (Fig. 87).

branching of, 45, 133 (Fig. 107). functions of, 167 .

growing-point of, 102 (Figs, 84, 86).

growth in thickness of, 138 (Figs. 109, 110).

primary, 44, 347.

structure of, 109 (Fig. 91), 115

(Figs. 94-96), 125 (Fig. 102).

Root-cap, 44, 104 (Figs. 84, 86), 109.

Root-hairs, 46, 110 (Fig. 91) 168 (Fig. 123).

Root-pressure, 182.

Root-tubercles, 191.

Rostellum, 413 (Fig. 244), 504.

Rotate, 458 (Fig. 274).

Rotation of protoplasm, 204.

Runner, 26.

Sac, 98 (Figs. 58, 78, 79).

Sagittate, 37.

Salicin, 187.
Samara, 473, 516 (Fig. 326), 545 (Fig. 357).

Saprophyte, 189, 275.

Scalariform vessels, 74 .

Scaly leaves, $42,175$.

Scape, 442.

Scattered development, 10.

Schizocarp, 473 (Fig. 287).

Schizogenous, 89, 98.

Scion, 229.

Sclerenchyma, 92, 111, 120, 140.

Sclerenchymatous tissue, function of, 164.

Sclerotic cells, 92 (Figs. 70, 71).

Sclerotium, 277, 285, 290 (Fig. 176).

Scorpioid cyme, 21 (Fig. 11), 441. dichotomy, 19 (Fig. 9).

Scutellum, 477 (Fig. 292).

Scutiform leaf, 377.

Secondary bast, 139, 143. conjunctive tissue, 144. cortical tissue, 149, 154. members, 8, 132.

sclerenchyma, 140.

tegumentary tissue, 149, 151.

tissues, differentiation of, 145 . formation of, 137.

tracheal tissue, 140.

wood, 140 (Fig. 111).

wood-parenchyma, 140.

Secretion, 166.

Secretum, 101 (Fig. 82).

Sectile pollinium, 504 .

Seed, 53, 62, 394, 414 (Fig. 245), 431. Segmentation of apical cell, 104 (Figs. 85, 86).

Segmentation of body, 3 .

Self-pollination, 409.

Semi-amplexicaul, 30.

Sensitive petiole, 175 (Fig. 127).

plant, 174 (Fig. 126), 212, 221, 226.

Sepal, 58, 175, 443.

Septate body, 63.

Septicidal dehiscence, 475 (Fig. 289).

Septifragal dehiscence, 475 (Fig. 289).

Septum, 1, 63, 81.

Serrate, 35, 37.

Sessile, 32 (Fig. 20), 55, 439.

Seta, 54, 315, 319, 337 (Figs. 208, 211).

of Carex, 498.

Sex, 231.

Sexual form, 2.

organs, 60.

process, 50, 232.

system, 233.

Sexuality, 230.

Shield, 261. 
Shoot, 3, 22.

Sieve-plates, 94. -tissue, 94 (Fig3. 74, 75), 165. -tubes, 94 .

Silicon. 189, 193.

Silicula, 474, 535 (Fig. 348).

Siliqua, 474, 535 (Fig. 318).

Simple conidiophore, 279, 291 (Fig. 170).

hair, 46 (Fig. 31).

leaf, 35.

inflorescences, 439, 441.

sporophore, 54, 285 (Fig. 165).

Simultaneous whorl, 10.

sleep-movements, 213.

Sliding growth, 147.

Sodium, 189, 193.

Soft bast. 143 .

Sorediun, 306 (Fig. 186).

Sorosis, 472, 501 (Fig. 311).

Sorus, 52, 348.

Spadix, 439.

Spathe, 439.

Species, 235.

Spermatium, 212, 272 (Fig. 160), 278, 292,300 .

Spermatozoid, 59, 211 (Figs. 147, 150, 158), 311 (Figs. 192, 193), 351 (Fig. 222), 407.

Spermogonium, 292, 300 (Fig. 178), 305 (Fig. 185).

Sphærocrystal, 83 (Fig. 59).

Spicate capitulum, 441. raceme, 441.

Spike, 439 (Fig. 259).

Spikelet, 439.

Spine, 42 (Fig. 29), 112.

Spiral vessels, 74 (Fig. 44).

Spire, 14.

Spongy parenchyma, 114 (Fig. 92), 172.

Spontaneous movement, 206.

Sporangium, 51, 243, 278, 374, 396, 433.

Spore, 2, 50, 230.

asexually produced, 51,230 .

development of, 85 .

-reproduction, 50, 227, 230.

-sac, 338.

sexually produced, 58, 230 .

Sporidium, 299, 300 (Figs. 179, 181).

Sporocarp, 373 (Figs. 221, 225).

Sporogonium, 309, 315 (Fig. 196), 319, 337 (Figs. 206, 208-11).

Sporophore, 51, 54, 279, 302.

Sporophyll, 43, 51, 55, 56, 176, 348, $395,421$.

Sporophyte, 2, 229.

Spur, 455.

Spurious iruit, 414, 471.
Spurious tissue, 88.

whorl, 11.

Stamen, 56, 395.

Staminate flower, 56, 395, 459.

Staminode, 462.

Starch, 79, 187, 201.

-grains, 78 (Fig. 53).

-sheath, 185.

Stearin, 187.

Stele, 101, 116.

Stem, 3, 27.

function of, 169.

herbaceous, 27.

monostelic, $102,117$.

polystelic, 117.

-tendril, 27 (Fig. 15), 171.

trunk, 27.

twining, 27 (Fig. 15), 171.

winged, 28.

Stereom, 92, 120 (Fig. 98), 164.

Sterigma, 291, 292, 300, 303 (Fig. 181).

Stichidium, 271 (Fig. 159).

Stigma, 395, 467 (Fig. 283).

Stimulus, 211, 222.

Stipe, 302.

Stipel, 31.

Stipule, 30 (Fig. 19), 42.

Stock, 229.

Stolon, 26.

Stomata, 107 (Figs. 88, 89)

function of, 163, 179 .

Stomium, 364 (Fig. 215).

Stratification of cell-wall 74 (Fig. 46).

Streaming of protoplasm, 206.

Striation of cell-wall, 74 (Fig. 50).

Stroma, 291 (Fig. 176).

Strophiole, 416.

Strychnin, 186.

Style, 395, 466 (Fig. 283).

Sub-hymenial layer, 303 (Fig. 183).

Successive whorls, 10.

Succulent fruits, 475.

Succubous leaves, 326 (Fig. 201).

Sucroses, 187.

Sugars, 187, 201.

Sulphur, 188, 191.

Superficial placentation, 468.

Superior ovary, 444.

Superposed members, 13, 416.

Supply of energy, 194.

Suppression, 452.

Suspensor, 347, 387, 393 (Fig. 234), 401 (Figs. 238, 239), 425 (Figs, 249,250 ).

Syconus, 472.

Symbiosis, $190,275$.

Symmetry of body, 4 (Figs. 1, 2).

of flower, 453 (Figs. 269-273). 
Sympodium, 19, 519.

Synangium, 52, 349, 389.

Syncarpous, 465 (Fig. 281), 472.

Syncyte, 64 .

Synergidæ, 408 (Fig. 242).

Syngenesious anthers, 462.

Systems of classification, 233.

Systole, 206.

Tangential longitudinal section, 4 .

Tannin, 187.

Tapetum, 53, 363, 396, 463.

Tap-root, 44, 419.

Tartaric acid, 187.

Tegumentary tissue -system, 101.

function of, 162.

primary, 106.

secondary, 149.

Teleutospore, 299 (Figs. 178, 179).

Temperature, 160.

Tendril, 27 (Fig. 15), 41 (Fig. 19), $171,175,212$.

Tentacle, 48 (Figs. 33, 34), 189.

Terminal bud, 11 .

Termination of vascular bundle, 130.

Ternate, 37 (Fig. 23).

Testa, 415.

Tetracyclic, 450 .

Tetradynamous, 462, 535.

Tetrasporangium, 244.

Tetraspore, 244, 271 (Fig. 159).

Thalloid shoot, 22.

Thallophyte, 3 .

Thallus, 3, 22, 132, 237.

Theca of Bryophyta, 52, 54, 337 (Figs. 208-210).

of anther, 463 .

Thein, 186.

Theobromin, 186.

Thorn, 27 (Fig. 16), 171.

Tissue, 65, 88.

aqueous, 115.

conjunctive, 116, 118, 140.

cuticularised, 91 (Fig. 69).

embryonic, 90.

forms of, 90 .

functions of, 162.

glandular, 96 (Figs. 76-82), 147, 166.

ground-, 101, 110.

heterogeneous, 65 .

homogeneous, 65.

permanent, 90.

prosenchymatous, 90.

sclerenchymatous, 92 (Fig. 70), 164.

secondary, 137 (Figs. 108-117).

sieve-, 94 (Figs. 74, 75), 165.

spurious, 88 .
Tissue-systems, 101.

tegumentary, 101, 149, 162.

thick-walled parenchymatous, 91.

thin-walled parenchymatous, 90 (Fig. 69), 163.

tracheal, 93 (Fig. 73), 121, 164.

vascular, 121, 126.

Torus of flower, 55,443 .

Trabeculæ, 52, 357 (Fig. 213).

Tracheæ, 94 (Fig. 73).

Tracheal tissue, 93, 140, 164.

Tracheid, 93 (Fig. 73).

Trama, 303 (Fig. 183).

Transfusion-tissue, 119, 120.

Transition from root to stem, 128.

Transmission of stimuli, 221.

Transpiration, 179.

-current, 181, 183.

Transverse section, 4 .

Trichogyne, 61, 242, 259 (Fig. 148), 272 (Figs. 160, 161), 291 (Fig. 172).

Trimorphic flowers, 412.

Tripinnate, 35.

Truncate, 37.

Trunk, 27.

Tuber, 25 (Fig. 13), 505 (Fig. 317).

Tubercles of roots, 191 .

Tuberous root, 45 .

Tumid, 28.

Turgid, 159.

Turgidity, 159, 179, 225.

Twining of climbing-stems, 223. of tendrils, 212.

Tyloses, 94 .

Tyrosin, 186, 199.

Umbel, 440 (Fig. 259), 548.

Umbellule, 440.

Umbo, 435 .

Uniaxial, 23, 438.

Unijugate, 35 .

Unilocular ovary, 465. sporangium, 52.

Unisexual, 61, 395.

Unit of protoplasm, 63.

Unseptate body, 63 .

Uredospore, 299 (Fig. 178).

Urn, 343.

Utriculus, 493 (Fig. 304).

Vacuole, 66 (Fig. 36). contractile, 206.

Vaginula, 315.

Vallecular cavities, 383 (Fig. 230).

Valve of Diatoms, 265. of fruits, 475 .

Valvular dehiscence of anther, 463. 
Variation, movements of, 207. in direction of growth, 209. in rate of growth, 208.

Variety, 235.

Vascular bundles, 121 (Figs. 99-105). tissue-system, 101, 121.

Vegetative cell, 393, 406. reproduction, 49,227 . reproductive organs, 49, 228.

Velamen, 93, 106 (Fig. 87).

Velum, 302 (Fig. 182), 356 (Fig. 213).

Venation, free, 38 (Fig. 24). furcate, 38. parallel, 38 (Fig. 25). reticulate, 39 (Fig. 26).

Venter, 311,350 .

Ventral, 7. canal-cell, 311 (Fig. 194). scales, 319. suture, 46 .

Vernation, 43, 211.

Versatile anther, 461 (Fig. 276).

Verticillaster, 442.

Vessel, 94, 147.

Vexillum, 557 (Fig. 369).

Vital functions of the tissues, 162.

Vittæ, 549 (Fig. 361).

Volva, 303.

\section{Wart, 48.}

Waste products, 158, 201.

Water-culture, 192.

Water, absorption of, 178. distribution of, 181. -stoma, 97 (Fig. 89), 108.

Wax, 107.

Whorl, 10, 12 (Figs. 4, 5), 445.

Wing, of flower, 545 . of fruits, 473,545 (Fig. 357 ). of leaf, 29.

Wood, 121, 129, 139 (Figs. 112-115), 165.

Wood-parenchyma, 129, 140.

Woody fibre, 140 (Fig. 111).

Xylem, 121, 164.

Zine, 189, 193.

Zonate tetraspores, 271.

Zoogloea-stage 281 (Fig. 163).

Zoospore, 51, 67, 72, 85 (Fig. 62), 230, 247, 257 (Fig. 147), 264, 289 (Fig. 169).

Zygomorphic symmetry, 4, 7, 454.

Zygospore, 58, 240, 249, 254, 257, 27 7 , 285 (Figs. 145, 146, 165, 166). 


\section{PART II.-CLASSIFICA'TION AND NOMENCLATURE.}

Abies, 422 (Fig. 247), 434 (Fig. 255).

A bietineæ, 434 .

Acacia, 559 (Fig. 371).

Acer, 545 (Fig. 357).

Aceraceæ, 513, 545 .

Aceras, 506.

Acetabularia, 251 (Fig. 141).

Achillea, 581 (Fig. 397).

Achlya, 289 (Fig. 169).

Aconitum, 465 (Fig. 281), 528 (Fig. 342), 530.

Acorus, 482 (Fig. 294).

Acrocarpæ (Musci), 345.

Acrogynæ (Hepaticæ), 330.

Acrosticheæ, 361.

Actæa, 529.

Adder's-tongue Fern, 355.

Adiantum, 360, 366 (Fig. 219), 368 (Fig. 222), 371.

Adlumia, 534.

Adonis, 529.

Adoxa, 576.

Æcidiomycetes, 280, 298.

Acidium, 300.

Egopodium, 550 .

Esculus, 545 (Fig. 356).

Ethalium, 284.

Æthusa, 550.

Agapanthus, 498.

Agaricinæ, 303.

Agaricus, 277, 301 (Fig. 182), 302 (Fig. 183).

Agave, 508 .

Agavoideæ, 508.

Agopyrum, 491.

Agrimonia, 555.

Agrostidere, 490.

A grostis, 490 .

Aira, 490.

Ajuga, 564.

Ajugoideæ, こ63.

Alaria, 265.

Alchemilla, 5๊อ๊.

Alder, 517.
Aldrovanda, 561.

Algæ, 234, 237.

Alisma, 403 (Fig. 239), 495 (Fig. 306).

Alismaceæ, 481, 495.

Alismales, 481, 494.

Alkanet, 570 .

All-good, 523.

Allioideæ, 498.

Allium, 461 (Fig. 277), 498.

All-seed, 532.

Almond-tree, 554 .

Alnus, 518 (Figs. 328, 329).

Aloe, 498.

Alopecurus, 488, 490.

Alpine Rose, 573.

Alpinia, 502 (Fig. 313).

Alsineæ, 532.

Alsophila, 361, 372.

Althæa, 541 (Fig. 352).

Alyssineæ, 537.

Alyssum, 537.

Amanita, 303 (Fig. 182).

Amaryllidaceæ, 481, 507.

Amaryllidoideæ, 507.

Amaryllis, 507.

Amelanchier, 557.

Amentales, 512, 517 (Fig. 327 ).

American Aloe, 508.

Ammi, 550.

Ammineæ, 549.

Amomales, 481, 501.

Amorpha, 557.

Ampelidaceæ, 513, 547.

Ampelopsis, 547.

Amygdalus, 554 .

Amylum Marantæ, 503.

Anabæena, 245 (Fig. 136).

Anacharis, 500.

Anacrogynæ, 329.

Anagallis, 572.

Ananas, 501 (Fig. 311).

Anaptychia, 305 (Fig. 185).

Anchusa, כ̌69 (Fig. 383). Andromeda, 573.
Andropogon, 489.

Andropogoneæ, 489.

Aneimia, 358, 372.

Anelatereæ, 329.

Anemone, 528 (Fig. 342).

Anemoneæ, 527.

Aneura, 327, 329, 330.

Angelica, 550 .

Angeliceæ, 550 .

Angiopteris, 349, 355 .

Angiospermæ, 234, 438.

Angræeum, 507.

Angustiseptæ, 537.

Antennaria, 581.

Anthemideæ, 580.

Anthemis, 581.

Anthericum, 498.

Anthoceros, 330 (Fig. 203).

Anthocerotaceæ, 330 .

Anthoxanthum, 489.

Anthrisens, 550 .

Anthurium, 483.

Anthyllis, 558.

Antiaris, 515.

Antirrhinum, 564 (Fig. 378).

Antirrhoideæ, 564.

A pera, 490.

A phanomyces, 289.

A piocystis, 248.

Apium, 550.

Aplanes, 289.

A pple-tree, 556.

A pricot, 555 .

Aquilegia, 529 (Fig. 343).

Arabideæ, 537.

A raceæ, 481. 482.

Arachis, 558.

Arales, 481, 482.

Araliaceæ, 513, 550.

Arbutoideæ, 573.

Arbutus, 573.

Archangelica, 550.

Arctium, 581.

Aretostaphylos, 573.

Arcyria, 284 (Fig. 164).

Areca, 486 (Fig. 298).

Arenaria 532. 
Aria, $5 \tilde{5} \overline{\text {. }}$

Arisarum, 482, 484.

Aristolochia 412 (Fig. 243), 524.

Aristolochiaceæ, 512,524.

A rmeria, 572.

A rmillaria, 303.

Arnica, 580 (Fig. 396).

Arnoseris, 582.

Aroideæ, 483.

Arrhenatherum, 490.

Arrow-grass, 495.

Arrow-head, 495.

A rrow-root, 502 .

Artemisia, 580 (Fig. 397).

Artichoke, 581.

Artocarpus, 515.

Arum, 483 (Fig. 295).

Arundinaria, 492.

Asarabacca, 524.

Asarales, 512, 524.

Asarum, 524 (Fig. 338).

Ascobolus, 278, 290.

Ascolichenes, 306.

Ascomycetes, 280, 290.

A scophyllum, 268.

Ash, 570 .

Asparagoideæ, 499.

Asparagus, 499.

Aspergillus, 291.

Asperula, 575.

Asphodeloideæ, 498.

Asphodelus, 498.

Aspidieæ, 372.

Aspidium, 361 (Fig. 215), 372.

Asplenieæ, 371.

Asplenium, 360(Fig. 214), 371.

Aster, $5 \pi 9$.

Asterales, 513, 577.

Asterocephalus, 578 .

Asteroideæ, 579.

Astragalus, 558.

Astrantia, 549.

Athyrium, 371.

Atragene, 528.

Atrichum, 339.

Atriplex, 52:3.

Atropa, 568 (Fig. 382).

A ulacomnium, 334, 337.

Aurantieæ, 543 .

A uricularia, 304.

A uricularieæ, 303.

Autobasidiom ycetes, 305 .

Autumn Crocus, 498.

A vena, 490 (Fig. 302).

A veneæ, 490.

A vens, 556.

Averrhoa,. 543 .
Awl-wort, 537.

Azalea, 573 .

Azolla, 373, 380.

Bacillus, 281 (Fig. 163).

Bacterium, 281 (Fig. 162).

Ballota, 563.

Balm, 563.

Balsaminaceæ, 513, 543 .

Bamboo, 492.

Bambusa, 486 (Fig. 299), 492.

Bambuseæ, 492.

Banana, 502.

Baneberry, 529.

Bangia, 272.

Bangiaceæ, 271.

Banyan, 515.

Barbarea, 537.

Barberry, 531.

Barbula, 339, 345.

Barley, 492.

Bartsia, 565.

Basidiolichenes, 306.

Basidiom ycetes, 280, 301 .

Bastard Toad-flax, 525.

Batatas, 567.

Batrachospermum, 272.

Bauhinia, 559.

Bean, 559.

Bearberry, 573.

Bed-straw, 575.

Beech, 520.

Bee Orchis, 506.

Beetroot, 523.

Belladonna Lily, 507.

Bellis, 580.

Bent-Grass, 490.

Berberidaceæ, 512, 531.

Berberis, 531.

Bergenia, 560 (Fig. 372).

Bertholletia, 554.

Beta, 523.

Betel-Palm, 485.

Betony, 563.

Betula, 518.

Betulaceæ, 512, 517.

Bidens, 581.

Bilberry, 573.

Bind weed, 567.

Biophytum, 543.

Biota, 436 (Fig. 256).

Birch, 518.

Bird-Cherry, 555 5๊.

Bird's-foot Trefoil, 558.

Bird's nest, 573 .

Bird's-nest Orchid, 507.

Birthwort, 524.

Bitter or Seville Orange, 544.
Bittersweet, 568.

Blackberry, 556 (Fig. 368 ).

Black Bryony, 500.

Black Pine, 435.

Black Thorn, 554 .

Bladder-Fern, 372.

Blaeberry, 573.

Blasia, 325 , 330.

Blechnum, 359, 371.

Blue bell, 497.

Blue-bottle, 581.

Blyttia, 328.

Bog-Asphodel, 498.

Bog-bean, 570.

Bog-Orehis, 507.

Bog-Rush, 492.

Bishmeria, 515.

Boletus, 303.

Borage, 570.

Boraginaceæ, 513, 569.

Borago, 570.

Borecole, 537.

Boschia, 321.

Botrychium, 354 (Fig. 212).

Botrydium, 251 (Fig. 144).

Botryococcus, 218.

Botrytis, 291.

Brachy podium, 491.

Brachythecium, 346.

Bracken, 371.

Brasenia, 531.

Brassica, 537 (Fig. 348).

Brassiceæ, 537.

Brazil Nut, 554.

Bread-fruit, 515.

Briza, 491.

Broccoli, 537.

Brodiæa, 498.

Brome-Grass, 491.

Bromeliaceæ, 481, 500.

Bromus, 491.

Brookweed, 572.

Broom, 558.

Broomrape, 566.

Broussonetia, 515.

Brussels-sprouts, 537.

Bryineæ, 338, 312.

Bryonia, 5 ā1.

Bryophyta, 234, 309.

Bryum, 334.

Buck-bean, 570.

Buckthorn, 547.

Buckwheat, 521.

Bulbochrete, 258.

Bulgaria, 297.

Bulgarieæ, 297.

Bullace, 555. 
Bulrush, 481 ; 493.

Bupleurum, 5๊ 50.

Burdock, 581.

Bur-reed, 484.

Butcher's Broom, 499.

Butomaceæ, 481, 495.

Butomus, 398, 495 (Fig. 306), 496 (Fig. 307).

Butter-bur, 580.

Buttercup, 529.

Butterfly Orchis, 506.

Butterwort, 566 .

Cabbage, 537.

Cabomba, 531.

Cabombeæ, 531.

Cæsalpinia, 559 .

Cæsalpinieæ, 559.

Cakile, 538.

Cakilineæ, 538.

Calabar Bean, 559.

Calamagrostis, 490 .

Calamintha, 563.

Calamus, 485 .

Calceolaria, 564 .

Calenduleæ, 581.

Calendula, 581.

Calla, 483.

Callistephus, 580.

Callithamnion, 271.

Calloideæ, 483.

Calluna, 573.

Calocera, 304.

Calothamnus, 553 (Fig. 365 ).

Caltha, 529.

Calycifloræ, $513,547$.

Calypogeia, 329 .

Calystegia, 445, 567.

Camassia, 497.

Camelina, 537.

Camelineæ, 537.

Campanales, 513, 574.

Campanula, 574 (Figs. 388,389 ).

Campanulaceæ, 513, 574.

Campion, 532.

Campylospermex, 550.

Candytuft, 537.

Canna, 503 (Fig. 314).

Cannabinaceæ, 51:2, 515.

Cannabis, 516.

Cannaceæ, 502.

Canterbury-bell, 574.

Caprifoliaceæ, 513,576 (Fig. 391).

Capsella, 402 (Fig. 238), 537.

Capsicum, 568.
Caraway, 550.

Cardamine, 537.

Cardamom, 502.

Carduus, 581.

Carex, 493 (Fig. 304).

Caricoideæ, 493.

Carlina, 581.

Carline Thistle, 581.

Carnation, 532.

Carob-tree, 559.

Carpinus, 519 (Fig. 332).

Carrot, 550.

Carthamus, 581.

Carum, 473 (Fig. 287), 549 (Fig. 362).

Carya, 522.

Caryophyllaceæ, 512,531.

Caryophyllales, 512, 531.

Cassia, 559 (Fig. 370).

Castanea, 521.

Castor-oil Plant, 527.

Catchfly, 532.

Catmint, 563.

Cat's Ear, 582.

Cat's-tail Grass, 490.

Caucalineæ, 550.

Caucalis, 550 .

Cauliflower, 537.

Cedar, 435.

Cedrus, 435 .

Celandine, 529, 533.

Celastraceæ, 513, 546 .

Celastrales, $513,546$.

Celery, 550.

Celsia, 564.

Celtis, 517.

Centaurea, 581.

Centaury, 570.

Centranthus, 577 (Fig. 393).

Cephaelis, 575.

Cephalanthera, 506.

Cephalanthereæ, 506.

Cerastium, 532.

Cerasus, 555.

Ceratodon, 316 (Fig. 197), 345.

Ceratonia, 559.

Ceratozamia, 432.

Cercis, 456 (Fig. 272), 559.

Cestreæ, 569.

Ceterach, 372.

Cetraria, 307.

Chærophyllum, 550 .

Chætocladieæ, 285.

Chætomorpha, 25 2.

Chætopteris, 239 (Fig. 133).

Chamæcyparis, 436.
Chamædorea, 485 (Fig. 297 ).

Chamæorchis, 506.

Chamærops, 485.

Chamomile, 580.

Chantransia, 272.

Chara, 260 (Figs. 149, $150,151)$.

Characeæ, 246, 260.

Characium 248.

Chareæ, 263.

Charlock, $5: 37$.

Charoideæ, 248, 260.

Cheilanthes, 362, $3 \overline{7} 1$.

Cheiranthus, 537.

Chelidonium, 533 (Fig. 345).

Chelone, 561.

Chenopodiaceæ, 512, 522.

Chenopodiales, 512, 522.

Chenopodium, 523 (Fig. 336).

Cherry Laurel, 555.

Chervil, 550.

Chickweed, 532.

Chickweed Wintergreen, 572 .

Chicory, 582.

Chili Pepper, 569.

Chiloscyphus 324 .

China Aster, 580.

Chives, 498.

Chlamydomon a d a ceæ, 249.

Chlamydomonas, 249.

Chlora, 570.

Chlorideæ, 491.

Chlorochytrium, 248.

Chlorococcum, 248.

Chlorophyceæ, 238, 246.

Chlorosphæra, 218.

Chondriopsis, 272.

Chorda, 265.

Chordaria, 266.

Christmas Rose, 529.

Chroococcaceæ, 244.

Chrysanthemum, 580.

Chrysodium, 361.

Chrysosplenium, 560.

Cibotium, 372.

Cicendia, 570 .

Cichorieæ, 581.

Cichorium, 582.

Cicuta, 550 .

Cinchona, 575.

Cinchoneæ, 575.

Cinquefoil, 556.

Circæa, 454 (Fig. 270), 5 ล2 2 .

Cistaceæ, 512, 538. 
Cistus, 538.

Citron, 544.

Citrullus, วัฒ1.

Citrus, 544 (Fig. 355).

Cladonia, 307.

Cladophora, 252 (Fig. 143).

Cladophoraceæ, 246, 252.

Cladophoreæ, 252.

Cladostephus, 264, 266 (Figs. 153, 154).

Clary, 563.

Classification of Algæ, 238.

of Angiospermæ, 476. of Ascomycetes, 294.

of Basidiom ycetes, 305 . of Bryophyta, 317.

of Chlorophyceæ, 247. of Coniferæ, 434.

of Dicotyledones, 5̃12. of Filicinæ, 352.

of Fungi, 280.

of Gymnospermæ, 431.

of Hepaticæ, 320.

of Monocot yledones, 181.

of Musci, 340.

of Phæoph yсеæ, 264.

of Phanerogamia, 418.

of Phycomycetes, 285.

of Plants, 233.

of Pteridophyta, 352.

Clavaria, 305 .

Clavarieæ, 303.

Claviceps, 277, 290, 297 (F1g. 176).

Cleistocarpæ, 338, 343.

Clematis, 528, 556.

Closterium, 254 (Fig. 144).

Clostridium, 282.

Clover, 558.

Club Moss, 386.

Club Rush, 498.

Cluster Narcissus, 508.

Cluster Pine, 435.

Cnicus, 581.

Cobæa, 567.

Coccus, 281 (Fig. 162).

Cochlearia, 537.

Cock's Foot Grass, 491.

Coco-nut Palm, 485.

Cocos, 485.

Codium, 251.

Colospermeæ, 550 .

Conogonium, 306.

Coffea, 575.

Coffeer, 575.

Coffee-tree, 575 .
Colchiceæ, 498.

Colchicoideæ, 498.

Colchicum,474(Fig. 288), 497 (Fig. 309).

Coleanthus, 488 .

Coleochæte, 246, (Fig. 148).

259

Coleochætaceæ, 253, 258.

Coleosporium, 299.

Coleus, 563.

Collabium, 504.

Collema, 306 (Fig. 187).

Collemaceæ, 306.

Colt's Foot, 580.

Columbine, 529.

Colza, 537.

Comarum, 556.

Comfrey, 569.

Common Basil, 568.

Comnion Bugloss, 570.

Compositæ, 513, 579 (Fig. 395).

Conferva, 257.

Confervoideæ, 248, 253.

Coniferæ, 432.

Conium, 548 (Fig. 361).

Conjugatæ, 247, 253, 254.

Conopodium, 550.

Convallaria, 499.

Convolvulaceæ, 518, 567 .

Convolvulus, 458 (Fig. $274), 567$.

Copper Beech, 521.

Coprinus, 277, 303.

Corallinaceæ, 272.

Corallorhiza, 507.

Coral Root, 507.

Corchorus, $\mathbf{5} 40$.

Cord yceps, 279, 296.

Cord yline, 498.

Coreopsis, 581.

Coriandreæ, 550 .

Coriandrum, 548 (Fig. 361).

Cork-oak, 520.

Corn Cockle, 532.

Corn Flag, 509.

Corn-flower, 581.

Cornish Heath, 573.

Cornish Money wort, 565.

Corn-salad, 577.

Coronilla, 558.

Corrigiola, 533.

Corsinia, 324.

Corsinieæ, 324.

Corydalis, 534.

Corylacee, 512, 518.

Corylus, 519 (Figs. 330, $331)$.

Cotoneaster, 556.
Cotton, 541.

Cotton-Grass, 493.

Couch-Grass, 491.

Cowberry, 573.

Cow-Parsley, 550.

Cow-Parsnip, 550.

Cowslip, 5ั72.

Cow-tree, 515 .

Cow Wheat, 565 .

Crambe, 538.

Cranberry, 573.

Crane's-bill, 542.

Crassula, 561.

Crassulacæ, 513,561 .

Cratægus, 556.

Creeping Bugle, 564.

Crepis, 582.

Cress, 537.

Crithmum, 550.

Crocoidex, 508.

Crocus, 508.

Cross-leaved Heath, ว̄73.

Crowfoot, 529.

Crown Imperial, 496.

Cruciferæ, 512, 535 (Figs. 347,348 ).

Cryptogamia, 234.

Cryptogramme, 372.

Cryptoneminæ, 274.

Cuckoo-pint, 483.

Cucubalus, 532.

Cucumber, 551.

Sucumis, 551 (Fig. 363).

Cucurbita, 397 (Fig. 235),

$551 \cdot$ (Fig. 363).

Cucurbitaceæ, 513, 551.

Cudweed, 581.

Cupressus, 436.

Cupressinæ, 436.

Cupressineæ, 436.

Curcuma, 502 .

Currant, 561.

Cuscuta, 567 (Fig. 381).

Cut-grass, 489.

Cutleria, 265, 267.

Cutleriacex, 264, 265.

Cyanoph ycere, 238, 244.

Cyathea, 361,372

Cyatheacer, 352,372 .

Cyathus, 304, 305.

Cycadacere, 431.

Cycas, 432 (Fig. 253).

Cyclamen, 572.

Cydonia, 556.

Cynara, 581.

Cynaree, 581.

Cynodon, 491.

Cynoglossum. 57̄0.

Cy peraceæ, 481, 492.

Cyperus, 492. 
Cypress, 436.

Cypripedium, 505 (Figs. 315,318 ).

Cypripediinæ, 505.

Cystopteris, 372.

Cystopus, 287.

Cystoseira, 269.

Cytisus, 558.

Daboecia, 573.

Dacryomyces, 304.

Dactvlis, 491.

Daffodil, 508.

Dahlia, วิ 1 .

Daisy, 580 .

Damasonium, 495.

Dame's Violet, 537.

Damson, 555 .

Danæa, $35 \overline{\text {. }}$

Daudelion, 582.

Danewort, 576

Daphne, 458 (Fig. 274).

Darnel, 491.

Dasya, 272 (Fig. 159).

Dasylirion, 499.

Date, 477 (Fig. 291).

Date Palm, 485 .

Datura, 569.

Datureæ, 569.

Daucineæ, 550 .

Daucus, 550.

Davallia, 360 (Fig. 214).

Deadly Nightshade, 569.

Dead Nettle, 563.

Delphinium, 45̄7 (Fig. $273), 530$.

Dendrobium, 507.

Dentaria, 537.

Desmidieæ, 246, 254.

Desmids, 25t (Fig. 144).

Desmodium, 558 .

Dewberry, 556 .

Diandræ, 505.

Dianthus, 459 (Fig. 275), 532.

Diarrhena, 488.

Diatomaceæ, 263, 265.

Dicentra, 534 (Fig. 346).

Dicksonia, 360, 372.

Dicotyledones, 234, 509.

Dicranum, 345 .

Dictamnus, 452 (Fig. 268), 543 (Fig. 354).

Dictyosphærium, 248.

Dictyosteliaceæ, 284.

Didymium, 284 (Fig. 164).

Diervilla, 577.

Digitalis, 564.

Digitaria, 489.
Dionæa, 561.

Dioscoreaceæ, 481, 500.

Dioscorea, 500.

Dioscoreales, 481, 500.

Diotis, 581.

Diplocolobeæ, 536.

Diplotaxis, 537.

Dipsaceæ, 513, 577.

Dipsacus, 578.

Discifloræ, 513, 541 .

Discomycetes, 296.

Dock, 524.

Dodder, 567.

Dog's Mercury, 527.

Dog's-tooth Grass, 491.

Dog's-tooth Violet, 496.

Dog-Violet, 538 .

Doronicum, 580 .

Dothideaceæ, 296.

Draba, 537 (Fig. 348).

Dracuneulus, 484.

Dracæna, 499.

Dracænoideæ, 498.

Dragon's Tree, 499.

Dropwort, 554.

Drosera, 561.

Droseraceæ, 561.

Dryas, 556.

Duck-weed, 484.

Dudresnaya, 271.

Durra, 489.

Dwarf Elder, 576.

Dwarf Wheat, 492.

Earth-almond, 558.

Echeveria, 561.

Echinocloa, 489.

Echinophora, 550.

Echinops, 581.

Echium, 569.

Ectocarpaceæ, 264.

Ectocarpus, 264, 266 (Fig. $155)$.

Eglantine, 554 .

Elais, 486.

Elatereæ, 330 .

Elder, 576.

Elecampane, 581.

Eletteria, 502.

Elm. 516.

Elodea, 500.

Elymus, 492.

Elyna, 493.

Encaly pta, 344.

Enchanter's Nightshade, 552.

Endive, 582.

Endocarpon, 306.

Endosphæra, 248.
Endosporeæ, 283.

English Wheat, 492.

Enteromorpha, $2 \overline{\mathbf{z}}$.

Entyloma, 301.

Ephedra. 437.

Ephemerum, 332，339, 343 (Fig. 207).

Epilobium, 464 (Fig. 280), 552 (Fig. 364).

Epimedium, 531.

Epipactis, 413 (Fig. 244), 506.

Epipogium, 506.

Equisetaceæ, 353, 380.

Equisetinæ, 234, 353, 380.

Equisetum, 380 (Figs. $227-230$ ).

Eranthis, 529.

Eremascus, 278, 290, 293 (Fig. 171).

Eremurus. 498.

Ergot, 290,297 (Fig. 176).

Erica, 573 (Fig. 387).

Ericaceæ, 513, 572.

Ericales, 513, 572.

Ericoideæ, 573.

Erigeron, 580.

Eriobotrya, 557.

Eriophorum, 493.

Erodium, 542.

Eryngium, 549.

Erysimum, 537.

Erysipheæ, 278, 290, 29\% (Fig. 173).

Erythræa, 569 (Fig. 381).

Erythronium, 496.

Erythrotrichia, 275.

Euastrum, 254 (Fig. 144).

Eucalyptus, 553.

Eugenia, 503.

Euon ymus, 546.

Eupatorieæ, 579.

Eupatorium, 579.

Euphorbia, 526 (Fig. 311).

Euphorbiaceæ, 512, 526.

Euphorbiales, 512, 525.

Euphrasia, 565.

Eurhynchium, 316.

Eurotium, 290, 296 (Fig. 175).

Eusagus, 495.

Eusporangiatæ, 354.

Evening Primrose, 552.

Evernia, 307.

Exidia, 304.

Exoascus, 294.

Exosporeæ, 281.

Eyebright, 565. 
Fagacex, 512, 520.

Fagus, 520.

False Oat-grass, 490.

Fatsia, 5\%0.

Feather-grass, 490.

Fegatella, 324.

Fenugreek, 5ะ8.

Ferns, 359.

Ferm-Roval. 372.

Fescue-grass, 491.

Festuca, 488, 491.

Festucer, 490.

Ficus, 515 (Fig. 324).

Field Poppy, 533.

Fig, 515.

Figwort, 5้65.

Filago, 581 .

Filices, 358 .

Filicinæ, 234, 352, 354 .

Filicinæe Eusporangiatæ, 352,354 .

Filicinæ Leptosporangiatæ, $352,358$.

Fir, 435.

Fistulina, 304.

Flag, 508.

Flax, 542.

Flax Dodder, 567.

Fleabane, 581.

Florideæ, 271.

Flowering Rush, 496.

Fly Orchis, 506.

Foeniculum,548(Fig.361).

Fontinalis, 333(Fig. 204), 344 (Fig. 209).

Fool's-Parsley, 550 .

Forget-me-not, 569.

Fossombronia, 325, 330.

Foxglove, 565.

Foxtail-grass, 490.

Fragaria, 556.

Fraxinus, 570 (Fig. 385े).

French Bean, 559.

Fritillaria, 496.

Frog's Bit, 500 .

Frullania, 324, 326 (Fig. 202), 330.

Fucaceæ, 265, 268.

Fuchsia, 454 (Fig. 270), 552 (Fig. 364).

Fucus, 269 (Fig. 156), 270 (Figs. 157, 158).

Fuligo, 284.

Fumaria, 534.

Fumariacere, 512, 533.

Fumitory, 5̋34.

Funaria, 310 (Fig. 191), 311 (Fig. 192), 313 (Figs. 195, 196), 344 (Figs. 208, 210).
Fungi, 234, 275.

Furze, 558 .

Fustic, 515.

Gagea, 498.

Gaillardia, 581.

Galactodendron, 515 .

Galanthus, 507 .

Galegeæ, 558.

Galeopsis, 563.

Galingale, 492.

Galinsoga, 581 .

Galium, 575.

Galtonia, 497 .

Gamopetalæ, 513, 562.

Garlic, 498.

Gasteromycetes, 308, 305 .

Gaultheria, 573.

Gean, 555.

Geaster, 305 .

Gelidiaceæ, 274.

Genista, 558.

Genisteæ, 558.

Gentian, 570.

Gentiana, 5ั0.

Gentianaceæ, 513, 570.

Gentianales, 513,570 .

Gentianeæ, 570.

Georgiacere, 343.

Geraniaceæ, 513, 542.

Geraniales, 513, 541.

Geranium, 542 (Fig. 353).

Geum, 556.

Gigartinaceæ, 273.

Gilia, 567.

Ginger, 502.

Ginkgo, 406 (Fig. 240), 437.

Gladiolus, 509.

Gladioleæ, 509.

Glass-Wort, 523.

Glaucium, 533.

Glaux, 572.

Gleditschia, 559 .

Gleichenia, 372.

Ġleicheniaceæ, 352, 361, 372.

Globba, 502.

Globbeæ, 502 .

Globe-flower, 529.

Globe-Thistle, 581.

Gloeocapsa, 244 (Fig. 134).

Gloeosiphonia, 271.

Gloriosa, 498.

Glumales, 481, 486.

Glumifloræ, 481, 486.

Glyceria, 491.

Glycyrrhiza, 558.

Gnaphalium, 581.

Gnetaceæ, 431, 437.
Gnetum, 437.

Goat's-beard, 582.

Golden Rod, 580.

Gold-of-pleasure, 537.

Goodyera, 507.

Gooseberry, 561.

Goose-foot, 523.

Gorse, 558.

Gossypiurn, 541.

Gout-Weed, 550.

Graminacere, 481, 486.

Grape-Hyacinth, 497 .

Grape-Vine, 547.

Graphidex, 307.

Graphis, 308 (Fig. 190).

Grasses, 486.

Grass of Parnassus, 61 .

Grass-Wrack, 494.

Grateloupia, 271.

Gratiola, 564.

Great Burnet, 555.

Green-weed, 558.

Grimmia, 35 .

Gromwell, 569.

Ground Ivy, 563.

Ground-nut, 558.

Groundsel, 580.

Guelder Rose, 576.

Guttiferales, 512, 539.

Guttulinere, 284.

Gymnadenia, 50;) (Fig. 317 ).

Gymnadenieæ, 506.

Gymuoasceæ, 294.

Gymnoascus, 290, 294.

Gymnogramme, 364.

Gymnospermæ, 234, 419

Gymnostomum, 344.

Gynerium, 491.

Gyromitra, 297.

Habenaria, 506.

Hæmatococcus, 216, 249.

Hæmatoxylon, 559.

Hair-grass, 490.

Halarachnion, 271.

Halidrys, 269.

Halosphæra, 248.

Halymenia, 271, 272.

Haplomitrium, 324, 330.

Hard Fern, 359, 371.

Hard Wheat, 492.

Hare-bell, 574.

Hart's-tongue Fern, $37 \mathbf{7}$.

Havers, 490.

Hawk's-bearl, 582.

Hawkbit, 582.

Hawkweed, 582.

Haw thorn, 556.

Hazel, 519. 
Heart's-ease, 538.

Heather, 573.

Hedera, 550 .

Hedge-Mustard, 537.

Hedychieæ, 502.

Hedychium, 502 (Fig. 313).

Hedysareæ 558.

Helenioideæ, 581.

Helenium, 581.

Helianthermum, 538.

Helianthoideæ, 581.

Helianthus, 581 .

Heliconia, 501 .

Heliconieæ, 501.

Helleboreæ, 529.

Helleborines, 506.

Helleborus,469 (Fig. 284), 529 (Fig. 342).

Helmint hora, 271.

Helminthostachys, 354.

Helvella, 297.

Helvellaceæ. 296.

Hemerocallis, 498.

Hemitelia, 372.

Hemlock, 550 .

Hemp, 516.

Hemp-Agrimony, 579.

Hemp-Nettle, 568.

Henbane, 569.

Hepaticæ, 234, 317, 320.

Heracleum, 455 (Fig. 271), 548 (Fig. 361).

Herb Christopher, 529.

Herb Paris, 499.

Herb Robert, 542.

Herminium, 506.

Herniaria, 533.

Hesperis, 537.

Hevea, 527.

Hibisceæ, 541.

Hibiseus, 541.

Hickory, 522.

Hieracium, 582.

Hildenbrandtı, 275.

Himanthalia, 268.

Hippocrepis, 558.

Holcus, 490.

Holly Fern, 372.

Hollyhock, 541 .

Holosteum, 532.

Honesty, 537.

Honey-grass, 490.

Honeysuckle, 576.

Hooped-Petticoat Daffodil, 507.

Hop, 516 (Fig. 325).

Hordeæ, 491.

Hordeum, 492.

Horehound, 563.
Hormotila, 248.

Hornbeam, 519.

Horned Pondweed, 494.

Horned Poppy, 533.

Horse Chestnut, 545.

Horse-radish, 537.

Horse-shoe Vetch, 558.

Horse-tail, 380.

Hottonia, 572.

Hound's-tongue, 570 .

House-leek, 561.

Humulus, 516 (Fig. 325).

Hutchinsia, 537.

Hyacinth, 496 (Fig. 308).

Hyacinthus, 497.

Hydneæ, 303.

Hydnum, 305.

Hydrales, 481, 500.

Hydrilleæ, 500 .

Hydrocharidaceæ, 500.

Hydrocharis, 500 .

Hydrocotyle, 549.

Hydrocotyleæ, 549.

Hydrodic tyaceæ, 250,253.

Hydrodictyon, 253.

Hydropteridex, 373.

Hylocomium, 346.

Hymenogaster, 304.

Hymenomycetes, 305.

Hymenophyllaceæ, 352, 371.

Hymenophyllum, 361, 371.

Hymenostomum, 344.

Hyoseyamus, 569 .

Hypecoum, 534.

Hypericaceæ, 512, 539.

Hypericum, 539 (Fig. 350 ).

Hypnum, 346.

Hypochæris, 582.

Hуросreaceæ, 296.

Hyssop, 563.

Hyssopus, 563.

Hysterium, 279.

Iberis, 537.

Iceland Moss, 307.

Illecebraceæ, 533 .

Illecebrum, 533 .

Illicieæ, 530.

Illicium, 472 (Fig. 286), 530.

Impatiens, 543.

Imperatoria, 550 .

Indigo, 558.

Indigofera, 558.

Inula, 581.

Inuloideæ, 581.
Ipecachuana, 575.

Iridaceæ, 481, 508.

Iridioideæ, 508.

Iris, 508 (Fig. 319).

Irish Heath, 573.

Isaria, 291.

Isatideæ, 537.

Isatis, 537 (Fig. 348).

Isnardia, 552.

Isoetaceæ, 352, 355 .

Isoetes, 348,355 (Fig. 213).

Ivy, 550 .

Ixioideæ, 509.

Jacob's Ladder, 567.

Jambosa, 553 (Fig. 366).

Jasione, 574.

Jasminum, 571.

Jerusalem Artichoke, 581.

Jonquil, 508.

Judas-tree, 559.

Juglandaceæ, 512, 521.

Juglans, 521 (Fig. 334).

Juncaceæ, 481, 499.

Juncaginaceæ, 481, 495.

Juncus, 499.

June Berry, 557.

Jungermannia, 330 .

Jungermanniaceæ, 320 , 324.

Juniper, 436.

Juniperinæ, 436.

Juniperus, 433, 436 (Fig. 257).

Jute, 540.

Kalınia, 573.

Kaulfussia, 355 .

Kerria, 554 .

Kidney-Vetch, 558.

Knapweed, 581.

Knautia, 578.

Knawel, 533.

Kniphofia, 498.

Kobresia, 493.

Koleria, 491.

Kohl-rabi, 537.

Labiatifloræ, 581.

Labiatæ, 513, 562.

Laboulbeniaceæ, 278 , 291.

Lactarius, 276.

Lactuca, 582.

Ladies' Fingers, 558.

Lady Fern, 371.

Lady's Mantle, 5̌55.

Lady's Slipper, 505.

Lady's Tresses, 506. 
Lamb's-lettuce, 577.

Lamb's Succory, 582.

Lamiales, 513, 562.

Laminaria, 265.

Laminariaceæ, 265.

Lamium, 562 (Fig. 376), 563.

Lapsana, 582.

Larch, 435 .

Larix, 435.

Larkspur, 530.

Lastræa, 372.

Lathræa, 566.

Lathyrus, 559.

Latiseptæ, 537.

Laurustinus, 576.

Lavandula, 563.

Lavender, 563.

Lecanora, 307.

Lecanoreæ, 307,

Lecidea, 307.

Lecideaceæ, 307.

Leek, 498.

Leersia, 489.

Leguminosæ, 513, 55̄7.

Lejeunia, 327, 330.

Lemanea, 272,

Lemna, 481 (Fig. 296).

Lemnaceæ, 481, 484.

Lemon, 544 .

Lens, 559.

Lentibulariaceæ, 564 (Fig. 377), 566.

Lentil, 559.

Leontodon, 582.

Leonurus, 563.

Lepidineæ, 537.

Lepidium, 537.

Lepidozia, 329, 330.

Lepigonum, 532.

Lepiota, 303.

Leptolegnia, 289.

Leptosporangiatæ, 352 , $358,373$.

Leptothrix, 282.

Lesser Celandine, 529.

I Lesser Dodder, 567.

Lettuce, 582.

Leucobryum, 342, 345.

Leucodon, 346.

Leucojum, 507.

Leuconostoc, 281.

Leycesteria, 576 391).

Lichenes, 305.

Iigulifloræ, 581.

Ligusticum, 550.

Ligustrum, 571.

Lilac, 571.

Liliaceæ, 481, 496.
Liliales, 481, 496.

Lilioideæ, 496.

Lilium, 461 (Fig. 276), 496.

Lily, 467 (Fig. 238), 496.

Lily of the Valley, 499.

Lime, 544.

Lime-tree, 540.

Limnanthemum, 570.

Limosella, 564.

Linaceæ, 513, 542.

Linaria, 564.

Ling, 578.

Linnæa, 577,

Linum, 542.

Liparidinæ, 507.

Liparis, 507.

Liriodendron, 530.

Listera, 506.

Lithoderma, 268.

Lithospermum, 569.

Litorella, 566.

Liverworts, 317, 318.

Lloydia, 496.

Lobelia, 574 (Fig. 389).

Loiseleuria, 573.

Lolıum, 491.

Lomaria, 371.

Lomentaceæ, 537.

Lomentaria. 271.

Lonicera, 576 (Fig. 392).

513, Lonicereæ, 576.

Loosestrife, 553.

Lophocolea, 324.

Loquat, 557.

Loranthaceæ, 512, 525.

Lords and Ladies, 483.

Loteæ, 558.

Lotus, 531; 557 (Fig. 369).

Louse wort, 565.

Lucerne, 558.

Lunaria, 537.

Lung-wort, 570 .

Lunularia, 323.

Lupinus, 558.

Luziola, 488.

Luzula, 499.

Lychnis, 532 (Fig. 344).

Lycium, 569.

Lycoperdon, 305.

Lycopersicum, 568.

Lycopodiaceæ, 353, 386.

(Fig. Lycopodinæ, 234, 353, 386.

Lycopodium, 386 (Fig. 231).

Lycopsis, 569.

Lycopus, 563.

L godium, 358, 372.

Lyme-grass, 492.
Lysimachia, 572 .

Lythraceæ, 513, 553.

Lythrum, 553.

Mace, 415.

Maclura, 515.

Macrocystis, 268.

Madder, 575 .

Magnolia, 530.

Magnoliaceæ, 512, 530.

Magnolieæ, 530.

Mahonia, 531.

Maianthemum, 499.

Maiden-hair Fern, 371.

Maiden-hair Tree, 437.

Maize, 489.

Malaxis, 507.

Male Fern, 372.

Mallow, 541.

Malopeæ, 541.

Malus, 556.

Malva, 541 (Fig. 352).

Malvaceæ, $512,540$.

Malvales, 512, 539.

Mandarin Orange, 544 .

Mangold, 523.

Manihot, 527.

Manna-ash, 571.

Man Orchis, 506.

Maple, 510 (Fig. 321), 545 (Fig. 357).

Maranta, 503.

Marantaceæ, 481, 502.

Marattia, 355 .

Marattiaceæ, 352, 355.

Marchantia, 311 (Fig. 193), 312 (Fig. 194), 320 (Fig. 198), 322 (Fig. 199).

Marchantiacese, 320.

Marchantieg, 324.

Marjoram, 563.

Marrubium, 563.

Marsh Andromeda, 573.

Marsh Cinquefoil, 556.

Marsh-mallow, 541.

Marsh-marigold, 529.

Marsh-samphire, 523.

Marsilea, 375 (Fig. 225).

Marsileaceæ, 352, 373, 380.

Mat-grass, 491.

Matricaria, 580.

Matthiola, 537.

Maurandia, 564.

May, 556.

Maydeæ, 489.

Meadow-grass, 191.

Meadow-rue, 528.

Meadow Saffron, 498. 
Meadow-sweet, 554.

Meconopsis, 533.

Medicago, 558.

Medlar, ๖̄56.

Melampsora, 299 (Figs. $179,180)$.

Melampyrum, 565 .

Melanthioider, 498.

Melica. 487, 490.

Melic-grass, 490.

Melilotus, 465 (Fig. 281), 558.

Melissa, 563.

Melissinere 563.

Melittis, 563.

Melobesia, 240, 271.

Melon, 551.

Mentha, 563.

Menthoideæ, 563.

Menyanther, 570.

Menyanthes, 570.

Menziesia, 573.

Mercurialis, 526.

Merismopedia, 244.

Mertensia, 570.

Mespilus, 556.

Metroxylon, 485.

Metzgeria, 324 (Fig. 200), 330.

Meum, 550.

Mildew, 295.

Milfoil, 581.

Milium, 490.

Milkwort, 546.

Milla, 498.

Millet, 489.

Millet-grass, 490.

Millet-sced, 489.

Mimosa, 559.

Mimoseæ, 559.

Mimulus, כ64.

Mint, 563.

Mistletoe, 525 (Fig. 340),

Moenchia, 532.

Mohria, 361 (Fig. 216), 372.

Molinia, 491.

Monandræ, 506.

Monardeæ, 563.

Monk's-hood, 530.

Monochlamydeæ, 512, 514.

Monocotyledones, 234, $418,476$.

Monogramme, 370.

Monospora, 271.

Monostroma, 257.

Monotropa, 573.

Monotropeæ, 573.

Montbretia, 503 .
Moon-wort, 3อ̆อ̆.

Moor-grass, 491.

Moraceæ, 512, 515.

Morchella, 297.

Morell, 297.

Morello Cherry, 5๊ว๊.

Morus, 515.

Moschatel, 576.

Mosses, 332.

Mother-wort, 563.

Mould, 275, 295.

Mountain Ash, 50̃7.

Mountain Avens, 5 56.

Mouse-tail, 529.

Mucor, 279, 287 (Figs. $165,166)$.

Mucoraceæ, 285.

Mucorinæ, 285.

Mudwort, 564 .

Mulberry, 515 .

Mullein, 564.

Musa, 502 (Fig. 312).

Musaceæ, 481, 501.

Muscari, 497.

Musci, 234, 332.

Muscineæ, 317.

Museæ. 501.

Mushroom, 279, 301.

Musk, 564.

Musk Orchis, 506.

Musschia, 574.

Mustard, 537.

Mutisia, 581.

Mutisieæ, 581.

Mycorhiza, 275.

Myosotis, 569.

Myosurus, 529.

Myrionema, 266.

Myristica, 415 (Fig. 246).

Myrrhis, 550.

Myrtaceæ, 513, 553.

Myrtales, 513, 552.

Myrtle, 553.

Myrtus, 553.

Myxomycetes, 280, 283.

Naiadaceæ, 481, 491.

Naias, 396, 494.

Nandina, 531.

Napobrassica, 537.

Napus, 537.

Narcissales, 481, 507 .

Narcissus, 507.

Nardus, 491.

Narthecium, 498.

Nasturtium, 537.

Navew, 537.

Neckera, 316.

Nelumbieæ, 531.

Nelumbium, 531.
Nemalion, 272 (Fig. 160).

Nemastoma, 271.

Neotinea, 506.

Neottia, 506.

Neottiinæ, 506.

Nepenthes, 41 (Fig. 28).

Nepeta, 563.

Nepeteæ, 563.

Nephrodium, 360 (Fig. 214), 372.

Nereocystis, 268.

New Zealand Flax, 498.

Nicotiana, 458 (Fig. 271), 569.

Nigella, 529.

Nigritella, 506.

Nipplewort, 582.

Nitelleæ, 263.

Nostoc, 244 (Figs. 135, 136).

Notorhizeæ, 536.

Nothoscordum, 498.

Nucumentaceæ, 537.

Nuphar, 531.

Nutmeg, 415 (Fig. 216).

Nux Vomica, 414 (Fig. $245)$.

Nyctalis, 304.

Nymphæa, 530.

Nymphæaceæ, 512, 530.

Nymphæinæ, 530.

Oak, 520.

Oat, 490.

Oat-grass, 490.

Ochlandra, 488.

Ocimoideæ, 563.

Ocimum, 563.

Octaviana, 304.

Elogoniaceæ, 253, 25i.

(Edogonium, 216, 25 (Fig. 147).

Enanthe, 550.

Enothera, 552.

Oil Palm, 486.

Old Man's Beard, 528.

Olea, 571.

Oleaceæ, 513, 570.

Olfer'sia, 360.

Oligoporus, 304.

Olive, 571.

Onagraceæ, 513, 552.

Oncidium, 507 .

Onion, 498.

Onobrychis, $55 \mathrm{~s}$.

Onoclea, 359, 372 .

Ononis, 558 .

Onopordon, 581.

Oocvstis, 248.

Oomycetes, 278, 280, $28 \%$. 
Ophioglossaceæ, 352, 354 .

Ophioglossum, 354.

Ophrydinæ, 506.

Ophrys, 506.

Orache, 523.

Orange, 514 .

Orchidaceæ, 481, 503.

Orchidales, 481, 503.

Origanum, 563.

Orchis, 504 (Figs. 315, 316 ).

Ornithogalum, 497.

Orobanchaceæ, 513, 566.

Orobanche, 566.

Orobus, 559.

Orpine, 561.

Orthoclada, 488.

Orthoploceæ, 536.

Orthospermeæ, 549.

Orthotrichum, 339, 345.

Oryza, 489.

Oryzeæ, 489.

Oscillaria, 214 (Fig. 135).

Oscillariaceæ, 214.

Osmunda, 359, 372 (Fig. 261), 406.

Osmundaceæ, 352, 364, 372.

Ostrya, 520.

Oxalidaceæ, 513, 543.

Oxalis, 543.

Ox-eye Daisy, 580.

Oxlip, 572.

Oxycedrus, 436.

Oxymitra, 324.

\section{Pæonia, 530.}

Pæonieæ, 530.

Paigle, 572.

Palm, 485.

Palmaceæ, 481, 484.

Palmales, 481, 481.

Palmella, 247.

Palmodictyon, 248.

Palmophyllum, 248.

Pampas Grass, 491.

Pandorina,249 (Fig.138).

Panicex, 489.

Panicoideæ, 489.

Panicum, 487 (Fig. 300).

Pannaria, 306.

Pansy, 533.

Papaver, 474, 533.

Papaveraceæ, 512, 533.

Paper Mulberry, 515.

Papilioneæ, 557.

Papyrus, 492.

Pariana, 488, 492.

Parietales, 512, 533.

Parietaria, 515.
Paris, 461 (Fig. 277), 499 (Fig. 310).

Parmelia, 307.

Parnassia, 561 (Fig. 373).

Parnassieæ, 560.

Paronychieæ, 532.

Parsley, 550.

Parsley Fern, 372.

Parsnip, 500 .

Passiflorales, 513, 550.

Pastinaca, 550.

Patchouli, 563.

Paulownia, 564.

Pea, 559.

Peach, 554.

Pearl-wort, 532.

Pear-tree, 556.

Pediastrum, 2033.

Pedicularis, 565.

Pelargonium, 542.

Pellia, 324, 330.

Peltigera, 306, 307.

Pelvetia, 268.

Penicillium, 278,

(Fig. 170), 295.

Penny-cress, 537.

Pentstemon, 564.

Peony, 530.

Peplis, 553.

Perisporiaceæ, 295.

Perisporieæ, 295.

Peronospora, 279, 287.

Peronosporaceæ, 277, 287.

Personales, 513, 564.

Pertusaria, 308 (Fig. 190).

Petaloidew, 481, 494.

Petasites, 580.

Petroselinum, 550 .

Petunia, 569.

Peucedaneæ, 550.

Peucedanum, 550.

Peziza, 277, 297 (Fig.177).

Pezizaceæ, 296.

Phacidieæ, 297.

Phacotus, 249.

Phæogamæ, 265, 268.

Phæoph yceæ, 238, 263.

Phæosporeæ, 264, 265.

Phalarideæ, 489.

Phalaris, 489.

Phalloider, 304.

Phallus, 305.

Phanerogamia, 234, 394.

Phascum, 339, 312.

Phaseoleæ, 559.

Phaseolus, 559.

Pheasant's Eye, õ29.

Pheasant's Eye Narcissus, 508.
Phegopteris, 372.

Philodendroidew, 483.

Phleum, 490.

Phlox, 567.

Phoenix, 477 (Fig. 291), 485 (Fig. 298)

Phormium, 498 .

Photinia, 557.

Phraymites, 491.

Phycochromacez, 244.

Phycomycetes, 280, 285.

Phyllanthus, 5:27.

Phyllobium, 218.

Phyllocladus, 437.

Phyllodoce, 573.

Phylloglossum, 386.

Physalis, 568.

Physcia, 307.

Physospermum, 550.

Physostigma, 505.

Physureæ, 507.

Phytelephas, 486.

Phyteuma, 574.

Phytophthora, 287 (Figs. 167, 168), 288.

Picea, 125 (Fig. 249), $4: 26$ (Fig. 250), 428 (Fig. $252), 435$.

Picris, 582.

Pilacre, 304.

Pilacrea, 304.

Pilularia, 373, 350.

Pimpernel, 572.

Pimpinella, 550.

Pinaster, 435.

Pine, 435.

Pinea, 435.

Pine-apple, 501 (Fig. 311).

Pinguicula, 566.

Pink, 532.

Pinnularia, 265 (Fig. 152).

Pinoideæ, 433.

Pinus, 407 (Fig. 241), 422 (Fig. 248), 427 (Fig. 251), 433 (Fig. 254), 435.

Piptocephalideæ, 285.

Pisum, 559.

Pithophora, 252.

Plagiochila, 326 (Fig. 201), 330.

Plantaginaceæ, 513, 565.

Plantago, 565 (Fig. 379).

Plantain, 502; 565 .

Platycerium, 360 .

Platycodon, 574.

Pleospora, 279, 294.

Pleurocarpe, 345. 
Pleurocladia, 268.

Pleurococcaceæ, 248.

Pleurococeus, 248 (Fig. $13 \overline{7}$.

Pleurorhizeæ, 536.

Plocamium, $2 \overline{71}$.

Plumbaginaceæ, $513,572$.

Plumbago, 5īe.

Plume-thistle, 581.

Pea, 491.

Podophyllum, 5331.

Pogostemon, 563.

Polemoniaceæ, 513, 56 6 .

Polemoniales, 513, 567.

Polemonium, 567.

Polybotrya, 361.

Polrcarpex, 532.

Polycarpon, 532.

Polygala, 546 (Fig. 358).

Polygalaceæ, $513,545$.

Pol ygonaceæ, 512, 523.

Polygonatum, 499.

Polygonum, 523 (Fig. 337).

Polypetalæ, 512, 527.

Polypodiaceæ, 352, 371.

Polyporieæ, 372.

Polypodium, 358, 360 (Fig. 214), 369 (Fig. 223), $3 \bar{\imath}^{2}$.

Polyporeæ, 303.

Polyporus, 303.

Polysiplıonia, 271.

Polytrichum, 339, 344 (Fig. 211).

Pomeæ, 556 (Fig. 367).

Pomegranate, 504.

Pond weed, 494.

Pooideæ, 489.

Poplar, 522 (Fig. 335).

Poppy, 533.

Populus, 522.

Portugal Laurel, 555.

Potamogeton, 491.

Potato Plant, 568.

Potentilla, 459 (Fig. 275), 556.

Potentilleæ, 555 (Fig. 367 .

Poterieæ, 555.

Poterium, 555 5.

Pothoider, 483.

Pothos, 483.

Pot-Marigold, 581.

Pottia, 314.

Preissia, 322.

Prickly Samphire, 550.

Primrose, 572.

Primula, 453 (Fig. 269), 571 (Fig. 386).
Primulaceæ, 513, 571.

Primulales, 513, 571 .

Privet, 571.

Protobasidiomycetes, 304, 305.

Protococcaceæ, 248.

Protococcoideæ, 247, 248.

Protomyces, 301.

Pruneæ; 554 (Fig. 367).

Prunella, 563.

Prunophora, 554.

Prunus, 554.

Psalliota, 303.

Pseudoneura, 327.

Pseudosolaneæ, 564.

Psilotaceæ, 35̄3, 389.

Psilotum, 389.

Pterideæ, 371.

Pteridium, 371.

Pteridophyta, 234, 346.

Pteris, 360 (Fig. 214), 366 (Fig. 218), 367 (Fig. 220), 371.

Puccinia, 279, 298 (Fig. 178).

Puff ball, 301, 305.

Pulicaria, 581.

Pulmonaria, 570.

Pumpkin, 551.

Punica, 554.

Purple Beech, 521.

Pycnophycus, 268.

Pylaiella, 266.

Pyrenomycetes, 295.

Pyrola, כ̌̃̄2 (Fig. 387).

Pyrolaceæ, 513, 573.

Pyronema, 278, 293 (Fig. 172).

Pyrus, 556.

Pythium, 287, 288.

Quaking-grass, 491.

Quercus, 520 (Fig. 3333).

Quince, 556.

Racodium, 306.

Radiola, 542.

Radish, 538.

Radula, 324, 330.

Ramalina, 307.

Rampion, 574.

Ranales, $512,527$.

Ranunculaceæ, 512, 527.

Ranunculus, 528 (Fig. 342), 529.

Rapa, 537.

Rape, 537.

Raphaneæ, 538.

Raphanus, 535 (Fig. 318), 538.
Raphiolepis, 557.

Raspberry, 556.

Rattle, 565.

Ravenala, 501.

Reed, 491.

Reed-grass, 489.

Reed-mace, 484.

Reindeer Moss, 307.

Rest-harrow, 558.

Rhamnaceæ, $513,546$.

Rhamnus, 465 (Fig. 281), 546 (Fig. 359).

Rheum, 469 (Fig. 281), 524 (Fig. 337).

Rhinanthoideæ, 564.

Rhinanthus, 56 .

Rhizocarpæ, 373.

Rhizoclonium, 253.

Rhizomorpha, 305.

Rhizopogon, 305.

Rhodochiton, 564.

Rhododendroideæ, วั3.

Rhododendron, 573.

Rhodomelaceæ, 271.

Rhodophyceæ, 238, 271.

Rhodotypus, 554 .

Rhodymeniaceæ, 273.

Rhubarb, 524.

Rhytisma, 297.

Ribes, 561 (Fig. 374).

Ribesieæ, 561 .

Ribwort, 566.

Riccia, 324.

Riccieæ, 322, 324.

Rice-plant, 489.

Richardia, 442, 483.

Ricinus, 462 (Fig. 278), 526.

Riella, 324, 329.

Rielleæ, 329.

Rivulariaceæ, 244.

Robinia, 558.

Roccella, 307.

Rock-rose, 538 .

Romulea, ว08.

Rosa, 451 (Fig. 267), 554.

Rosaceæe, 513, 554 .

Rosales, 513, 554 .

Rose, 554.

Roser, 555 (Fig. 367).

Rosemary, 563.

Rosmarinus, 5ั63.

Rowan-tree, 5ั57.

Rubia, 575 (Fig. 390).

Rubiaceæ, 513, 574.

Rubiales, 513, 574.

Rubus, 555 (Fig. 368), 556.

Rudbeckia, 581 .

Rue, 543. 
Rumex, 523 (Fig. 337).

Ruppia, 405, 494.

Ruscus, 499.

Rush, 499.

Rust, 275, 298, 299.

Ruta, 543.

Rutaceæ, 513, 543.

Ruteæ, 543.

Rye, 491 .

Rye-grass, 491.

Sabina, 436.

Saccharomyces, 295 (Fig. 174).

Saccharomycetes, 295.

Saccharum, 489.

Safflower, 581.

Saffron Crocus, 508.

Sage, 563.

Sagina, 532.

Sagittaria, 495.

Sago, 485.

Sainfoin, 558.

Salad Burnet, 555.

Salicaceæ, 512, 522.2.

Salicornia, 523.

Salisburia, 437 .

Salix, 522 (Fig. 335).

Sallow, 522.

Salsafy, 582 .

Salsola, 523.

Salt-wort, 523.

Salvia, 461 (Fig. 276), 562.

Salvinia, 347, 374 (Fig. 224), 379 (Fig: 226).

Salviniaceæ, 352, 373, 380 .

Sambuceæ, 576.

Sambucus, 458 (Fig. 274), 463 (Fig. 279), 576.

Samolus, 572.

Samphire, 550.

Sandal-wood, 525.

Sand-wort, 532.

Sanguisorba, 555 .

Sanicula, 549.

Saniculeæ, 549.

Santalaceæ, 512, 524.

Santalales, 512, 524 .

Santalum, 525.

Sapindaceæ, 544.

Sapindales, 513, 544 .

Sapindus, 545.

Saponaria, 532.

Saprolegnia, 289.

Saprolegniaceæ, 278, 289.

Sarciua, 281.

Sargassum, 269.

Sarothamnus, 558.
Sarsaparilla, 499.

Satureia, 563.

Satureineæ, 563.

Saussurea, 581.

Savoy-cabbage, 537.

Saw-wort, 081.

Saxifraga, 465 (Fig. 281), 560.

Saxifragaceæ, 513 , 560 .

Saxifragales, 513, อ๊

Saxifrageæ, 560.

Scabiosa, 578 (Fig. 394).

Scandiceæ, 550 .

Scandix, 550.

Scapania, 327, 330.

Scarborough Lily, 507.

Scarlet-runner, 5๊59.

Scenedesmus, 248.

Scheuchzeria, 495.

Schistostega, 344.

Schizæa, 359, 365, 372.

Schizæaceæ, 352, 372.

Schizomycetes, 246,276 , 280.

Schizophyta, 246, 283.

Schlerochloa, 491.

Schœenus, 492.

Schollera, 573.

Sciadium, 248.

Scilla, 497.

Scilleæ, 497.

Scirpoideæ, 492.

Scirpus, 493 (Fig. 303).

Scitamineæ, 481, 501.

Scleranthus, 583.

Sclerotinieæ, 277.

Scolopendrium, 359, 362 (Fig. 217), 371.

Scorpion-grass, 569.

Scorzonera, 582.

Scots Pine, 435.

Scottish Äsphodel, 498.

Scrophularia, 565.

Scrophulariaceæ, 564 (Fig. 377), 565 (Fig. 378).

Seurvy-grass, 537.

Scutellaria, 563.

Scutellarieæ, 563.

Scytonema, 244.

Scytonemacese, 244.

Seytosiphon, 267.

Sea-blite, 523.

Sea-bugloss, 570.

Sea-kale, 538.

Sea-la vender, 572 .

Sea-milkwort, $5 \bar{i} 2$.

Sea-purslane, 532.

Sea-rocket, 538.

Secale, 491.
Sedge, 493.

Sedum, 561 (Fig. 375 ).

Selaginella, 390 (Fig. 232), 391 (Fig. 233), 392 (Fig. 234).

Selaginellaceæ, 353,389

Sempervivum, 561.

Senebiera, 537.

Senecio, 580.

Senecionidere, 580.

Sensitive Plant, 559.

Serapiadere, 506 .

Serrutula, 581.

Service-tree, $55 \overline{7}$.

Seseli, 550.

Seselineæ, 550.

Sesleria, 491.

Shaddock, 544.

Shalot, 498.

Sheep's-bit, 574 .

Shepherd's Purse, 537.

Sherardia, 575.

shield-Fern, 372.

Sibbaldia, 556.

Sibthorpia, 565.

Silaus, 550 .

Silene, 532.

Sileneæ, 532.

Siler, 550.

Siliculosæ, 537.

Siliquosæ, 536.

Silver Fir, 435.

Silver-weed, 556.

Simethis, 498.

Sinapis, 537.

Siphonaceæ, 250.

Siphonoideæ, 246, 248 250.

Sirogonium, 255.

Sison, 550.

Sisymbrieæ, 537.

Sisy mbrium, 537 .

Sium, 550.

Skullea.p, 563.

Sloe, 554.

Small Reed, 490.

Smilacoider, 499.

Smilax, 499.

Smut, 275, 298, 300.

Smyrnieæ, 550.

Smyrnium, 550.

Snake's Head, 497.

Snapdragon, 564.

Snowberry, 577.

Snowdrop, 507.

Soap-wort, 532.

Solanacere, 513, 567 .

Solanex, 568.

Solanum, 568.

Soldanella, 571. 
Solidago, 580.

Solomon's Seal, 499.

Sonchus, 582.

Sorbus, $55 \overline{7}$.

Sordaria, 278.

Sow-bread. 572.

Sow-thistle, 582 .

spadicifloræ, 181, 482.

Spanish Chestnut, 521 .

Sparaxis, 509.

sparganium, 481.

Spartina, 491.

Suearwort, 5:99.

specularia, 574 .

speed well, 565.

spelt, 492.

spergula, 532 .

Spergularia, 532.

Spermaphyta, 234, 394.

Spermothamnion, $\quad 274$

(Fig. 161).

Sphacelaria, 263, 264.

sphærella, 249.

Sphæriaceæ, 296.

Sphærocarpus, 327, 329.

Sphæroplea, 247, 252.

Sphæropleæ, 252.

Sphærotheca, 293.

Sphagnaceæ, 312, 316, 340.

Sphagnum, 332, 341 (Figs. 205, 206).

Spider Orchis, 506.

Spinach, 523.

Spinacia, 523.

Spindle-tree, 546.

Spiræa, 554.

Spiræeæ, 554 .

Spirantheæ, 506.

Spiranthes, 506.

Spirillum, 281 (Fig. 162).

Spirochrete, 281.

Spirogyra, 246, (Fig. 145).

Spirolobeæ, 536.

Splachnum, 338.

Spring Snowflake, 507.

Spruce Fir, 435.

Spurge, 527.

Spurrey, 532.

Squamariaceæ, 272.

Squinancy-wort, 575.

Stachydeæ, 563.

Stachys, 563.

Stangeria, 432.

Star-Anise, 530.

Star Daffodil, 508.

Star-fruit, 495 .

Star of Bethlehem, 498.

Statice, 572.
Staurastrum, 254.

Stegocarpæ, 338, 343.

Stellaria, 532.

Stellatæ, 575.

Sticta, 307 (Fig. 188).

Stinging Nettle, 514 .

Stipa, 487, 490.

Stitch-wort, 532.

St. Dabeoc's Heath, 573.

St. John's Wort, 539.

Stocks, 537.

Stone Pine, 435.

Stonecrop, 561.

Stork's-bill, 542.

Strap-wort, 533.

Stratioteæ, 500.

Stratiotes, 500.

Strawberry, 556.

Strelitzia, 501.

Sturmia, 507.

Stypoeaulon, 239 (Fig. 133).

Suæda, 523.

Subularia, 537.

Succisa, 578.

Sugar-cane, 489.

Summer Savory, 563.

Summer Snow flake, 507.

Sundew, 561.

Sunflower, 581.

Sweet Basil, 563.

Sweet Briar, 554.

Sweet Flag, 483.

Sweet Orange, 544.

Sweet Potato, 567.

Sycamore, 545 .

Symphoricarpus, 577.

Symphyogyna, 327.

Symphytum, 569.

Syringa, 571.

Tagetes, 581.

Tamarindus, 559 .

Tamus, 500.

Tanacetum, 581 397 ).

Tansy, 581.

Tapioca, 527.

Taraxacum, 582 (Fig. 397).

Tassel Pondweed, 494.

Taxeæ, 437.

Taxoideæ, 439, 436.

Taxus, 396,437 (Fig. 258).

Teazle, 578.

Teesdalia, 537.

Telegraph-plant, 558.

Tetraphis, 337, 345 .

Tetraspora, 248.

Teucrium, 564.
Thalamifloræ, 512, 527.

Thalictrum, 528.

Thallophyta, 234, 237.

Thelidium, 306.

Thesium 525 (Fig. 339).

Thistle, 581.

Thlaspi, 537 (Fig. 348).

Thlaspideæ, 537.

Thorn-apple, 569.

Thrift, 572 ,

Thuidium, 346.

Thuja, 436 (Fig. 256).

Thyme, 563.

Thymus, 568.

Tiger-lily, 496.

Tilia, 461 (Fig. 276), 540 (Fig. 351).

Tiliaceæ, 512, 539.

Tilletia, 300 (Fig. 181):

Timothy-grass, 490.

Tmesipteris, 389.

Toad-flax, 564.

Toadstool, 301.

Tobacco-plant, 569.

Todea, 372:

Tofieldia, 498.

Tomato, 568.

Tordylium, 550.

Torilis, 550 .

Tragopogon, 582.

'Trapa, 552.

Treacle mustard, 537.

Tree-fern. 358, 372.

Tremella, 303 (Fig. 184).

Tremellineæ, 303.

Trentepohlia, 306.

Trichomanes, 360 (Fig. $214), 371$.

Trientalis, 572.

Trifolieæ, 558.

Trifolium, 5058.

Triglochin,495(Fig.305)

Trigonella, 558.

Trinia, 550 .

Triticum, 478 (Fig. 292), 491.

Tritonia, 509.

Trollius, 529.

Tropæolum, 457 (Fig. 273).

Trumpet Lily, 483.

Tubulifloræ, 579.

Tuburcinia, 301.

Tulip, 496.

Tulipa, 496.

Tulipeæ, 496.

Tulip-tree, כั30.

Tulostoma, 304.

Turk's Cap Lily, 496.

Turmeric, 502. 
Turnip, 537.

Tussilago, 580.

Tutsans, 539 .

Twayblade, 506.

Typha, 484.

Typhaceæ, 481, 481. .

Typhula, 277, 304.

Ulex, 558.

Ulmaceæ, 512, 516.

Ulmus, 516 (Fig. 326).

Ulothricaceæ, 253, 256.

Ulothrix, 216, 256 (Fig. 146).

Ulva, 246, 257.

U'lvaceæ,.253, 257.

Umbellales, 513, 547.

Umbelliferæ, 513, 548.

Uncinula, 295 (Fig. 173).

Uredineæ, 299 (Fig. 179).

- Uredo, 299.

Urocystis, 301.

Urospora; 253.

Urtica", $514^{-}$(Figs. 322, 323). -

Urticaceæ, 512, 514.

Urticales, 512, 514.

Usnea, 307 (Figs. 186, 189).

Ustilagineæ, 298, 300.

Ustilago, 300 (Fig. 181).

Utricularia, 566 (Fig. 380 ).

Uvularia, 498.

Vacciniaceæ, 513, 573.

Vaccinium,461(Fig.277), 572 (Fig. 387).

Valerian, 577 (Fig. 393).

Valeriana, 577.

Valerianaceæ, 513, 577.

Valerianella, 577.

Valisneria, 500.

Valisnerieæ, 500.

Vallota, 507.

Vanda, 507.

Vanilla, 507.

Vascular Cryptogams, 346.

Vaucheria, 250 (Fig. 140).

Venus' Fly-trap, 561.
Venus' Looking-glass, 574.

Veratrum, 498.

-Verbascum, 564.

Vernal grass, 489.

Veronica, 564 (Figs. 377, 378).

Vetch, 559 .

Viburnum, 576.

Vicia, 456 (Fig. 272), 510 (Fig. 320), 559 .

Vicieæ, 558.

Victoria, 531.

Villarsia, 570.

Viola, 538 (Fig. 349).

Violaceæ, 512, 538.

Violet, 538.

Viper's Bugloss, 569.

Virginian Creeper, 547.

Viscum, 525 (Fig. 340).

Vitis, 547 (Fig. 360).

Vittaria, 370.

Volvocaceæ, 249.

Volvocoideæ, 247, 249.

Volvox, 246, 249 (Fig. 139).

Wall-flower, 537.

Wall-Pellitory, 515.

Wall-Rue, 371.

Walnut, 522.

Water-Chestnut, 552.

Water-cress, 537.

Water Crowfoot, 529.

Water-Hemlock, 550.

Water-Lily, 531.

Water Melon, 551.

Water Plantain, 495.

Water-Purslane, 553.

Water-Soldier, 500 .

Water-Violet, 572.

Weeping Willow, 522.

Weigelia, 577.

Welwitschia, 437.

Wheat, 487 (Fig. 301), 490 (Fig. 302).

Whin, 558.

White Beam, 557.

White Thorn, 556 .

Whitlow-grass, 537.

Whortleberry, 573.

Wild Balsam, 543.
Wild Garlic, 498.

Wild Oats, 490.

Wild Parsnip, 550.

Wild Plum, 555.

Wild Rosemary, 573.

Wild Sage, 563.

Willow, 522.

Willow Herb, 552.

Winter Aconite, 529.

Winter Cherry, 568.

Winter-green, 573.

Wistaria, 559.

Woad, 537.

Wolffia, 405 .

Wolf's-bane, ว30.

Wood Germander, 564.

Woodruff, 575.

Woodsia, 372.

Wood-sorrel, 543.

Woody Nightshade, 568

Wormwood, 580.

Wound wort, 558.

Wych Elm, 517.

Xiphion, 508.

Yam, 500.

Yarrow, 581.

Yeast, 295 (Fig. 174).

Yellow Flag, 509.

Yellow Loosestrife, 572.

Yellow Monkey-flower, 564.

Yellow Rocket, 537.

Yellow Welsh Poppy, 533.

Yew, 437 (Fig. 258).

Yucea, 498.

Zamia, 432 (Fig. 253).

Zanardinia, 265.

Zannichellia, 494.

Zantedeschia, 483.

Zea, 479 (Fig. 293), 489.

Zingiber, 502.

Zingiberaceæ, 481,502 .

Zingiberex, 502.

Zinnia, 581.

Zostera, 494.

Zygnema, 255 (Fig. 144).

Zygnemeæ, 254.

Zygogonium, 256.

Zygomycetes, 280, 285. 


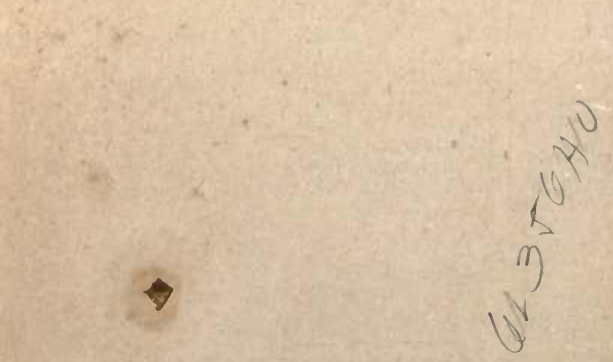




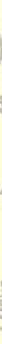

University of California

SOUTHERN REGIONAL LIBRARY FACILITY 405 Hilgard Avenue, Los Angeles, CA 90024-1388 Return this material to the library from which it was borrowed.

OCOCT1 1996
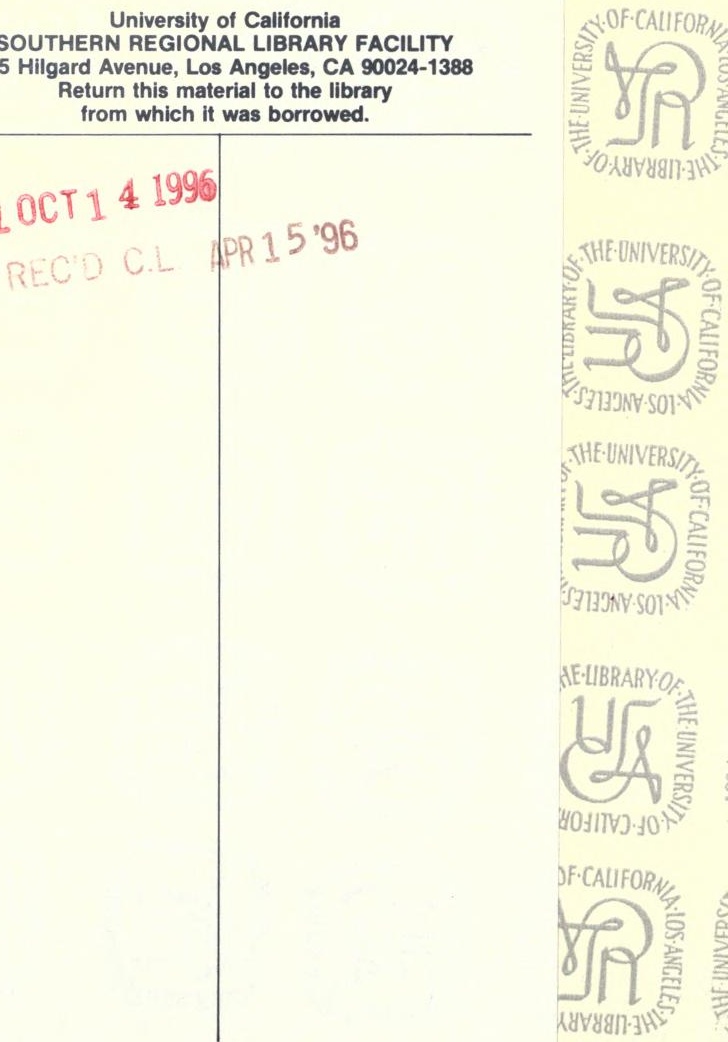

(HOSITH].10)

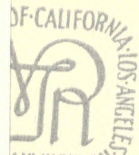
ᄉมษ

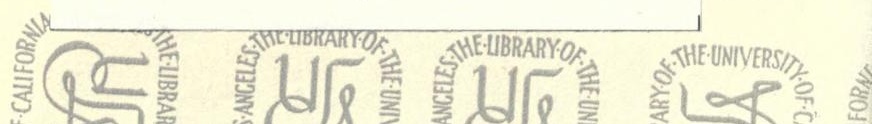




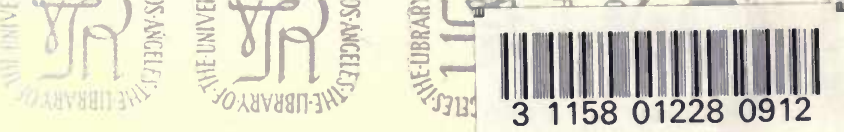
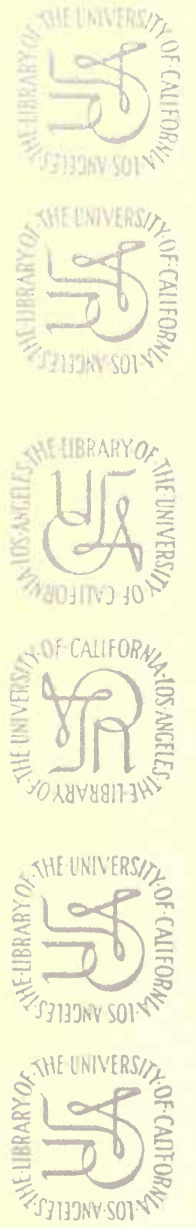
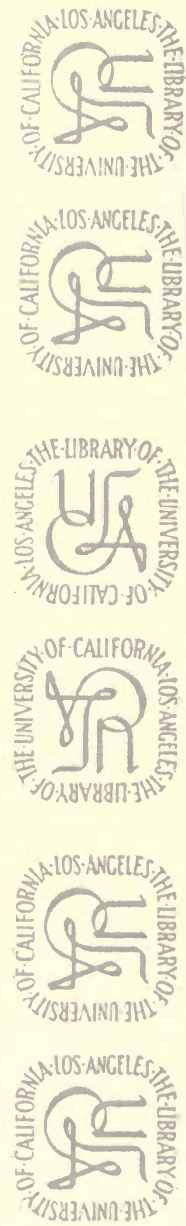
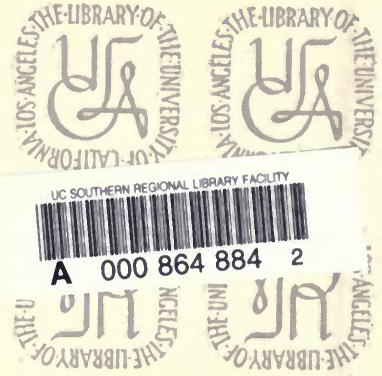

离
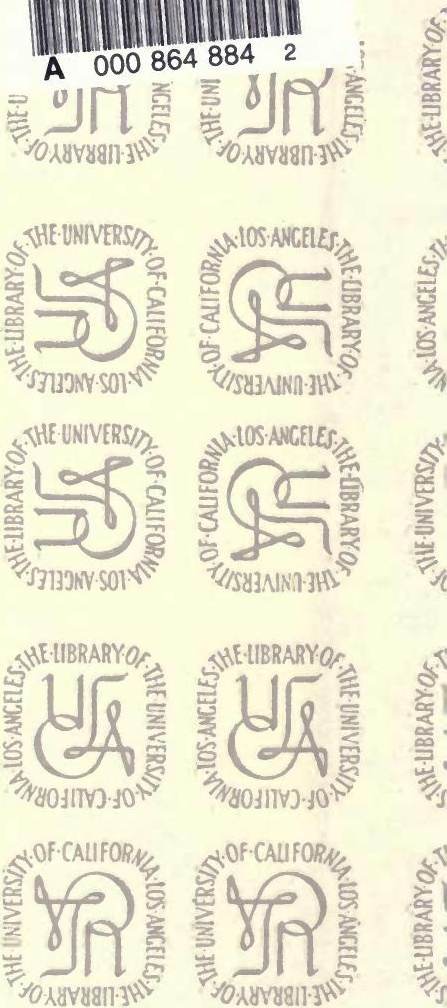

$\frac{5}{\frac{5}{5}}$ 
